\title{
Réseaux politiques et économiques
}

Henri Bresc (dir.)

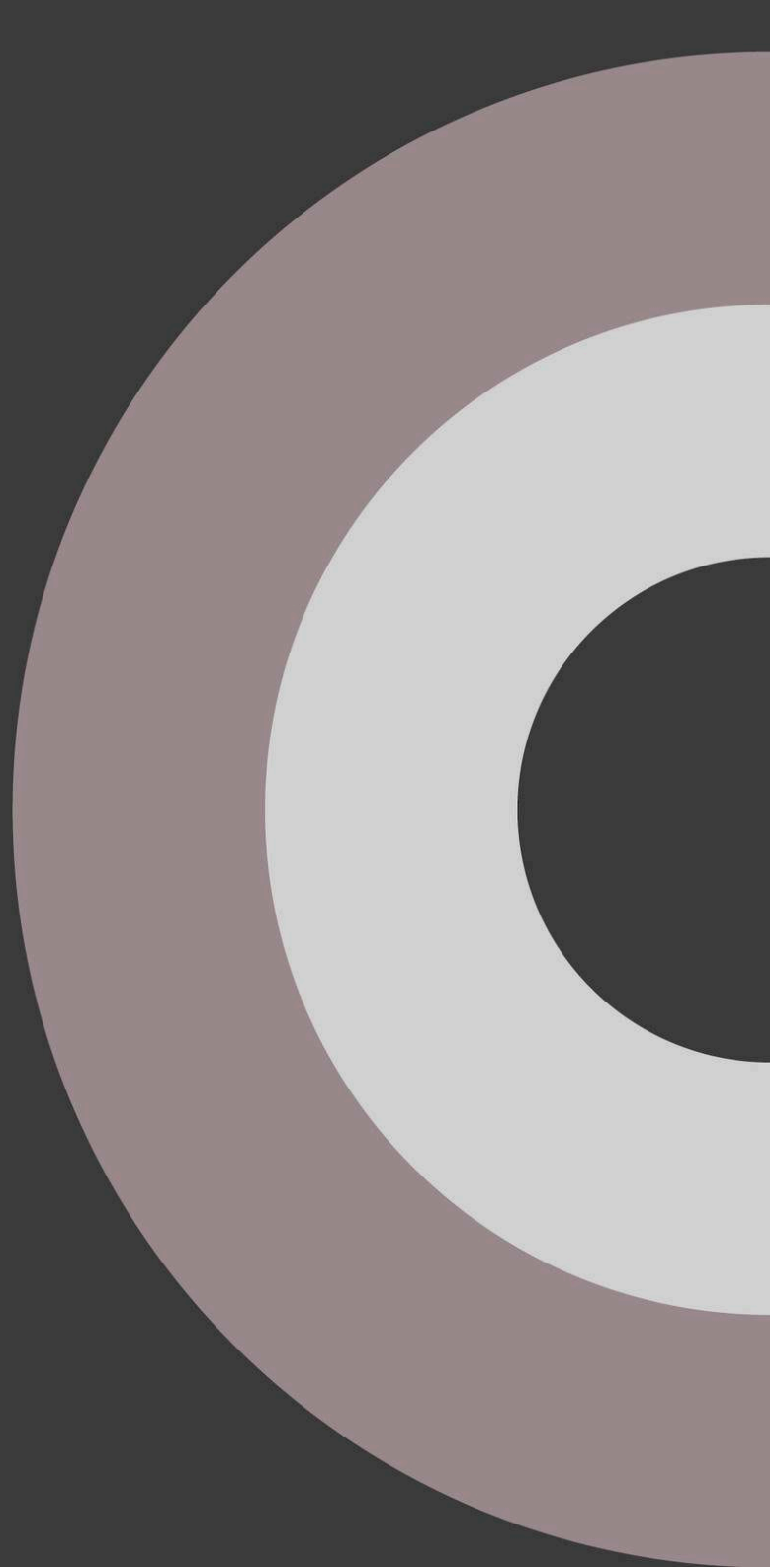




\section{Réseaux politiques et économiques}

\section{Henri Bresc (dir.)}

DOI : $10.4000 /$ books.cths. 2096

Éditeur : Éditions du Comité des travaux historiques et scientifiques Année d'édition : 2016

Date de mise en ligne : 13 novembre 2018

Collection : Actes des congrès nationaux des sociétés historiques et scientifiques

ISBN électronique : 9782735508761

\section{Sbooks}

http://books.openedition.org

\section{Édition imprimée}

Nombre de pages : 271

\section{Référence électronique}

BRESC, Henri (dir.). Réseaux politiques et économiques. Nouvelle édition [en ligne]. Paris : Éditions du Comité des travaux historiques et scientifiques, 2016 (généré le 10 décembre 2020). Disponible sur Internet : <http://books.openedition.org/cths/2096>. ISBN : 9782735508761. DOI : https://doi.org/ 10.4000/books.cths.2096.

(C) Éditions du Comité des travaux historiques et scientifiques, 2016

Conditions d'utilisation:

http://www.openedition.org/6540 
COMITÉ DES TRAVAUX HISTORIQUES ET SCIENTIFIQUES

\section{Réseaux politiques et économiques}

Sous la direction de

Henri BRESC

ÉDITIONS DU CTHS

2016 
Ministère de l'Éducation nationale, de l'Enseignement supérieur et de la Recherche

Congrès national des sociétés historiques et scientifiques $140^{\mathrm{e}}$, Reims, 2015

Collection Actes des congrès des sociétés historiques et scientifiques, Version électronique

ISSN 1773-0899 


\section{TABLE DES MATIÈRES}

\section{Introduction, Henri BRESC}

\section{L'individu au centre des convergences}

Pouvoirs locaux et réseaux sous la VI dynastie égyptienne (vers 2350-2200 avant notre ère): un exemple des usages et des apports de l'analyse des réseaux en égyptologie

Émilie MARTINET

Constantin IX Monomaque : Empereur ou homme de réseau? Éric LIMOUSIN

Devenir évêque à Byzance au XII siècle : une nécessaire intégration dans des réseaux de pouvoir?

Lucile HERMAY \& Jack ROSKILLY

Henri de La Tour et les Grands sous

la régence de Marie de Médicis

Romain MARCHAND

Les multiples réseaux formels et informels

d'un apothicaire parisien : l'échevin

Matthieu-François Geoffroy

Olivier LAFONT

\section{L'espace en réseaux}

Le réseau des foires de Champagne (XII - XIV siècles)

Émergence, structuration et connexions

Jean-Marie YANTE

Les gribanniers de la Somme: monopole et embargo

d'une communauté sur le transport fluvial

durant les XVII et XVIII siècles

Christophe CLOQUIER

Réseaux marchands et industriels russes au XIXe siècle : le cas de la dynastie sibérienne des Basnine

Solange BAUDOUIN 
Le moulin à grain hydraulique dans

sa chaîne économique, technique et sociale:

$l^{\prime}$ exemple de l'Alençonnais XVII ${ }^{e}-X^{e}$ siècles

Patrick BIRÉE

p. 107

\section{Au service de l'économie}

Reconstruire des réseaux d'affaires à partir de sources comptables : des exemples toscans

(XIV ${ }^{e}-X V I^{e}$ siècles)

Ingrid HOUSSAYE MICHIENZI

De la circulation de la grâce à la République de l'argent, marché, relations familiales et relations marchandes

en Sicile (1287-1460)

Henri BRESC

Réseaux commerciaux et financement

de la carrière des Indes dans la

seconde moitié du XVIII siècle

Robert CHAMBOREDON

Famille et réseaux sociaux de

l'élite sucrière martiniquaise

(fin $X I X^{e}$-début $X^{e}$ siècle)

Marie HARDY

\section{Les réseaux et le pouvoir}

L'impératrice byzantine au cœur des réseaux aristocratiques L'exemple de Marie d'Alanie et d'Irène Doukaina-Comnène Bénédicte BRUN

Côté ville et côté cour : concurrence ou complémentarité des réseaux en Italie centrale $\mathrm{XIV} V^{e}-\mathrm{XV}^{e}$ siècles Philippe JANSEN

Les échevins et prévôts des marchands dans le paysage institutionnel lyonnais (1680-1740)

Rosemonde LETRICOT

Réseaux et identité chez les Colombiens

en France : un vécu transculturel

María Isabel QUINTANA MARÍN \&

Mary Luz MARÍN POSADA 
Du réseau au parti politique moderne et post-moderne

Les «factieux de Lodève » : développement et déclin d'un réseau jacobin héraultais

Nathalie ALZAS

p. 227

La Société des saisons : un réseau républicain sous la monarchie de Juillet

Jérôme LOUIS

p. 235

Un réseau politique de l'opposition libérale dans le département de la Meuse

(1820-1830)

Jean-Paul STREIFF

Mettre à jour les réseaux politiques

ou définir le populisme?

L'attitude des médias face à la

droite populiste allemande

Lionel PICARD

p. 262 


\title{
Introduction
}

\author{
Henri BRESC \\ Professeur émérite d'histoire médiévale \\ Université Paris Ouest - Nanterre-La Défense \\ Extrait de : Henri BRESC (dir.), Réseaux politiques et économiques, Paris, \\ Édition électronique du CTHS (Actes des congrès des sociétés historiques et scientifiques), 2016. \\ Cet article a été validé par le comité de lecture des Éditions du CTHS dans le cadre de la publication \\ des actes du $140^{\circ}$ Congrès national des sociétés historiques et scientifiques tenu à Reims en 2015.
}

Les communications des historiens de l'économie et de la politique au congrès de Reims ont manifesté l'intérêt de leur communauté pour la problématique des réseaux, quelquefois nouvelle pour eux. On retrouve l'insatisfaction vis-à-vis du schéma causal, des déterminismes économiques et sociaux qui ont dominé les sciences sociales et humaines, devant un monde chaotique, à l'organisation désordonnée et réfractaire, symbolisée dans les sciences dites dures par le mouvement brownien. La recherche des réseaux est donc une solution pour ordonner le chaos des relations multilatérales potentiellement infinies, rendre compte de l'incertitude, des choix, des risques pris, des changements de stratégie, des échecs plutôt qu'offrir un discours linéaire téléologique vers le succès. Nos communications explicitent rarement les préoccupations théoriques qui font de beaucoup de livres et d'articles sur le thème réticulaire des manifestes et des expérimentations, au demeurant utiles, mais disproportionnés ; elles montrent également une utilisation encore hésitante des instruments informatiques: deux d'entre elles seulement déclarent utiliser des logiciels pour classer et représenter les données exploitées. On trouve ainsi dans l'article d'Émilie Martinet un usage fin des concepts et des techniques de la social network analysis qui débouche sur une critique fondée de ses principes et de ses résultats et Rosemonde Letricot fait appel à un algorithme pour organiser une vaste prosopographie des échevins lyonnais. L'appel à la prosopographie pour constituer la base de la reconstitution des réseaux se retrouve dans l'analyse de l'ascension des Basnine, marchands et industriels sibériens, de même que la généalogie et l'étude des alliances matrimoniales qui sous-tendent l'analyse de l'élite sucrière martiniquaise

\section{Les concepts et les outils mis en æuvre}

Les concepts qui structurent l'analyse de réseaux sont utilisés avec prudence, rarement explicités et plus rarement discutés et critiqués. La notion de "réseau égocentré » est très largement adoptée, même s'il arrive qu'elle soit critiquée, car elle ne donne qu'un point de vue, centré, celui d'une araignée sur sa toile, sur un ensemble de relations multilatérales. Cette limite est fortement soulignée par Émilie Martinet: la documentation impose une image égocentrée des réseaux de Khouenoukh et de Pépiankh-héri-ib et valorise leur analyse comme "clientèles ", mais on perçoit des liens transverses qui suggèrent d'utiliser le concept de «clique ", c'est-à-dire de groupe parfait, cohésif, à l'intérieur duquel tous les liens possibles sont réalisés et redondants. La clique apparaît rarement parfaite et on parlera de "quasi-clique», faute sans doute de documentations croisées qui mettent en valeur les relations internes d'un groupe, mais on sait que l'on peut percevoir la multilatéralité à travers des correspondances croisées, comme celles des cardinaux avignonnais: la diffusion des chiffres qui codaient leurs lettres secrètes révèle les solidarités les plus fortes, les partis familiaux, les formations 
communes. On notera que plusieurs des documentations et des analyses mettent en valeur la " chaîne » ou " axe horizontal », amorce de réseau ou articulation géographique d'une association ou d'un métier, corporation des gribanniers de la Somme, ou simple représentation graphique d'une solidarité qui s'inscrit dans le temps, comme celle qui va de l'agriculteur au boulanger par le meunier et qu'évoque Patrick Birée, ou encore la transmission des idées politiques dans l'Allemagne $\mathrm{du} \mathrm{XXI}^{\mathrm{e}}$ siècle étudiée par Lionel Picard. L'enchaînement des relations met en valeur des «nœuds » et des relais, comme les intermédiaires du commerce italien des $\mathrm{XIV}^{\mathrm{e}}$ et $\mathrm{XV}^{\mathrm{e}}$ siècles projetés dans l'espace maghrébin ou à Constantinople, des "articulateurs » aussi, comme à la périphérie des « quasi-cliques » de marchands génois et pisans de Palerme où l'on perçoit plusieurs "trous structuraux", situations où un "troisième larron" joue le rôle de nœud indispensable et profitable avec d'autres groupes, notamment à Barcelone, Montpellier et Florence, illustrant l'axiome, bien connu des sociologues, de la «force des liens faibles » qui permettent une circulation renouvelée de l'information et du capital. La pluralité des identités, exprimée par la métaphore de "chauve-souris » permet la pénétration et l'enracinement. On retrouve cette situation dans l'analyse de María Isabel Quintana Marín et Mary Luz Marín Posada : à côté des réseaux volontaires créés par l'ambassade colombienne en France pour quadriller les migrants, un mouvement spontané, «transculturel », suscite des réseaux parallèles indépendants.

La formation des réseaux est en effet une préoccupation générale des historiens: l'opposition entre "réseau donné, hérité » et « réseau construit » est la trame de l'étude de Bénédicte Brun qui confronte les héritages de l'impératrice Irène Doukaina et d'Anna Delasséné à la stratégie d'une princesse étrangère, Marie d'Alanie, qui bâtit ses relations ; cette opposition nourrit les communications de Lucile Hermay et Jack Roskilly, de Philippe Jansen et d'Olivier Lafont. L'alternance entre "réseau centripète " et « centrifuge », introduite par Solange Baudouin, anime le développement, puis le déclin de la fortune des Basnine, grands marchands et industriels sibériens.

La notion de « capital social » schématisée par Pierre Bourdieu dans une vision mécaniste et utilitariste qui le subordonne aux capitaux économiques et culturels (« Avoir des amis, c'est avoir du pouvoir ») est exploitée par Émilie Martinet. Dans l'Égypte pharaonique, son caractère individuel paraît moins assuré: la durée et la stabilité des élites provinciales contrastent avec l'érosion qui frappe les élites palatines, usées par la compétition, et permettent leur renouvellement. On retrouve le concept dans l'analyse de Marie Hardy qui s'appuie sur les listes de témoins de mariage des planteurs de la Martinique; leur présence témoigne justement de l'étendue des liens et sans doute les affiche, mais aussi de la volonté d'intégrer de nouveaux acteurs au réseau, lui donnant un dynamisme sans lui ôter son caractère utilitaire. La présence redoublée d'un ingénieur métropolitain signale une alliance et une inflexion stratégique de la plantation à l'industrie sucrière. Les candidats à l'épiscopat à Byzance peuvent être intégrés à des réseaux familiaux, protégés et promus par «népotisme» (rappelant la formule de Bourdieu, «ce sont les neveux qui font le népotisme »), mais Lucile Hermay et Jack Roskilly font noter la rareté de familles épiscopales et le jeu d'autres ressorts, la solidarité du vivier de formation. Ici c'est l'école ou le monastère de Patmos, dont ont été moines de nombreux évêques. Et il va de soi que marchands génois, toscans et nîmois entrent dans le champ que ce concept éclaire et qui va se prolonger en Italie jusqu'au XXI ${ }^{\mathrm{e}}$ siècle, opposant les communautés septentrionales et tyrrhéniennes à l'articulation souple et multiple aux rigides sociétés méridionales. La transitivité des relations est également évoquée, comme une conjecture qui soutient l'hypothèse plus vaste de « capital social ».

Dans le domaine politique, Romain Marchand introduit le concept d'«intégration», explicité comme une appartenance sans la capacité de diriger. Et dans celui de l'histoire commerciale, d'autres concepts sont critiqués ou omis, comme par un accord implicite ; ce sont ceux qui ont été introduits abusivement à partir d'une idéologie mécaniste : « encastrement », « diaspora marchande », « communauté ». 
Au fond, les historiens sont attachés à la spécificité de leur méthode et de leur discipline, au temps et à l'espace, à la cartographie et à la généalogie, à la mutation et à la diffusion, à l'instabilité. Ils n'utilisent qu'avec une infinie précaution les schémas théoriques et les représentations graphiques qui risquent de figer le temps, d'écraser la chronologie, et d'abolir la diversité de l'espace. L'utilisation du graphe suscite la crainte du schématisme : il réduit la relation à l'essentiel et uniformise sa représentation; si son ordre, sa densité et sa connexité font ressentir des relations encore mal perçues et permettent de les analyser, jouant donc un rôle heuristique peut-être insuffisamment exploré par les historiens, le graphe exprime difficilement l'intensité de ces rapports et le contenu même des relations, il aplatit l'information et risque donc d'être un artefact éloquent, mais menteur. Liens forts et liens faibles ne sont pas aisément représentés, tandis que "nœuds» et "articulateurs» apparaissent à l'évidence. On peut laisser échapper des "éminences grises", dont le rôle a pu être essentiel sans qu'ils se manifestent dans la documentation écrite, tandis que les liens oraux échappent définitivement.

L'espace est partout ou presque mis en valeur: le jeu entre géographique et calendaire met ainsi les foires de Champagne à la confluence des réseaux nationaux et urbains de marchands, des hanses, des cycles de réunions, des réseaux routiers et des réseaux de crédit. Et la cartographie soutient la représentation : espace commerçant de la Sicile, de la Carrière des Indes, espace politique de l'Égypte pharaonique, des Marches et de la Romagne, espace du transport dans la vallée de la Somme.

\section{Les sources}

Les sources sont évidemment très variées, depuis les inscriptions funéraires égyptiennes jusqu'aux analyses de la presse en ligne allemande sur le phénomène trop vite baptisé "populiste", mais elles sont essentiellement discursives : chroniques et hagiographies, mais surtout correspondances d'entreprises et de chefs politiques, papiers de famille, rapports de police, journaux personnels; seuls les actes notariés appartiennent à la pratique juridique, au caractère plus froid, plus objectif. On note l'efficacité de la problématique réticulaire à mettre en œuvre les indices les plus ténus: les réseaux épistolaires sont bavards quand l'éloignement impose d'évoquer, sinon de révéler explicitement, l'état des affaires, les objectifs et les acquis des stratégies mises en œuvre. Ils sont nécessairement prolixes sur les prix, les mouvements de marchandises, de navires qui soutiennent l'économie marchande : toute l'information passe par les lettres. Comme l'a montré Quentin Van Dosselaere, seule la commenda évite de passer par l'étape du choix stratégique des destinations et donc d'une collecte précise de l'information, en confiant la décision à l'associé mandataire, mais au prix d'un rendement inférieur. La correspondance, dans la Cadix du XVIII ${ }^{\mathrm{e}}$ siècle, est aussi nécessaire au fonctionnement de l'entreprise, à la circulation de l'information et à la prise de décision qu'elle l'est dans l'enchevêtrement des alliances négociées par Henri de la Tour d'Auvergne, duc de Bouillon, analysé ici par Romain Marchand.

Les limites de ces sources sont évidentes: c'est d'abord le secret. Romain Marchand évoque l'indispensable part d'oralité dans les relations entre comploteurs. C'est aussi la rareté, qui engendre l'incomplétude. Émilie Martinet évoque le prisme que le monde des morts constitue de la carrière des vivants, mais, partout, la reconstruction du réseau ne peut être qu'hypothétique et indicative. L'usage des sources suppose ensuite l'analyse préalable du langage employé : le ton des lettres n'est pas anonyme, elles prennent le style de l'affectivité et le lexique des valeurs qui unissent les élites communales italiennes, concorde, bien commun, «bon état». C'est au contraire le vocabulaire de la famille et de l'amitié que l'on retrouve dans les correspondances des marchands nîmois étudiés par Robert Chamboredon comme des officiers des seigneuries italiennes de la fin du Moyen Âge, qui constituent une part de la «famille élective » du prince, unie à lui par l'amour réciproque. On observe cet amalgame entre l'expression de la relation de 
dépendance et l'intimité familiale dans les grandes études sur les correspondances politiques et économiques, dans celle de la Carrière des Indes, dans celle de Francesco di Marco Datini, le marchand de Prato, avec ses associés et les directeurs de ses filiales, étudiée par Jérôme Hayez et ici par Ingrid Houssaye Michienzi, comme dans les innombrables billets de la Geniza du Caire analysés et publiés par Salomon D. Goitein et par ses élèves. Le langage de l'amitié n'est pas un simple masque, il lubrifie les rapports hiérarchiques, comme les vertus, la délicatesse exigée des collaborateurs des marchands de Cadix, la bonté, la générosité, la charité des maîtres du sol à la Martinique, ou la sociabilité amicale et nostalgique qui réunit les notables néo-jacobins de l'Hérault à Montplaisir autour de Bernard Barthélemy Luchaire, analysée par Nathalie Alzas.

La nature de ces sources, enfin, focalisées sur l'émetteur des lettres, sur le rédacteur du journal ou du carnet, favorise la construction de schémas autocentrés, egocentrés, de même que le rôle politique ou économique dominant d'une personnalité, haut fonctionnaire égyptien, empereur byzantin, grand seigneur comploteur. L'histoire s'attardant sur les vainqueurs et ignorant les perdants, les laissés pour compte de la compétition économique comme politique, l'échec est ici rarement envisagé, même si son ombre plane sur le duc de Bouillon ou sur Constantin IX Monomaque.

\section{Les éclairages}

Par son absence de rigidité, la problématique réticulaire éclaire l'analyse des relations entre centre et périphérie et la constitution, la coagulation des partis. Elle permet ainsi de percevoir et de nommer les intermédiaires, les articulateurs, entre la Cour et les temples et les sociétés provinciales de l'Égypte pharaonique, de signaler les médiateurs, les «coordinateurs » dans le langage de la sociologie, entre le pouvoir seigneurial de type nouveau, celui de l'État régional, et les communes intégrées dans l'Italie des XIV et XV siècles, de préciser et d'articuler les schémas pluriséculaires de la maison de commerce, depuis l'Avignon des Papes, la Palerme des derniers siècles du Moyen Âge jusqu'à Nîmes et Cadix de l'établissement Fornier. Le noyau familial, renforcé à l'occasion par des mariages endogames, s'appuie sur des réseaux de correspondants et de bailleurs de fonds. La maison Fornier présente ainsi un double modèle : un entonnoir, qui capte et rassemble les épargnes en amont, et une pomme d'arrosoir, en aval, une recherche méthodique des hommes d'affaires locaux "intéressés ", à qui on prêtera pour qu'ils soutiennent l'écoulement des produits. Un point commun et intéressant est l'absence de fermeture religieuse: les huguenots nîmois ont des relais catholiques et sépharades, comme ont des relais juifs et conversos les Pisans de Palerme en Sicile et les Toscans d'Avignon au Maghreb et à Constantinople. Ce sont aussi les conclusions des chercheurs qui ont analysé récemment les papiers de la Geniza et l'implantation des marchands européens dans l'espace indien aux XVI ${ }^{\mathrm{e}}, \mathrm{XVII}^{\mathrm{e}}$ et XVIII ${ }^{\mathrm{e}}$ siècles, Nathalie Goldberg, Kirti N. Chandhuri, Sanjay Subramanyam, et maintenant Francesca Trivellato.

La formation des partis gagne aussi à une approche réticulaire: Henri de La Tour d'Auvergne fonde son rôle politique, celui de «brillant second » du prince de Condé dont il est le bouclier, sur la rencontre d'appuis multiples, les grands, les parlementaires, les protestants, coalition fragile et disparate, mais puissante et dangereuse. C'est le cas aussi de Constantin IX Monomaque : en opposition à l'image de l'empereur cible des réseaux d'influence, Éric Limousin le montre habile stratège, combinant les coalitions, multipliant et assemblant les soutiens, handicapé finalement par l'absence de femmes dans sa maison qui permettraient des alliances matrimoniales. La notion d' " agglomérat » est au centre, comme aussi dans l'analyse que dresse Jean-Paul Streiff du parti libéral dans la Meuse, outil électoral qui rassemble en réseau des éléments disparates, militaires, notables et juristes autour des députés et fédère bonapartistes, républicains et orléanistes. Une position centrale, plus ou moins durable, peut être consolidée par une stratégie d'acquisition du monopole des liens directs, comme l'ont montré John Padgett et Christopher Ansell : la concentration des connexions rejette les concurrents éventuels en bout de ligne et les isole en position dépendante. L'articulation décrite par Philippe 
Jansen, c'est-à-dire la réunion, sans abolition, des réseaux multiples horizontaux de la société communale et des réseaux verticaux mis en place par le prince, combine ainsi la concentration et la dépendance dans l'honneur. Et c'est aussi le cas de la toile d'entreprises tissée par Francesco di Marco Datini, associé majoritaire de chacune et unique lien institutionnel qui les fédérait.

\section{Questions transverses et débats}

La plupart des communications, sinon toutes, posent implicitement ou explicitement le problème des relations entre les réseaux «construits» et la solidarité que l'on dit " naturelle» ou «mécanique » offerte par la parenté. Les réponses offrent une vaste gamme d'appréciations: la famille apparaît généralement comme un outil, successivement noyau, tremplin, réserve et refuge, mais avec une grande variété de solutions. La discipline rigoureuse de la maison sucrière martiniquaise affecte chacun à sa tâche, pilote les mariages et les alliances, met strictement la famille, "réquisitionnée à la cause commune", au service de l'économie ; l'endogamie, dans les limites permises par la loi, est mise en œuvre pour renforcer la solidité du groupe familial. Les maisons de commerce qui opèrent à Palerme combinent l'alliance, y compris à longue distance, pour créer d'efficaces « liens faibles », et le remembrement lignager pour consolider le noyau. L'aristocratie byzantine utilise également l'alliance matrimoniale pour favoriser les parcours individuels: alors que la solidarité familiale est improbable, minée par la compétition, la solidité des pactes passés avec les beaux-frères assure durée et efficace aux partis personnels; l'exogamie rigoureuse imposée par la norme religieuse et la loi impériale permet d'ailleurs de rompre les unions inutiles. La découverte tardive des empêchements légaux permet à l'alliance de suivre les changements de stratégie. D'où l'importance d'un niveau élevé de nuptialité et la nécessité d'avoir des filles et des sœurs à marier. Mais l'imprévisibilité de l'histoire généalogique rétablit le chaos, comme celle des conduites individuelles, tandis que la famille, le nom familial, demeure un drapeau de longue durée, comme le montre l'exemple d'Irène Doukaina.

Le rôle de la communauté, religieuse ou « nationale », au sens médiéval du lieu d'origine et de la langue parlée à la maison, est partout limité : tant à Cadix qu'à Palerme, les réseaux qui animent l'économie ne se conforment pas aux limites communautaires; outre les revendeurs, les courtiers, les "intéressés", des associés et des correspondants permanents se recrutent dans des communautés religieuses différentes, juifs, conversos sépharades, catholiques, et dans des groupes de marchands assez solidaires et souvent en compétition avec celui auquel appartient le réseau, comme les Catalans par rapport aux Pisans à Palerme. La notion de "diaspora marchande » homogène et aboutie est donc écartée, comme la formule de l'«encastrement». Enfin, l'alliance de longue durée entre l'élite économique des "grands békés » avec l'élite politique de couleur, qui occupe durablement, depuis 1870, les fonctions de représentation. Marie Hardy montre qu'il faut renoncer à l'image racialisée d'un bloc « béké » s'opposant à un «bloc » de couleur.

Le rôle central des valeurs est mis en évidence dans l'espace de l'économie : Robert Chamboredon énumère les qualités qui justifient le choix des collaborateurs. Ce ne sont pas les liens familiaux, mais l'honnêteté, la confiance, l'efficacité, la diligence, la sagesse, l'assiduité, la délicatesse enfin. On retrouve dans cette liste les vertus qu'on exige à Prato et à Avignon au XIV siècle, au témoignage de la correspondance de Datini, et à Fustat au $\mathrm{XI}^{\mathrm{e}}$ selon les papiers de la Geniza. En corollaire, le caractère individuel des stratégies est au cœur des analyses et s'étend au domaine politique à Byzance, à la Cour au XVII ${ }^{e}$ siècle, à Lyon à la fin du siècle et au XVIII ${ }^{\mathrm{e}}$.

Un faisceau de concepts secondaires donne au réseau une image moins rigide que dans le modèle sociologique, et même fragile : la multiplicité, entre hérité et acquis, dans les articles d'Olivier Lafont et de Solange Baudouin, le cumul, dans celui de Rosemonde Letricot, l'agglomérat dans ceux d'Éric Limousin, de Lucile Hermay et Jack Roskilly, la complexité dans ceux de Marie Hardy et de Robert Chamboredon, la vulnérabilité aussi 
qui frappe de faillites successives la maison Fornier, la mutabilité, mise en valeur par Solange Baudoin, dans l'analyse des trois étapes de Lenzoto, la versatilité encore soulignée par Lionel Picard, qui invoque aussi la porosité, les glissements, les idées et les attitudes, vrais marqueurs politiques du passage aux partis post-modernes. Cette variété n'est pas synonyme de faiblesse: les réseaux de finance sont plus efficaces que les institutions et contribuent à la durée et à la force de la grande monarchie composite bâtie à partir de l'entreprise napolitaine d'Alphonse le Magnanime et accomplie par Charles Quint. L'articulation par les Basnine de compétences multiples, celles du marchand, du savant, puis de l'entrepreneur minier, enfin du banquier, a fait la fortune de la maison.

Nos communications n'ont pas donné des réponses à toutes les suggestions proposées par les organisateurs du congrès: les signes d'appartenance n'ont guère retenu l'attention, ni la thématique de l'institutionnalisation, et la réponse à la question de la pérennité a été nuancée. C'est le signe même de la vitalité de la recherche et de la fertilité de la réflexion. Au terme de cette présentation, ces communications suggèrent des explorations et des approfondissements : l'ouverture sociale du pouvoir municipal dont témoigne le recrutement des échevins lyonnais incite à nuancer la formule habituelle d'oligarchie. Sur le modèle du recrutement des évêques byzantins, il serait intéressant d'envisager l'épiscopat latin médiéval du point de vue des relations fondées sur l'éducation en commun, dans une Église où les chaînes sont innombrables, ou d'autres sociétés qui ont leur base dans la formation collégiale, comme les Mamlûks. L'État régional princier appuyé sur les réseaux municipaux est un beau modèle pour les monarchies polycentriques, qui combineront concentration des liens et circulation de $l^{\prime}$ «Internationale » des hauts officiers, des juges et des forces militaires signalée par Fernand Braudel. Le choix d'entrer dans les partis politiques, évoqué par Nathalie Alzas et Jean-Paul Streiff, singulièrement dans les partis armés, en pointillé dans la communication de Jérôme Louis, est aujourd'hui de primordiale importance : comment entrait-on dans les Semaines? Quelle sociabilité soutenait l'action clandestine? Il reste aussi sans doute des réflexions à poursuivre: ainsi de la fermeture oligarchique des élites, souvent donnée comme explication du ralentissement économique de l'Italie de la Renaissance; met-elle fin à cette ouverture des réseaux? Il n'en va pas ainsi à la Martinique où elle se combine avec de bonnes relations de voisinage et des collaborations latérales. La suggestion d'une fonction indispensable des réseaux pour compenser et corriger les raideurs des économies planifiées ou des partis politiques modernes pose enfin la question de la durabilité. La construction en réseau des partis post-modernes, explosive, peut-elle déboucher sur une stabilité dynamique ou est-elle le signe et la conséquence d'un délitement? 
L'individu au centre des convergences 



\title{
Pouvoirs locaux et réseaux sous la $\mathrm{VI}^{e}$ dynastie égyptienne (vers 2350 - 2200 avant notre ère) : un exemple des usages et des apports de l'analyse des réseaux en égyptologie
}

\author{
Émilie MARTINET \\ UMR 8167 Orient et Méditerranée \\ Laboratoire « Mondes pharaoniques » - membre associé \\ Extrait de : Henri BRESC (dir.), Réseaux politiques et économiques, Paris,
Édition électronique du CTHS (Actes des congrès des sociétés historiques et scientifiques), 2016. \\ Cet article a été validé par le comité de lecture des Éditions du CTHS dans le cadre de la publication \\ des actes du $140^{\mathrm{e}}$ Congrès national des sociétés historiques et scientifiques tenu à Reims en 2015.
}

Les élites provinciales ont comme particularité d'avoir régulièrement réussi à garder le contrôle des affaires civiles du nome, du temple local ou encore des fondations royales sur plusieurs générations, à l'inverse des élites palatines qui, à cause d'une concurrence plus rude et de la présence de fonctionnaires en plus grand nombre, n'ont pas conservé leur position à la capitale aussi longtemps ${ }^{1}$.

À partir de la $\mathrm{VI}^{\mathrm{e}}$ dynastie, l'obtention de plus en plus régulière du vizirat et de la direction des bureaux centraux fait partie du processus de promotion des élites provinciales ${ }^{2}$. Cette promotion découle notamment de la prise en compte par le pouvoir central des particularités de ces élites.

Malgré l'éloignement géographique des élites provinciales par rapport à la capitale, des liens sont attestés avec les milieux palatins. Quant au pouvoir central, basé à Memphis en Basse-Égypte à l'époque de l'Ancien Empire, il avait besoin de la collaboration des élites locales, notamment de la Haute-Égypte, afin de mener à bien ses projets politiques ${ }^{3}$. L'intégration de ces élites à la structure administrative de l'État a donné le moyen au roi « de jouer le rôle d'arbitre suprême entre les factions", de même que le temps de présence à la Cour a permis de faire converger les intérêts de ces élites locales, éloignées de leur nome, avec ceux de la monarchie ${ }^{4}$.

Il s'agira d'analyser les réseaux personnels de deux dignitaires provinciaux dans le but de proposer une première approche du processus qui a conduit certains membres de l'élite provinciale à obtenir le pouvoir, c'est-à-dire à devenir l'élite dominante dans une province donnée, ainsi qu'à s'élever dans la hiérarchie et à utiliser les éléments de la culture formelle palatine $e^{5}$.

Les trois éléments majeurs qui permettent de définir le rang occupé dans la société sont le revenu, le prestige et le pouvoir ${ }^{6}$. Dans le cadre de cette étude, la notion de capital social

1. J. C. Moreno Garcia, «Introduction. Élites et États tributaires », p. 35-36.

2. É. Martinet, L'administration provinciale à l'Ancien Empire, vol. II, p. 485, 640, 650-651. Il s'agit de notre thèse de doctorat soutenue le 9 décembre 2013 en Sorbonne, dont la publication est en cours de préparation.

3. J. C. Moreno Garcia, «Les temples provinciaux et leur rôle dans l'agriculture institutionnelle de l'Ancien et du Moyen Empire », p. 107-111 ; id., «Introduction. Élites et États tributaires », p. 39-47 ; id., « La gestion sociale de la mémoire dans l'Égypte du III ${ }^{\mathrm{e}}$ millénaire. Les tombes des particuliers, entre utilisation privée et idéologie publique», p. 215-232.

4. J. C. Moreno Garcia, «Introduction. Élites et États tributaires », p. 44.

5. Cf. H. Willems, Les Textes des Sarcophages et la démocratie. Éléments d'une histoire culturelle du Moyen Empire égyptien, p. 26 ; J. C. Moreno Garcia, «Deux familles de potentats provinciaux et les assises de leur pouvoir: Elkab et El-Hawawish sous la VI $\mathrm{I}^{\mathrm{e}}$ dynastie », p. 109.

6. A. Degenne, M. Forsé, Les réseaux sociaux, p. 135. 
est fondamentale 7 . P. Bourdieu le définit comme « l'ensemble des ressources actuelles ou potentielles qui sont liées à la possession d'un réseau durable de relations plus ou moins institutionnalisées d'interconnaissance et d'interreconnaissance ${ }^{8}$. Ainsi, ce n'est pas tant le nombre de contacts qui est déterminant, mais bien l'ensemble des ressources des contacts qui peuvent être mobilisées par ego à son profit ${ }^{9}$.

Il était en effet nécessaire pour les élites provinciales d'avoir des relations et de bénéficier de certaines ressources tant au niveau local, qu'à la capitale. Il s'agira donc d'effectuer une réflexion à deux échelles, comportant à la fois une analyse des stratégies des élites au niveau local centrée sur l'étude des relations sociales entre les personnes, mais également entre les institutions et les personnes, et une analyse des liens avec le pouvoir royal et la Cour. À partir de l'étude d'un petit nombre de réseaux à l'aide du logiciel Gephi, il est possible de mettre en évidence les réseaux qui structuraient les sociétés provinciales et d'analyser le processus par lequel un fonctionnaire provincial a pu accéder à un statut social plus élevé.

\section{L'étude des réseaux en égyptologie}

Bien que l'étude de la société égyptienne ancienne et des réseaux sociaux du III millénaire avant notre ère soit présente dans les problématiques de recherche actuelles ${ }^{10}$, l'analyse quantitative et systématique de ces réseaux, à l'aide de logiciels ${ }^{11}$ et d'une technique issue des travaux de la sociologie, a rarement été appliquée aux données de cette époque ${ }^{12}$. En ce qui concerne les périodes postérieures à l'Ancien Empire, il faut noter l'application récente de la social network analysis aux élites locales datées du Nouvel Empire $^{13}$ et de l'époque byzantine ${ }^{14}$.

Pour étudier les élites provinciales et reconstruire les réseaux, il est possible d'utiliser les inscriptions qui se trouvent sur les monuments funéraires (parois des tombes (fig. I), stèles et statues inscrites), les archives conservées sur des papyrus, ainsi que les inscriptions qui se trouvent sur divers objets offerts à des membres de l'élite locale et qui ont été entreposés dans leurs tombes. Par exemple, le riche matériel qui provient des tombes de la nécropole de Qoubbet el-Hawa ${ }^{15}$, située dans le $1^{\text {er }}$ nome de Haute-Égypte à l'extrémité sud du pays, comprend des vases inscrits à l'encre qui permettent de reconstituer des réseaux de clientèle ${ }^{16}$. En effet, ces vases qui représentaient des offrandes destinées au défunt contribuent à faire le lien entre plusieurs personnes, dans la mesure où les noms et les titres des personnes qui ont présenté des offrandes, ainsi que la nature de celles-ci, sont précisés ${ }^{17}$. Quant aux inscriptions biographiques gravées dans les

7. Concernant cette notion, cf. P. Mercklé, Sociologie des réseaux sociaux, p. 42-47; A. Degenne, M. Forsé, Les réseaux sociaux, p. 123-154.

8. P. Bourdieu, « Le capital social : notes provisoires », p. 2.

9. A. Degenne, M. Forsé, Les réseaux sociaux, p. 134-136.

10. Cf. S. Donnat, J. C. Moreno Garcia, «Intégration du mort dans la vie sociale égyptienne à la fin du troisième millénaire avant J.-C.», p. 179-207; D. Vischak, Community and Identity in Ancient Egypt. The Old Kingdom Cemetery at Qubbet el-Hawa; H. Willems, «Zum sozialen Hintergrund der Bestimmungen des N.y-kA-anx bei Tihna al-Jabal », p. 241-262.

11. Cf. notamment Gephi, NodeXL, PAJEK, SocNetV, Tulip, UCINET et yED.

12. $C f$. la très récente communication de V. Dulíková et R. Marík intitulée « Social Network Analysis in the Old Kingdom Society : a Nepotism Case » à l'occasion du colloque Abousir et Saqqara qui a eu lieu du 22 au 26 juin 2015 à Prague.

13. Cf. le poster de V. Chollier intitulé «Analyzing Elites Networks in Ancient Egypt: Thinking about Methodological Solutions » et présenté à Gand en 2014. V. Chollier prépare actuellement une thèse de doctorat intitulée Administrer les cultes provinciaux au Nouvel Empire. Stratégies sociales et territoriales (université Lyon 2).

14. G. Ruffini, Social Networks in Byzantine Egypt.

15. M. Höveler-Müller, Funde aus dem Grab 88 der Qubbet el-Hawa bei Assuan (Die Bonner Bestände); id., "'Tales from the Crypt' : What the Inscribed Pottery from the Qubbet el-Hawa Can Tell Us », p. 254-265.

16. S. Donnat, J. C. Moreno Garcia, «Intégration du mort dans la vie sociale égyptienne à la fin du troisième millénaire avant J.-C. », p. 198. Des centaines de vases ont été trouvés dans les tombes de cette nécropole. 17. Ibid., p. 198 
tombes, elles peuvent également apporter des informations supplémentaires sur les réseaux personnels.

À partir des données qui proviennent des tombes (fig. I), il est possible de reconstituer le réseau de parenté, puisque les membres de la famille du défunt sont mentionnés (ses parents, son épouse, ses frères, ses enfants et même ses petits-enfants). Les noms, les titres et le rang détenu dans la société sont également indiqués. La nature du lien de parenté est minutieusement décrite. Malgré l'insuffisance des sources et leur caractère sélectif, celles-ci témoignent de l'importance des liens familiaux dans la société provinciale. Cette importance des liens de parenté en province va de pair avec « une forte conscience d'appartenance à des lignages prestigieux » dans la société provinciale qui a été mise en évidence par J. C. Moreno Garcia ${ }^{18}$. De même, dans sa tombe, le défunt a souhaité que soient mentionnés tous ses subordonnés qui sont représentés dans le cadre d'activités quotidiennes. Leur nom, leurs fonctions ainsi que leur titre de rang, s'ils en avaient un, sont précisés (fig. I).

Malgré certaines limites, ces sources se prêtent tout à fait à une social network analysis. Ce type de sources permet en effet de reconstituer des réseaux égocentrés, c'est-à-dire des réseaux personnels centrés sur ego. Le réseau personnel peut être défini comme un " ensemble formé d'un individu, des individus qui sont en relation directe avec lui, et des relations que ces individus entretiennent les uns avec les autres $"{ }^{19}$. Notre étude dépasse ce cadre dans la mesure où il s'agit également de nous intéresser au rôle de certaines institutions qui permettaient de mettre en contact les personnes au sein d'un réseau personnel. Ces liens sont notamment perceptibles par la présence de certains titres relatifs à une ou plusieurs institutions, que ce soit au niveau local ou au niveau central, dans les titulatures des membres du réseau.

\section{Analyse de réseaux et problèmes méthodologiques}

Dans le cadre de cette analyse, il est intéressant de se concentrer sur les réseaux des dignitaires du $14^{\mathrm{e}}$ nome. En effet, cette province de Haute-Égypte se distingue de la plupart des autres, tant par le nombre élevé de personnes répertoriées ${ }^{20}$ que par l'importance du rang détenu par les plus hauts fonctionnaires qui y ont été inhumés sous la $\mathrm{VI}^{\mathrm{e}}$ dynastie ${ }^{21}$. Par ailleurs, en l'état actuel de nos connaissances, certains dignitaires de cette province disposaient des réseaux d'influence les plus étendus de la Haute-Égypte.

\section{Le réseau de Khouenoukh (fig. II)}

Khouenoukh, qui a été inhumé à Qoseir dans le $14^{\mathrm{e}}$ nome de Haute-Égypte (fig. I), était un responsable du temple local dédié à la déesse Hathor ${ }^{22}$.

Les inscriptions qui proviennent de sa tombe ${ }^{23}$ ont permis de reconstituer son réseau (fig. II). Outre les relations entre les personnes, nous avons également fait apparaître les

18. Ibid., p. 189-190.

19. P. Mercklé, Sociologie des réseaux sociaux, p. 32 ; J. L. Moreno, Who shall survive?, tr. fr. Fondements de la sociométrie.

20. Un peu plus de 200 personnes portant au moins un titre sont attestées dans le $14^{\text {e }}$ nome de Haute-Égypte. Ce chiffre tient compte des propriétaires des tombes et des autres titulaires d'une charge représentés sur les parois de ces tombes. Cf. A. El-Khouli, N. Kanawati, Quseir el-Amarna. The Tombs of Pepy-ankh and Khewen-wekh; A. M. Blackman, M. R. Apted, The Rock Tombs of Meir V ; N. Kanawati, The Cemetery of Meir I. The Tomb of Pepyankh the Middle ; M. Blackman, The Rock Tombs of Meir IV.

21. Par exemple, Pépi-ankh-héri-ib a exercé les charges de vizir, de directeur de Haute-Égypte et de directeur d'au moins un service central. Il était également chargé de la gestion du temple d'Hathor. Cf. É. Martinet, « La structure administrative du $14^{\mathrm{e}}$ nome de Haute-Égypte et le développement de 1'administration supraprovinciale sous la VIe dynastie » (Bulletin de l'Institut Français d'Archéologie Orientale 115, 2015, p. 299-324) ; id., Le nomarque sous l'Ancien Empire, p. 206-207.

22. A. El-Khouli, N. Kanawati, Quseir el-Amarna. The Tombs of Pepy-ankh and Khewen-wekh, p. 33-57, pl. 32, 34, 35, $36 \mathrm{ab}, 37,38,40$.

23. Tombe 2 à Qoseir el-Amarna : ibid., p. 33-57, pl. 32-46. 
liens entre les personnes et deux institutions : celle du temple qui avait une importance considérable au niveau local en tant que pôle de pouvoir ${ }^{24}$, et celle du per-âa, " Grand Palais ", institution à laquelle étaient rattachées les personnes qui appartenaient donc à $l^{\prime}$ administration palatine ${ }^{25}$. La présence de membres de l'administration palatine en province était liée à la nécessité d'assurer un contrôle des institutions centrales par l'État "bureaucratisé ${ }^{26}$. Les relations entre les individus et ces deux institutions peuvent être déduites à partir des titres portés par certains membres du réseau et qui sont mentionnés dans la tombe de Khouenoukh ${ }^{27}$.

Ce réseau est bien évidemment hiérarchisé autour du propriétaire de la tombe, et il peut être décomposé en deux sous-graphes.

Le réseau de parenté (fig. II, en bleu) se caractérise par une forte densité. En effet, les relations entre chacune des personnes mentionnées peuvent être établies; ce sont des liens forts. Ce réseau de parenté peut être qualifié de clique, puisque toutes les personnes se connaissaient.

Quant à la représentation et à l'analyse du réseau de dépendance (fig. II, en rouge), nous avons rencontré davantage de difficultés. Si l'existence d'un lien hiérarchique avec le propriétaire de la tombe est évidente, les sources dont nous disposons ne permettent pas de vérifier l'existence ou non de contacts entre les subalternes eux-mêmes. Nous avons donc fait le choix de représenter en pointillé les liens entre les différents subordonnés. Il y avait probablement des liens entre eux, dans la mesure où ils sont bien mentionnés dans une même tombe et qu'ils étaient subordonnés à la même personne. Cette problématique rejoint la question de la "transitivité » des relations ${ }^{28}$. En effet, si ego avait des contacts avec dépendant 1 et avec dépendant 2 , il est possible d'envisager que dépendant 1 et dépendant 2 étaient en relation ${ }^{29}$. Néanmoins, il convient de rester prudent: ces subordonnés n'ont peut-être pas tous exercé leurs charges en même temps. Cependant, il existe une exception pour les subalternes 1 et 4 qui dépendaient d'ego et qui étaient également rattachés à l'administration palatine ( $c f$. fig. II). Du fait de leur appartenance à cette institution, ils étaient reliés entre eux de façon indirecte. Il est difficile de savoir s'ils avaient un quelconque lien direct, car nous ne savons pas s'ils ont été présents en même temps dans la province. Nous avons représenté en pointillé les liens entre le temple local et les dépendants 2,3 et 5 , dans la mesure où ceux-ci avaient des responsabilités dans la gestion des troupeaux qui appartenaient peut-être au temple local ${ }^{30}$.

Si les liens directs ne sont pas connus entre les membres du réseau de parenté de Khouenoukh et ses dépendants, il est possible d'évoquer la présence de liens indirects qui passent tous par ego. Par ailleurs, Khouenoukh était également rattaché à l'administration palatine par deux chemins différents, c'est-à-dire par des liens indirects (dépendant 1 et dépendant 4). Il a probablement eu des liens directs avec la Cour au cours de sa carrière. En effet, sur l'ensemble de sa titulature (vingt-cinq titres), trois semblent impliquer l'existence de fonctions palatines qui ont probablement été exercées à la capitale avant son retour en province ${ }^{31}$.

24. J. C. Moreno Garcia, «Les temples provinciaux et leur rôle dans l'agriculture institutionnelle de l'Ancien et du Moyen Empire », p. 96, 98-99, 102, 105-107 ; R. Bußmann, Die Provinztempel Ägyptens von der 0. bis zur 11. Dynastie. Archäologie und Geschichte einer gesellschaftlichen Institution zwischen Residenz und Provinz, I : Text, p. 10, 506-512.

25. O. Goelet, « The Nature of the Term pr-'3 during the Old-Kingdom », p. 77-90.

26. M. G. Morony, «'In a City without Watchdogs the Fox is the Overseer' : Issues and Problems in the Study of Bureaucracy », p. 10-15; M. Trapani, « Anthropologie politique de l'Ancien Empire égyptien : fonctionnaires de cour et fonctionnaires provinciaux », p. 48, n. 16.

27. Cf. A. El-Khouli, N. Kanawati, Quseir el-Amarna. The Tombs of Pepy-ankh and Khewen-wekh, p. 33-57, pl. 44.

28. Pour un état de la question, cf. P. Mercklé, Sociologie des réseaux sociaux, p. 63-65.

29. Il s'agit d'une probabilité et non d'une loi : cf. les travaux de B. Wellman, « Network analysis : some basic principles », p. 155-200.

30. A. El-Khouli, N. Kanawati, Quseir el-Amarna. The Tombs of Pepy-ankh and Khewen-wekh, pl. 32, 35, 37, 41, 44, 46b.

31. Ibid., pl. 12, 17, 32-34, 36a, 37-38, 40 ; É. Martinet, L'administration provinciale sous l'Ancien Empire, vol. II, p. 493-494. 
Ce réseau montre que les sphères publiques et privées n'étaient pas cloisonnées. Les données apportent des informations tant sur les liens familiaux de Khouenoukh que sur le réseau administratif de ce dignitaire local.

\section{Le réseau de Pépi-ankh-héri-ib (fig. III)}

Pépi-ankh-héri-ib de Meir (14 ${ }^{\mathrm{e}}$ nome de Haute-Égypte) (fig. I) a obtenu la direction de la Haute-Égypte, ainsi que le titre de vizir ${ }^{32}$ qui correspond à la fonction la plus élevée dans l'administration centrale. En l'état actuel de nos connaissances, il s'agit du réseau le plus étendu connu en Haute-Égypte, ce qui témoigne de l'influence de ce haut fonctionnaire à la fin de 1'Ancien Empire. En effet, vingt-six membres de sa famille (liés par le sang ou par alliance) sont représentés dans sa tombe ${ }^{33}$, ainsi que quatre-vingt-dix-sept personnes qui appartenaient à son réseau de dépendance ${ }^{34}$ mais $n^{\prime}$ avaient pas de lien de parenté avéré avec le propriétaire de la tombe. En raison du nombre élevé de personnes, un code composé d'une lettre et d'un chiffre a été attribué à chacune d'entre elles. Les membres du réseau de parenté ont un code qui commence par la lettre p. La numérotation des différents membres de sa famille a été effectuée à partir de l'ordre suivant : ascendants, collatéraux, parents liés par alliance et descendants. Quant aux membres du réseau de dépendance, des codes composés à partir de la lettre $\mathbf{d}$ leur ont été attribués. Le chiffre qui suit la lettre $\mathbf{d}$ rend compte de la position de chacun des individus dans l'ordre " alphabétique» égyptien. Ainsi, le code d16 a été attribué au seizième membre du réseau de dépendance suivant l'ordre "alphabétique " égyptien. Par ailleurs, les personnes sont représentées par des « ronds »-il s'agit en fait de nœuds reliés entre eux par des liens - dont la taille est proportionnelle au nombre de liens connus. Quant aux institutions, comme le temple local, elles sont représentées par des « carrés ».

Le réseau de Pépi-ankh-héri-ib est composé de cinq sous-ensembles plus ou moins bien reliés entre eux (fig. III). Au total, nous avons répertorié 604 liens à partir des sources dont nous disposons. Une partie du réseau (en bleu) est isolée du reste du réseau, dans la mesure il n'a pas été possible de déterminer l'existence de liens avec les autres personnes mentionnées dans la tombe. Il s'agit de subordonnés reliés par une relation de dépendance au propriétaire de la tombe. Quant au réseau de parenté (en violet), il est très dense puisque l'ensemble des membres se connaissaient. Le sous-ensemble qui est figuré en vert est un des plus intéressants, dans la mesure où des membres du réseau de parenté et de dépendance sont mis en relation. L'institution du temple local a permis de mettre en contact des personnes de statut divers et qui détenaient des titres relatifs au temple local et à son fonctionnement. En effet, au moins $17 \%$ des membres du réseau ayant au moins un titre détenaient des responsabilités en rapport avec le temple local $^{35}$.

Certains subalternes occupent une position d'intermédiaire en raison de leurs liens avec d'autres membres du réseau. Il faut ainsi noter que d33 et d53 possèdent une position centrale dans le réseau. En effet, d33 a des liens directs avec vingt personnes, alors qu'il ne semble pas appartenir à la famille de Pépi-ankh-héri-ib ${ }^{36}$. Il est à la fois en contact avec des membres de la famille d'ego et avec des personnes de rang moins élevé qui n'avaient pas de lien de parenté avéré avec Pépi-ankh-héri-ib. Il s'agit vraisemblablement d'un courtisan originaire de la capitale qui appartenait donc à d'autres réseaux de pouvoir ${ }^{37}$. De même, d53 détient des liens directs avec vingt-trois personnes. Ces deux personnes jouaient probablement un rôle d'articulateur entre certains membres du réseau de parenté et les subalternes. Si ces deux acteurs étaient supprimés du graphe, cela affaiblirait la connexité du réseau. De plus, nous avons indiqué des liens entre tous les détenteurs du titre hrj-tp nzwt, «premier avec le roi » qui est porté par quinze membres

32. N. Kanawati, The Cemetery of Meir I. The Tomb of Pepyankh the Middle, pl. 75a-b, 76, 83-87.

33. Tombe D2 à Meir (14 ${ }^{\text {ème }}$ nome de Haute-Égypte) : ibid., p. 13-19, pl. 76ab, 79-85, 88-89.

34. Ibid., p. 19-24, pl. 75def, 79-85, 88-89.

35. Ibid., pl. 75e, 76ab, 79-85, 88. Seize personnes sur quatre-vingt-seize personnes connues par au moins un titre avaient des charges en rapport avec le temple local et son fonctionnement.

36. Il s'agit de Niankhkhénémou : ibid., pl. 79, 81-82, 84-85, 89.

37. É. Martinet, L'administration provinciale à l'Ancien Empire, vol. II, p. 198-201. 
de ce réseau ${ }^{38}$ et qui représentaient une partie des agents locaux du roi basés dans cette province.

Enfin, les sous-ensembles représentés en jaune et en rouge et qui comprennent également des individus faisant partie d'autres sous-ensembles regroupent les personnes qui appartenaient à l'administration palatine et avaient des liens avec la Cour, ainsi que les personnes rattachées à l'administration d'État. Les membres de la famille de Pépi-ankhhéri-ib et les personnes de rang moins élevé qui portent des titres comprenant les termes «Grand Palais » dépendaient de l'administration palatine. Pépi-ankh-héri-ib se trouvait donc relié à cette institution centrale de façon indirecte par l'intermédiaire de sept personnes (p8, p17, p19, d33, d38, d82 et d90). Au total, $30 \%$ des membres du réseau possédaient un lien plus ou moins important à l'État ou à la Cour, qu'il s'agisse de fonctionnaires reliés à l'État ou à la Cour, ou d'agents locaux du roi ${ }^{39}$.

\section{Conclusions}

\section{Réseaux, ressources et pouvoir}

Le réseau de Pépi-ankh-héri-ib (fig. III) permet d'analyser le processus de formation et de circulation des élites locales. Pépi-ankh-héri-ib était relié à la capitale par l'intermédiaire de membres de son réseau rattachés à l'administration palatine et ayant des contacts avec la Cour. Ce n'est pas tant la taille du réseau qui a été déterminante dans ce processus, mais plutôt la position occupée par certains membres du réseau. Si l'étendue du réseau d'influence de Pépi-ankh-héri-ib a contribué à augmenter son pouvoir, l'appartenance de certains membres de son entourage à d'autres réseaux et à d'autres sphères de pouvoir a joué un rôle prépondérant. La présence d'agents locaux du roi et de membres de l'administration palatine auprès de lui est révélatrice de l'étendue géographique de son influence. Son réseau a sans doute contribué à lui faire obtenir une position sociale plus élevée, ainsi que de hautes fonctions dans l'administration. La mention de l'ensemble des subalternes dans les tombes des élites correspondait à une volonté de les intégrer dans "a specific social system and hierarchy " ${ }^{40}$ et à l'existence de réseaux sociaux basés sur des relations de patronage ${ }^{41}$.

L'importance des connexions des membres des réseaux de Khouenoukh et de Pépi-ankhhéri-ib avec le temple local est également un élément important dans la montée en puissance des élites locales. En effet, les élites de cette province semblent s'être appuyées sur le temple, afin de s'élever dans la hiérarchie et de bénéficier d'une influence dans la province et à la capitale ${ }^{42}$. Il faut donc noter l'importance du rôle du temple local dans leur enrichissement et comme assise territoriale de leur pouvoir. De plus, l'institution du temple local a certainement joué un rôle dans l'organisation des relations sociales, permettant de mettre en contact des personnes qui appartenaient à différentes strates de la société et dont certaines étaient reliées à l'administration palatine.

\section{Les apports de l'analyse des réseaux sociaux en égyptologie}

L'approche formalisée des réseaux confirme certains éléments perçus par l'approche intuitive et qualitative et permet d'avoir une vision plus fine de la structure des organisations sociales des élites provinciales datées de la fin du troisième millénaire avant notre ère. Elle contribue par ailleurs à mettre en évidence la position particulière de

38. N. Kanawati, The Cemetery of Meir I. The Tomb of Pepyankh the Middle, pl. 75d, 76b, 79-81, 83-84, 88-89.

39. É. Martinet, L'administration provinciale sous l'Ancien Empire, vol. II, p. 506.

40. M. Bárta, «Egyptian Kingship during the Old Kingdom », p. 275.

41. Ibid., p. 275 ; J. C. Moreno Garcia, "The 'Other' Administration : Patronage System and Informal Networks of Power in Ancient Egypt », p. 1050.

42. É. Martinet, «La structure administrative du $14^{\mathrm{e}}$ nome de Haute-Égypte et le développement de l'administration supra-provinciale sous la VIe dynastie », p. 299-324. 
certains membres à l'intérieur du réseau et à mieux cerner les stratégies sociales des élites. La combinaison des deux approches est intéressante, notamment dans le cadre de très grands réseaux sociaux qui impliquent un nombre élevé de personnes et dont l'analyse n'est pas possible sans l'utilisation de l'informatique. Cette approche permet ainsi d'envisager une analyse systématique et comparative de ces réseaux sociaux.

Cette étude dépasse le cadre de la notion de réseau personnel. En effet, les sources que nous avons utilisées contribuent à analyser à la fois les relations entre les personnes, mais également entre les personnes et les institutions. Dans la mesure où nous avons constaté que ces réseaux personnels et réseaux administratifs étaient imbriqués, les termes de « réseau de pouvoir » ou " réseau d'influence » devraient être utilisés de préférence dans le cadre de cette étude, car ils permettent d'intégrer l'ensemble des personnes ayant eu un lien avec le propriétaire de la tombe.

\title{
Les limites de l'analyse des réseaux sociaux en égyptologie
}

Il faut bien évidemment souligner le caractère partiel et fragmentaire des sources pour des époques aussi reculées dans le temps. Ce sont surtout les élites, et notamment les hommes, dont il est possible de reconstituer les réseaux personnels, qui peuvent faire l'objet d'une analyse de réseau ${ }^{43}$. En effet, les sources dont nous disposons ne portent que sur quelques membres de l'élite, c'est-à-dire sur les personnes qui avaient les moyens de parvenir à se faire construire des tombes décorées et inscrites.

Par ailleurs, il s'agit de sources indirectes dans la mesure où les données utilisées proviennent majoritairement des tombes, lesquelles pourraient a priori fournir davantage d'informations sur des éléments d'ordre funéraire que sur la structure des organisations sociales.

Notre connaissance des réseaux personnels de la très haute Antiquité reste donc très incomplète ${ }^{44}$. En effet, ce type de sources ne permet d'avoir qu'une perception unilatérale du point de vue d'ego et non bilatérale. Il est rarement possible d'évaluer l'existence des liens entre les subalternes. De plus, la présence de cimetières secondaires autour de nécropoles principales témoigne de l'existence de réseaux de dépendance, cependant l'identité et le rôle précis des personnes concernées ne sont pas toujours connus. Dans le $14^{\mathrm{e}}$ nome de Haute-Égypte, des personnes ayant appartenu aux réseaux étudiés plus haut ne sont pas connues dans la mesure où les sources qui les mentionnaient n'ont pas été conservées ou n'ont pas encore été trouvées.

\begin{abstract}
Résumé
Les inscriptions qui proviennent des tombes des élites provinciales datées de la $\mathrm{VI}^{\mathrm{e}}$ dynastie (2350 à 2200 avant notre ère) permettent de mettre en évidence les réseaux qui structuraient la société provinciale en Égypte ancienne à cette époque. À partir de l'étude d'un petit nombre de réseaux égocentrés, il est possible d'analyser le processus par lequel le fonctionnaire principal peut accéder à un statut social plus élevé. Si l'étendue du réseau contribue à augmenter son pouvoir, les liens de certains des membres du réseau avec différentes sphères du pouvoir et leur appartenance à d'autres réseaux sont déterminants dans ce processus. Ces deux exemples de réseau permettront de proposer un aperçu des nouvelles perspectives de recherche offertes par la social network analysis en égyptologie.
\end{abstract}

43. Cf. M. Bertrand, C. Lemercier, «Introduction : où en est l'analyse de réseaux en histoire ? », p. 12-23.

44. $C f$. les limites de ces méthodes en l'égyptologie de ces méthodes évoquées par V. Chollier, «Analyzing Elites Networks in Ancient Egypt: Thinking about Methodological Solutions » (poster), Gand, Historical Network Research Conference, 18-19 septembre 2014. 


\section{Bibliographie}

BÁRTA Miroslav, "Egyptian Kingship during the Old Kingdom», dans HILL Jane A., JONES Philip, MORALES Antonio J. (éd.), Experiencing Power, Generating Authority. Cosmos, Politics, and the Ideology of Kingship in Ancient Egypt and Mesopotamia, Philadelphie, Upenn, 2013, p. 257-283.

BERTRAND Michel, LEMERCIER Claire, «Introduction: où en est l'analyse de réseaux en histoire? », Revista hispana para el análisis de redes sociales, vol. 21, décembre 2011, p. 12-23.

Blackman AYLWARD Manley, The Rock Tombs of Meir IV, Londres, Egypt Exploration Society (Archaeological Survey of Egypt, 25), 1924.

BlackMAn AYlWARD Manley, APTED Michael R., The Rock Tombs of Meir V, Londres, Egypt Exploration Society (Archaeological Survey of Egypt, 28), 1953.

BOURDIEU Pierre, «Le capital social: notes provisoires", Actes de la recherche en sciences sociales, $\mathrm{n}^{\circ} 3,1980$, p. 2-3.

BubMANN Richard, Die Provinztempel Ägyptens von der 0. bis zur 11. Dynastie. Archäologie und Geschichte einer gesellschaftlichen Institution zwischen Residenz und Provinz, I: Text, Leyde, Boston, Brill (Probleme der Ägyptologie, 30), 2010.

CHOLLIER Vincent, "Analyzing Elites Networks in Ancient Egypt: Thinking about Methodological Solutions » (poster), Gand, Historical Network Research Conference, 1819 septembre 2014.

DegenNe Alain, Forsé Michel, Les réseaux sociaux, 2éd., Paris, Armand Colin, 2004.

DONNAT Sylvie, MORENO GARCIA Juan Carlos, «Intégration du mort dans la vie sociale égyptienne à la fin du troisième millénaire avant J.-C.», dans MOUTON Alice, PATRIER Julie (éd.), Life, Death and Coming of Age in Antiquity: Individual Rites of Passage in the Ancient Near East and adjacent Regions, Leyde, Nederlands Instituut voor het Nabije Oosten te Leiden, 2015, p. 179-207.

DulíKOVÁ Veronika, MARíK Radef, "Social Network Analysis in the Old Kingdom Society : a Nepotism Case », dans BARTÁ Miroslav, COPPENS Filip, KREJCí Jaromír (éd.), Abusir and Saqqara in the Year 2015, Prague, Czech Institute of Egyptology (à paraître).

El-Khouli Ali, Kanawati Naguib, Quseir el-Amarna. The Tombs of Pepy-ankh and Khewenwekh, Sydney, The Australian Centre for Egyptology (Reports, 1), 1989.

GOELET Ogden, «The Nature of the Term pr-' 3 during the Old-Kingdom », Bulletin of the Egyptological Seminar 10, 1989/90, p. 77-90.

HÖVELER-MÜLLER Michael, Funde aus dem Grab 88 der Qubbet el-Hawa bei Assuan (Die Bonner Bestände), Wiesbaden, Harrassowitz (Bonner Sammlung von Aegyptiaca, 5), 2006.

HÖVELER-MÜLLER Michael, «'Tales from the Crypt' : What the Inscribed Pottery from the Qubbet el-Hawa Can Tell Us », dans MOREnZ Ludwig David, HÖVELER-MÜLLER Michael, EL-HAWARY Amr (éd.), Zwischen den Welten: Grabfunde von Ägyptens Südgrenze, Rahden, Marie Leidorf, 2011, p. 254-265.

Kanawati Naguib, The Cemetery of Meir I. The Tomb of Pepyankh the Middle, Oxford, The Australian Centre for Egyptology (Reports 31), 2012.

MARTINET Émilie, Le nomarque sous l'Ancien Empire, Paris, PUPS, 2011. 
MARTINET Émilie, «La structure administrative du $14^{\mathrm{e}}$ nome de Haute-Égypte et le développement de l'administration supra-provinciale sous la $\mathrm{VI}^{\mathrm{e}}$ dynastie », Bulletin de l'Institut Français d'Archéologie Orientale 115, 2015, p. 299-324.

MARTINET Émilie, L'administration provinciale à l'Ancien Empire, Paris, Paris-Sorbonne, 9 décembre 2013, 2 vol. (thèse de doctorat dont la publication est en cours de préparation).

MerCKLÉ Pierre, Sociologie des réseaux sociaux, 2e éd., Paris, éd. La Découverte, 2011.

MORENO Jacob Levy, Who shall survive?, 1943, tr. fr. Fondements de la sociométrie, Paris, PUF, 1954.

MORENO GARCiA Juan Carlos, «Deux familles de potentats provinciaux et les assises de leur pouvoir : Elkab et El-Hawawish sous la VI dynastie », Revue d'Égyptologie 56, 2005, p. $95-128$.

MORENO GARCIA Juan Carlos, «Les temples provinciaux et leur rôle dans l'agriculture institutionnelle de l'Ancien et du Moyen Empire », dans MORENO GARCIA Juan Carlos (éd.), L'agriculture institutionnelle en Égypte ancienne: état de la question et perspectives interdisciplinaires, Villeneuve-d'Ascq, Université Charles-de-Gaulle - Lille 3 (Cahiers de Recherche de l'Institut de Papyrologie et d'Égyptologie de Lille 25), 2006, p. 93-124.

MORENO GARCIA Juan Carlos, «La gestion sociale de la mémoire dans l'Égypte du III millénaire. Les tombes des particuliers, entre utilisation privée et idéologie publique », dans FITZENREITER Martin, HERB Michael (éd.), Dekorierte Grabanlagen im Alten Reich-Methodik und Interpretation, Londres, Golden House Publications (Internet-Beiträge zur Ägyptologie und Sudanarchäologie, 6), 2006, p. 215-232.

MORENO GARCIA Juan Carlos, «Introduction. Élites et états tributaires : le cas de l'Égypte pharaonique", dans MORENO GARCIA Juan Carlos (éd.), Élites et pouvoir en Egypte ancienne, Villeneuve d'Ascq, Université Charles-de-Gaulle - Lille 3 (Cahiers de Recherche de I'institut de Papyrologie et d'Égyptologie de Lille, 28), 2009-2010, p. 11-50.

MorenO Garcia Juan Carlos, "The 'Other' Administration: Patronage System and Informal Networks of Power in Ancient Egypt », dans MORENO GARCIA Juan Carlos (éd.), Ancient Egyptian Administration, HdO, I.104, Boston, Leyde, Brill, 2013, p. 1029-1066.

MORONY Michael Gregory, "'In a City without Watchdogs the Fox is the Overseer': Issues and Problems in the Study of Bureaucracy », dans GIBSON McGuire, BIGGS REDFORD D. (éd.), The Organization of Power. Aspects of Bureaucraty in the Ancien Near East, Chicago, The Oriental Intitute of the University of Chicago (Studies in Ancient Oriental Civilizations, 46), 1987, p. 10-15.

RuFFINI Giovanni, Social Networks in Byzantine Egypt, Cambridge University Press, New York, 2008.

TRAPANI Marcella, «Anthropologie politique de l'Ancien Empire égyptien: fonctionnaires de cour et fonctionnaires provinciaux", dans MENU Bernadette (éd.), Égypte pharaonique : déconcentration, cosmopolitisme, Paris, éd. L'Harmattan (Méditerranées, 24), 2000, p. 41-52.

VISCHAK Deborah, Community and Identity in Ancient Egypt. The Old Kingdom Cemetery at Qubbet el-Hawa, Cambridge University Press, New York, 2015.

WELLMAN Barry, "Network analysis: some basic principles», dans COLLINS Randall (éd.), Sociological Theory, vol. 1, San Francisco, Jossey-Bass, 1983, p. 155-200. 
WiLlems Harco, Les Textes des Sarcophages et la démocratie. Éléments d'une histoire culturelle du Moyen Empire égyptien, Paris, Cybèle, 2008.

Willems Harco, «Zum sozialen Hintergrund der Bestimmungen des N.y-kA-anx bei Tihna al-Jabal », dans FISCHER-ELFERT Hans-Werner, PARKINSON Richard B. (éd.), Studies on the Middle Kingdom. In Memory of Detlef Franke, Wiesbaden, Harrassowitz (Marburger altertumskundliche Abhandlungen, 41), 2013, p. 241-262.

\section{Illustrations}

Figure I : Pépi-ankh-héri-ib et les membres de son réseau représentés sur les parois de sa tombe à Meir (tombe D2, 14 nome de Haute-Égypte).
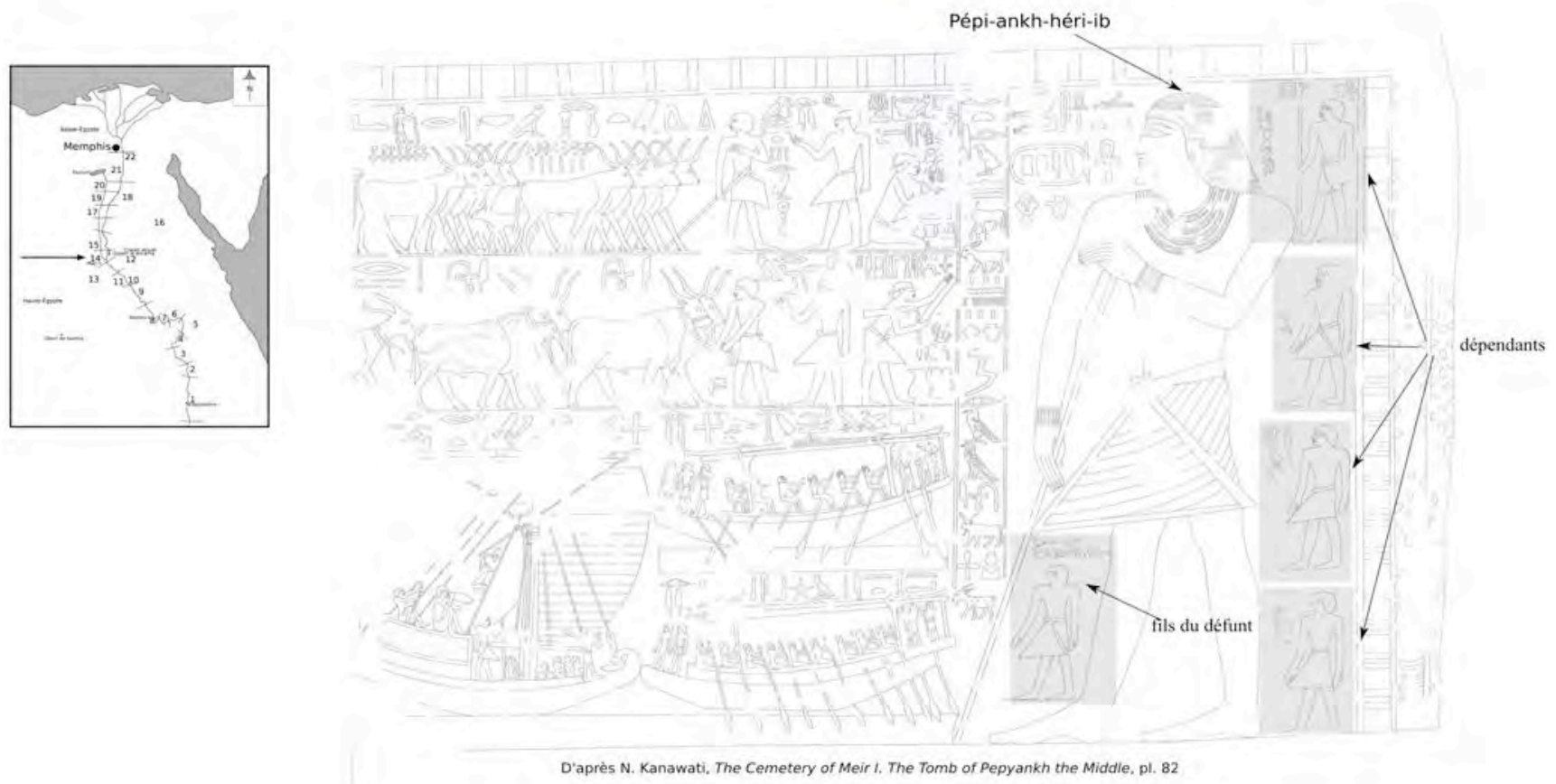

Figure II : Le réseau de Khouenoukh (réalisé avec le logiciel Gephi).

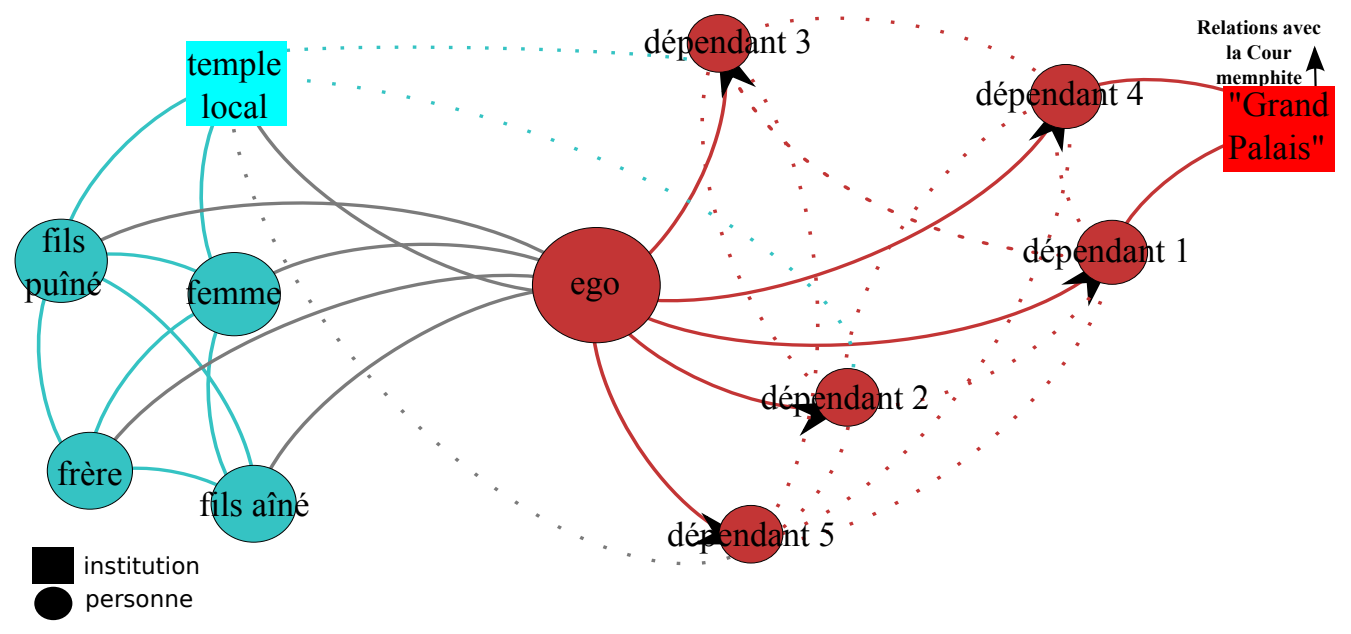


Figure III : Le réseau de Pépi-ankh-héri-ib (réalisé avec le logiciel Gephi).

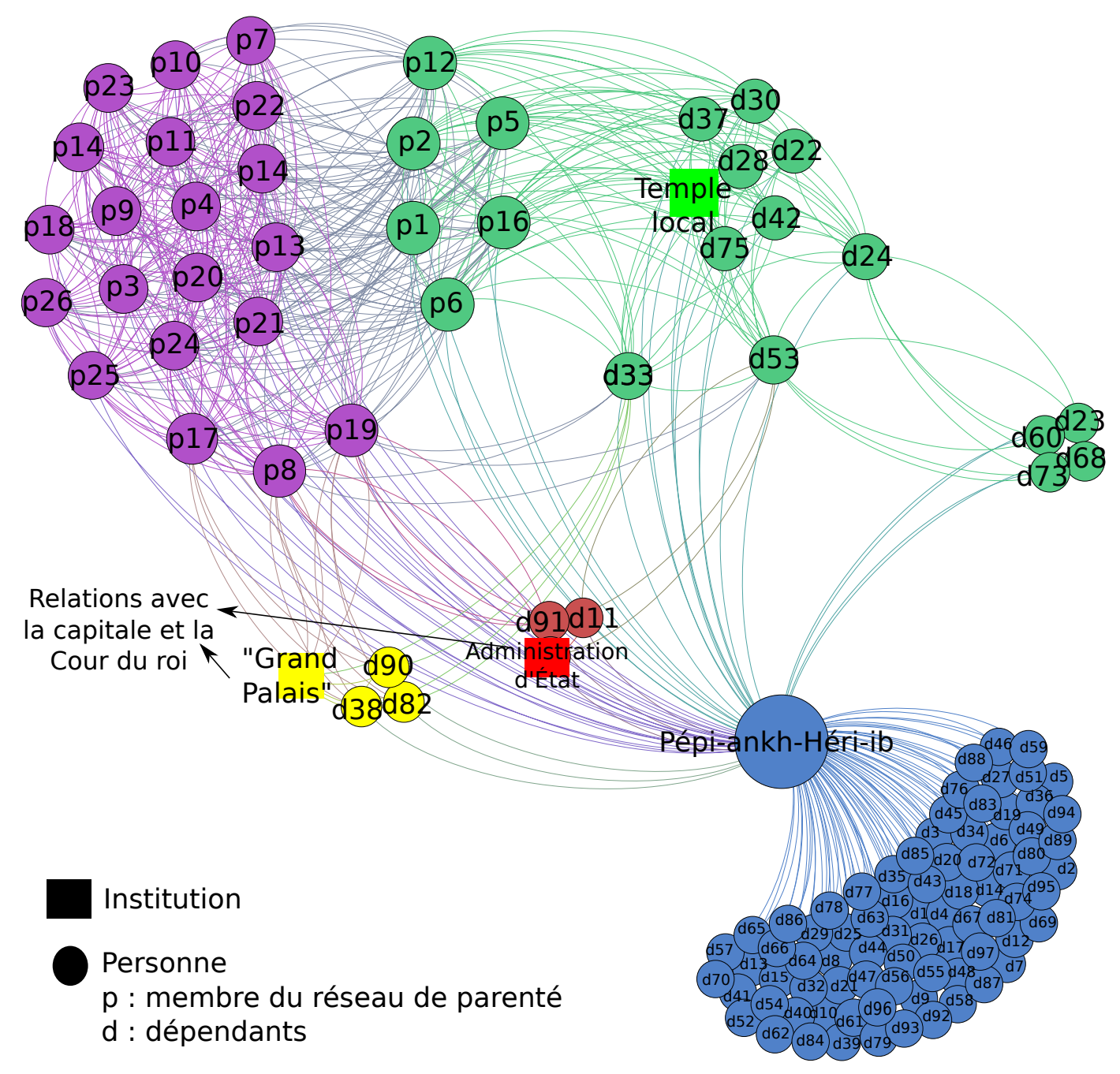




\title{
Constantin IX Monomaque : empereur ou homme de réseau?
}

\author{
Éric LIMOUSIN \\ Maître de conférences \\ Université de Bretagne-Sud \\ Centre d'histoire et de civilisation byzantine \\ UMR 8167 Orient et Méditerranée
}

\begin{abstract}
Extrait de : Henri BRESC (dir.), Réseaux politiques et économiques, Paris, Édition électronique du CTHS (Actes des congrès des sociétés historiques et scientifiques), 2016.

Cet article a été validé par le comité de lecture des Éditions du CTHS dans le cadre de la publication des actes du $140^{\mathrm{e}}$ Congrès national des sociétés historiques et scientifiques tenu à Reims en 2015.
\end{abstract}

Faire l'histoire des réseaux dans l'empire byzantin n'est pas une tâche facile pour l'historien. Certes, quelques corps ou groupes sociaux s'y prêtent mieux que d'autres, ainsi étudier les relations établies à l'intérieur de l'épiscopat est possible ${ }^{1}$. C'est peut-être plus facile avec les intellectuels et les milieux scolaires, car les historiens disposent de correspondances qui permettent l'étude de ses relations ${ }^{2}$. Enfin, dernier élément de comparaison, les travaux désormais classiques de Jean-Claude Cheynet montrent bien que les connexions entre les familles de l'aristocratie aboutissent à la création de réseaux familiaux qui participent à la construction de «partis politiques » $^{3}$. Toutefois, dans cette thématique, l'empereur est absent, ou plutôt, il est la cible des réseaux qui cherchent à s'en approcher mais qui ne l'incluent pas. En effet, les mariages avec la famille impériale sont des événements rares pour les familles aristocratiques byzantines ${ }^{4}$.

C'est pourquoi cette étude va tenter de montrer que le pouvoir peut également utiliser les réseaux pour gouverner. L'empereur au centre de cette étude reste en grande partie un mystère. En effet, les historiens qui cherchent à comprendre le règne de Constantin IX Monomaque dépendent principalement de l'œuvre de Michel Psellos. Or de quel Michel Psellos s'agit-il ? De l'auteur de panégyriques à la gloire de Constantin, de l'auteur plus critique de la Chronographie qui n'hésite pas à décrire les défauts de l'empereur ou de l'auteur et courtisan qui œuvre dans les palais impériaux pour favoriser sa carrière et celle de ses amis ? ${ }^{5}$

1. Voir par exemple, B. Moulet, Évêques, pouvoir et société à Byzance (VIII $-X I^{e}$ siècle), Paris, 2011, 613 p. (Byzantina Sorbonensia, 25).

2. Voir l'étude pionnière de P. Lemerle, Cinq études sur le XI siècle, « Le gouvernement des philosophes », p. 191249. Sur les correspondances, en particulier celle de Michel Psellos, il faut se référer aux travaux de S. Papaioannou, Michael Psellos, Rhétoric and Authorship in Byzantium, en attendant l'édition des lettres par le même auteur.

3. J.-C. Cheynet, Pouvoirs et contestations à Byzance (963-1210), p. 262-301, et J.-C. Cheynet, «Partis et contestations : une vie politique », in A. Ducellier, M. Balard, Constantinople 1054-1261. Tête de la Chrétienté, proie des Latins, capitale grecque, p. 71-83.

4. Avant le milieu du XI $\mathrm{I}^{\mathrm{e}}$ siècle, les familles des épouses des empereurs sont difficilement identifiables, voir par exemple, L. Garland, Byzantine Empresses, Women and Power in Byzantium ad 527-1204.

5. Nous disposons d'un répertoire des œuvres de Michel Psellos: P. Moore, Iter Psellianum, grâce auquel nous pouvons repérer deux lettres, sept discours, sept œuvres poétiques ou didactiques adressés à Constantin IX Monomaque. L'œuvre majeure restant la Chronographie où le règne de cet empereur occupe une place centrale : Michel Psellos, Chronographie, I, 6, p. 117-II, p. 71. Pour le portrait peu élogieux de Constantin IX Monomaque, Michel Psellos, Chronographie, I, 6-XIX, p. 132, et sur les contradictions de la Chronographie, A. Kaldellis, The Argument of Psellos' Chronographia, p. 132-141. 
Nous devons donc à propos de cet empereur confronter Michel Psellos à lui-même mais également aux autres sources, comme Michel Attaleiatès ou Jean Skylitzès ${ }^{6}$. En effet, sans cet exercice critique, nous sommes condamnés à hésiter entre un Constantin IX simple jouet de ses courtisans et conseillers, et un Constantin IX homme politique avisé et averti, au fait des conditions d'exercice du pouvoir. Cet empereur a été capable d'établir un pouvoir dans la lignée de la politique des Macédoniens alors que rien, si ce n'est le mariage avec Zoé, ne l'y rattache. En effet, c'est par une progressive prise de contrôle de l'appareil d'État et par une lente réunion de tous les intérêts aristocratiques que Constantin IX Monomaque peut établir un pouvoir sans la légitimité des Macédoniens et sans le prestige et l'efficacité militaire des Phokas et de Jean Tzimiskès ${ }^{7}$.

\section{Un homme seul au pouvoir?}

Les historiens comptent une dizaine de membres entre Nicétas Monomaque à la fin du VIII $^{\mathrm{e}}$ siècle et Manuel Monomaque au tournant des $\mathrm{XI}^{\mathrm{e}}$ et $\mathrm{XII}^{\mathrm{e}}$ siècles ${ }^{8}$. Si l'on en croit Michel Psellos, ils sont originaires d'Antioche mais s'installent rapidement à Constantinople ${ }^{9}$. La famille montre un attachement à saint Georges dont ils posséderaient un fragment de l'épée. Cette dévotion est mise en valeur dans l'iconographie des sceaux identifiés et dans la construction par Constantin IX Monomaque de l'oikos de SaintGeorges des Manganes ${ }^{10}$.

Les parents les plus proches de Constantin mènent des carrières dans les sekreta fiscaux comme Paul qui est logothète du genikon puis sacellaire alors que le père de l'empereur, Théodose, a été juge au palais impérial. Michel Psellos mentionne l'existence de deux sœurs pour Constantin : Hélène l'aînée et Euprépia sans indiquer avec qui elles auraient été mariées ${ }^{11}$. Constantin a également un cousin prénommé Théodose comme son père alors que ce prénom est relativement rare chez les laïcs ${ }^{12}$ (Fig. 1).

Le père de l'empereur, Théodose, a été mêlé à un complot contre Basile II sans que l'on sache ni la date ni la réalité de la fonction de Théodose, «juge suprême " restant une description vague ${ }^{13}$. Nous avons donc affaire à une des familles importantes de Constantinople, capable d'occuper des postes essentiels, mais également capable de participer à des complots non pour remplacer l'empereur mais pour se rapprocher davantage de l'exercice du pouvoir. Après ce complot, le futur empereur connaît comme d'autres une semi-disgrâce qui ne le met ni en danger ni à l'écart des postes de l'administration comme le montre le déroulement postérieur de sa carrière ${ }^{14}$.

6. L'œuvre de Jean Skylitzès est disponible dans JEAN SKYLITZÈS, Synopsis historiarum, éd. I. Thurn, et dans la traduction française, Jean Skylitzès, Empereurs de Constantinople, Trad. et comm. J.-C. Cheynet, B. Flusin, et nous disposons d'une nouvelle édition de Michael Attaleiates, The History, trad. A. KAldellis et D. Krallis.

7. J.-C. Cheynet, Pouvoirs et contestations à Byzance (963-1210), p. 277-280, mais nous pensons que cette politique d'alliances matrimoniales peut être avancée d'une génération et prendre place dès les années 1040-1050.

8. Le premier Monomaque est attesté au VIII ${ }^{\mathrm{e}}$ siècle, D. Papachryssanthou, «Un confesseur du second iconoclasme, la vie du patrice Nicétas $(+836) »$.

9. Michel Psellos, Orationes Panegyricae, n 6, p. 90, 1. 57-58.

10. Voir J.-C. Cheynet, «Par saint Georges, Par saint Michel », p. 119-124 et V. Stankovic, "Le tropaiophoros chez Michel Psellos. Un exemple de l'utilisation politique de la rhétorique », p. 133-147.

11. Michel Psellos, Chronographie, II, C, p. 14-15.

12. Contemporain de l'empereur, il est connu uniquement par ses sceaux, il est d'abord protospathaire, épi tôn koitônos et parathalassitès (V. Laurent, Corpus, II, n¹126), puis magistre, vestès, épi tès sakellès (Istanbul n779-59) et enfin magistre et éphore (Fogg 3689).

13. Aristakès de Lastivert, Récit des malheurs de la nation arménienne, p. 42 utilise un terme arménien qui peut se traduire par «chef de la justice » ou peut être apparenté à la dignité de césar ; sur ce complot, J.-C. Cheynet, Pouvoirs et contestations à Byzance (963-1210), n²2 ; Michel Psellos, Chronographie, I, p. 128 et Michel Psellos, Orationes Panegyricae, ${ }^{\circ} 2$, p. 40, 1. 551-554, il est probable que le complot se situe à la fin du règne de Basile II. 14. En effet, si sa carrière connaît un coup d'arrêt après 1028, il est toutefois patrice et juge de 1'Hellade en 1042, Jean Skylitzès, éd. Thurn, p. 423, trad. p. 351-352. 
Il peut nouer des relations matrimoniales avec les femmes de l'aristocratie la plus en vue de Constantinople. Comme l'écrit Michel Psellos, il se marie une première fois avec une femme appartenant à une « des familles les plus considérables. Tout d'abord allié avec le premier des personnages en vue (ta prôta tô prôtô tôn episèmôn andrôn), quand il eut perdu sa femme, emportée par une maladie » ${ }^{15}$. Ensuite, Romain III Argyros, avant 1028, organise son mariage avec une fille de sa sœur Pulchérie et de Basile Sklèros. Il est de nouveau veuf en 1042. Comme son père, il complote vers 1035 contre les Paphlagoniens avec d'autres et est exilé par la suite pendant sept ans ${ }^{16}$ (figure 2).

Par conséquent, en 1042, au moment de la déposition de Michel V, Constantin Monomaque n'est pas l'homme isolé que son nom et les sources pourraient faire croire. Certes, Michel Psellos insiste sur le caractère inoffensif de l'individu pour la dynastie macédonienne, en fait, fort de ses alliances matrimoniales, Constantin représente la victoire d'un groupe aristocratique ancien (les Sklèroi, Argyroi et Radènoi) allié à un groupe aristocratique plus récent, également opposé aux Paphlagoniens (CérulaireMakrembolitzès). Cela peut être vu comme la revanche des familles éloignées par Michel IV et son frère Jean l'Orphanotrophe ${ }^{17}$.

Les premières mesures de Constantin IX Monomaque cherchent à faire l'unité derrière l'empereur et à rassembler les groupes aristocratiques. Jean Skylitzès décrit ses premières mesures comme pleine d'attention pour la famille paphlagonienne ${ }^{18}$. Cette description est relayée par le discours de Michel Psellos. Utilisant la métaphore classique du soleil, le polygraphe relate au moment de sa naissance un phénomène naturel plus brillant que le soleil, phénomène qui se reproduit pendant son exil à Mytilène annonçant ainsi que son destin était lié au gouvernement de l'empire ${ }^{19}$. Ensuite, en 1042 :

« toute opposition cessa et ce furent l'élan populaire et l'adhésion du Sénat. [...] L'accord fut unanime. [...] Parvenu au centre de l'empire, tu dispenses à tout le monde ta lumière et ta chaleur ${ }^{20}$ (Fig. 3)

\section{Un agglomérat de soutiens}

Cible première de l'action de Constantin IX Monomaque, les élites politiques du palais, souvent qualifiées de basilikoi sont l'objet de toutes les attentions de l'empereur. L'entreprise de charme réussit parfaitement puisqu'en 1047, on retrouve le groupe de brillants intellectuels autour de Jean Mauropous et Constantin Leichoudès. Comme il a été montré par ailleurs, Constantin s'attache à rallier à lui les basilikoi ${ }^{21}$. Ces hommes, au pouvoir depuis Basile II, se sont maintenus (ou sont revenus) au pouvoir avec les Paphlagoniens ${ }^{22}$. Aux familles aristocratiques ralliées s'ajoute désormais le groupe des basilikoi: ces fonctionnaires appartiennent pour certains aux familles de la Ville et se maintiennent dans l'entourage du pouvoir. Probablement moins intégrés dans la haute aristocratie que les précédents, ils sont toutefois liés entre eux par des solidarités nées pendant leurs années de formation et de collaboration au service des empereurs précédents ${ }^{23}$.

15. Michel Psellos, Chronographie, I-VI-b, XV, p. 1247-11, Michel Psellos joue peut-être dans son texte avec le nom de famille Prôteuôn, ce qui indiquerait le nom de famille de la première épouse de Constantin Monomaque. 16. J.-C. Cheynet, Pouvoirs et contestations à Byzance (963-1210), nº 39.

17. Michel Psellos, Chronographie, I, XVIII, p. 126 ; les frères Cérulaire ont comploté vers 1040 mais ont été démasqués par Jean l'Orphanotrophe, J.-C. CHEYNET, Pouvoirs et contestations à Byzance (963-1210), $\mathrm{n}^{\circ} 50$.

18. Jean Skylitzès, éd. Thurn, p. 423, trad. p. 352.

19. Une comète probablement, Michel Psellos, Orationes Panegyricae, nº 6, p. 90, 1. 59-66 et n², p. 41-42, 1. 591618.

20. Ibid., n 6, p. 92, 1. 105-120.

21. É. Limousin, «Zoé : derrière l'image et les mariages, une politique ? », p. 77-79.

22. Sur les basilikoi, Michel Psellos, Chronographie, I, p. 3018-19, pour une analyse du groupe, voir J.-C. Cheynet, « "L'homme" du basileus ", vol. I, p. 139-154 et avec un point de vue différent, É. Limousin, "Obtenir l'autorité du prince à Byzance au XI ${ }^{\mathrm{e}}$ siècle », p. 233-253.

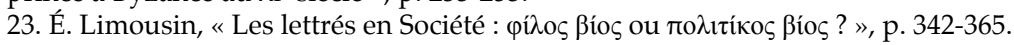


Étonnamment, Michel Psellos et Jean Skylitzès ne parlent pas de la situation du patriarcat de Constantinople. À la mort d'Alexis Stoudite en 1043, Jean Skylitzès décrit comment Michel Cérulaire lui succède. Il est clair que la nomination de Michel Cérulaire correspond à un remerciement pour services rendus envers une famille qui a favorisé sa prise du pouvoir. En effet, si Cérulaire est un véritable néophyte, cette nomination ne choque ni n'étonne personne ${ }^{24}$. En effet, les liens entre la famille Monomaque et le groupe Makrembolitzès-Cérulaire sont attestés depuis le début du XI siècle. Autour d'eux, la Vie de Lazare le Galésiote mentionne les familles Bareis, Solômon, Kampanarios, Proteuôn et Mitas $^{25}$.

La phase suivante se déroule au moment où Constantin IX Monomaque s'éloigne de plus en plus du modèle macédonien. D'une part, on assiste à quelques révoltes et complots organisés par d'anciens proches des Macédoniens comme celle de Théophile Erotikos puis celle de Georges Maniakès. Ces deux hommes appartiennent à des familles qui ont profité de la politique de Basile II et des Paphlagoniens mais qui ont été, volontairement ou non, oubliées par la politique de séduction de Monomaque ${ }^{26}$. Comme le remarque Jean Skylitzès, c'est à l'occasion de ces révoltes que l'on procède, probablement à l'initiative de Théodora, à l'élimination des derniers Paphlagoniens ${ }^{27}$.

D'autre part, en 1044, en mettant en avant la Sklèraina en lieu et place des impératrices, la procession impériale provoque une émeute ${ }^{28}$. Cet épisode montre bien que le contrôle de la ville de Constantinople par Constantin IX Monomaque n'est pas suffisamment assuré, malgré le poids des familles aristocratiques de la bureaucratie (les sugklètikoi des discours de Michel Psellos) $)^{29}$. Les élites économiques, en plein développement du fait de la conjoncture et de la politique macédonienne, ont peu profité des premiers temps du règne de Constantin. Elles expriment leur mécontentement en 1044, lors de l'émeute contre la Sklèraina, et surtout en 1047 au moment de la révolte de Léon Tornikios qui cherche à s'appuyer sur ce mécontentement ${ }^{30}$ (figure 4).

À partir de la révolte de Léon Tornikios, la politique de Constantin IX Monomaque s'infléchit même si le moment précis de cette rupture politique est malheureusement impossible à dater précisément. Il s'agit de ce que l'on appelle " l'ouverture du Sénat » ${ }^{31}$. Désormais bien décrite et bien comprise, elle correspond à la vente de dignités sénatoriales aux plus riches familles de Constantinople, familles enrichies par le travail de l'administration fiscale comme précédemment mais également des familles enrichies dans le commerce de Constantinople (métaxoprates et marchands-armateurs) ${ }^{32}$. Par cette action, Constantin IX espère créer un lien direct entre lui et les élites économiques et la petite bureaucratie issue de ces mêmes familles. Aux aristocrates qui se détachent de lui peu à peu, il cherche à substituer une nouvelle aristocratie issue des bureaux et des élites économiques de Constantinople.

24. J.-C. Cheynet, « Patriarches et empereurs : de l'opposition à la révolte ouverte », p. 4-8.

25. J.-C. Cheynet, « Par saint Georges, Par saint Michel», p. 115-134 (Mélanges Dagron), p. 124.

26. J.-C. Cheynet, Pouvoirs et contestations à Byzance (963-1210), Paris, n59 et 61. La famille Erôtikos est liée aux Comnènes, comme l'indique Nicéphore Bryennios, Histoire, p. 75-77, les orphelins Isaac et Jean Comnène ont été élevés à Constantinople par Basile II.

27. Jean Skylitzès, éd. Thurn, p. 429, trad. p. 357, les haines personnelles peuvent perturber les politiques les plus réfléchies.

28. Sur l'émeute, voir le récit de Jean Skylitzès, éd. Thurn, p. 434, trad. p. 361, sur la Sklèraina, la bibliographie est assez maigre, à Polemis, on peut ajouter N. Oikonomides, "Saint George of Manganes, Marie Skleraina and the "Malyj Sion" of Novgorod ", p. 239-246.

29. A. P. Kazdhan, M. McCormick, « The Social World of the Byzantine Court », p. 76-185.

30. Pour une analyse de la révolte de 1047, voir É. Limousin, «Les métiers à Constantinople : un élément du contrôle social et politique de la ville », à paraître au PUM.

31. Infléchissement probablement amorcé dès 1044 et l'émeute contre la Sklèraina, sur "l'ouverture du Sénat ", voir en premier lieu P. Lemerle, "Byzance au tournant de son destin (1025-1118) », in Cinq études sur le XI siècle, p. 287-293 et J.-C. Cheynet, " Le rôle de la "Bourgeoisie" constantinopolitaine », p. 89-104.

32. M. Kaplan, «Du cocon au vêtement de soie : concurrence et concentration dans l'artisanat de la soie à Constantinople aux $\mathrm{X}^{\mathrm{e}}-\mathrm{XI}^{\mathrm{e}}$ siècles », p. 313-327. 


\section{Fragilité des réseaux}

Passé 1047, le pouvoir de Monomaque est solidement établi et les révoltes suivantes sont liées uniquement à des problèmes frontaliers et/ou militaires ${ }^{33}$. Par conséquent, par une série de relations interpersonnelles, Constantin IX Monomaque est parvenu à consolider son pouvoir personnel selon le schéma suivant : (figure 5).

Il est probable que la diffusion du modèle iconographique de saint Georges correspond à cette période d'apogée du pouvoir de Constantin IX. Toutefois la mort de Zoé vers 1050 a entraîné un refroidissement des relations de l'empereur avec la dynastie macédonienne désormais représentée par Théodora, entourée de ses vieux collaborateurs ${ }^{34}$.

La rupture principale liée au schisme de 1054 qui voit l'affrontement entre le patriarche de Constantinople, Michel Cérulaire, et le légat pontifical Humbert de Moyenmoutiers est également un problème $d^{\prime}$ histoire politique byzantine ${ }^{35}$. Il est clair que cet événement est un tournant dans le règne de Constantin IX Monomaque. L'empereur, affaibli par la maladie, vieilli, usé, fatigué, ne parvient plus à tenir l'aristocratie de Constantinople, en particulier Michel Cérulaire. Celui-ci prend de plus en plus d'importance à l'occasion de la conversion des Petchénègues. De plus cette brouille se déroule dans un palais perturbé par l'émergence de nouvelles coteries ${ }^{36}$.

Depuis sa victoire face aux légats pontificaux, sa position confortée, il peut mener la vie dure au vieil empereur. Toutefois, la position de Michel Cérulaire n'est pas consolidée, car, à la mort de Constantin, il ne peut empêcher le retour de Théodora, forte de sa légitimité familiale, et la désignation de Michel VI Bringas. Cependant, la rupture personnelle de Michel Cérulaire avec l'empereur n'a, semble-t-il, pas freiné la carrière des Makrembolitzai puisque les neveux du patriarche poursuivent leurs carrières même sous Théodora et Michel $\mathrm{VI}^{37}$.

Il est possible que l'éloignement entre Michel Cérulaire et Constantin soit lié à ce que rapporte Michel Attaleiatès en 1053. Il indique que :

« Deux ans avant sa mort, [Constantin IX Monomaque] fit valoir un changement inattendu dans son comportement. Il employa les collecteurs d'impôts les plus terrifiants, que dans le langage administratif on appelle les sekretikoi, pour mettre en œuvre des amendes inattendues et pour percevoir les arriérés. ${ }^{38}$

Cette mise à l'écart des premiers conseillers au profit de techniciens de l'administration correspond au remplacement d'une équipe au pouvoir depuis le milieu des années 1040. Elle est également la manifestation de l'ascension des élites de la Ville, intégrées au Sénat depuis les années 1045-1050, qui désormais peuplent les bureaux de l'administration impériale, chassant les vieux conseillers ${ }^{39}$ (figure 6).

33. J.-C. Cheynet, Pouvoirs et contestations à Byzance (963-1210), nº 67 à 72 . A l'agitation aux frontières, s'ajoutent les intrigues des courtisans sans portée politique.

34. La haine de sa belle-sœur Théodora semble inextinguible et concerne également les favoris de Constantin, Jean Xiphilin et surtout Michel Psellos doivent déployer des trésors de courtisanerie pour tenter de revenir en grâce après 1055, É. Limousin, «La rhétorique au secours du patrimoine, Psellos, les impératrices et les monastères », p. 163-176.

35. Sur le schisme, la bibliographie est innombrable, pour les aspects politiques de l'affaire, voir J.-C. Cheynet, «Le patriarche "tyrannos" : le cas Cérulaire », p. 1-16.

36 Les changements dans l'entourage impérial sont perceptibles dans la Chronographie, Michel Psellos décrit avec amertume le remplacement des vieux conseillers par des gens de moindre qualités comme le favori Boïlas, Michel Psellos, Chronographie, II, 6-CLXXXIX, p. 64.

37. P. Gautier, « La curieuse ascendance de Jean Tzetzès », p. 212-216.

38. Michael Attaleiatès, The History, p. 50 [trad. p. 89-90].

39. Jean Xiphilin, nomophylax, est peu à peu mis sur la touche et se fait moine, Michel Psellos, toujours hypatos des philosophes, ne parvient pas à se maintenir au premier plan. C'est une des explications de la détestation des nouvelles élites par Michel Psellos, cf. l'étude de la lettre Michel Psellos, Scripta minora, éd. Kurtz-Drexl, II, 
La deuxième faiblesse de la politique de Constantin correspond à son incapacité à établir une dynastie. En effet, une descendance est impossible et la greffe de la famille Monomaque sur la souche macédonienne échoue comme le montre Jean Skylitzès :

«Comme un autre mal s'était déclaré en plus et que déjà la mort approchait, les plus hauts dignitaires du palais - c'est-à-dire le logothète Jean, le principal conseiller de l'empereur après que Leichoudès eut été chassé, le protonotaire du drome Constantin, le préposé à l'Encrier Basile et tous ceux qui étaient proches de l'empereur à quelque autre titre réfléchissaient à la personne qu'ils allaient installer sur le trône impérial. Tous furent d'avis que le bon candidat, pour cela, était Nicéphore Proteuôn. On envoya donc un courrier rapide en Bulgarie pour le faire venir de là : car à cette époque, il se trouvait être gouverneur de ce pays. Apprenant cela, les serviteurs de l'impératrice Théodora - Zoé avait déjà quitté ce monde -, je veux parler de Nicétas Xylinitès, de Théodore et Manuel, firent monter Théodora sur une galère et l'amenèrent dans les salles princières du Grand Palais où ils l'acclamèrent comme autokratôr. ${ }^{40}$

Par conséquent, à la mort de Constantin, Théodore Proteuôn, prévu comme successeur par Constantin, est écarté par Théodora malgré le soutien d'une partie des conseillers de l'empereur. Son cousin, Théodose Monomaque, quant à lui, est exilé à Pergame par Michel VI. D'ailleurs, peu de Monomaques sont repérés dans la seconde moitié du $\mathrm{XI}^{\mathrm{e}}$ siècle ${ }^{41}$.

Enfin et surtout, la famille macédonienne survit à Constantin en la personne de Théodora, et la légitimité en construction de Constantin ne peut rien contre la tradition impériale. En outre, Théodora poursuit cette épuration en s'attaquant aux plus anciens soutiens de son beau-frère. Les vieux conseillers macédoniens réapparaissent dans les textes, et l'on assiste à la prise de contrôle de l'appareil d'État par Léon Paraspondylos au détriment des vieux conseillers de Constantin Monomaque, Constantin Leichoudès, Jean Xiphilin et Jean Mauropous, Michel Psellos ${ }^{42}$. Enfin, les familles qui ont soutenu Monomaque sont en disgrâce : Makrembolitzai, Doukai et Comnène sont exclues des distributions de roga et de pensions ${ }^{43}$.

Toutefois, l'impératrice et ensuite Michel VI, ne changent pas la politique à destination de la ville et de ses élites. La Ville demeure pour cette Macédonienne un souci permanent et elle reste aux aguets face aux mouvements de la population. Alors qu'en 1042, elle était plutôt du côté des sygklétikoi et basilikoi, la vieille impératrice ne semble pas dévier de la ligne choisie en 1047 par Constantin IX Monomaque. Cette permanence ne permet pas à ces opposants d'agréger les mécontentements, ainsi les proches de Monomaque, ou Bryennios ne parviennent pas à rallier la population de Constantinople ${ }^{44}$.

\section{Une postérité politique et littéraire}

Michel Psellos est le principal artisan de la fabrication de l'image de Constantin IX Monomaque, ses écrits concernant directement ou indirectement cet empereur sont très nombreux. L'essentiel se situe évidemment dans la Chronographie qui renomme l'empereur en Constantin Evergète, mais aligne ensuite les défauts de son protecteur ${ }^{45}$. Néanmoins, l'image de l'empereur reste positive. Certes, Jean Skylitzès critique la prodigalité de l'empereur :

$\mathrm{n}^{\circ} 129$, à un métropolite de Chalcédoine, p. 152 par P. Lemerle, «Byzance au tournant de son destin (10251118) », in Cinq études sur le XI siècle, p. 290.

40. Skylitzès, éd. Thurn, p. 477-478, trad. p. 394. (« Réalités byzantines », 9).

41. On connaît un Théodore Monomaque et un Manuel Monomaque, G. Schlumberger, Sigillographie, p. 681.

42. Sur Michel Psellos et Théodora, Michel Psellos, Chronographie, II, 7213-16.

43. Cette suppression des rogai est le prétexte de la révolte de 1057, voir J.-C. Cheynet, Pouvoirs et contestations à Byzance (963-1210), $\mathrm{n}^{\circ} 80$.

44. Michel Psellos, Orationes Panegyricae, n 11 , p. 12054-61, J.-C. Cheynet, Pouvoirs et contestations à Byzance (9631210), p. 66, fiche $\mathrm{n}^{\circ} 76$.

45. Michel Psellos, Chronographie, I, 117-118 
«Engagé dans la construction d'un monastère consacré à saint Georges le Mégalomartyr, au lieu-dit "Les Manganes", l'empereur dépensait sans compter l'argent de l'État dans ces constructions [...]. Cependant, les belles actions ne lui furent pas tout à fait étrangères, et on rapporte même quelques œuvres qui méritent d'être retenues par l'histoire. Le monastère que j'ai dit, les asiles de vieillards qui s'y trouvent, les hospices et les hôpitaux méritent des louanges, et ce qu'il fit pour la Grande Église est également digne d'éloges. » ${ }^{46}$

Mais il reconnaît une politique coûteuse mais utile lorsqu'il décide la fondation de l'oikos des Saint-Georges-des-Manganes.

Constantin IX Monomaque est donc le premier empereur à concevoir une solution politique post-macédonienne. En effet, comme ses contemporains, il est conscient que la légitimité macédonienne va cesser et qu'il est indispensable de proposer une solution alternative. Pour Constantin, la solution tient dans la multiplication des soutiens pour faire en sorte que l'empereur soit le point de convergence. Il utilise probablement le serment pour conforter son pouvoir et lier les élites de Constantinople à son destin comme en $1047^{47}$. Il développe les relations personnelles entre lui et ses conseillers : Jean Mauropous et Constantin Leichoudès lui restent attachés malgré toutes les vicissitudes. Les familles aristocratiques de premier plan sont associées à la conduite de l'Empire comme le montre l'exemple des Makrembolitzès. Cependant, la famille Monomaque étant limitée en nombre, elle ne peut multiplier les alliances matrimoniales supposées plus solides.

Cette politique est reprise par les empereurs suivants, Constantin X Doukas, Romain IV Diogénès et surtout les Comnènes de manière plus solide et plus systématique. Il est remarquable que Constantin $\mathrm{X}$ au pouvoir rappelle ou maintienne en place le personnel qui a fait ses classes sous Monomaque ${ }^{48}$.

\begin{abstract}
Résumé
Le règne de l'empereur Constantin IX Monomaque (1042-1055) pose des problèmes d'interprétations aux historiens. En effet, il est difficile d'identifier les ressorts et les motivations de sa politique. Présenté par Michel Psellos comme un empereur insouciant et frivole, il est en fait un habile politicien capable de fédérer autour de lui des familles aristocratiques et des groupes sociaux de Constantinople.

En étudiant attentivement les sources, il est possible d'identifier les soutiens de Constantin. Il est aussi significatif de constater que ses soutiens varient en fonction du temps. Néanmoins, le but de cette politique reste le même : proposer une alternative à la disparition prévisible de la légitimité.
\end{abstract}

46. Skylitzès, éd. Thurn, p. 476-477, trad. p. 392-393.

47. Sur le serment à Byzance, N. Oikonomides, « Le serment de l'impératrice Eudocie », REB 21 (1963), p. 101128 .

48. Michel Psellos, Chronographie, II, p. 124 sur la nomination de Constantin Leichoudès comme patriarche de Constantinople; sur Jean Mauropous, voir l'article de A. P. Kazhdan, "Some problems on the biography of John Mauropous ». 


\section{Sources}

Aristakès de LASTIVERT, Récit des malheurs de la nation arménienne, trad. franç. Par Marius CANARD, Bruxelles, 1973.

Nicéphore BRYENNIOS, Histoire, Intr., texte, trad. et notes par Paul GAUTIER (CFHB 9), Bruxelles, 1975.

MOORE Paul, Iter Psellianum, Toronto, 2005.

Michel PSEllos, Chronographie, I et II, éd. et trad. par Émile RENAULD («Collection Byzantine »), Paris, 2 vol., 1967, 2 éd., LXXXVIII-154 p et 199 p.

Michel PSEllos, Scripta Minora, vol. II, éd. Edouard Kurtz et Frantz Drexl, Milan, 19361941, XX-349 p.

Michel PsEllos, Orationes Panegyricae, éd. Georges T. Dennis, Stuttgart-Leipzig, 1994.

Jean SKYLITZÈS, Synopsis historiarum, éd. Ioannes Thurn, Berlin-New-York (CFHB V), 1973.

Jean SKYLITZÈS, Empereurs de Constantinople, trad. et comm. par Jean-Claude CHEYNET, Bernard Flusin, Paris (« Réalités byzantines », 9), 2003.

Michael AtTAleiATES, The History, trad. Anthony KALDELlis et Dimitri KRALLIS, Cambridge (Mass), Harvard University Press, 2012.

Laurent VitALIEN, Le corpus des sceaux de l'empire byzantin, II, l'administration centrale, Paris, 1981.

SCHLUMBERGER Gustave, Sigillographie de l'empire byzantin, réédition Turin, 1963, 748 p.

\section{Bibliographie}

CHEYNET Jean-Claude, Pouvoirs et contestations à Byzance (963-1210), Paris, 1990.

CHEYNET Jean-Claude, "Le patriarche "tyrannos": le cas Cérulaire », Ordnung und Aufruhr im Mittelhalter, Francfort, 1995, p. 1-16.

CHEYNET Jean-Claude, "Partis et contestations : une vie politique », dans A. DuCELLIER, M. BALARD, Constantinople 1054-1261. Tête de la Chrétienté, proie des Latins, capitale grecque, Paris, Éditions Autrement, 1996.

CHEYNET Jean-Claude, «Par saint Georges, par saint Michel », Travaux et Mémoires, XIV (2002) (Mélanges Dagron), p. 119-124.

CHEYNET Jean-Claude, "L'homme" du basileus", Puer Apuliæ, Mélanges offerts à J. M. Martin, Paris, 2008, vol. I, p. 139-154.

CHEYNET Jean-Claude, "Le rôle de la "Bourgeoisie" constantinopolitaine », Zbornik Radova Vizantolozkog Instituta, 46, 2009, p. 89-104.

CHEYNET Jean-Claude, "Patriarches et empereurs : de l'opposition à la révolte ouverte ", dans GRÜNBART Michael, Zwei Sonnen am Goldenen Horn? - Kaiserliche und patriarchale Macht im byzantinischen Mittelalter, Munster, 2013, p. 1-18.

GARLAND Lynda, Byzantine Empresses, Women and Power in Byzantium ad 527-1204, Londres, 1999. 
GAUTIER Paul, " La curieuse ascendance de Jean Tzetzès ", Revue des Études Byzantines, 28, 1970, p. 212-216.

KALDELLIS Anthony, The Argument of Psellos' Chronographia, Leyde, 1999.

Kaldellis Anthony, The Byzantine Republic, People and Power in New Rome, Londres, 2015.

KAPLAN Michel, «Du cocon au vêtement de soie : concurrence et concentration dans $\mathrm{l}^{\prime}$ artisanat de la soie à Constantinople aux $\mathrm{x}^{\mathrm{e}}-\mathrm{XI}^{\mathrm{e}}$ siècles", in Eupsychia (Mélanges Ahrweiler), Paris, 1998, p. 313-327.

KAZHDAN Alexander, «Some problems on the biography of John Mauropous », Jahrbuch der Österreichischen Byzantinistik, 43, 1993, p. 87-111.

KAZDHAN Alexander, McCormick Michael, «The Social World of the Byzantine Court », in MAGUiRE Henry (éd.), Byzantine Court Culture from 829-1204, Washington, 1997, p. 76185.

Lemerle Paul, Cinq études sur le XI ${ }^{e}$ siècle, Paris, 1977.

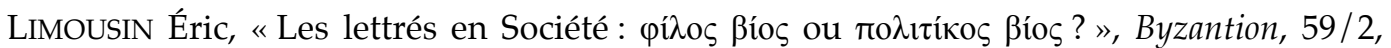
1999 , p. 342-365.

LIMOUSIN Éric, «Obtenir l'autorité du prince à Byzance au $\mathrm{XI}^{\mathrm{e}}$ siècle », dans QUAGHEBEUR Joëlle, PICARD Jean-Michel, OUDARD Hervé (ed.), Le Prince, son peuple et le bien commun (Actes du Colloque de Lorient, septembre 2007), Rennes, PUR, 2013, p. 233-253.

LiMOUSIN Éric, «Zoé : derrière l'image et les mariages, une politique?», in Élisabeth MALAMUT, Andréas NiCOLAÏDES (ed.), Impératrices, princesses, aristocrates et saintes souveraines en Orient chrétien et musulman au Moyen Âge et au début des temps modernes (Journée d'étude internationale de la MMSH 29 mars 2010), Presses Universitaires de Provence, 2014, p. 77-79.

LIMOUSIN Éric, «La rhétorique au secours du patrimoine, Psellos, les impératrices et les monastères ", in THEIS Liba, MULLET Margaret, GRÜNBART Michael (ed.), Female Founders in Byzantium and Beyond (Actes du Colloque de Vienne), Vienne, 2014, p. 163-176.

LiMOUSIN Éric, « Les métiers à Constantinople : un élément du contrôle social et politique de la ville ", in MALAMUT Élisabeth, OUERFELLI Mohammed (ed.), Villes en Méditerranée au Moyen-Âge et à l'époque Moderne, Colloque du 24-27 septembre 2014, à paraître au PUM.

MOUlEt Benjamin, Évêques, pouvoir et société à Byzance (VIII'-XI siècle), Paris, Publications de la Sorbonne (Byzantina Sorbonensia, 25), 2011.

OIKONOMIDES Nicolas, « Saint George of Manganes, Marie Skleraina and the "Malyj Sion" of Novgorod », Dumbarton Oaks Papers, 34/35, 1980-1981, p. 239-246.

PAPACHRYSSANTHOU Denise, "Un confesseur du second iconoclasme, la vie du patrice Nicétas († 836) », Travaux et Mémoires, III, 1968, p. 309-351.

PapaIOANNOU Stratis, Michael Psellos, Rhetoric and Authorship in Byzantium, Cambridge, 2013.

StANKOVIC Vlada, "Le tropaiophoros chez Michel Psellos. Un exemple de l'utilisation politique de la rhétorique», Zbornik Radova Vizantolozkog Instituta, 41, 2004, p. 133-147 (avec résumé français, p. 148-152). 


\section{Illustrations}

Figure 1 : La famille Monomaque.

Paul Monomaque

Magistre $1^{\text {oro }} \mathrm{k} / 2$ du $X^{c} s$.

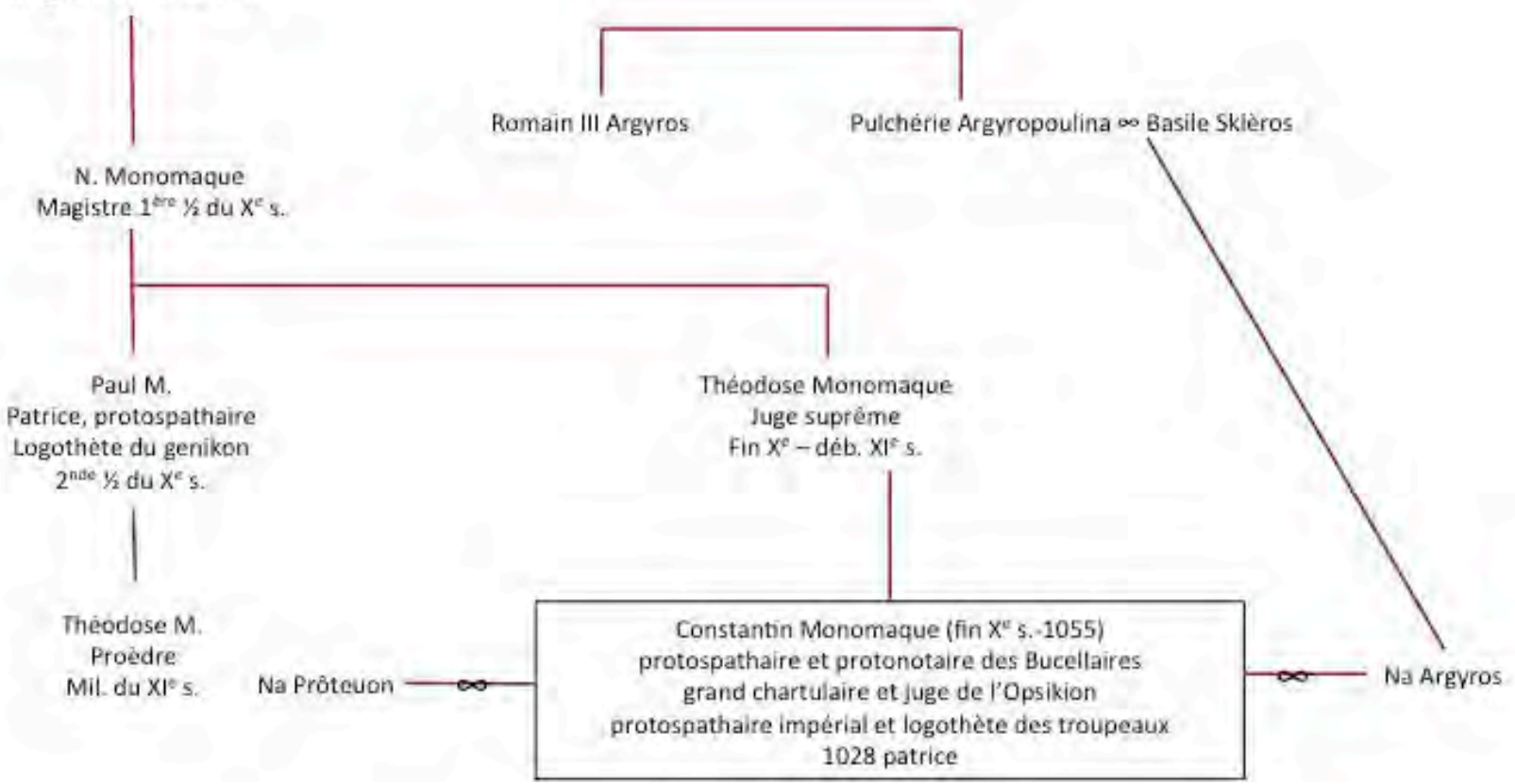

Figure 2 : Constantin Monomaque et les forces politiques de Constantinople avant 1042.
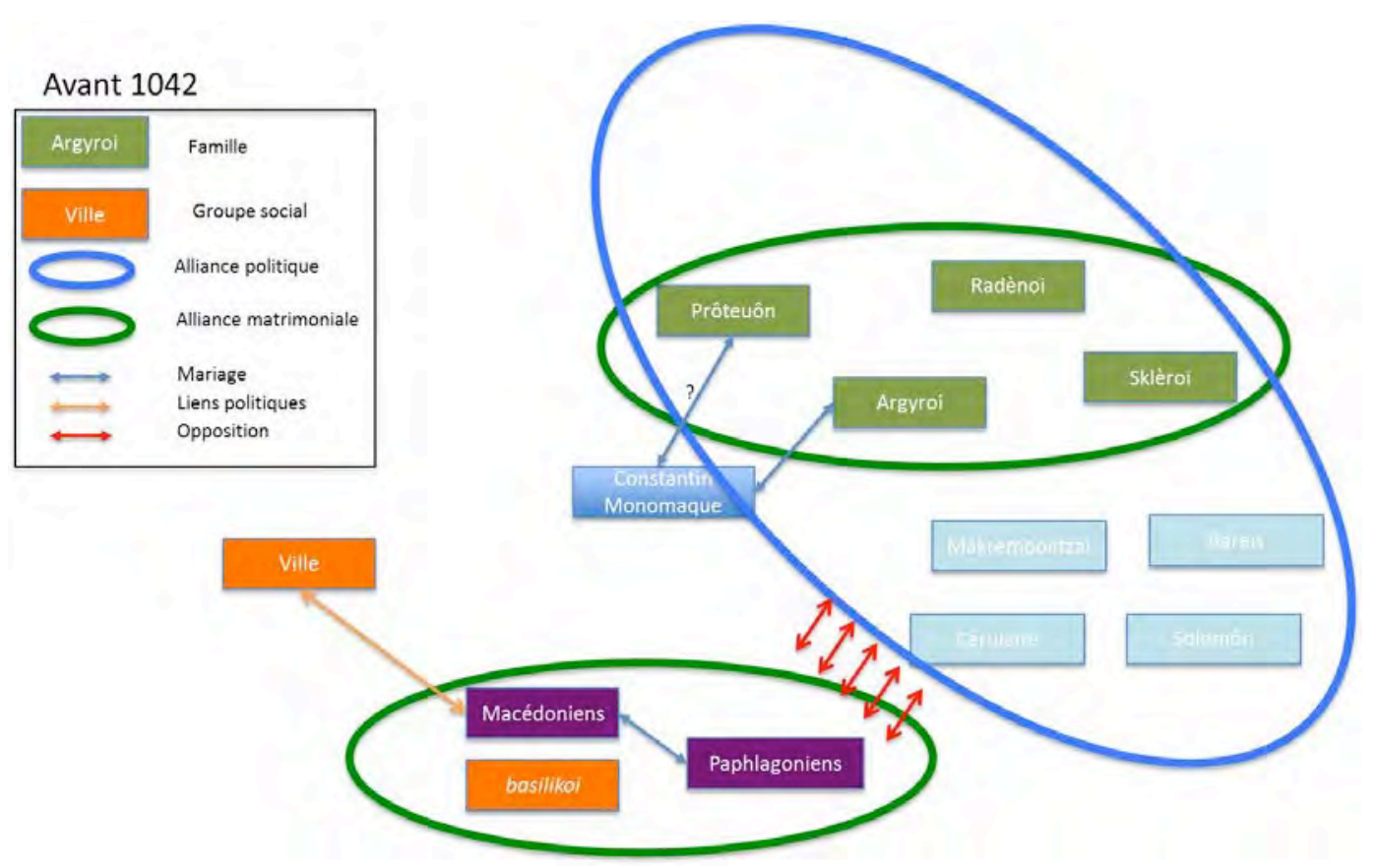
Figure 3: Constantin Monomaque et les forces politiques de Constantinople de 1042 à 1044.

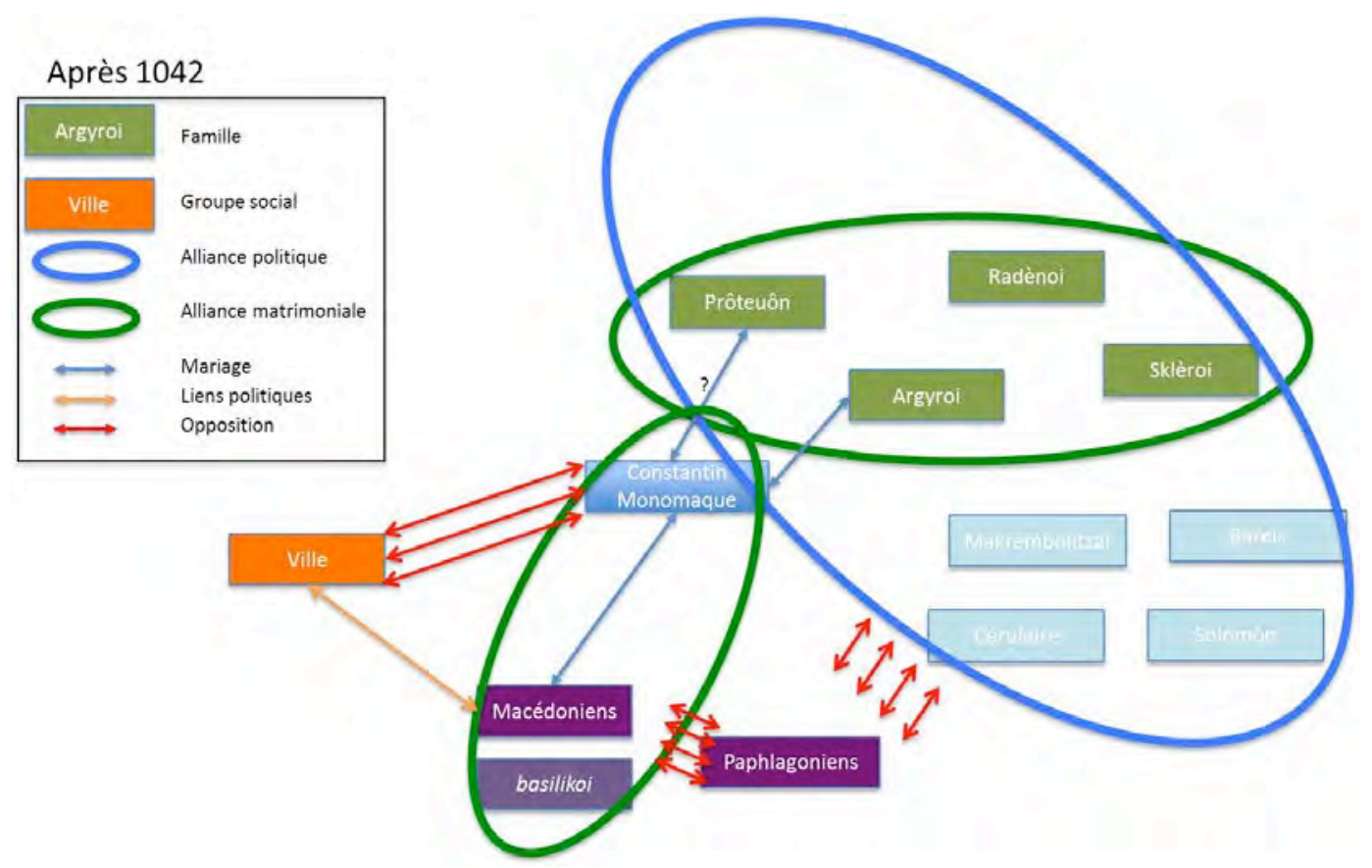

Figure 4 : Constantin Monomaque et les forces politiques de Constantinople en 1044.

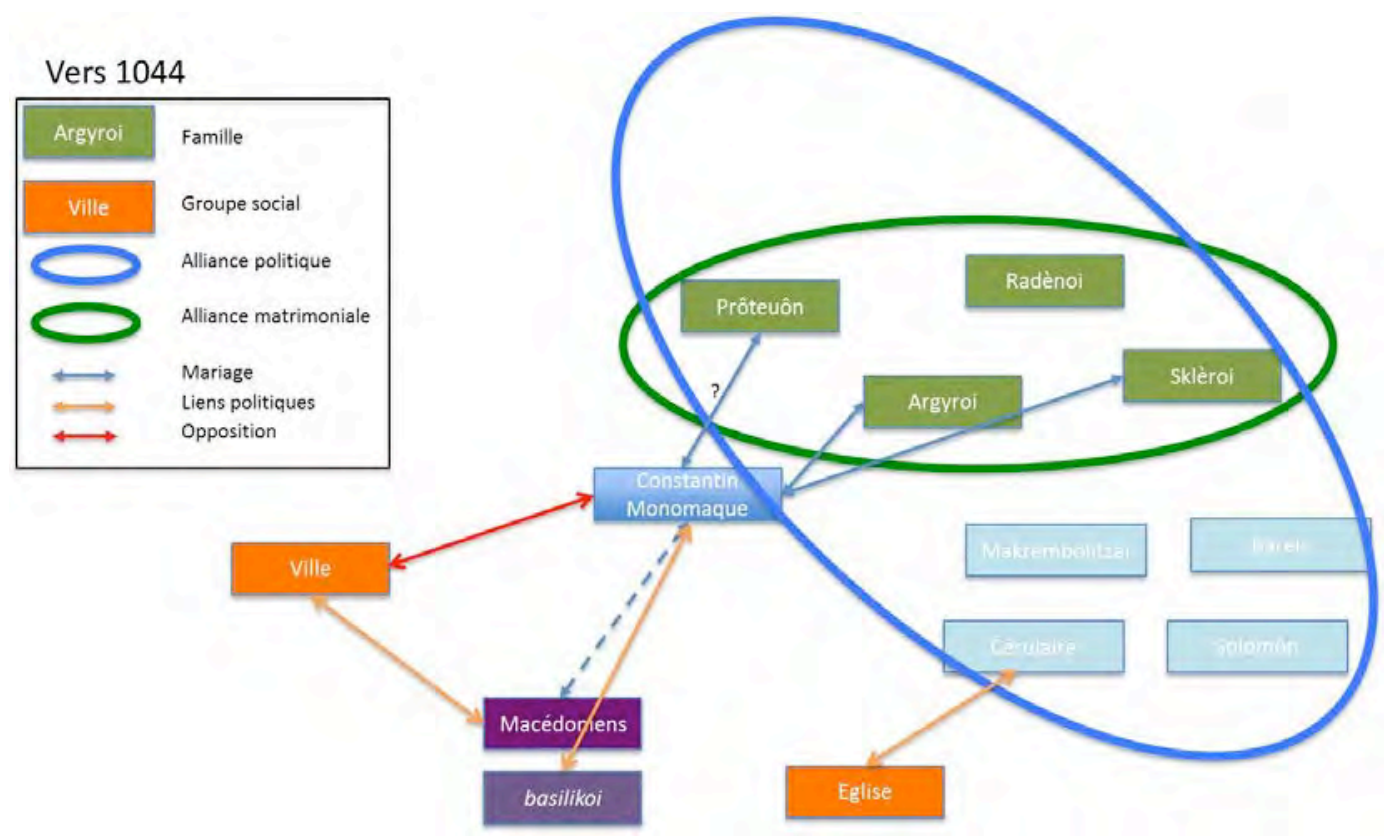


Figure 5 : Constantin Monomaque et les forces politiques de Constantinople après 1047.

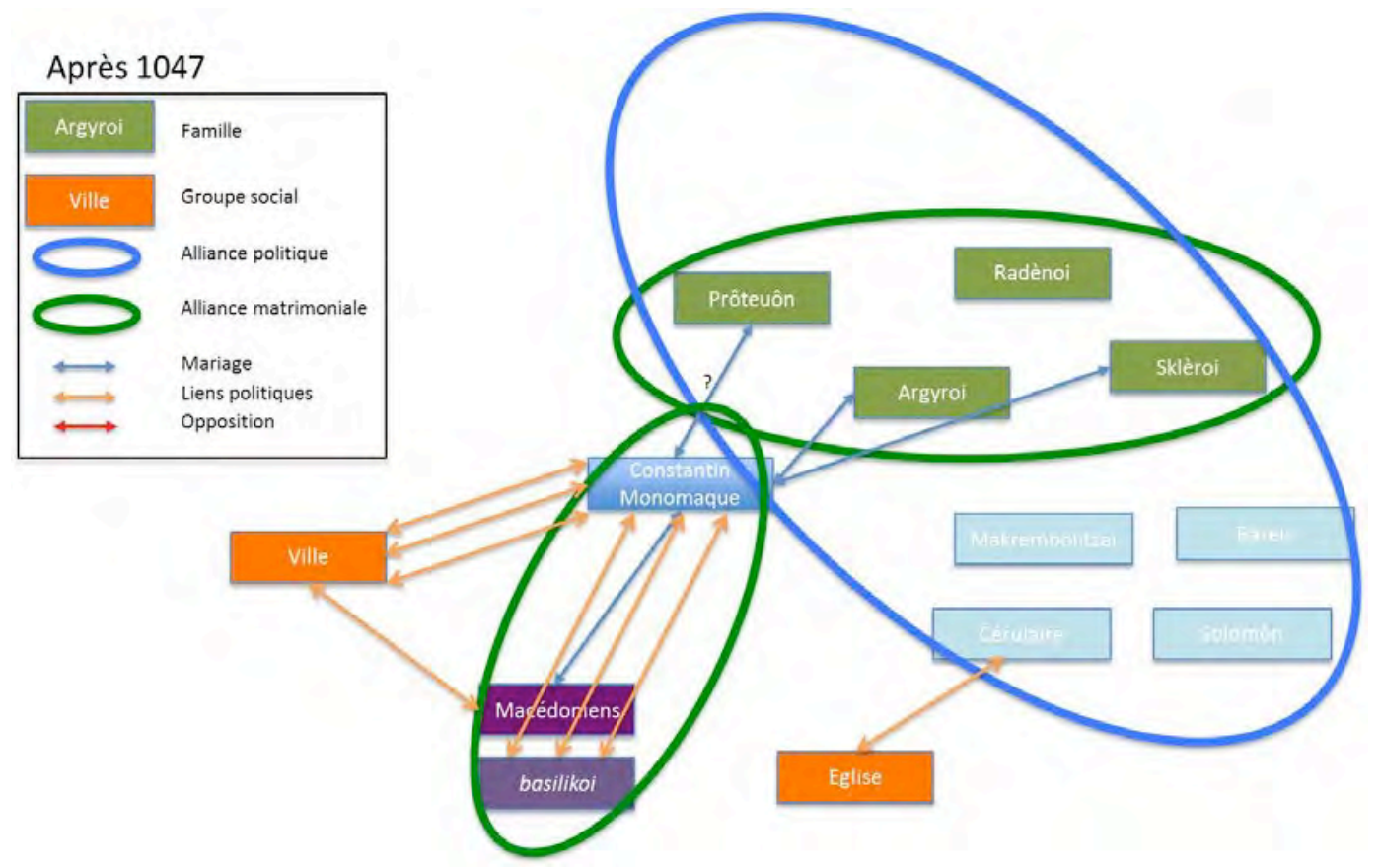

Figure 6 : Constantin Monomaque et les forces politiques de Constantinople après 1054.

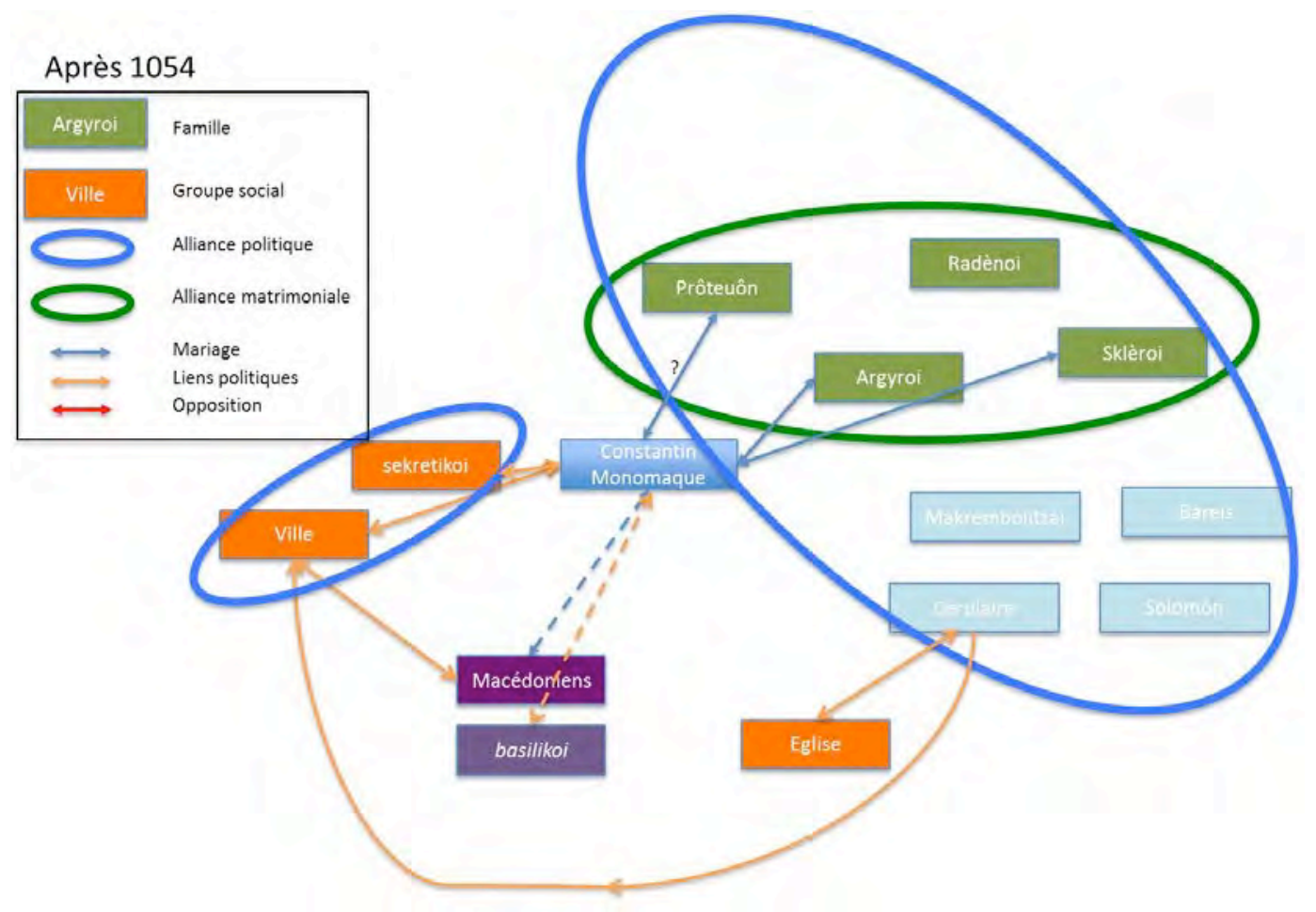




\title{
Devenir évêque à Byzance au XII siècle : une nécessaire intégration dans des réseaux de pouvoir?
}

\author{
Lucile HERMAY, \\ doctorante à l'Université Paris-Sorbonne, \\ ATER à l'Université Paris Ouest Nanterre La Défense \\ Jack ROSKILLY, \\ doctorant contractuel à l’Université Paris 1 Panthéon-Sorbonne \\ Extrait de : Henri BRESC (dir.), Réseaux politiques et économiques, Paris, \\ Édition électronique du CTHS (Actes des congrès des sociétés historiques et scientifiques), 2016. \\ Cet article a été validé par le comité de lecture des Éditions du CTHS dans le cadre de la publication \\ des actes du $140^{\mathrm{e}}$ Congrès national des sociétés historiques et scientifiques tenu à Reims en 2015.
}

En 1204, Euthyme Tornikès prononça l'éloge funèbre de son oncle Euthyme Malakès, métropolite de Néopatras. Il le décrivit ainsi :

«Tu étais devenu l'image des grâces abondantes et de l'ensemble des vertus par les diverses couleurs et teintures avec lesquelles les mains habiles de Dieu forgèrent et achevèrent $l^{\prime}$ homme $[. .$.$] et en plus de cela tu as revêtu l'habit épiscopal. » { }^{1}$

Il trace un parallèle entre vertus personnelles et accès à l'épiscopat. Si la nomination à un évêché important était communément présentée par les rhéteurs comme le fruit de ses qualités personnelles, dans les faits, les nominations épiscopales mettaient en jeu des logiques de pouvoir complexes mobilisant des réseaux tout autant ecclésiastiques, qu' aristocratiques ou impériaux d'autant plus qu'au XII siècle, les élections épiscopales se déroulaient dans la capitale, dans un contexte de centralisation du pouvoir ${ }^{2}$. Ces enjeux de pouvoir autour de ces élections concernaient avant tout les plus hauts sièges éminemment stratégiques, les patriarcats, les métropoles et les archevêchés autocéphales. Il fallait donc pour devenir évêque nouer des liens avec le pouvoir impérial, patriarcal ou même l'aristocratie. Les futurs évêques devaient s'intégrer dans les complexes réseaux de pouvoir constantinopolitains et tisser un ensemble de relations sociales les menant jusqu'au sommet du pouvoir à l'instar des aristocrates laïques.

Le concept de réseau emprunté à la sociologie et appliqué à l'histoire byzantine permet de mettre en évidence les systèmes de relations nouées entre les élites de l'Empire. Plus précisément ici, il permet d'étudier la nature et le poids des relations sociales nouées par le candidat à l'épiscopat. Aussi, les sources du XII siècle, tant par leur variété que par leur nature permettent souvent de reconstituer au moins en partie ces réseaux. Nous utiliserons les lettres et discours, mieux conservés au XII ${ }^{\mathrm{e}}$ siècle. Ces documents sont des témoins de liens personnels, dans la mesure où l'auteur et le destinataire sont connus. Ils permettent de comprendre les relations qui unissaient les correspondants et les avantages que chacun pouvait tirer de la relation à l'autre. Nous analyserons également les textes hagiographiques, rares au XII ${ }^{\mathrm{e}}$ siècle, parce qu'ils permettent de mettre en évidence à la fois le réseau personnel du saint ainsi que celui des constructeurs de sa sainteté. Ainsi, nous nous proposons d'étudier les logiques de réseau qui permettent de devenir évêque et d'analyser leur spécificité.

1. J. Darrouzès, « Les discours d'Euthyme Tornikès », p. 84.

2. Les élections des métropolites et archevêques se déroulaient à Constantinople depuis le début de l'époque médiobyzantine (B. Moulet, Évêques, pouvoir et société à Byzance (VIII $-\mathrm{XI}^{e}$ siècle). Territoires, communautés et individus dans la société provinciale byzantine, p. 246-247). À partir $\mathrm{du} \mathrm{XI}^{\mathrm{e}}$ siècle, les élections des évêques suffragants eurent également lieu dans la capitale (N. Oikonomidès, «Un décret synodal inédit du patriarche Jean VIII Xiphilin concernant l'élection et l'ordination des évêques», p. 58-59 (=V. Grumel et J. Darrouzès, Les regestes des actes du patriarcat de Constantinople, vol. 1 : les actes des patriarches (381-1206), fasc. II et III : les regestes de 715 à 1206, n 900a). 
L'élection des évêques, en particulier des métropolites et des patriarches, était centralisée à Constantinople depuis le $\mathrm{VIII}^{\mathrm{e}}$ siècle. Elle était organisée en principe par le synode permanent, qui regroupait les hauts prélats de l'Empire et qui désignait trois noms, parmi lesquels le patriarche de Constantinople choisissait l'élu. Bien que les interventions laïques dans les élections épiscopales soient prohibées, le rôle de l'empereur dans la désignation des évêques était prépondérant à partir du règne d'Alexis Ir Comnène (10811118). Un pamphlet de Nicétas, métropolite d'Ancyre et opposant à la politique ecclésiastique $\mathrm{d}^{\prime}$ Alexis $\mathrm{I}^{\mathrm{er}}$, reprocha à l'empereur d'influer sur les élections épiscopales. Celui-ci avait l'habitude d'envoyer au synode des billets, annulant l'élection afin de promouvoir le candidat impérial et menaçant les membres du synode s'ils n'obéissaient pas $^{3}$. Le texte de Nicétas d'Ancyre montre que les interventions impériales étaient fréquentes et relativement nouvelles à son époque pour justifier une réaction virulente. Les successeurs d'Alexis ne démentirent pas la mainmise impériale sur les élections d'évêques et de patriarches ${ }^{4}$.

L'accès à l'empereur n'était pas toujours direct et passait parfois par la médiation des réseaux de la haute aristocratie byzantine. Cela valait pour tous les aristocrates, qui pouvaient ainsi obtenir des avantages pour leurs dépendants. Les évêques n'échappaient pas à ce constat. Eustathe de Thessalonique, lorsqu'il était maître des rhéteurs ${ }^{5}$, avait entretenu une longue correspondance amicale avec Nicéphore Comnène, petit-fils d'Anne Comnène et de Nicéphore Bryennios. Nicéphore Comnène fut duc de Nicomédie puis préposé aux pétitions avant de mourir prématurément à vingt-neuf ans en $1173^{6}$. Dix-sept lettres d'Eustathe à Nicéphore ont été conservées ce qui est remarquable dans l'épistolaire byzantine ${ }^{7}$. Cette correspondance atteste qu'Eustathe avait intégré le puissant réseau des Comnènes. D'une part, Eustathe fut probablement le maître de Nicéphore ${ }^{8}$, d'autre part ce fut certainement grâce à cet intermédiaire qu'il accéda à l'empereur et favorisa sa carrière. Eustathe fut en effet nommé métropolite de Myra en Lycie en 1174, sans que l'on en sache davantage sur les acteurs de son élection. Avant de prendre sa fonction, il fut cependant transféré vers le siège plus prestigieux de Thessalonique ${ }^{9}$. Il s'agissait d'une promotion, fait relativement rare à cette époque, puisque Thessalonique était alors une ville prospère tandis que Myra se situait dans un espace frontalier plus dangereux. Au XIII ${ }^{\mathrm{e}}$ siècle, l'archevêque de Bulgarie Dèmètrios Chomatènos justifia ce transfert dans une réponse canonique :

«Tandis que le très sage Eustathe, neveu de Kataphlôron, diacre de la Grande Église et maître des rhéteurs, fut élu et reçu avec joie pour la métropole des Lyciens Myra et qu'il se préparait pour l'ordination, un décret du bienheureux empereur transmit au synode l'ordre d'accepter que ledit Eustathe fût transféré vers l'illustre métropole des Thessaloniciens, comme elle était disponible en ce moment. ${ }^{10}$

3. J. Darrouzès, Documents inédits d'ecclésiologie byzantine, p. 240-248. Nicétas cite les canons réglant les élections épiscopales pour montrer qu'à aucun moment l'empereur n'intervient dans le processus de désignation.

4. En 1147, Manuel $1^{\text {er }}$ Comnène parvint à imposer comme patriarche de Constantinople Nicolas Mouzalôn. Ce dernier avait pourtant démissionné de l'archevêché de Chypre trente ans auparavant et s'était retiré au monastère. Manuel Comnène rencontra une opposition de certains membres du synode qui considéraient qu'un évêque démissionnaire ne pouvait ensuite retrouver le sacerdoce. Nicolas, évêque de Méthonè, rédigea un discours au synode pour défendre le choix de Mouzalôn comme patriarche. Il y rappela que celui-ci fut nommé

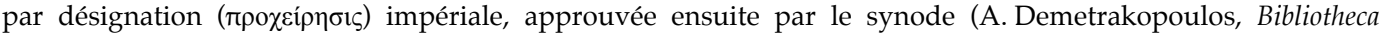
Ecclesiastica, p. 275-276). On retrouve bien la prépondérance du choix de l'empereur.

5. Le maître des rhéteurs était l'un des postes d'enseignants les plus élevés de Constantinople. Il était recruté parmi le clergé de la capitale. Voir P. Magdalino, The Empire of Manuel I Komnenos (1143-1180), p. 248 et 326-327.

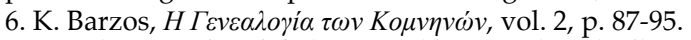

7. F. Kolovou, Die Briefe des Eustathios von Thessalonike, p. 3-57.

8. Ibid. p. 51-52 : dans sa lettre 14, Eustathe dit à Nicéphore que celui-ci améliore son âme en lui parlant et en lui écrivant.

9. Dans les notices épiscopales du $\mathrm{XII}^{\mathrm{e}}$ siècle, Thessalonique occupe le seizième rang, tandis que Myra est au vingtième rang (J. Darrouzès, Notitiæ episcopatuum Ecclesiae Constantinopolitanae, p. 348, 358, 374 et 380).

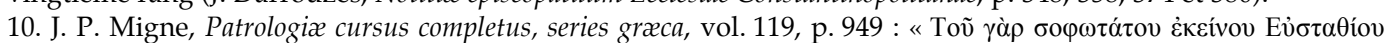

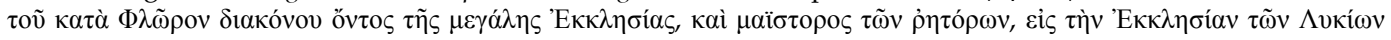

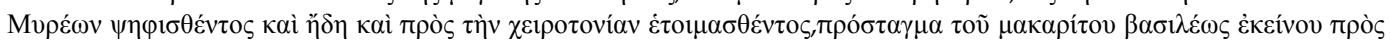

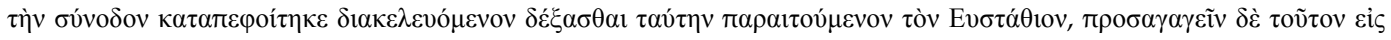

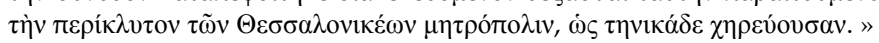


Le rôle du décret impérial est particulièrement souligné par Chomatènos. Nous pouvons donc supposer que l'amitié de Nicéphore permit à Eustathe d'intégrer le cercle proche de l'empereur Manuel $1^{\text {er }}$ Comnène.

Cette logique du rattachement au réseau impérial accentuait la proximité des évêques avec le reste de l'aristocratie. Les prélats dépendaient cependant de réseaux qui leur étaient spécifiques. Les liens familiaux devinrent fondamentaux dans l'organisation de l'aristocratie à l'époque des Comnènes. L'accès aux plus hautes fonctions de l'État reposait désormais sur les liens de parenté avec l'empereur qui favorisa les membres de sa famille ainsi que des familles satellites, liées aux Comnènes par des alliances matrimoniales ${ }^{11}$. Ce constat ne s'impose pas aux évêques. Peu de prélats du XII siècle furent issus de la famille des Comnènes ou des grandes familles de l'aristocratie. Le réseau familial personnel ne semble pas avoir pesé dans la nomination des évêques. L'exception de la nomination d'Adrien Comnène est assez significative. Neveu de l'empereur Alexis $\mathrm{I}^{\mathrm{er}}$ Comnène, il entama une carrière militaire comme duc de Chaldie avant de se retirer au monastère. Il en sortit entre 1139 et 1143 lorsqu'il fut nommé archevêque de Bulgarie ${ }^{12}$.

Durant son épiscopat, il signa des documents synodaux en précisant sa dignité de sébaste réservée aux membres de la famille impériale depuis sa création par Alexis I ${ }^{\mathrm{er}}$ Comnène ${ }^{13}$. Il fut le seul évêque du XII ${ }^{\mathrm{e}}$ siècle à signer avec cette dignité ${ }^{14}$. Cela montre qu'il fut sans doute le seul prélat issu de la famille impériale. Cette exception s'explique par le rôle particulier de l'archevêque de Bulgarie qui était un quasi-ambassadeur de Constantinople auprès du roi de Serbie. Nous retrouvons ici les logiques de réseau caractéristiques du système des Comnène qui consistaient à nommer des affins aux plus hautes fonctions de l'État. Le poids relativement faible du réseau familial dans l'accès à l'épiscopat nous oblige à rechercher une spécificité du réseau épiscopal et à nous intéresser à la période de formation des futurs évêques.

Les évêques du XII ${ }^{\mathrm{e}}$ siècle furent pour beaucoup formés dans les écoles de Constantinople avant leur épiscopat. Durant cette période, ils acquirent des qualités intellectuelles qui leur permirent de développer leur réseau et de se rapprocher de l'empereur et de la famille impériale. Avant de devenir métropolite de Philippoupolis en 1143, Michel Italikos avait occupé les plus hautes chaires d'enseignement à Constantinople, notamment les trois postes de didascale qui correspondaient à l'enseignement de théologie de haut niveau ${ }^{15}$. Parallèlement à sa carrière d'enseignant, il avait tissé des liens avec l'ancienne impératrice Irène Doukaina qui lui avait proposé un poste de «didascale des médecins ». Italikos le refusa car le traitement n'était pas assez élevé ${ }^{16}$. Un discours d'éloge à Irène prononcé par Italikos montre par ailleurs que ce dernier avait intégré le

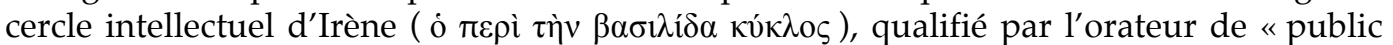
très savant " et qui comprenait «les autres princesses " (sans doute les filles d'Irène Doukaina, Anne, Marie, Eudocie et Théodora, et la fille d'Anne Comnène, Irène Doukaina) et "le césar », très probablement Nicéphore Bryennios, gendre d'Irène Doukaina ${ }^{17}$. Ces liens apparaissent importants dans le parcours d'Italikos vers l'épiscopat. Son ascension dépend à la fois de ses compétences intellectuelles et de son réseau qu'il a progressivement construit.

11. J.-Cl. Cheynet, Pouvoir et contestations à Byzance : 963-1210, p. 374-375.

12. L. Stiernon, «Notes de titulature et de prosopographie byzantines. Adrien (Jean) Comnène et Constantin Comnène, sébastes », p. 190-191.

13. J.-Cl. Cheynet, Pouvoir et contestations à Byzance : 963-1210, p. 373.

14. Par exemple le décret synodal du 30 octobre 1143 qui prend acte de l'anathème de deux évêques hérétiques, voir J. Gouillard, "Quatre procès de mystiques à Byzance (vers 960-1143). Inspiration et autorité », p. 78-80 (= V. Grumel et J. Darrouzès, Les regestes des actes du patriarcat de Constantinople, vol. 1 : les actes des patriarches (3811206), fasc. II et III : les regestes de 715 à $\left.1206, \mathrm{n}^{\circ} 1014\right)$.

15. P. Gautier, Michel Italikos. Lettres et discours, p. 16-26.

16. Ibid., p. 98.

17. Ibid., p. $147-151$. 
Le cas un peu plus tardif de Michel Chôniatès permet d'éclairer le poids relatif de ces deux facteurs. Il devint métropolite d'Athènes en 1182 après une carrière moins prestigieuse qu'Italikos et sans avoir occupé une grande fonction d'enseignant dans la capitale $^{18}$. En revanche, il se greffa au réseau de son maître, Eustathe de Thessalonique, ce qui peut expliquer son accès à l'épiscopat. Nous avons déjà analysé les liens entre Eustathe de Thessalonique et la famille des Comnènes. Nous pouvons y ajouter l'amitié qu'il entretenait avec Euthyme Malakès, métropolite de Néopatras et homme d'influence à la cour de Constantinople ${ }^{19}$. Malakès et Eustathe étaient de la même génération comme l'atteste l'éloge funèbre d'Eustathe prononcée par Malakès ${ }^{20}$. Ils purent probablement se connaître dans la capitale avant leur épiscopat. Par ailleurs, Chôniatès avait entretenu une correspondance avec Malakès ${ }^{21}$. Michel Chôniatès avait donc hérité du réseau de son maître et, malgré une carrière pré-épiscopale moins glorieuse que d'autres, il obtint finalement un siège.

Les futurs évêques se reposaient sur des réseaux différents des aristocrates laïques pour avoir accès à l'empereur, notamment sur ceux qu'ils construisaient durant leurs années de formation. Cela leur permettait de compenser un réseau familial relativement plus faible. Si les mécanismes de désignation des évêques furent simplifiés au XII siècle par le biais de la nomination impériale, nous remarquons cependant que les logiques de réseaux restaient finalement complexes.

L'exemple de la nomination de moines originaires du monastère de Saint-Jean-leThéologien de Patmos à des évêchés clés au XII siècle permet de mettre en évidence ce constat. Athanase, patriarche d'Antioche, nommé en 1157, est connu pour avoir rédigé un enkomion dédié à Christodoulos le fondateur du monastère de Patmos (fig. 1) ${ }^{22}$. Ce personnage avait été lui-même membre de cette communauté monastique. Dans son œuvre, il fait en effet plusieurs fois référence au monastère et insiste particulièrement sur le rôle de l'higoumène Sabas qui lui commanda cette œuvre littéraire ${ }^{23}$. De plus, à partir d'un extrait de sa vie conservé dans un manuscrit du Sinaï, le Sinaiticus 482, et édité par A. Failler, nous apprenons que son patronyme était Manassès ${ }^{24}$. Ce détail est précieux puisque si ce patronyme est rare pour le XII ${ }^{\mathrm{e}}$ siècle, il $\mathrm{n}^{\prime}$ est pas inconnu. À la même époque Constantin Manassès se distingua comme courtisan et lettré sous le règne de Manuel I ${ }^{\text {er }}$ Comnène. Il fut l'auteur de nombreux enkomia ainsi que d'une chronique dédicacée à Irène, la sœur par alliance de l'empereur ${ }^{25}$.

$\mathrm{Au} \mathrm{vu}$ de la rareté du patronyme, nous pouvons suspecter que ces personnages étaient parents voire frères. Le niveau d'éducation d'Athanase était assez élevé et comparable à celui de Constantin. A. Failler souligne l'utilisation par le moine dans son éloge de références homériques, de règles de rhétorique complexes, de préverbes et de mots rares $^{26}$. Ce haut niveau de langue laisserait supposer une formation dans la capitale, parallèle à celle de son parent, lui aussi homme de lettres. Athanase aurait donc été intégré grâce à son réseau familial mais aussi peut-être grâce à son réseau de formation aux cercles de pouvoir constantinopolitains. Sa nomination à la fonction de patriarche d'Antioche était peut-être liée à l'ascension de Constantin à la cour et à son rôle d'intermédiaire.

18. Il était simple secrétaire du patriarche, voir F. Kolovou, Michaelis Choniatæ epistulæ, p. 3-4.

19. Ibid., p. 98-99: dans une lettre à Malakès, Chôniatès se plaignait de sa situation d' « esclave » en province tandis que Malakès « gouvernait » en restant à Constantinople.

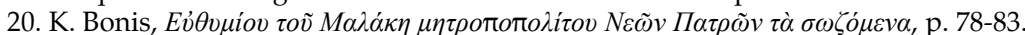

21. Nous avons conservé leurs échanges épistolaires réciproques, ce qui est assez rare. Une lettre de Malakès à

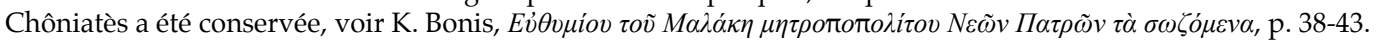

22. La date de rédaction fait néanmoins débat. Selon A. Failler, ce texte aurait été écrit alors qu'Athanase n'était pas encore patriarche. A. Failler, "Le patriarche Athanase I ${ }^{\text {er }}$ Manassès (1157-1170) ", p. 65. Alors que pour E. Vranousis, Athanase avait déjà été nommé patriarche au moment de la rédaction et s'apprêtait à partir du

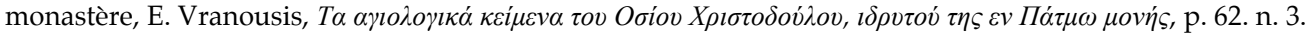

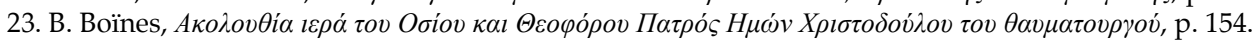

24. A. Failler, «Le patriarche Athanase $\mathrm{I}^{\mathrm{er}}$ Manassès (1157-1170) », p. 65-66

25. O. Lampsides, Constantini Manassis Breviarium chronicum, I, p. 4.

26. A. Failler, « Le patriarche Athanase $\mathrm{I}^{\mathrm{er}}$ Manassès (1157-1170) », p. 65. 
Selon P. Magdalino, ces deux personnages étaient issus d'une "bourgeois gentry » d'un rang social moyen cherchant à placer leur enfant à des hauts postes ecclésiastiques ou dans la haute bureaucratie ${ }^{27}$. L'importance du réseau personnel du moine fut certainement renforcée par l'existence d'une stratégie familiale ecclésiastique, phénomène pourtant rare à Byzance. En effet, plusieurs évêques portant ce nom détinrent des postes épiscopaux aux XII et XIII siècles. Un Constantin Manassès fut évêque de Panion, petit siège dépendant $\mathrm{d}^{\prime}$ Héraklée $^{28}$. Il a été établi avec certitude qu'il s'agissait d'un homonyme du rhéteur et non du même personnage ${ }^{29}$. Ce personnage pourrait être son cousin ou son neveu. À la fin du XII ${ }^{\mathrm{e}}$ siècle un Manassès, mentionné dans une lettre de son neveu Jean Apokaukos, fut quant à lui métropolite de Naupacte ${ }^{30}$. Enfin dans les années 1233, un autre Manassès est attesté comme métropolite d'Éphèse ${ }^{31}$. Si ces sièges sont d'une moindre importance qu'Antioche, nous pouvons remarquer que les Manassai exercèrent avec une certaine continuité des fonctions ecclésiastiques.

Athanase ne fut pas le seul moine du monastère de Saint-Jean-le-Théologien de Patmos nommé à un poste ecclésiastique important. Une vingtaine d'années plus tard Léontios, l'higoumène de ce même monastère, fut nommé patriarche de Jérusalem, autre évêché éminemment stratégique (fig. 1). La vie de ce personnage est particulièrement bien connue puisqu'une hagiographie est conservée, écrit rare pour le XII siècle, rédigée peu de temps après sa mort par un de ses disciples, Théodosios Goudélis. Originaire de Thrace et arrivé au monastère dans les années 1130, Léontios devint tout d'abord économe puis higoumène de cette communautét ${ }^{32}$. En raison de ces responsabilités, il fut ainsi amené à fréquenter régulièrement Constantinople pour défendre les intérêts de son monastère. Ces voyages lui offrirent l'occasion de s'insérer dans les réseaux impériaux et aristocratiques les plus puissants de la capitale. En 1172, il se rendit à Constantinople parce que le blé et les pièces d'or que le monastère recevait de Crète ne lui étaient plus octroyés $^{33}$. Il se lia alors au grand drongaire. S'il n'est pas nommé directement dans la Vie, sa fonction permet de l'identifier à Andronic Kamatéros ${ }^{34}$ qui occupa ce poste de 1156 à 1179. Impressionné par ses vertus, ce personnage, selon l'auteur de la Vie de Léontios, introduisit Léontios auprès de Manuel $\mathrm{I}^{\text {er }}$ Comnène ${ }^{35}$.

Nous voyons à l'œuvre le réseau social construit personnellement par Léontios. Cependant, pour l'hagiographe, il s'agissait plus de souligner les qualités et les vertus du saint que de décrire les modalités de construction de son réseau. L'empereur, impressionné par sa pâleur, sa maigreur mais aussi par ses paroles pleines de sagesse et

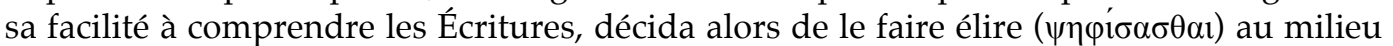
des années 1170 à un poste ecclésiastique éminent. Nous avons donc l'exemple d'une intervention impériale directe. Manuel proposa tout d'abord à Léontios de devenir archevêque des ${ }^{2} \tilde{\omega} \varsigma^{36}$, puis archevêque de Chypre $^{37}$ et finalement patriarche de Jérusalem ${ }^{38}$. Cette nomination avait une portée politique importante puisqu'elle s'inscrivait dans le prolongement de la politique d'expansion de Manuel I ${ }^{\text {er }}$ Comnène en Orient $^{39}$.

27. P. Magdalino, "In Search of the Byzantine Courtier: Leo Choirosphaktes and Constantine Manasses", p. 161.

28. V. Laurent, Corpus des sceaux de l'Empire byzantin V, vol. 2, p. 228.

29. O. Lampsides, «Zur biographie von Konstantinos Manasses und zu seiner Chronike Synopsis », p. 97-111.

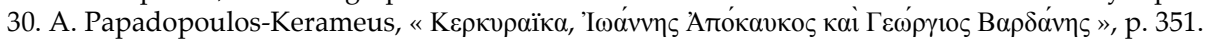

31. J. Munitiz, Nicephori Blemmydx Autobiographia sive curriculum vitae ; nec non Epistula universalior, I, 37, p. 21 ;

II, 19, p. 53-54. Dans ces deux derniers cas, ces appellations pourraient aussi renvoyer à un prénom, Manassès. L'usage de ce prénom demeure cependant relativement rare.

32. Th. Goudelis, The Life of Leontios, Patriarch of Jerusalem. Text, Translation, Commentary, 27, p. 62 et 37, p. 74.

33. Ibid., p. 190, n. 61.1

34. Ibid., p. 191-2, n. 63.2

35. Ibid., 58, p. 99.

36. Ibid., 64, p. 106.

37. Ibid., 65, p. 106.

38. Ibid., 66, p. 106. Sur cette " mise aux enchères », pour reprendre l'expression de M. Kaplan, voir M. Kaplan, «Léontios de Jérusalem, moine ou évêque ?", p. 306-307.

39. M. Kaplan, «Un patriarche byzantin dans le royaume latin de Jérusalem : Léontios », p. 484-488. 
Ainsi pour expliquer et comprendre les logiques de ces nominations, nous devons nous interroger sur l'existence de liens monastiques et impériaux s'ajoutant à ces liens familiaux ou personnels et donc mettre en évidence la multiplicité des stratégies de réseau de ces moines. Premièrement, le monastère de Patmos avait été patronné depuis sa fondation dans les années 1080 par Alexis I ${ }^{\mathrm{er}}$ Comnène puis par son fils Jean II et son petit-fils Manuel $\mathrm{I}^{\mathrm{er}}$. Il fut qualifié de $\sigma \varepsilon \beta \alpha \sigma \mu i \alpha \mu$ ov̀ dans un chrysobulle impérial dès $1088^{40}$ et était donc institutionnellement lié au pouvoir impérial. Depuis la fin du $\mathrm{XI}^{\mathrm{e}}$ siècle, les moines de Patmos se rendaient fréquemment à la capitale et avaient certainement tissé des liens avec l'administration impériale. Deuxièmement, Athanase et Léontios ne furent pas les deux seuls moines du monastère à être nommés à un poste ecclésiastique important. Le dossier hagiographique de Christodoulos de Patmos comprend en effet une Vie rédigée au XII ${ }^{\mathrm{e}}$ siècle par Jean, métropolite de Rhodes (fig. 1). Si l'identification de cet auteur avec Jean de Rhodes, métropolite de 1070 à 1110 établie par T. Évangelidès a été traditionnellement reprise ${ }^{41}, E$. Vranousis l'a contestée à partir d'une critique interne de ce texte ${ }^{42}$. L'historienne mit en évidence un passage de la Vie démontrant que l'auteur, encore moine, écrivait sous le règne de Jean II Comnène ${ }^{43}$. Il fut donc nommé métropolite soit à la fin du règne de celui-ci soit au début de celui de Manuel I ${ }^{\text {er }}$ Comnène. Elle postule donc que l'auteur était un autre Jean, lui aussi métropolite de Rhodes à partir du deuxième quart du XII siècle. De plus, si l'on s'interroge sur les sources de son texte, il paraît assez assuré que Jean eût séjourné au monastère de Saint-Jean-le-Théologien puisqu'il eut selon toute vraisemblance accès aux archives du monastère et plus précisément aux propres écrits de Christodoulos. Ainsi, ce moine de la communauté de Patmos aurait préalablement accédé à un poste ecclésiastique important avant la nomination d'Athanase et de Léontios. Ces trois nominations laissent donc supposer que le monastère de Saint-Jean-le-Théologien de Patmos pouvait servir de vivier de hauts dignitaires ecclésiastiques, notamment pour des postes au sud-est de l'Empire. Cette région était marquée à cette période par une instabilité géopolitique. Les moines de Patmos pouvaient cependant représenter des candidats idéals, car ils étaient de fins connaisseurs de celle-ci. L'exemple de Patmos montre surtout que l'insertion à un seul réseau de pouvoir ne suffisait pas pour devenir évêque au $\mathrm{XII}^{\mathrm{e}}$ siècle. Un examen prosopographique attentif de ces personnages met en évidence la multiplicité des réseaux mis en jeu pour devenir évêque. Les postulants multipliaient leurs insertions dans différents réseaux. Ces réseaux étaient aussi bien hérités, comme le montre l'exemple des Manassai, que construits, par Léontios notamment, et autant institutionnels, le statut du monastère facilitait les liens avec l'administration impériale qu'informels.

$\mathrm{Au} \mathrm{XII}^{\mathrm{e}}$ siècle, les futurs évêques disposaient de réseaux spécifiques pour obtenir leur charge et se distinguaient ainsi des fonctionnaires laïcs. Alors qu'à cette époque les liens familiaux apparaissaient essentiels dans les logiques de pouvoir, ils étaient moins décisifs pour les évêques, bien qu'ils ne fussent pas totalement absents. Le réseau de formation constantinopolitain était bien plus déterminant parce qu'il permettait de tisser des liens avec la plus haute aristocratie et plus particulièrement avec la famille impériale. Enfin, l'exemple du recrutement des moines du monastère de Saint-Jean-le-Théologien de Patmos montre comment le réseau monastique permettait d'investir des sièges épiscopaux et met aussi en évidence des stratégies régionales de nomination. Il montre surtout qu'en s'insérant dans des réseaux de différents types, le futur évêque multipliait ses voies d'accès au pouvoir et ainsi ses chances d'être promu.

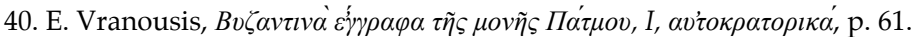

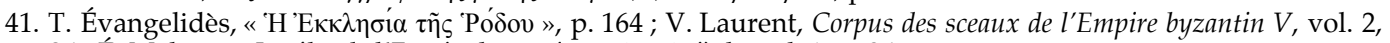
p. 526 ; É. Malamut, Les îles de l'Empire byzantin, VII ${ }^{e}$-XII ${ }^{e}$ siècle, vol. 1, p. 365.

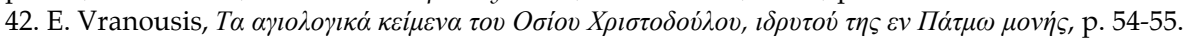

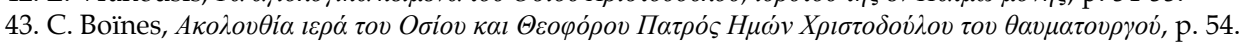




\begin{abstract}
Résumé
$\mathrm{Au} \mathrm{XII}^{\mathrm{e}}$ siècle, l'élection des évêques byzantins se déroulait désormais dans la capitale, dans un contexte de centralisation du pouvoir. La question du choix de l'individu pour occuper un siège répondait donc à de nouvelles logiques. Les futurs évêques étaient intégrés dans des réseaux de pouvoir variés. Plusieurs sources de notre période permettent de reconstituer partiellement les réseaux de certains évêques, principalement les lettres et discours des prélats, dans la mesure où le destinataire est connu. Ces réseaux pouvaient être familiaux, donc hérités, ou construits pendant la carrière du futur évêque, par exemple lors de son passage dans un monastère ou dans le clergé de la capitale. Ils rassemblaient surtout des membres de la haute aristocratie. Nous montrerons que cette intégration dans des réseaux était un facteur essentiel dans la nomination d'un évêque et nous réfléchirons surtout sur le poids respectif des différents liens pour accéder à l'épiscopat.
\end{abstract}

\title{
Bibliographie
}

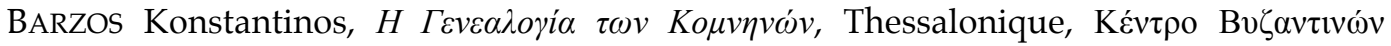

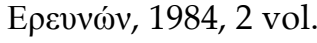

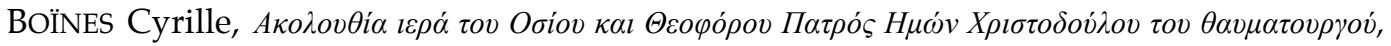

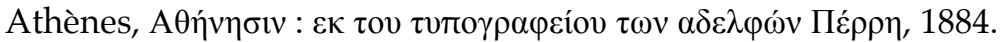

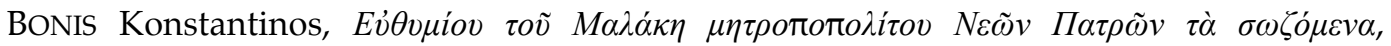

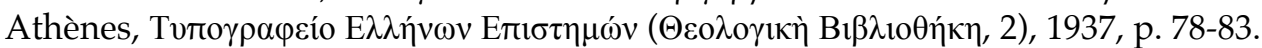

CHEYNET Jean-Claude, Pouvoir et contestations à Byzance : 963-1210, Paris, Publications de la Sorbonne (Byzantina Sorbonensia, 9), 1990.

DARROUZÈS Jean, Documents inédits d'ecclésiologie byzantine, Paris, Institut Français d'Études Byzantines (Archives de l'Orient Chrétien, 10), 1966.

DARROUZÈs Jean "Les discours d'Euthyme Tornikès", Revue des Études Byzantines, vol. XXVI, 1968, p. 49-121.

DARrouZÈs Jean, Notitix episcopatuum Ecclesiæ Constantinopolitanæ, Paris, Institut Français d’Études Byzantines (Géographie ecclésiastique de l'Empire byzantin, 1), 1981.

DemetraKopoulos Andronikos, Bibliotheca Ecclesiastica, $2^{\mathrm{e}}$ éd., Hildesheim, Georg Olms Verlagsbuchhandlung, 1965.

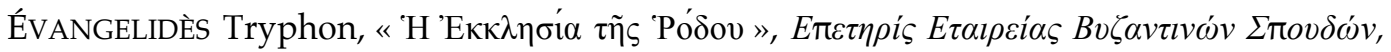
vol. VI, 1929, p. 145-179.

FAILLER Albert, «Le patriarche Athanase I Ir Manassès (1157-1170) », Revue des Études Byzantines, vol. LI, 1993, p. 63-75.

GAUTIER Paul, Michel Italikos. Lettres et discours, Paris, Institut Français d'Études Byzantines (Archives de l'Orient Chrétien, 14), 1972.

GOUDELIS Théodosios, The Life of Leontios, Patriarch of Jerusalem. Text, Translation, Commentary, Leyde, Brill (The Medieval Mediterranean, 2), 1993.

GOUILLARD Jean, «Quatre procès de mystiques à Byzance (vers 960-1143). Inspiration et autorité », Revue des Études Byzantines, vol. XXXVI, 1978, p. 5-81. 
GRUMEL Venance et DARROUZÈS Jean, Les regestes des actes du patriarcat de Constantinople, vol. 1 : les actes des patriarches (381-1206), fasc. II et III : les regestes de 715 à 1206, 2e éd., Paris, Institut Français d'Études Byzantines (Le Patriarcat byzantin, 1), 1989.

KAPLAN Michel, "Léontios de Jérusalem, moine ou évêque? », E. KounTOURA-GALAKÈ

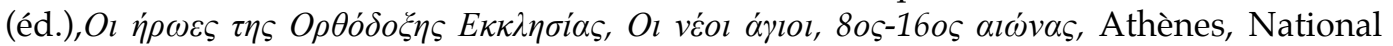
Hellenic Research Foundation (Institute for Byzantine Research, International Symposium, 15), 2004, p. 295-311, repris dans id., Pouvoirs, Église et Sainteté, essais sur la société byzantine, Paris, Publications de la Sorbonne (Les classiques de la Sorbonne, 3), 2011, p. 183-200.

KAPLAN Michel, «Un patriarche byzantin dans le royaume latin de Jérusalem: Léontios", Chemins d'outre-mer, Études d'histoire sur la Méditerranée médiévale offertes à Michel Balard, Paris, Publications de la Sorbonne (Byzantina Sorbonensia, 20), 2004, p. 475-488, repris dans id., Pouvoirs, Église et Sainteté, essais sur la société byzantine, Paris, Publications de la Sorbonne (Les classiques de la Sorbonne 3), 2011, p. 200-220.

Kolovou Foteini, Michaelis Choniatx epistulx, Berlin, Walter De Gruyter (Corpus Fontium Historiae Byzantinae, 41), 2001.

Kolovou Foteini, Die Briefe des Eustathios von Thessalonike, Munich, K. G. Saur, 2006.

LAMPSIDES Odysseus, "Zur biographie von Konstantinos Manasses und zu seiner Chronike Synopsis », Byzantion, vol. LVIII, 1988, p. 97-111

LAMPSIDES Odysseus, Constantini Manassis Breviarium chronicum, Athènes, Academia Athenensis (Corpus Fontium Historiae Byzantinae, 36), 1996, 2 vol.

LAURENT Vitalien, Corpus des sceaux de l'Empire byzantin V, Paris, Éditions Nationales du Centre de la Recherche Scientifique, 1963, 1965, 1972, 3 vol.

Magdalino Paul, The Empire of Manuel I Komnenos (1143-1180), Cambridge, Cambridge University Press, 1993.

Magdalino Paul, «In Search of the Byzantine Courtier: Leo Choirosphaktes and Constantine Manasses ", MAGUIRE Henry (éd.), Byzantine Court Culture from 829 to 1204, Washington, Harvard University Press, 1997, p. 141-165.

Malamut Élizabeth, Les îles de l'Empire byzantin, VII - XII siècles, Paris, Publications de la Sorbonne (Byzantina Sorbonensia, 8), 1988, 2 vol.

Migne Jacques Paul, Patrologiæ cursus completus, series græca, Paris, Petit-Montrouge, 18571910, 167 vol.

MOUlet Benjamin, Évêques, pouvoir et société à Byzance (VIII - XI siècle). Territoires, communautés et individus dans la société provinciale byzantine, Paris, Publications de la Sorbonne (Byzantina Sorbonensia, 25), 2011.

MuNITIZ Joseph, Nicephori Blemmydx Autobiographia sive curriculum vitx nec non Epistula universalior, Louvain, Turnhout (Corpus Christianorum. Series graeca, 13), 1985.

OIKONOMIDĖS Nicolas, «Un décret synodal inédit du patriarche Jean VIII Xiphilin concernant l'élection et l'ordination des évêques ", Revue des Études Byzantines, vol. XVIII, 1960 , p. 55-78.

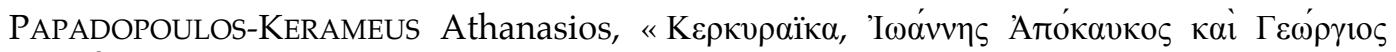

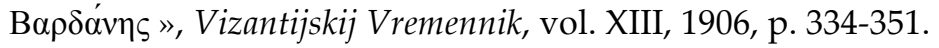


STIERNON Lucien, « Notes de titulature et de prosopographie byzantines. Adrien (Jean) Comnène et Constantin Comnène, sébastes ", Revue des Études Byzantines, vol. XXI, 1963, p. $179-198$.

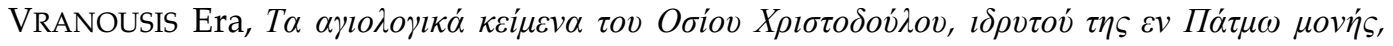

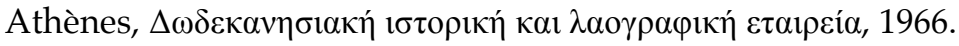

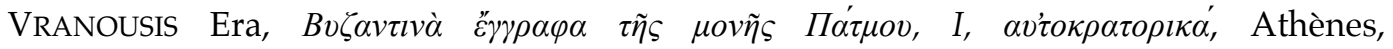

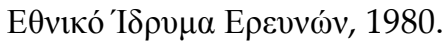

\section{Illustrations}

Figure 1 : De moine à évêque, des logiques de réseaux multiples.

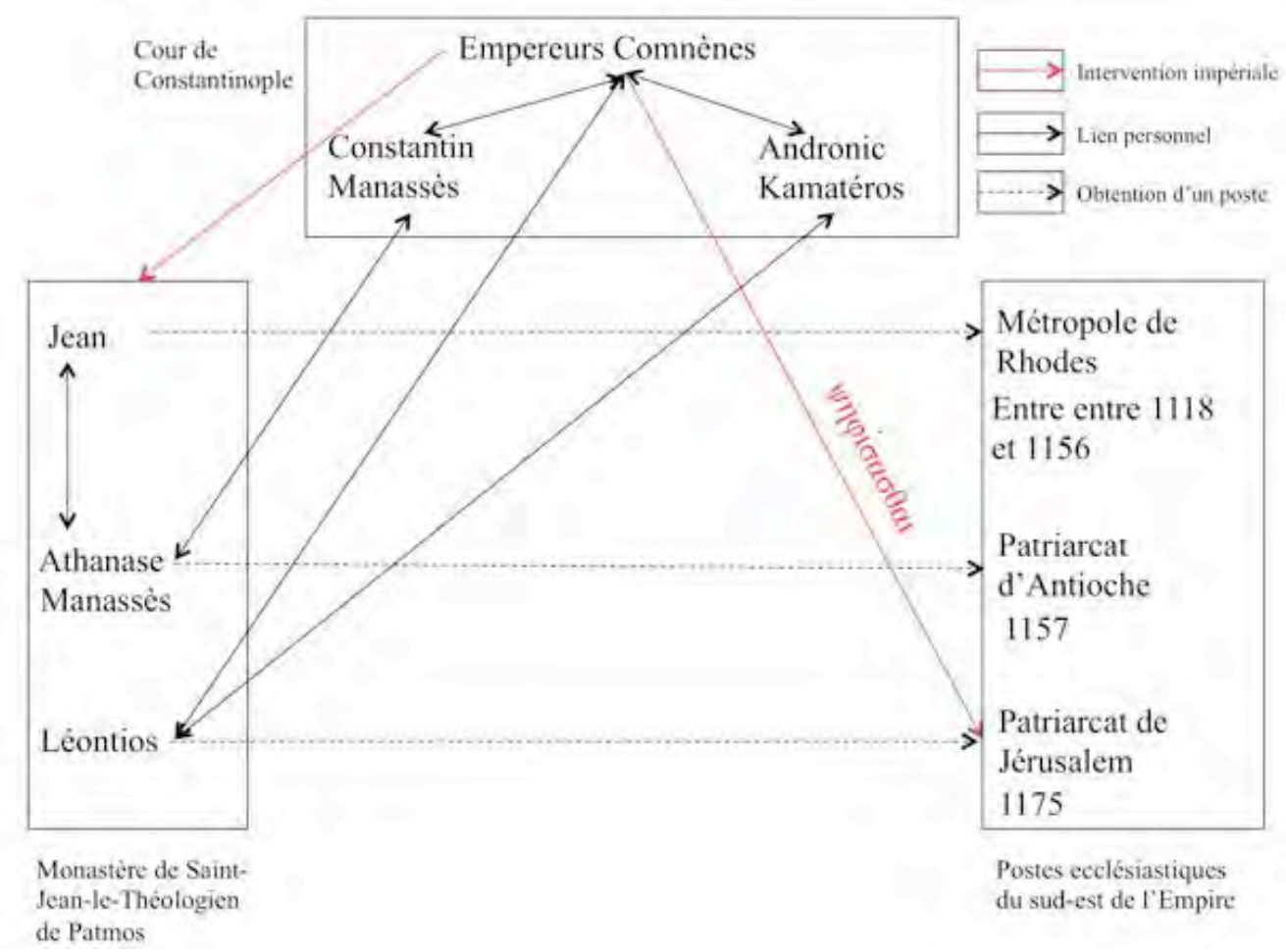




\title{
Henri de La Tour et les Grands sous la régence de Marie de Médicis
}

\author{
Romain MARCHAND \\ professeur agrégé d'histoire \\ Extrait de : Henri BRESC (dir.), Réseaux politiques et économiques, Paris, \\ Édition électronique du CTHS (Actes des congrès des sociétés historiques et scientifiques), 2016. \\ Cet article a été validé par le comité de lecture des Éditions du CTHS dans le cadre de la publication \\ des actes du $140^{\circ}$ Congrès national des sociétés historiques et scientifiques tenu à Reims en 2015.
}

La période qui sépare le régicide, en mai 1610, de la chute de Concini, en avril 1617, est dominée par l'opposition entre Marie de Médicis, à qui est confiée la régence du royaume de France jusqu'en octobre 1614, puis le gouvernement des affaires, et le prince de Condé, qui demeure l'héritier du trône en cas de décès du jeune Louis XIII et devient le chef de l'opposition à la reine mère. Ce conflit et les tensions politiques qui en découlent sont une constante de l'historiographie de la période et les biographies du prince de Condé, de Marie de Médicis, de Concini, de Louis XIII, ainsi que les études de libelles, se focalisent sur cette question et confèrent à l'étude de cette période une dimension très individuelle opposant des personnalités qui élaborent des projets différents pour le royaume et tentent de les faire valoir par des moyens variés. Le conflit entre le prince de Condé et Marie de Médicis se termine par l'arrestation du premier, l'exil à Blois de la reine mère, et permet l'émergence spectaculaire du jeune Louis XIII qui, soutenu par Luynes, élimine Concini.

La biographie de Marie de Médicis par Jean-François Dubost met en valeur les soutiens réels dont bénéficie la reine mère pendant son septennat ${ }^{1}$. Ils sont également connus pour le prince de Condé : les Grands d'une part, avec parmi eux Henri de La Tour, duc de Bouillon, présenté comme un éternel trublion; les parlementaires et le parti protestant d'autre part. Est-il possible de passer de l'étude des soutiens dont il dispose à la cartographie d'un réseau et d'en déterminer le fonctionnement ? Le triptyque dominer contrôler - être intégré, utilisé par Thierry Rentet dans l'étude des réseaux du connétable Anne de Montmorency, permet-il de comprendre la place de chacun des acteurs?

La séquence évènementielle de la période, les interventions des uns et des autres et leurs motifs officiels sont bien connus, en particulier par les libelles dont les pics ponctuent chaque événement majeur, et par les mémoires des contemporains. Il s'agit en l'occurrence de comprendre comment s'organisent les relations entre les différents soutiens $\mathrm{du}$ prince de Condé et de quelle manière ils sont simultanément ou alternativement sollicités, en éclairant le corpus de sources habituellement sollicité par la correspondance conservée d'Henri de La Tour, vicomte de Turenne, prince souverain de Sedan et duc de Bouillon et de son épouse Élisabeth de Nassau, malgré ses lacunes.

1. J.-F. Dubost, Marie de Médicis, la reine dévoilée. 


\section{De la correspondance au réseau}

Pour la période 1610-1617, 182 lettres écrites et 118 lettres reçues par le duc de Bouillon sont recensées, auxquelles s'ajoutent 227 lettres dans lesquelles il est mentionné, dont 56 écrites par son épouse, laquelle cite 271 personnages dans ses missives ${ }^{2}$. Les occurrences des différents auteurs, destinataires et personnages mentionnés permettent de dresser le tableau suivant :

\begin{tabular}{|c|c|c|c|c|}
\hline & $\begin{array}{l}\text { Correspondance } \\
\text { active }\end{array}$ & $\begin{array}{l}\text { Correspondance } \\
\text { passive }\end{array}$ & $\begin{array}{ll}\text { Mentions } & \text { du } \\
\text { duc } & \text { de } \\
\text { Bouillon } & \end{array}$ & $\begin{array}{l}\text { Personnages } \\
\text { mentionnés dans } \\
\text { les lettres } \\
\text { d'Élisabeth de } \\
\text { Nassau }\end{array}$ \\
\hline $\begin{array}{l}\text { Princes et ministres } \\
\text { étrangers }\end{array}$ & 66 & 53 & 12 & 17 \\
\hline Charlotte-Brabantine & 39 & & & \\
\hline Duplessis-Mornay & 11 & 15 & 83 & 5 \\
\hline Louis XIII & 11 & 8 & 4 & 3 \\
\hline Henri de La Trémoille & 8 & & & \\
\hline Le président Jeannin & 6 & 1 & 3 & 1 \\
\hline Montmorency & 5 & & & \\
\hline Marie de Médicis & 4 & 10 & 2 & \\
\hline Villeroy & 4 & 2 & & 2 \\
\hline Élisabeth de Nassau & 3 & 3 & & \\
\hline Prince de Condé & 2 & 2 & & 10 \\
\hline Duc de Nevers & & 1 & & \\
\hline Lesdiguières & & 5 & 1 & 2 \\
\hline Sully & & 2 & & 4 \\
\hline Richelieu & & & 7 & \\
\hline Éperon & & & & 5 \\
\hline Luynes & & & & 3 \\
\hline Concini & & & & 2 \\
\hline
\end{tabular}

L'importance de la correspondance échangée avec les princes étrangers met en exergue une caractéristique majeure du duc de Bouillon qui le distingue de l'ensemble des grands : c'est un prince souverain qui a épousé une Nassau, il fait donc partie du cercle des princes protestants européens, $c^{\prime}$ est pourquoi sa correspondance est régulière avec ces derniers.

Ce qui au contraire surprend est la rareté, voire l'inexistence, des lettres échangées entre Henri de La Tour et les Grands, ce qui empêche a priori de procéder à une étude de réseau. Faut-il y voir de sa part une méfiance face à « l'utilisation qui pouvait être faite de ses écrits $»^{3}$ ? Dans ce cas-là, on s'attendrait à constater une baisse des échanges épistolaires entre Henri de La Tour et les Grands après 1610 lorsqu'ils entrent progressivement dans l'opposition à la reine mère. Or, le nombre de lettres reste faible avant comme après 1610, ce qui conduit à revenir au principe de tout recours à la lettre : si la lettre implique la séparation physique, elle est inutile pour Henri de La Tour et les Grands qui se fréquentent à la cour ou dans la capitale de façon quotidienne, voire se

2. Principalement dans les lettres qu'elle échange environ deux fois par mois avec sa sœur Charlotte-Brabantine, duchesse de la Trémoille, conservées au chartrier de Thouars (Archives nationales, 1 AP 333 à 336) et publiées par P. Marchegay, "Transcription de vingt-trois lettres d'Élisabeth de Nassau et Charlotte Brabantine », ainsi que par Jean-Luc Tulot sur son site internet Le monde des La Trémoille dans le premier XVII siècle (http:/ / jeanluc.tulot.pagesperso-orange.fr/01LMDLT.htm).

3. Jean-Luc Tulot affirme en effet que le duc de Bouillon «se méfiait de l'utilisation qui pouvait être faite de ses écrits et de ce fait écrivait avec parcimonie » (J.-L. Tulot, Correspondance d'Élisabeth de Nassau, duchesse de Bouillon (1577-1642), p. 9). 
rencontrent en province comme le duc de Bouillon et le duc de Nevers à Sedan, Charleville et la Cassine. De même, l'intensité des échanges du duc de Bouillon avec la famille royale croît lors de chacun de ses départs de la cour.

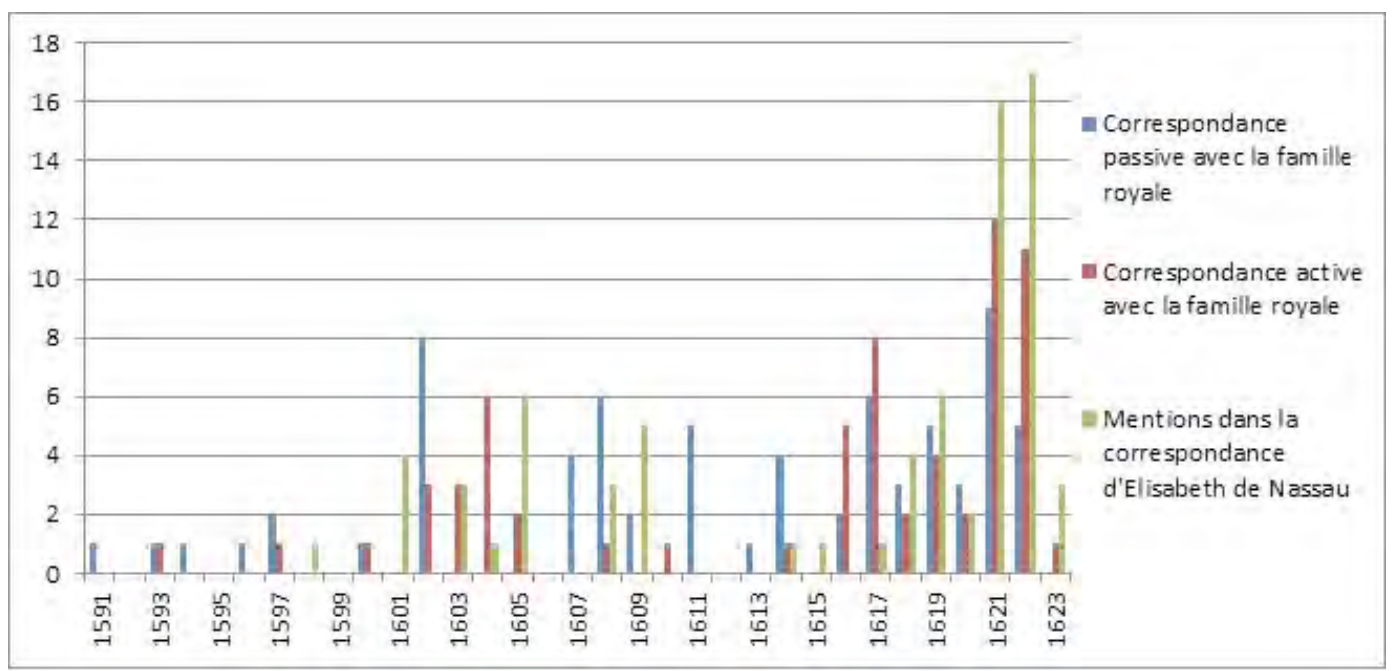

La famille royale dans la correspondance du duc de Bouillon et de son épouse (1591-1623)

Sur ce graphique apparaissent clairement l'exil sedanais de 1602-1606, ses retraites estivales à Sedan de 1607 à 1610, la prise de distance géographique avec la capitale au cours des guerres civiles de 1614-1617, et enfin son départ pour Sedan après avril 1617 jusqu'à sa mort en mars 1623. Le nombre limité de lettres conservées traduit probablement une activité épistolaire réduite et invite à mesurer et analyser autrement l'activité du réseau des Grands, qui malgré le faible nombre de missives font partie des correspondants les plus actifs du duc de Bouillon, en particulier le duc de Nevers et le prince de Condé4.

D'autre part, la rareté des lettres n'empêche pas nécessairement d'appréhender l'action des différents membres du réseau des Grands puisque Henri de La Tour à partir de 1614 écrit régulièrement à ses correspondants étrangers ou à sa belle-sœur CharlotteBrabantine de Nassau, duchesse de la Trémoille, pour justifier les prises d'armes, expliquer le déroulement des opérations et des négociations à Sainte-Menehould et à Loudun, solliciter des appuis ou évoquer ses propres préparatifs militaires. D'autres sources permettent par ailleurs de compléter l'étude, comme les libelles, le journal de Pierre de l'Estoile, les mémoires des contemporains, sources qui toutes associent dès le mois de mai 1610 le nom du duc de Bouillon à ceux des Grands et du prince de Condé, ou au parti protestant et aux parlementaires. Peut-on esquisser la position de chacun d'entre eux dans le réseau des Grands?

\section{Domination, contrôle et intégration dans le réseau des Grands}

Le prince de Condé semble le seul à exercer une domination sur le réseau des Grands, que Thierry Rentet définit comme une « autorité incontestable et incontestée " ${ }^{5}$. C'est en effet autour de lui que s'organise ce réseau dès son retour à Paris, qui inquiète Marie de Médicis, mais auquel Henri de La Tour participe :

4. Voir tableaux 16 et 17 : Personnages revenant le plus souvent dans la correspondance d'Henri de La Tour et de son épouse pour la période 1591-1606 et 1606-1623 (par ordre décroissant), in R. Marchand, « Henri de La Tour (1555-1623)», p. 551.

5. T. Rentet, Anne de Montmorency, grand maitre de François 1er, p. 266. 
«Le vendredi $9^{\mathrm{e}}$, M. de Bouillon sortit de Paris, pour aller au devant de M. le prince de Condé, avec Madame la princesse sa mère, M. de La Trimouille et plusieurs autres, seigneurs et dames. La Reine ne trouva bon que les Princes y allassent et leur en fit faire défenses fondées, ainsi qu'on disait, sur leurs querelles. » ${ }^{6}$

Cette domination rend compte du rang du prince de Condé parmi les Grands et de sa position d'héritier de la couronne en cas de décès du jeune Louis XIII. Elle se traduit par l'impulsion qu'il donne aux phases de tension politique ou de ralliement à Marie de Médicis: aucun des Grands ne prend les armes sans son accord, il désigne le duc de Bouillon pour conduire l'armée des princes de Noyon en Picardie jusqu'en Poitou, il est de loin le principal bénéficiaire des paix successives, entre autres celle de Loudun. Il est l'objet d'une attention particulière de la régente et de Concini, qui, inquiets de ses discussions avec les Grands à l'été 1616 , le font arrêter le $1^{\mathrm{er}}$ septembre, afin d'empêcher une nouvelle prise d'armes en mettant hors d'état de nuire le chef de l'opposition.

Pourtant, paradoxalement, cette opposition fait face à la volonté gouvernementale de la réduire dans les mois qui suivent. Après une période de surprise et d'hésitation, marquée par la fuite des Grands hors de la capitale, les Grands s'organisent, répondent aux accusations lancées à leur encontre par Richelieu dans la déclaration du 13 février 1617 et leur situation ne devient critique qu'au printemps 1617, soit six mois après l'arrestation du prince. C'est ici qu'intervient un second personnage, qui semble exercer le contrôle de ce réseau, à savoir la "responsabilité partagée avec d'autres personnages » ce qui le rend « susceptible d'être remis en cause ${ }^{7}$. Il s'agit du duc de Bouillon qui devient dès 1610 l'un des principaux conseillers du prince $^{8}$ :

«Il n'y avoit point de Seigneur en France que le Prince estimât plus que le Duc de Bouillon ; \& dès la première fois qu'ils se revirent, le Prince le pria d'être de ses amis, \& de compter sur son amitié \& sur sa confiance. Rien ne convenoit mieux aux projets du Duc; ainsi la liaison fut bien-tôt formée. »9

Le rôle spécifique d'Henri de La Tour n'apparaît que tardivement dans les actions des Grands, car il agit dans un premier temps exactement comme eux : l'opposition à Marie de Médicis ${ }^{10}$ et Concini ${ }^{11}$ explique les départs de la cour, les prises $\mathrm{d}^{\prime}$ armes et leurs justifications ${ }^{12}$. Il en est de même dans les libelles, car la plupart d'entre eux mêlent les noms du prince de Condé, des ducs de Mayenne, de Nevers, de Vendôme, de Bouillon ainsi que du marquis de Cœuvres à partir de 1614, sans toutefois les hiérarchiser. Pourtant la détérioration de la figure du duc de Bouillon dans ce type de sources est remarquable dès la première prise d'armes et s'accentue sans cesse : il devient la cible principale des libelles contre les princes, ce qui permet d'épargner le prince de Condéc ${ }^{13}$ qu'Henri de La Tour est accusé de manipuler ${ }^{14}$, d'affaiblir politiquement en quittant la coalition des princes ${ }^{15}$, $\mathrm{d}^{\prime}$ avoir insuffisamment préparé les défenses de Sedan ${ }^{16}$ ou au contraire de préparer les prises d'armes à $\mathrm{l}^{\prime}$ abri des terres souveraines ${ }^{17}$. Cette dernière activité est attestée pour chaque prise d'armes par les importantes commandes de

6. P. de L'Estoile, Mémoires, t. 3, 1610-1611, p. 141.

7. T. Rentet, Anne de Montmorency, p. 264.

8. Bibliothèque de Sedan - section du patrimoine, Ms 35.

9. J. Marsolier, Histoire de Henry de La Tour, p. 257.

10. J.-F. Dubost, Marie de Médicis, la reine dévoilée, chapitre 21 : « Marie contre Condé ».

11. H. Zuber, Recherches sur l'activité politique et diplomatique de Henri de La Tour, t. 1, quatrième partie, chap. 2 : «Avec Condé contre Concini».

12. Le manifeste de Monsieur le Prince, envoyé à Monsieur le Cardinal de Joyeuse ensemble le lettre de Monsieur de Bouillon, envoyée à Madame de la Trimouille.

13. R. Marchand, « Henri de La Tour (1555-1623)», p. 605-609.

14. Libre harangue faicte par Mathault en la presence de Monsieur le Prince en son Chasteau d'Amboise, le seiziesme iour de Iuin, p. 5.

15. Archives nationales, 1 AP 434, f ${ }^{\circ}$ 60, lettre d'Élisabeth de Nassau à Charlotte-Brabantine de Nassau du 12 juin 1614.

16. Ibid., $\mathrm{f}^{\circ} 187$, lettre $\mathrm{d}^{\prime}$ Élisabeth de Nassau à Charlotte-Brabantine de Nassau du 10 mars 1616 ; Stratagème et valeureuse entreprise du marquis de Spinola, pour recognoistre les forteresses de la ville de Sedan.

17. J'ay veu catuveu, s.l., 1616, p. 4. 
matériel d'artillerie passées à Sedan en 1613, 1615, 1616, 1617 ${ }^{18}$ : Henri de La Tour, prince souverain, peut anticiper les prises d'armes en commandant du matériel dans les terres souveraines à des artisans qui sont renommés - en 1600-1601 Sully avait commandé des boulets à Sedan pour le compte du roi de France. C'est par ailleurs le duc de Bouillon qui permet au prince de Condé de bénéficier de l'appui des parlementaires au printemps 1615, puis du parti protestant en $1616^{19}$. Ses relations avec ces deux groupes sont anciennes : le financier Scipion Sardini a sollicité les parlementaires parisiens au milieu des années 1580 pour financer la rançon du vicomte de Turenne, alors captif à Hesdin ${ }^{20}$; une décennie plus tôt, le même vicomte avait quitté la cour, s'était rallié au roi de Navarre et au parti protestant avant de se convertir au calvinisme ${ }^{21}$.

La position de contrôle exercée par le duc de Bouillon est attestée dès 1614 par l'appel du duc de Nevers à rejoindre les princes $^{22}$ et par son intervention pour sauver le duc de Mayenne, assiégé dans Soissons par les troupes royales, en avril 1617. Ce contrôle passe par les conseils au prince de Condé, l'évaluation de la situation politique, la mobilisation des partisans des Grands lors des révoltes comme les protestants et les parlementaires. Sans doute ce rôle de conseil et d'intermédiaire avec les appuis des princes justifie la dégradation de l'image du duc de Bouillon, d'autant qu'il ridiculise les troupes royales commandées par Boisdauphin en 1615. Ces dernières n'arrivent pas à l'empêcher de se rendre de Noyon à Loudun en franchissant la Seine puis la Loire avec deux jours d'avance.

Il est, en l'état actuel de la documentation et de l'avance de l'étude, difficile de préciser pour chacun des Grands si son rôle relève du contrôle ou de l'intégration. Il faudrait poursuivre l'étude au cas par cas. Il semble néanmoins que la moindre hostilité des libelles à leur égard et leur situation de dépendance à l'égard du prince de Condé invitent plutôt à penser leur participation comme une intégration, c'est-à-dire «le fait $\mathrm{d}^{\prime}$ appartenir à un réseau sans posséder la capacité à le diriger ${ }^{23}$. En ce qui concerne le parti protestant et les parlementaires, la position est clairement une position d'intégration ponctuellement mise en œuvre. Les parlementaires constituent le dernier recours institutionnel des Grands pour faire valoir leur projet politique après l'échec des États généraux de 1614, et leur rapide réduction à l'obéissance par la reine mère explique le recours systématique à la prise d'armes pour les Grands après le printemps 1615 puisqu'ils ne disposent plus de relais politique ${ }^{24}$. Dans ce contexte, le parti protestant renforce leurs moyens militaires et leur poids politique lors de l'opposition aux mariages espagnols, mais la méfiance est croissante à l'égard du duc de Bouillon : on ne sait s'il agit d'abord en Grand du royaume ou en chef de file du parti protestant, et la méfiance va devenir distance lorsque Rohan et Soubise vont entraîner les protestants dans la guerre pour défendre les clauses de l'Édit ${ }^{25}$.

18. Archives municipales de Sedan, fonds Gourjault, cartons 50 et 55 .

19. R. Marchand, « Henri de La Tour (1555-1623) », p. 598-600.

20. Ibid., p. 573-576.

21. Ibid., chapitre 4

22. Bibliothèque de l'Institut, Coll. Godefroy, Mss 267, $\mathrm{f}^{\circ} 186$ : lettre du duc de Nevers au duc de Bouillon du 15 août 1614 .

23. T. Rentet, Anne de Montmorency, p. 262

24. R. Marchand, « Henri de La Tour (1555-1623)», p. 600-601.

25. Ibid., p. 632-636. 
Dans la continuité des recherches menées dans le cadre de ma thèse sur Henri de La Tour, l'étude du réseau des Grands fait émerger son rôle particulier dans les retournements politiques de la période 1610-1617. Elle permet également de s'affranchir des oppositions de personnes entre le prince de Condé et Marie de Médicis, les Grands et Concini, le duc de Bouillon et Sully ou Rohan, et de mettre en valeur les nombreux appuis dont bénéficiait le prince de Condé pour faire valoir ses options politiques.

\section{Résumé}

La régence de Marie de Médicis s'accompagne, de janvier 1611 à avril 1617, de l'éviction de Sully, des révoltes des Grands et de la chute de Concini, qui font ressortir le rôle du prince de Condé et des Grands. Peut-on parler, à l'égard de ces derniers, d'un réseau ? Comment ce dernier s'organise-t-il et fonctionne-t-il ? De quels relais dispose-t-il ?

Après l'étude, en doctorat, des relations entre Henri de La Tour et les Grands, il s'agit ici d'élargir la perspective et de bien saisir, par-delà leurs motivations, les modalités de fonctionnement du réseau des Grands qui soutient le prince de Condé.

\section{Bibliographie - sitographie}

\section{Sources}

Archives nationales, 1 AP 434 (lettres éditées par Jean-Luc Tulot: http: / / jeanluc.tulot.pagesperso-orange.fr/01LMDLT.htm)

Archives municipales de Sedan, fonds Gourjault, cartons 50 et 55.

Bibliothèque de Sedan - section du patrimoine, Ms 35.

Bibliothèque de l'Institut, Coll. Godefroy, Mss 267

J'ay veu catuveu, s.1., 1616, p. 4.

L'Estolle Pierre de, Mémoires, dans Nouvelle collection des mémoires pour servir à l'histoire de France, deuxième série, I, Paris, édition Michaud-Poujoulat, 1837.

Le manifeste de Monsieur le Prince, envoyé à Monsieur le Cardinal de Joyeuse ensemble la lettre de Monsieur de Bouillon, envoyée à Madame de la Trimouille, s.l.n.d.

Libre harangue faicte par Mathault en la présence de Monsieur le Prince en son Chasteau d'Amboise, le seiziesme iour de Iuin, s.l., 1614, p. 5.

MARChEGAY Paul, "Transcription de vingt-trois lettres d'Élisabeth de Nassau et Charlotte Brabantine ", in Bulletin de la société d'histoire du protestantisme français, t. 15, 1866, p. 36-51 et p. 78-99.

MARSOLIER Jacques, Histoire de Henry de La Tour d'Auvergne duc de Bouillon où l'on trouve ce qui s'est passé de plus remarquable sous les Regnes de François II, Charles IX, Henri III, Henri IV, la minorité de Louis XIII E les premières années du Regne de Louis XIII, Paris, François Barois, 1719.

Tulot Jean-Luc, Correspondance d'Élisabeth de Nassau, duchesse de Bouillon (1577-1642) à sa sœur Charlotte-Brabantine, duchesse de la Trémoille, http://jeanluc.tulot.pagespersoorange.fr/Edenassau.01. 
Stratagème et valeureuse entreprise du marquis de Spinola, pour recognoistre les forteresses de la ville de Sedan, "Par M.C.D. Tullois, Advocat en Parlement», Paris, Jean Bourriquant, 1615.

\section{Travaux}

DubOSt Jean-François, Marie de Médicis, la reine dévoilée, Paris, Payot, 2009.

MARCHAND Romain, «Henri de La Tour (1555-1623)», thèse dirigée par Jean DuMA, Nanterre, Université Paris Ouest, 2014.

RENTET Thierry, Anne de Montmorency, grand maitre de François $I^{e r}$, Rennes, Presses Universitaires de Rennes, 2011.

ZUBER Henri, Recherches sur l'activité politique et diplomatique de Henri de La Tour, vicomte de Turenne puis Duc de Bouillon (1573-1623), Paris, École Nationale des Chartes, 1982, 2 volumes. 


\title{
Les multiples réseaux formels et informels d'un apothicaire parisien : l'échevin Matthieu-François Geoffroy
}

\author{
Olivier LAFONT \\ Président de la Société d'Histoire de la Pharmacie, \\ Membre de l'académie nationale de Pharmacie \\ Extrait de : Henri BRESC (dir.), Réseaux politiques et économiques, Paris, \\ Édition électronique du CTHS (Actes des congrès des sociétés historiques et scientifiques), 2016. \\ Cet article a été validé par le comité de lecture des Éditions du CTHS dans le cadre de la publication \\ des actes du $140^{\mathrm{e}}$ Congrès national des sociétés historiques et scientifiques tenu à Reims en 2015.
}

Matthieu-François Geoffroy (1644-1708) exerçait la profession de maître apothicaire, rue Bourg-Tibourg, à Paris. C'était un notable local, puisqu'il occupa les fonctions de commissaire des pauvres de sa paroisse (1677), de marguillier de la fabrique de l'Église Saint-Paul (1683), de garde de la communauté des apothicaires parisiens (1684), de premier échevin de la ville de Paris (août 1685, 1686, août 1687) et de premier consul en 1964.

\section{Sources}

Les sources s'avèrent fort nombreuses à son propos. Son Journal a été publié par Paul Dorveaux, au début du $\mathrm{XX}^{\mathrm{e}}$ siècle ${ }^{1}$. Le Registre des délibérations des apothicaires parisiens est conservé dans le fonds ancien de la Bibliothèque Interuniversitaire de Santé, pôle Pharmacie ${ }^{2}$. Un article du Journal des Sçavans relate la part prépondérante que MatthieuFrançois prit à une démonstration publique de thériaque en $1684^{3}$. L'Éloge de son fils Guillaume-François, publié par Fontenelle dans l'Histoire de l'Académie royale des sciences mentionne ses relations avec les milieux scientifiques ${ }^{4}$. Les Archives de la ville de Paris font état de son activité échevinale ${ }^{5}$. La relation du voyage de Martin Lister à Paris permet de connaître l'aspect de sa boutique ${ }^{6}$. Enfin, sa biographie a été publiée en $2008^{7}$. Les multiples réseaux auxquels ce bourgeois de Paris appartenait, pouvaient être formels ou informels.

\section{Réseau des apothicaires}

Logiquement, sa famille et sa profession le conduisirent à évoluer au sein d'un réseau formel, celui des apothicaires parisiens, organisés en communauté structurée. Déjà, son grand-père Étienne $\mathrm{I}^{\text {er }}$ était un notable de cette communauté et de la bourgeoisie parisienne. Maître apothicaire depuis 1586, il fut élu garde de la communauté en 1634 et accéda, deux ans plus tard, aux fonctions d'échevin de Paris. Tout en étant commissaire des pauvres, il participa à la juridiction consulaire, comme consul en 1642, puis comme

1. P. Dorveaux, Journal de Matthieu-François Geoffroy, maître apothicaire de Paris, p. 505-577.

2. Registre des délibérations du corps des apothicaires parisiens, Bibliothèque interuniversitaire de santé, Paris - Pôle Pharmacie, Registre 37.

3. Journal des Sçavans, Lundy 28 février 1684, p. 61-71.

4. Fontenelle, Eloge de M.Geoffroy, p. 93-100.

5. A. de Coëtlogon et L. Tisserand, Les Armoiries de la Ville de Paris, passim.

6. M. Lister, Voyage à Paris, p. 212.

7. O. Lafont, Échevins E apothicaires, passim. 
juge, en 1656. Quant à son père, Étienne II, qui était également maître apothicaire depuis 1638, il fut élu garde en 1665. Geoffroy entretenait également des relations avec des correspondants provinciaux, puisqu'il envoya son fils aîné à Montpellier chez l'apothicaire Pierre Sanche, afin qu'il pût suivre les cours que la Faculté de Médecine de cette ville organisait pour les élèves apothicaires, tandis que lui-même recevait à Paris François, le fils de son confrère ${ }^{8}$.

\section{Réseau des anciens élèves du Collège de Clermont}

Matthieu François appartenait également à un réseau informel, mais très influent, celui des anciens élèves du Collège de Clermont ${ }^{9}$. Il fréquenta, en effet, ce prestigieux établissement, fleuron de l'enseignement de la Compagnie de Jésus, en même temps que le marquis de Louvois. Bien que celui-ci fût nettement plus âgé, puisqu'il était élève de philosophie quand Matthieu François entra en cinquième, des relations durables se nouèrent entre eux, qui s'étendirent à leurs familles. Des liens s'établirent ainsi tant avec le père de Louvois, le Chancelier Le Tellier, qu'avec sa mère, Élisabeth Turpin, avec qui ils prirent un tour plus personnel, puisque Matthieu-François mentionne dans son Journal $^{10}$ que cette dame lui rendit visite lorsqu'il se trouvait alité et le coucha sur son testament. Par ailleurs, le ministre de la guerre confia à Matthieu-François, en 1672, la tâche de fabriquer des remèdes pour l'Armée, lors de la préparation de la guerre de Hollande $^{11}$. Louvois lui procura également des places de commissaires des guerres pour ses deux frères ${ }^{12}$. Durant la maladie du ministre, en 1690, Matthieu-François lui fournit de nombreux médicaments ${ }^{13}$. À la génération suivante, leurs fils, Étienne-François Geoffroy et l'Abbé de Louvois firent ensemble le voyage d'Italie ${ }^{14}$.

\section{Réseau scientifique}

Le réseau des savants avec qui Matthieu-François était en relation s'avère impressionnant. Geoffroy fit ainsi appel à Simon Boulduc, un apothicaire qui allait devenir membre de l'Académie royale des Sciences, lorsqu'il dut choisir un " conducteur » pour l'examen de maîtrise de son fils aîné. Le naturaliste Martin Lister, membre de la Royal Society, quand il accompagna l'ambassadeur Lord Portland à Paris, visita l'officine familiale qu'il décrivit de façon fort élogieuse et ce médecin anglais rapporta dans sa relation de voyage ${ }^{6}$ : "J'ai beaucoup à me louer de la politesse de ce savant à mon égard». Quant aux "conférences réglées » que Geoffroy organisa à son domicile pour l'éducation de son fils et qui attirèrent, comme le rapporte Fontenelle ${ }^{15}$, un public de qualité, elles permettent de juger de sa capacité à mobiliser des personnalités en vue du monde scientifique. Se déplacèrent ainsi, à sa demande, Jean-Dominique Cassini, le célèbre astronome, le Père Sébastien Truchet, dont Fontenelle vante le génie pour la «méchanique», Louis Joblot, le spécialiste des aimants et de l'usage du microscope, Gabriel du Vernay, l'anatomiste bien connu, ainsi que Guillaume Homberg, chimiste renommé d'origine hollandaise et ami de la famille.

\section{Réseau artistique}

Matthieu François ne négligeait pas pour autant les milieux artistiques. En témoignent des portraits réalisés par des maîtres réputés, comme Nicolas de Platte-Montagne ou Nicolas de Largillière (Fig. 1). Il était en relation suivie avec Sébastien Leclerc qui dessina son ex-voto et réalisa pour ses fils des gravures destinées à orner leurs synthèses - sortes d'affiches au format in-plano, rédigées en latin et destinées à annoncer le programme de

8. P. Dorveaux, Journal de Matthieu-François Geoffroy, p. 568-569.

9. G. Dupont-Ferrier, Du Collège de Clermont au Lycée Louis-le-Grand, passim.

10. P. Dorveaux, Journal de Matthieu-François Geoffroy, p. 573.

11. Ibid., p. 508

12. Ibid., p. $512-513$.

13. Ibid., p. 513-515.

14. Fontenelle, Éloge de M. Geoffroy, p. 94.

15. Ibid., p. 93. 
leurs examens de soutenance de maîtrise d'apothicaire, ainsi que la composition du jury. Lorsque son fils cadet, Claude-Joseph, et son petit-fils, Claude-François, moururent, la vente de leur collection ${ }^{16}$ comportait notamment des milliers d'estampes, ainsi que des dessins originaux, dont certains de la main de Philippe de Champaigne.

\section{Réseau de ceux à qui ils fournissaient des médicaments}

Ce que nous appellerions sa clientèle huppée constituait un autre réseau de personnalités influentes. On relève ainsi, dans son journa ${ }^{17}$, les noms de Charles d'Albert d'Ailly, duc de Chaulnes, gouverneur de Bretagne et ami de Madame de Sévigné, de Nicolas-Jean Foucault, intendant de Caen, ou encore de l'Abbesse de Vernon, sœur de Madame de Saint-Pouange, l'épouse de Gilbert Colbert de Saint-Pouange, un proche collaborateur de Louvois au ministère de la guerre, personnage que l'on croise également, à plusieurs reprises, dans son Journal. Geoffroy, comme l'on pouvait s'y attendre, fournissait personnellement de nombreux médicaments à Louvois. Il eut même l'occasion, en dépit du grand nombre d'apothicaires privilégiés qui gravitaient à la Cour, d'effectuer, "par ordre du Roy et de Monseigneur», le voyage de Versailles, afin d'administrer à la dauphine «de l'extrait de quinquina en petites pilules dorées " ${ }^{18}$. L'extrait de quinquina constituait une forme d'administration de cette drogue plus concentrée que la simple poudre, donc efficace sous un plus petit volume, mais l'amertume s'en trouvait encore augmentée, ce qui rendait nécessaire d'enrober les pilules dans une feuille d'or, afin d'en dissimuler la saveur désagréable au patient.

Ce traitement novateur et souverain contre les fièvres, se trouvait malheureusement inadapté à la lutte contre la tuberculose, dont on pense que souffrait l'épouse du Grand Dauphin. Cette intervention ne parvint, naturellement pas, à sauver Marie-Anne-Victoire de Bavière. L'infortunée princesse se trouvait alors à la dernière extrémité et elle mourut, moins d'un mois plus tard, à l'âge de trente ans.

\section{Réseau échevinal}

Un dernier réseau peut être identifié, il s'agit du plus prestigieux, celui des échevins et anciens échevins de Paris. Si le réseau des échevins de Paris possède incontestablement un caractère formel, celui des anciens échevins qui n'avait pas d'existence formalisée, n'en demeurait pas moins extrêmement efficace. Le billet d'enterrement du grand-père de Matthieu-François, Étienne $\mathrm{I}^{\mathrm{er}}$, reproduit par Maurice Bouvet ${ }^{19}$, ne manquait pas, bien des années après la fin de son échevinage, de signaler sa qualité de «doyen des eschevins", ce qui montre l'importance attachée à ce titre, puisqu'il semblait ne pas se perdre après la fin des fonctions et que son plus ancien titulaire était qualifié de doyen. Le Journal de Matthieu-François porte, au titre de l'année 1685, une mention fort sobre ${ }^{20}$ : « Le jeudy 16 aoust j'ay este eslû premier échevin ». Cette date est conforme à la tradition, puisque les élections ont, en principe, toujours lieu le lendemain de la fête de l'Assomption, le jour de la Saint-Roch. Une seule exception peut se produire, lorsque le 16 tombe un dimanche, dans ce cas, l'élection est reportée au 17.

\section{Les conséquences de l'appartenance au réseau échevinal}

Le simple fait d'appartenir au réseau échevinal allait offrir à Geoffroy plusieurs occasions d'approcher le roi Louis XIV. Dès le premier dimanche suivant l'élection, une première rencontre eut lieu. Matthieu-François nota dans son Journal ${ }^{21}$ : «Le Dimanche 19, j'ay eu l'honneur de prester serment entre les mains du Roy à Versailles ». Là encore, il ne

16. Catalogue des livres et estampes de défunts Mrs. Geoffroy, , passim.

17. P. Dorveaux, Journal de Matthieu-François Geoffroy, passim.

18. Ibid., p. 513.

19. M. Bouvet, Les apothicaires échevins de Paris, p. 436.

20. P. Dorveaux, Journal de Matthieu-François Geoffroy, p. 509.

21. Ibid., p. 509. 
s'agissait que du respect de la tradition : tout nouveau bureau de la Ville devait prêter serment lors de sa prise de fonction.

En revanche, une occasion fut manquée, le 28 mars 1686. En effet, à cette date eut lieu l'inauguration de la place des Victoires, offerte au roi par le maréchal de La Feuillade. L'état de santé du roi, tracassé par sa fistule, ne lui permit pas d'y assister. Geoffroy se borna à noter : « Le jeudy 28 mars, j'estois en qualité d'Echevin à la cérémonie de la place des Victoires ${ }^{22}$. Il ne mentionna même pas que les échevins avaient, en cette circonstance, reçu Monseigneur le dauphin, Monsieur, le frère du roi, et Madame, la princesse palatine, ainsi que de nombreuses personnalités.

Une autre opportunité allait toutefois se présenter. Le 18 novembre 1686, à Versailles, le roi subit, en présence de Louvois et de Madame de Maintenon, l'importante opération de la fistule anale, pour laquelle son premier chirurgien mit au point le célèbre bistouri à la royale. Matthieu-François ne manqua pas de mentionner ce fait dans son Journal :

«Le 18 novembre, l'opération de la fistule à l'anus a esté faite au Roy par M. Félix, son premier chirurgien. $»^{23}$

Le roi se rendit à Paris pour remercier Dieu de sa guérison, en assistant à un office d'action de grâce à la cathédrale Notre-Dame. À cette occasion, afin de sceller solennellement le pardon qu'il accordait au peuple de sa capitale, Louis XIV accepta, pour la première fois depuis les malheurs de la Fronde, d'être reçu à souper à l'Hôtel de Ville. Naturellement, toute l'organisation de cette cérémonie somptueuse reposa sur le prévôt des marchands et les échevins. Geoffroy nota fièrement dans son Journal :

«Le jeudy, 30 Janvier, le Roy, après avoir entendu la messe à Nostre-Dame, vint disner à l'Hostel-de-Ville ; M. de Fourcy, prévost des marchands, eut l'honneur de servir Sa Majesté, et moy celuy de servir Monseigneur le Dauphin en qualité de premier Échevin. ${ }^{24}$

Le premier personnage de l'État était ainsi servi par le premier personnage de la ville, le prévôt des marchands, tandis que le second personnage de l'État, son héritier le Dauphin, l'était par le premier échevin, deuxième personnage de la ville. Les hiérarchies, si importantes au $\mathrm{XVII}^{\mathrm{e}}$ siècle se trouvaient donc respectées et cette situation symbolisait la soumission de la ville au pouvoir royal, lequel, en retour, accordait à la capitale son pardon solennel pour sa participation aux troubles de la Fronde.

Ce dîner hautement symbolique fut jugé suffisamment important pour mériter une large publicité, mise en œuvre par l'État et dont Geoffroy se trouva tout particulièrement en charge, au nom de la ville, ce qui lui donna de nouvelles occasions de se rendre à Versailles. Dès le vendredi, il fut du voyage pour remercier Louis XIV de sa visite :

«Le lendemain, 31 janvier, la ville fut à Versailles remercier le Roy de l'honneur qu'il luy avoit fait. $»^{25}$

Le premier support choisi pour cette propagande fut celui des médailles. On sait l'importance que Louis XIV accordait à ce mode de communication. Près de six mois après la réception du roi, Geoffroy mentionna un nouveau voyage du bureau de la ville à Versailles et cela marqua la première apparition des médailles dans son Journal :

« Le dimanche 15 juin, la Ville fut à Versailles présenter au roy et à toutte la cour des médailles qui avoient este frapées exprès au sujet de l'honneur qu'elle avoit receu. ${ }^{26}$ 
Cette médaille fit l'objet d'une reproduction dans l'ouvrage consacré aux médailles du règne ${ }^{27}$, sous le titre de :

«1687. Festin fait au Roy dans l’Hostel de Ville.»

L'avers est orné du visage du roi et le côté pile illustre l'événement. Cette face fait l'objet d'une description dans le texte explicatif :

«On y voit le Roy assis sous un dais. Il a devant luy une table, où la Ville de Paris pose avec respect une corbeille pleine de fruits. »

Le neveu du roi, fils de Monsieur et futur duc d'Orléans ne se trouvait pas à la cour, ce jour-là, et ce fut Geoffroy qui se trouva chargé de se rendre à Saint-Cloud pour lui apporter la fameuse médaille :

«Le mercredy, 30 Juillet, j'ay este député de la Ville pour aller à Saint-Cloud présenter les médailles à M. le Duc de Chartres, qui n'estoit point à Versailles lorsque la Ville y fut en distribuer. $»^{28}$

Bien que son temps d'échevinat fût terminé depuis le 16 août 1687, Geoffroy s'occupa personnellement, au cours de l'année 1688, de tout ce qui concernait ces médailles et leur diffusion.

Il nota ainsi successivement dans son Journal :

« Le vendredy 12 mars, $M$. Petit, $\mathrm{M}^{\mathrm{e}}$ du balancier du roy m’a livré cent deux médailles que le roy avoit fait frapper au sujet du disné qu'il avoit fait frapper au sujet du disné qu'il avoit fait à l'Hostel-de-Ville, pour estre distribuées à messieurs de la Ville »

puis :

«Le samedy 13, j'ai este à Versailles prendre l'ordre du roy de M. de Louvois pour en faire la distribution que je fis les trois jours suivans. ${ }^{29}$

Un second support publicitaire fut utilisé pour relater cette visite historique, l'estampe. On connaît la grande diffusion et le rôle politique joué par les almanachs, tout au long du règne. Deux d'entre eux, au format in-plano et concernant l'année 1688, évoquaient la réception du roi par la ville. Pour des raisons évidentes, les évènements illustrés avaient toujours eu lieu l'année précédente. Dans les deux cas, on peut y reconnaître, sans aucune ambiguïté, le premier échevin, représenté dans l'exercice de ses fonctions.

La gravure de Lepautre (Fig. 2) qui illustrait le premier de ces calendriers était intitulée : « Louis le Grand, l'amour et les délices de son peuple». Elle représentait la grande salle de l'Hôtel de Ville, la table du banquet, les prestigieux convives assis et, debout derrière le roi et les princes, le bureau de la ville en grande tenue. On distingue très nettement Matthieu-François, placé derrière le Dauphin (Fig. 3). Le premier échevin est revêtu de sa robe mi-partie et tient entre ses mains un plateau d'argent chargé d'une carafe, ainsi que d'un verre à pied. Il est représenté au côté du prévôt qui porte lui-même un plateau identique. Le trait de la gravure est précis et l'on identifierait sans peine Geoffroy, même sans l'aide de la mention de son nom qui figure pourtant dans la légende.

Quant à la seconde estampe, elle concerne «La joye publique et la réception du roy ». Louis XIV, à sa descente de carrosse, est accueilli sur les marches de l'Hôtel de Ville par M. de Fourcy et les échevins. Le prévôt s'incline devant le roi et lui présente son épouse ;

27. Médailles sur les principaux événements du règne de Louis le Grand, p. 220.

28. P. Dorveaux, Journal de Matthieu-François Geoffroy, p. 511.

29. Ibid., p. 511. 
il est entouré par les échevins en robe et, là encore, on reconnaît très bien le premier d'entre eux, Geoffroy (Fig. 4).

La seule mention d'une estampe qui figure dans le Journal ${ }^{30}$ de Geoffroy ne permet pas d'identifier celle de ces gravures dont l'ancien échevin s'occupa de la diffusion :

«J'ay fait dans le mois de décembre [1687] la distribution de l'estampe que la Ville a fait graver au sujet de la venue du roy à l'Hostel-de-Ville. »

La date confirme bien, en revanche, qu'il s'agissait d'un calendrier pour l'année 1688, mais c'était le cas des deux documents qui nous sont parvenus.

\section{Le réseau de la juridiction consulaire}

Enfin, Geoffroy appartint à un autre réseau formel, celui de la juridiction consulaire, ancêtre de nos tribunaux de commerce. Il fut en effet élu consul en 1694. Il mentionna le fait dans son Journal ${ }^{31}$ :

«Le samedy 30 [janvier 1694] l'on a fait l'élection des consuls : M. Legrand pour grand juge, et MM. Geoffroy, Baudequin, Dumont et Billet pour consuls. Le lundy $1^{\text {er }}$ février, prestation de serment à la Grande Chambre et installation au siège ».

Geoffroy resta exactement une année en fonction, puisque le 29 janvier 1695, il nota dans son Journal :

«Le samedy 29, j'ay quitté le Consulat, l'élection aiant este faite de M. Tranchepin pour juge et MM. Creton, Berard, Edme et Chauvin pour consuls. »

Cette brillante carrière aux confins de la marchandise et de l'administration n'aurait certainement pas été possible sans l'appartenance de Matthieu-François Geoffroy à un ensemble aussi important de réseaux, tant formels qu'informels. L'appartenance au réseau des anciens élèves du Collège de Clermont a certainement joué un rôle essentiel lors de plusieurs étapes de cette vie bien remplie, puisque l'indéfectible protection des Le Tellier s'est souvent avérée déterminante. Faire partie d'un réseau signifiait bien souvent la possibilité d'accéder à un autre. Il est ainsi notoire que la plupart des maîtres apothicaires, anciens échevins, ont fait partie de la juridiction consulaire, même si ce fut le cas également de bien d'autres. L'originalité de Matthieu-François résidait dans le nombre et la diversité des réseaux dont il faisait partie. 


\section{Résumé}

Matthieu-François Geoffroy (1644-1708), appartenait à un réseau formel, celui des apothicaires parisiens réunis au sein d'une communauté régie par des statuts, dont il fut garde en 1684, mais il appartenait également à de nombreux réseaux informels très influents. L'étude de son journal ainsi que de nombreux autres documents (éloge de son fils Étienne-François, article du Journal des Savants, archives de la ville, etc.) permet de constater leur multiplicité et leur importance dans le déroulement de sa carrière aux confins de l'administration et de la marchandise. Le réseau informel des anciens élèves des Jésuites du Collège de Clermont, où il fut le condisciple de Louvois, lui ouvrit les portes du réseau politico-administratif constitué autour de la famille Le Tellier. Les conférences scientifiques $\mathrm{qu}^{\prime} \mathrm{il}$ organisait dans son officine pour l'éducation de ses enfants montrent qu'il se trouvait au cœur d'un réseau scientifique comportant de nombreux membres (Cassini, Joblot, du Vernay, Homberg) de l'Académie des sciences, compagnie dont deux de ses fils firent ultérieurement partie. Il convient de ne pas négliger le réseau d'artistes (Sébastien Le Clerc, Nicolas de Plate-Montagne, Nicolas de Largillière) avec lequel ses fonctions lui permirent des contacts fructueux. Un réseau influent était constitué par les membres de sa clientèle aristocratique avec qui il entretenait une relation privilégiée.

Matthieu-François était en relation avec le réseau des échevins de Paris avant même son élection à ce poste prestigieux (1685), grâce à son grand-père Étienne $\mathrm{I}^{\text {er }}(1586-1673)$ qui l'avait précédé, en 1636, dans ces fonctions. Son fils Claude-Joseph occupa, lui aussi, cette position enviée. Il fit ensuite partie de la juridiction consulaire (1694), autre réseau institutionnel, dont son grand-père lui avait ouvert la voie. L'appartenance de Geoffroy à un aussi grand nombre de réseaux était exceptionnelle, même à l'époque, et explique en partie sa réussite sociale.

\section{Bibliographie}

Bouvet Maurice, «Les apothicaires échevins de Paris », Revue d'histoire de la Pharmacie, 1952, tome $X, 40^{\mathrm{e}}$ année, $\mathrm{n}^{\circ} 135$, p. 433-446.

CoËTlogon Anatole et TISSERAND Lazare Maurice, Les Armoiries de la Ville de Paris, Paris, Imprimerie Nationale, 1875.

DorveAux Paul, "Journal de Matthieu-François Geoffroy, maître apothicaire de Paris », Bulletin de la Société d'histoire de la Pharmacie, $17^{\mathrm{e}}$ année, $\mathrm{n}^{\circ} 66,1906$, p. 505-577.

DuPONT-FerRIER Gustave, Du Collège de Clermont au Lycée Louis-le-Grand (1563-1920), Paris, Hachette, 1920.

FONTENELle, «Éloge de M. Geoffroy», Histoire de l'Académie Royale des Sciences, année 1731, Histoire, p. 93-100.

Journal des Sçavans, Lundy 28 février 1684, p. 61-71.

LAFONT Olivier, Échevins \& Apothicaires sous Louis XIV, La vie de Matthieu François Geoffroy, bourgeois de Paris, Paris, Pharmathèmes, 2008.

LISTER Martin, Voyage de Lister à Paris en 1698, Paris, Société des bibliophiles français, 1873.

Médailles sur les principaux événements du règne de Louis le Grand, Imprimerie Royale, 1702. 


\section{Illustrations}

Figure 1

Portrait gravé de Matthieu-François Geoffroy d'après Largillière.

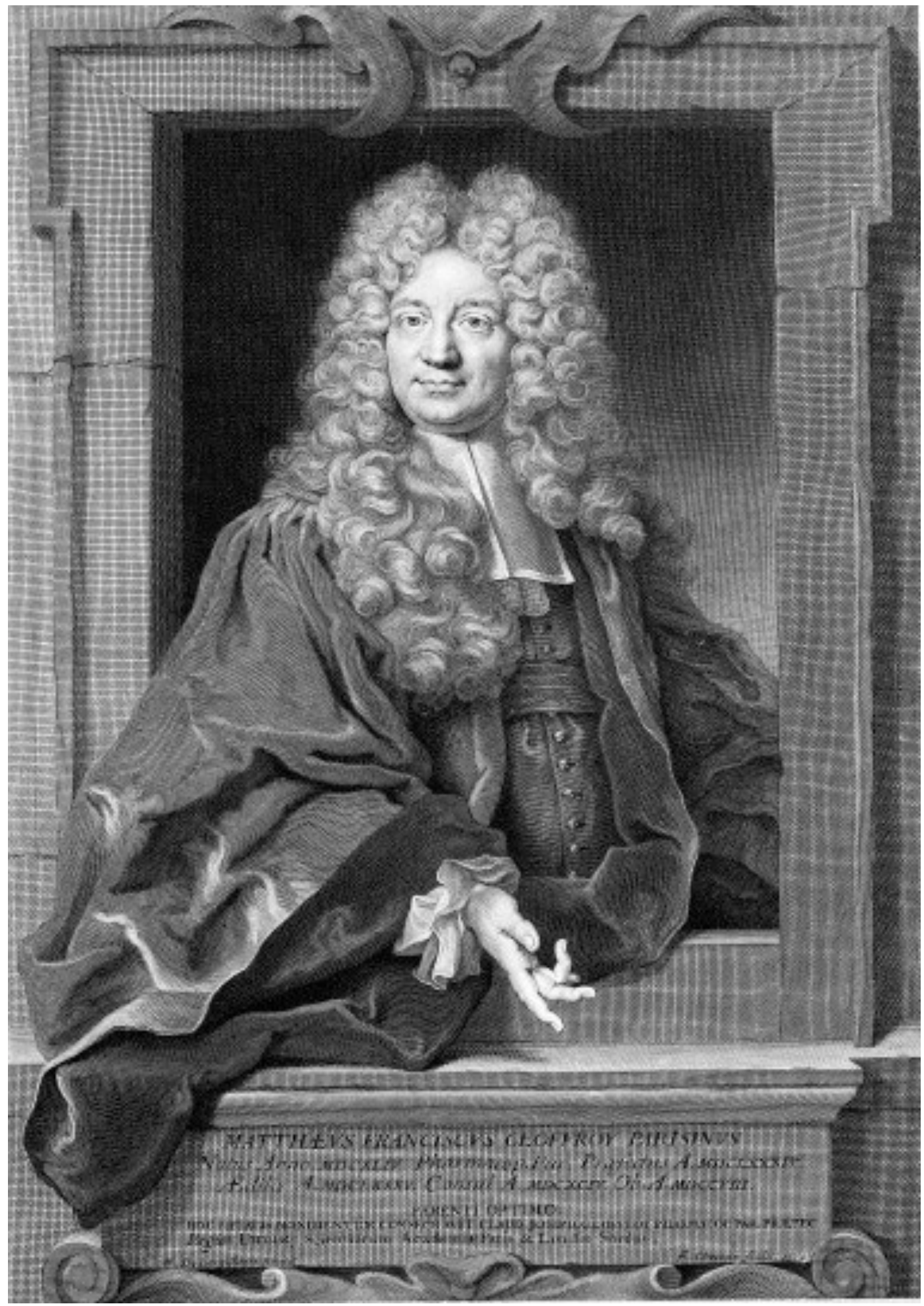


Figure 2

Almanach gravé par Lepautre pour l'année 1688.

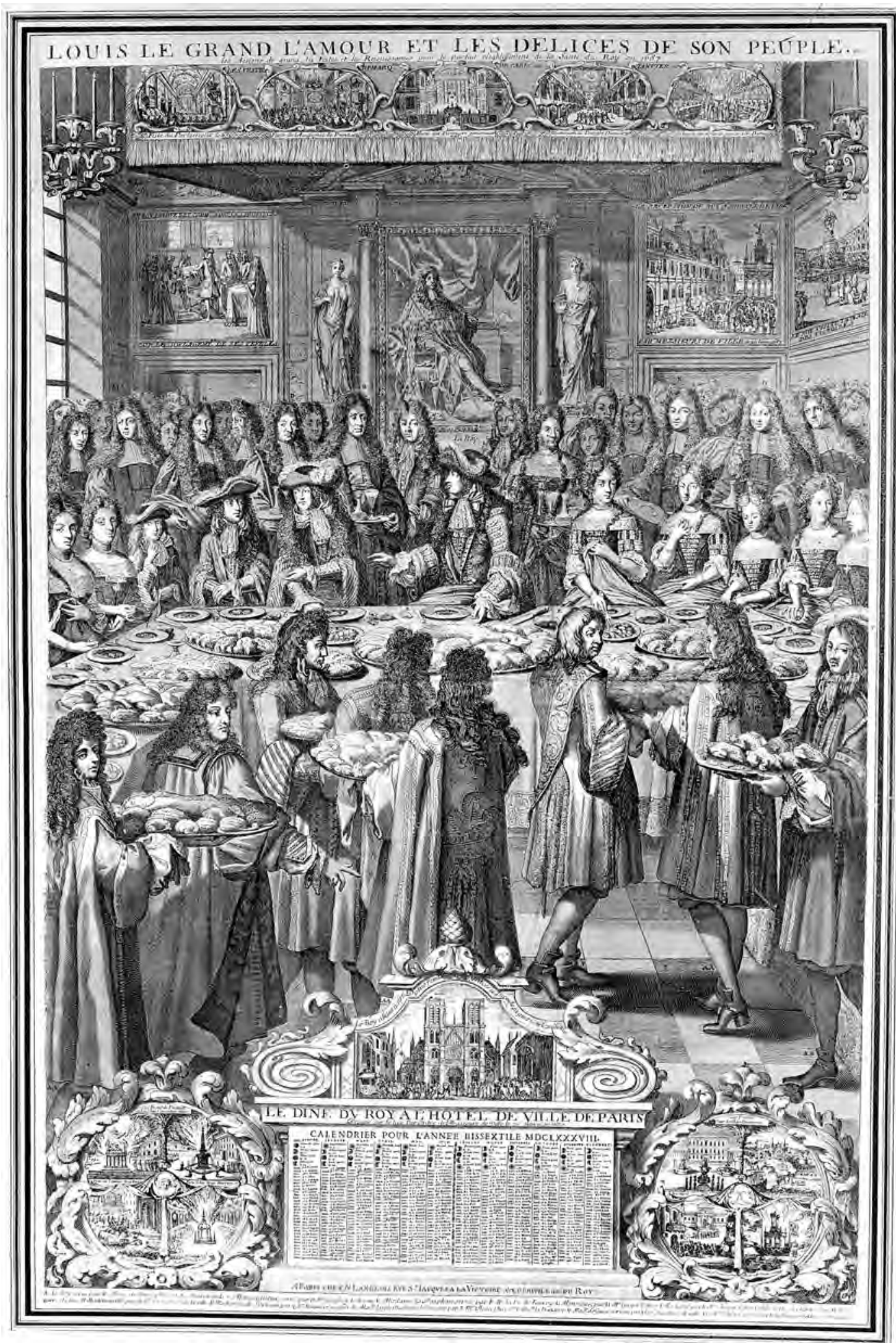




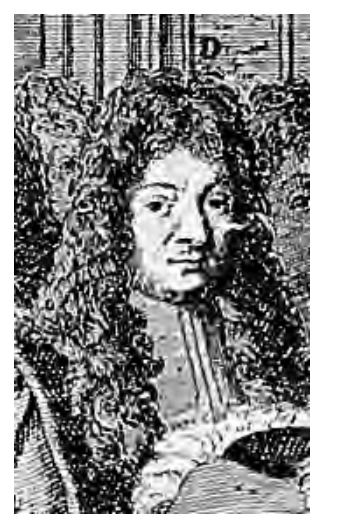

Figure 3

Matthieu-François Geoffroy, détail de la gravure de Lepautre.

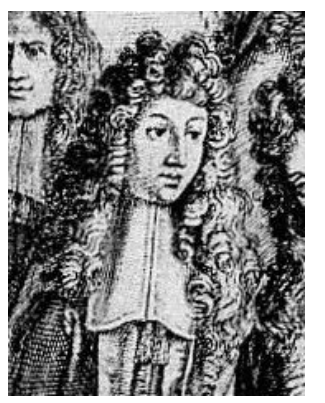

Figure 4

Matthieu-François Geoffroy, détail de l'Almanach 1688 représentant l'arrivée du roi à Notre-Dame. 
L'espace en réseaux 


\title{
Le réseau des foires de Champagne (XII ${ }^{e}-X I V^{e}$ siècles) Émergence, structuration et connexions
}

\author{
Jean-Marie YANTE, \\ Professeur à l’Université catholique de Louvain \\ Extrait de : Henri BRESC (dir.), Réseaux politiques et économiques, Paris, \\ Édition électronique du CTHS (Actes des congrès des sociétés historiques et scientifiques), 2016. \\ Cet article a été validé par le comité de lecture des Éditions du CTHS dans le cadre de la publication \\ des actes du $140^{\mathrm{e}}$ Congrès national des sociétés historiques et scientifiques tenu à Reims en 2015.
}

L'émergence du cycle des foires de Champagne ${ }^{1}$, réseau d'échanges structuré par l'autorité comtale au XII ${ }^{\mathrm{e}}$ siècle, ne peut être abordée sans l'évocation conjointe d'autres cycles de réunions marchandes en Europe occidentale, sans non plus celle des réseaux internes au milieu du négoce, des réseaux du crédit et, last but not least, du réseau routier, élément capital pour le rayonnement d'assises majeures du commerce international jusqu'au début voire au milieu du XIV ${ }^{\mathrm{e}}$ siècle. Largement tributaire de l'état actuel de la recherche, la présente contribution se veut avant tout un provisoire et partiel état de la question.

\section{La constitution du cycle des foires champenoises}

Aux dires de Fernand Braudel, des foires d'Occident plongent «dans le passé d'interminables racines $»^{2}$. Des historiens en repoussent les origines au-delà de Rome, jusqu'aux grands pèlerinages celtiques. Avec la réanimation des échanges $d u \mathrm{XI}^{\mathrm{e}}$ au XIII ${ }^{e}$ siècle, voire déjà plus tôt, le réseau gagne en densité, mais il convient de distinguer les foires à réputation internationale et d'autres, assurément majoritaires, au recrutement régional ou local.

L'organisation des foires médiévales d'un même espace économique en un cycle rigoureusement structuré peut être la résultante d'une nécessité logique plus ou moins précocement ressentie ou d'initiatives de princes éclairés. Au milieu du XIX siècle, le cas champenois a retenu l'attention de Félix Bourquelot dans un ouvrage qui demeure incontournable ${ }^{3}$. Plus récemment, Michel Bur a consacré plusieurs études à l'origine des rendez-vous régionaux $x^{4}$. Il a notamment dégagé l'existence de deux générations de foires ou plus exactement de deux générations de villes accueillant les foires de Champagne: d'abord les vieilles cités épiscopales (à l'exception de Reims) puis, à partir de la seconde moitié du $\mathrm{XI}^{\mathrm{e}}$ siècle, des réunions près de châteaux comtaux (Provins, Bar-sur-Aube) ou d'abbayes comtales (Lagny, Rebais, Épernay). Souvent, leur durée n'est pas connue. Vers

1. Article capital : R.-H. Bautier, «Les foires de Champagne. Recherches sur une évolution historique », p. 97147. Voir aussi F. Irsigler et W. Reichert, "Les foires de Champagne », p. 89-105.

2. F. Braudel, Civilisation matérielle, économie et capitalisme, XV -XVIII siècle, t. II : Les jeux de l'échange, p. 63.

3. F. Bourquelot, Études sur les foires de Champagne, sur la nature, l'étendue et les règles du commerce qui s'y faisait aux XII ${ }^{e}$ XIII et XIV siècles.

4. Sur les foires créées par le pouvoir comtal : M. Bur, « Remarques sur les plus anciens documents concernant les foires de Champagne », p. 45-62 ; M. Bur, La formation du comté de Champagne (v.950 - v.1150), p. 292-305; M. Bur, « Note sur quelques petites foires de Champagne », p. 255-267. À propos des foires non comtales : M. Bur, "Les 'autres' foires de Champagne», p. 349-365. Les trois articles sont reproduits dans M. Bur, La Champagne médiévale. Recueil d'articles, p. 463-514. 
1150, la foire provinoise de Saint-Ayoul et celle de Bar-sur-Aube s'étalent sur quinze jours; celle de Lagny, sur plus de dix.

Les dynastes champenois, singulièrement Thibaud II, jouent un rôle essentiel dans la constitution d'un cycle. On doit à ce prince la création de la foire de mai à Provins, la fixation du cadre chronologique, topographique et fiscal des autres rendez-vous, dès lors la concentration autoritaire $\mathrm{du}$ commerce international dans quelques centres, soigneusement sélectionnés, de la Champagne méridionale. Les anciennes foires de Rebais et d'Épernay sont victimes de cette politique. La seconde est déplacée à Troyes entre 1130 et 1136 .

$\mathrm{Au}$ milieu du $\mathrm{XII}^{\mathrm{e}}$ siècle, le cycle des foires comtales est composé de dix réunions, s'échelonnant de janvier à décembre, à Bar-sur-Aube, Lagny, Provins, Sézanne et Troyes. Quatre de ces foires au moins durent quinze jours, mais ce laps de temps s'avère insuffisant, puisque déjà en d'autres endroits les échanges commencent à durer plus de deux semaines. De ce fait, une nouvelle sélection des villes de foire s'impose ainsi qu'un réajustement du calendrier. C'est chose faite aux alentours de 1190. Les foires de Sézanne disparaissent ainsi qu'une foire de Provins et une autre à Troyes ${ }^{5}$.

\section{Cycle des foires au milieu du XII ${ }^{\mathrm{e}}$ siècle}

\begin{tabular}{|l|l|l|}
\hline date & localité & dénomination \\
\hline $1^{\text {er }}-15$ janvier (?) & Lagny & foire des Innocents \\
\hline 22 janvier -5 février & Troyes & foire du Clos \\
\hline $3^{\text {e }}$ et $4^{\text {e }}$ semaines de Carême & Bar-sur-Aube & \\
\hline semaine de la Passion & Sézanne & \\
\hline mai & Provins & foire de mai \\
\hline 24 juin & Troyes & foire de la Saint-Jean d'été \\
\hline $1^{\text {ere }}$ quinzaine de septembre & Provins & foire de la Saint-Ayoul \\
\hline $1^{\text {er }}$ octobre & Troyes & foire de la Saint-Remi \\
\hline 11 novembre & Provins & foire de la Saint-Martin d'hiver \\
\hline décembre & Sézanne & foire de la Saint-Nicolas \\
\hline
\end{tabular}

La sécurité des transactions est une condition sine qua non pour la viabilité et l'essor de ces rendez-vous. Deux initiatives comtales contribuent à leur rayonnement. Le " conduit des foires " garantit la protection des marchands et de leurs cargaisons tant à l'aller qu'au retour et, le cas échéant, une indemnisation pour les dommages subis. Quant à la " garde des foires ", elle devient peu à peu une instance à prétention universelle enregistrant les contrats et veillant à leur exécution, notamment par la poursuite des débiteurs défaillants ou « fuitifs $»^{6}$.

\section{Autres cycles de foires en Europe occidentale}

Un rapprochement s'impose avec d'autres cycles de foires attestés en Europe occidentale au Moyen Âge. Pour l'heure, des chronologies restent çà et là à préciser, et il convient encore de scruter le sens, la nature et l'ampleur des influences.

En Flandre, cinq grandes foires se tiennent tour à tour dans les villes de Bruges, Lille, Messines, Torhout et Ypres. On ne connaît guère le processus ou le mécanisme de la formation de ce cycle avant la fondation de la foire de Bruges en 1200. À l'origine, chaque réunion a une durée d'un jour ou deux, est donc très limitée dans le temps. De plus, ces foires sont placées à intervalle irrégulier et plutôt concentrées sur deux saisons, le printemps et l'automne. À partir du milieu et surtout dans le dernier tiers du XII ${ }^{\mathrm{e}}$ siècle, quatre foires (Lille, Messines, Torhout et Ypres) semblent dominer les autres et former un

5. M. Bur, La formation du comté de Champagne (v.950 - v.1150), p. 293 et 298-301.

6. J.-M. Yante, « Le contentieux économique et financier aux foires de Champagne (XIII ${ }^{\mathrm{e}}-\mathrm{XIV} \mathrm{e}^{\mathrm{e}}$ siècles) », p. 15-27. 
cycle, mais il faut attendre 1200 pour apercevoir une organisation nouvelle. Cette annéelà, Baudouin IX crée une nouvelle foire à Bruges qui aura la même durée que les autres rendez-vous du comté, et il stipule qu'elle devra suivre les usages en vigueur à Torhout. Selon toute vraisemblance, le pouvoir comtal assume un rôle important dans la constitution progressive du cycle. Spécialement durant les années 1160-1180, les souverains de la dynastie d'Alsace contribuent à l'animation des activités marchandes et à l'aménagement du territoire dans la région maritime ${ }^{7}$. En un mot, une «politique économique » $\mathrm{s}^{\prime}$ inscrit à leur actif ${ }^{8}$.

Le cas anglais, analysé par Ellen Wedemeyer Moore, s'avère quelque peu différent. Il ne $\mathrm{s}^{\prime}$ agit pas d'un cycle au sens champenois ou flamand du terme, mais de la concentration à l'est du pays de rencontres proches de centres de production drapière et aussi de voies d'eau et de routes. Une véritable «politique économique » d'initiative princière n'y est pas réellement patente?

On doit à Franz Irsigler d'avoir attiré l'attention sur deux cycles de foires en pays rhénan : dans la vallée du Rhin inférieur (Aix-la-Chapelle, Cologne, Duisburg et Utrecht) et dans celle du Rhin moyen (Oppenheim, Spire et Worms). Il a également dégagé l'émergence en cours aux XII ${ }^{\mathrm{e}}-\mathrm{XIII}{ }^{\mathrm{e}}$ siècles d'autres cycles plus à l'est, notamment dans la région Wetterau-Main (Francfort, Friedberg, Gelnhausen et Würzburg) et aux environs plus ou moins immédiats du lac de Constance, et il en a esquissé le calendrier ${ }^{10}$.

En Normandie aussi les foires finissent par se constituer en véritables cycles ${ }^{11}$ et, en Languedoc, un peu avant le milieu du XIV ${ }^{\mathrm{e}}$ siècle, la précellence des réunions de Pézenas et de Montagnac s'affirme sans conteste. La succession de six foires y couvre une bonne partie de l'année ${ }^{12}$. Sans prétendre à quelque exhaustivité, on mentionnera encore le cycle de sept rendez-vous instauré en 1233 par Frédéric II dans les terres continentales de son royaume de Sicile ${ }^{13}$.

\section{Les réseaux internes au monde marchand}

Les marchands eux aussi s'organisent. À l'origine, ils n'ont pas, semble-t-il, de représentation particulière et permanente aux foires de Champagne. Dès avant le milieu du XIII ${ }^{\mathrm{e}}$ siècle toutefois, les Italiens instaurent un consulat pour chacune de leurs colonies commerçantes. Le plus ancien connu est celui des Siennois en 1246. Les consuls ne sont pas les représentants de corporations de métiers, mais des consuls au sens plein du terme. Ils s'avèrent l'émanation de l'autorité supérieure de leur cité, tant à l'égard de leurs concitoyens que des princes ou des justices étrangères, tiennent les assemblées de leurs compatriotes présents aux foires, arbitrent leurs différends et représentent leurs intérêts en justice auprès du comte de Champagne ou du roi de France, en Parlement ou en cour de justice. Dans la seconde moitié du XIII ${ }^{\mathrm{e}}$ siècle, une quinzaine de consulats ont été repérés pour des villes italiennes. Les Catalans disposent d'une semblable structure ${ }^{14}$.

Par ailleurs, après le milieu du XIII ${ }^{\mathrm{e}}$ siècle, les «Italiens " et les «Provençaux » se constituent en societas et universitas. Un capitaine est élu à leur tête. Le premier cas attesté est la désignation en 1278 de celui des Italiens par les consuls de douze cités toscanes et lombardes, habilité à traiter avec le roi de France pour une installation marchande à

7. M. Yamada, « Le mouvement des foires en Flandre avant 1200 », p. 773-789.

8. H. Van Werveke, De economische politiek van Filips van de Elzas (1157-68 tot 1191) ; A. Verhulst, « Initiative comtale et développement économique en Flandre au XII ${ }^{\mathrm{e}}$ siècle : le rôle de Thierry et de Philippe d'Alsace (1128-1191)», p. 227-240.

9. E. Wedemeyer Moore, The fairs of Medieval England. An introductory study, p. 10-12.

10. F. Irsigler, «Jahrmärkte und Messesysteme im westlichen Reichsgebiet bis ca. 1250 », notamment p. 13-14.

11. L. Musset, " Foires et marchés en Normandie à l'époque ducale », p. 12-13.

12. J. Combes, «Les foires en Languedoc au Moyen Âge », p. 240.

13. E. Maschke, « Die Wirtschaftspolitik Kaiser Friedrichs II. im Königreich Sizilien », p. 24.

14. R.-H. Bautier, «Les foires de Champagne. Recherches sur une évolution historique », p. 126-127. 
Nîmes, à représenter l'ensemble des marchands d'Outremont auprès de celui-ci, des princes ou des justices, et à exercer une juridiction sur ses concitoyens opérant dans le royaume. Le capitaine des Provençaux et Languedociens, quant à lui, est choisi par le Conseil de la ville de Montpellier ${ }^{15}$.

Les marchands septentrionaux (Nord de la France et Pays-Bas) ne disposent pas de semblables structures, mais il convient d'évoquer à leur propos la Hanse des XVII villes (Fig. 1). Henri Laurent ${ }^{16}$ a été le premier à étudier systématiquement cette organisation, longtemps confondue avec la Hanse flamande de Londres ${ }^{17}$. Selon lui, il s'agit d'une fédération de villes drapières unies par les intérêts communs du commerce d'exportation des produits du Nord français vers les foires de Champagne et, en même temps, d'une véritable entente patronale entre les gildes. Les travaux ultérieurs de Louis Carolus-Barré et de Fernand Vercauteren ont enrichi et, à certains égards, corrigé la connaissance de cette institution.

En 1965, dans une brève mais dense communication à l'Académie des Inscriptions et Belles-Lettres, de Paris, Louis Carolus-Barré a repris le dossier de la création, de l'appellation, de la composition primitive et de l'aire de rayonnement de la Hanse des XVII villes. Pour lui, cette association de villes drapières, presque toutes situées dans l'ancienne province ecclésiastique de Reims, est antérieure à 1213 et pourrait remonter au dernier tiers du $\mathrm{XII}^{\mathrm{e}}$ siècle. Originellement, elle réunit exactement dix-sept villes - ce qui met fin à de nombreuses hypothèses - et est dirigée par un conseil composé d'Ypres (peut-être avec prééminence), d'Arras, Cambrai, Douai et Saint-Quentin. Se démarquant d'Henri Laurent qui limitait l'action de la Hanse aux foires de Champagne, Louis Carolus-Barré affirme son activité, dès le dernier quart du $\mathrm{XII}^{\mathrm{e}}$ siècle, dans les diverses foires du royaume, dont celle du Lendit aux portes de Paris, et jusqu'aux ports méditerranéens ${ }^{18}$.

Fernand Vercauteren, quant à lui, a établi en 1950 que cette Hanse ne disparaît pas avec le déclin des foires de Champagne, mais change au XIV ${ }^{\mathrm{e}}$ siècle de nature et d'objet. De commerciaux, les rapports entre les villes membres deviennent corporatifs pour tous les métiers ressortissant au secteur textile ${ }^{19}$.

Par ailleurs, nombre de villes marchandes possèdent des hôtels particuliers dans une ou plusieurs villes de foires. Ces bâtiments peuvent disposer d'une galerie couverte pour la vente et offrent des locaux de stockage, des dortoirs pour les marchands et des écuries pour leurs montures. Il s'agit de véritables institutions au sens sociologique du terme, témoignant de la régularité et de l'intensité des relations avec les foires ${ }^{20}$.

À la fin $\mathrm{du} \mathrm{XII}{ }^{\mathrm{e}}$ siècle, on bâtit en pierre un grand nombre de ces immeubles afin de résister aux incendies alors fréquents dans les villes. L'affluence d'étrangers accroît la valeur de la propriété immobilière dans les quartiers accueillant les foires. Le comte de Champagne, des nobles et des établissements religieux deviennent propriétaires de halles $^{21}$. Certaines communautés marchandes investissent pareillement dans l'une ou l'autre ville.

15. Ibid., p. 130-133

16. H. Laurent, «Un comptoir de vente international au Moyen Âge. Nouvelles recherches sur la Hanse des XVII Villes », p. 81-94; H. Laurent, Un grand commerce d'exportation au Moyen Âge. La draperie des Pays-Bas en France et dans les pays méditerranéens (XIII'-XV siècle), p. 86-95 et 235-241; H. Laurent, "La Hanse des XVII villes, hanse flamande de France ", p. 409-412. Remarques critiques: R.-H. Bautier, "Les foires de Champagne. Recherches sur une évolution historique », p. 128-130.

17. Confusion levée par H. Pirenne, «La hanse flamande de Londres », p. 105-108.

18. L. Carolus-Barré, "Les XVII villes. Une hanse vouée au grand commerce », p. 20-30. Faute d'indications précises, exception faite pour la foire du Lendit, des réserves ont été formulées à propos de l'expansion géographique des activités de la hanse : P. Desportes, Reims et les Rémois aux XIII et XIVe siècles, p. 114, note 142.

19. F. Vercauteren, « Note sur la survivance de la Hanse des XVII villes du XV ${ }^{\mathrm{e}}$ au XVII ${ }^{\mathrm{e}}$ siècle », p. 1078-1091.

20. H. Laurent, Un grand commerce d'exportation au Moyen Âge. La draperie des Pays-Bas en France et dans les pays méditerranéens (XIII $-X V^{e}$ siècle), p. 95 et 269-273.

21. E. Chapin, Les villes des foires de Champagne des origines au début du XIVe siècle, p. 108 et 118-120. 
Félix Bourquelot ${ }^{22}$, Elizabeth Chapin $^{23}$ et Henri Laurent ${ }^{24}$ ont procédé à de premiers repérages. L'enquête est à poursuivre. Pour l'heure, on dénombre une petite centaine de halles ou maisons marchandes dans les villes de foires, dont une trentaine à Bar-surAube, à Provins et à Troyes. Seule la maison de Toulouse, connue sous la dénomination de "grange aux dîmes », a survécu à Provins, mais des sous-sols dans cette ville et à Barsur-Aube attestent d'affections commerciales médiévales.

Des villes du Midi français - Marseille, Montauban, Montpellier (présente dans les quatre villes de foires), Orange et Toulouse - disposent de telles infrastructures. C'est le cas, pour le nord de l'Espagne, de Barcelone, Lérida et Valence. Les Provençaux ont une halle à Lagny et les Espagnols à Provins (Fig. 2). Des Italiens d'Asti, Bologne, Florence, Gênes, Lucques, Plaisance, Rome, Sienne et Venise occupent pareillement une ou plusieurs halles ou maisons marchandes. On devrait y ajouter les Lombards (mais cette désignation pose problème, on y reviendra) et les Toscans (Fig. 3). Et, dans l'état actuel des investigations, on dénombre une trentaine de villes du Nord et du Centre de la France ou des Pays-Bas détentrices d'un tel immeuble dans une ou plusieurs villes champenoises, qu'elles en soient propriétaires ou locataires (Fig. 4). Sans parler des Allemands, notamment du Sud, tels les marchands de Constance implantés tout à la fois à Bar, Lagny, Provins et Troyes ${ }^{25}$.

Une autre facette des réseaux internes au monde des affaires est l'existence de bonne heure, entre les foires de Champagne et les compagnies de commerce italiennes y trafiquant, d'un échange incessant de nouvelles. Le fait est attesté dès 1260. L'Arte di Calimala, puissante corporation de fabricants et marchands de drap de laine à Florence dès le début du XIII ${ }^{\mathrm{e}}$ siècle, est en relation constante avec les foires. Vers 1250-1350, l'Arte fait partir régulièrement un courrier de Florence vers la Champagne et de la Champagne vers Florence. Le service des cursores est toutefois réservé aux membres de l'Arte. Seules peuvent être transmises par ce moyen les lettres adressées à ses membres ou expédiées par ceux-ci ${ }^{26}$.

\section{Les connexions avec d'autres réseaux}

Il convient encore d'évoquer les connexions du réseau champenois des foires avec deux autres réseaux : celui du crédit d'abord, le réseau routier ensuite.

\section{Le réseau du crédit ${ }^{27}$}

On sait que la communauté juive champenoise est particulièrement ancienne et fournie, même si le chiffre de 30000 personnes, naguère avancé, ne s'avère pas crédible ${ }^{28}$. Il existe une forte présomption d'une présence juive à Provins dès le $\mathrm{XI}^{\mathrm{e}}$ siècle ${ }^{29}$. Troyes abrite

22. F. Bourquelot, Études sur les foires de Champagne, sur la nature, l'étendue et les règles du commerce qui s'y faisait aux XII ${ }^{e}$ XIII et XIV siècles, notamment t. II, p. 8-10, 13-19, 24 et 28-29.

23. E. Chapin, Les villes des foires de Champagne des origines au début du XIV siècle, p. 108-118.

24. H. Laurent Un grand commerce d'exportation au Moyen Âge. La draperie des Pays-Bas en France et dans les pays méditerranéens (XIII $-X^{e}$ siècle), p. 100-101. Voir aussi J.-M. Yante, "Pays-Bas et foires de Champagne (XIIXIV e siècles). L'état du dossier », p. 27, carte 2.

25. H. Ammann, «Untersuchungen zur Geschichte der Deutschen im mittelalterlichen Frankreich. I. Deutschland und die Messen der Champagne », p. 313-314; J.-M. Yante, "Présence allemande aux foires de Champagne (XIII - -XIV ${ }^{\mathrm{e}}$ siècles) », p. 32-35.

26. A. Schaube, «Der Kurierdienst zwischen Italien und den Messen von Champagne », p. 542-550 et 571-581; P. Huvelin, «Quelques données nouvelles sur les foires de Champagne », p. 377-380.

27. À propos du crédit aux foires : A. Schönfelder, Handelsmessen und Kreditwirtschaft im Hochmittelalter.

28. H. d'Arbois de Jubainville, avec la coll. de L. Pigeotte et A. Longnon, Histoire des ducs et des comtes de Champagne, t. IV, 2e partie, p. 827-836 (concerne exclusivement le XIII siècle) ; G. Nahon, "Les communautés juives de la Champagne médiévale (XI ${ }^{\mathrm{e}}-\mathrm{XII}^{\mathrm{e}}$ siècles) », p. 33-78.

29. Sur la présence juive dans la ville, voir notamment F. Bourquelot, Études sur les foires de Champagne, sur la nature, l'étendue et les règles du commerce qui s'y faisait aux XII ${ }^{e}$, XIII et XIV siècles, t. I, p. 144-146 et 263-266; B. Blumenkranz, «Les Juifs à Provins au Moyen Âge », p. 15-19; B. Blumenkranz, « Encore les Juifs à Provins », p. 40 . 
pareillement une colonie dès cette époque. À la fin du XII ${ }^{\mathrm{e}}$ siècle et au début du XIII, le riche banquier Vaalin réside dans la cité. En 1288, le fanatisme populaire condamne au bûcher treize juifs locaux sous l'accusation de «crime rituel » ${ }^{30}$. Et une rue des Juifs est fréquemment mentionnée à Bar-sur-Aube au XIII ${ }^{\mathrm{e}}$ siècle ${ }^{31}$. L'ampleur des transactions aux foires par les coreligionnaires échappe malheureusement aux investigations.

Les opérations des Lombards se hisseraient à un niveau nettement supérieur. Sous cette appellation, on désigne au $\mathrm{XIII}^{\mathrm{e}}$ siècle tous les immigrés originaires de l'Italie septentrionale et, à une époque plus tardive, ceux de l'Italie centrale jusqu'à Rome. Des marchands d'Asti, de Gênes, de Plaisance... sont présents aux foires à la fin du XII siècle et mettent au point un système de transfert d'argent. Des distinctions s'imposent cependant entre les mercatores, agissant à l'échelle internationale, et les modestes usurarii, de même entre les compagnies, associations de marchands d'une même ville disposant souvent d'une large assise financière, armature du grand commerce, et les " singuliers » (travailleurs indépendants) incontestablement plus nombreux et exerçant les métiers les plus divers, comme tenanciers de tables de prêt. Toutefois, selon l'estimation de RobertHenri Bautier, le nombre des Italiens présents aux foires n'a pas dû dépasser quelque 300 personnes ${ }^{32}$. En dépit d'un relevé récent ${ }^{33}$, le rôle des Lombards, actifs dans les quatre villes, reste difficile à cerner car le départ est délicat, sinon impossible entre les sociétés et/ou commerçants impliqués dans des opérations d'achats et de ventes et les praticiens du crédit et du change.

\section{Le réseau routier}

On a abandonné aujourd'hui l'idée d'un Moyen Âge qui « a construit peu de routes, (...) a vécu tout entier et a cheminé pendant des siècles sur les débris de la voirie romaine ${ }^{34}$. Force est à présent de constater que les voituriers tantôt restent fidèles à de grands axes de facture romaine, voire antérieure, tantôt hissent au rang de voies majeures des diverticula et autres liaisons secondaires, tantôt encore empruntent des tronçons de création incontestablement médiévale. Il faut aussi mettre en garde contre les datations romaines, imprudemment avancées, d'aménagements routiers peut-être réalisés au Moyen Âge, voire à l'aube des Temps modernes.

L'importance du réseau routier pour expliquer le choix des villes des foires de Champagne, affirmée par Elizabeth Chapin ${ }^{35}$, a été remise en question par Robert-Henri Bautier, qui se demande "si, au lieu d'être à l'origine des foires, le système routier ne s'est pas formé au Moyen Âge en fonction d'elles et pour les servir ${ }^{36}$.

La reconstitution de ce réseau aux XII $-\mathrm{XIV}^{\mathrm{e}}$ siècles, en liaison avec les ouvrages d'art et les péages qui le jalonnent, nécessite le repérage et la mise en œuvre de sources fort dispersées $^{37}$. Le recueil d'itinéraires connu sous le nom d'Itinéraire de Bruges résulte de la compilation d'itinéraires reliant Bruges à diverses parties du monde connu de l'époque. Si la réalisation de ce manuscrit, conservé aujourd'hui à la Bibliothèque de l’Université de

30. Importante littérature dont H. d'Arbois de Jubainville, avec la coll. de L. Pigeotte et A. Longnon, Histoire des ducs et des comtes de Champagne, t. IV, p. 828-833; S. Abramovitsch, "Influence exercée par les Juifs dans le domaine intellectuel et économique à Troyes et en Champagne au XII et au XIII ${ }^{\mathrm{e}}$ siècles ", p. 3-10; S. Abramovitsch, " L'Autodafé de Troyes. Un fait historique sur le XIII siècle (24 avril 1288) », p. 3-8.

31. H. d'Arbois de Jubainville, avec la coll. de L. Pigeotte, Histoire de Bar-sur-Aube sous les comtes de Champagne, 1077-1284, p. 109-110.

32. R.-H. Bautier, «Le marchand lombard en France aux XIII ${ }^{\mathrm{e}}$ et XIV ${ }^{\mathrm{e}}$ siècles », p. 63-80 ; P. Racine, « Les Lombards et le commerce de l'argent au Moyen Âge ».

33. W. Reichert, Lombarden in der Germania-Romania. Atlas und Dokumentation, 2e partie, p. 100-101 et 396-397; 3e partie, p. 609-611 et 751-753.

34. F. Imberdis, «Les routes médiévales: mythes et réalités historiques », p. 411 (reprise des mots de l'abbé Cochet, 1857).

35. É. Chapin, Les villes des foires de Champagne des origines au début du XIVe siècle, p. 10-13 et 233-236.

36. R.-H. Bautier, «Les foires de Champagne. Recherches sur une évolution historique », p. 103-104.

37. J.-M. Yante, «Les comtes de Champagne, les foires et les routes (XII $-\mathrm{XIV}^{\mathrm{e}}$ siècles)», p. 32-35. 
Gand $^{38}$, date incontestablement de la fin du $\mathrm{XV}^{\mathrm{e}}$ siècle, la compilation serait plus ancienne, probablement du $\mathrm{XIV}^{\mathrm{e}}$ siècle $^{39}$. Douze itinéraires transitent par la Champagne ou ses marges. Procédant de préoccupations fort diverses, ceux-ci ne constituent pour l'heure que des matériaux bruts pour la restitution du réseau routier champenois ${ }^{40}$. Faut-il rappeler que la route médiévale est un être vivant, qu'elle se révèle zone et non ligne, que plusieurs possibilités s'offrent généralement au voyageur, au marchand ou au voiturier traversant une région ou se rendant en un lieu déterminé. Comme l'écrivait Marc Bloch :

«La circulation, en un mot, ne se canalisait pas selon quelques grandes artères; elle se répandait, capricieusement, en une multitude de petits vaisseaux. ${ }^{41}$

Protection accordée à un individu ou à un groupe de personnes traversant une région ou se rendant en un lieu déterminé, le conduit ou sauf-conduit, notion remontant à l'Antiquité, contribue au développement de la circulation et des échanges. Avec le renouveau économique des $\mathrm{XI}^{\mathrm{e}}$-XIII ${ }^{\mathrm{e}}$ siècles, l'institution se développe et se généralise. Alors que la protection est généralement limitée au territoire du concédant, Thibaud II de Champagne s'efforce d'étendre celle-ci bien au-delà des frontières de sa principauté. Un pas décisif est franchi quand, en décembre 1199, Philippe Auguste place sous conduit royal les marchands, italiens et autres, gagnant les foires de Champagne ${ }^{42}$.

Dans la principauté, le conduit comtal serait gratuit ${ }^{43}$, mais n'exempte pas des péages. Ailleurs aussi, pour en bénéficier, le marchand doit normalement acquitter les fiscalités traditionnelles. Ainsi, en 1283, Rodolphe de Habsbourg garantit-il aux marchands italiens fréquentant les foires de Champagne, de Flandre et autres foires françaises, le libre passage à travers les terres impériales, moyennant le paiement des tonlieux ${ }^{44}$. À certains endroits, un prélèvement spécifique est instauré pour le conduit. Il arrive même, ainsi dans le comté de Namur en 1265, qu'un droit spécial soit exigé pour la protection des marchands, de Liège en l'occurrence, se rendant aux foires de Champagne ${ }^{45}$.

La sûreté des routes n'est pas pour autant garantie en tous temps et en tous lieux. Les actes de la pratique, pour l'heure en nombre non réellement significatif, datent pour l'essentiel d'une époque où ces assises du commerce international sont sur leur déclin.

La réouverture du vaste et fascinant dossier des foires de Champagne, dont seuls quelques aspects ont été présentement évoqués, s'impose à l'évidence. C'est la tâche que s'assigne, sous la présidence de Patrick Demouy, le CRECIM (Centre de recherches et d'études sur le commerce international médiéval) récemment créé à Troyes et hébergé aux Archives départementales de l'Aube.

38. E. Th. Hamy (éd.), Le Livre de la description des pays de Gille le Bouvier, dit Berry, premier roi d'armes de Charles VII, roi de France, appendice IV, p. 157-216.

39. R.-H. Bautier, « Recherches sur les routes de l’Europe médiévale. I. De Paris et des Foires de Champagne à la Méditerranée par le Massif Central », p. 118, note 5.

40. J.-M. Yante, « Florilège d'itinéraires routiers champenois (XII ${ }^{\mathrm{e}} \mathrm{XIV}^{\mathrm{e}}$ siècles) », p. 15-17.

41. M. Bloch, La société féodale, t. I : La formation des liens de dépendance, p. 104.

42. J. Monicat et J. Boussard (éd.), Recueil des actes de Philippe Auguste, roi de France, t. III, p. 192, n 1107

43. F. Bourquelot, Études sur les foires de Champagne, sur la nature, l'étendue et les règles du commerce qui s'y faisait aux XII ${ }^{e}$, XIII ${ }^{e}$ et XIV $V^{e}$ siècles, t. I, p. 325 et note 2.

44. J. Schwalm (éd.), Constitutiones et acta publica imperatorum et regum, t. III, p. 334-335, nº 351.

45. D. Brouwers (éd.), L'administration et les finances du comté de Namur du XIII au XVe siècle. Sources. I. Cens et rentes du comté de Namur au XIII' siècle, t. I, p. 22-23. 


\begin{abstract}
Résumé
À la lumière de travaux plus ou moins anciens et de contributions historiographiques récentes, l'émergence et la structuration du cycle des foires de Champagne, en place avant 1200, sont rapprochées de semblables réalisations attestées en Flandre, en Angleterre, dans les régions occidentales de l'Empire, dans diverses provinces françaises et dans le royaume de Sicile. L'évocation du réseau champenois, d'initiative comtale, est menée conjointement avec celle des réseaux internes au milieu marchand, du réseau du crédit et, last but not least, du réseau routier, élément capital pour le rayonnement d'assises majeures du commerce international jusqu'au début voire au milieu du XIV ${ }^{\mathrm{e}}$ siècle. La contribution se veut un provisoire état de la question et s'inscrit dans le cadre du projet de recherche initié par le CRECIM (Centre de recherches et d'études sur le commerce international médiéval) récemment créé à Troyes.
\end{abstract}

\title{
Bibliographie
}

ABRAMOVITSCH Samuel, «Influence exercée par les Juifs dans le domaine intellectuel et économique à Troyes et en Champagne au XII ${ }^{\mathrm{e}}$ et au XIII" siècles ", La Vie en Champagne, $14^{\mathrm{e}}$ année, $\mathrm{n}^{\circ} 142$, février 1966, p. 3-10.

ABRAMOVITSCH Samuel, "L'Autodafé de Troyes. Un fait historique sur le XIII siècle (24 avril 1288) », La Vie en Champagne, $14^{\mathrm{e}}$ année, $\mathrm{n}^{\circ} 143$, mars 1966, p. 3-8.

AMMANN Hektor, « Untersuchungen zur Geschichte der Deutschen im mittelalterlichen Frankreich. I. Deutschland und die Messen der Champagne ", Deutsches Archiv für Landes- und Volksforschung, vol. III, 1939, p. 306-333.

ARBOIS de Jubainville Henri d', avec la coll. de PigeOTTE Léon, Histoire de Bar-sur-Aube sous les comtes de Champagne, 1077-1284, Paris, Troyes et Bar-sur-Aube, 1859.

ARBOIS de Jubainville Henri d', avec la coll. de PigEOTTE Léon et LONGNON Auguste, Histoire des ducs et des comtes de Champagne, Paris, A. Durand, 1859-1869, 8 vol.

BAUTIER Robert-Henri, «Les foires de Champagne. Recherches sur une évolution historique ", dans Recueils de la Société Jean Bodin pour l'histoire comparative des institutions, vol. V : La foire, Bruxelles, Éd. de la Librairie encyclopédique, 1953, p. 97-147.

BAUTIER Robert-Henri, «Recherches sur les routes de l'Europe médiévale. I. De Paris et des Foires de Champagne à la Méditerranée par le Massif Central », Bulletin philologique et historique (jusqu'à 1610) du Comité des travaux historiques et scientifiques. Année 1960, vol. I, 1961, p. 99-143.

BAUTIER Robert-Henri, " Le marchand lombard en France aux XIII ${ }^{\mathrm{e}}$ et XIV ${ }^{\mathrm{e}}$ siècles », dans Le marchand au Moyen Âge. XIX Congrès de la Société des historiens médiévistes de l'enseignement supérieur public (Reims, juin 1988), s.l., S.H.M.E.S. et Cid éditions, 1989, p. 63-80.

BLOCH Marc, La société féodale, t. I : La formation des liens de dépendance, Paris, Albin Michel (L'Évolution de l'Humanité, 34), rééd. 1973.

BLUMENKRANZ Bernhard, «Les Juifs à Provins au Moyen Âge », Archives juives, $7^{\mathrm{e}}$ année, $\mathrm{n}^{\circ} 2,1970-1971$, p. 15-19. 
BLUMENKRANZ Bernhard, "Encore les Juifs à Provins », Archives juives, $7^{\mathrm{e}}$ année, $\mathrm{n}^{\circ} 3$, 1970-1971, p. 40.

BOURQUELOT Félix, Histoire de Provins, Paris, 1839-1840, 2 vol.

BOURQUELOT Félix, Études sur les foires de Champagne, sur la nature, l'étendue et les règles du commerce qui s'y faisait aux XII ${ }^{e}$, XIII et XIV siècles, Paris, Imprimerie impériale (Mémoires présentés par divers savants à l'Académie des Inscriptions et Belles-Lettres de l'Institut impérial de France, $2^{\mathrm{e}}$ sér., Antiquités de la France, 5), 1865-1866, 2 vol.

BRAUDEL Fernand, Civilisation matérielle, économie et capitalisme, XV'-XVIII siècle, t. II : Les jeux de l'échange, Paris, Armand Colin, 1979.

BROUWERS Dieudonné (éd.), L'administration et les finances du comté de Namur du XIII au $X V^{e}$ siècle. Sources. I. Cens et rentes du comté de Namur au XIII siècle, t. I, Namur, WesmaelCharlier, 1910.

BUR Michel, «Remarques sur les plus anciens documents concernant les foires de Champagne", Cahiers de l'Association interuniversitaire de l'Est, vol. 16: Les villes, 1972, p. $45-62$.

BUR Michel, La formation du comté de Champagne (v.950 - v.1150), Nancy, Université de Nancy II (Annales de l’Est. Mémoires, 54), 1977.

BUR Michel, "Note sur quelques petites foires de Champagne », dans Studi in memoria di Federigo Melis, Naples, Giannini, 1978, p. 255-267.

BUR Michel, «Les 'autres' foires de Champagne", dans EsCHER Monika, HAVERKAMP Alfred et HiRSCHMANN Frank-G. (dir.), Städtelandschaft - Städtenetz zentralörtliches Gefüge. Ansätze und Befunde zur Geschichte der Städte im hohen und späten Mittelalter, Mayence, Philipp von Zabern (Trierer Historische Forschungen, 43), 2000, p. 349-365.

BUR Michel, La Champagne médiévale. Recueil d'articles, Langres, Dominique Guéniot, 2005.

CAROLUS-BARRÉ Louis, «Les XVII villes. Une hanse vouée au grand commerce », Académie des Inscriptions et Belles-Lettres. Comptes rendus des séances de l'année 1965, Paris, 1966, p. 2030.

CHAPIN Elizabeth, Les villes des foires de Champagne des origines au début du XIVe siècle, Paris, Honoré Champion (Bibliothèque de l'École des Hautes Études. Sciences historiques et philologiques, 268), 1937.

COMBES Jean, «Les foires en Languedoc au Moyen Âge», Annales. Économies. Sociétés. Civilisations, vol. XIII, 1958, p. 231-259.

DESPORTES Pierre, Reims et les Rémois aux XIII et XIV siècles, Paris, Picard, 1979.

HAMY Ernest Théodore (éd.), Le Livre de la description des pays de Gille le Bouvier, dit Berry, premier roi d'armes de Charles VII, roi de France, Paris, Leroux (Recueil de voyages et de documents pour servir à l'histoire de la géographie depuis le XII jusqu'à la fin du XVI ${ }^{\mathrm{e}}$ siècle, 22), 1908.

HUVELIN Paul, "Quelques données nouvelles sur les foires de Champagne », Annales de droit commercial et industriel français, étranger et international, vol. XII, 1898, p. 376-392.

IMBERDIS Franck, "Les routes médiévales: mythes et réalités historiques », Annales d'histoire sociale, vol. I, 1939, p. 411-416. 
IRSIGLER Franz, « Jahrmärkte und Messesysteme im westlichen Reichsgebiet bis ca. 1250 » dans JOHANEK Peter et STOOB Heinz (dir.), Europäische Messen und Märktesysteme in Mittelalter und Neuzeit, Cologne, Weimar et Vienne, Böhlau Verlag (Städte Forschung. Reihe A : Darstellungen, 39), 1996, p. 1-33.

IRSIGLER Franz et REICHERT Winfried, «Les foires de Champagne », dans IRSIGLER Franz et PAULY Michel (dir.), Messen, Jahrmärkte und Stadtentwicklung in Europa. Foires, marchés annuels et développement urbain en Europe, Trèves, Porta Alba Verlag (Beiträge zur Landesund Kulturgeschichte, 5 ; Publications du CLUDEM, 17), 2007, p. 89-105.

LAURENT Henri, «Un comptoir de vente international au Moyen Âge. Nouvelles recherches sur la Hanse des XVII Villes », Le Moyen Âge, vol. XLV, 1935, p. 81-94.

LAURENT Henri, Un grand commerce d'exportation au Moyen Âge. La draperie des Pays-Bas en France et dans les pays méditerranéens (XIII $-X V^{e}$ siècle), Paris, Droz, 1935 (rééd. Brionne, Gérard Montfort, 1978).

LAURENT Henri, «La Hanse des XVII villes, hanse flamande de France », Revue historique de droit français et étranger, $4^{\text {e }}$ sér., vol. XIV, 1935, p. 409-412.

MASCHKE Erich, «Die Wirtschaftspolitik Kaiser Friedrichs II. im Königreich Sizilien », dans MASCHKE Erich, Städte und Menschen. Beiträge zur Geschichte der Stadt, der Wirtschaft und Gesellschaft 1959-1977, Wiesbaden (Vierteljahrschrift für Sozial- und Wirtschaftsgeschichte. Beiheft 68), 1980, p. 1-40.

MONICAT Jacques et BOUSSARD Jacques (éd.), Recueil des actes de Philippe Auguste, roi de France, Paris, Imprimerie nationale (Chartes et diplômes relatifs à l'histoire de France), t. III, 1966.

MUSSET Lucien, "Foires et marchés en Normandie à l'époque ducale», Annales de Normandie, vol. XXVI, 1976, p. 3-23.

NAHON Gérard, "Les communautés juives de la Champagne médiévale (XI- XII ${ }^{\mathrm{e}}$ siècles) », dans Rachi, Paris, Service technique pour l'éducation, 1974, p. 33-78.

PIRENNE Henri, «La hanse flamande de Londres », Académie royale de Belgique. Bulletin de la Classe des Lettres et des Sciences morales et politiques et de la Classe des Beaux-Arts, 1899, p. 65-108.

RACINE Pierre, "Les Lombards et le commerce de l'argent au Moyen Âge ", http:/ / www.clio.fr/ / BIBLIOTHEQUE/les_lombards_et_le_commerce_de_1_argent_au_ moyen_Age.asp (article de 2002, consulté le 11 juin 2015).

REICHERT Winfried, Lombarden in der Germania-Romania. Atlas und Dokumentation, Trèves, Porta Alba Verlag (Beiträge zur Landes- und Kulturgeschichte, 2), 2003, 3 vol.

SCHAUBE Adolf, «Der Kurierdienst zwischen Italien und den Messen von Champagne », Archiv für Post und Telegraph, vol. XXIV, 1896, p. 542-550 et 571-581.

SCHÖNFELDER Alexander, Handelsmessen und Kreditwirtschaft im Hochmittelalter. Die Champagnemessen, Sarrebruck (Schriften zur Wirtschaftsgeographie und Wirtschaftsgeschichte, 1), 1988.

SCHWALM Jakob (éd.), Constitutiones et acta publica imperatorum et regum, Hanovre (Monumenta Germaniae historica. Leges), t. III, 1904-1906. 
VAN WERVEKE Hans, De economische politiek van Filips van de Elzas (1157-68 tot 1191), Bruxelles, Palais des Académies (Mededelingen van de Koninklijke Vlaamse Academie voor Wetenschappen, Letteren en Schone Kunsten van België. Klasse der Letteren, 14/3), 1952.

VERCAUTEREN Fernand, « Note sur la survivance de la Hanse des XVII villes du XV au XVII ${ }^{\mathrm{e}}$ siècle », Revue belge de philologie et d'histoire, vol. XXVIII, 1950, p. 1078-1091.

VERHULST Adriaan, «Initiative comtale et développement économique en Flandre au XII ${ }^{\mathrm{e}}$ siècle : le rôle de Thierry et de Philippe d'Alsace (1128-1191)», dans Miscellanea mediaevalia in memoriam Jan Frederik Niermeyer, Groningen, J.-B. Wolters, 1967, p. 227-240.

WEDEMEYER Moore Ellen The fairs of Medieval England. An introductory study, Toronto, Pontifical Institute of Mediaeval Studies (Studies and Texts, 72), 1985.

YAMADA Masahiko, "Le mouvement des foires en Flandre avant 1200 », dans DUVOSQUEL Jean-Marie et DIERKENS Alain (dir.), Villes et campagnes au Moyen Âge. Mélanges Georges Despy, Liège, Éditions du Perron, 1991, p. 773-789.

YANTE Jean-Marie, "Pays-Bas et foires de Champagne (XII ${ }^{\mathrm{e}}-\mathrm{XIV}^{\mathrm{e}}$ siècles). L'état du dossier ", dans FILLIEUX Véronique, HONNORÉ Laurent et SERVAIS Paul (dir.), Angles d'approches. Histoire économique et sociale de l'espace wallon et de ses marges (XV ${ }^{e}-X X^{e}$ siècles), Louvain-la-Neuve, Academia Bruylant (Dossiers d'histoire économique et sociale, 1), 2003, p. 21-42.

YANTE Jean-Marie, «Le contentieux économique et financier aux foires de Champagne (XIII-XIV ${ }^{\mathrm{e}}$ siècles)», dans GARNOT Benoît (dir.), Justice et argent. Les crimes et les peines pécuniaires du XIII au XXI siècle, Dijon, EUD (Sociétés), 2005, p. 15-27.

YANTE Jean-Marie, "Florilège d'itinéraires routiers champenois (XII ${ }^{\mathrm{e}}-\mathrm{XIV}^{\mathrm{e}}$ siècles) », dans En passant par la Champagne. Pèlerins E marchands. Moyen Âge E Renaissance, Saint-Julienles-Villas, Maison du Patrimoine de l’Agglomération troyenne, 2007, p. 15-17.

YANTE Jean-Marie, "Les comtes de Champagne, les foires et les routes (XII $-\mathrm{XIV}^{\mathrm{e}}$ siècles) », dans En passant par la Champagne. Pèlerins $\mathcal{E}$ marchands. Moyen Âge E Renaissance, SaintJulien-les-Villas, Maison du Patrimoine de l'Agglomération troyenne, 2007, p. 32-35.

YANTE Jean-Marie, "Présence allemande aux foires de Champagne (XIII ${ }^{\mathrm{e}}-\mathrm{XIV}^{\mathrm{e}}$ siècles) », $L a$ Vie en Champagne, nouv. sér., $\mathrm{n}^{\circ} 53,2008$, p. 32-35. 


\section{Illustrations}

Figure 1 : Les membres de la Hanse des XVII villes (XIII $-\mathrm{XIV}^{\mathrm{e}}$ siècles).

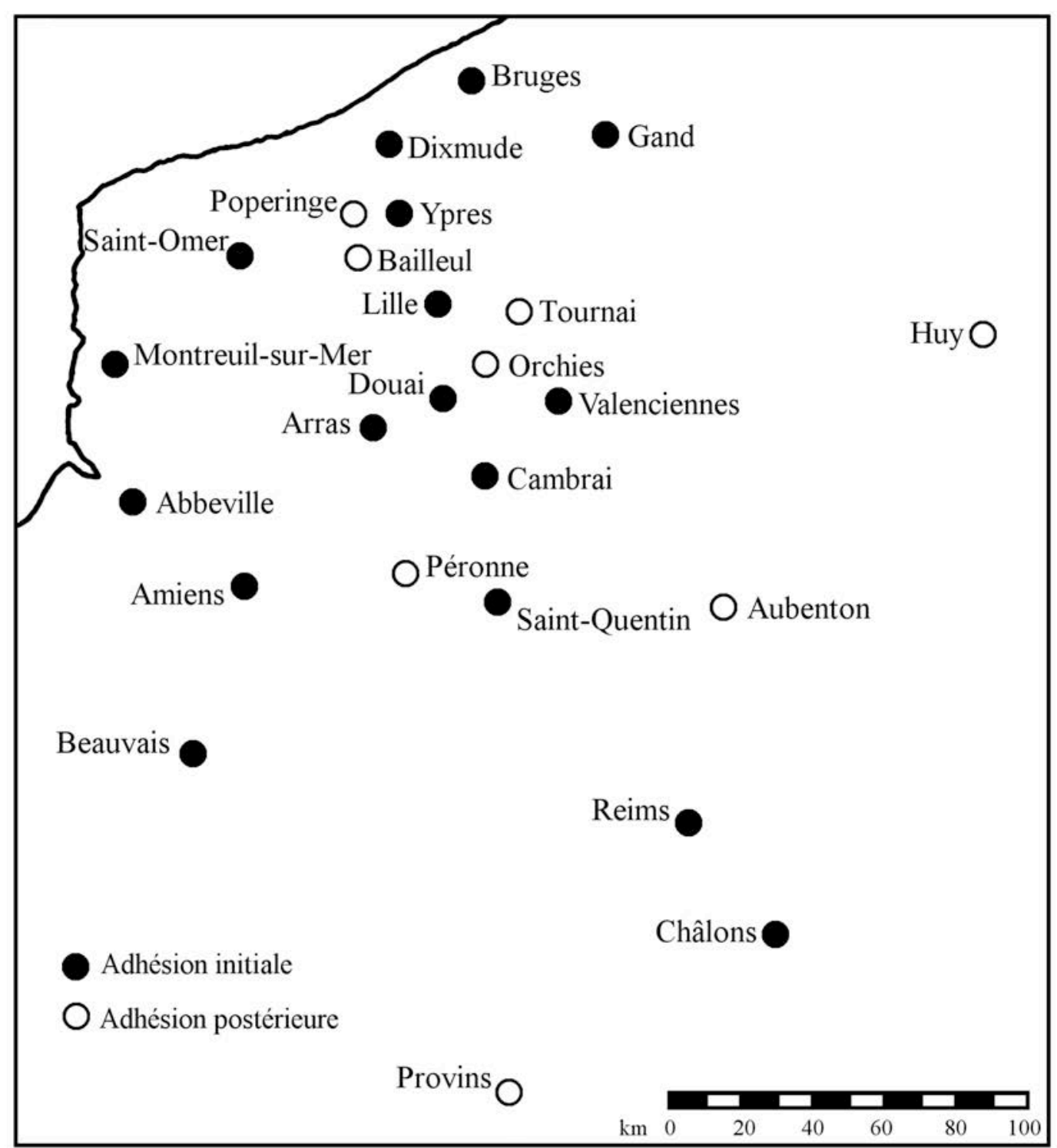


Figure 2: Halles et maisons marchandes du Midi français et l'Espagne septentrionale dans les villes des foires de Champagne (XIII ${ }^{\mathrm{e}}$-XIV ${ }^{\mathrm{e}}$ siècles)

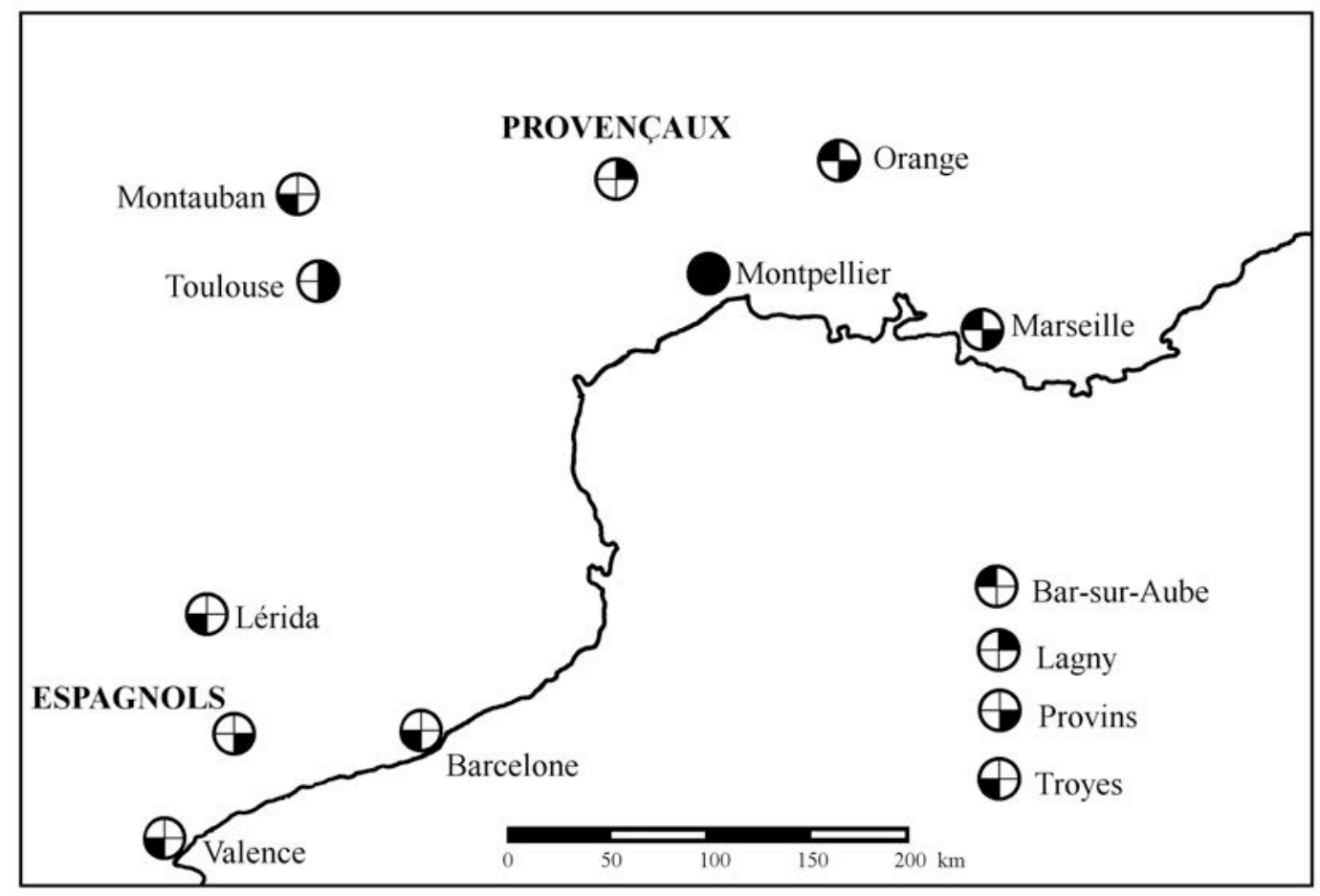


Figure 3: Halles et maisons marchandes italiennes dans les villes des foires de Champagne (XIII ${ }^{\mathrm{e}} \mathrm{XIV}^{\mathrm{e}}$ siècles).

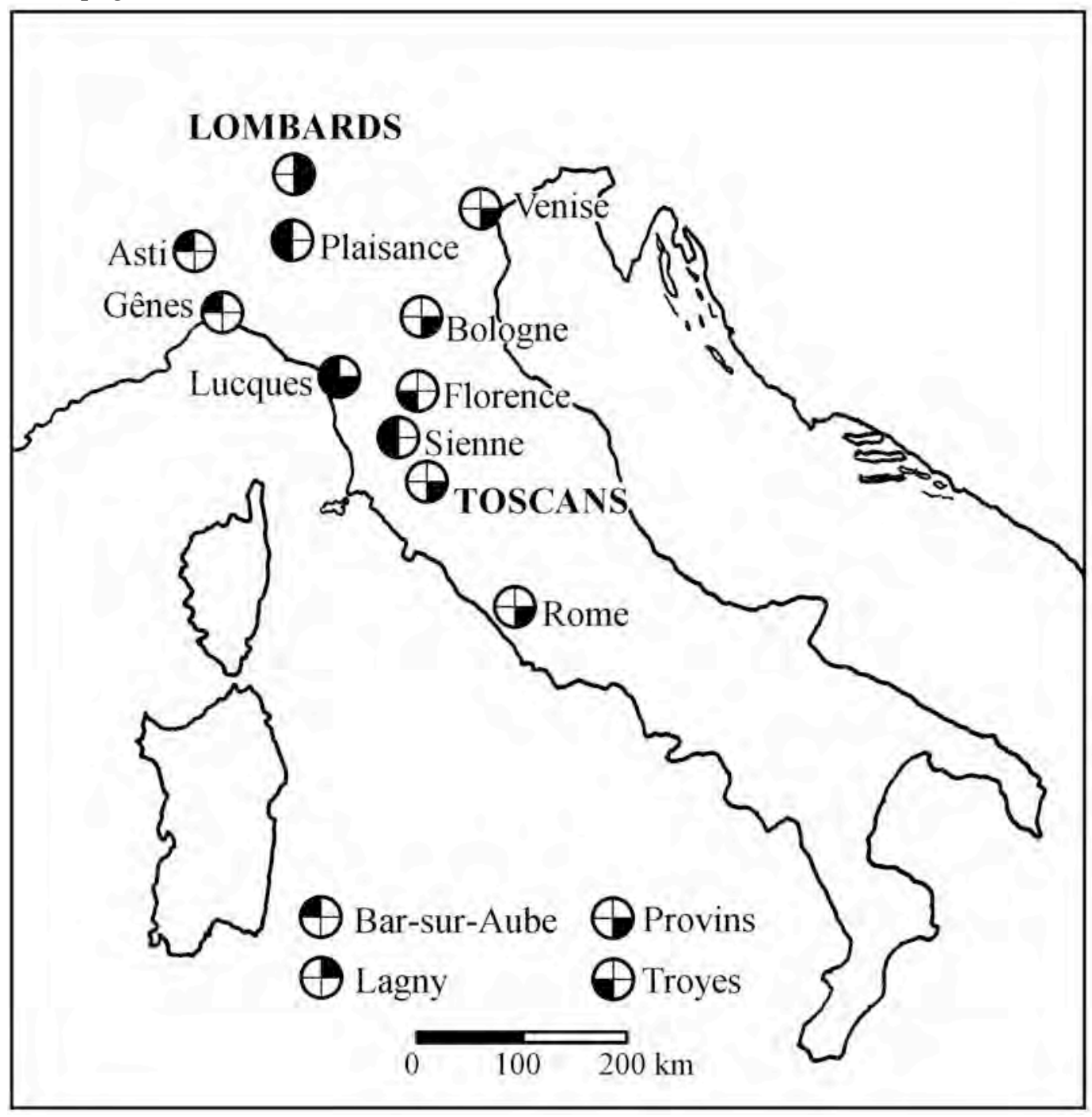


Figure 4 : Villes de la France septentrionale et centrale et des Pays-Bas disposant d'une ou de plusieurs halle(s) dans les villes des foires de Champagne (XIII ${ }^{\mathrm{e}} \mathrm{XIV}^{\mathrm{e}}$ siècles).

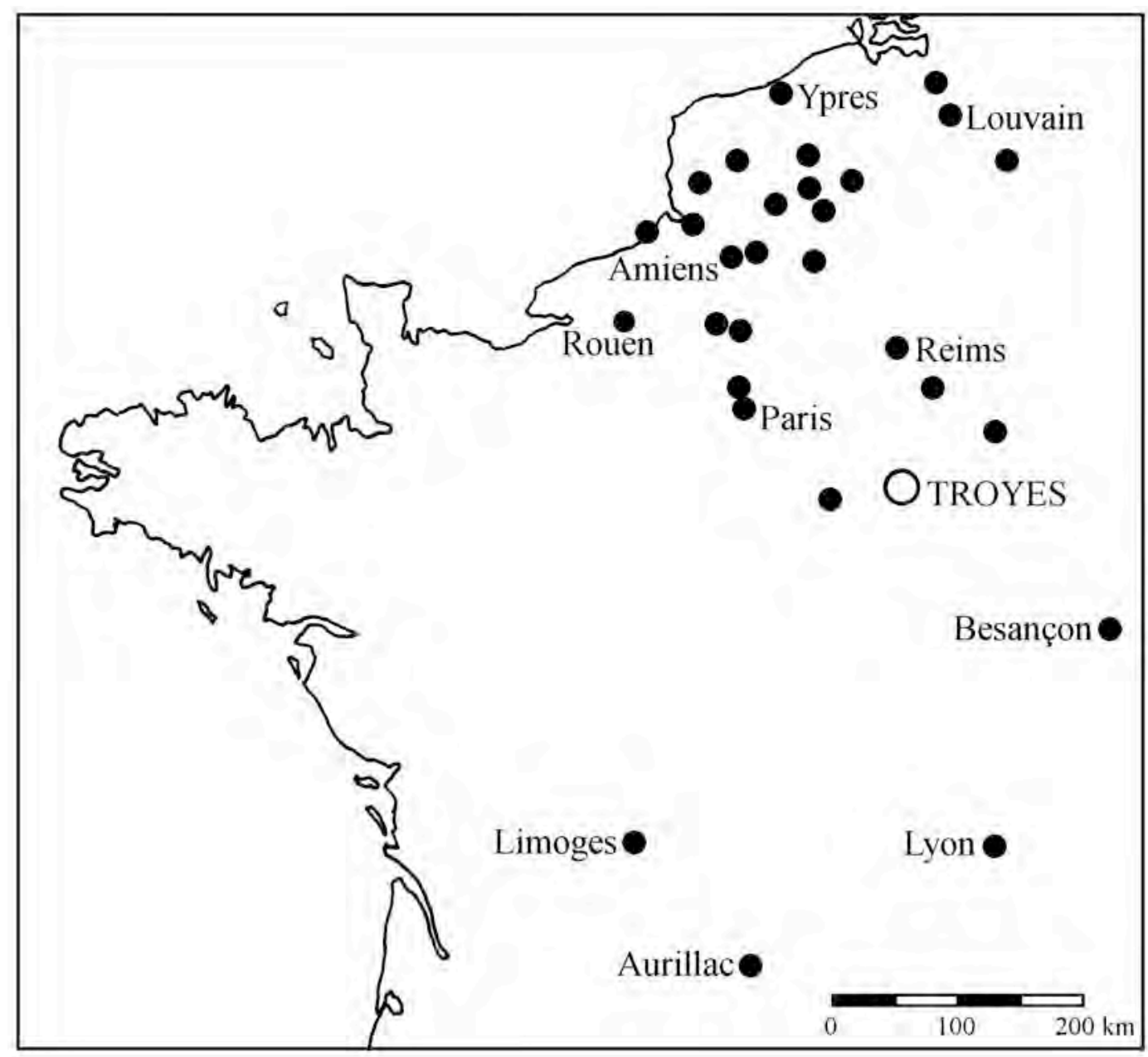




\title{
Les gribanniers de la Somme: monopole et embargo d'une communauté sur le transport fluvial durant les $\mathrm{XVII}^{e}$ et $\mathrm{XVIII}{ }^{e}$ siècles
}

\author{
Christophe CLOQUIER \\ Chercheur associé au Lamop, umr 8589 \\ Cnrs - Université de Paris 1 Panthéon-Sorbonne \\ Extrait de : Henri BRESC (dir.), Réseaux politiques et économiques, Paris, \\ Édition électronique du CTHS (Actes des congrès des sociétés historiques et scientifiques), 2016. \\ Cet article a été validé par le comité de lecture des Éditions du CTHS dans le cadre de la publication \\ des actes du $140^{\mathrm{e}}$ Congrès national des sociétés historiques et scientifiques tenu à Reims en 2015.
}

\begin{abstract}
Axe fluvial relativement rectiligne, le cours de la Somme constituait un élément important et remarquable d'un paysage de plaines légèrement vallonné, principalement traversé par des axes routiers rayonnant des grands centres urbains comme Abbeville ou Amiens. Il offrait également le seul débouché maritime d'une région agricole et commerciale particulièrement importante durant la période médiévale: la Picardie. Calme et paisible, il devint, au fil des siècles du premier millénaire, une voie commerciale privilégiée avec des possibilités de navigation sans risque majeur en toutes saisons.
\end{abstract}

Favorisée dès la fin du XII ${ }^{\mathrm{e}}$ siècle, la navigation fluviale sur la Somme fut renforcée dès le début du XIII ${ }^{\mathrm{e}}$ siècle par la canalisation de l'Avre, son principal affluent, et son ouverture à la navigation. Réglementée en juillet 1255, elle favorisa largement les exportations de produits picards comme la guède (Isatis tinctoria) puis du blé (Triticum aestivum), vers les Flandres et les îles britanniques, et inversement les importations de produits étrangers comme le fer, le plomb ou la laine. Au-delà des importations et des exportations, elle permettait surtout le transport des matériaux de construction, particulièrement lourds ou volumineux, comme le bois et la pierre, au plus près des chantiers de construction, notamment en milieu urbain.

Assuré par les bateliers et mariniers des villes d'Abbeville, Amiens et Corbie, implantées d'aval en amont sur le tronçon fluvial navigable, le transport des différents matériaux et produits se faisait sans encombre, au gré des marées et des saisons de l'aval vers l'amont et inversement. Toutefois, au milieu du XVII ${ }^{\mathrm{e}}$ siècle, il fut assorti d'un tour de rôle, instauré et organisé par les gribanniers d'Abbeville. Dès lors, il connut une succession de conflits, oppositions et autres affrontements entre les différents acteurs, à savoir les gribanniers et les marchands mais aussi les bateliers, mariniers et haleurs qui tentèrent également différentes actions communautaires. En pleine crise, le transport fluvial faisait à la fois l'objet d'un monopole et d'un embargo, préjudiciables aux marchandises et aux personnes. 


\section{Bateliers, mariniers et naveliers : les origines médiévales des gribanniers}

En août 1199, le roi Philippe Auguste établit que les marchands (mercatores) pourront naviguer librement sur la Somme, depuis Corbie jusqu'à la mer, sans qu'ils puissent être arrêtés ${ }^{1}$. Si le roi fit préciser les limites du tronçon navigable dans cet acte ${ }^{2}$, en revanche il laissa une imprécision notable et particulièrement ambiguë sur la fonction exacte des acteurs de cette navigation fluviale. En effet, avec le terme mercatores, il engloba vraisemblablement, ainsi que l'avança également Augustin Thierry, tous les marchands utilisant le fleuve, y compris les marchands étrangers, sans préciser pour autant si ces mercatores étaient uniquement les propriétaires des marchandises ou éventuellement les propriétaires et les transporteurs.

Dans un règlement commun, également établi en 1199 par les maires et échevins d'Abbeville, Amiens et Corbie - afin de faciliter et rendre plus sure la navigation sur le fleuve -, et dans une ordonnance royale promulguée vingt ans plus tard, afin de ne plus entraver la navigation sur la Somme par des barrières et péages, néfastes au commerce fluvial, aucune information sur la fonction ou le statut des transporteurs fluviaux ne fut consignée. En l'absence de document ou d'information explicite, la dénomination des personnes chargées de la conduite de bateaux sur la Somme et l'existence d'une communauté restent à préciser pour le XII ${ }^{\mathrm{e}}$ siècle et le début du XIII ${ }^{\mathrm{e}}$ siècle.

Dans un accord, établi en décembre 1240, les marchands de l'eau (mercatores aque) reçurent du seigneur de L'Étoile la promesse d'entretien du pont et d'indemnisation en cas de dommages causés aux bateaux lors de leurs passages au dit pont, dans le sens avalant et montant ${ }^{3}$. D'après une ordonnance des échevinages d'Abbeville, Amiens et Corbie de juillet 1255, les maronniers, alors désignés ceulz du métier de l'eau, ne pouvaient conduire qu'une seule nef chacun et qu'ils devaient confier la seconde, dans l'éventualité de la possession de deux bateaux par un preudomme du mestier, à un homme dont ce dernier devait répondre devant les maires et échevins de son lieu de résidence. Établi en quatre exemplaires, un pour chaque échevinage et un pour les maronniers, toujours appelés chil $d u$ métier de l'eau, ce document regroupe pour la première fois les termes : maistre, varlez ou vallet, compagnon et surtout preudomme du mestier ${ }^{4}$.

Augustin Thierry avait avancé l'idée d'une association de mariniers de la Somme, soumise à une police commune, et non des corporations isolées dans chacune des villes ${ }^{5}$. Il avança donc une dénomination fédérale pour désigner ces acteurs du transport fluvial. Avec cette ordonnance remise aux quatre parties, il est tentant de garder cette dénomination et d'assimiler les gens du métier de l'eau à un réseau ou une fédération de bateliers, identifié et reconnu pour tout le cours navigable du fleuve. Dans cette perspective, ce réseau était organisé avec des prud'hommes, des maîtres, des valets, des compagnons, apparemment installés dans chacune de ces trois villes et organisés au

1. Bibl. nat de France, Pic. 30 et arch. mun. Abbeville, AA 3 et AA 130 devenu bibl. mun. Abbeville, ms 114, fol. 6 édité par Augustin Thierry, Recueil des monuments inédits de l'histoire du Tiers Etat. 1ère série, Chartes, coutumes, actes municipaux, statuts des corporations d'arts et métiers de villes et communes de France. Région du Nord.... 4, contenant les pièces relatives à l'histoire municipale d'Abbeville et à celle des villes, bourgs et villages de la Basse Picardie, t. 1, p. 119-120.

2. $\mathrm{D}^{\prime}$ après ce document, elle était alors navigable sur un peu moins de $90 \mathrm{~km}$ de long dans le sens avalant et très certainement dans le sens montant, voir Fig. 1.

3. Arch. mun. Amiens, AA 1, fol. 167 et AA 5, fol. 23 édité par A. Thierry, Recueil des monuments inédits de l'histoire du Tiers Etat. 1ère série, Chartes, coutumes, actes municipaux, statuts des corporations d'arts et métiers de villes et communes de France. Région du Nord..., t. 1, p. 207-208.

4. Arch. mun. Amiens, AA 13, fol. 126v édité par A. Thierry, Recueil des monuments inédits de l'histoire du Tiers Etat. 1ère série, Chartes, coutumes, actes municipaux, statuts des corporations d'arts et métiers de villes et communes de France. Région du Nord..., t. 1, p. 217-218.

5. C. Schnakenbourg, Communautés de métiers contre liberté économique à la fin de l'Ancien régime: l'exemple des gribanniers de la Somme, p. 17-18 et A. Thierry, Recueil des monuments inédits de l'histoire du Tiers Etat. 1ère série, Chartes, coutumes, actes municipaux, statuts des corporations d'arts et métiers de villes et communes de France. Région du Nord..., p. 217. 
niveau du fleuve navigable, au point que les plus expérimentés puissent potentiellement être responsables, devant les échevins, de mariniers moins expérimentés pour la conduite d'un bateau en l'absence d'un maître marinier.

Dans une ordonnance de 1312, les conducteurs de bateaux furent mentionnés, sans être nommés, afin d'être identifiés et rattachés à l'une des deux enseignes de la ville: l'enseigne de la mer ou l'enseigne de la Somme. Ils furent associés à l'une des deux enseignes, soit à deux corporations ou deux communautés de métiers, en fonction du type de bateau qu'ils utilisaient. Ainsi, ceux qui avaient des bateaux (waisiaus) qui allaient en mer appartenaient à l'enseigne de la mer ${ }^{6}$. Dans une ville comme Abbeville, établie au fond de l'estuaire de la Somme, ces deux populations de conducteurs de bateaux pouvaient être des hommes de fleuve ou hommes de mer, des bateliers ou mariniers, voire même les deux à la fois puisque la ville constituait également un point de rupture de charge et abritait un important port fluvio-maritime ${ }^{7}$. Il convient de souligner que le terme maronniers, employé dans les brefs et ordonnances de juillet 1255, indiquerait une compétence maritime des gens du métier de l'eau.

Dans le registre aux chartes des années 1345 à 1483, Pierre Batel et Manessier Peusille furent désignés comme les maieurs de banieres des poissonniers d'eau douce et des naveliers pour l'année 1349 alors que seuls les maieurs de banieres des poissonniers d'eau douce furent listés les années précédentes. Ces deux hommes furent les seuls représentants mentionnés pour le XIV siècle $^{8}$. Dans ce même registre, Fremmot de Caigny, fils de Jehan de Caigny, maronnier, fut reçu maître maronnier par les eswars et compagnons dudit métier puis il fit serment devant eux le 16 mars 1446. En face de la mention marginale "varlet de navel», un navelier, nommé Jaques Doree, a établi et ordonné Jehan le Marchant à mener son navel, en date du 24 novembre $1456^{9}$. Par une ordonnance du 3 mars 1452, les naveliers furent tenus, suite à leurs requêtes et supplications, d'aller et assister à la totalité de l'enterrement ou du mariage de l'un des leurs ${ }^{10}$.

Durant le $\mathrm{XV}^{\mathrm{e}}$ siècle et probablement le siècle précédent, les maîtres mariniers et naveliers de chaque ville étaient reçus dans leur office devant les maieurs de banieres et les maîtres mariniers réunis. Ensuite, ils prêtaient serment devant les maires et échevins et pouvaient alors naviguer sur le fleuve en qualité de maître de bateau. Si plusieurs d'entre eux furent ainsi mentionnés pour Amiens, la perte des archives d'Abbeville et l'absence d'archives pour Corbie laissent un vide documentaire considérable et empêchent toute confirmation pour ces deux villes. Si aucune mention de gribannier ne fut repérée dans les différents documents médiévaux consultés ${ }^{11}$, plusieurs mentions de gribanes furent toutefois relevées dans des documents du $\mathrm{XV}^{\mathrm{e}}$ siècle ${ }^{12}$.

Dans La chronique d'Enguerran de Monstrelet ${ }^{13}$, pour 1436, la plus ancienne mention de gribane indiquait que les Anglais du Crotoy avaient deux bateaux nommés gabannes. Elles se multiplient ensuite pour la seconde moitié $d u X V^{e}$ siècle. Dans un registre contenant le compte de la valeur et revenue de la ville de Dieppe, pour 1478 et 1479, 8 nefs et

6. Bibl. mun. Abbeville, ms 115, fol 39v édité par A. Thierry, Recueil des monuments inédits de l'histoire du Tiers État. Première série, chartes, coutumes, actes municipaux, statuts des corporations d'arts et métiers des villes et communes de France. Région du Nord, Paris : Impr. impériale, 1870, t. IV, p. 103.

7. C. Cloquier, "Port et quai du bassin de la Somme : deux termes pour deux réalités du XII au XVIII ${ }^{\mathrm{e}}$ siècle ", p. 44-45.

8. Arch. mun. Amiens, AA 6, fol. 3. Il convient toutefois de souligner que ces deux noms furent également portés pour la même charge au fol.1 mais la réparation ne permet plus la lecture au delà du mot poissonnier. De plus, la partie relative au XIV e siècle se termine avec l'année 1382.

9. Arch. mun. Amiens, AA 6, fol. 82v et 112v. La partie relative au XVe siècle commence à l'année 1432.

10. Arch. mun. Amiens, AA 13, fol. 127.

11. C. Cloquier, «Les installations fluviales médiévales et modernes du cours de la Somme: approche archéologique et documentaire ».

12. F. Godefroy, Dictionnaire de l'ancienne langue française et de tous ses dialectes du IX au XV siècle..., 1885, t. 4, p. 196 , col. b et 1902 , t. 10 , p. 724 , col. b.

13. E. de Monstrelet, La chronique d'Enguerran de Monstrelet: en deux livres, avec pièces justificatives 1400-1444 publiée pour la Société de l'histoire de France par L. Douët-d'Arcq, t. 5, p. 262. 
bateaux, dont la gribenne d'Abbeville, furent faits à neuf ou rappareillés au port de Dieppe $^{14}$. Dans les statuts des métiers du 23 janvier 1489, la construction d'un bateau, appelé gribenne, halette ou goguet, imposait le paiement d'un droit de 6 deniers par les charpentiers de navires de la ville $\mathrm{d}^{\prime}$ Abbeville au profit de leur confrérie ${ }^{15}$. Dans un compte des années 1497 et 1498, des bateaux ou gribennes furent également mentionnés ${ }^{16}$.

Sur le plan d'Amiens et des hortillonnages, de 1542, plusieurs bateaux furent dessinés en aval et en amont de la ville ainsi que sur le seul bras navigable du fleuve, appelé le chemin de l'eau qui contournait la ville par le nord. Relevés à la proue et à la poupe, ils furent tous représentés avec un mât et un voile plié ou déplié de forme quadrangulaire. Si certains bateaux furent représentés sans membre d'équipage, d'autres étaient, en revanche, manœuvrés par une seule personne voire même deux personnes, le premier ajustait les voiles et le second utilisait un aviron ${ }^{17}$. Manifestement, ces bateaux ne furent pas représentés pour orner le plan, ils furent dessinés au niveau du seul bras navigable dans la ville et au niveau des installations portuaires, à savoir le Quay, établi en amont du pont Saint-Michel dans la partie occidentale de la ville, et le port du Don, établi en aval du pont Du Cange dans la partie orientale. Ils permettaient de restituer la réalité de la navigation fluviale au niveau de la ville d'Amiens mais rien ne permet de les assimiler à des gribanes.

Dans les dictionnaires ${ }^{18}$, les gabannes, gribanes ou gribennes désignaient des embarcations à fond plat d'un port de 30 à 60 tonneaux et en majorité 50. Garnies d'un seul mât de misaine avec son hunier, elles disposaient également d'un mât de beaupré. En usage sur les côtes de Normandie et de Picardie, elles naviguaient également sur la Seine et la Somme, fleuve sur lequel s'effectuait le transport de marchandises et matériaux pondéreux, entre le port de Saint-Valery et la ville d'Abbeville. De toutes ces formes, la forme gribane ou gribanne s'établit au début $\mathrm{du} \mathrm{XVII}^{\mathrm{e}}$ siècle, dans un arrêt du conseil d'état de 1612.

En l'absence de mention de gribannier, dans les sources documentaires médiévales, les conducteurs et utilisateurs des gribanes ont vraisemblablement pris le nom de ces bateaux; pour le bassin de la Somme et les côtes picardes, les plus anciennes mentions de gribanniers remontent au milieu du $X \mathrm{I}^{\mathrm{e}}$ siècle et proviennent d'Amiens. En 1550, un gribannier fut payé pour avoir mené le roi Henri II, et vraisemblablement sa suite, sur la Somme dans quatre bateaux ${ }^{19}$. Le 15 décembre 1552, des gribanniers furent payés pour le transport par bateaux de lansquenets et de gens de guerre à Abbeville ${ }^{20}$. En dépit de l'origine médiévale des gribanes, d'une part, et d'un réseau de mariniers, d'autre part, les gribanniers, regroupés en réseau, ne sont pas attestés explicitement dans les documents médiévaux. Avec deux occurrences du milieu du $X I^{\mathrm{e}}$ siècle, ils $\mathrm{n}^{\prime}$ apparaissent pas comme des acteurs principaux mais plutôt comme des acteurs spécialisés dans une situation de transport spécifique. Dans une ordonnance du 15 mai 1555, ils ne furent pas mentionnés; seuls des maîtres mariniers et des bateliers, en référence au métier de marinier, furent cités. En dépit de cette discrétion dans les sources du XVI ${ }^{\mathrm{e}}$ siècle, les gribanniers devinrent les acteurs incontournables du transport fluvial durant la seconde moitié du XVII ${ }^{\mathrm{e}}$ siècle.

14. Arch. dép. Seine-Maritime, G 529. Les 7 autres bateaux étaient 3 coquets, 2 crevelles, 1 cordier et 1 pêcheur.

15. Arch. mun. Abbeville, Registre des statuts, p. 338 édité par A. Thierry, Recueil des monuments inédits de l'histoire du Tiers État. Première série, chartes, coutumes, actes municipaux, statuts des corporations d'arts et métiers des villes et communes de France. Région du Nord, t. IV, p. 319.

16. Bibl. nat. de France, fr 12 016, p. 57.

17. Arch. dép. Somme, 1 Fi 72, voir Fig. 2.

18. W. von Warthburg, Französisches etymologisches Wörterbuch : ein darstellung des galloromanischen Sprachschatzes.

16. Band, germanische Elemente. G-R..., p. 386, col. a.

19. Arch. mun. Amiens, CC 151, fol. 76v.

20. Arch. mun. Amiens, BB 28, fol. 24v. 


\section{Monopole et embargo des gribanniers sur le transport fluvial}

Pour les $\mathrm{XVI}^{\mathrm{e}}$ et $\mathrm{XVII}{ }^{\mathrm{e}}$ siècles, en l'absence de statuts, la connaissance de la communauté des gribanniers et de son organisation professionnelle demeure encore inconnue; l'ordonnance, établie par les trois échevinages en 1255, ne contenant que les mesures de police du transport fluvial des marchandises. En dépit de ces lacunes juridiques, la communauté des gribanniers de la Somme fut une réalité économique et logistique durant l'époque moderne qu'il convient de souligner ${ }^{21}$.

N'étant mentionnés dans aucun document judiciaire antérieur au milieu du XVII ${ }^{\mathrm{e}}$ siècle, les gribanniers exercèrent manifestement leurs activités de transports fluvio-maritimes et fluvio-estuariens sans contestation, litige et réclamation notable. Toutefois, le 19 mai 1664, ils se rassemblèrent devant un notaire et firent enregistrer un tour de rôle, qualifié de traité, pour le transport fluvial des marchandises jusqu'à la mer. Ayant fait homologuer cette pratique par les maires et échevins d'Abbeville et les commissaires de la généralité $\mathrm{d}^{\prime}$ Amiens, avec la défense faite aux marchands d'y contrevenir à peine de 1000 livres d'amende, ils contribuèrent, consciemment ou inconsciemment, à poser les bases d'une situation de conflit et d'opposition avec les marchands qui allait évoluer durant le reste de l'époque moderne.

Une fois cette pratique établie, les gribanniers exercèrent leurs fonctions en suivant l'ordre inscrit au tableau en ne laissant aucun choix possible aux capitaines de navires de mer et aux marchands pour le transport des marchandises. En conséquence, ils furent dénoncés au maître des requêtes et commissaire départi pour la visite des ports, havres, côtes et amirautés du royaume, à l'initiative de Colbert. Toutefois, d'après l'ordonnance du 12 mars 1672, les maîtres gribanniers furent maintenus dans la réalisation du transport des denrées et marchandises à tour de rôle, de Saint-Valery à Amiens et autres lieux et inversement, en suivant l'ordre du tableau.

Dans cette perspective, ils devaient se présenter avec leur gribane en bon état, au lieu désigné du chargement, à savoir les puisoirs des magasins, situés sur le fleuve, ou le bord des navires de mer. Une fois le chargement effectué et au plus tard le lendemain, ils devaient partir pour se rendre sur le lieu de livraison et de déchargement, sans retard, afin de rendre les denrées et marchandises bien conditionnées en nombre, poids, qualité et quantité portés sur la lettre de voyage, sous peine d'être privé de son tour et de payer des dommages et intérêts, la première fois, et d'être enlevé de la liste des maîtres gribanniers et supprimé du tableau, en cas de récidive. De plus, ils étaient solidairement responsables les uns pour les autres, en cas de détériorations ou dommages causés aux denrées et marchandises. Sur ordre des maîtres égards et jurés de la communauté, ils étaient tenus de faire partir, de Saint-Valery vers Amiens, pour la commodité publique, tous les lundis et jeudis, l'un d'eux selon le tour de rôle, que sa gribane soit chargée ou non. Enfin, ils devaient respecter le tarif fixé par lest, soit 3600 livres pour la Picardie, pour le transport de différentes denrées et marchandises, de Saint-Valery à Abbeville puis d'Abbeville à Amiens ${ }^{22}$.

Par l'ordonnance du 28 septembre 1696, les gribanniers furent maintenus dans le monopole du transport fluvial des denrées et marchandises entre Abbeville et Amiens et inversement; les bateliers de ces villes et d'autres lieux étant de ce fait interdits de pratiquer ce type de transport fluvial. De plus, entre 1672 et 1723, ils tentèrent régulièrement de faire augmenter le prix de leurs prestations, en négociant le prix du fret, et obtinrent ponctuellement satisfaction jusqu'à obtenir une augmentation définitive

21. C. Schnakenbourg, Communautés de métiers contre liberté économique à la fin de l'Ancien régime: l'exemple des gribanniers de la Somme.

22. Arch. dép. Somme, 1 C 1385 . Le lest était une unité de masse sur laquelle était fixé le prix du fret pour les navires des mers du nord de l'Europe. Cette ordonnance fut confirmée par l'ordonnance du 22 janvier 1682 , notamment pour la jauge des barriques et donc du lest. 
de $25 \%$, accordée par les marchands amiénois avant l'été $1723^{23}$. Toutefois, avec la promulgation de l'arrêt du Conseil d'État le $1^{\text {er }}$ février 1724, ils perdirent ce monopole mais en partie seulement puisque tous les bateliers, établis sur le cours de la Somme, furent autorisés à voiturer les marchandises, de Saint-Valery à Amiens ou autres lieux et inversement, au prix convenu de gré à gré avec les marchands propriétaires ou commissionnaires, sans toutefois pouvoir dépasser le tarif de 1672, augmenté de $25 \%$, et avaient la charge de se faire inscrire dans la classe de l'amirauté de Saint-Valery. Dans cette nouvelle configuration, les gribanniers mécontents ou délaissés ne pouvaient perturber ceux qui auraient été choisis par les marchands sous peine de prison. De plus, les uns et les autres ne pouvaient plus faire construire des bateaux et gribannes dont le port serait supérieur à 20 tonneaux, sous peine d'amende et de confiscation, surcharger leur embarcation et enfin altérer ou détourner les marchandises transportées ${ }^{24}$.

Avec deux autres ordonnances de confirmation, rendues les 16 décembre 1737 et 19 décembre 1739, les gribanniers devaient être choisis librement par les marchands pour le transport de leurs marchandises, renforçant ainsi la suppression du tour de rôle établi au $\mathrm{XVII}^{\mathrm{e}}$ siècle et une nouvelle fois interdit par l'ordonnance du 8 février $1741^{25}$. Attachés à leurs pratiques initiales, ils multipliaient les exactions sur les denrées et marchandises qu'ils transportaient, les retards et les nuitées prolongées à Abbeville, contrairement aux prescriptions de l'ordonnance du $1^{\mathrm{er}}$ novembre $1744^{26}$.

Non contents de s'opposer aux marchands au sujet des prix du fret et du tour de rôle, les gribanniers s'opposèrent également aux entrepreneurs des voitures des sels à partir du mois d'avril 1763. D'après deux lettres des 29 et 30 avril, adressées à l'intendant de Picardie, ils refusèrent de conduire les dits sels. Le 2 mai suivant, ils furent accusés du préjudice que leur refus de transporter les marchandises causait aux commissionnaires de Saint-Valery. Occasionnant alors une nouvelle vague d'avis, de lettres, mémoires et requêtes, ils demandèrent un nouveau prix pour transporter les sels de Saint-Valery à Amiens. Dans cette ambiance printanière particulière, il convient d'ajouter qu'un négociant de Saint-Valery, qui était également le gendre du subdélégué d'Abbeville, s'empara de plusieurs gribanes pour son commerce et, sur l'opposition du commis des entrepreneurs de la voiture des sels, fit rendre par son beau-père une ordonnance qui l'y autorisait.

Ayant légalement perdu leur monopole et le tour de rôle associé, les gribanniers avaient régulièrement négocié et tenté de faire augmenter le prix du fret mais en vain. Cependant, le 25 juillet 1763, ils passèrent une convention, devant un notaire d'Abbeville, stipulant qu'ils refusaient de transporter les marchandises, de Saint-Valery à Amiens, à un prix inférieur à 10 sols du cent, au lieu des 7 sols 9 deniers qu'ils touchaient jusqu'à cette date. Par l'ordonnance du 29 juillet suivant, ils reçurent l'ordre de répondre à la première réquisition des commissionnaires et marchands, à peine de 300 livres d'amende. En refusant d'obéir aux volontés de l'intendant et aux demandes des marchands ${ }^{27}$, ils

23. Arch. dép. Somme, 1 C 1385 pour un mémoire des gribanniers, en date du 9 juin 1713, relatif à une demande d'augmentation du prix du fret et Arch. nat., F12 1512 pour un mémoire de l'intendant de Picardie, en date du 26 août 1723, relatif à l'acceptation de cette augmentation de 8 à 10 livres du fret par les marchands d'Amiens. Cet épisode fut détaillé par C. Schnakenbourg, Communautés de métiers contre liberté économique à la fin de l'Ancien régime : l'exemple des gribanniers de la Somme, p. 24-25.

24. Arch. dép. Somme, 1 C 1386 . En ouvrant aux bateliers de la Somme le transport fluvial, réservé jusqu'à cette date aux gribanniers, le roi les dirigea insidieusement vers une inscription de matelot classé et donc vers un service sur ses navires de guerre, identique à celui que les gribanniers lui devaient puisqu'ils étaient inscrit à l'amirauté de Saint-Valery et payèrent un lourd tribu en vies lors des conflits. C. Schnakenbourg, Communautés de métiers contre liberté économique à la fin de l'Ancien régime : l'exemple des gribanniers de la Somme, p. 30 releva 17 décès dans cette communauté de 70 membres lors de la guerre de Sept ans, voir arch. dép. Somme, 1 C 1398 , mémoire du 19 août 1763.

25. Arch. dép. Somme, 1 C 1389 et 1 C 1391.

26. Arch. dép. Somme, 1 C 1394. Certains gribanniers attendaient souvent plus d'une nuit à Abbeville, attendant pendant 7 ou 8 jours un flot favorable et une quantité d'eau suffisante pour remonter le cours du fleuve.

27. Dans une lettre du 31 juillet à l'intendant de Picardie, le subdélégué d'Abbeville, Bouteiller, écrivit : « [...] Ils m'ont fait clairement connaître qu'ils n'en étaient pas plus disposés à obéir, et que, telle peine qu'on put leur infliger, ils ne démarreraient pas, qu'ils ne fussent assurés d'être payés de leurs voitures, à raison de 10 sols du 
campèrent sur leurs positions et sur leur demande de tarif à 10 sols du cent, engendrant alors un véritable embargo sur les cargaisons des marchands. Ramenés à la raison par leurs épouses avant le $1^{\mathrm{er}}$ août ${ }^{28}$, ils acceptèrent finalement de lever l'embargo, d'obéir et de descendre à Saint-Valery, en dépit d'une hauteur d'eau particulièrement faible. Ainsi, après un court mais ferme blocage du transport fluvial, ils reprirent leurs rotations tout en réclamant le paiement de 18 livres par lest. Finalement, au début de l'année 1764, ils obtinrent le prix réclamé mais le projet d'arrêt associé les confirmait dans la perte du tour de rôle et permettait à tous bateliers de transporter toutes espèces de marchandises de Saint-Valery à Amiens, moyennant 18 livres, pour 3600 livres de poids ${ }^{29}$.

Rassurés, voire galvanisés par cette victoire tant réclamée sur le prix du fret, les gribanniers poursuivirent leurs augmentations de prix, notamment sur les sacs de blé qu'ils transportaient d'Amiens à Saint-Valery pour des exportations nouvellement autorisées. Ils doublèrent puis triplèrent et quadruplèrent même le prix du sac de blé, initialement fixé à 5 ou 6 sols. Dans une suite logique, ils remirent le tour de rôle en usage et firent même homologuer leur décision par l'amirauté d'Abbeville, rapportée dans une lettre du 30 novembre 1766, à l'intendant de Picardie. Dans un mémoire de la chambre de commerce, ils furent associés à des actes de violence, dès les premières lignes, et même à un cas d'abordage, commis par l'un d'eux, sur une gribane chargée de sucre qui faisait voile vers Abbeville et ne résista pas au $\operatorname{choc}^{30}$.

Au début de l'année 1775, toujours plus désireux de voir le prix du fret augmenter, les gribanniers adressèrent une nouvelle requête qui fut manifestement la requête de trop. Décriés pour leurs actions et pratiques communautaires contestées et illicites, ils reçurent pour réponse une nouvelle ordonnance, le 18 octobre 1775, encore plus restrictive que les précédentes. Certes, ils gardèrent le privilège de pouvoir voiturer sur le fleuve les marchandises, entre Saint-Valery et Amiens, ainsi que le prix, obtenu par l'embargo de 1764, mais ils furent, une nouvelle fois, interdits de tour de rôle, d'attroupement dans la perspective de bloquer les bateaux et de contrat collectif, écrit ou verbal, de refus du service. Ils pouvaient être refusés ou mis de côté par un marchand pour une absence de confiance ou une gribane en mauvais état, jugée dangereuse pour la sécurité des marchandises $^{31}$. Prêts à renouveler l'embargo de 1763, les gribanniers présents quittèrent le port de Saint-Valery et remontèrent jusqu'à Abbeville sans aucune marchandise et donc sans assurer le transport jusqu'à Amiens. À la suite d'une demande de l'intendant de Picardie, ils reçurent du commissaire aux classes à Saint-Valery l'ordre de partir pour Brest afin de servir sur les vaisseaux du roi. Les gribanniers qui refusaient le service furent particulièrement visés par cette mesure particulièrement coercitive et répressive ${ }^{32}$.

Poursuivant leurs demandes d'augmentation du prix du fret, les gribanniers engagèrent des tentatives avec les entrepreneurs de la voiture des sels des gabelles. Ainsi, en vertu de l'ordonnance du 7 mai 1784, les gribanniers chargés du transport des sels des grandes gabelles de Saint-Valery à Amiens furent autorisés à charger 11 muids de sel par gribane, à raison de 20 livres par muid, même pour celle qui n'en chargeaient habituellement que 9 ou 10. De ce fait, dans l'éventualité d'un allégement de leur gribane, ils pouvaient se faire rembourser, par les entrepreneurs généraux de la voiture des sels de grandes gabelles, les frais d'allégement pour 2 muids au maximum, le surplus d'allégement étant alors à leur charge. Ainsi, ils devaient être payés pour le transport de ce fret, de Saint-

cent [...]. Il n'y a point de représentations que je ne leur ai faites, pour tâcher de les ramener à leur devoir, soit par la voie de la douceur, soit en leur faisant envisager toutes les suites de leur désobéissance et de leur révolte, mais toutes mes remontrances ont été inutiles, et il n'est pas possible de leur faire entendre raison. [...]. ».

28. M. Bouteiller avait fait une dernière tentative auprès de leurs femmes. Il s'était glissé dans une maison du quartier des gribanniers, avait rassemblé plusieurs femmes et écouté leurs sentiments, identiques à ceux de leurs maris. Il avait réussi à les intimider et même à les inquiéter sur les suites de cette affaire.

29. Arch. dép. Somme, 1 C 1398 . Le projet d'arrêt fut daté du mois de décembre 1763.

30. Arch. dép. Somme, 1 C 1402 et 1 C 1406.

31. Arch. dép. Somme, 1 C 1406.

32. Arch. dép. Somme, 1 C 1406. 
Valery à Amiens, 220 livres, à raison de 20 livres par muid, plus 18 livres de frais d'allège même si aucun allégement ne devait être effectué ${ }^{33}$.

En défendant et en imposant le tour de rôle, officialisé en 1664, les gribanniers avaient la capacité de faire travailler et naviguer tous les membres de leur communauté, répartis entre Saint-Valery, Abbeville et Amiens. Indéniablement, ils avaient constitué un véritable réseau fédéral, organisé et solidaire, qui fut régulièrement dénoncé par les marchands de la Somme, le plus souvent amiénois. Avec une telle organisation, ils ne purent échapper aux responsabilités solidaires mises en avant par les intendants de Picardie successifs, notamment lorsqu'ils commettaient des exactions sur les denrées et marchandises, transportées de la baie vers l'intérieur des terres.

\section{Les excès des gribanniers : constatations et dénonciations $d u$ XVIII siècle}

Dans ce contexte de monopole, les gribanniers de la Somme furent à l'origine de nombreux et fâcheux excès, principalement constatés et dénoncés durant la seconde moitié $\mathrm{du} \mathrm{XVII}^{\mathrm{e}}$ siècle et le XVIII ${ }^{\mathrm{e}}$ siècle. Toutefois, et à leur décharge, ces acteurs du transport fluvial, farouches détenteurs et défendeurs d'un monopole contestable et contesté, exerçaient leur métier dans un environnement dégradé. En effet, si le cours de la Somme, préféré au cours de la Seine, était réputé pour la rareté des excès dans les étiages ou les débordements jusqu'au début $\mathrm{du} \mathrm{XVIII}^{\mathrm{e}}$ siècle $^{34}$, les gribanniers devaient en permanence composer, de l'aval vers l'amont, avec les bancs de sable de l'estuaire ${ }^{35}$, le canal Marchand et les arches des ponts à Abbeville ${ }^{36}$, les atterrissements multiples en amont d'Abbeville ${ }^{37}$, les seuils sous les ponts de Pont-Remy et Picquigny et enfin l'envasement régulier du Quay à Amiens ${ }^{38}$.

D'après un placet des marchands d'Amiens, envoyé au contrôleur général vers 1714, les gribanniers qui arrivaient de Saint-Valery ne pouvaient faire arriver et entrer qu'une seule gribane au Quay de la ville d'Amiens et ce avec beaucoup de peine, de grands renforts de personnes, manifestement pour le halage, et l'allégement d'une partie du chargement dans trois ou quatre bateaux ${ }^{39}$. De ce fait, ils se faisaient payer une fois et demie plus que le tarif prévu par le règlement, à cause des difficultés rencontrées pour arriver jusqu'au Quay, puis y entrer. De plus, ils laissaient leur gribane, entre deux chaînes, durant trois semaines à un mois et même parfois davantage pour attendre leur tour. D'après les marchands, désespérés de voir leurs marchandises en attente de déchargement, les gribanniers prétextaient ce retard pour augmenter le prix de leur voiture, largement préjudiciable pour la vente et les intérêts des plaignants. Ainsi, en retardant le déchargement des marchandises, ces transporteurs fluviaux, ainsi que leur équipage respectif, commettaient des exactions qualitatives et quantitatives sur les chargements, notamment sur les eaux-de-vie et les liqueurs. Profitant de l'immobilisation prolongée des gribanes chargées, ils pouvaient puiser et boire, à discrétion, le contenu

33. Arch. dép. Somme, 1 C 1153.

34. Arch. dép. Somme, 1 C 1692 et bibl. mun. Abbeville, ms 165, fol. 9-10v et ms 167, p. 29-33 pour la multiplication des basses eaux durant le XVIII ${ }^{\mathrm{e}}$ siècle.

35. Arch. nat., N III Somme 64, Bibl. nat. de France, Ge DD 2 987, arch dép. Somme, 1 Fi 339 , bibl. mun. Amiens, ms 800, C. Cloquier, «Les aménagements de l'estuaire de la Somme et l'amélioration de la navigation fluviomaritime (XVII ${ }^{-}$-XVIII ${ }^{e}$ siècles)», et $i d$., "Les installations fluviales médiévales et modernes du cours de la Somme : approche archéologique et documentaire », vol. 1, p. 328-329.

36. C. Cloquier, "Les installations fluviales médiévales et modernes du cours de la Somme: approche archéologique et documentaire », vol. 2, p. 338-339.

37. Arch. dép. Somme, 1 C 1410 pour des sables que la crue des eaux a charrié durant l'hiver 1783.

38. Arch. dép. Somme, 1 C 1389 , C. Cloquier, "Les installations fluviales médiévales et modernes du cours de la Somme : approche archéologique et documentaire », vol. 2, p. 403 et p. 435-436 et id., « Port et quai du bassin de la Somme : deux termes pour deux réalités du XII ${ }^{\mathrm{e}}$ au XVIII ${ }^{\mathrm{e}}$ siècle », p. 45-46.

39. Le type et les caractéristiques des bateaux utilisés comme allèges ne furent malheureusement pas précisés dans ce document. 
des tonneaux sans être inquiétés ou accusés de vols par les marchands puisqu'ils remplissaient d'eau les tonneaux ainsi allégés ${ }^{40}$.

Avec la publication de l'ordonnance du 22 février 1736, les gribanniers de Saint-Valery ou d'Abbeville ne devaient plus donner, et sous aucun prétexte, de l'eau-de-vie aux bateliers et haleurs qui les aidaient à remonter le cours du fleuve sous peine de 50 livres d'une amende et de prison, la première fois, et de 100 livres d'amende, moitié pour le marchand et moitié pour le dénonciateur, et de la privation à vie de la fonction de gribannier, en cas de récidive. Une fois de plus, comme ils appartenaient à une communauté professionnelle intercommunale et fédérale, ils furent mis devant leurs responsabilités collectives, aussi bien pour les qualités et les quantités d'eau-de-vie transportées que pour les désordres, insultes et violences, commis par ceux qui auraient consommés des eaux-de-vie, offertes par un des leurs. Pour renforcer l'interdiction de ces pratiques abusives et néfastes à l'ordre public, les gribanniers ne furent pas les seuls acteurs visés par cette ordonnance; les bateliers, haleurs et autres personnes ne devaient plus exiger ou réclamer d'eau-de-vie sous peine de prison ${ }^{41}$.

Loin d'arrêter de telles pratiques, certains gribanniers contournèrent cette ordonnance, comme ils avaient l'habitude de le faire avec les précédentes. D'après une requête du 12 décembre 1737, les gribanniers, chargés du transport des barriques d'eau-de-vie depuis Saint-Valery, avaient rempli les barriques avec de l'eau puisée à l'aide d'une cruche, devant les conducteurs d'allèges qui étaient venus d'Amiens au village de Dreuil ${ }^{42}$, pour transborder les barriques d'eau-de-vie. Ayant réalisé cette supercherie, ils furent, cette fois, démasqués par le marchand, lésé et arrivé sur les lieux par la voie terrestre, qui avait alors goûté le reste d'eau présent dans la cruche avant d'interroger les conducteurs $\mathrm{d}$ 'allèges qui avouèrent immédiatement. Forts de cette nouvelle exaction, les gribanniers coupables furent à l'origine d'une nouvelle ordonnance de l'intendant, datée du 31 décembre suivant, par laquelle les gribanniers étaient tenus de rendre les eaux-de-vie, dont ils avaient la charge, avec un écart d'un demi-pouce en été et un pouce en hiver, et de ne pas mettre d'eau dans les barriques, sous peine du paiement de dommages et intérêts, solidairement par toute la communauté ${ }^{43}$.

Rien n'y fit: en traitant cette ordonnance comme les précédentes, les gribanniers continuèrent leurs prélèvements en nature dans les barriques et le remplissage avec l'eau du fleuve. Inévitablement, ils furent encore à l'origine d'une nouvelle ordonnance, datée du 19 décembre 1739, soit moins de deux ans après la précédente. De nouveaux, ils furent rendus responsables, par le corps, des déprédations qui se commettaient sur les barriques d'eau-de-vie, lors de leur transport de Saint-Valery à Amiens, et tenus de payer, toujours par le corps, pour les dommages, faits et évalués par les subdélégués d'Abbeville ou Amiens en cas de simple requête par les marchands ${ }^{44}$. Par leurs pratiques, les gribanniers, chargés de ces barriques d'eau-de-vie, avaient probablement suscité, chez les bateliers du fleuve et les haleurs, des actions comparables sur d'autres cargaisons puisqu'une nouvelle ordonnance, datée du 13 mai 1741, interdisait à tous les bateliers et haleurs, chargés des cargaisons de bois ou de tourbes, d'altérer, sous prétexte d'aider à monter les bateaux, le nombre et la quantité de leur charge ${ }^{45}$. Il convient d'ajouter qu'à peine imprimée et publiée, cette nouvelle ordonnance fut aussitôt transgressée et contournée.

En effet, d'après un procès-verbal dressé le 6 juin suivant, un gribannier d'Abbeville, qui conduisait son bateau chargé d'eau-de-vie à Amiens, et un maître des bateaux de Picquigny, qui remontait le fleuve avec son bateau chargé de bois à brûler, se livrèrent à une manœuvre subtile en triangle. Le premier préleva la quantité d'une bouteille en verre

40. Arch. dép. Somme, 1 C 766.

41. Arch. dép. Somme, 1 C 1389 . Certains gribanniers donnaient de l'eau-de-vie aux bateliers et haleurs, en plus de leur salaire ordinaire, y compris pour l'emporter chez eux.

42. Actuelle commune de Dreuil-lès-Amiens, en aval d'Amiens.

43. Arch. dép. Somme, 1 C 1389.

44. Arch. dép. Somme, 1 C 1389.

45. Arch. dép. Somme, 1 C 1391. 
d'une barrique d'eau-de-vie, puis la livra aux haleurs de l'équipage du second pendant que celui-ci prenait dans le chargement de sa barque 8 ou 10 bûches de rondin de charme qu'il laissa au gribannier devenu débitant d'alcool ${ }^{46}$.

Régulièrement accusés de vols et dégradations sur les denrées et marchandises, les gribanniers rétorquèrent, dans un mémoire daté du 8 mars 1740, qu'ils pouvaient être accusés à tort puisqu'en l'absence de contrôle des cargaisons, à la sortie des cales des navires de mer lors des transbordements, personne ne pouvait les accuser de telles pratiques qui auraient pu être commises par les membres d'équipage des navires de mer ${ }^{47}$. Toutefois, en dépit des ordonnances, procès-verbaux d'infraction et autres requêtes des marchands, ils poursuivirent leurs prélèvements en nature ou cautionnèrent les prélèvements des haleurs qui se présentaient par dizaines pour les aider à remonter le cours du fleuve avec des gribanes trop chargées.

En effet, presque tous les gribanniers chargeaient leur embarcation au-delà des 18 à 20 tonneaux prescrits par les ordonnances et donc, en augmentant leur chargement, jusqu' 35 ou 40 tonneaux ${ }^{48}$, ils augmentaient le tirant d'eau de leur gribane qui s'échouait sur les bancs de sable estuariens ou les atterrissements fluviaux. Plus ponctuellement, ils subissaient également les manques d'eau et les conséquences d'autres activités humaines comme la meunerie et l'artisanat. Ainsi, d'après une requête des entrepreneurs généraux des voitures des sels, faite le 16 avril 1763, ils furent bloqués, avec des bateaux chargés de sel et d'autres marchandises, par les immondices, jetées dans le canal qui commence au pont Saint-Michel, et dans celui de la Croix, à Amiens ${ }^{49}$. Dans de telles situations, ils ne pouvaient être complètement tenus pour responsables des blocages et autres retards de navigation et livraison mais ils y contribuaient fortement en surchargeant les gribanes au point de ne pouvoir fermer les écoutilles.

D'après une requête du 25 novembre 1766, un gribannier d'Abbeville ne pouvait ignorer qu'une grande quantité d'eau avait été introduite dans deux barriques d'eau-de-vie, transportées de Saint-Valery à Amiens dans sa gribane ${ }^{50}$. Dans un mémoire du 15 mars 1768, les gribanniers furent impliqués dans un nouveau désordre pour le transport fluvial et un nouvel abus, considéré comme un brigandage public, digne d'éprouver toute la sévérité des lois, et de fixer l'attention de l'autorité. Au niveau des villages de PontRemy, Long et Picquigny, ils étaient habituellement aidés par les paysans riverains de ces villages pour le passage des ponts, où la rapidité des eaux rendait le halage indispensable. En plus de leur payer des salaires de plus en plus importants depuis deux ans, les gribanniers devaient leur donner de l'eau-de-vie à discrétion et voyaient ainsi le bien du marchand livré au pillage par 50 à 60 haleurs. De plus, ils ne pouvaient que constater les suites fâcheuses de ce désordre qui se répétaient plusieurs fois à chacun des passages et, comme il en résultait un vide trop frappant dans les barriques d'eau-de-vie, ils se trouvaient dans la nécessité de remplir d'eau ces mêmes barriques, dans l'espoir d'échapper à la vigilance du marchand ${ }^{51}$.

Dans une déclaration du 9 décembre 1769, un gribannier d'Abbeville, sa femme, et sept hommes d'équipage, pris à Abbeville, arrivèrent avec une gribane en charge d'eau-de-vie au niveau de la côte de Montières, en aval d'Amiens. Ils virent alors, sur l'autre bord de la Somme, une trentaine de porteurs du quai d'Amiens faisant également les fonctions de haleurs, depuis le faubourg de Saint-Maurice jusqu'à Amiens. Ces derniers, ne pouvant approcher de la gribane pour $s^{\prime} y$ rassasier d'eau-de-vie, les invectivèrent. Afin de poursuivre leur trajet fluvial jusqu'à Amiens, ils furent obligés de leur donner de l'eaude-vie, à deux reprises, sans avoir pu contenter les 42 haleurs qui avaient auparavant

46. Arch. dép. Somme, 1 C 1391.

47. Arch. dép. Somme, 1 C 1390.

48. Arch. dép. Somme, 1 C 1389.

49. Arch. dép. Somme, 1 C 1399. Voir Fig. 3.

50. Arch. dép. Somme, 1 C 1402.

51. Arch. dép. Somme, 1 C 1403. 
refusés de se mettre au travail ${ }^{52}$. Par une nouvelle ordonnance du 18 octobre 1775, les gribanniers risquaient la confiscation de leur gribane et le paiement de dommages et intérêts s'ils donnaient de l'eau-de-vie à leur équipage et aux haleurs ${ }^{53}$.

D'après une lettre du 12 janvier 1784, deux gribanniers étaient en retard pour une livraison, prévue en la ville d'Amiens, à cause de la nature même de la marchandise dont la gribane était chargée; les haleurs, sentant de l'eau-de-vie à Saint-Valery, ne se souciaient pas de remonter des fromages ${ }^{54}$. D'après une autre lettre, 15 février 1785 , un maître de gribane remontait le fleuve avec sa gribane chargée de barriques d'eau-de-vie. Arrivé au niveau du village de Pont-Remy, il se heurta au refus des haleurs qui réclamèrent logiquement de l'eau-de-vie en plus du prix ordinaire ou le paiement de 15 livres ${ }^{55}$.

Le 19 juin 1789, trois députés du comité de l'association civique proposèrent d'établir un halage avec des chevaux pour faire le service des gribanes qui doivent amener les grains pour la subsistance de la ville d'Amiens et des autres villes de la province. Ils avancèrent que sans ce halage, il était impossible de pourvoir à la subsistance de cette province d'une manière efficace. Une fois les orateurs retirés, il fut délibéré en séance que le conducteur principal des travaux des routes devrait se transporter sur les lieux afin de reconnaitre l'exécution, pour la marée suivante, d'un halage provisoire pour faire le service des gribanes et ce pendant l'espace de trois mois ${ }^{56}$. Dans un contexte économique troublé qui engendra une augmentation régulière du prix du grain, de la farine et du pain, il serait tentant de voir dans cette proposition, même si aucune information ne l'indique dans la délibération, un moyen d'assurer non seulement le transport fluvial des cargaisons de blé, dans le sens montant, mais également de garantir l'intégrité des sacs de grains, depuis la baie de Somme jusqu'aux différentes villes fluviales de destination puisqu'une ordonnance de l'intendant de Picardie du 7 mai 1789 défendait aux habitants d'apporter des empêchements aux transports de grains sur la Somme ${ }^{57}$.

Pour le bassin de la Somme, si les origines des marchands de l'eau et des bateliers peuvent être restituées pour le Moyen Âge, celles des gribanniers restent à préciser. En effet, en utilisant les sources documentaires, elles peuvent être connues à partir de la fin $\mathrm{du} \mathrm{XII}^{\mathrm{e}}$ siècle pour les acteurs du commerce fluvial et à partir du milieu du XIII ${ }^{\mathrm{e}}$ ou du XIV ${ }^{\mathrm{e}}$ siècle pour deux des trois types d'acteurs du transport fluvial. En revanche, pour le troisième type d'acteurs, les gribanniers, en l'absence de mention antérieure au milieu du $\mathrm{XVI}^{\mathrm{e}}$ siècle, seules les origines médiévales des gribanes, attestées dès 1346, peuvent combler les absences ou les lacunes. De plus, l'ancienneté de ces groupes de personnes ne peut être connue et leur étude réalisée à partir de données archéologiques ou iconographiques.

Acteurs emblématiques mais contestés du transport fluvio-maritime entre le port maritime de Saint-Valery, établi au cœur de la baie de Somme, et le Quay de la ville d'Amiens, établi au trois-quarts du tronçon navigable de la Somme, les gribanniers constituaient une communauté forte et solidaire mais dépourvue de statuts. En dépit de cette absence réglementaire, ils possédaient néanmoins un banc d'œuvre dans l'église Saint-Georges d'Abbeville, ville dans laquelle habitait la majorité d'entre eux. Également implantés dans les villes d'Amiens et de Saint-Valery, ils étaient ainsi présents dans les trois centres urbains qu'ils desservaient et constituaient plus un réseau de transporteurs fluviaux intercommunaux plutôt qu'une communauté urbaine unique.

52. Arch. dép. Somme, 1 C 1 404. Voir Fig. 4.

53. Arch. dép. Somme, 1 C 1406.

54. Arch. dép. Somme, 1 C 1410.

55. Arch. dép. Somme, 1 C 1411.

56. Arch. dép. Somme, 1 C 2 013, p. 566-567.

57. Arch. dép. Somme, 1 C 1384. 
Liés, depuis 1664, par un traité garantissant la pratique d'un tour de rôle, ils s'assuraient un partage du transport et une unité fédérale face aux commissionnaires et marchands soucieux de voir leurs denrées et marchandises remonter le cours du fleuve le plus rapidement possible. Avec une telle organisation et leur cohésion fluviale, ils purent régulièrement faire bloc afin de demander, proposer ou imposer des augmentations de prix du fret, en allant même jusqu'à la mise en place d'un véritable embargo sur le transport fluvial en 1763 alors que ce tour de rôle avait été supprimé en 1724 . Avec plus d'un siècle d'oppositions, de menaces et de revendications, les gribanniers apparaissent comme des acteurs intermédiaires, indispensables pour le transport fluvial des denrées et marchandises, régulièrement décriés et sous-payés par les commissionnaires et marchands, mais ils apparaissent également comme les dénonciateurs et détracteurs de la rentabilité commerciale et des pratiques marchandes contestables, notamment pour les quantités approximatives ou sous-évaluées.

En fonction des denrées et marchandises transportées, les gribanniers usèrent et abusèrent de leurs fonction, monopole et usage en prélevant ou laissant prélever par les bateliers et haleurs qui les aidaient, des quantités d'eaux-de-vie et de liqueurs particulièrement importantes, en ayant soin toutefois de les remplacer par l'eau du fleuve. Régulièrement dénoncés et même pris en flagrant délit, ils ne pouvaient contester de tels agissements et furent réprimandés et menacés, durant une grande partie du $\mathrm{XVIII}^{\mathrm{e}}$ siècle, pour ces pratiques frauduleuses, malhonnêtes et délictuelles. En évoluant dans un milieu clos mais dépeuplé, ces spécialistes du transport fluvial pouvaient, à discrétion, disposer des denrées et marchandises durant toute la durée de leur navigation, de jour comme de nuit. Pour cette raison et en dépit de leur monopole, ils furent vraisemblablement interdits de navigation de nuit, à partir de 1746, afin de limiter la contrebande de certains produits comme le sel ou le tabac.

En évoluant dans un environnement fluvial dégradé, les gribanniers de la Somme naviguaient avec difficulté à contre-courant en évitant les bancs de sable estuariens et les atterrissements fluviaux mais ils subissaient également les accélérations des eaux au niveau des ponts. Afin de rentabiliser au maximum leurs trajets et en dépit des difficultés de navigation, ils surchargeaient leur gribane et, de ce fait, rencontraient encore plus de difficultés de navigation. Ainsi, ils augmentaient et subissaient les prétentions et exigences des bateliers et haleurs qui venaient volontiers à leur secours pour le passage des obstacles. Alors embarqués dans le cercle vicieux de la rentabilité et de la surenchère, ils firent construire des gribanes plus grandes afin d'accroître leurs capacités de transport mais rencontrèrent alors, de plus en plus souvent, des difficultés pour remonter le cours du fleuve, au point de rester à quai, à Saint-Valery ou à Abbeville, plusieurs jours ou semaines, et profiter d'une marée favorable et d'une hauteur d'eau suffisante. À la veille de la Révolution, afin d'assurer un transport fluvial fiable des grains, ils furent concurrencés par une expérimentation de halage par des chevaux.

\footnotetext{
Résumé

Favorisée dès la fin $\mathrm{du} \mathrm{XII}^{\mathrm{e}}$ siècle, la navigation fluviale sur la Somme fut réglementée en 1255. Entièrement assurée et contrôlée, entre le port maritime de Saint-Valery et la ville d'Amiens, par la corporation des gribanniers d'Abbeville, elle permettait le transport des matières premières, des produits alimentaires et artisanaux aussi bien dans le sens avalant que dans le sens montant.

Souvent préférée à la Seine, la Somme occasionna, lors d'étiages, de débordements ou d'embâcles, autant d'empêchements et d'entraves à la circulation des gribanes, lourdement chargées.

En dépit de leur monopole, les gribanniers furent interdits de navigation de nuit, à partir de 1746, afin de limiter la contrebande. Pratiquant des tarifs excessifs pour le transbordement et le transport des marchandises, durant la seconde moitié du XVII ${ }^{\mathrm{e}}$ siècle puis le XVIII ${ }^{\mathrm{e}}$ siècle, ils exerçaient d'importantes pressions sur les marchands en retenant leurs marchandises à bord ou en assurant de véritables embargos.
} 


\section{Bibliographie}

CLOQUIER Christophe, « Les aménagements de l'estuaire de la Somme et l'amélioration de la navigation fluvio-maritime (XVII ${ }^{\mathrm{e}}$-XVIII ${ }^{\mathrm{e}}$ siècles) », dans MALÉZIEUX Jacques (dir.), Le milieu littoral, $124^{e}$ Congrès national des sociétés historiques et scientifiques, Nantes, 1999, Paris, éd. du CTHS, 2002, p. 205-219.

CLOQUIER Christophe, «Les installations fluviales médiévales et modernes du cours de la Somme: approche archéologique et documentaire ", thèse de doctorat, archéologie, université de Paris 1 Panthéon-Sorbonne, 2012, 3 vol.

CLOQUiER Christophe, "Port et quai du bassin de la Somme : deux termes pour deux réalités du $\mathrm{XII}^{\mathrm{e}}$ au $\mathrm{XVIII}^{\mathrm{e}}$ siècle», dans SERNA Virginie (dir.), Inventorier et décrire les constructions de l'eau: le vocabulaire des ports en milieu fluvial et estuarien, Paris, ministère de la culture et de la communication, 2015, p. 44-50.

GODEFROY Frédéric, Dictionnaire de l'ancienne langue française et de tous ses dialectes $d u I^{e}$ au $X V^{e}$ siècle..., Paris, F. Vieweg, t. 4, 1885, et Paris, Bouillon, t. 10, 1902.

MONSTRELET Enguerran de, La chronique d'Enguerran de Monstrelet: en deux livres, avec pièces justificatives 1400-1444 publiée pour la Société de l'histoire de France par L. Douët-d'Arcq, Paris, Mme veuve J. Renouard, 1861.

SCHNAKENBOURG Christian, Communautés de métiers contre liberté économique à la fin de l'Ancien régime: l'exemple des gribanniers de la Somme, Paris, Presses universitaires de France, 1976.

THIERRY Augustin, Recueil des monuments inédits de l'histoire du Tiers Etat. 1ère série, Chartes, coutumes, actes municipaux, statuts des corporations d'arts et métiers de villes et communes de France. Région du Nord..., Paris, Firmin Didot frères, t. 1, 1850.

WARTHBURG Walther von, Französisches etymologisches Wörterbuch: ein darstellung des galloromanischen Sprachschatzes. 16. Band, germanische Elemente. G-R..., Bâle, R. G. Zbinden, 1959. 


\section{Illustrations}

Figure 1 : carte de la Picardie. 1592 (arch. dép. Somme, 1 Fi 16, cliché conseil général de la Somme, archives départementales).

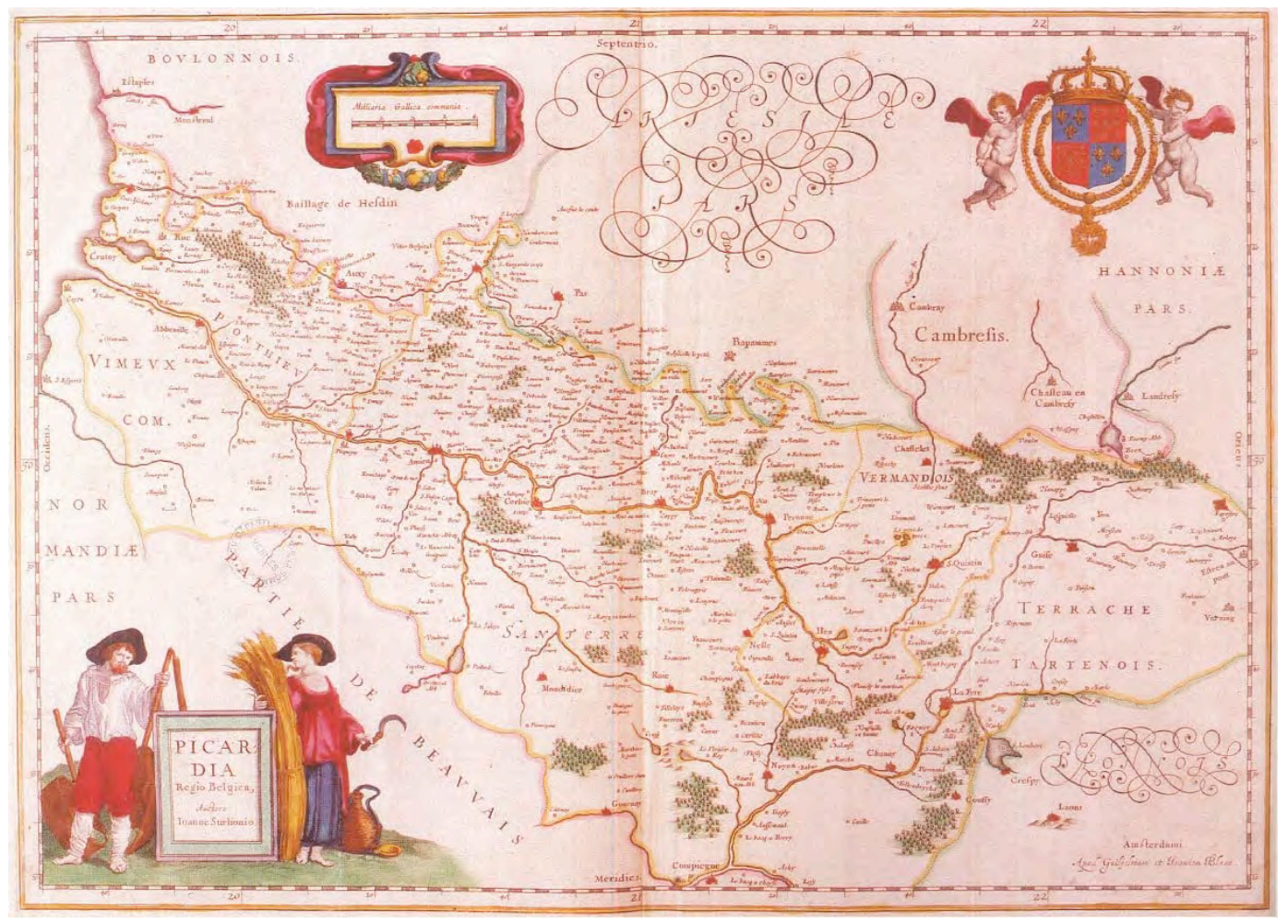

Figure 2: extraits du plan d'Amiens et des hortillonnages en 1542. 1950 (arch. dép. Somme, 1 Fi 72, clichés C. Cloquier).
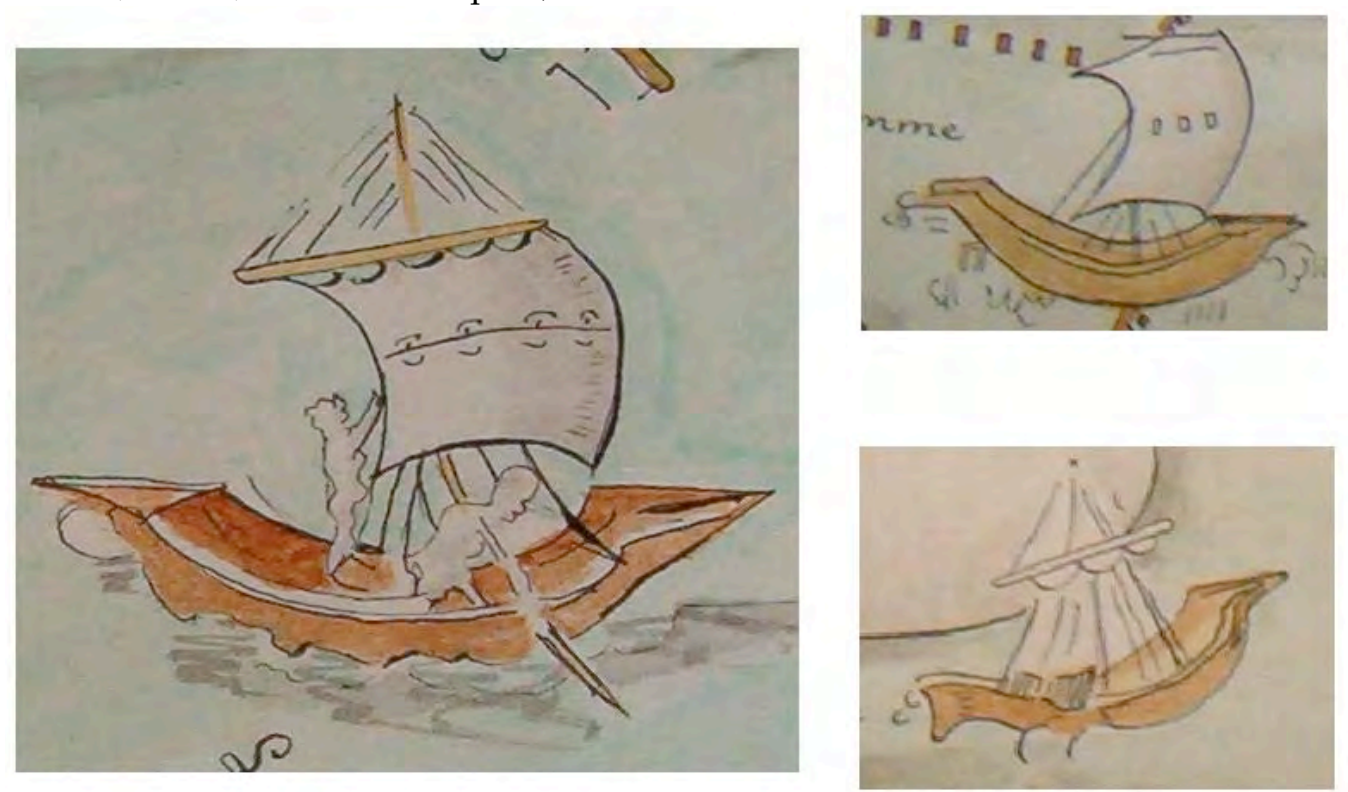
Figure 3 : vue d'Amiens au XVII ${ }^{\mathrm{e}}$ siècle. Sans date [XVII ${ }^{\mathrm{e}}$ s.] (bibl. mun. Abbeville, Am. Z 75, cliché bibl. mun. Abbeville).

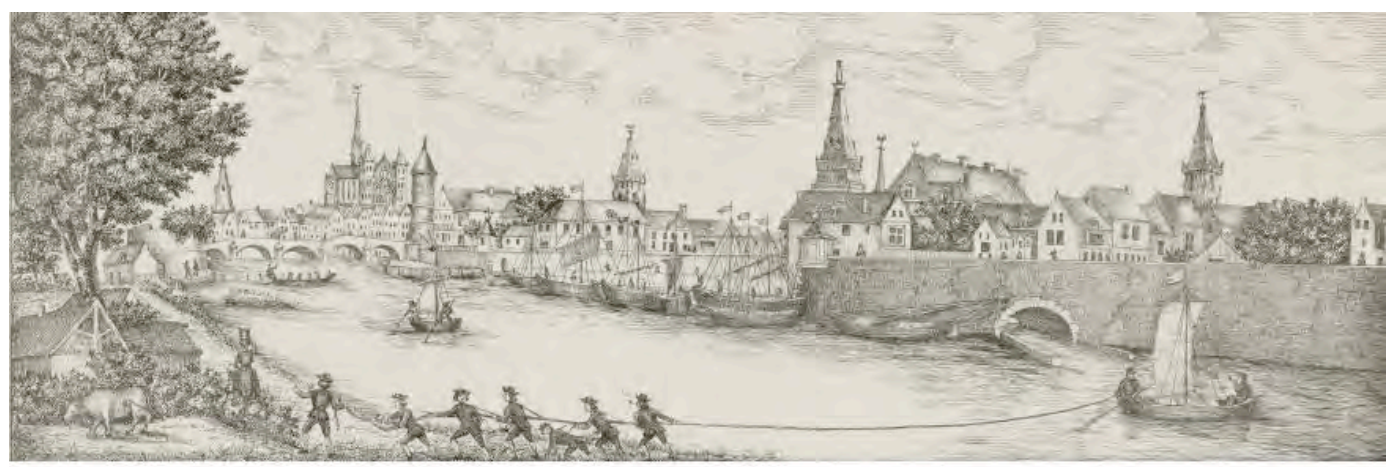

Figure 4 : extrait du plan du chasteau et jardin de Moustiers... 1658 (arch. dép. Somme, 3 G 108/2, cliché C. Cloquier).

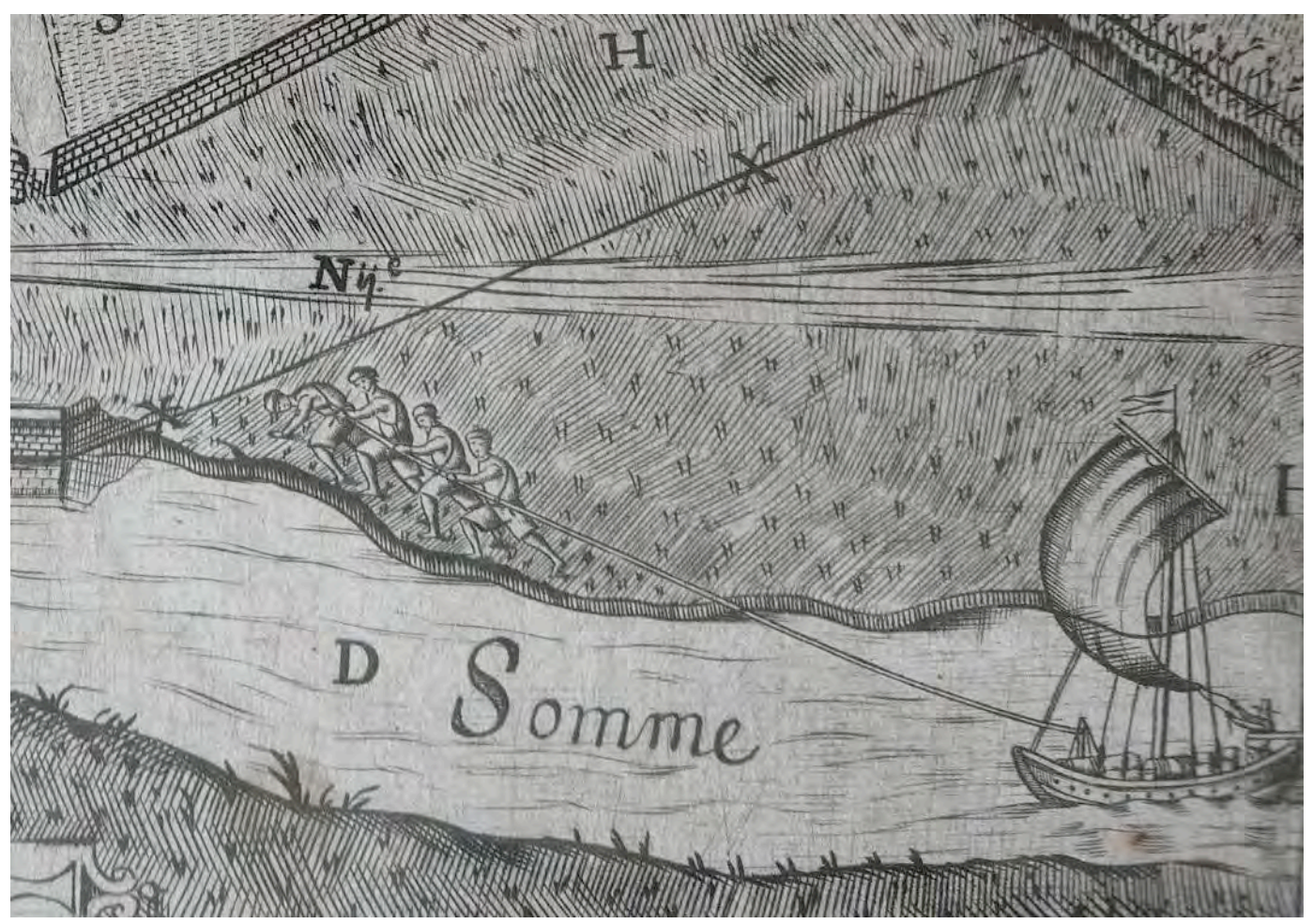




\title{
Réseaux marchands et industriels russes au XIX ${ }^{e}$ siècle: le cas de la dynastie sibérienne des Basnine
}

\author{
Solange BAUDOUIN, \\ doctorante à l'Institut National des Langues \\ et Civilisations Orientales (INALCO), \\ Extrait de : Henri BRESC (dir.), Réseaux politiques et économiques, Paris, \\ Édition électronique du CTHS (Actes des congrès des sociétés historiques et scientifiques), 2016. \\ Cet article a été validé par le comité de lecture des Éditions du CTHS dans le cadre de la publication \\ des actes du $140^{\mathrm{e}}$ Congrès national des sociétés historiques et scientifiques tenu à Reims en 2015.
}

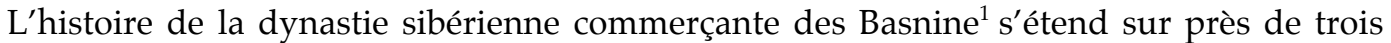
siècles. Si elle continue d'être explorée, elle a néanmoins déjà fait l'objet d'une recherche assez détaillée pour mériter d'être analysée en termes de réseau. Loin de prétendre à une quelconque exhaustivité, le présent article se concentre sur la trajectoire de quelques-uns de ses membres, ceux sur lesquels les informations sont d'ores et déjà disponibles, depuis le fondateur, Maksime jusqu'à son descendant en ligne directe, Piotr, ingénieur de son métier, reconverti plus tard au métier de journaliste et d'éditeur (fig.1).

En dépit de l'intérêt qu'elle présente pour l'historiographie actuelle, la classe marchande sibérienne demeure relativement peu explorée par les historiens, notamment en raison de l'absence relative de mémorialistes locaux dans l'ensemble des œuvres recensées. Ces mémorialistes, dont les écrits constituent la source principale pour les chercheurs, représentent à peine six pour cent des annuaires de bibliographie pour toute la Russie ${ }^{2}$, et ce sont pour la plupart des personnes ayant exercé des responsabilités politiques, essentiellement des représentants de la noblesse, et l'on n'y dénombre que quelques rares marchands. Une autre raison pour expliquer ce déficit des sources tient aussi au fait qu'en Russie Orientale, durant toute la période qui précéda la Révolution russe, les marchands, mémorialistes d'un genre nouveau, firent imprimer leurs textes dans des éditions populaires ${ }^{3}$, n'ayant peut-être eu ni l'intention, ni l'ambition de réaliser une œuvre pérenne. Par conséquent, on imagine aisément que la recherche historiographique continue d'être freinée par la dispersion de ces écrits et par une conservation vraisemblablement loin d'être optimale. Compte tenu des difficultés qui viennent d'être exposées, c'est en recourant plus à une prosopographie qu'à une méthode réticulaire stricto sensu que cette étude a été menée sur la famille Basnine.

1. Sauf pour les noms propres d'usage courant, le système de translittération utilisé pour les caractères cyrilliques est la norme ISO 9/1995 Goost 2002 sys A, excepté pour les lettres ю (ju) et я (ja). Pour faciliter la lecture du texte par un public français, la translittération Basnin du nom russe Баснин n'a pas été retenue, en faveur de Basnine, de même pour Максим pour lequel il a été préféré de prendre Maksime et non Maksim.

2. N. P. Mathanova, Mémoires des Sibiriaks au XIX', p. 3.

3. Parmi ces éditions populaires, on peut citer Rouskaja Starina (La Russie ancienne), Rouskij Arhiv (Les Archives russes), Vostočnoe Obozrenie (Revue de 1'Orient), Sibir (La Sibérie), ou encore Zurnal Sibirskij Arhiv (Journal des Archives de Sibérie). 


\section{La fondation du réseau des Basnine}

Il peut être intéressant de s'interroger sur les origines du fondateur de la dynastie. En fait, on sait peu de chose sur Maksime Basnine lui-même, si ce n'est par le truchement de ses descendants ${ }^{4}$. Né dans les dernières années du XVII ${ }^{\mathrm{e}}$ siècle, ce paysan originaire de la province d'Arkhangelsk était un contemporain de l'empereur russe Ivan le Terrible. Le tsar réalisait alors avec succès l'expansion de son territoire vers l'est de la Sibérie occidentale et fondait la ville de Novoholmogory ${ }^{5}$ en 1584, qui permettait d'ouvrir une porte sur l'Océan Arctique. Ivan IV était alors animé d'une volonté farouche d'exploiter cette ouverture maritime, en même temps qu'il favorisait le commerce des fourrures, qui constituait une manne pour le gouvernement russe de l'époque à court d'argent, et, en même temps, une source d'enrichissement pour les marchands. Ces derniers orchestraient la chasse de concert avec les trappeurs et ils organisaient à leur profit l'écoulement de cette précieuse marchandise. Les fourrures, ou encore l'or blanc comme on les désignait, constituaient même la pierre angulaire de l'économie russe.

En l'espace de deux générations seulement, le réseau familial des Basnine allait parvenir à se constituer en un groupe puissant, influent et riche au sein de la classe marchande, bien que l'on se situât à une période généralement considérée comme peu propice à un tel essor, en raison du cloisonnement entre les classes sociales en Russie et en raison aussi de l'arriération souvent incriminée du développement économique de la société russe. Ce constat amène à se poser la question de savoir de quelle manière l'ascension de Maksime Basnine avait-elle pu se réaliser.

Si l'on ne sait rien de l'enfance et des premières années d'apprentissage de Maksime, on retrouve sa trace à l'âge adulte, et il est cette fois-ci loin d'Arkhangelsk. Poussé vraisemblablement par l'appât du gain et incité à explorer des horizons plus propices, Maksime avait choisi de quitter le grand nord. Au début du XVIII siècle, on le retrouvait établi près des sources de la Léna, à l'ouest du lac Baikal. Même si l'explication le concernant d'un paysan fuyant le servage ne peut pas être totalement exclue, il est plus vraisemblable que le fondateur de l'empire des Basnine vienne d'une famille de paysans libres. Ces derniers n'étaient pas très nombreux en comparaison des paysans asservis, mais on les voyait parfois chercher fortune dans des zones inhospitalières, ce qui pourrait expliquer la naissance de ce paysan aux confins septentrionaux maritimes de l'empire russe. Maksime était-il un odnodvorec ? Cette hypothèse est tout à fait plausible, car si certains de ces odnodvorcy ${ }^{6}$, étaient des personnes d'origine noble en voie de paupérisation à la suite de sérieux revers de fortune, ce terme recouvrait plus largement les personnes libres de tout asservissement. À l'inverse des serfs, les odnodvorcy possédaient la terre qu'ils cultivaient, qui n'était souvent au départ qu'un simple lopin de terre, et ils pouvaient la transmettre à leurs héritiers mâles en priorité, mais également aux femmes de la famille. Le tableau présenté ici est loin d'être idyllique, car ces odnodvorcy restaient soumis à la capitation et aux longues années de recrutement militaire. Néanmoins, certains de ces paysans dont le nombre variait entre deux et trois millions d'individus, sont parvenus à atteindre une aisance matérielle réelle ${ }^{7}$ et il est fort probable que cela ait été le cas de Maksime Basnine, expliquant un essor aussi rapide de sa richesse. Utilisant le potentiel d'une liberté sans entraves, Maksime aurait su exploiter ce précieux atout au bénéfice de sa descendance qui aurait pu à son tour se constituer en un réseau familial prospère.

4. I.V. Kulaev, Sous une bonne étoile, p. 8.

5. Ancien nom d'Arkhangelsk.

6. Littéralement, ceux dont l'habitation ne possède qu'une seule porte.

7. A. Leroy-Beaulieu, «L'Empire des tsars et les Russes ». 
Toutefois, une autre hypothèse mérite d'être examinée. La loi russe de 1721, qui clarifiait le statut de commerçant, aurait constitué le prélude à la réussite de Maksime Basnine. Mais cette date est tardive pour le fondateur de la famille. De plus, malgré la volonté impériale de légiférer en la matière, il ne semble pas, autant sous le règne de Pierre le Grand que plus tard sous celui de Catherine II, que ce nouveau statut attribué aux négociants ait connu le succès espéré. Au moment de sa parution en janvier 1721, ce que l'on désigna sous le vocable de Règlement de la Magistrature Suprême sur le Statut des Négociants, était clairement destiné à alimenter les caisses de l'État, en organisant de façon systématique l'imposition des agglomérations et en augmentant la pression fiscale sur le corps marchand. Pour parvenir à ses fins, le gouvernement russe voulait à la fois changer le mode d'administration des villes et le statut de commerçant. Or, avant l'élaboration de ce premier document juridique qui donnait un cadre aux activités des négociants, ces derniers jouissaient d'une autonomie réelle au sein de leurs Guildes. Ils choisissaient euxmêmes leur responsable, le staroste, et ses collègues. Les plus importants parmi ces derniers se constituaient en Magistère avec voie consultative.

Les membres des Guildes bénéficiaient de privilèges inamovibles sur l'ensemble de leurs biens, qu'il s'agisse des domaines fonciers, des boutiques, des entrepôts ou encore des factoreries et des ateliers de fabrication. On comptait trois catégories de Guildes. La Première se caractérisait par un statut très privilégié, puisqu'elle seule pouvait se rendre propriétaire d'entreprises industrielles. En outre, elle avait un droit de regard sur les attributions de licence de négoce aux Deuxième et Troisième Guildes. Progressivement, les commerçants de la Première Guilde constituèrent une classe particulière dans l'État russe.

Les Guildes marchandes étaient, par conséquent, opposées au Règlement de la Magistrature Suprême, et celui-ci, de toute évidence, ne peut pas avoir constitué pour Maksime Basnine l'occasion de poser les premiers jalons de l'entreprise familiale. Il avait déjà fondé une famille et avait un fils de deux ans, Timofej, l'année même où Pierre le Grand tentait, par cette nouvelle loi, de créer une véritable bourgeoisie sous contrôle. Mais comme il a été mentionné plus haut, la mise en œuvre du Règlement prit du retard et ce sera au sein des Guildes désormais, que la famille Basnine allait poursuivre son ascension, à l'instar d'autres empires familiaux qui avaient fait florés en Europe Occidentale à des périodes plus récentes.

\section{Le réseau des Basnine se développe autour d'activités marchandes}

Dès lors, le réseau constitué par la cellule familiale allait prendre forme autour des activités de négoce. Le fils de Maksime, Timofej (1719-1799) s'établissait à la fois comme transporteur et comme commerçant, ce qui s'avéra avoir été un choix judicieux en prévision de l'avenir. Il assurait le transport de marchandises, par voie fluviale et par portage, sur l'axe reliant les deux villes d'Irkoutsk et de Ienisseïsk, fondées au cours du XVII siècle. Timofej pratiquait pour son propre compte le commerce des fourrures et du blé sur la Léna et ses affluents. Le trafic sur les grands fleuves russes connaissait au même moment un essor considérable et la ville septentrionale de Iakoutsk (sur la Léna) était alors considérée comme le rendez-vous de tous les chasseurs de fourrures qui se dirigeaient vers le nord pour traquer le précieux or blanc. Quand les fleuves sibériens se trouvaient prisonniers du gel pendant le long repos hivernal, Irkoutsk, à quelques encablures par traîneau, servait de gigantesque entrepôt pour les fourrures qui, de là, repartaient vers les riches clients, russes et étrangers. Par Irkoutsk, encore, transitaient d'importantes quantités de blé, de vin ou de sel, qui constituaient les denrées de base indispensables à la population sibérienne. 
Avec Timofej commençait l'histoire d'une famille qui allait s'enraciner dans le tissu social de la ville d'Irkoutsk, et qui bientôt figurerait parmi les notables de cette ville. Les débuts des Basnine à Irkoutsk étaient certes modestes, mais ils permettaient de prendre pied dans cette capitale régionale florissante qui présentait la particularité d'offrir aux classes marchandes des perspectives d'avenir plus étendues qu'ailleurs. C'est pourquoi en 1789, Timofej décida de s'installer dans cette ville et de s'inscrire dans la Troisième Guilde des Marchands, même si celle-ci ne jouissait pas du même prestige que les deux premières. Il n'était plus très jeune et ce choix lui était dicté par le souci de transmettre à sa descendance les biens qu'il avait acquis. Peu avant sa mort, une de ses dernières volontés fut que ses quatre fils, Vassilij, Nikolaj, Dmitri et Piotr, continuent de vivre sous le même toit, sans diviser l'héritage commun. Respectant à la lettre la volonté sacrée de leur père, les quatre fils dirigèrent conjointement l'affaire familiale et la firent fructifier. Ils géraient dorénavant un réseau commercial étendu à de nouvelles villes sibériennes.

La fidélité familiale exerçant son pouvoir d'attraction, le réseau, même s'il s'ouvrait à des tiers, faisait montre de sa capacité à rapporter en son centre les intérêts premiers du groupe, ce qui autorise à lui attribuer le qualificatif de réseau centripète.

Les héritiers de Timofej multipliaient le nombre d'entrepôts et ils continuaient le négoce de céréales et le transport des fourrures qu'ils échangeaient dans la ville frontière de Kjahta, contre des marchandises chinoises, au premier rang desquelles figurait le thé. Kjahta, un avant-poste de la pénétration cosaque aux confins de la Sibérie, devait sa fortune au monopole de l'importation du thé qui empruntait la voie terrestre ${ }^{8}$. Les produits de l'Empire Céleste achetés par les frères Basnine étaient écoulés par leurs soins sur les lointains marchés bien achalandés des provinces russes occidentales, comme celui de Moscou ou encore de Nijni Novgorod.

En 1814, un quart de siècle s'était écoulé depuis le décès de Timofej. Trois de ses fils s'inscrivaient dans les Guildes de commerçants de Kjahta. Vassilij, décédé en 1804, n'apparaissait plus désormais aux côtés de ses frères. Ces derniers continuaient de travailler ensemble et en 1829, ils ouvraient à Irkoutsk la maison de négoce des Frères Basnine. Les affaires seront menées conjointement par la fratrie encore quelques années jusqu'au moment où Nikolaj, Dmitri et Piotr décideront de se séparer et de se répartir l'héritage de l'affaire familiale.

Nikolaj Timofevič ${ }^{9}$ Basnine (1770-1843) possédait plus que les autres le goût du risque. Doté d'un caractère entreprenant, il ne se contentait pas de cumuler les fonctions honorifiques qui correspondaient dorénavant à son statut de riche commerçant : citoyen d'honneur, bourgmestre de la Magistrature, ou encore responsable de la Chambre de Commerce, il figurait également parmi les mécènes d'Irkoutsk. Néanmoins, les libertés qu'il prit avec la loi, en créant fictivement une pénurie de blé afin de faire grimper les cours céréaliers, finiront par se retourner contre lui.

I. B. Pestel occupait à cette période le poste de gouverneur général de Sibérie et son administration était chargée de faire la lumière sur les dérives constatées en matière de prix. Les fonctionnaires en charge du dossier finirent par porter le même chef $\mathrm{d}^{\prime}$ accusation contre les autres frères Basnine, et contre bien d'autres commerçants ${ }^{10}$. Il n'apparaît pas de trace des sanctions éventuelles encourues par les trois frères, mais les affaires de corruption prirent de telles proportions qu'à son tour, le gouverneur I.B. Pestel fit figure d'accusé. La corruption en Sibérie apparaissait alors à certains chroniqueurs comme un phénomène endémique qu'il était impossible d'enrayer ${ }^{11}$. Pour

8. À la fin du XVIII ${ }^{\mathrm{e}}$ siècle, la célèbre route du thé passait par Kjahta et ceci, ajouté au transfert de la douane depuis Irkoutsk, contribua à la fortune de la ville. En 1850 environ, les négociants étaient omniprésents à Kjahta et l'on comptait près de soixante entreprises commerciales qui réalisaient un chiffre d'affaires de trente millions de roubles annuel.

9. Le choix de conserver le patronyme, c'est-à -dire le prénom du père à côté du prénom de la personne comme il est d'usage en Russie, a ici pour but de faciliter le repérage des personnes dans la famille des Basnine.

10. P. I. Pejemski et V. A. Krotov, Chronique d'Irkoutsk.

11. Ibid. 
conclure sur la personne de Nikolaj, il convient d'ajouter qu'en plus de ses nombreuses activités, il participa, mais sans succès, à la fièvre de l'or qui s'était emparée du bassin amont de la Léna.

Piotr Timofevič Basnine (1778-1842) est celui des quatre fils de Timofej sur lequel on possède le plus d'éléments. On sait qu'il a rédigé de très volumineuses notes plutôt que des mémoires au sens habituel où on l'entend, et que ces notes ont heureusement pu faire l'objet de recherches de la part de deux personnes, l'historien russe V. S. Manassein ${ }^{12}$, vraisemblablement le premier à s'être intéressé à la famille Basnine, et Piotr Pavlovič Basnine, dont il sera question plus loin (à ne pas confondre avec son grand-père, Piotr Timofevič Basnine).

Piotr Timofevič, le plus jeune des quatre frères, était selon V. S. Manassein, un personnage peu ordinaire. Sur la fin de ses jours, ce sexagénaire à la silhouette trapue affichait un caractère affirmé et indépendant. Foncièrement honnête, il a livré dans ses écrits une critique acerbe à l'encontre de l'injustice et de l'incurie de l'administration russe en Sibérie. Jouissant d'une certaine renommée en tant que commerçant, mais aussi à titre de conseiller commercial et de citoyen d'honneur, Piotr Timofevič Basnine préférait l'action. Lors de l'invasion de la Russie par Napoléon $\mathrm{I}^{\mathrm{er}}$, il rejoignit l'armée des volontaires mobilisée pour repousser l'envahisseur « honni ». Sa bravoure fut reconnue et récompensée, ce qui fut pour lui l'occasion de faire le voyage de Saint-Pétersbourg afin de participer à la remise officielle des décorations. Il eut l'honneur d'être présenté à l'empereur Alexandre $\mathrm{I}^{\mathrm{er}}$, mais surtout, on l'accepta aux bals de la cour comme un représentant éminent des riches marchands de Sibérie, dont il ne manqua pas de faire valoir les intérêts.

On pouvait également voir en Piotr Timofevič Basnine un esprit pratique qui avait foi dans le progrès de la science et dans les avancées technologiques de son temps. Homme de réseau, il n'hésitait pas à se mêler aux différentes sphères de la société, ce qui lui donna l'opportunité de créer et maintenir de nombreux contacts. Membre de la Société agricole moscovite, ou encore membre actif de la Société d'élevage des races ovines, il étudia la possibilité de cultiver en Sibérie la betterave sucrière. Il caressait le projet de construire une raffinerie de sucre, mais les années s'écoulèrent sans qu'il pût mettre son projet à exécution, et ce fut finalement un autre négociant de Kjahta, Pilenkov, qui édifia la première usine du genre à Irkoutsk en 1842. Pour récompenser l'ensemble de son action en faveur de l'agriculture, de l'industrie et du commerce en Sibérie, Piotr Timofevič Basnine reçut la Médaille d'Or sur le Ruban de Vladimir, une décoration tout à fait prestigieuse pour l'époque. Il restait toutefois assez de temps au personnage pour relater les évènements, majeurs ou mineurs, auxquels il avait assisté pendant sa longue vie. Piotr était donc à sa manière un mémorialiste mais malheureusement, seuls quelques rares écrits issus de sa plume firent l'objet de publications.

Cette galerie de portraits serait incomplète sans celui d'Irina Timofeevna Nečaeva, née Basnine, qui était la fille de Timofej. Au décès de son époux, Irina se retira au couvent où elle prit le nom d'Ilaria. Bénéficiant de l'appui de ses frères, elle fut nommée supérieure du monastère, une nomination qui ne fut pas du goût de l'archevêque Irinej Nesterovič. Ce personnage lettré qui portait la responsabilité d'un immense territoire couvrant les régions d'Irkoutsk, de l'Amour et de Iakoutie, en vint à conclure que la nouvelle supérieure ne possédait pas un niveau d'instruction suffisant pour éduquer à son tour les membres du clergé qui figuraient sous sa houlette. L'archevêque fit part de ses critiques au Saint Synode, sans aucun succès.

L'Église orthodoxe, en cette première moitié du XVIII ${ }^{\mathrm{e}}$ siècle, avait choisi de rompre avec son isolement et de nouer des liens plus étroits avec le monde matériel, autrement dit le gouvernement et les affaires. Il n'était ni prudent, ni avisé de s'opposer au clan des Basnine, influents commerçants; à l'inverse de ce qu'il avait pu espérer, l'archevêque se 
vit infliger son propre éloignement tandis que la sœur supérieure Ilaria continua de diriger le monastère entre les années 1832 et 1837.

Au-delà de son aspect anecdotique, l'épisode illustre bien le processus d'intercession qui est mis en ouvre dans tout réseau, un processus qui atteindrait ici son acmé et qui marquerait la maturité du réseau d'origine des Basnine. Par la suite, cet état de fait allait changer, à l'occasion d'un décentrement de la puissance acquise par cette famille au fil des générations. Désormais, cette dernière s'ouvrirait largement à de nouveaux acteurs et le réseau des Basnine, qu'on aurait pu qualifier d'autarcique à ses débuts, en viendrait progressivement à s'ouvrir à d'autres réseaux de nature plus capitalistique. De commercial, il passerait insensiblement à une structure maillée plus complexe, englobant des activités manufacturières et de nouveaux acteurs. Le changement le plus marquant se déroulerait au tournant $\mathrm{du} \mathrm{XIX}^{\mathrm{e}}$ siècle, à l'occasion de la présence des Basnine dans la recherche aurifère des bords de la Léna. À ce moment clé, le réseau se transformait en profondeur, de même que les liens au sein de ce même réseau.

\section{L'ouverture du réseau des Basnine à des réseaux capitalistiques}

L'industrie aurifère de la Léna fournit un observatoire privilégié de certains membres de la famille Basnine. La quatrième génération deviendra partie prenante de ce secteur risqué et à la fois prometteur de richesse, par le truchement de Pavel Petrovič Basnine (1816-1867), fils de Piotr Basnine. Dans chacune des deux principales villes de la région, Irkoutsk et Kjahta, Pavel appartenait à la Première Guilde, ce qui constituait une indication claire de la progression de la famille dans l'échelle des marchands. Pour donner un ordre d'idée, alors qu'il suffisait de disposer d'un capital de huit mille roubles pour s'inscrire dans la Troisième Guilde, ce montant était presque décuplé quand il s'agissait d'accéder à la première d'entre elles. En complément de cette ascension, Pavel figurait désormais parmi les membres de la prestigieuse Société géographique impériale, comme parmi ceux de la Faculté d'économie. Désormais, il avait le loisir de consacrer une partie de son temps à des activités de mécénat. De surcroît, Pavel Basnine avait acquis le titre de citoyen d'honneur héréditaire, ce qui signifiait qu'il pouvait le transmettre à ses descendants, et que ce statut envié le rapprochait un peu plus de la noblesse.

Pavel Petrovič Basnine était assurément doté d'un certain éclectisme. À titre d'exemple, en 1840, il construisit près d'Irkoutsk une ferme expérimentale de semences de pavot, ce qui lui donna l'occasion de réaliser une communication auprès de la communauté scientifique sur l'état d'avancée de ses travaux. Plus tard, au cœur des questions soulevées par l'exploitation minière, il chercha avec certains de ses pairs des solutions pour l'amélioration des conditions de vie des mineurs. Les problématiques auxquelles ils étaient confrontés se rapportaient principalement à l'amélioration des conditions de logement des mineurs et de leur alimentation.

L'intérêt que portait Pavel Petrovič Basnine à ces sujets n'était pas d'ordre purement philanthropique car, prospecteur chanceux, il avait trouvé un gisement d'or dans la vallée de la Léna en 1850. Les sommes que demandait l'exploitation d'un tel filon dépassaient les moyens d'une seule personne, voire d'une seule famille, et c'est pour cette raison que Pavel créa avec un autre entrepreneur d'Irkoutsk, P.I. Katyševcev, la Société commerciale d'exploitation aurifère Lénienne, en abrégé, Lenzoto. Un important réseau de négociants sibériens se mobilisa alors autour de ces deux hommes, et de concert, les Basnine, les Katyševcev, mais encore d'autres personnes comme Serguej Trapeznikov - lui-même membre d'une illustre dynastie marchande d'Irkoutsk anoblie, ou encore Ivan Bazanov - financèrent l'expédition de 1866 vers le bassin de l'Oliokma, à cinq cents kilomètres environ au sud-ouest de Iakoutsk, une expédition dirigée par le célèbre géographe et futur révolutionnaire, P. A. Kropotkine ${ }^{13}$.

13. P. Kropotkin, Memoirs of a revolutionist, p. 210. 
Avec Pavel Petrovič Basnine, on voit que le réseau de ces commerçants et en même temps entrepreneurs débouchait sur un autre réseau essentiel à l'époque, celui des géographes de l'Empire. Ces explorateurs, à leur tour, agissaient au cœur d'immenses réseaux, matériels et immatériels, et se livraient aussi à des activités plus secrètes dont le Grand Jeu nous fournit peut-être le meilleur exemple. Dans le cas présent, l'intérêt de l'expédition vers l'Oliokma s'avérait de nature plus commerciale que politique, et il avait été fixé au géographe pour mission de trouver la voie de passage la plus directe pour conduire le bétail sur le lieu d'exploitation des mines d'or, en passant par les rivières Vitim, Oliokma et leurs affluents.

Toujours dans le cadre de l'exploitation aurifère centrée sur le bassin de la Léna, cette quatrième génération des Basnine voit ses réseaux gagner en complexité, à l'aune d'autres maillages composites de négociants, d'entrepreneurs, et d'industriels émergeant de l'immense territoire qu'est la Russie orientale (fig. 3). Dorénavant, les liens qui unissent ces nouveaux capitaines d'industrie revêtent une nature capitalistique.

Avec Piotr Pavlovič Basnine (1852-1904), le fils de Pavel, on vit émerger une nouvelle figure centrale de ce réseau. Piotr Pavlovič avait effectué ses études à l'Institut des Mines de Saint-Pétersbourg qui le destinaient à une carrière d'ingénieur dans l'industrie aurifère. Au décès de son père en 1867, cette vocation semblait se préciser puisqu'il devenait, grâce à l'héritage paternel, un des principaux actionnaires de Lenzoto. Dans les quatre années qui suivirent, Katyševcev allait de la même manière donner les parts qu'il détenait dans Lenzoto à ses deux fils. À partir de ce moment, le réseau d'actionnaires gravitant autour de Lenzoto peut être vu comme un réseau ouvert animé par des forces centrifuges. Des raisons d'ordre économique accélérèrent en quelque sorte ce processus.

Succédant à l'euphorie de l'extraction facile des premiers temps, les filons d'or commençant à s'épuiser, l'exploitation exigea que l'on recourût à des moyens techniques plus sophistiqués et à plus d'ouvriers. Il fut bientôt nécessaire de mobiliser des ressources financières très importantes, ce que ni les Basnine, ni les Katyševcev ne pouvaient réaliser à eux seuls. L'histoire de l'entreprise aurifère prenait alors le pas sur l'histoire de ses créateurs. Lenzoto, petite société au capital détenu au départ par quelques personnes, allait devenir un géant, et son parcours se transformer en une véritable épopée.

En 1872, l'entreprise Meyer and Co se créait et parallèlement, apparaissait sur les bords de la Léna la dynastie des Guinzbourg qui contrôlaient en partie le capital de Meyer and Co. La Banque Guinzbourg qui avait été fondée en 1859 par Horace Guinzbourg, était considérée comme la première banque d'affaires en Russie. L'étape déterminante pour Piotr Pavlovič Basnine survint en 1882 quand le banquier Guinzbourg et la maison de négoce Meyer achetèrent la majorité du capital de Lenzoto. Le processus de transformation de cette entreprise allait se poursuivre et plus tard, l'on verrait même apparaitre au rang des actionnaires de la société ${ }^{14}$, le Ministre des Finances russe, S. Iu. Witte ou encore l'impératrice douairière, Maria Fedorovna.

Mais à partir de là, on peut considérer que Piotr Pavlovič Basnine n'est désormais plus lié au réseau de Lenzoto. Comme il a été mentionné brièvement dans l'introduction, le personnage de Piotr Pavlovič réapparait comme une source majeure de l'importante recherche prosopographique en cours sur les Basnine, consistant pour l'essentiel au dépouillement de périodiques contenant les articles qu'il a rédigés. Piotr Pavlovič Basnine, décédé en 1904, avait lui-même exploité pour ses publications une série de carnets provenant de ses ancêtres, ce qui explique pourquoi il constitue une référence incontournable pour les chercheurs contemporains. Tous ces travaux sont complémentaires et devraient permettre en particulier de combler un vide sur l'histoire des mines de la Léna. Il est symptomatique, à ce propos, que le nom des Basnine ne soit pas mentionné dans l'excellent ouvrage de Michael Melancon consacré à ce sujet ${ }^{15}$ et ce constat à lui seul ouvre un nouveau champ d'études.

14. La Société de la Léna laissa son nom dans l'histoire avec le sinistre épisode du massacre des mineurs en avril 1912.

15. M. Melancon, The Lena Goldfields massacre and the crisis of the Late Tsarist State, p. 26-29. 
Le réseau familial des Basnine est-il de nature à pouvoir demeurer, au fil du temps, objet de recherche? La réponse que l'on serait tenté de formuler est duale car elle peut correspondre à deux aspects différents de la question. On peut d'un côté considérer qu'étant donné le choix initial de traiter des aspects commerciaux de ce réseau, d'autres structures réticulaires empruntant le même objet de recherches existent et qu'elles restent à exploiter. On répondrait donc par l'affirmative à la question posée. En revanche, on peut imaginer qu'une autre manière d'aborder cette même question serait de se concentrer sur l'aspect dynamique que la recherche sous-tend et de considérer que, sous cet angle, le réseau à l'origine de la famille des Basnine a connu une transformation identitaire et qu'il n'est plus le même. La réponse serait donc non. Néanmoins, à condition de redéfinir l'objet de recherche initial, la recherche historique fondée sur les réseaux ne rencontrerait pas d'obstacle particulier à être poursuivie.

\section{Résumé}

En dépit de l'intérêt porté par l'historiographie actuelle, la classe marchande sibérienne demeure peu explorée en raison de la rareté relative des mémorialistes régionaux. La dynastie des Basnine a cependant pu faire l'objet de recherches, et, en cela, elle mérite d'être étudiée en termes de réseau. L'article se concentre sur certains de ses membres, depuis le fondateur Maksime, un paysan né près d'Arkhangelsk avant 1700, jusqu'à son descendant Piotr Pavlovič, ingénieur des mines de formation. Fortune faite grâce à la découverte de filons d'or, Piotr devait céder ses parts dans Lenzoto, qui deviendra la première entreprise d'exploitation aurifère de la Léna, mais qui laissera aussi son nom associé au massacre des mineurs d'avril 1912. Piotr, devenu journaliste et éditeur, pouvait désormais exercer ses talents de mémorialiste par la rédaction d'articles sur la vie de ses ancêtres. Son travail constitue un des apports principaux à la recherche prosopographique sur la famille. 


\section{Bibliographie}

KULAeV Ivan Vasilevič, Sous une bonne étoile, RoyalLib.com (en russe, Pod cčactlivoj zbezdoj).

KROPOTKIN Peter, Memoirs of a revolutionist, Houghton, Miffun, 1899.

Leroy-Beaulieu Anatole, "L'Empire des Tsars et les Russes ", Revue des Deux Mondes, T. $14,1876$.

MEDVEDEV Serguej I., Les Liens du temps, les Basnine dans l'histoire d'Irkoutsk, Irkoutsk, 2008 (en russe, Sviaz vremën : Basniny v istorii Irkutska).

MelanCON Michael, The Lena Goldfields massacre and the crisis of the Late Tsarist State, ed. Texas A\&M, University Press, 2006.

Mathanova Natalja Petrovna, Mémoires des Sibiriaks au XIX siècle (en russe, Memuary sibiriakov XIX vek.), Novossibirsk, 2003.

Pejemski Piotr Ilič et Krotov V. A., Chronique d'Irkoutsk, Irkoutsk, 1911.

\section{Illustrations}

Figure 1 : Arbre généalogique des Basnine.

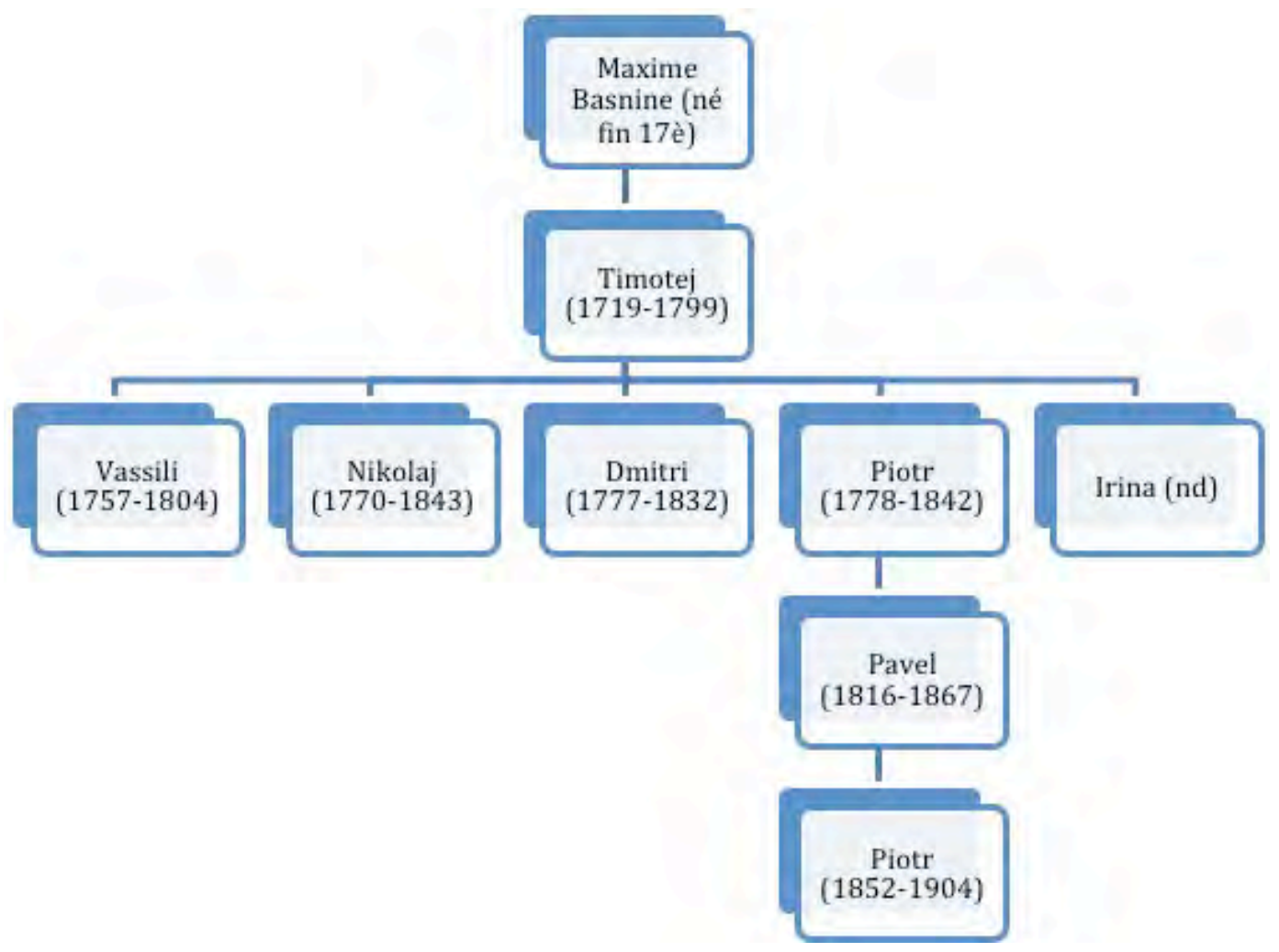


Figure 2 : Les réseaux des Basnine

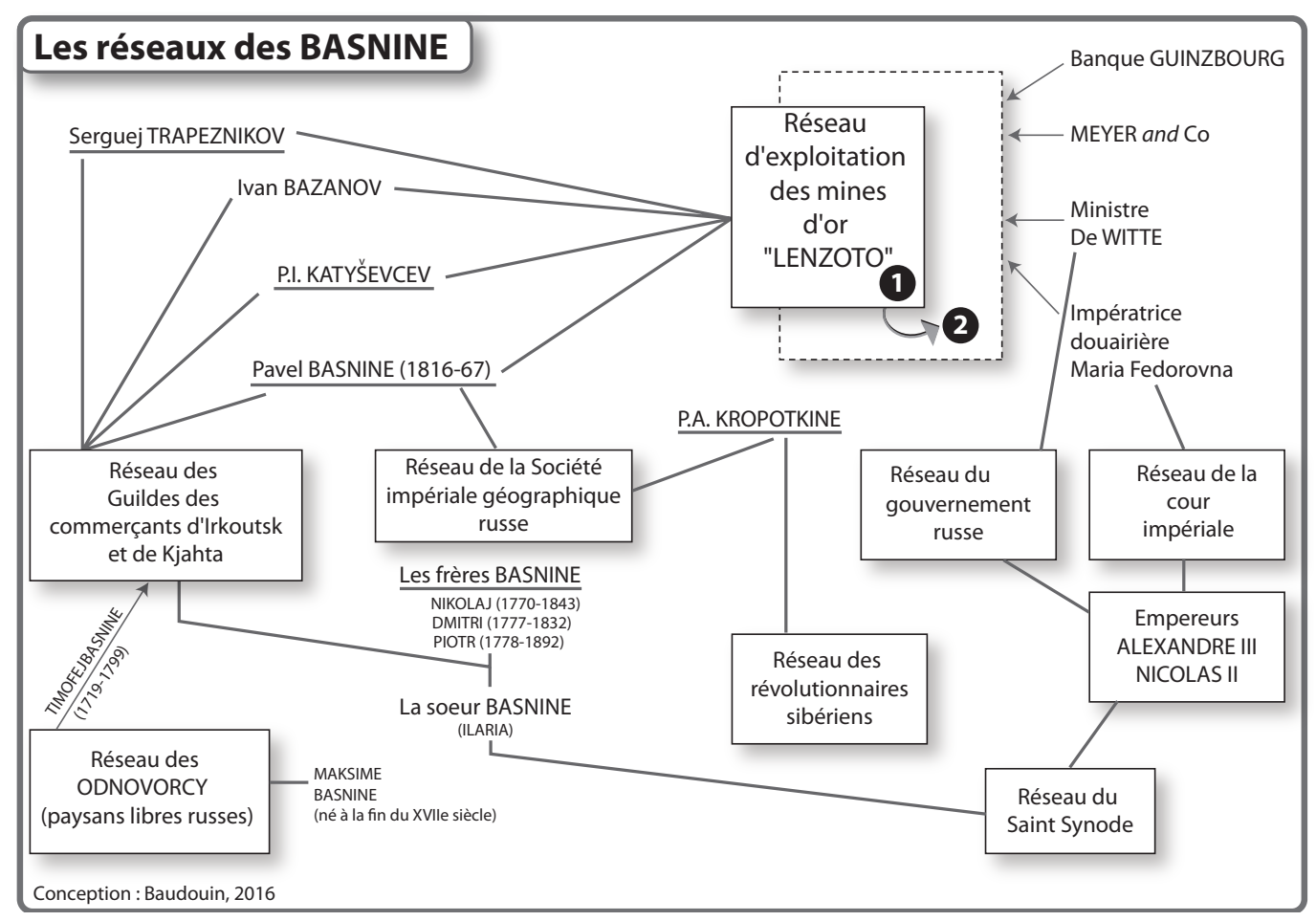

Figure 3 : Carte de la Sibérie.

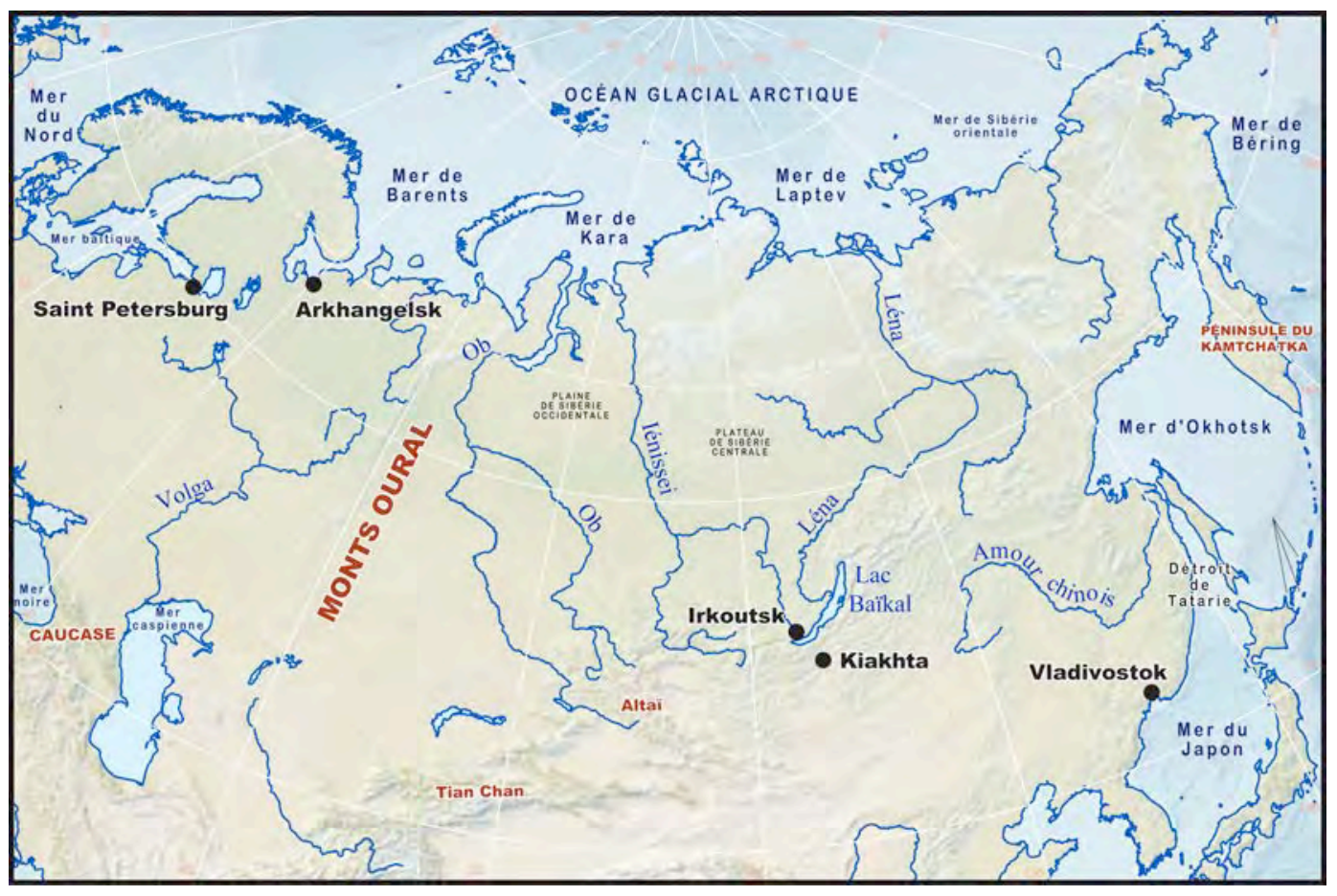




\title{
Le moulin à grain hydraulique dans sa chaîne économique, technique et sociale : $l^{\prime}$ exemple de l'Alençonnais $\mathrm{XVII}^{e}-\mathrm{XX}^{e}$ siècles $^{1}$
}

\author{
Patrick BIRÉE \\ Secrétaire de la Société historique et archéologique de l'Orne, \\ doctorant à l'Université de Caen \\ Extrait de : Henri BRESC (dir.), Réseaux politiques et économiques, Paris, \\ Édition électronique du CTHS (Actes des congrès des sociétés historiques et scientifiques), 2016. \\ Cet article a été validé par le comité de lecture des Éditions du CTHS dans le cadre de la publication \\ des actes du $140^{\mathrm{e}}$ Congrès national des sociétés historiques et scientifiques tenu à Reims en 2015.
}

Un triptyque de 1493 présenté dans un ouvrage majeur de Claude Rivals sur la meunerie est éloquent pour situer le moulin à grain dans sa chaîne économique entre l'agriculteur qui produit les céréales et le boulanger qui fabrique, enfourne le pain et le vend ${ }^{2}$. Parce qu'il obtient la farine, le meunier est un personnage central dans les sociétés anciennes, villageoises ou urbaines, quand le pain est à la base de l'alimentation ${ }^{3}$. Sa position a toujours été stratégique dans l'histoire de l'approvisionnement en France même si cela est moins une réalité de nos jours. Le moulin se trouve au centre d'une chaîne économique et sociale paralocale reliant de nombreux partenaires sociaux différents en termes de statuts et de fonctions. Le meunier y évolue paré d'un certain prestige ou alors accablé de critiques. Mais le moulin c'est aussi "une machine", une "usine ». Ceux à eau sont coûteux. Au Moyen Âge, seuls l'aristocratie et les ordres religieux peuvent supporter un tel investissement. Chaque seigneur entreprend la construction de cette usine à grains sur son fief, et en cède aux meuniers le droit d'exploitation contre le paiement d'un loyer et la charge d'entretien (ce qui n'est pas forcément le même cas pour les autres types de moulins à tan, papier, foulon, etc., où l'on remarque que les propriétaires présentent des profils différents). Par la suite, au XIX siècle, les meuniers s'approprient progressivement leur outil de production. Ceux-ci deviennent de moins en moins nombreux, mais leur productivité augmente. Les meuniers sont intégrés à des réseaux complexes.

Cette dimension était le thème du $140^{\mathrm{e}}$ congrès du Comité des travaux historiques et scientifiques organisé en mai 2015 sur le thème : « Réseaux et société ». La recherche effectuée s'inscrit dans ce cadre à travers deux réseaux plus ou moins formels qui se sont façonnés selon un axe différent. L'axe horizontal est l'axe technique et interprofessionnel. Il marque l'aspect économique correspondant à la chaîne de production, du produit brut, le grain, jusqu'au produit fini, le pain, partant donc des agriculteurs et allant jusqu'aux boulangers, en

1. Cette communication est une partie de sa thèse d'histoire consacrée aux moulins de l'Alençonnais des XVII ${ }^{\mathrm{e}}$ $\mathrm{XX}^{\mathrm{e}}$ siècles (sous la direction de Jean-Marc Moriceau). Cette étude s'appuie sur un territoire qui correspond grosso modo aux deux cantons d'Alençon-ouest et Alençon-est, soit une quarantaine de communes, pour environ 40000 habitants, au plus.

2. C. Rivals, Le Moulin et le meunier. Mille ans de meunerie en France et en Europe, p. 16.

3. Les grains panifiables sont le blé-froment, le seigle, le méteil, mélange de blé-seigle, voire l'orge, comme le précise en 1808 le rapport statistique du préfet Lamagdelaine qui mentionne l'utilisation de l'orge pour le pain en ces termes: «L'arrondissement de Mortagne est le seul où l'on fasse pour le pain usage de l'orge mélangé avec le blé ». Le sarrasin, qui n'est pas une céréale, est surtout consommé en bouillie ou sous forme de crêpes : "Le sarrasin consommé en bouillie serait un aliment assez agréable s'il était bien assaisonné, mais le plus souvent on fait cette bouillie avec du sel et rarement avec du beurre ou du lait. Dans les jours de régal, on fait des crêpes au Carême avec la fleur de sarrasin, et ce mets n'est pas désagréable quand on emploie du lait et des œufs et qu'on étend dessus un peu de beurre frais ». Arch. dép. Orne, 252 J 283, Rapport statistique pour l'Orne, 1808, manuscrit sans pagination. 
passant évidemment par les meuniers et y intégrant des intermédiaires. L'axe vertical est hiérarchique et infra professionnel : il structure l'organisationnel, du pouvoir de décision à l'exécution des tâches. Seul, le premier axe sera développé dans cet article. Cette chaîne de production, entre blé ${ }^{4}$ et farine, comprend les agriculteurs, mais aussi les blatiers ou fariniers et les grainetiers qui échangent les produits soit en amont, soit en aval des meuniers (surtout jusqu'au milieu du XIX ${ }^{e}$ siècle), puis les boulangers. Au moins à deux étapes, les produits sont transformés.

Cette chaîne fonctionne depuis des siècles. Elle est par exemple, bien réelle en 1738 dans un procès-verbal des « Dires de Marie-Élizabeth Guille des Buttes et des habitants et boulangers $\mathrm{d}^{\prime}$ Alençon et projet d'arrêt du conseil ». On y note que le fermier des moulins banaux d'Alençon est déchargé de l'obligation d'avoir un commis qui enregistre jour par jour et date les grains qui leur sont apportés ${ }^{5}$. De même en 1926, comme le montre un courrier émanant du directeur de la Direction de l'Agriculture de l'Orne au préfet de l'Orne. On y mentionne des directives pour connaître les stocks de blé disponibles dans le département de l'Orne, «tant en culture, que chez les grainetiers, minotiers et boulangers », avec courrier spécifique pour chacune des professions concernées ${ }^{6}$. Depuis des siècles, les politiques de l'État en matière d'approvisionnement en grains ont oscillé entre dirigisme et libéralisme recherchant à s'adapter ou à anticiper les crises de subsistances qui sont intervenues ${ }^{7}$. Cela a engendré une législation importante dans le cadre d'une politique du commerce des blés en France sous l'Ancien Régime, puis aux siècles suivants.

\section{Produire le grain : les agriculteurs}

La plaine d'Alençon a depuis fort longtemps une vocation agricole. Dans un ouvrage concernant la généralité d'Alençon en $1698^{8}$, l'intendant de la généralité, Jean-Baptiste de Pomereu, ne manque pas de souligner les attraits que sont production agricole et élevage. Dans un paragraphe intitulé Qualité et terroir de la campagne d'Alençon, il décrit ainsi la situation :

«La campagne d'Alençon, qui s'estend depuis la forêt d'Escouves, située en Normandie, jusqu'à celle de Perseigne, qui est de la province du Maine, ainsy que de la plus grande partie des terres et villages qui sont aux environs, dans un paysage assez uni, sont fertiles et abondantes en toutes sortes de grains, fourrages, chanvres et fruits, et particulièrement des pommes et des poires qui servent à faire du cidre et du poiré, dont est composé la boisson ordinaire du pays ; mais il n'y a point de vignes. Il s'y trouve aussi beaucoup de bons pasturages dans lesquels on met quantité de bœufs et de vaches que l'on mène à Paris, Rouen et Picardie. »

Il ajoute que l'on fait commerce de blé du côté d'Alençon pour les provinces voisines, du Maine, du Perche, de l'Anjou et de l'Orléanais ${ }^{9}$. Cependant, la production ne se cantonne pas à ce produit, blé ou blé-froment, mais aussi au seigle, à l'orge à l'avoine (les autres gros grains), et divers menus grains (sarrasin, chènevis, etc.) comme le montrent des enquêtes menées par

4. Le terme générique «blé » signifie la plupart du temps les grains panifiables dans les sources historiques. 5. Arch. nat., Q1 879, 8 juillet 1738 .

6. Arch. dép. Orne, M 1742. Enquête sur les quantités disponibles de blé dans le département de l'Orne, Préfecture de l'Orne, 13 mars 1926.

7. Les grandes crises démographiques du XVII siècle allient crise frumentaire et peste, celles du XVIII ${ }^{\mathrm{e}}$ sont plus atténuées, les dernières se rencontrent encore au XIX siècle.

8. J.-B. de Pomereu, Mémoires sur la généralité d'Alençon, p. 13.

9. Ibid., p. 119-120. 
l'administration royale. Suivant les statistiques de l'élection d'Alençon pour l'exercice $1772^{10}$, mesurées en boisseaux, pour la récolte de l'année concernée, déduction faite de la semence, pour les grains servant pour la farine panifiable, la culture du blé-froment vient en tête avec 71548 boisseaux (32\%), suivi du seigle avec 32117 boisseaux (14,5\%). La production de sarrasin en propre n'est pas connue, contenue dans celle des menus grains (12 677 boisseaux), seulement environ 5, 6\% de la production. Pour les grains d'alimentation pour animaux, l'avoine présente une production de 72170 boisseaux (32,2\%), contre 32255 pour l'orge $(15,7 \%)$. L'approvisionnement des moulins peut donc s'effectuer sur une base locale.

Au XIX ${ }^{e}$ siècle, dans l'Orne comme ailleurs en France, l'agriculture va évoluer profondément, même si ce département garde longtemps une population active liée au secteur primaire. Le couchage en herbe, élément caractéristique de l'agriculture ornaise au XIX siècle, n'épargne pas la plaine d'Alençon. Les chiffres fournis par Pierre Brunet sont très évocateurs concernant les cantons d'Alençon-est et d'Alençon-ouest. La superficie des cultures est en nette diminution entre 1855 et 1935, passant de 7546 à 3842 hectares, soit une diminution de moitié, avec l'exemple du blé qui diminue de 2481 à 1469 hectares. Les autres cultures, seigle et méteil, orge, avoine, sarrasin sont aussi concernées par ce phénomène au profit des cultures fourragères et des prairies artificielles (sainfoin et luzerne), mouvement qui se poursuivra au $\mathrm{XX}^{\mathrm{e}}$ siècle ${ }^{11}$.

\begin{tabular}{|l|c|c|c|}
\hline Cultures & Année 1855 Surfaces en ha & Année 1935 Surfaces en ha & Différence \\
\hline Blé & 2481 & 1469 & -1012 \\
\hline Seigle et méteil & 1000 & 78 & -922 \\
\hline Orge & 2166 & 920 & -1246 \\
\hline Avoine & 1641 & 1287 & -354 \\
\hline Sarrasin & 258 & 88 & -340 \\
\hline Total & 7546 & 3842 & -3704 \\
\hline
\end{tabular}

Tableau 1 : comparaison des surfaces agricoles en hectares dans les cantons d'Alençon-est et -ouest entre 1855 et 1935.

$\mathrm{Au}$ fil des décennies, la production céréalière locale de l'Alençonnais s'amoindrit sensiblement, ce qui n'est pas sans incidences sur les professionnels de la meunerie incités à chercher des marchés de plus en plus lointains. La base territoriale concernée par l'essentiel de l'approvisionnement en céréales panifiables (blé-froment, seigle, méteil, sarrasin) ou céréales animales (orge, avoine) est, au XVIII ${ }^{\mathrm{e}}$ siècle et hors période de crise frumentaire, la paroisse. Ce territoire d'approvisionnement, qui correspond à la commune après 1790, reste le même dans la première moitié du XIX ${ }^{e}$ siècle. On passe par la suite à un approvisionnement dans les communes proches, puis à un échelon cantonal avant de passer à un plus lointain à l'échelle départementale voire régionale. Ainsi pour les cantons d'Alençon, l'aire d'approvisionnement correspond au milieu du XIX ${ }^{\mathrm{e}}$ siècle au bassin de production du sud de l'Orne, mais aussi le nord de la Sarthe et le nord de la Mayenne. Cette aire ne va cesser de s'agrandir comme nous le montre l'exemple du moulin de Saint-Germain-du-Corbéis qui, à la fin $\mathrm{du} \mathrm{XX}^{\mathrm{e}}$ siècle, qui s'approvisionne dans un rayon de 200 kilomètres à la ronde. Jusque vers 1880, les ventes de produits (grains, farines et son) ont lieu à la Halle-aux-grains

10. Arch. dép. Orne, C 93, Statistiques agricoles de la généralité d'Alençon, l’Élection d'Alençon, 1772-1773. À cette époque, l'élection d'Alençon comporte vingt paroisses dont la plupart vont se retrouver dans les cantons d'Alençon est et ouest mis en place en 1790 et intégrant 26 communes. Le boisseau, mesure d'Alençon, était différent selon le produit; il valait 2, 095 décalitres pour le blé, 2, 38 décalitres pour l'avoine. Préfecture de l'Orne, Tables de comparaison entre les mesures anciennes du département de l'Orne et celles qui les remplacent, Alençon, An X, p. 34.

11. P. Brunet, «Essai sur l'évolution de l'agriculture dans le département de l'Orne (1800-1940)», p. 5-20. Pour l'année 1935, les tableaux statistiques citent des récoltes médiocres pour le blé et le sarrasin, moyennes pour l'avoine, l'orge et le seigle. Arch. dép. Orne, M 1912, Statistiques agricoles ornaises, année 1935. 
d'Alençon. Celle-ci ferme à cette époque car les transactions ont lieu directement entre producteurs, meuniers et boulangers, avant que n'existent les coopératives agricoles au début $\mathrm{du} X \mathrm{X}^{\mathrm{e}}$ siècle. Les crises frumentaires n'ont pas épargné la région. Des approvisionnements de céréales sont fréquents au XVIII ${ }^{\mathrm{e}}$ siècle, parfois venant de très loin (Écosse, Pays-Bas).

\section{Transformer le grain en farine : les meuniers}

L'enquête de 1809 révèle l'omniprésence de moulins sur le territoire ornais, puisque 750 (essentiellement hydrauliques) sont recensés pour l'Orne, la plupart d'origine fort ancienne. Les moulins des deux cantons du bassin alençonnais sont au nombre de 39 sur 26 communes, selon des caractéristiques qui s'intègrent dans celles du département ${ }^{12}$. Ces moulins ont pour la plupart une existence pluriséculaire. S'il n'est pas possible de quantifier la production sous l'Ancien Régime, les données statistiques ultérieures, aux XIX ${ }^{\mathrm{e}}$ et $\mathrm{XX}^{\mathrm{e}}$ siècles, le permettent. L'enquête de 1809 devient d'alors d'une grande pertinence puisqu'elle nous dresse de façon statistique tous les moulins de l'Alençonnais, ce qui n'était jamais arrivé auparavant. Ce territoire, comme celui de l'Orne, présente un maillage dense des moulins mais où l'on note une différence importante de la production. Sur les deux cantons concernés, le grand moulin de Sarthe à Alençon est le plus productif avec 18 quintaux par jour alors que les moins productifs fournissent un seul quintal quotidiennement. A cette époque, production communale de céréales et mouture dans les moulins de proximité sont encore en adéquation.

Au XIX $X^{e}$ siècle, les moulins locaux, comme les autres, sont pris dans la nasse du progrès et de l'évolution industrielle. $\mathrm{Si}$ on note un petit regain du nombre des moulins à grains vers 1820/1830, la tendance de fond est à la baisse par la suite. L'enquête sur le ravitaillement dans l'Orne de 1892 est révélatrice de la disparition d'un certain nombre d'entre eux au cours du siècle ${ }^{13}$. La production des sites meuniers est mentionnée pour les cantons d'Alençon-est et d'Alençon-ouest. On ne parle guère encore de minoteries même si quelques-uns disposent de turbines (et encore moins de moteurs thermiques car le premier site à l'adopter est Condésur-Sarthe avant le premier conflit mondial). La première constatation par rapport à l'enquête de 1809 : près de la moitié a disparu puisqu'il n'en reste plus que 22 sur 39 . Second élément: les plus grosses productions annuelles $s^{\prime}$ observent surtout sur les moulins de la plaine et non ceux des terres surélevées des côteaux : Condé-sur-Sarthe (18 615 qx), suivi des moulins de Saint-Germain-du-Corbéis et Raines de la Roche-Mabile (17 520 qx), puis le moulin de Sarthe à Alençon (13140 qx), le moulin de Lancrel à Alençon (12410 qx), le moulin de la Forge de La Roche-Mabile (11 680 qx), les moulins du Pont et de Gallet à Saint-Denissur-Sarthon (10220 qx chacun), tous au-delà des 10000 quintaux, les 14 autres se situant endessous. Pour donner un ordre d'idée, à cette époque le moulin de Saint-Germain-du-Corbéis a une production journalière de 14 quintaux/jour et celui de Condé-sur-Sarthe de 16 quintaux/jour.

La diminution du nombre des sites meuniers continue au $\mathrm{XX}^{\mathrm{e}}$ siècle. Plusieurs enquêtes réalisées avant et après le premier conflit mondial nous renseignent sur l'activité de ces moulins. On n'y note plus que onze sites recensés dont six moulins utilisent uniquement des cylindres (Alençon, Condé-sur-Sarthe, Hesloup, etc.), un seul, celui de Saint-Germain-duCorbéis, utilise cylindres et meules, ceux de Cérisé, Aché à Valframbert, et La Lacelle, utilisent uniquement des meules. Après le conflit de 1914-1918, le nombre de minoteries locales passe à six, puis seules trois restent actives après 1950. Une parmi elles, SaintGermain-du-Corbéis, est toujours en activité en 2015.

12. P. Birée et A.-G. Chaussat, «L'enquête de 1809 sur les moulins: le cas de l'Orne», p. 195-210.

13. Arch. dép. Orne, M 1460, Enquêtes sur le ravitaillement de l'Orne, 1892. 


\section{Transformer encore, puis vendre le pain : les boulangers}

Les boulangers forment le dernier maillon de la chaîne de production reliant les consommateurs. Ils présentent des interactions très particulières avec les autres métiers du secteur. Les boulangers semblent globalement ne pas interférer dans les affaires de l'agriculture avec, par exemple, une exploitation à des fins commerciales d'une entreprise agricole ou la vente de produits de la terre. Ils ne sont pas en conflit avec les producteurs agricoles. Il n'en est point de même concernant leur relation avec les seigneurs banaux et leurs représentants, les fermiers. Depuis le Moyen Âge et jusqu'à la Révolution française, ils font partie des catégories de personnes, avec les bourgeois des villes ou quelques habitants des campagnes, à pouvoir acheter des blés et de la farine pour faire cuire le pain chez eux. Le pain lié à la prospérité publique a toujours engendré un régime de surveillance très particulier. Comme l'explique Marcel Arpin, la législation concernant les boulangers est fournie et ancienne - par exemple à Paris - qui sert de marqueur au royaume ${ }^{14}$. Encore à la fin $d u X V I I I^{e}$ siècle, la taxe sur le pain heurte les boulangers parisiens qui réclament « la liberté de travailler et de vendre les produits de leur fabrication comme le font les autres métiers ». Arpin ajoute que le prix du pain étant basé sur celui du blé, «on a toujours trouvé dangereux que ces deux commerces, meunier et boulanger, puissent être accaparés par la même personne ». La vente du pain est toujours très réglementée par la suite comme le montre un règlement de la ville d'Alençon qui fixe ainsi toute la réglementation municipale pour la police des marchés et de la vente des grains et du pain en $1858^{15}$.

La loi du 22 juin 1863 qui proclame la liberté du commerce de la boulangerie donne un peu d'air à cette profession. Bien qu'une certaine réglementation encore contraignante soit de nouveau de rigueur (poids et qualité des pains, utilisation de balances et poids en bon état, prix justifié en correspondance avec le poids, débit possible en morceaux), cette libéralisation va permettre la création de fonds de boulangeries en milieu rural dans la seconde moitié du $\mathrm{XIX}^{\mathrm{e}}$ siècle. Les boulangers ont de tout temps été nombreux dans la ville d'Alençon et sont en première ligne lors des crises frumentaires ou des hausses du pain. Pour l'Ancien régime, ils forment une corporation importante : 28 en 1660, 36 en 1684, 32 en 1776, mais ne sont plus que 28 en 1789. Ces données restent stables au XIX ${ }^{\mathrm{e}}$ siècle et au début du XX $\mathrm{XX}^{\mathrm{e}}$ car la population des deux cantons alençonnais reste globalement identique, un peu à la hausse ${ }^{16}$. Le nombre des boulangers à Alençon se monte à 31 en l'an X, et l'Annuaire de l'Orne donne la liste des 31 boulangers pour l'année 1884 . Une statistique de 1893 confirme ce chiffre ${ }^{17}$. Onen dénombre 29 pour 1924. Le pain est longtemps fabriqué en ville, puis revendu à la campagne. Dès 1805, Jean-Jacques Gautier confirme cette dimension urbaine de la fabrication du pain ${ }^{18}$. $\mathrm{D}^{\prime}$ après lui, le commerce du pain existe pour la consommation de la ville mais aussi pour celle des campagnes, qu'il irrigue :

«On en exporte journellement dans les campagnes qui environnent Alençon, et surtout dans celles qui avoisinent les forêts où l'on mange qu'un pain très grossier. La boulangerie d'Alençon fournit dans les campagnes le pain des personnes riches et aisées, des enfants, des vieillards et

14. Sous le règne de Jean II le Bon, entre 1350 et 1364 furent établit trois sortes de pain, de poids différents, le blanc, le coquillé et le bis, ensemble appelé le petit pain. En 1415, on interdit aux boulangers d'exercer la profession de meunier car on craignait qu'ils ne prennent pour eux la meilleure farine et qu'ils retardent les moutures des particuliers pour obliger le public à se fournir chez eux. M. Arpin, Historique de la meunerie et de la boulangerie, depuis les temps préhistoriques jusqu'en 1914, t. 2, p. 55-56.

15. Arch. dép. Orne, M 1750, Règlements pour la vente du pain concernant les villes d'Alençon, années 1840/1860.

16. Chiffre de la population pour les cantons Alençon-est et Alençon-ouest selon l'Annuaire de l'Orne: 26360 habitants en 1806 et 28219 en 1911.

17. Arch. dép. Orne, M 1751, statistiques concernant les boulangeries de l'Orne, 1893.

18. J.-J. Gautier, Histoire d'Alençon, p. 228-229. 
des malades. On en transporte jusqu'à 5 myriamètres $^{19}$, dans le Maine et dans le pays bocage. Comme on ne récolte dans ces pays que du seigle et du sarrasin, on n'y fait point de pain blanc ; c'est la boulangerie d'Alençon qui fournit les particuliers, les marchands et tous les cabarets. Aussi les boulangers sont très multipliés à Alençon, et il en est qui cuisent jusqu'à quatre à cinq fois par jour. Quarante et un fours sont toujours brûlants, et il y a tel boulanger qui exporte deux cents charretées par an. »

Au cours du XIX $X^{\mathrm{e}}$ siècle, on assiste à un phénomène d'expansion inverse de celui des moulins : si le nombre de ceux-ci est fortement en baisse, celui des boulangers est en hausse. De plus, caractéristique particulière, il se développe en campagne. Plusieurs créations de boulangeries sont remarquées à partir des années 1870/1880, dans des villages éloignés d'Alençon, comme à Radon. Cette « irrigation » de la campagne est mise en évidence dans les enquêtes effectuées lors du conflit de 1914-1918 et se poursuit ensuite ${ }^{20}$.

Les moyens de transport influent sur le marché en modifiant rapidité, volume et distance. Le rôle du chemin de fer est capital pendant la Première Guerre mondiale. Si le transport hippomobile est encore de mise au début du $\mathrm{XX}^{\mathrm{e}}$ siècle, l'automobile (voitures et camions) va se développer, augmentant son poids total en charge (PTC), comme dans le cas du moulin de Saint-Germain-du-Corbéis. Il est alors loin le temps de la livraison de la farine par le meunier à dos d'âne...

Le réseau est transformé au fil du temps par ces nouvelles données spatio-temporelles. L'emprise des moulins devient peu à peu départementale au cours du $X X^{\mathrm{e}}$ siècle. La récolte des grains dépend du type de culture (le seigle est semé en septembre/octobre par exemple) et de l'assolement en place. Auparavant, l'assolement triennal présentait une rotation des cultures régulière sur trois années, encore présent dans l'Orne au début du XIX ${ }^{\mathrm{e}}$ siècle, comme le souligne le préfet Lamagdelaine dans un de ses rapports concernant l'agriculture ornaise ${ }^{21}$. Il laisse sa place au cours $\mathrm{du} \mathrm{XIX}^{\mathrm{e}}$ siècle à d'autres assolements, quadriennaux, voire quinquennaux. D'une manière générale, le calendrier annuel de la récolte est forcément changeant suivant les plantes et les types d'assolements. Les mois de récolte sont donc juin à octobre. Or, cela correspond le plus souvent à l'inactivité des moulins, ou pour le moins, à une réduction de leur activité.

Pour l'Alençonnais c'est aussi un problème récurrent. Dans la première moitié du XIX ${ }^{e}$ siècle, les céréales sont moissonnées, puis assemblées en meules et enfin battues à la main au cours de l'hiver suivant et jusqu'au printemps dans les granges ${ }^{22}$. La qualité des grains n'est pas altérée par ce processus récolte/battage car, cueillies avant la maturité physiologique, les céréales mûrissent lors du séchage à l'extérieur ou en grange. À cette période, il n'y a donc pas inadéquation entre les calendriers céréaliers et molinologiques. Le problème vient plus des mauvaises conditions, qui peuvent bloquer les moulins, rencontrées lors de la période hivernale (gel, neige, pluies abondantes), tout au long du XIX ${ }^{\mathrm{e}}$ siècle.

Si l'on y ajoute une insuffisance des approvisionnements, on trouve les raisons des crises frumentaires, avec des mois sous tension d'avril, mai, juin et septembre. Par la suite, la mécanisation, puis la motorisation transforment les systèmes de production et augmentent les rendements même si le calendrier agraire reste identique. Au fil du temps, toute la chaîne de production n'est plus contrainte aux mêmes exigences climatiques: les minoteries

19. Le myriamètre est une unité de mesure adoptée sous la Révolution. D'une valeur de dix mille mètres (10 km), elle correspondait à trois lieues.

20. P. Birée, «Les moulins de l'Alençonnais dans de nouveaux réseaux économiques lors de la guerre 1914-1918 », à paraître.

21. Arch. dép. Orne, 252 J 283, J. V. A. Lamagdelaine (dir.), Mémoires statistiques pour le département de l'Orne, t. 4, L'Agriculture, 1809.

22. Informations recueillies en 2014 auprès de Jean-Marie Taupin, agriculteur dans la plaine d'Alençon. 
deviennent moins dépendantes de l'énergie hydraulique car elles utilisent, la machine à vapeur, puis parfois le moteur à gaz pauvre, avant le moteur à huile lourde et enfin l'électricité. Les possibilités de stockage et de conservation sont accrues par la construction de grands silos en maçonnerie au début du XIX ${ }^{e}$ siècle. Ceci préfigure les nombreux silos de coopératives agricoles construits par la suite entre les deux guerres. Les contraintes liées au calendrier deviennent moins prégnantes par la suite. Les boulangers sont soumis eux aussi à tous ces aléas pour la fabrication et la vente de leur pain. Jusqu'à la fin du XIX siècle et à l'avènement des techniques et sources d'énergie nouvelles, cette vente peut être sous tension les mois de printemps et d'été à cause des augmentations.

Les agriculteurs, les meuniers et les boulangers forment des professions distinctes, mais ont forcément toujours travaillé en réseau. Leur intérêt n'a pas toujours été le même au fil des siècles, cependant la recherche de la qualité des produits devient encore plus une volonté commune au cours du $\mathrm{XX}^{\mathrm{e}}$ siècle. L'interaction entre ces trois parties est mise en avant lors d'une réunion interprofessionnelle, tenue en 1922 à Paris. Selon les propos de Paul Héroin, président du Syndicat de la Boulangerie Française :

«La boulangerie est heureuse de voir les meuniers étudier, de concert avec les agriculteurs, le moyen d'améliorer la qualité de leurs blés et de leurs farines, lesquelles donneront ainsi satisfaction au Boulanger et au Consommateur. $»^{23}$

$C^{\prime}$ est toujours une exigence actuelle au début du XXI siècle, comme l'exprime le site en ligne de la meunerie française ${ }^{24}$. L'évolution de la technologie et de l'architecture a, au fil du temps, permis aux professionnels de ce secteur d'être plus performants, tant en quantité qu'en qualité, mais aussi de s'affranchir des contraintes du calendrier. Outre la spatialité de leurs activités et de leurs liens qui a évolué, ce sont leurs relations de transitivité qui ont été transformées au fil des siècles. Sous l'Ancien Régime, il était interdit à un meunier d'exercer l'activité de boulanger et ils n'étaient pas directement liés à la production agricole. La vente des produits s'effectue de manière linéaire entre ces professions, souvent par l'entremise des blatiers et/ou des fariniers, dans le cadre du marché de la Halle-aux-Blés d'Alençon. Au cours de la seconde moitié du XIX $X^{\mathrm{e}}$ siècle, ces marchés deviennent plus libres, avant d'être régulés par les coopératives agricoles après le conflit de 1914-1918. Certains meuniers se procurent des terres pour produire leurs propres céréales. D'autres ont même leur propre boulangerie...

23. M. Arpin, Historique de la meunerie et de la boulangerie, depuis les temps préhistoriques jusqu'en 1914, t. 2, p. 291-294. 24. http://www.meuneriefrancaise.com/ Espace presse. 


\begin{abstract}
Résumé
L'actuel département de l'Orne, présentait un territoire autrefois plus industrialisé que de nos jours. La force hydraulique y actionnait les « usines », c'est-à-dire des moulins aux fonctions très diverses, surtout moulins à grains, moulins à fer, moulins à foulon, moulins à papier et moulin à tan. Les données sont les suivantes vers $1801-1802,587$ moulins à grain (88\% du nombre total), 46 moulins ou "tournants » des 16 sites sidérurgiques, 12 moulins à foulons, 12 moulins à papier et 11 moulins à tan. Chacun s'intégrait dans une chaîne technologique partant du produit brut (céréales, chiffons et tissus, écorce de chêne, tissus de laine, métal) au produit fini (farine, papier, tan, papier, étoffes de laine, fonte et fer). Toute une gamme de personnes, aux statuts et aux fonctions très différentes travaillaient en réseau, de la production à la distribution. Les plus nombreux des réseaux sont ceux des sites meuniers à farine : la production céréalière part des agriculteurs et au bout de la chaîne, les boulangers utilisent la farine pour confectionner le pain. Se constituent au fil du temps des trames plus ou moins complexes de maillage des territoires. L'exemple de l'Alençonnais est traité ici.
\end{abstract}

\title{
Bibliographie
}

ARPIN Marcel, Historique de la meunerie et de la boulangerie, depuis les temps préhistoriques jusqu'en 1914, tome 2, Paris, éd. Le Chancelier, 1948, Paris, 1948.

BIRÉE Patrick, «Les moulins de l'Alençonnais dans de nouveaux réseaux économiques lors de la guerre 1914-1918», La Normandie en guerre, Actes du 20 Congrès des Sociétés historiques et archéologiques de Normandie, 2015.

BIRÉE Patrick et CHAUSSAT Alain-Gilles, "L'enquête de 1809 sur les moulins : le cas de l'Orne", Eaux vives, eaux dormantes en Normandie, Actes du $18^{\mathrm{e}}$ Congrès des Sociétés Historiques et Archéologiques de Normandie, 2013, p. 195-210.

BRUNET Pierre, «Essai sur l'évolution de l'agriculture dans le département de l'Orne (18001940) », Agriculture et paysans dans l'Orne, Bulletin de la Société Historique et Archéologique de l'Orne, Tome CXX, n 3, septembre 2001, p. 5-20.

GAUTIER Jean-Jacques, Histoire d'Alençon, Alençon, 1806.

POMEREU Jean-Baptiste de, Mémoires sur la généralité d'Alençon, Alençon, 1698, édition présentée par Louis Duval dans son ouvrage, État de la Généralité d'Alençon sous Louis XIV, Alençon, 1890, p. 13.

Rivals Claude, Le Moulin et le meunier. Mille ans de meunerie en France et en Europe (préface de Jacques LE GOFF), Vol. 1 : Une technique et un métier. Roques-sur-Garonne, Empreinte Éditions, 2000. 


\section{Illustrations}

Figure 1 : Le réseau horizontal entre grain et pain au XIX ${ }^{\mathrm{e}}$ siècle.

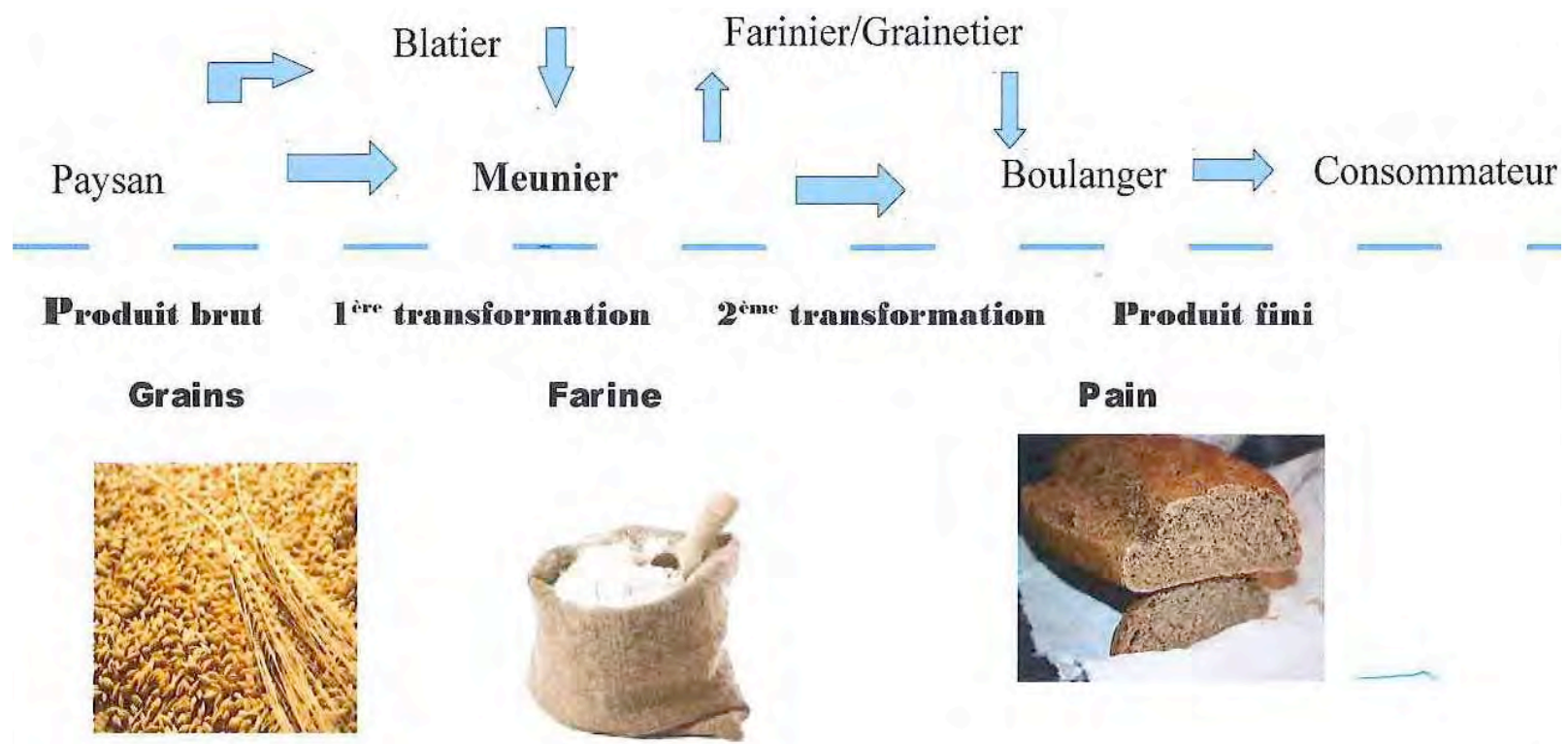

Figure 2: Quantité annuelle de blé moulu en quintaux pour les 22 moulins en activité dans les cantons Alençon-est et Alençon-ouest, année 1892, M 1640, Arch. dép. Orne.

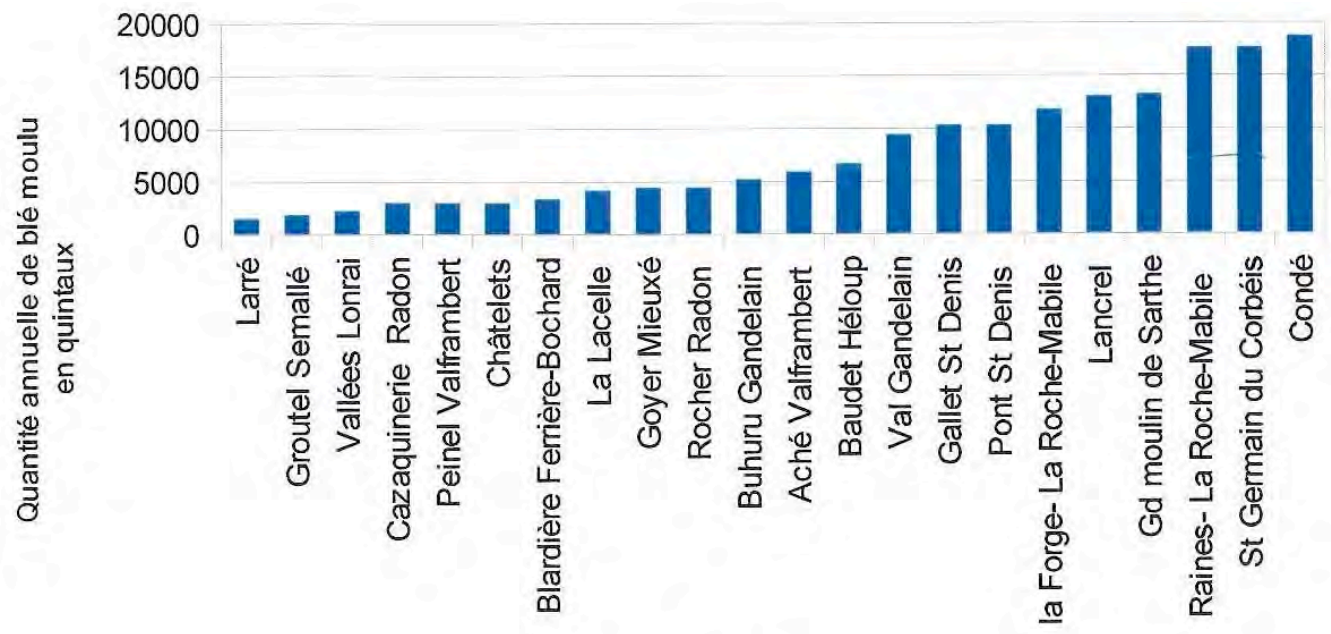

Moulins 
Figure 3 : Le calendrier annuel de la production au four du boulanger au cours du XIX ${ }^{\mathrm{e}}$ siècle.

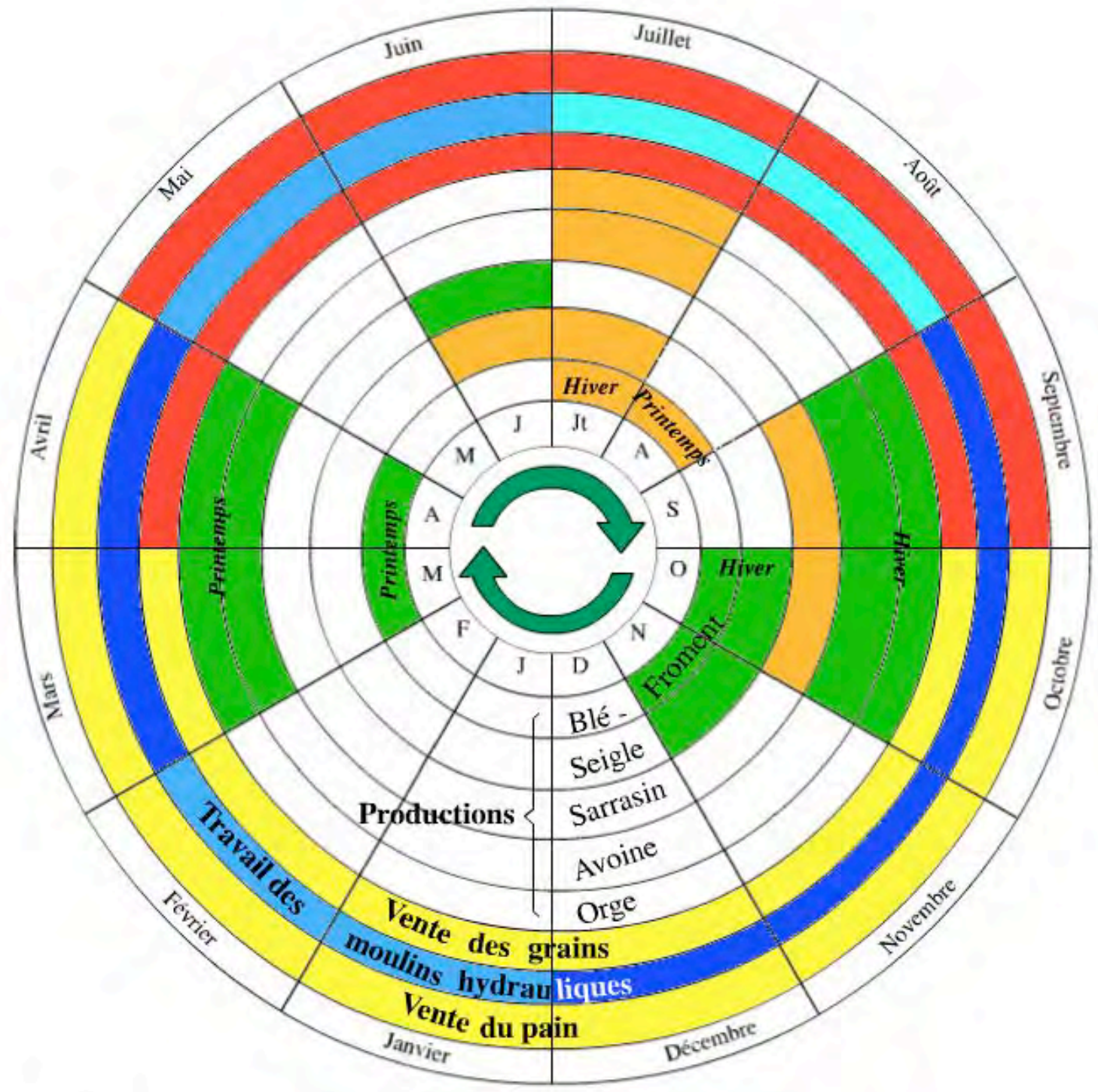

Légende :

Semis

Vente des grains

Travail des moulins hydrauliques

Vente du pain
Récolte

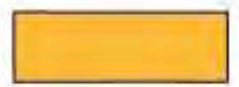

normale perturbẽe

optimal perturbé limité

normale perturbée 
Carte 1 : Aire d'approvisionnement du moulin de Saint-Germain-du-Corbéis.

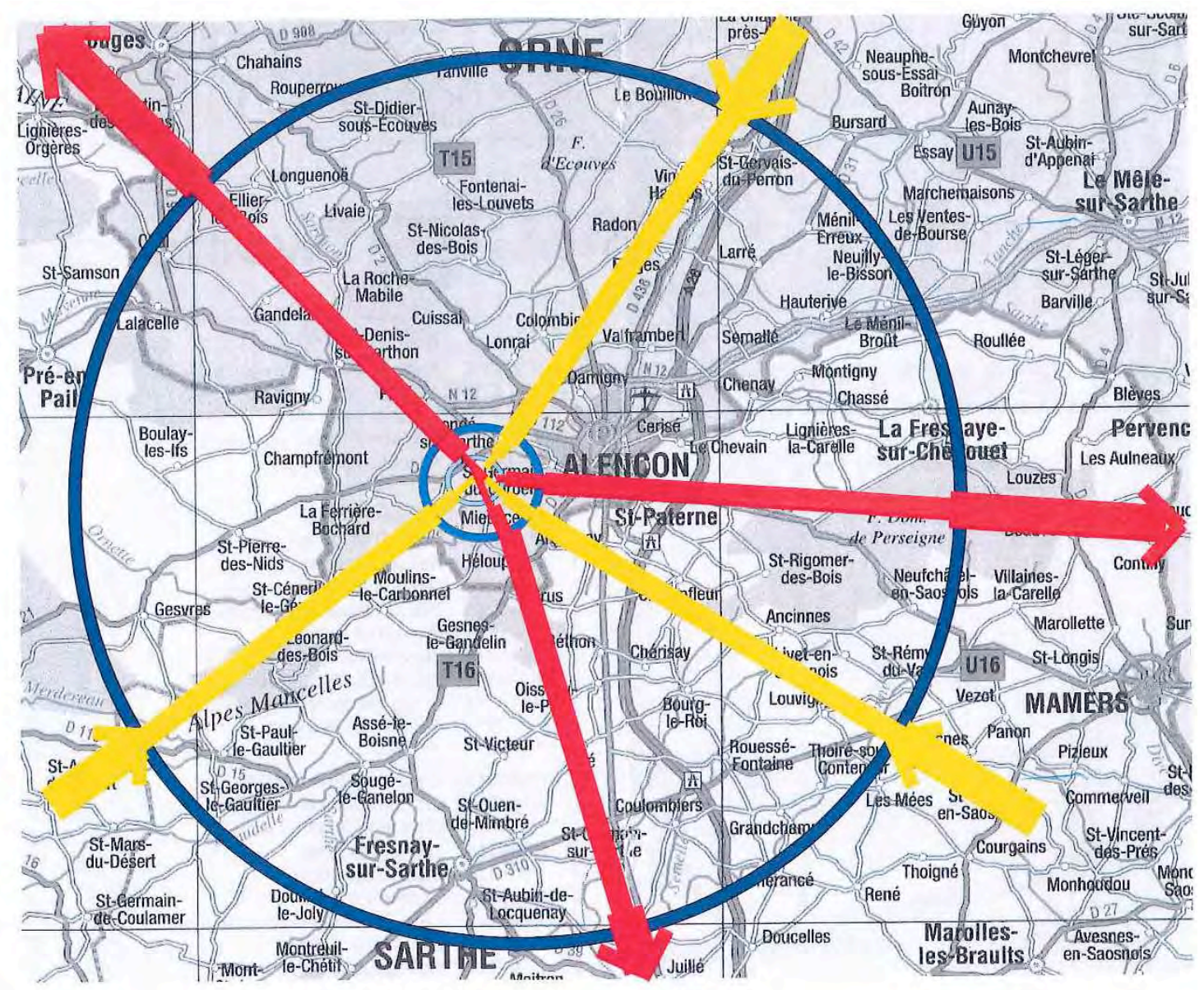

Légende:

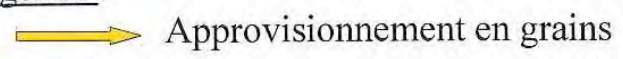

$\longrightarrow$ Vente des produits

Emprise du moulin aux XVIIIe et XIXe siècles

Emprise du moulin fin XIXe siècle - début XXe siècle

Emprise du moulin jusqu'au milieu du XXe siècle 
Carte 2 : Les moulins en 1809 dans les cantons d'Alençon (est et ouest).

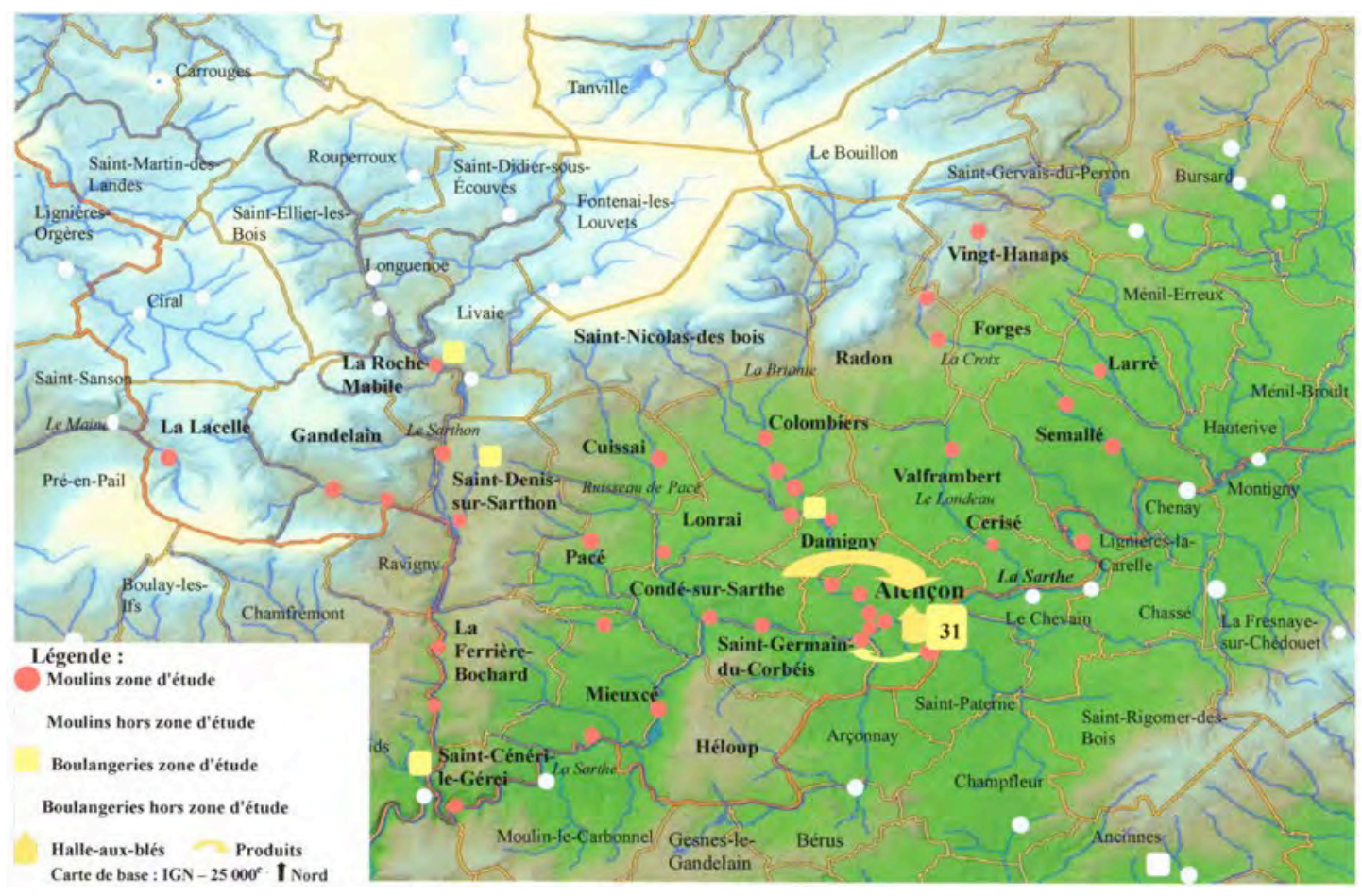




\section{Illustration}

Le moulin de Saint-Germain-du-Corbéis au début du XX⿳亠丷厂犬 siècle.

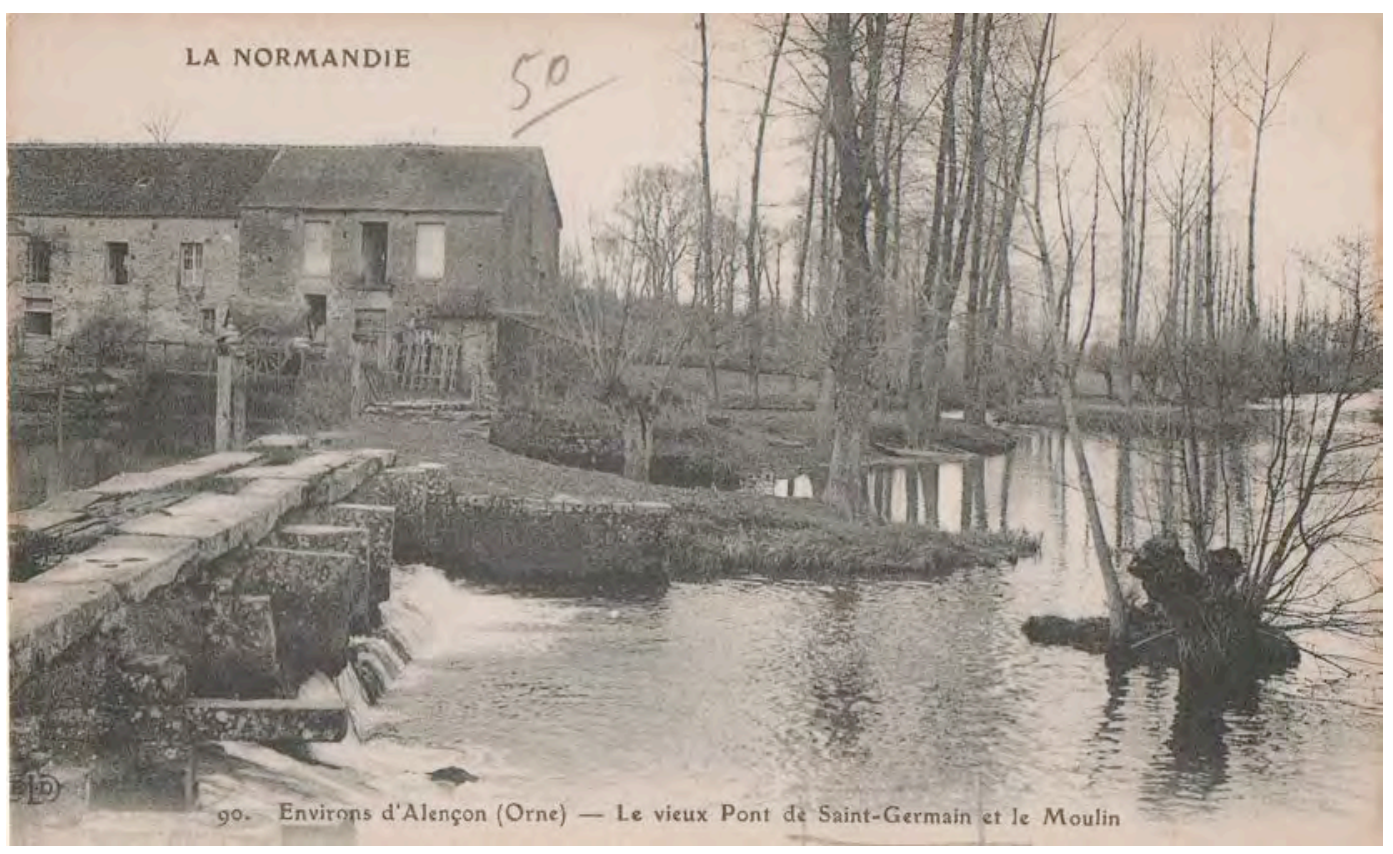

Photographies de la boulangerie Fortin à Radon au début du XX $x^{\mathrm{e}}$ siècle.

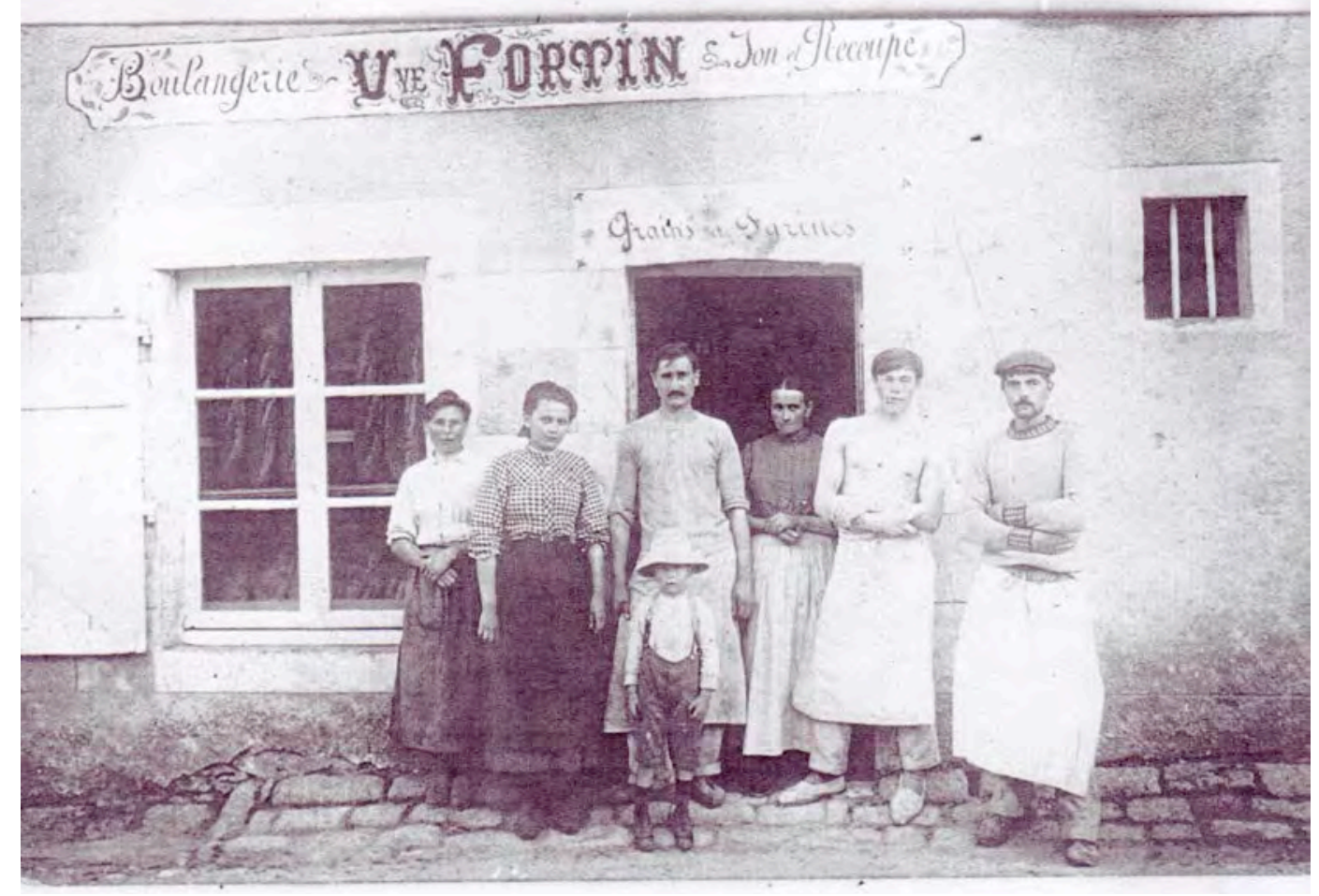


Au service de l'économie 


\title{
Reconstruire des réseaux d'affaires à partir de sources comptables: des exemples toscans (XIV ${ }^{e}-X V I^{e}$ siècles)
}

\author{
Ingrid HOUSSAYE MICHIENZI \\ Fellow à Villa I Tatti - The Harvard University Center \\ for Italian Renaissance Studies (Florence, Italie)

\begin{abstract}
Extrait de : Henri BRESC (dir.), Réseaux politiques et économiques, Paris, Édition électronique du CTHS (Actes des congrès des sociétés historiques et scientifiques), 2016.

Cet article a été validé par le comité de lecture des Éditions du CTHS dans le cadre de la publication des actes du $140^{\mathrm{e}}$ Congrès national des sociétés historiques et scientifiques tenu à Reims en 2015.
\end{abstract}

Le fonds Datini des archives de Prato et le fonds Salviati de la Scuola Normale Superiore de Pise, tous deux en Toscane, comptent parmi les plus riches fonds d'entreprises de la première modernité européenne. Ils permettent d'identifier et de caractériser d'importants réseaux d'affaires parcourant les espaces européen et méditerranéen de la fin du $X{ }^{\mathrm{e}}$ siècle au $\mathrm{XVI}^{\mathrm{e}}$ siècle. Les modus operandi apparaissent en effet très clairement dans les livres comptables, consentant la reconstruction des interactions entre compagnies d'affaires florentines et la mise en lumière des opérateurs des places commerciales où les marchands florentins étaient implantés.

Si l'étude des comptabilités d'entreprise aux époques préindustrielles est aujourd'hui un peu plus répandue qu'elle ne l'a été, cette branche de l'histoire économique reste encore très peu fréquentée. L'analyse de la documentation d'entreprise et en particulier des comptabilités a longtemps été l'apanage d'un petit nombre d'érudits, en particulier de médiévistes, qui produisirent sur quelques documents, voire quelques fonds, des monographies encore aujourd'hui classiques ${ }^{1}$. Écrites avec rigueur et fondées sur un grand nombre de sources, ces études visaient notamment à mettre en avant le rôle des élites entrepreneuriales dans la modernisation de l'économie européenne et la " naissance du capitalisme ». Plus récemment, la question a été renouvelée à travers des recherches centrées davantage sur le fonctionnement des places et des réseaux d'affaires. Des auteurs tels Pierre Jeannin sur les villes germaniques, Reinhold Mueller sur les réseaux vénitiens ou Richard Goldthwaite sur l'économie florentine, ont donné un nouveau souffle à l'utilisation de la documentation comptable. L'emploi de telles sources, qui nécessite l'acquisition préalable d'un savoir-faire technique, contribue pour beaucoup à une meilleure connaissance de l'organisation des mouvements commerciaux et financiers. Grâce à l'analyse fine de corpus déterminés, il est effectivement possible d'observer comment des réseaux de marchands locaux, régionaux et internationaux pouvaient s'emboîter, s'articuler, se superposer et se réorganiser.

Les registres de comptes, à la fois produit et témoignage des pratiques marchandes, sont à replacer dans des espaces construits et articulés. Divers exemples concrets, issus de l'étude minutieuse de livres de comptes des fonds Datini et Salviati, démontreront ainsi l'efficacité de leur usage et permettront de prendre la mesure du lien étroit entre comptabilités d'entreprise et reconstruction de réseaux marchands.

1. Voir les travaux d'Armando Sapori, Tommaso Zerbi et Edwin S. Hunt sur les compagnies des XIII ${ }^{\mathrm{e}}$-XIV ${ }^{\mathrm{e}}$ siècle, Yves Renouard sur les relations avec la Papauté, Federigo Melis sur le fonds Datini, Raymond De Roover sur les compagnies Médicis ou Aloys Schulte sur la Grande Compagnie de Ravensburg. Les références figurent dans la bibliographie. 


\section{Les fonds Datini et Salviati : fonctionnement et apport des comptabilités toscanes à partie double}

Les fonds Datini et Salviati sont des archives d'entreprise, c'est-à-dire que la documentation conservée résulte de la production écrite des entreprises industrielles, commerciales et bancaires. Parmi les outils de gestion, deux grandes catégories émergent: les correspondances et les comptabilités. C'est sur ces dernières que j'orienterai mon propos.

Le fonds Datini ${ }^{2}$ est lié à la carrière d'un individu, Francesco di Marco Datini (v. 13351410), et couvre les années 1360-1420. Riche d'environ 150000 lettres $^{3}$ et 600 registres de comptes, il témoigne de l'étendue des activités d'un marchand impliqué à la fois dans les secteurs industriels, bancaires et commerciaux. Il démarra ses activités à Avignon, puis après son retour en Toscane en 1382, il les développa à Prato (sa ville natale), à Pise, à Florence et à Gênes. Les années 1390 virent le déploiement de ses activités dans le bassin méditerranéen, notamment dans l'aire ibérique à travers l'implantation de filiales à Barcelone, Valence et Majorque ${ }^{4}$. Toutes les filiales étaient indépendantes; seule la personne de Francesco Datini les réunissait puisqu'il était l'associé majoritaire de chacune d'entre elles. Si elles avaient tendance à coopérer davantage les unes avec les autres, elles fonctionnaient néanmoins entre elles comme avec d'autres entreprises florentines. Elles prélevaient en effet les mêmes frais de commission.

Le fonds Salviati ne correspond pas au même type de structure. Il contient des milliers de livres comptables et documents issus également d'activités industrielles, bancaires et commerciales, écrits du XIV ${ }^{\mathrm{e}}$ siècle au XVII ${ }^{\mathrm{e}}$ siècle. Cependant, les documents qu'il contient ne sont pas le résultat des activités d'une unique entreprise établie, à travers des filiales, dans la majorité des places commerciales dynamiques de ce temps. Ces 3000 registres sont issus de comptabilités personnelles ou de compagnies créées par des membres de la famille Salviati, une éminente famille du patriciat florentin. Il s'agit davantage d'une nébuleuse, parcourant les espaces européen et méditerranéen, du nord au sud et d'est en ouest, sans que les liens organiques entre les différentes compagnies apparaissent clairement ${ }^{5}$.

Ces deux fonds présentent toutefois des organisations comptables similaires à travers une grande diversité de livres dédiés à différents types d'enregistrement. Il s'agit tout d'abord de comptabilités à partie double qui existaient ainsi bien avant leur codification par Luca Pacioli dans son traité de comptabilité (Summa de arithmetica, geometria, proportioni e proportionalità) paru à Venise en 1494. Cet ouvrage, qui compilait les savoirs en la matière des marchands de son temps, fut à l'origine de la diffusion de cette technique comptable dans $1^{\prime}$ Europe marchande ${ }^{6}$. La notion de partie double implique que chaque écriture dans un compte doive trouver une contrepartie symétrique dans un autre compte. De fait, tout montant porté en comptabilité sera transcrit deux fois: une première fois au débit d'un compte et une seconde fois au crédit d'un autre compte. Ce principe permet d'assurer l'équilibre des opérations comptables puisque tout montant

2. Au sujet du fonds Datini, voir entre autres B. Dini, «L'Archivio Datini » ; J. Hayez, « L'Archivio Datini, de l'invention de 1870 à l'exploration d'un système d'écrits privés ».

3. Celles-ci sont intégralement numérisées et disponibles librement sur le site des archives de Prato: http: / / datini.archiviodistato.prato.it

4. Pour de plus amples détails voir I. Houssaye Michienzi, Datini, Majorque et le Maghreb (XIV -XV siècles). Réseaux, espaces méditerranéens et stratégies marchandes.

5. Ce fonds d'archives est actuellement mis en valeur par une équipe de chercheurs réunis dans le programme ANR ENPrESa: Entreprise, Négoce et Production en Europe (XIV $-X^{\mathrm{e} V I}{ }^{\mathrm{e}}$ siècles). Les compagnies Salviati. http:/ / salviati.hypotheses.org

6. La référence en la matière est Raymond De Roover, notamment « Aux origines d'une technique intellectuelle : la formation et l'expansion de la comptabilité à partie double ». Divers travaux permettent actuellement de situer l'origine de la partie double en Toscane, à la fin du XIII ${ }^{\mathrm{e}}$ siècle. Voir à ce sujet: T. Zerbi, Le origini della partita doppia, ou A.C. Littleton, B.S. Yamey (ed.), Studies in the History of Accounting. 
crédité sur un compte devra être compensé par un mouvement identique au débit d'un autre compte. Dans les comptabilités toscanes des $\mathrm{XIV}^{\mathrm{e}}-\mathrm{XVI}^{\mathrm{e}}$ siècles, le grand livre (nommé libro mastro, libro grande ou libro debitori e creditori) réunissait ainsi les écritures de synthèse qui étaient l'aboutissement d'une chaîne comptable particulièrement complexe. En effet, les agents florentins multipliaient les écritures préparatoires, le plus souvent enregistrées de manière quotidienne. Les journaux (giornali) consignaient ainsi les opérations au jour le jour, avant que celles-ci ne soient reportées au débit et au crédit dans le grand livre.

L'exemple des figures 1 à 3 (Figure 1: Journal-vente de draps de laine à Samuello (Ismael), le 31 octobre $1491^{7}$, figure 2 : Grand livre - Opération en débit dans le grand livre $^{8}$, figure 3: Grand livre - Opération en crédit dans le grand livre ${ }^{9}$ ) est issu de registres tenus à Constantinople entre 1491 et 1493, et conservés dans le fonds Salviati.

Dans le registre intitulé Giornale e Ricordi, Giovanni Salviati inscrit les activités quotidiennes (giornale) et les aide-mémoire (ricordi). L'information enregistrée était écrite une nouvelle fois dans le grand livre qui contenait les comptes de personnes ou de marchandises ayant contracté une dette ou un crédit. Des références indiquant les pages de l'autre registre figurent dans les deux livres: dans la marge gauche sous la forme d'une fraction dans le journal (dans le cas présent : 2/3), et dans le texte à l'intérieur du grand livre. Ceci permettait et permet encore une circulation facile entre les livres comptables.

Ainsi, l'information se référant à une vente de draps de laine à un Turc nommé Samuello (Ismaël) est écrite une première fois dans le journal, au moment de la vente, et plus tardivement, deux autres fois dans le grand livre : page 2 pour le débiteur (Ismaël) et page 3 pour le créditeur (les draps de laine ou panni di garbo). Les écritures étaient ensuite biffées pour indiquer qu'elles étaient closes et que le paiement avait été effectué.

Les livres d'écritures préparatoires pouvaient se multiplier de manière très importante. La liste des registres comptables de la filiale Datini de Majorque, pour une quinzaine d'années d'exercice (1396-1411), est impressionnante. Le fonds contient en effet neuf grands livres, sept livres de recettes et dépenses (entrata e uscita), six mémoriaux (memoriali), quatre cahiers concernant les remises en mains propres de paiements comptants et autres dépenses liées au fonctionnement du comptoir majorquin, un cahier de caisse, dix cahiers listant les réceptions et envois de marchandises ainsi que les divers frais attenants, deux cahiers dédiés aux achats de laine, quinze cahiers voués aux analyses financières.

Il s'agit donc de 54 livres conservés, chacun ayant une fonction précise dans l'enregistrement des opérations. Huit catégories émergent, allant des frais de bouche des agents aux analyses financières des exercices comptables. Les livres renvoient souvent les uns aux autres par des jeux d'écriture constants. De fait, le seul moyen de comprendre réellement les opérations est de cumuler les indications contenues dans les différents registres. De manière générale, les livres les plus ciblés sur une activité précise sont ceux qui offrent le plus de détails. Plus l'information remonte vers le grand livre, plus celle-ci est synthétisée. Par conséquent, seul un jonglage permanent entre les registres, grâce aux renvois internes, consent à glaner le maximum d'informations. Les deux exemples suivants permettront une véritable illustration de l'utilisation possible de sources complexes, d'apparence aride, pouvant rebuter les chercheurs peu enclins à se pencher

7. Scuola Normale Superiore di Pisa, Archivio Salviati (désormais Salviati), série I (désormais I), 398, Giornale, fol.2g. : " † 1491, † a dì 31 d'otob(r)e. 2/3. Fa debitore Samuello, turcho, stiavo fu di Chairadin(n)o, e creditore pan(n)i di rag[i]one di Franc(esc)o di Gherardi da asp. 22140 ; sono p(er) lla soma di pan(n)i 18 di gharbo bagniati e cinati ; te(m)po mesi 3, paghato i(n) 5, c[i]oè 10 tt(urchin)i, 3 v(er)deb(r)un(n)i, 2 paonazi, 3 festichin(n)i ; montano asp. 22140 ».

8. Salviati, I, 397, Debitori e Creditori, fol.2g. : « † 1491. Samuello, turcho, stiavo fu di Chairadin(n)o, botteghaio i(n) Andrinopoli, de' dare, a dì 31 d'ottobre asp. ve(n)tiduemilacie(n)toquara(n)ta ; sono p(er) lla mo(n)ta di pan(ni) dic[i]otto, te(m)po mesi 3, paghati i(n) 5, di rag[i]one du Franc(esc)o Gherardi ; posto pan(ni) av(er)e i(n) q(uest)o c.3, al g[i]ornale c.2. asp. $22140 »$.

9. Salviati, I, 397, Debitori e Creditori, fol.3d. «† 1491. 18 pann(i) di gharbo di rag[i]one di Franc(esc)o di Gherardo Gherardi deono av(er)e a dì 31 d'ott[o]b(r)e asp. 22140 ; sono p(er) lla mo(n)ta di pan(ni) 18 vie(n)duti a Samuello p(er) asp. 1230 peza ; posto Samuello dare i(n) q(uest)o c.2 asp. 22140 ». 
sur ces séries sans fin de chiffres et de noms. Leur analyse lève pourtant le voile sur les différentes mains, les points de contact et les acteurs des réseaux d'affaires déployés par les marchands florentins, et éclaire d'un jour nouveau l'histoire économique mais aussi sociale de ce temps.

\section{Le fonds Datini de Majorque : la mise à jour d'un réseau d'intermédiaires commerciaux}

L'implantation de la compagnie Datini dans l'île de Majorque répondait à plusieurs objectifs. Elle consistait tout d'abord à se positionner sur une plateforme d'échanges dynamique et multiscalaire : l'île était une étape de circuits de navigation se rendant en Flandre, en Italie et même au Levant, en plus d'être un point important d'un trafic régional entre les côtes ibériques, africaines et baléares. Un second objectif était celui de pénétrer les marchés africains. Cependant, la concurrence dans ce domaine était rude et les marchands majorquins ne voyaient pas d'un bon œil l'arrivée de ces négociants florentins. Réunis au sein de ligues, ils cherchaient à monopoliser le trafic entre l'île de Majorque et les côtes du Maghreb central et occidental ${ }^{10}$. Confrontés à des mesures protectionnistes, les agents de la compagnie, qui ne purent jamais directement mener des opérations en Afrique, durent envisager des solutions et recourir à des intermédiaires.

En apportant l'enregistrement de chaque opération commerciale réalisée, la comptabilité dévoile la considérable importance des intermédiaires juifs - majorquins et nordafricains - et des juifs convertis, responsables d'environ $65 \%$ à $70 \%$ des opérations réalisées par la compagnie Datini et qui engageaient des produits expédiés au Maghreb ou bien en provenant. Dès 1396, au moment où la compagnie de Majorque prend son envol à travers sa propre comptabilité, elle achetait déjà la plupart des produits africains à des juifs ou des nouveaux chrétiens de Majorque. Ainsi, en janvier, la compagnie acheta 2070 plumes d'autruche au nouveau chrétien Giame di Sportelg pour le compte des compagnies Datini de Gênes et de Florence ${ }^{11}$. Le premier intermédiaire juif apparaît en juillet de cette même année : il s'agit de Davit Cohen, un juif d'Alger, qui échangea alors un drap de laine contre du fil de chaîne ${ }^{12}$. De telles références sont présentes massivement dans les livres de comptes de la compagnie durant la totalité de son existence.

Ces réseaux s'étendaient de part et d'autre de la Méditerranée et s'étaient intensifiés suite aux émeutes anti-juives de 1391 qui avaient entraîné, en plus des conversions forcées, un important flux migratoire des juifs majorquins vers l'Afrique du Nord et en particulier vers Tlemcen. Les juifs exilés, maintenant d'étroits liens familiaux et financiers avec les juifs majorquins restés sur place et avec les conversos (nouveaux chrétiens), permirent un renforcement des contacts, car les juifs étaient alors les meilleurs connaisseurs des itinéraires maghrébins. Beaucoup de familles juives étaient réparties entre Majorque et le Maghreb et leurs membres effectuaient de nombreux voyages entre les deux rives ${ }^{13}$.

Par ailleurs, les juifs de Majorque, tout comme les nouveaux chrétiens, étaient intégrés aux ligues qui contrôlaient les transports entre l'île et l'Afrique, et vendaient à la compagnie Datini des biens qu'ils avaient pris soin d'acquérir au Maghreb, à l'exemple de l'opulent marchand Astruch Xibili. Un grand nombre d'entre eux avait fondé des compagnies de commerce qui duraient quelques années tout au plus, regroupaient les

10. Voir à ce sujet I. Houssaye Michienzi, « Relazioni commerciali tra la compagnia Datini di Maiorca e le città del Maghreb alla fine del Trecento ».

11. Archivio di Stato di Prato (désormais ASPo), fonds Datini (désormais D.) 886, 113524, lettre/extrait de compte Majorque-Barcelone, Ambrogio di Rocchi à comp. Datini et Luca del Sera, 02/01/1396.

12. ASPo, D.666, 410202, lettre/extrait de compte Majorque-Florence, comp. Datini et Cristofano di Bartolo à comp. Lorenzo di Cresci, 03/07/1396.

13. Voir I. Houssaye Michienzi, «Entre Majorque et l'Afrique : configuration de l'espace et réseaux juifs d'après des sources commerciales italiennes ». 
deux caractéristiques majeures de la commenda, soit le travail et le capital, organisaient pour la plupart une division des bénéfices proportionnelle au capital, et avaient à leur tête un directeur possédant un salaire fixe ou une rétribution liée à un pourcentage sur les bénéfices ${ }^{14}$. Les associations de part et d'autre de la Méditerranée étaient nombreuses. Ainsi le converso Pere Pardo gérait différentes compagnies opérant en Afrique du Nord, à Bône, Tenès, Honein, Alcudia et Fès. Il possédait également quelques facteurs à Collo (Miquel Borrás), Tunis (Francesc Pardo), Bougie (Jacob Albó) et constitua une société avec Ayon Sciyari qui focalisait ses opérations sur Honein et Tenès. Ce même Pere Pardo procura à la compagnie Datini de Majorque, de 1397 à 1411, près de 250 cantares de cire, environ 12300 plumes d'autruche et 58 fasci de cuirs et de peaux, soit à peu près 580 peaux.

La comptabilité permet d'identifier ces intermédiaires et d'évaluer leur poids. Ils n'apparaissent que par leur nom dans les grands livres, avec tout au plus, un qualificatif indiquant une appartenance religieuse : juif (giudeo) ou nouveau chrétien (cristiano novello ou converso). Toutefois, grâce aux renvois présents dans le grand livre, il est possible de remonter jusqu'aux écritures préparatoires, qui sont plus bavardes. Elles indiquent l'appartenance religieuse, mais parfois également les liens de parenté ou d'affaires (fils de, frère de... ou travaillant avec untel), l'occupation professionnelle, l'origine géographique (juif d'Alger, juif d'Honein...) ou le lieu de résidence (nom de la paroisse ou du quartier). Ces écritures donnent aussi la date précise de l'opération et son déroulement, consentant à relever la fréquence et la régularité des contacts. Il existe également pour Majorque un type de registre très particulier, contenant les attestations de remise en mains propres d'argent comptant, et où émerge une pluralité linguistique. Le marchand, juif ou converti, écrivait dans la boutique du négociant florentin, au sein d'un registre tenu par la compagnie, avoir reçu une certaine somme d'argent. L'écriture de sa propre main conférait une valeur juridique au document. De fait, le marchand s'exprimait par écrit dans sa propre langue (le plus souvent arabe ou hébreu, parsemé de catalan) en utilisant la plupart du temps des caractères hébraïques ${ }^{15}$. Un résumé en toscan figurait en général sous chacun de ces témoignages. Ces mentions, toutes datées, attestent de contacts réguliers et quotidiens entre ces groupes de marchands juifs, convertis et florentins.

Éplucher les comptes de la compagnie de Majorque permet ainsi de mettre en lumière une foule d'intermédiaires eux-mêmes organisés en réseaux d'affaires pouvant relier l'île de Majorque aux marchés du Sahel. La comptabilité ne livre toutefois que la strate supérieure des opérations: celle de l'achat par les Florentins de marchandises ayant parcouru parfois des milliers de kilomètres depuis leur lieu de récolte ou de production à travers le trafic caravanier ${ }^{16}$. L'exemple suivant, issu de registres du fonds Salviati, consent cette fois-ci à suivre l'itinéraire d'une cargaison de marchandises du lieu de fabrication à celui de la vente, c'est-à-dire dans ce cas précis de Florence à Constantinople.

14. Voir M. D. López Pérez, La Corona de Aragón y el Magreb en el siglo XIV (1331-1410) essentiellement le chapitre 7, au sujet des compagnies de commerce majorquines.

15. Voir I. Houssaye Michienzi, J. Olszowy-Schlanger, «Écrits comptables et commerce interreligieux : les cas des registres d'Ugo Teralh de Forcalquier et de la compagnie Datini (XIVe-XV siècles) ».

16. Voir par exemple : I. Houssaye Michienzi, « Le commerce des plumes d'autruche de l'Afrique subsaharienne aux marchés européens ». 


\section{Le fonds Salviati: le suivi d'une cargaison de tissus des ateliers de Florence au Bazar de Constantinople}

Le fonds Salviati conserve les trois seuls registres de comptes tenus par des marchands florentins à Constantinople que nous connaissons à ce jour. Giovanni di Marco Salviati tint la comptabilité d'octobre 1491 à août 1493. Il tomba ensuite malade et mourut de la peste en novembre 1493. Deux de ces registres fonctionnent ensemble: le premier, nommé Giornale e Ricordi, contient les écritures préparatoires du second, un grand libre qui comprend les comptes des débiteurs et des créditeurs (Debitori e Creditori). Le troisième registre, également de type Debitori e Creditori, fut tenu de mars à août 1493. Il contient, en plus de comptes de personnes, de marchandises et de gestion, des listes d'articles réceptionnées pour le compte d'Alfieri Strinati, un marchand florentin. À partir d'une liste de 160 pièces de draps de laine, il est possible de remonter jusqu'à la comptabilité des ateliers florentins et de connecter ainsi les ateliers de production, les entreprises commerciales, la circulation des marchandises, leur réception et leur vente à Constantinople.

La liste des draps de laine réceptionnés à Constantinople concerne l'envoi de 160 draps expédiés en 40 balles $^{17}$. Chaque balle, possédant un numéro (de 1 à 40 ) et un intitulé se référant à la qualité du drap expédié, contenait quatre draps. Pour chacun d'entre eux étaient décrits la couleur, le fabricant et les mesures. L'expéditeur de ces produits textiles était la compagnie commerciale d'Alamanno di Averardo et Iacopo di Giovanni Salviati, établie à Florence.

Les livres de comptes de la compagnie d'Alamanno et Iacopo Salviati sont également conservés dans le fonds Salviati. Un registre, intitulé Giornale e ricordanze. G., couvrant les années 1490-1492, fait également mention de ces draps de laine, dans sa dernière section.

Ce registre est en effet divisé en cinq sections : le journal (giornale) où sont enregistrées les opérations au quotidien, les remises d'argent comptant (denari rimessi), les rappels de lettres de change envoyées ou reçues (lettere di cambio mandate e ricevute), les copies de comptes expédiées (ricordanze di partite), la liste des marchandises reçues ou expédiées (robe mandate e ricevute).

Dans cette dernière section figure le legaggio ${ }^{18}$, c'est-à-dire l'inventaire précis des marchandises expédiées, que Giovanni Salviati aura pris soin de recopier dans son livre de debitori e creditori. La liste de Constantinople fut rédigée au moment de la réception, en 1493, mais indique l'année de l'expédition, c'est-à-dire 1492. La liste de Florence est plus explicite, puisqu'elle informe de la date de l'envoi effectué le 16 octobre 1492. Si l'on se penche ensuite sur la partie Giornale de ce même livre, dont les enregistrements comptables sont réalisés de manière chronologique, une deuxième liste concernant ces envois figure à la date du 16 octobre $1492^{19}$. Cette seconde liste diffère de la première puisqu'il s'agit d'un compte énumérant le coût de 165 draps achetés et les frais engendrés (conto di costo e spese di panni). Les draps sont cette fois-ci rangés par fabricant et la liste des frais est reportée à la fin. Pour chacun sont indiqués les mesures et le coût. Cette même liste figure également dans le même registre de Constantinople ${ }^{20}$. Les deux comptes indiquent des achats de 165 draps réalisés entre le 20 août et le 12 octobre 1492 et sont complètement identiques, à l'exception d'une ou deux fautes de copie réalisées certainement par Giovanni Salviati lorsqu'il reproduisit ce compte dans son registre. Ce sont les mêmes draps contenus dans le legaggio qui figurent dans cette liste mais les indications concernant les couleurs, les mesures et les fabricants sont plus détaillées dans

17. Salviati, I, 399, Constantinople, Debitori e creditori, fol. 100 d. à $101 \mathrm{~d}$.

18. Salviati, I, 363, Florence, Giornale e ricordanze .G., fol. $238 v^{\circ}$ à $240 r^{\circ}$.

19. fol. $112 \mathrm{v}^{\circ}$ à $113 \mathrm{v}^{\circ}$ : «† A dì XVI d'ottob(r)e. Chopia d'un chonto mandato i' Levante a Alfieri Strinati ».

20. fol. $99 \mathrm{~g}$. à $100 \mathrm{~g}$. 
le legaggio. Les informations peuvent également différer, notamment en ce qui concerne des couleurs perçues comme très proches comme sbiadato/turchino, deux nuances de bleu. Néanmoins, à l'exception de huit d'entre eux, il est possible de recoller les deux listes et de constater que plusieurs artisans disparaissent de la comptabilité finale. Certains artisans, certainement de plus faible envergure, vendirent directement leur production à d'autres artisans qui étaient en contact avec les grandes compagnies d'affaires et agissaient en tant qu'intermédiaires. Par exemple, Francesco da Barberino vendit à la compagnie commerciale Salviati de Florence, en plus des siens, 13 autres draps de laine qui, dans les inventaires, apparaissent comme ayant été fabriqués par Domenico del Milanese.

Parmi ces draps, 160 étaient à vendre sur le marché de destination et cinq étaient destinés au conditionnement (per involtura); c'est la raison pour laquelle seuls les 160 draps à vendre figurent dans les legaggi de Florence et de Constantinople. Grâce aux répertoires alphabétiques figurant dans les grands livres ${ }^{21}$, aux renvois contenus dans les différents comptes et à de multiples allers retours entre les registres, il est possible de remonter les opérations qui ont précédé l'envoi de ces draps à Constantinople. La compagnie commerciale Salviati de Florence réalisa ses achats de draps auprès de différents artisans de Florence issus de l'Arte della Lana (art de laine) ou de celle de la Tinta (art de la teinture). Ils achetèrent tout d'abord, le 20 août, 42 draps de qualité moyenne à Francesco d'Antonio da Barberino e comp. lanaioli nella via del Palagio pour un montant de 874 fiorini larghi. Puis, les 14 et 15 septembre, ils achetèrent deux draps pour emballer les marchandises: un à Giovanni di Battista da Genova, pour 13 fiorini larghi payés comptants $^{22}$, et un autre à Lorenzo di Stefano Masolini e comp. tintori, pour 12,5 fiorini larghi, également payés comptants. Le 11 octobre, ils firent l'acquisition de 8 draps à l'héritier de Matteo di Michele pour 124 fiorini larghi, et le jour suivant, de deux draps grossiers (corsivi) à Ristori d'Alexandro e comp. lanaioli. La plus importante quantité de draps fut achetée à la compagnie d'Averardo et Giovanni Salviati, lanaioli étant à la fois impliqués dans la production du drap de haute qualité réalisé à partir de laines anglaises (dit San Martino) et de panni di garbo, de qualité inférieure, à travers leur atelier de la via del Palagio. Ils étaient les cousins germains des acheteurs et vendirent 111 draps pour un montant de 3 143,5 fiorini larghi. Grâce à la documentation de cette compagnie artisanale, également conservée dans le fonds Salviati, il est possible de trouver la trace de cette vente dans leur grand livre, au débit de la compagnie commerciale d'Alamanno et Iacopo $^{23}$, mais on ne peut remonter davantage la production puisque le journal et les ricordanze ne sont pas conservés, tout comme les livres concernant les ouvriers.

À la fin de la liste d'achats dans le compte concernant les draps de laine figure également la liste de frais pour un montant total de 285 fiorini larghi: un florin pour laver les draps (lavatura di panni), 27 florins et demi pour en teindre une partie (tintura di panni), 50 florins pour les couper et leur donner une apparence uniforme (governatura e cimatura di panni), un florin et demi pour marquer 136 d'entre eux (marchiatura di panni 136), 22 florins pour acheter des bandelettes (bandinelle 160), quatre florins et demi pour les conditionner en quarante balles (legatura di balle 40), 38 florins et demi pour les taxes (gabella di panni), 140 florins pour les expédier jusqu'à Lecce, dans les Pouilles (vettura di qui a Leccio), en Italie du Sud.

Dans les registres de Constantinople, il est possible de trouver la référence à un autre compte écrit toujours dans le même registre, donnant des précisions quant au trajet effectué. Le 26 mars 1493, une copie d'un compte envoyé aux marchands florentins (la compagnie commerciale d'Alamanno et Iacopo Salviati), fait état des frais de Dimitri présenté comme nostro garzone in Pera, et qui devait certainement travailler pour le compte de Giovanni Salviati. Il voyagea jusqu'à Lecce chercher la marchandise et fit

21. Les grands livres sont le plus souvent accompagnés de répertoires alphabétiques où les personnes disposant d'un compte apparaissent. A côté de leur nom figurent les numéros des pages les concernant.

22. Le drap fut enregistré payé en argent comptant c'est-à-dire qu'aucun compte ne fut ouvert au nom du créditeur.

23. Salviati, I, 424, Florence, Debitori e creditori .CC., fol. $58 \mathrm{~g}$. 
l'itinéraire en sens inverse, de Lecce à Pera en effectuant plusieurs étapes : trajet maritime de San Cataldo (près de Lecce) à Valona (Vlora, Albanie), puis terrestre avec un convoi de 24 chevaux en passant par Kastoria (Macédoine) et Andrinople (Edirne) jusqu'à Constantinople ${ }^{24}$.

Si le compte concernant les frais de Dimitri a été rédigé dans le livre de Giovanni Salviati le 26 mars, les tissus ne peuvent être arrivés après cette date. Ce même registre, dont l'intitulé est exactement Questo libro è di Giovanni di Marcho Salviati in sul quale si ter rà co $n$ to di robe man date di Fi ren ze $p$ er Alfieri Strinati, est organisé sous la forme débiteurs / créditeurs et contient des ventes de draps de laine et de tissus effectuées entre le 29 mars et le $1^{\text {er }}$ juillet 1493 qui se rapportent aux importations depuis Florence. Le registre est en effet complètement dédié à ces marchandises : d'un côté les comptes en débit et en crédit des différents acheteurs, de l'autre les legaggi et les comptes concernant les envois depuis Florence. Le registre recense la vente de 87 panni sopramani, 33 panni bastardi, 24 panni corsivi, 5 panni garbi sans précision, 7 panni sanmartini, soit au total 156 draps de laine de différentes qualités pour un montant de 153256 aspres ; soit environ 2947 ducats. Le tableau ci-dessous (tableau 1) récapitule les ventes effectuées, les acheteurs et les prix.

\begin{tabular}{|c|c|c|c|}
\hline $\begin{array}{l}\text { DATE } \\
(1493)\end{array}$ & ACHETEUR & MARCHANDISES & $\begin{array}{l}\text { PRIX (asp./duc.) } \\
\text { total et unitaire }\end{array}$ \\
\hline 29 mars & $\begin{array}{l}\text { Baba e Iacupe di Iusefe } \\
\text { Juifs }\end{array}$ & 20 panni sopramani & $\begin{array}{l}30800 / 592 \\
1540 / 30\end{array}$ \\
\hline 2 avril & $\begin{array}{l}\text { Sofi Mecomedi } \\
\text { boutiquier à Gallipoli }\end{array}$ & $\begin{array}{l}11 \text { panni corsivi } \\
1 \text { panno bastardo }\end{array}$ & $\begin{array}{l}15240 / 293 \\
1270 / 25\end{array}$ \\
\hline 19 avril & $\begin{array}{l}\text { Baba di Davit } \\
\text { juif, boutiquier au Bedesten de } \\
\text { Constantinople }\end{array}$ & 7 panni sanmartini & $18336 / 353$ \\
\hline 10 mai & $\begin{array}{l}\text { Iusteffino e Muse Calamiti } \\
\text { juifs, boutiquiers au Bedesten de } \\
\text { Constantinople }\end{array}$ & 16 panni bastardi & $\begin{array}{l}20800 / 400 \\
1300 / 25\end{array}$ \\
\hline 13 mai & $\begin{array}{l}\text { Muse e Elia Calamiti } \\
\text { juifs, boutiquiers au Bedesten de } \\
\text { Constantinople }\end{array}$ & 8 panni bastardi & $\begin{array}{l}10400 / 200 \\
1300 / 25\end{array}$ \\
\hline 13 mai & $\begin{array}{l}\text { Begliamino } \\
\text { Juif }\end{array}$ & 8 panni bastardi & $\begin{array}{l}10400 / 200 \\
1300 / 25\end{array}$ \\
\hline 3 juin & Sengerage Ugoli & 1 panno garbo & $1100 / 21$ \\
\hline 3 juin & $\begin{array}{l}\text { Mordecai e Abram comp. } \\
\text { Juifs }\end{array}$ & 8 panni corsivi & $\begin{array}{l}9280 / 178 \\
1160 / 22\end{array}$ \\
\hline 3 juin & $\begin{array}{l}\text { Maomet } \\
\text { turc, boutiquier au Bedesten de } \\
\text { Constantinople }\end{array}$ & 5 panni corsivi & $\begin{array}{l}5950 / 114 \\
1190 / 22\end{array}$ \\
\hline 5 juin & $\begin{array}{l}\text { Baba di Davit } \\
\text { juif, boutiquier au Bedesten de } \\
\text { Constantinople }\end{array}$ & 12 panni sopramani & $\begin{array}{l}18960 / 365 \\
1580 / 30\end{array}$ \\
\hline 5 juin & $\begin{array}{l}\text { Iacuda Luco } \\
\text { juif, boutiquier au Bedesten de } \\
\text { Constantinople }\end{array}$ & 4 panni garbi & $\begin{array}{l}4240 / 82 \\
1060 / 20\end{array}$ \\
\hline 5 juin & $\begin{array}{l}\text { Sabatino Luco } \\
\text { juif, boutiquier au Bedesten de } \\
\text { Constantinople }\end{array}$ & 5 panni sopramani & \begin{tabular}{lc|}
7 & 750 \\
$1550 / 30$
\end{tabular} \\
\hline 29 juin & Sublime Porte & 50 panni sopramani & $\begin{array}{l}69500 / 1337 \\
1390 / 28\end{array}$ \\
\hline & & 156 panni & $153256 / 2947$ \\
\hline
\end{tabular}

Tableau 1 : Les acheteurs des draps expédiés de Florence à Constantinople 
Peu de relations de clientèle semblaient scellées avec les Turcs ottomans. Les marchands florentins avaient quelques contacts directs avec eux, notamment avec les plus riches et les plus puissants, à l'exemple de la Sublime Porte, c'est-à-dire le gouvernement central de l'Empire ottoman, qui fit l'achat de 50 draps en juin 1493. Les Florentins semblaient davantage vendre leurs produits à des boutiquiers juifs qui devaient certainement euxmêmes les revendre dans le bazar de Constantinople. Dans le tableau recensant les ventes de Giovanni Salviati, les juifs apparaissent dans dix ventes sur 13 ventes réalisées. Ces juifs étaient principalement des boutiquiers du Bedesten de Constantinople (bottegaio in Bisestano). Il s'agissait du cœur économique de la ville, construit sous Mehmed II en 14561461. Les juifs occupaient dans l'Empire une position clef au niveau commercial, notamment dans les douanes et les finances ${ }^{25}$. Ils offraient des facilités aux Européens dans leurs démarches administratives et devinrent logiquement des intermédiaires privilégiés entre marchands latins et turcs ottomans.

Les deux exemples retracés dans cet article permettent de constater l'apport de la comptabilité à la reconstruction de réseaux marchands parcourant les espaces européen et méditerranéen. Celui issu du fonds Datini met en lumière les intermédiaires ; celui du fonds Salviati connecte des ateliers de production florentins aux marchés ottomans et focalise davantage sur la circulation de marchandises. Les documents comptables, d'une extrême précision, révèlent des détails occultés par la correspondance et par ce biais sont essentielles à notre compréhension à la fois des stratégies des acteurs et des dynamiques d'entreprises.

\begin{abstract}
Résumé
Le fonds Datini des archives de Prato et le fonds Salviati de la Scuola Normale Superiore de Pise, tous deux en Toscane, comptent parmi les plus riches fonds d'entreprises de la première modernité européenne. Ils permettent d'identifier et de caractériser d'importants réseaux d'affaires parcourant les espaces européen et méditerranéen de la fin du XIV ${ }^{\mathrm{e}}$ siècle $\mathrm{au} \mathrm{XVI}{ }^{\mathrm{e}}$ siècle. Les modus operandi apparaissent en effet très clairement dans les livres comptables, consentant la reconstruction des interactions entre compagnies d'affaires florentines et la mise en lumière des opérateurs des places commerciales où les marchands florentins étaient implantés. À travers des exemples concrets d'opérations commerciales réalisées par la compagnie Datini de Majorque et la compagnie Salviati de Constantinople, l'article permet de prendre la mesure du lien étroit entre reconstruction de réseaux et comptabilités d'entreprise.
\end{abstract}

25. Au sujet des juifs dans l'Empire ottoman, voir notamment B. Arbel, Trading Nations. Jews and Venetians in the Early Modern Eastern Mediterranean ; B. Braude, B. Lewis (ed.), Christians and Jews in the Ottoman Empire: the Functioning of a Plural Society; M. A. Epstein, The Ottoman Jewish Communities and Their Role in the Fifteenth and Sixteenth Centuries; H. Inalcik, "Jews in the Ottoman Economy 1450-1500»; M. Rozen, History of the Jewish Community in Istanbul: The Formative Years, 1453-1566 ; A. Shmuelevitz, The Jews of the Ottoman Empire in the Late Fifteenth and Sixteenth Centuries: Administrative, Economic, Legal and Social Relations as Reflected in the Responsa; S. Yerasimos, « La communauté juive d'Istanbul à la fin du XVI ${ }^{\mathrm{e}}$ siècle ». 


\section{Bibliographie}

ARBEL Benjamin, Trading Nations. Jews and Venetians in the Early Modern Eastern Mediterranean, Leyde, Brill, 1995.

BRAUDE Benjamin, LEWIS Bernard (ed.), Christians and Jews in the Ottoman Empire: the Functioning of a Plural Society. Volume I : the Central Lands, New York - Londres, Holmes \& Meier Publishers, 1982.

De ROOVER Raymond, "Aux origines d'une technique intellectuelle: la formation et l'expasion de la comptabilité à partie double », Annales d'histoire économique et sociale, t. 9, $\mathrm{n}^{\circ} 45$, mai 1937, p. 270-298.

De RoOver Raymond, Il banco Medici dalle origini al declino (1397-1494), Florence, La Nuova Italia, 1970.

DINI Bruno, «L'Archivio Datini », dans Cavaciocchi Simonetta (ed.), L'impresa, industria, commercio, banca secc. XIII-XVIII (Atti della "Ventiduesima Settimana di Studi" 30 aprile - 4 maggio 1990, Istituto Internazionale di Storia Economica "F. Datini", Prato), Florence, Le Monnier, 1991, p. 45-60.

EPSTEIN Mark Alan, The Ottoman Jewish Communities and Their Role in the Fifteenth and Sixteenth Centuries, Fribourg, K. Schwarz, 1980.

HAYEZ Jérôme, «L'Archivio Datini, de l'invention de 1870 à l'exploration d'un système d'écrits privés », HAYEZ Jérôme (ed.), Le carteggio Datini et les correspondances pratiques des $X I V^{\mathrm{e}}-X V I^{\mathrm{e}}$ siècles, Mélanges de l'École française de Rome - Moyen Âge 117/1, 2005, p. 121191.

HOUSSAYE MiCHIENZI Ingrid, « Relazioni commerciali tra la compagnia Datini di Maiorca e le città del Maghreb alla fine del Trecento ", TANZINI Lorenzo, ToGNETTI Sergio (ed.), "Mercatura è arte". Uomini d'affari toscani in Europa e nel Mediterraneo tardomedievale, Rome, Viella, 2012, p. 149-178.

HousSAYE MICHIENZI Ingrid, Datini, Majorque et le Maghreb (XIV ${ }^{e}-X V^{e}$ siècles). Réseaux, espaces méditerranéens et stratégies marchandes, Leyde, Brill, The Medieval Mediterranean 96, 2013.

HOUSSAYE Michienzi Ingrid, «Entre Majorque et l'Afrique : configuration de l'espace et réseaux juifs d'après des sources commerciales italiennes (fin XIV-début $X V^{\mathrm{e}}$ siècle) ", Revue des Études Juives, n¹73, 1-2, janvier-juin 2014, p. 139-174.

HOUSSAYE MichiEnZI Ingrid, OlszOWY-SCHLANGER Judith, «Écrits comptables et commerce interreligieux: les cas des registres d'Ugo Teralh de Forcalquier et de la compagnie Datini (XIV $-\mathrm{XV}^{\mathrm{e}}$ siècles) », Les Cahiers de Framespa 16, mis en ligne le 1er juillet 2014, consulté le 2 juillet 2014. URL : http:/ / framespa.revues.org/ 2917

HOUSSAYE MiCHIENZI Ingrid, «Le commerce des plumes d'autruche de l'Afrique subsaharienne aux marchés européens (fin $\mathrm{XIV}^{\mathrm{e}}$-début $\mathrm{XV}^{\mathrm{e}}$ siècle) », BONNET Alain, COQUERY Natacha, Le commerce du luxe - le luxe du commerce. Production, exposition et circulation des objets précieux du Moyen Âge à nos jours, Paris, Mare \& Martin, 2015.

Hunt Edwin S., The Medieval Super-Companies. A Study of the Peruzzi Company of Florence, Cambridge, Cambridge University Press, 1994. 
INALCIK Halil, "Jews in the Ottoman Economy 1450-1500 », BOsWORTH Clifford E., IssAWI Charles (ed.), Essays in Honor of Bernard Lewis. The Islamic World, Princeton, Darwin Press, 1989, p. 513-555.

LitTleton Ananias C., B.S. Yamey Basil S. (ed.), Studies in the History of Accounting, Londres, Sweet \& Maxwell, 1956.

LÓPEZ PÉReZ Maria Dolores, La Corona de Aragón y el Magreb en el siglo XIV (1331-1410), Barcelone, CSIC, 1995.

MeLIS Federigo, Aspetti della vita economica medievale, Sienne, Monte dei Pashi, 1962.

RENOUARD Yves, La papauté à Avignon, Paris, PUF, 1954.

Rozen Minna, History of the Jewish Community in Istanbul : The Formative Years, 1453-1566, Leyde, Brill, 2002.

SAPORI Armando, Una compagnia di Calimala ai primi del Trecento, Florence, Olschki, 1932.

SCHULTE Aloys, Geschichte der Grossen Ravensburger Handelsgesellschaft (1380-1530), Stuttgart, Deutsche Verlags-Anstalt, Deutsche Handelsakten des Mittelalters und der Neuzeit 3, 1923, 3 vol.

SHMUELEVITZ Aryeh, The Jews of the Ottoman Empire in the Late Fifteenth and Sixteenth Centuries: Administrative, Economic, Legal and Social Relations as Reflected in the Responsa, Leyde, Brill, 1984.

YERASIMOS Stéphane, "La communauté juive d'Istanbul à la fin du XVI siècle », Turcica, $\mathrm{n}^{\circ} 27,1995$, p. 101-130.

ZERBi Tommaso, Il mastro a partita doppia di un azienda mercantile del trecento, Côme, Cavalleri, 1936.

ZERBI Tommaso, Le origini della partita doppia: gestioni aziendali e situazioni di mercato nei secoli XIV e XV, Milan, Carlo Marzorati, 1952. 


\section{Illustrations}

Figure 1 : Journal : vente de draps de laine à Samuello (Ismael), le 31 octobre 1491

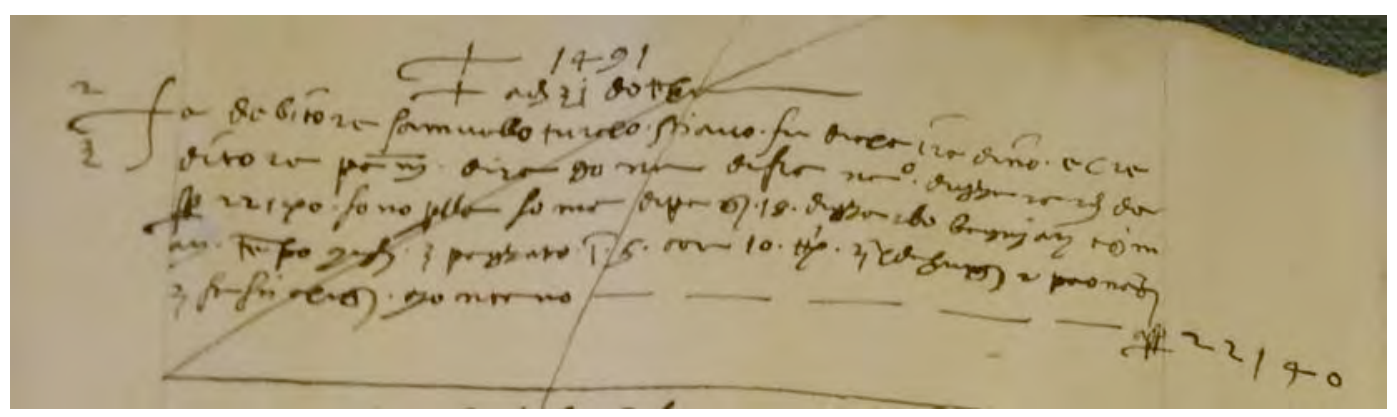

Figure 2 : Grand livre : Opération en débit dans le grand livre

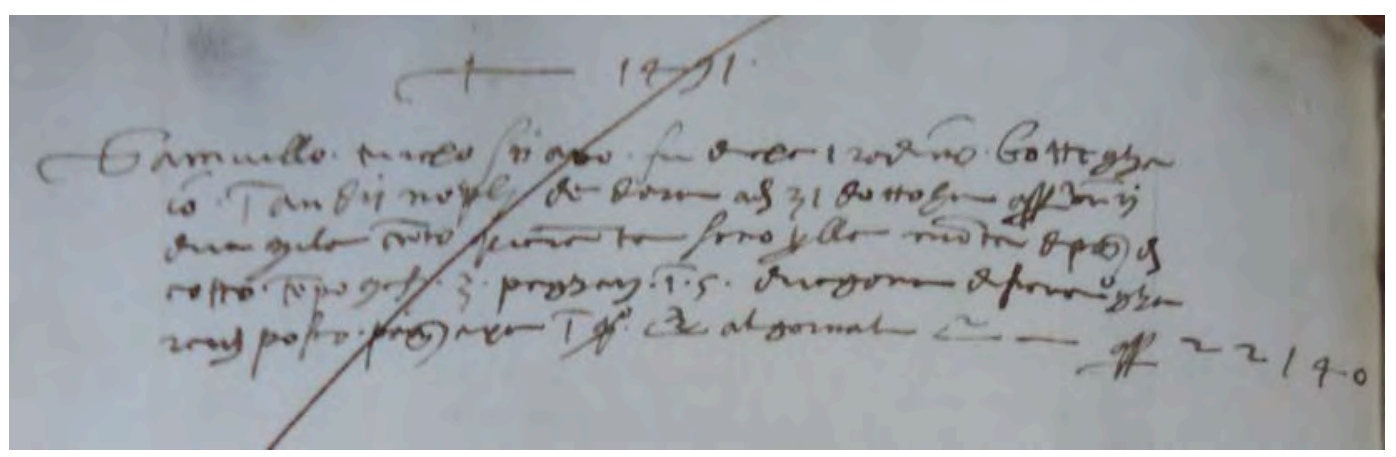

Figure 3 :Grand livre : Opération en crédit dans le grand livre

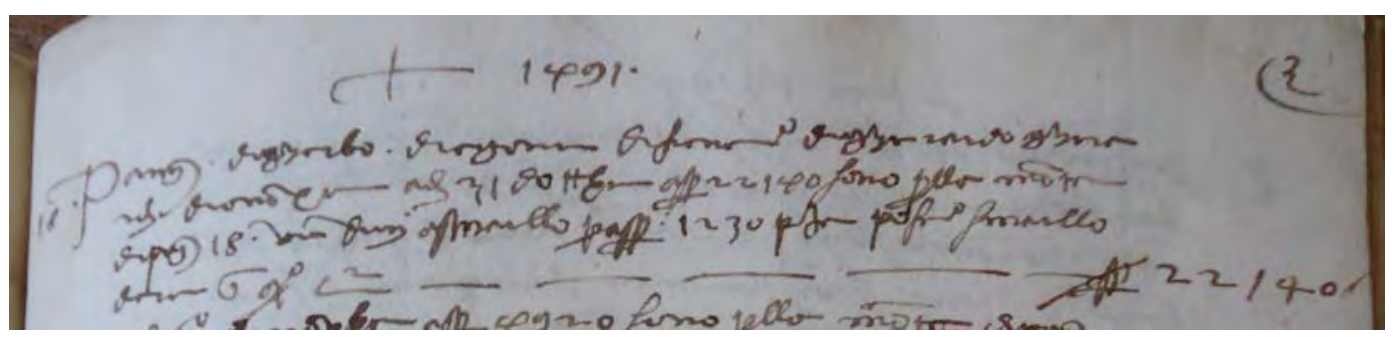




\title{
De la circulation de la grâce à la République de l'argent, marché, relations familiales et relations marchandes en Sicile (1287-1460)
}

\author{
Henri BRESC \\ Professeur émérite d'histoire médiévale \\ Université Paris Ouest - Nanterre-La Défense \\ Extrait de : Henri BRESC (dir.), Réseaux politiques et économiques, Paris, \\ Édition électronique du CTHS (Actes des congrès des sociétés historiques et scientifiques), 2016. \\ Cet article a été validé par le comité de lecture des Éditions du CTHS dans le cadre de la publication \\ des actes du $140^{\mathrm{e}}$ Congrès national des sociétés historiques et scientifiques tenu à Reims en 2015.
}

Le concept de réseau est largement utilisé en histoire économique du Moyen Âge, en général sans grande rigueur, pour signifier les relations marchandes qui présentent quelque stabilité. Cet usage implique souvent une hypothèse inavouée, celle d'un encastrement des rapports économiques dans une armature géographique et anthropologique déterminante. La solidarité familiale est supposée a priori naturelle et efficace, alors qu' on la sait construite et manipulée ${ }^{1}$. Le concept de diaspora marchande implique ainsi la stabilité communautaire, la permanence, sinon l'«ethnicité», l'organicité de la base sur laquelle se greffe la dispersion des marchands issus des grandes cités dynamiques du monde méditerranéen (Fustat aux $\mathrm{X}^{\mathrm{e}}$ et $\mathrm{XI}^{\mathrm{e}}$ siècles, Amalfi aux $\mathrm{XI}^{\mathrm{e}}$ et $\mathrm{XII}^{\mathrm{e}}$, Pise, Gênes, Venise et Florence ensuite, puis Barcelone, Valence et les autres villes catalanes), et ce sur un modèle supposé, celui de la diaspora juive qui unirait activité, fermeture religieuse et "ethnie», mais ce modèle est lui-même en lambeaux. Anthony Molho note que Fernand Braudel s'est obstinément et fort justement refusé à utiliser le terme de "diaspora » et qu'il a réservé celui de réseau au petit groupe des banquiers italiens de la fin du Moyen Âge et du XVI siècle $^{2}$.

La théorie communautaire a été particulièrement poussée par Philip D. Curtin ${ }^{3}$ et Avner Greif ${ }^{4}$. La critique des historiens du haut Moyen Âge et de l'époque moderne a été sévère : dans l'étude de la société des marchands juifs de la Geniza, Jessica Goldberg a montré que les relations économiques ne coïncidaient pas avec le réseau synagogal, mais engageaient des partenaires musulmans et chrétiens ${ }^{5}$. Dans leur synthèse sur le commerce indien au XVI ${ }^{\mathrm{e}}$ siècle ${ }^{6}$, A. Molho et Diogo Ramada Curto ont réuni les observations de Kirti Chaudhuri, de Sanjay Subrahmanyam et de Francesca Trivellato, très critiques à l'égard du concept de « diaspora » et de la théorie communautaire.

1. L. Feller, «Groupements, alliances et réseaux. L'organisation des solidarités familiales dans l'Italie médiévale », p. 235.

2. A. Molho et D. Ramada Curto, «Les réseaux marchands à l'époque moderne », p. 571.

3. P. Curtin, Cross-Cultural Trade in World History, p. 1-5: le concept de "trade diaspora " est emprunté à Abner Cohen, et explicité «nation composée de communautés socialement interdépendantes, mais dispersées spatialement ».

4. A. Greif, Institutions and the path to the modern economy : lessons from medieval trade, p. 58-90.

5. J. L. Goldberg, Trade and Institutions in Medieval Mediterranean. The Geniza Merchants and their Business World, p. 52.

6. A. Molho et D. Ramada Curto, « Les réseaux marchands à l'époque moderne », p. 569-589. 
Contre l'idée souterraine d'une détermination anthropologique dans l'établissement des relations marchandes et celle, plus explicite, d'un marché bridé et éclaté ${ }^{7}$, le marché libre est au centre d'une vaste et récente bibliographie : Gérard Delille a souligné la relation étroite entre le choix spécifique de l'exogamie par le christianisme et le développement d'un marché ouvert ${ }^{8}$. L'exigence de la circulation de la charité et de la grâce, à la base des décisions conciliaires, entraîne une conséquence économique considérable, la circulation du patrimoine à travers les dots (40\% par génération). Paolo Prodi a mis en lumière l'émergence d'une éthique normative du marché et l'ouverture d'un marché libre dès le $\mathrm{XII}^{\mathrm{e}}$ siècle ${ }^{9}$ et Giacomo Todeschini celle d'une conception salvatrice de la richesse dans la théologie franciscaine ${ }^{10}$.

La rupture est donc accomplie avec l'altérité anthropologique sur laquelle reposent encore les réserves de Jacques Le Goff ${ }^{11}$ et elle bouscule aussi la théorie polanyienne du "grand renversement», du passage de l'économie encastrée dans les relations sociales aux relations sociales encastrées dans l'économie, que Karl Polanyi datait du $\mathrm{XVIII}^{\mathrm{e}}$ siècle $^{12}$. Une étude plus poussée, amorcée dans une rencontre romaine ${ }^{13}$, devrait permettre de baliser les étapes de la constitution du marché libre, jusqu'à sa conséquence ultime, la circulation internationale de l'argent, au service des grandes monarchies transnationales, mais aussi par-dessus les frontières politiques, qui est la marque du XVI et du XVII ${ }^{\mathrm{e}}$ siècle $^{14}$.

La Sicile peut être un bon laboratoire de cette recherche : elle offre, dès le XII ${ }^{\mathrm{e}}$ siècle, l'image d'un marché de produits manufacturés importés et de denrées brutes de l'agriculture et de la pêche (blé, coton, thon salé) ouvert depuis 1150 aux commerçants des «nations » marchandes, mis en concurrence. La Sicile est aussi le banc d'essai où la monarchie, à partir de 1398, a mis en œuvre le programme politique élaboré par les franciscains Francesc Eiximenis, Andrea de Pace, puis Matteo de Girgenti : sur les bases de la fides et de la caritas, il fonde l'État sur la pratique parlementaire et le conseil représentatif, et l'économie sur un marché libre, en libérant par exemple les tribunaux arbitraux entre marchands de la tutelle des juristes ${ }^{15}$.

Deux questions serviront de fil rouge : d'abord celle de la primauté du contexte et des relations extra-économiques inspirée de Pierre Bourdieu et acceptée par Harrison White ${ }^{16}$ ou, au contraire, celle d'une éthique interreligieuse, apportant la garantie d'une morale commune et permettant en toute confiance la collaboration entre acteurs appartenant à des groupes différents. Puis celle de la coïncidence des relations multiples qui engagent les marchands, parenté et vicinat, rapports commerciaux, appartenance à la "nation » et à l'État. Et ce en trois temps: d'abord, une synthèse des informations qu'apportent les contrats recueillis dans les registres notariés palermitains de 1287 à 1460 ; puis l'analyse de quelques « carnets » de marchands, recopiés dans les registres notariés à l'occasion des successions ou reconstitués; enfin, dans un troisième volet, l'étude des relations entre famille et économie à trois époques successives, pour les groupes qui occupent des positions dominantes.

7. A. Guerreau, « Avant le marché, les marchés ».

8. G. Delille, L'Économie de Dieu. Famille et marché entre christianisme, hébraïsme et islam.

9. P. Prodi, Settimo non rubare. Furto e mercato nella storia dell'Occidente.

10. G. Todeschini, Richesse franciscaine. De la pauvreté volontaire à la société de marché.

11. J. Le Goff, Le Moyen Âge et l'argent.

12. K. Polanyi, La Grande transformation: aux origines politiques et économiques de notre temps.

13. Séminaire de l'École française «Famiglia e mercato tra cristianesimo, ebraismo e islam » (jeudi 3 avril 2014) à paraître.

14. A. De Maddalena et H. Kellenzbenz (dir.), La repubblica internazionale del denaro tra XV e XVII secolo.

15. P. Evangelisti, I Francescani e la costruzione di uno Stato. Linguaggi politici, valori identitari, progetti di governo in area catalano-aragonese, p. 287-307.

16. H. White, Identité et contrôle. Une théorie de l'émergence des formations sociales, p. 347-349. 


\section{La Sicile dans le contexte méditerranéen}

Le contexte est celui d'une Méditerranée largement ouverte aux immigrations marchandes, favorable à leur intégration : la citoyenneté s'obtient par mariage ou par un séjour bref, accompagné de la fixation du foyer. Partout, la part des commerçants étrangers est forte. En Sicile elle est toujours prépondérante; de plus, une part des marchands siciliens est d'origine toscane dès le XIII ${ }^{\text {e }}$ siècle, particulièrement d'origine pisane $\mathrm{au} \mathrm{XIV}^{\mathrm{e}}$ et au $\mathrm{XV}^{\mathrm{e}}$ siècle. L'espace méditerranéen est animé par des mouvements $\mathrm{d}$ 'hommes, de marchandises et d'argent qui ont pour centre les grandes villes de la Tyrrhénienne et du Golfe du Lion et de la Méditerranée catalane, Pise, Gênes, Marseille, Collioure, Barcelone, Valence et Majorque, croisés avec des mouvements, plus modestes, de marchandises, de fonds et même d'hommes partis des centres mineurs. Comme l'Atlantique des $\mathrm{XVI}^{\mathrm{e}}-\mathrm{XVIII}^{\mathrm{e}}$ siècles, la Méditerranée est multidirectionnelle.

La Sicile présente des caractères particuliers: les Normands ont unifié précocement l'espace commercial du royaume par la suppression des péages, en 1187, depuis les Abruzzes jusqu'à Trapani ${ }^{17}$, et, sur le modèle champenois, Frédéric II a organisé en 1234 une succession de foires qui s'enchaînent du Nord au Sud, Sulmona (avril-mai), Capoue (mai-juin), Lucera (juin-juillet), Bari (juillet-août), Tarente (août-septembre), Cosenza (septembre-octobre) et Reggio (octobre-novembre), et celles de Piazza dans l'île, en mai et en septembre ${ }^{18}$. Quand l'île se sépare du reste du royaume, en 1282, une dynastie nationale, de 1296 à 1392, l'engage dans une guerre inégale de cent vingt ans contre les Angevins de Naples. Elle finance cet effort belliqueux, surtout naval, par le développement $\mathrm{d}$ 'une fiscalité originale de royalties sur l'exportation du froment, la " traite ». L'île est enfin intégrée en 1392 dans un Empire composite, celui de la royauté aragonaise, multinationale, engagée à partir de 1420 dans la conquête du royaume de Naples, et dont la structure financière repose sur la circulation des ressources de la fiscalité par lettres de change souscrites auprès des marchands depuis Valence, Barcelone, Majorque, Palerme et Cagliari vers les camps d'Alphonse le Magnanime, puis vers la Cour, à Naples. Avec des moyens plus modestes et sans structure de filiales, les marchands-banquiers pisans et catalans suivent alors le modèle des grandes compagnies florentines et toscanes qui ont servi la Chambre pontificale d'Avignon jusqu'en 1340.

Une immigration massive fait affluer les marchands en Sicile: un dépouillement incomplet des archives siciliennes dénombre 3349 marchands entre 1299 et 1458, dont $73 \%$ sont étrangers ou immigrés récents; un sixième de Toscans, un cinquième de Génois, un quart de Catalans ${ }^{19}$. Mais l'efficacité économique est inversement proportionnelle au nombre : les derniers sont moins au fait des techniques avancées de commerce et de banque mieux dominées par les Toscans ; ainsi, le 6 mai 1299, entre deux marchands catalans de Girone, ce sont les Bardi qui transfèrent par lettre de change 912 1/2 besants de millarès de Pere Beltrami, opérant à Tunis, à Francesc de Sant Felix, à Palerme $^{20}$. Les Toscans seront cependant écartés par la crise de leurs grandes compagnies autour de 1348. Les trois "nations" assument une série de positions dominantes, les Toscans avant $1350^{21}$, les Génois jusqu'en 1390, les Catalans ensuite un bref moment, profitant de la conquête, les Toscans de nouveau après 1420. Mais, en dehors de courtes exclusions par le pouvoir royal de l'une ou l'autre des «nations », devenues ennemies, expulsions aussitôt corrigées par l'usage des sauf-conduits et de la naturalisation des résidents ${ }^{22}$, le principe durable est celui de la liberté de commerce : «il n'est pas juste d'enlever la liberté et l'initiative aux marchands » (non est justum quod tolletur arbitrium

17. C. Minieri Riccio, Saggio di codice diplomatico formato sulle antiche scritture dell'archivio di Stato di Napoli, Supplemento I, p. $20, \mathrm{n}^{\circ} 12$.

18. C. A. Garufi (ed.), Ryccardi de Sancto Germano Chronica, p. 187.

19. H. Bresc, Un Monde méditerranéen : économie et société en Sicile (1300-1460), p. 380.

20. P. Gulotta, Le imbreviature del notaio Adamo de Citella a Palermo ( ${ }^{\circ}$ Registro : 1299-1299), p. 297-298, $\mathrm{n}^{\circ} 385$.

21. G. Petralia, "Sui Toscani in Sicilia tra Due e Trecento: la penetrazione sociale e il radicamento nei ceti urbani ».

22. H. Bresc, Un Monde méditerranéen : économie et société en Sicile (1300-1460), p. 376. 
mercatoribus). La multiplication des privilèges accordés aux Républiques maritimes finit par raboter leur efficacité et établir une égalité de traitement à peu près totale ${ }^{23}$.

La documentation notariée des archives de Palerme montre d'abord la réalité d'un marché ouvert, bourse de l'exportation des grains pour toute l'île et de l'importation des draps pour les deux tiers des bourgs, comme le montre la distribution sur la carte (Figure $n^{\circ} 1$ ) des revendeurs de draps approvisionnés à Palerme en $1307-1309^{24}$ : on compte 60 drapiers dans la métropole et 103 revendeurs qui interviennent dans 586 ventes à crédit en deux années indictionnelles; chacun de ces derniers achète dans deux, trois, quatre boutiques palermitaines. Si l'on prend un échantillon de quelques clients du principal drapier, Lombardo de Roberto Speciario, on perçoit un échange très ouvert, un ensemble de relations entrecroisées à l'infini, l'amorce d'un réseau (Figure $\mathrm{n}^{\circ} 2$ ). Il y manque cependant des nœuds régionaux ou des relais. Un seul revendeur fait à son tour fonction de semi-grossiste en direction de revendeurs de bourgs voisins, Simon Venturi d'Arezzo, habitant de Caltavuturo ${ }^{25}$.

Les marchands s'intègrent aisément au milieu commerçant : les outils de cette intégration sont les procurations, les commandes et les fidéjussions et garanties qu'ils trouvent dans la «nation » d'origine ou dans le groupe religieux pour les juifs, les musulmans siciliens ayant presque disparu et les marchands d'origine maghrébine n'étant qu'une poignée à fréquenter les ports siciliens. D'autres institutions, moins formelles, favorisent ou même imposent la collaboration entre "nations » : l'arbitrage entre marchands, et, à un niveau plus modeste, l'appareil d'hôtelleries qui sert de bourse d'informations et de transports, les muletiers faisant fonction de relais vers l'hinterland, le courtage, enfin, assumé en particulier par des juifs et des juives (un tiers des 28 courtiers répertoriés en activité et un quart des 41 courtiers qui prêtent serment en 1389 et fournissent des garants ${ }^{26}$ ). Comme à Marseille, où plus de neuf sur dix des courtiers sont juifs ${ }^{27}$ et en bien d'autres points, la fides publica n'est pas réservée aux chrétiens, mais étendue aux juifs ${ }^{28}$, qui prêtent serment sur la Torah ou sur les franges du vêtement, et une confiance semblable est accordée aux rares marchands musulmans ${ }^{29}$. La même foi apparaît dans les contrats entre artisans : ils travaillent dans le même atelier, tandis que des hôteliers, un chrétien et un juif, s'entendent pour tenir le « fondaco » qui jouxte la synagogue de Palerme.

Une statistique incomplète et sans doute révisable de quelques centaines de contrats relevés dans les registres notariés permet de distinguer les formes traditionnelles de la coopération économique et les formes innovantes. Les premières réunissent les sociétés de grand commerce, les associations de petit commerce, les procurations, indices de "coopération amicale» à peine formalisée, et les commandes (Tableau $n^{\circ} 1$ ). Ces coopérations élémentaires unissent des marchands, étrangers comme locaux, pour deux ou trois ans, quelquefois une simple et brève opération, en forte majorité à l'intérieur de la «nation» ou du groupe religieux. Cette "nation» peut être clairement définie, marchands de Barcelone, de Perpignan, de Majorque ou de Valence, tous qualifiés de Catalans, Génois de Gênes, de Savone ou des autres ports ligures. Les "Toscans » sont en revanche une nébuleuse où se distinguent à l'occasion Pisans et Florentins. On note que très peu de ces contrats associent des membres de même patronyme, au maximum un sur dix ; le pourcentage est cependant sous-estimé, car on ne connaît pas les liens cognatiques de marchands qui ne passent qu'un temps dans l'île. Dans l'ensemble, la «nation » joue un rôle essentiel d'intégration des jeunes et des migrants, sans doute aussi pour leur

23. Ibid., p. 373

24. Archivio di Stato, Palermo, Miscellanea archivistica II, Notaio Bartolomeo de Citella 127a et 127b.

25. Ibid., $127 \mathrm{~b}$, fol. $55 \mathrm{v} ; 16$ octobre 1308 .

26. H. Bresc, Un Monde méditerranéen : économie et société en Sicile (1300-1460), p. 402.

27. J. Sibon, Les Juifs de Marseille au XIVe siècle, p. 125-128.

28. Un contrat de Trapani prévoit que la parole du créditeur juif, Muxa de Cathalano, fera foi. Il a reçu 10 onces

(50 florins) pour commercer, ad traficandum, d'un médecin chrétien; Archivio di Stato, Trapani, Notaio Scanatello $178 ; 8$ Novembre 1420 .

29. Le 21 janvier 1437, le Tunisois Mahomet Elffaki s'engage à rembourser, à Tunis, 60 doubles à un marchand catalan devant quatre témoins, tous ifrîqiyyens; Archivio di Stato, Palermo, Notai defunti, Prima stanza, Giacomo Comito 845. 
logement comme à Barcelone ${ }^{30}$, mais la «maison», l'albergo génois ou la famille patrilinéaire n'ont qu'une place modeste : seules les compagnies à filiales florentines, qui opèrent à Palerme dès les dernières décennies du XIII ${ }^{\mathrm{e}}$ siècle $^{31}$, les Cambi de Sienne et quelques maisons catalanes, avant 1348 ont une structure fondée sur un noyau familial. L'hypothèse anthropologique d'une articulation des relations marchandes sur les structures familiales connaît donc dès l'abord une application limitée.

\section{Les instruments du commerce en Sicile 1287-1458}

Les formes innovantes (Tableau $\mathrm{n}^{\circ} 2$ ), appliquées au risque et à l'incertain, manifestent une ouverture croissante entre les «nations » et le groupe religieux des juifs : prêts et changes maritimes, changes et lettres de change, assurances enfin, qui apparaissent d'ailleurs en Sicile assez tardivement et successivement, les changes dès la fin du XIII ${ }^{\mathrm{e}}$ siècle, les assurances vers 1337 et les lettres de change vers 1370, unissent des partenaires d'origine diversifiée, Toscans et Génois au XIV ${ }^{\mathrm{e}}$ siècle, Pisans et Catalans au $X V^{\mathrm{e}}$. Ce sont les premiers indices d'une circulation généralisée, d'une « République de l'argent ", comme le montre, en 1371, une lettre de change tirée de Palerme à Gênes (bailleur et bénéficiaire Joan Cudines, marchand catalan de Barcelone, tireur et tiré le Génois Giovanni Squarciafico), qui prévoit un rechange à $7,1 \%$ et masque à peine un prêt ${ }^{32}$. Ce financement « hors sol » et ce commerce de l'argent par-dessus les frontières de dominations politiques fréquemment antagonistes se multiplieront au $\mathrm{XV}^{\mathrm{e}}$ siècle.

\section{Les carnets de marchands}

Une confirmation des conclusions tirées de cette rapide statistique est apportée par l'examen des « carnets » de marchands (Tableau $\mathrm{n}^{\circ} 3$ ), qu'il s'agisse de l'inventaire des créances conservées par le notaire (Gregorio Denti à Palerme en 1348 ${ }^{33}$ ), de la reconstitution d'un livre de poche à partir de deux ensembles de registres notariés particulièrement riches (Brachonus Mizoc à Palerme entre 1361 et $1362^{34}$ et Benedetto de Perino de Trapani en 1414-1418 ${ }^{35}$ ) ou encore d'un carnet recopié par le notaire au moment de la succession (Girard de Guy, marchand valencien de Termini, dont le petit livre de comptes couvrait les années $1406-1411^{36}$ ). Ce sont quatre marchands moyens, mais non pas médiocres (les affaires comptabilisées vont de 930 à 3835 florins).

Gregorio Denti est grossiste de draperie, mais il livre aussi du thon salé des madragues de Sicile occidentale et des fournitures de luxe à des clients de la noblesse et son frère Simon est l'un des rares marchands siciliens à tenter l'aventure de se fixer en Lombardie $^{37}$.

Brachon Mizoc finance une tannerie gérée par d'autres juifs palermitains et une taverne qui vendra du vin rituel (kasher), mais il s'occupe aussi d'exportation vers la Sardaigne (vin blanc et rouge, coton, sucre, eau de rose et casse fistule, dinanderie) et il réserve près d'un tiers de ses investissements à des patrons de barques qui vont commercer en

30. Maria Elisa Soldani, «Tra reti internazionali e spazio urbano. Forme mercantili di comunicazione, solidarietà e gestione degli affari nel Mediterraneo occidentale bassomedievale », p. 96.

31. H. Bresc, Un Monde méditerranéen : économie et société en Sicile (1300-1460), p. 400 : Bardi, Peruzzi, Acciajuoli, Gambacurta, Bonaccorsi, Campisani, Guidolotti.

32. Archivio di Stato, Palermo, Notai defunti, Prima stanza, Bartolomeo Bononia Spezzone $17 \mathrm{~N} ; 5$ mars 1371.

33. Archivio di Stato, Palermo, Notai defunti, Prima stanza, Rustico de Rusticis 81, fol. $267 ; 17$ mars 1348.

34. Archivio di Stato, Palermo, Notai defunti, Prima stanza, Bartolomeo Bononia 122, fol. 8v, 55v, 137,31 janvier 1359-28 janvier 1360 ; deux fragments séparés du registre 122 : Spezzone 125, 23 juin 1361; Spezzone 45N, 8 juillet 1361 ; l'essentiel dans le registre 123, fol. 3v, 47, 47v, 59, 60, 61v, 64v, 66, 67v, 71, 71v, 76, 76v, 82v, 95, 98, $102 \mathrm{v}, 112,120,132,134,138 \mathrm{v}, 142,150,151,153 \mathrm{v}, 154,154 \mathrm{v}, 160,160 \mathrm{v}, 161,165,172,174,175 \mathrm{v}, 176,176 \mathrm{v}, 6$ septembre 1361-18 août 1362 .

35. C. Trasselli, Note per la storia dei banchi in Sicilia nel XV secolo, Parte II. I banchieri e i loro affari, p. 85-89.

36. H. Bresc, « Reflets dans une goutte d'eau : le carnet de Girard de Guy, marchand catalan à Termini (14061411)».

37. Archivio di Stato, Palermo, Protonotaro 2, fol. 222 ; 9 décembre 1355. 
Valdemone, région montagnarde, de Cefalù à Taormine, riche en bois, en vin, en soie grège. C'est le seul des quatre marchands à manifester une forte spécialisation au sein de son groupe, ici le groupe religieux, mais c'est une spécialisation technique (la tannerie, d'ailleurs partagée) et rituelle qui l'explique : la part des juifs dans ses affaires est un peu supérieure à la moitié de ses investissements.

$\mathrm{Au} \mathrm{XV}$ siècle, Girard de Guy est un modèle de relais (broker) entre les importateurs catalans de draps de Palerme et les clients, nobles et revendeurs des bourgs montagnards de la Sicile centrale; il possède aussi une boutique de drap tenue par un associé. L'essentiel de son activité est cependant l'achat de blé et de fromage pour l'exportation. Il finance par des prêts trente-trois petits marchands qui joueront le rôle d'acheteurs dans les bourgs, assurant la collecte du grain à la moisson et du fromage. Ce sont les foires qui lui donnent l'occasion de renouer avec ces collecteurs, en particulier celle de Polizzi, gros bourg rural de la montagne.

Le dernier "carnet», celui de Benedetto de Perino de Trapani a été reconstitué par Carmelo Trasselli pour les quatre années 1414-1418, attiré par un indice fugitif, l'accusation d'usure portée contre lui après sa mort. L'intérêt d'un prêt, qui devait être restitué à la première demande, a été en effet fixé à $42,8 \%$, mais le remboursement, étalé sur six et même sept ans, a réduit ce taux à un prélèvement raisonnable ${ }^{38}$. Les activités sont différentes, essentiellement le prêt, quelques affaires d'exportation vers Pise où Benedetto a un facteur, Peri de Zampino, des achats de sucre produit en Sicile, un peu de financement de la piraterie orientée vers le littoral africain.

L'ensemble de ces documents reconstitués permet de confirmer l'ouverture du marché : les juifs y sont toujours présents, leur part modeste, mais régulièrement sous-estimée. Ils sont 8 des 67 correspondants locaux de Girard de Guy (12\%) et ceux qui assurent les plus fortes livraisons de grain, mais elles ne sont pas comptabilisées dans le carnet. Trois des marchands ont des affaires au Maghreb : Gregorio Denti a vendu du drap à un juif de Djerba, Girard de Guy a expédié une cargaison de froment aux Monts de Barca (Cyrénaïque) dans le cadre de l'échange grain-esclaves africains livrés par les traitants du trafic transsaharien et Benedetto de Perino a expédié des noisettes à Tunis.

Une autre déduction s'impose à l'analyse de ces documents : on ne voit pas de réseau, mais seulement des chaînes. Girard de Guy sert de relais entre les importateurs palermitains et les revendeurs comme entre les acheteurs de produits agricoles et les exportateurs. C'est sans doute le cas aussi de Gregorio Denti, sans preuve formelle. Pour ce dernier et pour les deux autres marchands, on ne peut qu'établir une toile d'araignée centrée sur leur boutique et qui ne mérite guère le nom de réseau, même baptisé « egocentré ». Pour repérer l'existence et l'utilisation des réseaux, il faut donc en venir à des analyses d'ensemble par moments clés de la documentation notariale.

\section{Famille, albergo et réseau : trois exemples}

L'hypothèse qui voit dans la fermeture familiale un élément essentiel de cohésion des sociétés économiques trouve dans la documentation sicilienne des confirmations et des nuances. Le modèle le plus remarquable de la combinaison entre clôture endogamique et mariage d'alliance est celui des juifs qui suivent les règles talmudiques. On retrouve l'articulation du remembrement familial et de l'alliance chez les Pisans de Palerme au début $\mathrm{du} \mathrm{XV} \mathrm{XV}^{\mathrm{e}}$ siècle et on sait que les grands alberghi génois $\mathrm{du} \mathrm{XIV}^{\mathrm{e}}$ et $\mathrm{du} \mathrm{XV}^{\mathrm{e}}$ siècle qui opèrent à Palerme cherchaient une solidarité renforcée dans des mariages croisés entre les lignées confédérées au sein de ces maisons artificielles, en prenant soin de ne pas glisser à l'endogamie telle que la définit la règle canonique ${ }^{39}$. Cette articulation entre clôture et ouverture est stratégique : elle fortifie un groupe au moment de l'offensive sur le marché sans compromettre l'intégration, qui conduit à de hautes fonctions politiques,

38. Ibid., p. 97.

39. E. Grendi, « Profilo storico degli alberghi genovesi », p. 295. 
auliques et bureaucratiques et à la féodalité. Plus on s'intègre, plus on se renforce : c'est une prudence élémentaire.

Les juifs ne comptent pas de grands marchands, sinon pendant la courte période qui va de 1360 à 1410, et ils font pour l'essentiel partie du tissu conjonctif de l'économie sicilienne. Leur enracinement, " millénaire », et la souplesse de leur système familial leur permettent d'établir des bases de commerce dans les bourgs, où une famille marchande peut détacher un fils ${ }^{40}$, comme en Cerdagne et en Roussillon ${ }^{41}$. Ils peuvent aussi établir des alliances, quelquefois lointaines, comme le mariage de Chasuna, fille du puissant Jusuf Chentorbi, homme de confiance des Chiaramonte, Seigneurs de Palerme, à un médecin de Cagliari en Sardaigne ${ }^{42}$, mais surtout, par des mariages endogames, de renforcer sans cesse la solidarité interne ${ }^{43}$. Les alliances sont évidemment beaucoup plus instables, comme le lien matrimonial lui-même, à la merci d'une rupture entre beauxfrères qui peut se traduire par une répudiation, un $g \hat{e} t^{44}$. La gestion du douaire par l'épouse est une garantie, certes, et aussi une épée de Damoclès sur l'époux, freiné dans ses aventures financières: Brachon Mizoc, qui investit 130 onces dans une affaire de tannerie, exige que les femmes de ses deux associés renoncent à mettre la main sur le capital, en cas de décès des époux, pour recouvrer dots et douaires. Le système matrimonial à chaînes courtes a l'avantage de la cohérence, mais le désavantage de raréfier les associations complexes et les relations internationales, outre la nécessaire fermeture sur le groupe religieux.

Vers 1370, quelques grandes figures apparaissent, qui investissent aussi dans la production agricole et l'élevage pour l'exportation: Samuel Cusintinus, Sufen Taguil, Salamon Nachuay. L'examen des généalogies (Figure $n^{\circ} 3$ ) montre que les familles engagées dans le grand commerce, anciennes et nobles (de Medico/Lu Medicu, Taguil et Xunina) et immigrées (les Cusintinus, originaires de Cosenza en Calabre), combinent l'alliance et la clôture matrimoniale, mariage avec la cousine parallèle patrilatérale ou avec la cousine croisée matrilatérale. La génération suivante verra un certain effacement des grandes maisons du milieu juif, avant une relance dans la seconde moitié du $\mathrm{XV}^{\mathrm{e}}$ siècle par $\mathrm{d}$ 'autres familles. Le manque de réseaux et de respiration internationale est la cause probable de ce déclin.

Les alberghi génois apparaissent dans la documentation palermitaine entre 1330 et 1340 ; vers 1350 une alliance politique avec la maison comtale des Chiaramonte et leur collaboration au gouvernement de la partie de la Sicile ralliée aux Angevins de Naples favorise leur pénétration sur le marché, sans qu'on puisse parler d'hégémonie; leur position dominante s'exprime dans l'enveloppement du groupe des marchands palermitains d'origine pisane par les Spinola et les Maruffo. La figure $\mathrm{n}^{\circ} 4$ permet de saisir des liens récurrents entre les grands marchands des alberghi et de repérer les relais : la plupart des sociétés de commerce sont conclues entre membres d'alberghi nobles, associant Squarciafico, Cibo, Cicala, Doria et Spinola, Spinola et Grillo, Leccavella et Imperiale, Pinelli, Spinola et Squarciafico, et plus rarement entre nobles et populaires (les Maruffo associés aux De Mari), sans que l'on sache les relations matrimoniales qui ont pu jouer entre ces alberghi. Pas de lien croisé, en revanche, mais des relations avec des marchands d'origine pisane, Federico Rustichelli, Nardo de Rustico et la fratrie des Falcono, relais très actif vers les commerçants palermitains, les juifs et les débouchés de l'exportation. Les Génois resteront actifs durant tout le $\mathrm{XV}^{\mathrm{e}}$ siècle, sans atteindre l'efficacité des Pisans: ils manquent de fortes compagnies à noyau familial et leur

40. Les Taguil, de Palerme à Corleone, par exemple; H. Bresc, Arabes de langue, Juifs de religion. L'évolution du judaïsme sicilien dans l'environnement latin, XII $-X V^{e}$ siècles, p. 155-156.

41. C. Denjean, «Réseaux relationnels des prêteurs juifs de Cerdagne et de Roussillon, 1260-1420 », p. 420.

42. Archivio di Stato, Palermo, Notai defunti Ia stanza, Bartolomeo Bononia 123, fol. 87v ; 29 décembre 1361 , restitution de la dot après la mort du mari.

43. H. Bresc, Arabes de langue, Juifs de religion. L'évolution du judaïsme sicilien dans l'environnement latin, XII $X V^{e}$ siècles, p. 153-155.

44. G. Delille, L'Économie de Dieu. Famille et marché entre christianisme, hébräsme et islam, p. 193. 
position politique ambiguë face aux ambitions des Transtamare les écarte du maniement des finances royales après 1410 .

La banque pisane, enfin, s'est développée en Sicile après l'intégration de Pise à la sphère de domination florentine: quelques exilés, mais surtout une grande masse d'immigrés dans la tradition des $\mathrm{XIII}^{\mathrm{e}}$ et $\mathrm{XIV}^{\mathrm{e}}$ siècle, quelquefois des mêmes familles, souvent de nouvelles maisons marchandes ${ }^{45}$. Solidement appuyés sur les profits de l'importation de produits manufacturés et de l'exportation des productions agricoles, ils font circuler l'argent de la fiscalité royale entre Barcelone, Valence, Cagliari, Palerme et le camp d'Alphonse le Magnanime, qui assiège Gaète, se fixe dans la ville conquise, puis assiège Naples, s'y installe pour peu de temps avant de reprendre une itinérance belliqueuse. Le service de la Cour royale conduit à quelques faillites, comme celle de leur associé catalan Pere Çimart, mais asseoit solidement Piero Gaetani, entré dans la noblesse bureaucratique comme maître rational, puis dans la féodalité, comme baron de Tripi, et Antonio da Settimo, qui place son fils Simonetto comme page à la Cour de Naples. C'est la récompense d'une efficacité rare : les banquiers pisans et leurs associés catalans ont su, par le mécanisme des lettres de change, faire circuler le précieux sang qui a irrigué l'armée et permis d'acheter les fidélités et les trahisons.

Le réseau des Pisans de Palerme, cohésif, une quasi-clique (Figure $\mathrm{n}^{\circ}$ 5), fonctionne autour d'un noyau: Piero Gaetani et Antonio da Settimo sont beaux-frères, le premier ayant épousé la sœur utérine du second, et ils ont renforcé leur lien en mariant la fille du premier, d'un second mariage, avec le fils du second. Giovanni Abbatellis, Palermitain d'une antique immigration florentine, est à la fois leur représentant, associé avec un Pisan, Benedetto di Ser Tommaso, et intégré à la noblesse bureaucratique, comme maître "secreto » (administrateur du fisc en Sicile), et à la féodalité. Des chaînes de procurations et de délégations, de procurations, leur rattachent les Tosinghi, les da Caprona (en Sicile, Crapona), les Agliata et des Aiutamicristo, des Buonconti, des Vernagalli. On note que, bien loin d'une économie encastrée dans les structures de la famille, ici ce sont les structures familiales qui sont mises au service de l'économie, sans distorsion des règles canoniques. Le remembrement familial, qu' on note aussi chez les Agliata par un mariage entre lointains parents de branches déjà suffisamment éloignées, est un fait bien établi chez les marchands-banquiers toscans, sans cependant peser sur la gestion des firmes commerciales $^{46}$. On ne note rien de tel, au moins en Sicile, dans le monde des marchands génois et catalans, et c'est sans doute cet isolement relatif qui fait leur relative faiblesse. Les Pisans, de plus, comme certains Catalans, ont su jouer d'une identité multiple; palermitains par citoyenneté acquise, siciliens par "naturalité » accordée par le prince, ils gardent une solidarité impressionnante: ils sont trente-deux sur les trente-huit marchands que la quasi-clique réunit et les unions matrimoniales regroupent les maisons ; Antonio da Caprona épouse la fille de son associé Baldassare Buonconti et Troiano Abbate, représentant à Palerme des Miroballo napolitains celle de Benedetto Agliata ${ }^{47}$. Leurs alliances avec la noblesse bureaucratique et avec les maisons baronniales de la féodalité leur permettent aussi de recycler dans les affaires commerciales et dans la banque les réserves que la rente féodale accumule dans les caisses de leurs alliés et affins: Mario Buonconti épouse une Biondo de Palerme, Beatrice da Settimo Pietro Carastono.

45. Prosopographie de G. Petralia, Banchieri e famiglie mercantili nel Mediterraneo aragonese. L'emigrazione dei Pisani in Sicilia nel Quattrocento, en particulier p. 102-117 (Agliata), p. 145-152 (Buonaconti), p. 159-164 (da Caprona), p. 185 (Gaetani) et p. 250-253 (da Settimo).

46. En 1458, aucun des directeurs des douze compagnies de Côme de Médicis n'est membre de la famille Medici.

47. H. Bresc, Un Monde méditerranéen : économie et société en Sicile (1300-1460), p. 412. 
En Sicile, l'articulation entre l'alliance et le remembrement lignager a assuré, sur un marché ouvert, des positions fortes. Elle a protégé le rôle, subalterne, mais régulier, des juifs et consolidé l'efficace des savoirs commerciaux et financiers des Pisans et des autres Toscans. Les réseaux de commerce et de finance, fugitifs et instables, se sont organisés autour de coalitions capables de durer pendant une génération et qui étaient la réponse la plus adéquate à l'offre d'un marché animé par le mouvement «brownien » de marchands aux origines multiples et dispersés. Ces grumeaux sont capables d'attirer et de faire converger des acteurs appartenant à d'autres «nations » et de soutenir puissamment un État transnational aux ambitions et aux dimensions impériales.

\begin{abstract}
Résumé
Dans une Méditerranée largement ouverte aux immigrations marchandes, la Sicile présente la figure particulière d'un royaume précocement unifié et dont la force repose sur le commerce des blés. La documentation notariale y montre un marché ouvert où les «nations » commerçantes collaborent avec confiance, sans que les structures familiales ou les communautés d'origine dictent les coopérations et orientent les affaires : ni « diasporas » marchandes ni exclusive nationale. Les juifs, en particulier, y participent largement: l'articulation du remembrement familial et de l'alliance consolide les positions fortes des grands marchands juifs de la fin du XIV siècle et c'est une des garanties du succès des Pisans, négociants et banquiers, qui assument une position dominante au $\mathrm{XV}^{\mathrm{e}}: \mathrm{c}^{\prime}$ est autour des coalitions qu'ils réalisent que l'on perçoit pour la première fois des réseaux qu'anime leur dynamisme.
\end{abstract}

\title{
Bibliographie
}

BRESC Henri, Arabes de langue, Juifs de religion. L'évolution du judaïsme sicilien dans l'environnement latin, XII'-XV siècles, Paris, Bouchène, 2001.

BRESC Henri, Un Monde méditerranéen : économie et société en Sicile (1300-1460), Paris-RomePalerme, École française de Rome-Accademia di Scienze, Lettere e Arti di Palermo (Bibliothèque des Écoles françaises d'Athènes et de Rome, fasc. 262), 1986.

BRESC Henri, «Reflets dans une goutte d'eau: le carnet de Girard de Guy, marchand catalan à Termini (1406-1411) », Archivio storico messinese, 77, 1998, p. 5-47.

COUlOn Daniel, PICARD Christophe et VALÉRIAn Dominique (dir.), Espaces et réseaux en Méditerranée, $V I^{e}-\mathrm{XVI}^{e}$ siècle, I. La configuration des réseaux, Paris, Bouchène, 2007 et, II. La formation des réseaux, Paris, Bouchène, 2010.

CuRTIN Philip D., Cross-Cultural Trade in World History, Cambridge et New York, Cambridge University Press, 1984.

DeLILLE Gérard, L'Économie de Dieu. Famille et marché entre christianisme, hébraïsme et islam, Paris, Les Belles Lettres, 2015.

De Maddalena Aldo et Kellenzbenz Hermann (dir.), La repubblica internazionale del denaro tra XV e XVII secolo, Bologne, il Mulino, 1986.

DENJEAN Claude, «Réseaux relationnels des prêteurs juifs de Cerdagne et de Roussillon, 1260-1420 », dans COUlON Daniel, PICARD Christophe et VAlÉRIAN Dominique (dir.), Espaces et réseaux en Méditerranée, $V I^{e}-X V I^{e}$ siècle, II, La formation des réseaux, p. 255-273. 
Evangelisti Paolo, I Francescani e la costruzione di uno Stato. Linguaggi politici, valori identitari, progetti di governo in area catalano-aragonese, Padoue, Edizioni francescane (Fonti e ricerche, 20), 2006.

FELLER Laurent, "Groupements, alliances et réseaux. L'organisation des solidarités familiales dans l'Italie médiévale", dans COULON Daniel, PICARD Christophe et VALÉRIAN Dominique, Espaces et réseaux en Méditerranée, $V I^{e}-X V I^{e}$ siècle, II, La formation des réseaux, p. 233-243.

GARUFI Carlo Alberto (ed.), Ryccardi de Sancto Germano Chronica, Città di Castello (R.I.S., VII, II), 1938.

GOLDBERG Jessica L., Trade and Institutions in Medieval Mediterranean. The Geniza Merchants and their Business World, Cambridge, Cambridge University Press (Cambrige Studies in Economic History), 2012.

GREIF Avner, Institutions and the path to the modern economy: lessons from medieval trade, New York, Cambridge University Press, 2006.

GRENDI Edoardo, «Profilo storico degli alberghi genovesi », Mélanges de l'École française de Rome, Moyen Âge, 87, 1975, p. 241-301.

GUERREAU Alain, «Avant le marché, les marchés », Annales HSS, 56, 6, 2001, p. 1129-1175.

GulotTa Pietro, Le imbreviature del notaio Adamo de Citella a Palermo $\left(2^{\circ}\right.$ Registro : 1299 1299), Rome, Centro di ricerca Pergamene medievali e protocolli notarili (Fonti e studi del Corpus membranarum italicarum, 3a serie, Imbreviature, matricole, statuti e formulari notarili medievali), 1982.

Le Goff Jacques, Le Moyen Âge et l'argent, Paris, éd. Perrin, 2010.

MINIERI RICCIO Camillo, Saggio di codice diplomatico formato sulle antiche scritture dell'archivio di Stato di Napoli, Supplemento I, Naples, 1883.

MOLHO Anthony et Diogo RAMADA CURTO, «Les réseaux marchands à l'époque moderne ", Annales HSC, 58, 3, 2003, p. 569-589.

PETRALIA Giuseppe, Banchieri e famiglie mercantili nel Mediterraneo aragonese. L'emigrazione dei Pisani in Sicilia nel Quattrocento, Pise, Pacini, 1989.

PetRAlia Giuseppe, «Sui Toscani in Sicilia tra Due e Trecento : la penetrazione sociale e il radicamento nei ceti urbani », dans TANGHERONI Marco ed., Commercio, finanza, funzione pubblica. Stranieri in Sicilia e in Sardegna nei secoli XIII-XV, Naples, éd. Liguori (Gisem, Europa mediterranea, Quaderni, 3), 1989, p. 129-218.

POLANYI Karl, La Grande transformation : aux origines politiques et économiques de notre temps, Paris, Gallimard, 1983.

PRODI Paolo, Settimo non rubare. Furto e mercato nella storia dell'Occidente, Bologne, il Mulino, 2009.

SIBON Juliette, Les Juifs de Marseille au XIV siècle, Paris, Éditions du Cerf (Nouvelle Gallia Judaica, 6), 2011.

SOLDANI Maria Elisa, «Tra reti internazionali e spazio urbano. Forme mercantili di comunicazione, solidarietà e gestione degli affari nel Mediterraneo occidentale bassomedievale», dans COUlON Daniel, PICARD Christophe et VALÉRIAN Dominique 
(dir.), Espaces et réseaux en Méditerranée, $V I^{e}-X V I^{e}$ siècle, I. La configuration des réseaux, p. 81109.

TODESCHINI Giacomo, Richesse franciscaine. De la pauvreté volontaire à la société de marché, Lagrasse, 2008.

TRASSELLI Carmelo, Note per la storia dei banchi in Sicilia nel XV secolo, Parte II. I banchieri e $i$ loro affari, Palerme, Banco di Sicilia, Fondazione Mormino, 1968.

White Harrison C., Identité et contrôle. Une théorie de l'émergence des formations sociales, Paris, EHESS (EHESS-Translations), 2011.

\section{Illustrations}

\section{Tableau 1 : les formes traditionnelles}

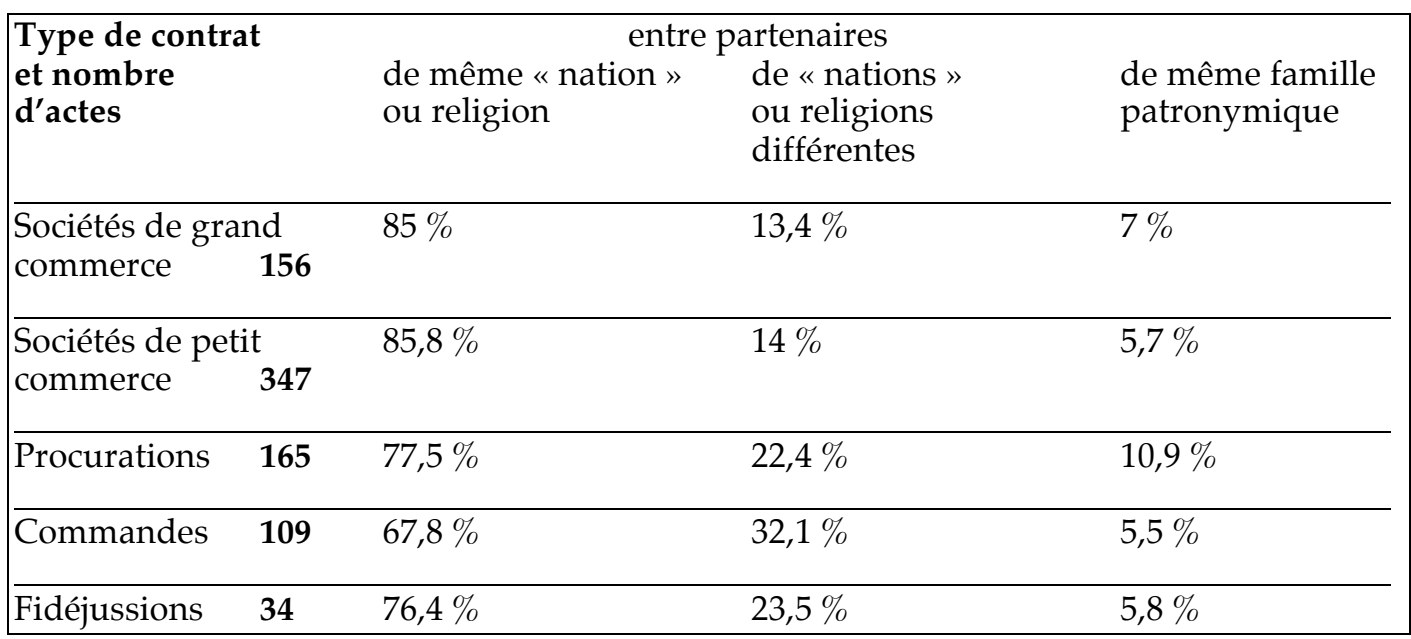

Tableau 2 : les formes innovantes

\begin{tabular}{|c|c|c|c|}
\hline $\begin{array}{l}\text { Type de contrat } \\
\text { et nombre } \\
\text { d'actes }\end{array}$ & $\begin{array}{l}\text { de même « nation » } \\
\text { ou religion }\end{array}$ & $\begin{array}{l}\text { entre partenaires } \\
\text { de « nations » } \\
\text { ou religions }\end{array}$ & $\begin{array}{l}\text { de même famille } \\
\text { patronymique } \\
\text { différentes }\end{array}$ \\
\hline $\begin{array}{l}\text { Prêts et changes } \\
\text { maritimes } \quad 198\end{array}$ & $46 \%$ & $54 \%$ & 0 \\
\hline $\begin{array}{lc}\begin{array}{l}\text { Changes } \\
\text { Lettres de } \\
\text { change }\end{array} & \mathbf{8 4} \\
& \mathbf{1 7 3}\end{array}$ & $\begin{array}{l}60,7 \% \\
50 \%\end{array}$ & $\begin{array}{l}39,2 \% \\
50 \%\end{array}$ & $\begin{array}{l}0 \\
0\end{array}$ \\
\hline $\begin{array}{l}\text { groupe d'assureurs } \\
\text { multinational } \\
\text { Assurances } \quad 311\end{array}$ & $24,1 \%$ & $75,8 \%$ & $51,7 \%$ \\
\hline
\end{tabular}


Tableau $n^{\circ} 3$ : les « carnets »

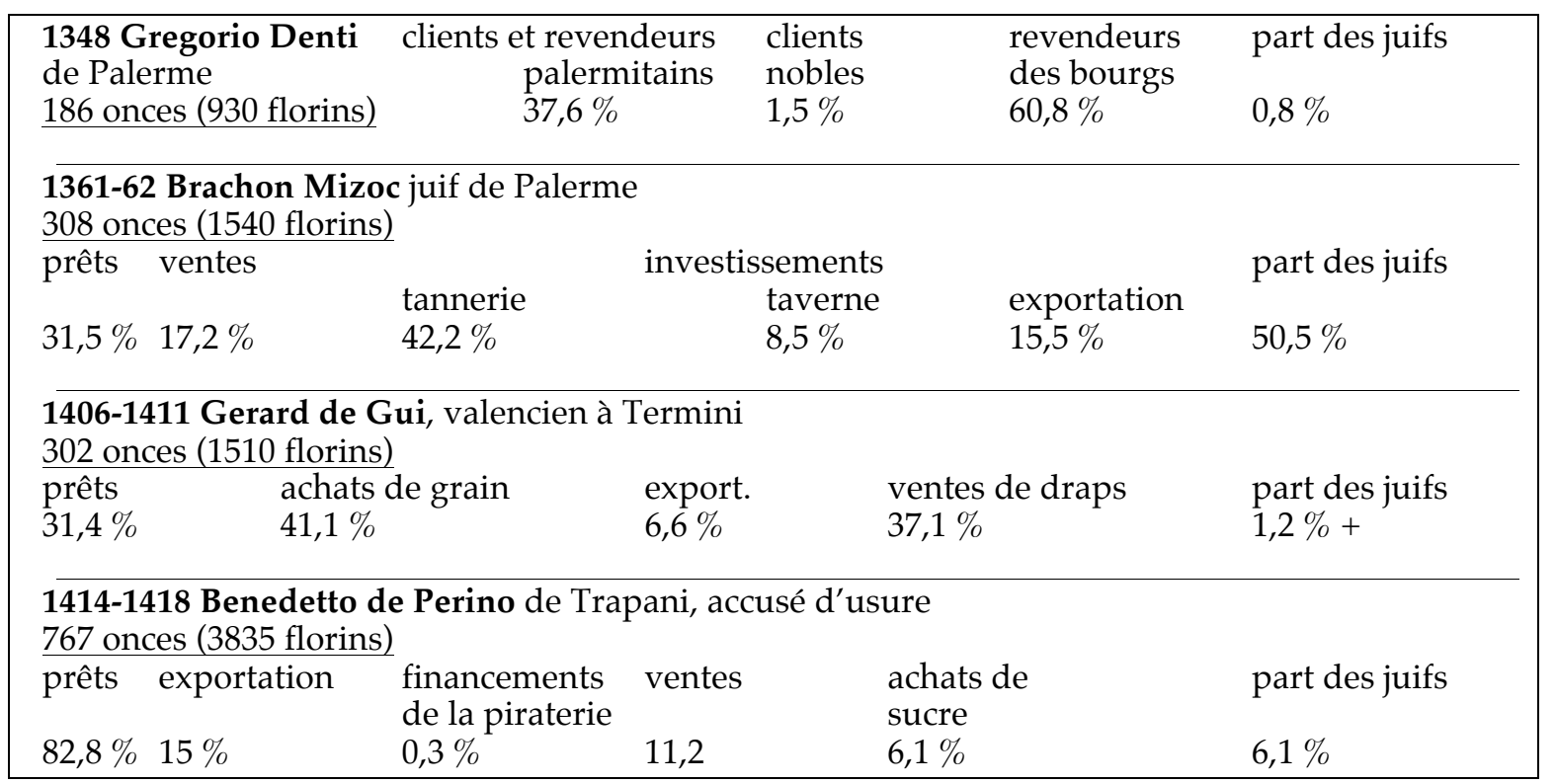

Figure 1 : Le réseau des revendeurs de draps approvisionnés à Palerme 1307-1309.

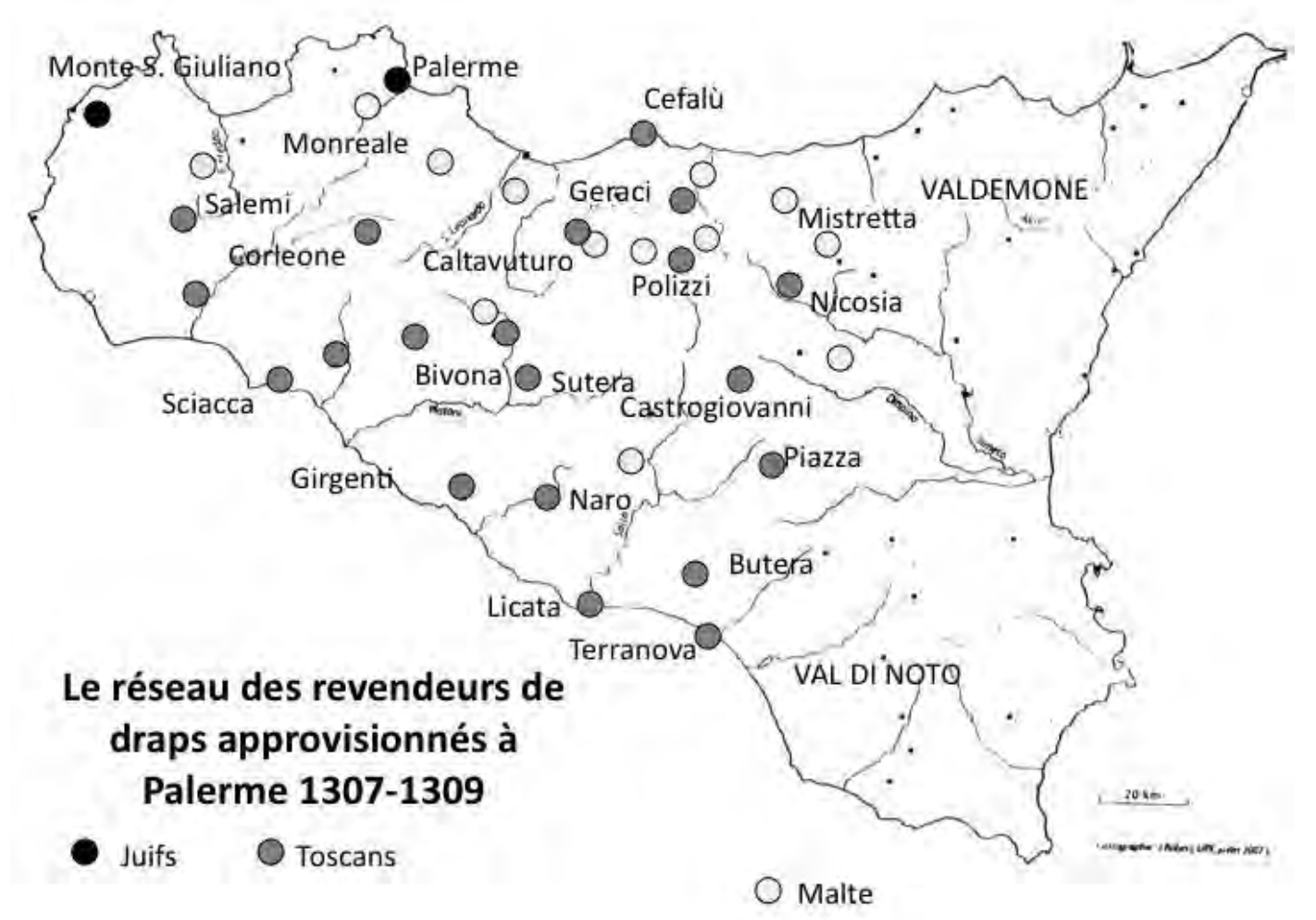


Figure 2: Un marché ouvert: échantillon de relations d'achats à crédit entre drapiers grossistes de Palerme et revendeurs des bourgs (1307-1309).

\section{Un marché ouvert : échantillon des relations d'achats à crédit entre drapiers grossistes de Palerme et revendeurs des bourgs (1307-1309)}

Grossistes

\section{Vendeurs}

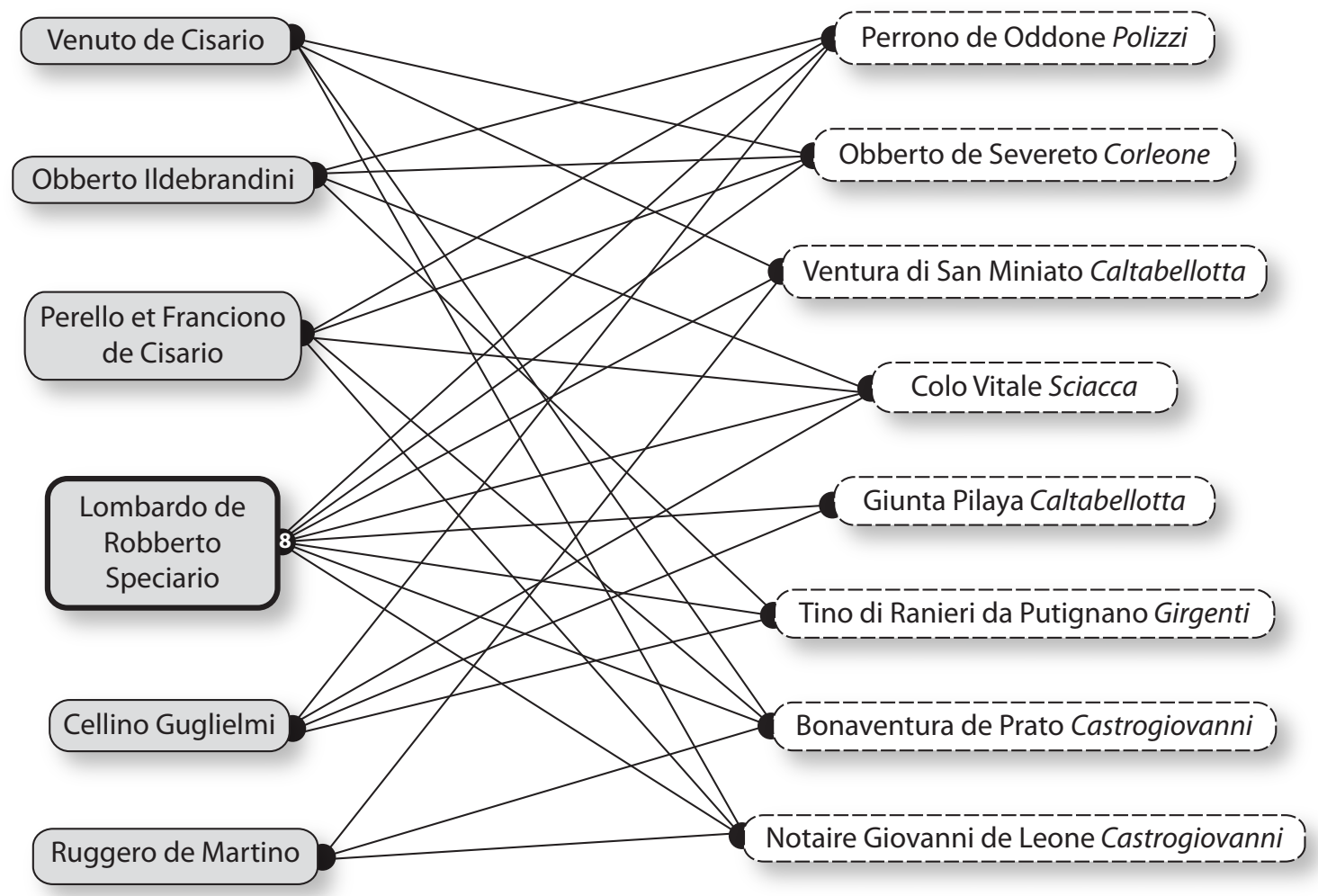


Figure 3 : Les sociétés commerciales des juifs de Palerme, enchaînement et clôture.

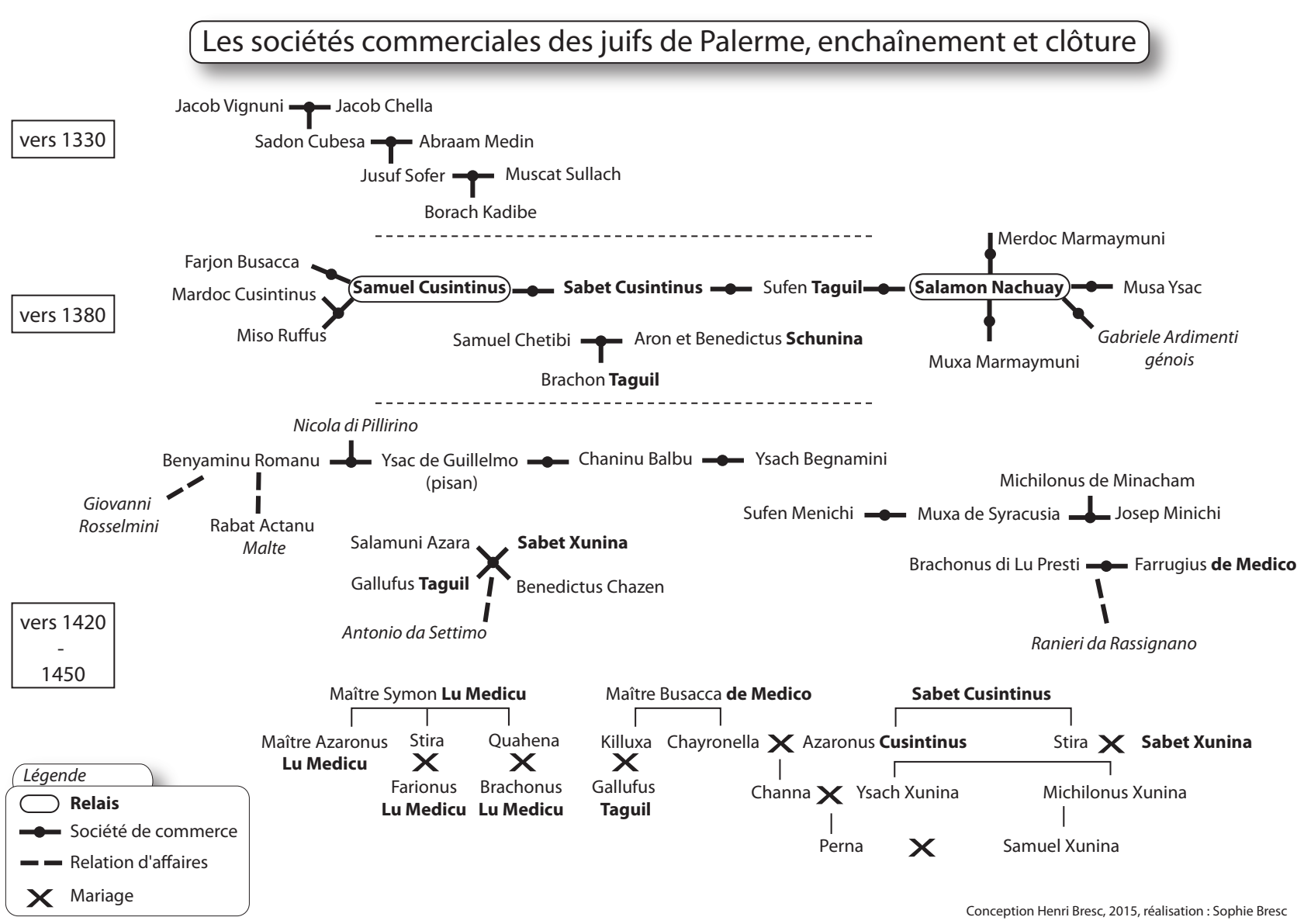


Figure 4 : Réseau ou chaîne des marchands génois et pisans à Palerme ? 1370-1380.
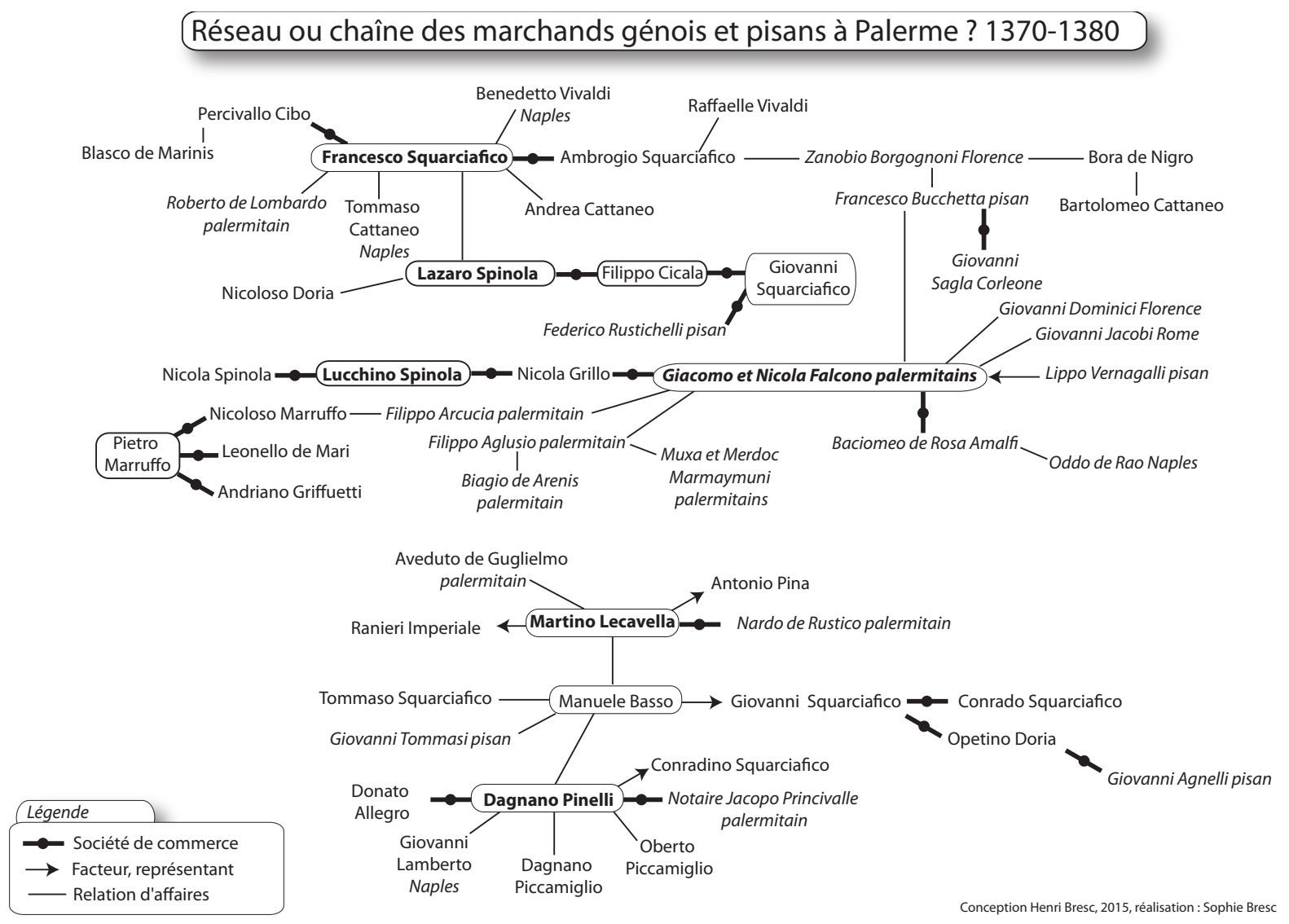
Figure 5 : Le réseau des marchands pisans à Palerme vers 1440.

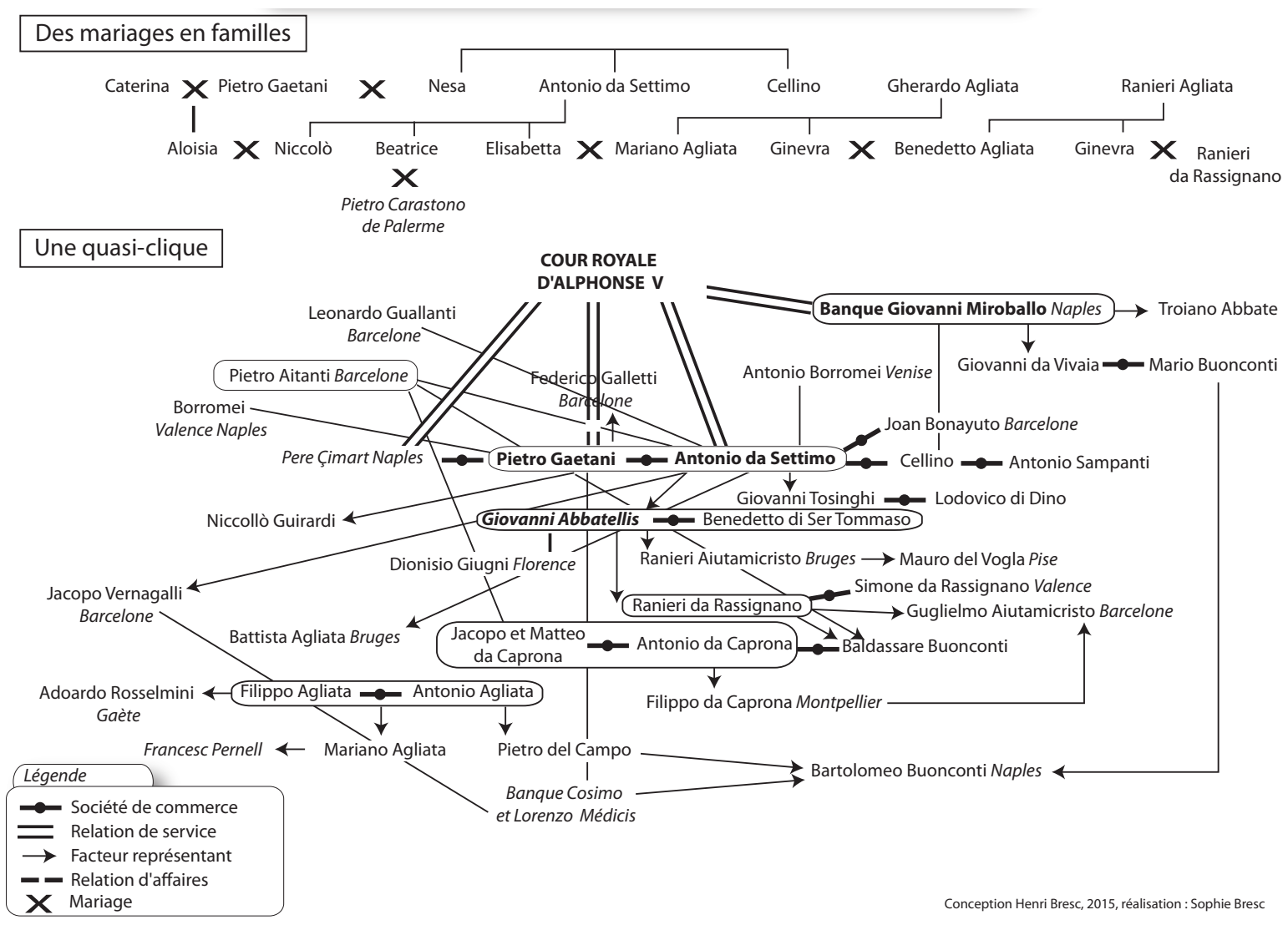




\title{
Réseaux commerciaux et financement de la carrière des Indes dans la seconde moitié $d u \mathrm{XVIII}$ siècle
}

\author{
Robert CHAMBOREDON \\ Professeur honoraire de chaire supérieure \\ Extrait de : Henri BRESC (dir.), Réseaux politiques et économiques, Paris, \\ Édition électronique du CTHS (Actes des congrès des sociétés historiques et scientifiques), 2016. \\ Cet article a été validé par le comité de lecture des Éditions du CTHS dans le cadre de la publication \\ des actes du $140^{\mathrm{e}}$ Congrès national des sociétés historiques et scientifiques tenu à Reims en 2015.
}

«Il s'agit de se faire des amis dans toutes les places et vous aurez surtout un apprentissage délicat à faire pour tirer le meilleur parti des achats en tout genre, bien connaître les sources, les fabricants, les usages de paiement et le degré de solidité. »"

Tenus six mois après la création à Cadix de la société Simon Arnail Fornier et $C^{\text {ie }}$ par un de ses commanditaires résidant à Nîmes (Barthélemy Fornier), ces propos adressés à son frère (Simon Fornier), principal gérant de l'établissement, mettent l'accent sur l'intérêt majeur de posséder des correspondants dans les places commerciales et sur les lieux de fabrique, afin de se procurer les produits manufacturés destinés avant tout à l'empire espagnol d'Amérique - les Indes occidentales -, d'écouler les produits coloniaux qui en provenaient - les fruits des Indes - et d'assurer les paiements en lettres de change - les traites et remises - un négoce ayant partie liée avec le commerce des piastres et autres matières d'or et d'argent dont le port andalou était le point d'arrivée essentiel en Europe.

Parlant d'une maison lilloise, Jean-Pierre Hirsch a montré combien sa valeur se mesurait "autant à l'étendue de sa correspondance qu'à son chiffre d'affaires ${ }^{2}$; il ne saurait en aller différemment pour les maisons françaises installées à Cadix qui tenaient le haut du pavé dans le commerce transatlantique, et plus particulièrement pour celle dont les archives ont alimenté nos travaux de recherche ${ }^{3}$. Prenant la succession de l'établissement fondé au début du XVIII siècle par les Gilly de Montpellier, celui que dirigèrent les frères Fornier - Simon et Jacques-Arnail - qui effectuèrent l'apprentissage des affaires sous la tutelle de leurs oncles Gilly à partir de 1748, fut du nombre des dix principaux établissements régnicoles présents sur les rivages atlantiques. S'il vient après ceux des Magon, Lecouteulx ou Cayla, il effectua, sous des raisons sociales différentes, la traversée du siècle, de 1701 à $1786^{4}$.

1. Archives départementales du Gard $73 \mathrm{~J} 378$ bis ; lettre de Barthélemy Fornier, de Nîmes, à Simon Fornier, à Cadix, 10 avril 1769.

2. J.-P. Hirsch, Les Deux rêves du commerce. Entreprise et institution dans la région lilloise (1780-1860), p. 271. À propos de la maison de François Briansiaux.

3. R. Chamboredon, "Fils de soie sur le théâtre des prodiges du commerce La maison Gilly-Fornier à Cadix au XVIII siècle (1748-1786)».

4. Fondé en 1701 par Élisée Gilly, le comptoir gaditan vécut jusqu'en 1724 sous les noms de Gilly et Cie et Gilly Galibert et Cie ; si le patronyme disparaît de 1724 à 1732, rien n'interdit de penser que les Gilly commanditèrent la maison Massip Cusset et Cie dans laquelle Jacques-Arnail Gilly fut placé en apprentissage ; de 1732 à $174 \mathrm{O}$, l'établissement fonctionna sous la raison sociale Gilly Cusset et Cie, puis, de 1740 à 1756, sous l'appellation Gilly frères et Cie, avant de devenir Gilly frères et Fornier frères de 1756 à 1767. Sous la direction des Fornier, la maison s'appela Simon Arnail Fornier et Cie, puis Simon et Arnail Fornier et Cie, de 1768 à 1783 et enfin Simon Fornier de Ribaupierre Médard et Cie, entre 1783 et 1786. 
Les archives consulaires conservées aux Archives nationales et au Centre des archives diplomatiques de Nantes; le fonds Roux déposé aux Archives de la chambre de commerce de Marseille Provence et le fonds Fornier de Clausonne mis en dépôt aux Archives départementales du Gard permettent, entre autres, d'attirer l'attention sur le mode de financement des expéditions vers les Amériques, dans le cadre de la carrière des Indes, autrement dit tout ce qui a trait à la navigation entre l'Espagne et ses colonies américaines $^{5}$, par le biais de l'intéressement. Le "Registre des expéditions vers l'Amérique » qui couvre les années $1748-1767^{6}$, les bilans et autres pièces comptables annuellement adressés par les gérants gaditans de la maison Fornier aux commanditaires résidant en France, de 1768 à 17867, nous ont permis, avec la correspondance commerciale et particulière conservée, de mettre en évidence l'importance des placements des particuliers dans le négoce hispano-américain, qui supposaient l'existence d'un réseau de correspondants dense et étoffé en Europe; ce faisant, nous prolongeons les travaux ébauchés par Charles Carrière il y a de cela une quarantaine d'années ${ }^{8}$.

Après avoir montré la place centrale de l'intéressement du temps des Gilly et de leurs neveux Fornier, nous tracerons les contours du réseau constitué sous ces derniers, une fois devenus seuls maîtres à bord, avant de dégager les enseignements qu'autorise l'existence de sources privées de grande qualité.

\section{L'intéressement saisi grâce à un document exceptionnel}

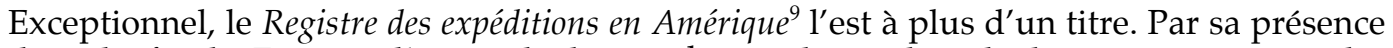
dans le fonds Fornier, l'unité de la graphie et la qualité de la présentation, et les informations qu'il contient (Fig. 1).

Y sont répertoriées les 178 expéditions qu'effectuèrent 140 bâtiments, entre Cadix et les Indes occidentales - à une exception près ${ }^{10}$ - entre le 14 mars 1748 et le 10 février 1767 , expéditions dans lesquelles les sociétés Gilly frères et $C^{\text {ie }}$ puis Gilly frères et Fornier frères furent intéressées. Parce qu'ils voulaient prouver leur innocence dans la faillite de cette dernière au début 1767 , et montrer qu'elle résultait des mauvaises opérations entreprises par leurs oncles Gilly, Simon et Jacques-Arnail Fornier firent recopier le registre original figurant dans le fonds de faillite demeuré à Cadix. Le dernier nommé l'amena avec lui lorsqu'il vint à Nîmes rencontrer son père et ses frères afin de signer le contrat de société du nouvel établissement fondé sous la direction desdits Fornier ${ }^{11}$. C'est donc une copie qui figure aux Archives du Gard; si elle ne va pas sans poser quelques problèmes ${ }^{12}$, elle n'en constitue pas moins un des fleurons des quelque 570 liasses et registres qui composent le fonds Fornier.

À côté des marchandises expédiées pour le compte des commissionnaires, qui occupent une place marginale, trois types d'opérations figurent sur le folio de droite (Fig. 2) en dessous de la date de départ et de la présentation du bâtiment (tonnage ; équipage ; encadrement...) et de la mention de sa destination; sous la rubrique Marchandises sont

5. A. García-Baquero González, La Carrera de Indias histoire du commerce hispano-américain (XVI - XVIII siècles) ; Cadiz y el Atlantico (1717-1778).

6. Archives départementales du Gard 73 J 339.

7. Ibidem $73 \mathrm{~J} 421-425$.

8. C. Carrière, « Renouveau espagnol et prêt à la grosse aventure (Notes sur la place de Cadix dans la seconde moitié du XVIII ${ }^{\mathrm{e}}$ siècle)».

9 Formellement, il s'agit d'un ouvrage de 193 folios à la couverture parcheminée d'assez grandes dimensions (38 cm de haut, $28 \mathrm{~cm}$ de large, $4,9 \mathrm{~cm}$ d'épaisseur), avec un foliotage identique sur les pages se faisant face.

10. Le Prince Charles, de la Compagnie royale de Suède, leva l'ancre vers la Chine le 31 mars 1751 ( $\left.f^{\circ} 57\right)$.

11. En juin 1768 ; il séjourna en France jusqu'en septembre de la même année.

12. Outre quelques erreurs, d'importance minime, dans le chiffrage des opérations, l'orthographe des noms des intéressés, parfois sujette à caution, et des imprécisions se rapportant à ces derniers du fait de la concision des écritures. Cf. R. Chamboredon, Fils de soie...., t. 2 p. 367, notes 2168, 2170 et 2176. 
indiquées les pacotilles expédiées outre-Atlantique, sous celle Argent figurent les prêts à la grosse aventure consentis tandis que l'appellation Expédition s'applique aux opérations d'armement. Ce ne sont pas moins de 619 pacotilles, 254 contrats de grosse et 11 opérations d'armement qui furent enregistrées vingt années durant, le tout représentant 8 millions de piastres courantes environ ${ }^{13}$.

Sur le folio de gauche sont indiqués les retours, autrement dit le produit des différentes opérations portées sur celui de droite, ce qui permet de se faire une idée de la rentabilité des expéditions ultramarines (Fig. 3).

Ce qui, sur les folios de droite, à côté de la description de chaque affaire, attire l'attention du lecteur, ce sont les listes de noms, allant de l'unité jusqu'à 123. Il s'agit des intéressés pour chacune d'entre elles, avec le montant hors frais, puis frais compris, de leur placement et, pour les pacotilles, la part de l'ensemble que celui-ci représente sous forme de pourcentage ou de fraction. Pour les trois contrats de grosse conclus sur Le SaintGeorges, parti le $1^{\text {er }}$ décembre 1751 pour Buenos Aires, nous relevons 20 intéressés pour le contrat de 22000 ps., 12 pour celui de 12000 ps., et 4 pour le dernier de 4000 ps. Si nous prenons Le Saint-Christ-du-Secours - Santo Christo del Auxilio - parti pour la Mer du Sud le 14 décembre 1753, nous nous trouvons en présence de deux contrats montant respectivement à 8500 ps. et 200000 ps. ; pour le premier, un seul intéressé : la maison Gilly frères et $C^{\text {ie }}$; sur le second, le plus important contrat signé par la société (Fig. 4a et 4b), on en dénombre $123^{14}$, pour des sommes allant de 12000 à 50 piastres hors frais. De la noblesse d'épée (le comte de Choiseul) au simple commis (Ventre), en passant par Voltaire et Madame d'Épinay, des fermiers généraux, des officiers de finances, des parlementaires, des négociants, des fabricants ou de simples particuliers, nous avons affaire à un panel fort différencié du corps social, comme le perçut fort bien le consul de France à Cadix qui tint les propos suivants :

«Une infinité de personnes de tous états en France ont voulu s'y intéresser [c'est-à-dire au commerce des Indes occidentales] tant par l'appât du gain qu'elles se promettaient que par l'abondance de l'argent qu'il y avait dans le royaume qu'on est embarrassé de bien placer. $\gg^{15}$

Les 508 appellations correspondant à 6284 intérêts ou participations, relevées dans le registre ne donnent qu'un aperçu très approximatif du nombre d'intéressés aux expéditions gaditanes. Outre certaines identifications sujettes à caution ${ }^{16}$, se pose la question des personnes morales. Ainsi, pour les Cops, de Haarlem, nous rencontrons les dénominations suivantes: Cops Guillaume Philippe et $\mathrm{C}^{\mathrm{ie}}$, Cops Guillaume Philippe et frères, Cops Guillaume et fils, Cops Guillaume, Cops Nicolas Guillaume ; seules des recherches dignes des mauristes permettraient peut-être d'identifier le nombre exact de personnes impliquées dans les intérêts pris; 131 appellations comprennent la formule " et $C^{\text {ie }}$ ", « et fils » ou encore « et frères ». On peut penser en conséquence que le nombre total d'intéressés est bien supérieur à 508, sans pour autant affirmer qu'il est plus proche de 700, voire davantage...

Socialement parlant, sachant que, faute de mieux, nous avons effectué les calculs à partir des 508 dénominations observées, 197 intéressés proviennent du monde du Négoce et de la Fabrique (30), 40 de celui de la Finance et de la Banque, 28 de la Robe, 13 de l'Épée, les 230 restants, sans appellation, représentant les « capitalistes » - c'est-à-dire les détenteurs de capitaux - autrement dénommés rentiers à la recherche de placements lucratifs. Géographiquement, compte tenu du fait que 76 n'ont pu être identifiés, la part du royaume de France domine, avec 297 mentions, Paris en totalisant à lui seul 150, très loin devant Nîmes (14) et Amiens (13). Le reste de l'Europe figure dans les 135 mentions restantes, Cadix (43) précédant Londres et Genève (20 pour chacun des deux) ou Berne

13. 8600275 piastres, y compris les envois pour le compte des commissionnaires ; 7936740 piastres sans ces dernières. La piastre courante compte 8 réaux, chaque réal équivalant à 16 quartos.

14. $\mathrm{F}^{\circ} 109$. C'est le plus grand nombre d'intéressés pour un contrat dans le registre.

15. Archives nationales, Affaires étrangères,. B \& 268, lettre du 27/9/1751.

16. S'il existe un Bellanger receveur et un Bellanger notaire, la simple mention Bellanger peut correspondre à un des deux précédents, ou à un troisième du même nom... 
(12). La place nettement plus importante des villes de l'intérieur où se situent les centres financiers (Paris, Lyon...) et les lieux de fabrique (Amiens, Silésie...) au lieu et place des franges maritimes et des ports, s'explique par le plus grand nombre d'opportunités de placements réalisables dans ces derniers.

Le négoce ne fonctionne pas en vase clos; il sollicite des adjuvants externes. D'où la quête, la recherche d'intéressés, à laquelle se livraient intensément les maisons de commerce gaditanes, à commencer par celles de la Nation française qui possédaient, suivant les calculs opérés par Antonio Garcia Baquero, les deux tiers de la valeur des cargaisons au sein de la carrière des Indes ${ }^{17}$. Tant les archives de la Chambre de commerce de Marseille Provence (fonds Roux), que celles du Centre des archives diplomatiques de Nantes, contiennent des listes d'intéressés au commerce hispanoaméricain. Par exemple, nous relevons un contrat de 28860 ps. souscrit par Garnier Mollet et Dumas sur La Conception, autrefois appelé Le Victorieux, parti le 18 novembre 1750 pour le Callao de Lima ; sur ce même bâtiment, Gilly frères et $C^{\text {ie }}$ avaient signé un contrat s'élevant à 144000 ps., et nous trouvons dans la liste des intéressés au susdit contrat, les noms des frères Beaumont, de P. Pinel et fils (Carcassonne), de J. Bouer (Genève), d'Alexandre Cannet (Amiens), de Guiller (Nogent-le-Rotrou), parties prenantes à d'autres contrats dans la maison Gilly, ou encore Guillaume Philippe Cops lequel, détenteur d'un intérêt de 1200 ps. dans celui de 144 000, en possédait un de 950 ps. dans celui de $28860^{18} \ldots$ S'il arrivait que deux, voire plusieurs maisons de commerce signent ensemble un contrat avec des emprunteurs espagnols, elles se faisaient le plus souvent concurrence pour signer ces contrats et rechercher des intéressés.

Plusieurs raisons les y poussaient. Nouer des relations utiles avec les hommes d'affaires espagnols - armateurs, chargeurs, commissionnaires... - figurait au premier chef, tant les conditions spécifiques au commerce des Indes occidentales rendaient la question du crédit primordiale, en particulier - et c'était souvent le cas - lorsque les fonds encloués en Amérique tardaient à revenir, rendant aléatoire le financement des nouvelles expéditions, que ce fût par flottes ou par navires de registre : los navios sueltos. Prêter pour faciliter la vente des produits manufacturés importés des centres de fabrication européens et, partant, faire le vide dans les magasins, relevait du simple bon sens, de même que la perspective de réaliser de substantiels profits, étant donné le niveau usuraire des taux d'intérêt. Cela dit, les capitaux dont disposaient les établissements n'étant pas illimités, et la demande étant ce qu'elle était, chercher à réduire la part détenue par ceux-ci, en mobilisant l'épargne disponible en France et dans le reste de l'Europe les amenait à rechercher des intéressés dans les divers états que comptait la société, à constituer en quelque sorte un vivier. Diviser les risques et travailler avec l'argent des autres ne sont-ils pas au nombre des facteurs de la réussite en affaires? Et ce d'autant que les maisons gaditanes prélevaient, tant pour les placements que pour les retours, une commission de $2 \%$.

C'est pourquoi elles multipliaient leurs efforts pour inciter les capitalistes-rentiers à investir dans le commerce des Indes occidentales, en particulier dans les prêts à la grosse aventure, tant les taux nominaux étaient alléchants, avant de leur proposer de s'intéresser aux expéditions de pacotilles et aux opérations d'armement. Nous connaissons bien le mode de fonctionnement de ces relations d'affaires grâce aux liasses présentes dans le fonds Fornier se rapportant aux placements de Madame Labbé de la Pinquetterie et de Michel Fornier dont la maison de commerce nîmoise gérait, à l'évidence, les portefeuilles ${ }^{19}$. Une fois la décision prise de placer de l'argent à Cadix, l'intéressé adressait une lettre de change du montant correspondant à la somme investie, en précisant celui maximum du risque à courir sur chaque navire, exigeant parfois que les

17. A. Garcia Baquero, La Carriera de las Indias. Cf. note 5.

18. Centre des archives diplomatiques de Nantes, consulat de Cadix, 73.

19. Archives départementales du Gard, 73 J 337 et 355 pour Michel Fornier ; ibidem 354 pour Mme Labbé de la Pinquetterie. Depuis Nîmes, Barthélemy Fornier et, avant lui, son père François, ne ménageaient pas leurs efforts pour procurer des intéressés au comptoir gaditan, que ce soit par le truchement de la correspondance ou à l'occasion de leurs déplacements en Languedoc, à Marseille ou en Suisse. 
placements portent sur les bâtiments sur lesquels la société était également intéressée. La société de Cadix choisissait les embarcations sur lesquelles le risque courrait et leur destination, sans parler de l'époque présumée du départ de ces dernières. Un compte courant était ouvert au nom de l'intéressé(e) - une quarantaine de femmes figurent parmi les 508 appellations relevées - qui en recevait au moins un relevé annuel ; ledit compte était débité du montant des placements réalisés, et crédité de celui des rentrées de fonds opérées à ce titre. Une correspondance avec l'intéressé l'informait des résultats, indiquant les mouvements des navires et fournissant des informations diverses relatives au négoce transatlantique dans le cadre de la Carrière des Indes. Ainsi Voltaire, dont la correspondance montre combien il suivait les affaires qu'il avait à Cadix avec la maison Gilly frères et $C^{\text {ie }}$, n'a pas pu ne pas savoir que les 2500 ps. d'intérêt - 8500 l. t. environ -qu'il avait dans un contrat de grosse sur le Saint-Georges, précédemment évoqué, était un navire négrier qui, avant de gagner Buenos Aires, devait faire escale en Guinée (Fig. 1). Même si c'est à son corps défendant, il a bel et bien été impliqué dans la traite ${ }^{20}$.

La recherche d'intéressés était d'autant plus nécessaire que la longueur de nombreuses affaires décourageait ces derniers qui, à l'image de l'hôte de Ferney, s'inquiétaient de ne pas voir le retour de leurs fonds plus rapidement. La volatilité de l'offre des capitaux justifiait cette quête permanente ${ }^{21}$. Des événements personnels, la déception consécutive au mauvais résultat enregistré dans certaines affaires, à la suite de la défaillance des emprunteurs-débiteurs le plus souvent, la recherche de placements plus sûrs, ou encore le désir de ne pas renouveler un placement opéré pour obliger les associés de la maison de Cadix, entraînaient la fin des opérations, sinon la clôture du compte courant, une fois le retour des fonds devenu effectif, ce qui pouvait prendre du temps...

Gros cétacés et menu fretin cohabitaient parmi les intéressés, tous pris dans les rets des filets tendus par les maisons de commerce du port andalou; il y a loin, pour reprendre l'exemple du Saint Christ du Secours, entre les 12000 ps. placées par les négociants londoniens Abraham et Jacob Franco, et les 50 ps. déboursées par la Gaditane Francesca Padel mais il n'empêche: ce «capitalisme atomique» dont parla François Perroux, qualifié de «Lilliputien » par Pierre Vilar, fut, pour Charles Carrière « la forme la plus originale des liens unissant capitalisme occidental et grand négoce hispano-américain ${ }^{22}$ ». Il permit de mobiliser l'épargne dormante en Europe et, par capillarité, de la drainer vers le port andalou. Voilà qui supposait, pour les établissements qui y avaient pignon sur rue, de disposer d'un réseau de correspondants sur le Vieux continent.

\section{Le réseau européen de la Maison Fornier}

Vingt et un mois après la faillite de Gilly frères et Fornier frères, la maison Simon Arnail Fornier et $C^{\mathrm{ie}}$ voyait le jour ; elle devait poursuivre ses activités jusqu'en mars 1786, date à laquelle elle suspendit à son tour ses paiements ${ }^{23}$. Grâce aux dix-huit bilans et à leurs pièces annexes ${ }^{24}$, annuellement adressés par les gérants aux commanditaires de France, nous avons pu cartographier le réseau des correspondants de l'établissement. La correspondance, tant commerciale que particulière, a permis également d'être au fait des activités entreprises avec ceux-ci. Véritable faire-part de naissance, une lettre circulaire indiquant la raison sociale de la société, les noms des associés avec leur signature, et un aperçu jugé suffisant des facultés dont ils disposaient - «des fonds suffisants pour bénéficier de la confiance du public »; « des fonds assez considérables » -, soulignaient

20. R. Chamboredon, « Des placements de Voltaire à Cadix ».

21. 31,1\% des intéressés ne le furent que pour un an et 51,7\% pour deux; parmi les $17 \%$ restant, 19 d'entre eux le furent entre 10 et 13 ans. Voltaire eut des capitaux investis dans les expéditions de Gilly frères et Cie de 1749 à 1756.

22. C. Carrière, « Renouveau espagnol... », p. 234.

23. Pour éviter toute confusion, la conjonction et fut ajoutée entre Simon et Arnail, et le nom de ce dernier demeura même après son décès en 1773 ; à compter de 1783, la société roula sous l'appellation Simon Fornier de Ribaupierre Médard et Cie.

24. Archives départementales du Gard 73 J 421-425. 
les talents des gérants, leur expérience, leur savoir-faire, avant de manifester l'espérance que des relations réciproquement avantageuses seraient nouées avec les destinataires. Destinée à asseoir le crédit et la réputation du comptoir, elle revêtait un caractère à la fois publiciste et privatiste ${ }^{25}$.

Si nous ignorons le nombre des destinataires, nous pouvons supposer qu'elle fût adressée aux correspondants de la défunte maison Gilly, laquelle comptait 287 intéressés au moment de sa disparition ${ }^{26}$; nous savons, par ailleurs, que les commanditaires, véritables caisses de résonance, employèrent une part non négligeable de leur énergie à procurer des adresses et des recommandations à l'établissement gaditan. Depuis Paris, où il effectuait le commerce de banque, Arnail Fornier usa de ses relations avec la partie septentrionale de l'Europe, de l'Angleterre à la Prusse; depuis Nîmes, Barthélemy Fornier adressa la lettre circulaire à 52 maisons exerçant prioritairement leurs activités dans le bassin occidental de la Méditerranée et la partie médiane de l'Europe. À l'occasion de ses nombreux déplacements, en Suisse pour rendre visite à ses fils placés en pension, à Marseille où il allait rencontrer la parentèle, à Beaucaire et Alès au moment des foires de la Madeleine et de la Saint-Barthélemy, dans la région de Carcassonne et Toulouse pour y visiter les fabriques de draps, ou encore à Montpellier à l'occasion de la tenue des États de Languedoc, le commanditaire nîmois ne manquait pas de chanter les louanges de l'établissement gaditan et de chercher des intéressés pour les placements évoqués ci-devant. Et il faisait de même lorsqu'il accueillait des hôtes de passage dans la cité nîmoise ${ }^{27}$.

Moins de deux mois avant le début des activités de la nouvelle maison, il écrivit à Magon de La Blinais de Saint-Malo :

«Le malheur, la bonne conduite et le talent de nos deux frères nous a décidé [sic] de concourir à leur rétablissement par une société en commandite que nous avons faite avec eux et dont vous serez bientôt informé. $»^{28}$

Quatre ans plus tard, il recommandait aux gérants d'avoir plusieurs "amis » dans une même ville et de ne pas dépendre d'un seul ${ }^{29}$, après qu'il les eut conviés d'en avoir dans toutes les places $^{30}$. Qu'en résultât-il?

Les deux cartes dressées à partir des sources précédemment évoquées (Fig. 5 et 6) apportent des éléments de réponse ; la première, prenant en compte le nombre d'années de correspondance cumulées, présente un caractère exhaustif et diffus; la seconde, en ne prenant en considération que les personnes morales étant restées en correspondance avec la maison de Cadix durant sept années au moins, met en évidence l'ossature, la polarisation, du réseau. Si nous dénombrons 105 lieux sur l'une, il n'en reste plus que quarante sur l'autre. Quels enseignements en tirer?

Géographiquement, deux grands ensembles se distinguent en Europe. L'un, septentrional, de Nantes à Hambourg, avec l'appendice silésien en sus, correspond à l'espace de la toilerie, avec la Bretagne, la Normandie, l'Angleterre, les Pays-Bas autrichiens, les Provinces-Unies et la Prusse. L'autre, méridional, de Malaga à Naples, représente celui de la soierie avec son prolongement rhodanien et helvétique. Deux dominantes textiles mâtinées de draperie avec l'Angleterre et la Normandie pour la

25. Nous ne disposons pas d'un exemplaire de ladite lettre dans le fonds Fornier; son contenu a pu être établi à partir de bribes relevées dans la correspondance active de la maison de commerce de Nîmes que dirigeait Barthélemy Fornier (Ibidem 73 J 359-375). Nous avons trouvé des exemplaires de lettres circulaires dans le fonds Roux de la CCMP, en particulier celle de Massip Cusset et Cie, en 1729 (Archives de la Chambre de commerce de Marseille Provence L IX 856).

26. Quelques-uns de ses correspondants, à l'image de Guiguer de Prangins à Genève, Van Robais d'Abbeville, Quentin et Cie de Saint-Malo, cessèrent toute relation avec la maison Fornier.

27. R. Chamboredon, «Le négociant-hôte : une forme diffuse de sociabilité au XVIII siècle " Provence historique

28. Archives départementales du Gard 73 J 362.

29. Ibidem $73 \mathrm{~J} 366$, lettre à Simon Arnail Fornier et Cie du 6/7/1772.

30. $C f$. note 1 accompagnant la citation liminaire. 
première, le Haut-Languedoc pour la seconde. Les adeptes de la modélisation, à défaut de "banane bleue», pourront discourir sur l'existence, entre eux, d'une "diagonale aride » au sein de laquelle quelques « oasis » émergent : Madrid, Bayonne, Bordeaux ou encore Francfort pour nous limiter à l'essentiel.

Un mot sur les Indes occidentales, en tant que prolongement de l'Europe : la maison n'avait de représentant permanent que dans les principaux centres commerciaux: Veracruz, Lima, Carthagène. En règle générale, les commissionnaires qui embarquaient avec les cargaisons se chargeaient du retour des fonds; trois d'entre eux y étaient affectés, avec les ordres ad hoc. Ce disant, la lenteur desdits retours, en particulier à Buenos Aires et dans les finistères de l'empire (Campêche; Porto-Rico, la côte de Caraques...) obligeait les gérants à dépêcher parfois quelque fondé de pouvoir dans l'espoir de faciliter le recouvrement des fonds encloués outre-Atlantique.

Revenons sur le Vieux continent. Nous pouvons également distinguer entre les franges maritimes et l'intérieur des terres. Plusieurs pôles portuaires se détachent; en Méditerranée, Marseille domine largement Gênes et plus encore Livourne, Naples ou Valence; pour les mers épicontinentales de l'Atlantique, Amsterdam, Londres, Hambourg et Rouen affirment leur supériorité aux côtés de Gand dont la position relève des deux espaces que nous avons distingués. À l'intérieur, les lieux de fabrique sont aisément repérables: la Silésie, la Saxe, ou encore la Picardie au Nord; le HautLanguedoc au Sud. Centres manufacturiers, mais surtout financiers et bancaires, Paris, Lyon et les villes suisses ressortent également. Derrière le binôme ports-cités de l'intérieur, la concurrence se manifeste; ainsi, pour les toiles de Silésie - ces toiles "contrefaites » qui prirent le pas au XVIII siècle sur celles "légitimes » fabriquées en Bretagne $-60 \%$ furent commandées aux correspondants résidant à Hambourg, les $40 \%$ restant l'étant à Schmiedeberg, Landeshut ou Hirschberg; il en alla le plus souvent de même pour d'autres régions, à commencer par Londres qui éclipsa les centres industriels de la Grande-Bretagne. Pour ce qui est des « fruits des Indes », autrement dit les produits coloniaux, les maisons présentes dans les ports se chargeaient de leur redistribution dans leurs hinterlands respectifs. Faire jouer la concurrence, entretenir l'émulation, permettaient aux gérants d'obtenir des « douceurs » sur le montant de la commission, des provisions exigées, ou encore d'inviter leurs correspondants à s'intéresser aux expéditions de marchandises, tout en recherchant des produits de la meilleure qualité possible.

Quels furent les éléments structurants du réseau? Les liens familiaux priment sans l'ombre d'un doute. Fonctionnant, comme les sociétés Gilly, sur un mode triangulaire dont Cadix, Paris et Nîmes constituent les sommets, la maison Fornier correspondit en premier lieu avec des établissements dirigés par leurs parents; à Marseille, les cousins Jean et Jacques Fornier, issus d'une branche alésienne de la famille, furent aux premières loges, tout comme les Vernède d'Amsterdam qui furent leurs correspondants affidés dans le port hollandais. Les liens matrimoniaux jouèrent les premiers rôles ; en épousant, en 1759, Suzanne André, Barthélemy Fornier entra dans la parentèle d'une tribu prolifique s'il en fût ${ }^{31}$. À Londres, Antoine et Jean-Louis de leur côté, David du sien, tous trois frères, sont des cousins germains du commanditaire nîmois, de même que Guillaume installé à Naples; à Gênes, Joseph est son beau-frère, tout comme le sont David, Jean et François, tous trois associés à Lyon, le dernier nommé «montant » ensuite à Paris pour se livrer au négoce de banque sous la raison André et Bègue. Ajoutons à cela que la mère de Suzanne André est une Audibert dont les frères Joseph, Georges et Dominique tiennent le haut du pavé dans le négoce marseillais et ont passé des alliances matrimoniales avec les Hugues qui ne le leur cèdent en rien ${ }^{32}$. Quant à sa cousine germaine Isabelle, n'a-t-elle pas uni sa destinée à Louis Necker, le frère de Jacques, plus connu sous l'appellation Necker de Germany?

31. V. Monnier, Les André, une famille de négociants réformés de Nîmes au XVIII siècle.

32. C. Carrière, Négociants marseillais au XVIII siècle. Contribution à l'étude des économies maritimes. 
S'il faut faire une place aux «pays », c'est-à-dire aux Nîmois, tels les Maystre présents à Marseille et Gênes, ou encore les Teissier installés, en sus du port ligure, à Londres et Naples, c'est surtout vers l' «Internationale huguenote », la diaspora calviniste ou encore la «Banque protestante » chère à Herbert Lüthy qu'il convient de diriger nos regards ${ }^{33}$. Quasiment tous ses fleurons figurent au sein du réseau du comptoir gaditan : à Paris Thellusson Necker et $C^{\text {ie }}$ dont Germany Girardot et $C^{\text {ie }}$ puis Girardot Haller et $C^{\text {ie }}$ continuèrent les activités, fut, avec Arnail Fornier puis André et Bègue, son principal correspondant pour le commerce des traites et remises; à Marseille, aux côtés des Fornier, des Audibert et des Hugues, déjà cités, Peschier Bouillon et $C^{\text {ie }}$, Jean et Jacques Kick, Zeslin Languensée et $C^{\text {ie }}$, Jacques et Louis Seimandy, Dolier et $C^{\text {ie }}$ furent en affaires avec Cadix; à Londres, en sus des André, Pierre Thellusson, John et Francis Baring, Bourdieu et Chollet firent de même ; à Hambourg, Diodatti Poppe et $C^{\text {ie }}$, Pierre Boué et fils ou encore Gaspard Voght furent dans le même cas, et nous pourrions allonger la liste. Ce qui n'empêcha pas nos "parpaillots », l'œcuménisme commercial aidant, d'être en relation avec les très catholiques Magon et autres Lecouteulx, également présents à Cadix, Paris, Saint-Malo ou Rouen.

Autre diaspora, bien représentée dans la clientèle de la maison de Cadix, celle sépharade, avec, pour Londres, Jean et Alphonse de Eguino et Moïse Mendès Dacosta, qui succédèrent à Ephraïm de Aguilar ou encore Abraham et Jacob Franco qui commercèrent avec la société Gilly; pour Hambourg, Antoine de Sanpelayo ; pour Bordeaux, Azevedo et Robles fils - également présents à Bayonne - Azevedo et Dacosta, sans omettre Samuel Peixotto qui, en tant que directeur de l'hôtel de la Monnaie, était une référence incontournable pour le trafic des piastres et des autres matières d'or et d'argent donc Cadix était le principal centre européen, de même que pour la cochenille.

Sur les principales places de négoce, la société avait un correspondant affidé qui lui servait de facteur ou de commissionnaire principal, quel que soit le type d'affaires: Jean et Jacques Fornier et $C^{\text {ie }}$ dans la cité phocéenne, Vernède et $C^{\text {ie }}$ pour le pôle amstellodamois, ainsi que nous l'avons déjà mentionné, André frères et $C^{i e}$ à Lyon ou encore la maison Boissier Lamande et André à Gênes. Leur caractère familial en est la raison essentielle, mais non exclusive ${ }^{34}$. Sans que ce soit systématique, une tendance à la spécialisation, en fonction des produits échangés, put être observée: à Amsterdam, Wilhelm et Jean Willinck reçurent de préférence les produits coloniaux à partir de 1778, date à laquelle Hope et $C^{\mathrm{ie}}$, en liaison avec Girardot Haller et $C^{\text {ie }}$ furent impliqués - pour un volume somme toute limité - dans les affaires de banque que les Fornier souhaitèrent toujours distinguer, autant que faire se pouvait, de celles en marchandises; à Londres, si Pierre Thellusson s'occupa essentiellement du négoce des piastres, J. et F. Baring expédièrent en Andalousie des lainages et des toiles peintes, tandis que Édouard Van Harthals - ancien commis des Vernède en Hollande - réceptionnait les fruits des Indes ; pour Rouen, Horutener Huber et Cie firent de même avec le métal blanc en plus, Robert et Louis Durand importèrent du quinquina et du jalap, Nicolas Midy des cuirs et de la laine, Achard frères et Cie des produits coloniaux. Nous pourrions poursuivre dans le même sens en portant notre regard vers Lyon ou Marseille. Ce qui conduit à la question des critères de sélection qui prévalurent dans le choix des correspondants. "[Pour les] affaires majeures, n'ayez affaire qu'à des maisons du premier ordre35»: qu'entendre à pareille recommandation? Alors qu'Honoré Lieutaud, qui fut un temps du nombre des gérants de la maison de Cadix, allait effectuer un voyage dans les Pays-Bas autrichiens, Jacques-Arnail Fornier lui conseilla d'y rechercher des «maisons opulentes, délicates, honnêtes, prenant un intérêt. » ${ }^{36}$

33. H. Lüthy, La Banque Protestante en France de la Révocation de l'Édit de Nantes à la Révolution.

34. Les aptitudes, les talents priment. Ainsi, David André, le cousin germain installé à Londres, qui accumula les faillites, ne jouit pas d'une grande estime dans l'esprit du commanditaire nîmois.

35. Archives départementales du Gard $73 \mathrm{~J} \mathrm{372,} \mathrm{lettre} \mathrm{de} \mathrm{B.} \mathrm{Fornier} \mathrm{à} \mathrm{Simon} \mathrm{et} \mathrm{Arnail} \mathrm{Fornier} \mathrm{et} \mathrm{Cie} \mathrm{du}$ 4/2/1777.

36. Ibidem 73 J 394, lettre de J.-A. Fornier à Honoré Lieutaud, du 15/9/1772. Originaire de Digne, Honoré Lieutaud était de confession catholique. 
En quelques mots l'essentiel est dit. Les facultés, la solidité, la richesse, les moyens financiers donc, constituent le socle, le support du crédit ; mais cela ne saurait suffire. Les talents doivent également être au rendez-vous : être actif, diligent, dans la conduite des affaires, tout en opérant avec application, sagesse, assiduité, était très prisé au côté de la qualité des informations fournies au moyen d'une correspondance étoffée. Si l'honnêteté est mise en avant, elle va de pair avec la délicatesse dont il convient de faire montre : les petits gestes consistant à réduire le montant de la commission exigée, d'intervenir afin d'éviter le protêt d'une lettre de change, d'accorder un délai supplémentaire pour une créance à recouvrer contribuaient à renforcer la sympathie entre les partenaires dans leurs relations d'affaires, et ce au point d'invoquer l'amitié. Mais qu'on ne s'y trompe pas, la vigilance ne devait pas se relâcher, et le moindre manquement pouvait éveiller le soupçon. Parce qu'il est essentiel dans le monde du négoce, le crédit, au sens large du terme, devait être ménagé avec le plus grand soin, tant la moindre rumeur pouvait entraîner des effets dévastateurs.

Déployer des trésors de diplomatie était souvent indispensable. Plusieurs correspondants de l'établissement andalou dont nous nous occupons entretenaient des liens avec d'autres sociétés gaditanes : Magon de la Blinais avec Magon et Lefer frères ; David Auriol et fils, de Lyon, avec la même société Magon; Rogon et Dengallière, de Marseille, avec Cayla Solier Cabanes et Jugla, et nous pourrions continuer la liste. Il convenait alors de se tenir sur ses gardes et de ne pas fournir des informations susceptibles de se retourner contre les intérêts de l'établissement. Il arrivait, par ailleurs, que des jalousies existassent entre les maisons d'une même place entretenant des liens avec le comptoir gaditan. Ainsi, à Gênes, Joseph André se montrait susceptible à propos de ceux noués depuis Cadix avec les sociétés Garibaldi et Maystre dans le port ligure. Ménager tout un chacun nécessitait de la patience et du tact. Avoir en permanence l'œil sur les membres de son réseau de correspondants, rechercher le «point juste »- en paraphrasant Diderot dans Le Paradoxe sur le comédien - auquel il convenait de se placer et de s'arrêter dans les rapports avec eux n'allait pas toujours de soi. De solides principes et un pragmatisme de bon aloi pouvaient y contribuer. Ce d'autant que chaque société connaissait des changements qui n'étaient pas toujours perçus dans l'immédiat ; ainsi, la mort de Jacobs-Henry Vernède, très estimé pour ses qualités, en 1777, puis, trois ans plus tard, la retraite de son frère cadet Barthélemy-Jacques, "prudent et appliqué », ainsi que l'arrivée aux commandes de la maison d'Amsterdam de leur neveu Jean-Théophile, âgé de vingt ans, aux côtés de Schmith, commis de confiance élevé au rang d'associé, suscitèrent ce jugement de $B$. Fornier : «La maison Vernède a bien déchu dans l'opinion publique depuis la mort de l'aîné et déchoira encore plus avec la retraite en Suisse de Barthélemy Vernède ${ }^{37}$ ». Il convenait d'en prendre acte ; aucune position n'était à l'abri d'une mise en question.

Au terme de cette étude de cas, nécessairement limitée, du réseau d'un établissement qui figura parmi les principales maisons françaises opérant à Cadix, plusieurs centres d'intérêt peuvent être dégagés. Recourir aux métaphores de l'appareil sanguin ou du système nerveux pour rendre compte du fonctionnement d'un réseau - capillarité ; centre d'impulsion; points nodaux; connexions... - est tout à fait justifié. De même que l'existence d'une hiérarchie interne dont nous avons donné quelques exemples. L'ouverture des réseaux sur la société, par la voie de l'intéressement, mérite qu'on lui accorde la considération qu'elle mérite: le négoce a un besoin pressant d'adjuvants extérieurs; travailler avec l'argent des autres; rappelons le n'est-il pas une clef de la réussite dans le monde des affaires ? Supports des flux de marchandises, de capitaux, d'informations de tous ordres, les réseaux demeuraient fragiles, vulnérables, du fait des aléas de la conjoncture, et de nombreux efforts devaient être dispensés afin de les maintenir, élargir et les rendre les plus efficaces possibles. 
En raison même des spécificités du commerce au sein de la carrière des Indes, qui nécessitait de mobiliser d'énormes capitaux, et dont les pesanteurs, dans le cadre du monopole, entravaient la fluidité, la question du crédit revêtait à Cadix une importance hors pair. Si les prêts à la grosse aventure pouvaient présenter un caractère archaïque et léonin, ils étaient aussi adaptés aux caractères que revêtait le négoce transatlantique sous l'égide de l'Espagne, et ce ne fut pas le moindre des mérites des maisons étrangères installées sur les rives andalouses de l'Atlantique que de drainer vers elles les capitaux dormants en France et dans le reste de l'Europe.

C'est à la faveur de la mobilisation de ces fonds par le biais des réseaux que furent financées les expéditions vers les Indes occidentales espagnoles. Les sociétés étrangères présentes à Cadix rétrocédaient à des particuliers des portions d'intérêts qui diminuaient d'autant les sommes qu'elles investissaient dans ce négoce, ce qui leur permettait de ventiler les risques de toucher $2 \%$ de commission, tant à l'aller qu'au retour comme nous l'avons déjà indiqué, et de renforcer leurs relations avec les negociantes, cargadores, et autres perouleros, autrement dit les représentants des hombres de negocios péruviens. Il s'agissait bien d'intéressement et non d'actionnariat, comme quelques historiens l'ont écrit $^{38}$. Un effort de clarification est, à ce propos, nécessaire ${ }^{39}$.

Enfin, nous nous permettrons d'apporter notre caillou aux débats historiographiques à propos de la «nouvelle histoire Atlantique » qui a défrayé et défraie encore la chronique dans le landernau des historiens : à bien y regarder, par le truchement de l'intéressement et des flux souvent invisibles de capitaux, l'Atlantique commence aussi bien à Cadix qu'à Gênes ou Marseille, Schmiedeberg, Breslau ou Reims... Et Cadix est bien, ainsi que l'avait écrit le chevalier Bourgoing au siècle des Lumières, le «balcon de l'Europe ».

\footnotetext{
Résumé

Les documents commerciaux contenus dans le fonds Fornier de Clausonne déposé aux Archives départementales du Gard, à commencer par le Registre des expéditions vers l'Amérique (1748-1767) et les Bilans et pièces annexes couvrant la période 1768-1786, permettent de reconstituer le réseau des correspondants de la société dirigée par les Fornier à Cadix, qui fut du nombre des dix plus importants établissements français présents en Andalousie, et de révéler l'importance de l'intéressement pour le financement des expéditions vers les Indes occidentales lorsque deux des frères Fornier firent leur apprentissage à Cadix sous la houlette de leurs oncles Gilly avant de devenir associés gérants.

Outre la présentation de ces sources exceptionnelles, la communication expose les grandes lignes de l'intéressement au négoce hispano-américain en marchandises, prêts à la grosse aventure et armement, ainsi que le réseau européen de la maison Fornier, avant de dégager quelques conclusions.
}

38. L. Dermigny, Cargaisons Indiennes, Solier et Cie (1781-1793), t. 1, p. 169-184, qui écrit: «compagnie assez lâche, remaniée d'armement en armement, avec cependant un noyau permanent » et qui utilise le terme « actionnaies ».

39. O. Le Gouic, Lyon et la mer au XVIII siècle. Connexions atlantiques et commerce colonial. S'il écrit, p. 166 : «Le capital est divisé en parts d'intérêt, dont la valeur varie de quelques centaines à plusieurs milliers de livres ", il parle de recours à des « associés extérieurs », avant d'évoquer, trois pages plus loin, des "sous-intéressés » ou des «croupiers", mentionnant des «billets d'association » et de finir, à propos des placements de Melchior Philibert, en disant : « ses intéressements sont qualifiés d'intérêts en armement » ou « en pacotille »... 


\section{Bibliographie}

CHAMBOREDON Robert, «Fils de soie sur le thêâtre des prodiges du commerce La maison GillyFornier à Cadix au XVIII e siècle (1748-1786) », Université de Toulouse-Le Mirail, 1995. Thèse de doctorat sous la direction du professeur Bartolomé Bennassar, 3 vol.

Chamboredon Robert, «Des placements de Voltaire à Cadix », Cahiers Voltaire n 7, 2008, p. 41-72.

CHAMBOREDON Robert, "Le négociant-hôte: une forme diffuse de sociabilité au XVIII siècle ", Provence historique, tome 47, fascicule 187, 1997, p. 201-213.

GARCíA-BAQUERO González Antonio, La Carrera de Indias histoire du commerce hispanoaméricain (XVI - XVIII ${ }^{e}$ siècles), Paris, Desjonquères, 1997.

GarCíA-BAQUero GonZÁlez Antonio, Cadiz y el Atlantico (1717-1778), Séville, 1976, 2 vol.

CARRIÈRE Charles, Négociants marseillais au XVIII' siècle. Contribution à l'étude des économies maritimes, Marseille, 1973, 2 vol.

CARRIÈRE Charles, «Renouveau espagnol et prêt à la grosse aventure (Notes sur la place de Cadix dans la seconde moitié du XVIII ${ }^{\mathrm{e}}$ siècle)", Revue d'histoire moderne et contemporaine, avril-juin 1970, tome XVII, p. 221-252.

DeRMigny Louis, Cargaisons Indiennes, Solier et $C^{i e}$ (1781-1793), Paris, SEVPEN, 1959, 2 vol.

HIRSCH Jean-Pierre, Les Deux rêves du commerce. Entreprise et institution dans la région lilloise (1780-1860), Paris, Éditions de l’EHESS, 1991.

LE GOUIC Olivier, Lyon et la mer au XVIII siècle Connexions atlantiques et commerce colonial, Rennes, PUR, 2011

LÜTHY Herbert, La Banque Protestante en France de la Révocation de l'Édit de Nantes à la Révolution, Paris, SEVPEN, 1959-1962, 2 vol.

MONNIER Virginie, Les André, une famille de négociants réformés de Nîmes au XVIII siècle, Nîmes, Lacour, 1990. 


\section{Illustrations}

Figure 1 : Le Saint-Georges Folio 74

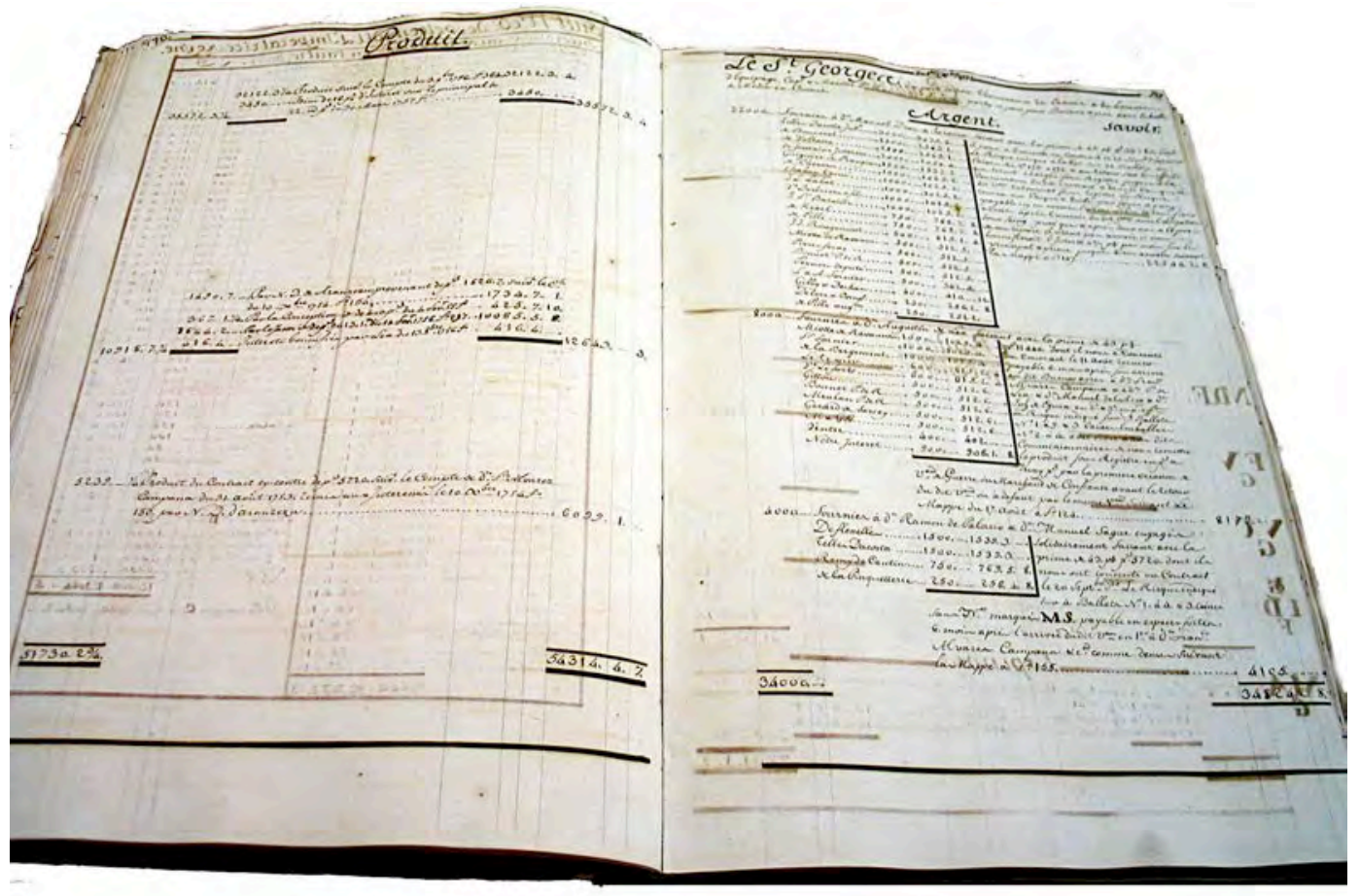


Figure 2 : Le Saint-Raymond Folio droit

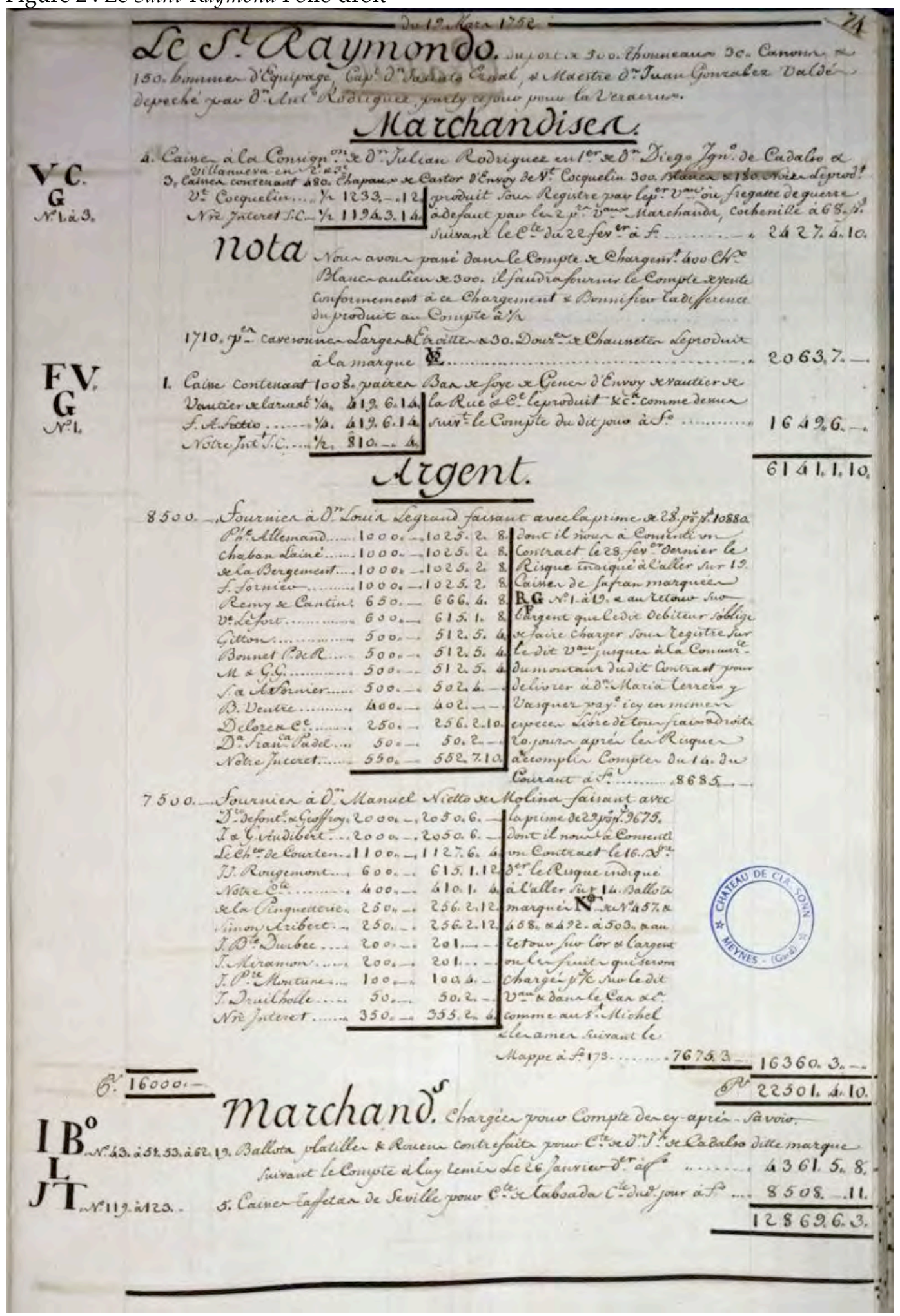


Figure 3 : Le Saint-Raymond Folio gauche

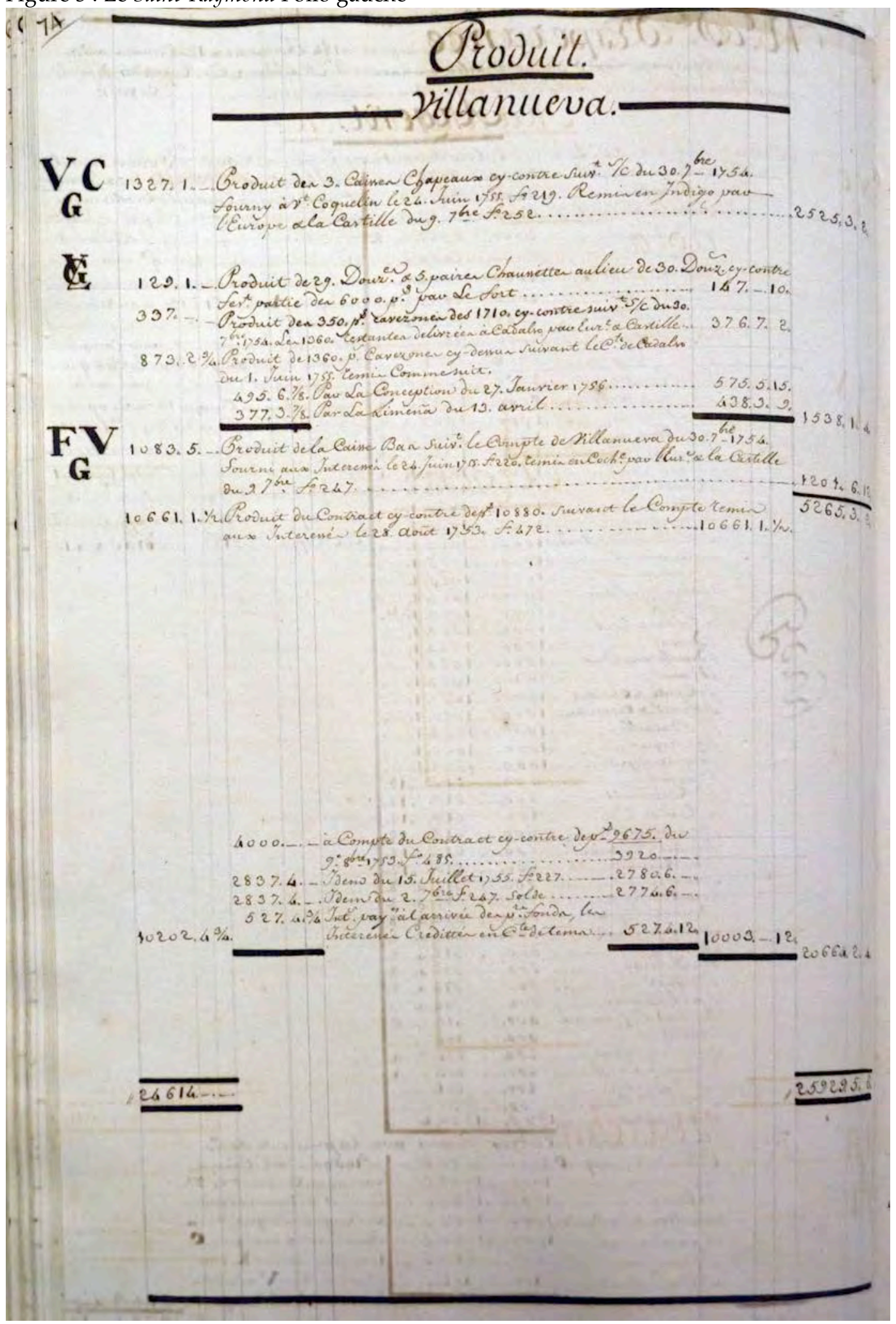


Figure 4 A Le Saint-Christ du Secours Folio droit 1

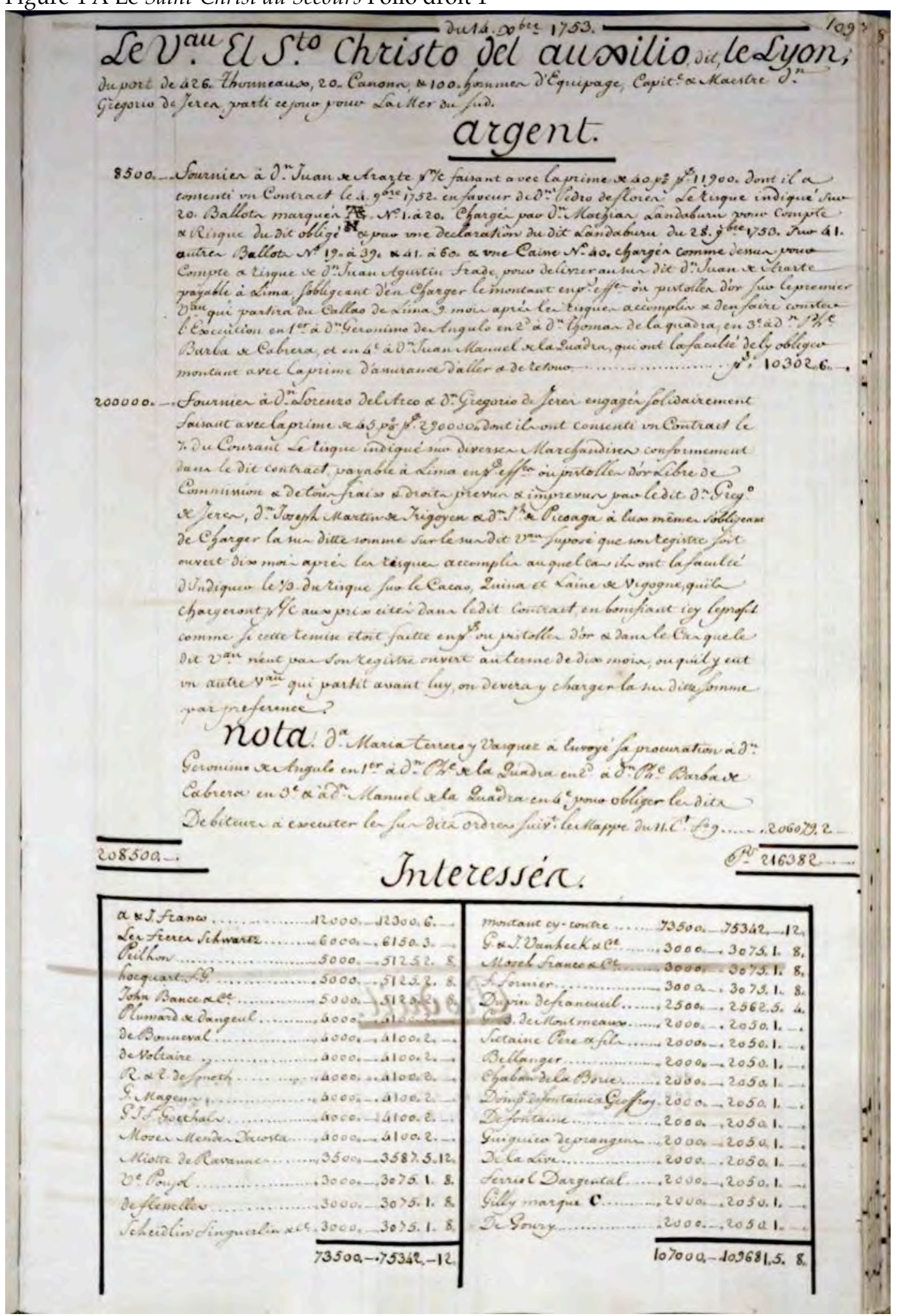


Figure 4 B : Le Saint-Christ du Secours Folio droit 2

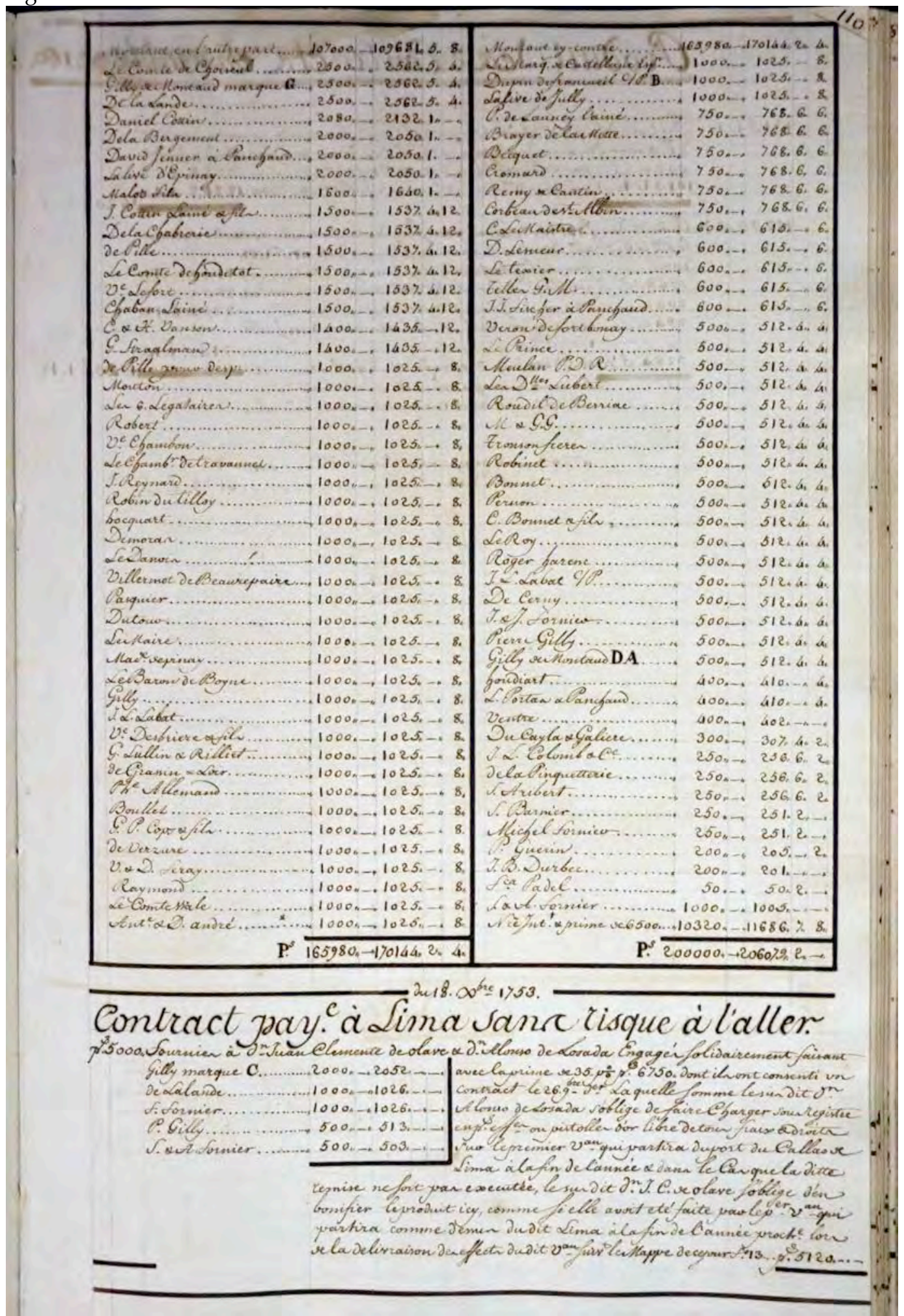


Figure 5 : Le réseau des correspondants de Simon Arnail Fornier et $C^{\text {ie }}$ (Diffusion)

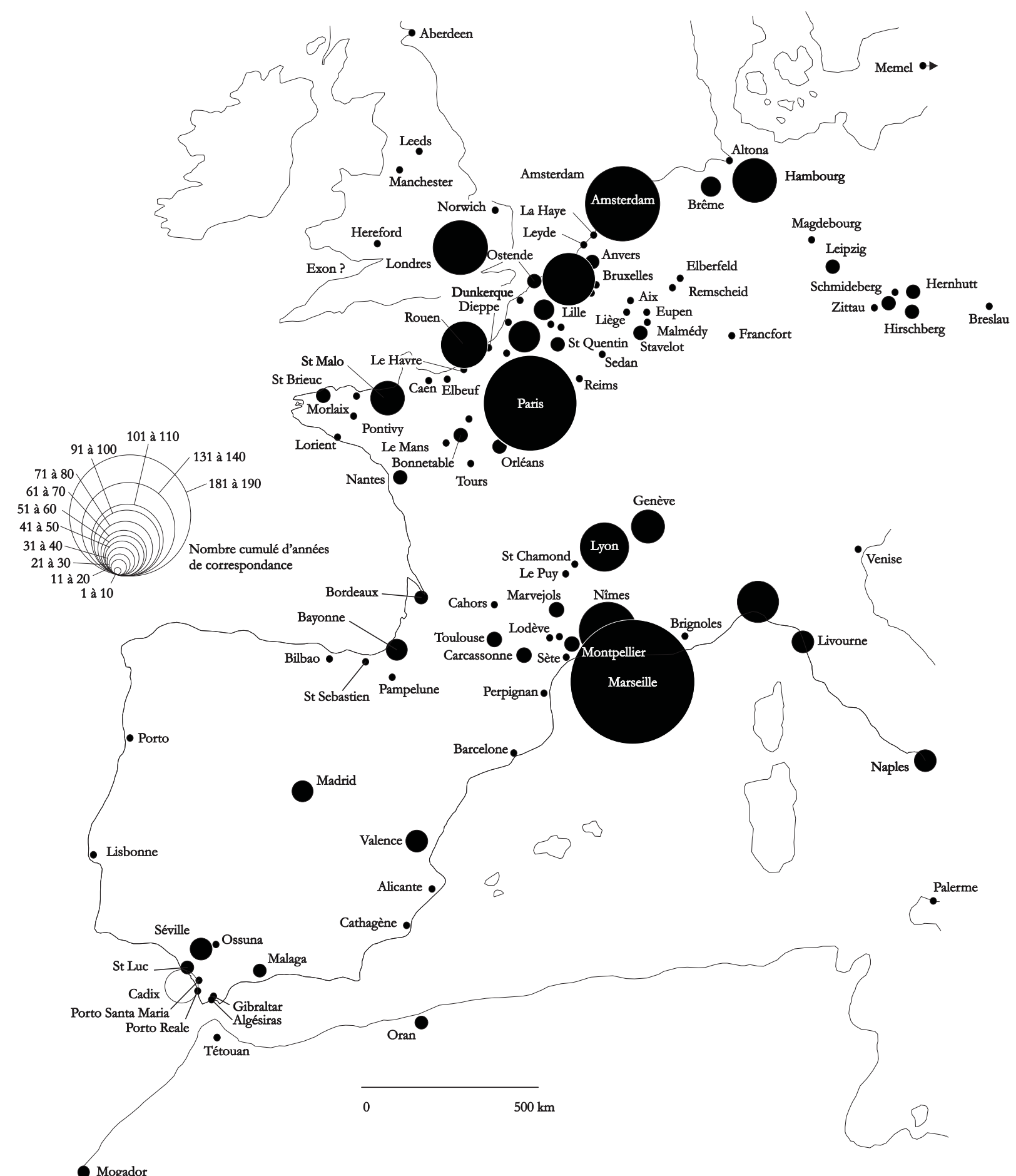


Figure 6 : Le réseau des correspondants de Simon Arnail Fornier et $C^{\text {ie }}$ (Ossature)

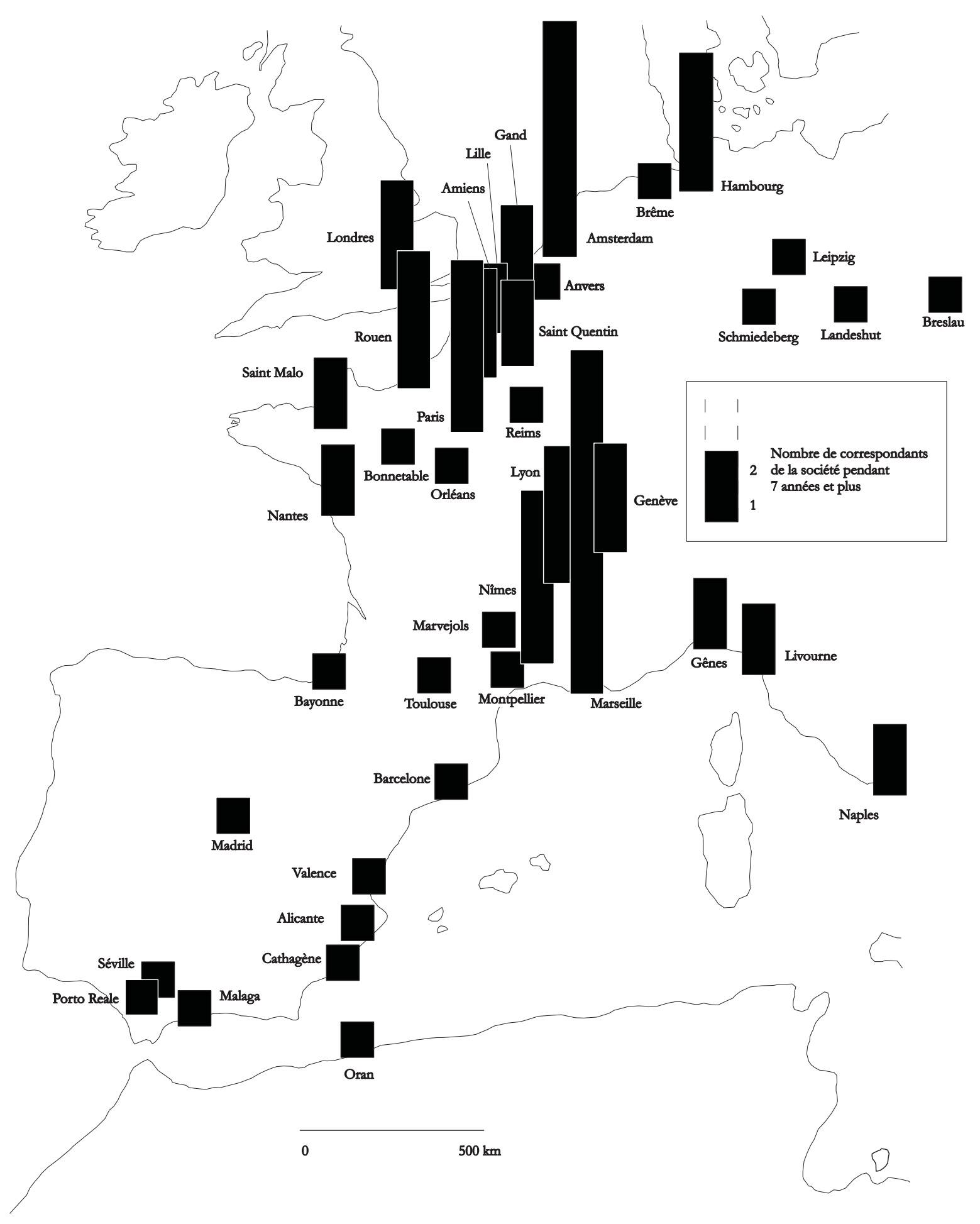




\title{
Famille et réseaux sociaux de l'élite sucrière martiniquaise (fin $X I X^{e}$-début $X X^{e}$ siècle)
}

\author{
Marie HARDY \\ Docteur en histoire, chargée de recherches \\ à la fondation Clément et membre associé \\ au laboratoire AIHP/GEODE EA929 \\ Extrait de : Henri BRESC (dir.), Réseaux politiques et économiques, Paris, \\ Édition électronique du CTHS (Actes des congrès des sociétés historiques et scientifiques), 2016. \\ Cet article a été validé par le comité de lecture des Éditions du CTHS dans le cadre de la publication \\ des actes du $140^{\mathrm{e}}$ Congrès national des sociétés historiques et scientifiques tenu à Reims en 2015.
}

L'article de Claire Lemercier $^{1}$ a fait apparaître l'intérêt de l'analyse formelle des sources pour l'approche des réseaux sociaux en histoire. Néanmoins, l'hétérogénéité des sources consultées pour la présente communication n'a pas permis d'envisager une telle approche. L'analyse présentée aujourd'hui est donc qualitative, elle repose sur le croisement et l'étude d'actes notariés, d'actes d'état-civil, de papiers de famille, de correspondance, de papiers d'entreprise. Elle a fait émerger l'histoire sociale d'une famille créole martiniquaise sur près de deux siècles (fin $X V I I{ }^{e}$-milieu $X X^{e}$ siècle), dont je voudrais tenter aujourd'hui une approche réticulaire. La société martiniquaise est très complexe en ce qu'elle repose sur une structuration à la fois économique et « raciale». Le premier graphique (fig. 1) donne un aperçu de la structuration de la société martiniquaise à la fin du XIX ${ }^{e}$ siècle. Le second, réalisé à partir des résultats de la présente étude, organise les groupes sociaux martiniquais en fonction des différents types de réseaux en interaction.

Ma thèse soutenue en juin dernier étudie les propriétaires d'habitations caféières en Martinique aux $\mathrm{XVIII}^{\mathrm{e}}$ et $\mathrm{XIX}^{\mathrm{e}}$ siècles, elle regroupe ces individus dans une catégorie intermédiaire essayant d'en comprendre l'originalité tout autant que la particularité. Elle a mis en évidence une société caféière complexe incluant petits et grands propriétaires, blancs ou de couleur. L'homogénéité du groupe repose sur un unique élément, celui de la différenciation que la société créole appliquait à ce corps. Petits ou grands, ils n'étaient que de simples caféiers ne pouvant aspirer au statut et à l'honorabilité des sucriers qui seuls bénéficiaient de la reconnaissance sociale.

Ensuite, l'étude de l'univers sucrier des $\mathrm{XIX}^{\mathrm{e}}$ et $X \mathrm{X}^{\mathrm{e}}$ siècles $\mathrm{m}^{\prime}$ a permis d'appréhender l'élite sucrière au plus près de sa réalité sociale grâce à l'étude des papiers d'une famille martiniquaise. Cette dernière est issue de petits propriétaires caféiers aux $\mathrm{XVII}^{\mathrm{e}}$ et $\mathrm{XVIII}{ }^{\mathrm{e}}$ siècles, révélant ainsi l'aspect mouvant et imbriqué de la société martiniquaise. Les possibilités d'évolution économique sont grandes pour qui sait s'adapter aux mutations structurelles de l'île. Cette famille a su en l'espace de trois siècles se reconvertir et faire preuve d'adaptation à chaque grand tournant de l'histoire martiniquaise. Elle délaisse la culture du café et se reconvertit dans la canne juste avant la faillite de la filière caféière qui s'opère après la période révolutionnaire martiniquaise (1789-1815). Elle se rapproche du milieu industriel sucrier à la fin du XIX ${ }^{e}$ siècle. Enfin, elle est à la tête des usines du sud de la Martinique, agrandit ses propriétés terriennes et s'implique activement dans la vie politique de l'île au début du $X^{\mathrm{e}}$ siècle. À mesure de sa réussite socio-économique, cette

1. C. Lemercier, « Analyse de réseaux et histoire». 
famille change de pratiques sociales, son réseau évolue quelque peu mais correspond globalement aux pratiques communautaristes métropolitaines du XIX ${ }^{\mathrm{e}}$ siècle mises en évidence dans l'étude de François Gourdon².

Cette communication tente une approche de l'évolution du réseau social de cette famille qui appartenait encore à la catégorie intermédiaire des caféiers à la fin du XVIII ${ }^{\mathrm{e}}$ siècle et qui devient constitutive de l'élite sucrière à la fin du XIX et au XX $X^{\mathrm{e}}$ siècle. Comment le réseau social de cette famille à l'ascension socio-économique fulgurante évolue-t-il au rythme des décennies? Quelle est son identité familiale et comment se construit-elle? Comment l'interdépendance et les liens résistent-ils? Il s'agit de recomposer des trajectoires à travers une continuité spatiale et sociale. Comment s'établit et se pérennise la continuité familiale au fil des générations ?

\section{Présentation de la notion de « réseau » pour le sujet}

Pour cette analyse, j'entendrais sous la notion de « réseau » les relations tissées ponctuellement ou non par une communauté avec des personnes n'intégrant pas forcément à terme la communauté. Il s'agit donc du tissu relationnel d'un groupe social à une occasion particulière ou à long terme, constitué dans un but précis. Je ne conçois pas le réseau social comme une communauté en ce que l'intégration à la communauté des personnes composant le réseau ne s'opère pas systématiquement. La communauté est de fait moins ouverte que son réseau peut l'être dans sa totalité. Le réseau concerne les liens sociaux à la fois internes et externes des composantes du groupe. Je le définis comme participant et à la fois procédant de la dynamique des relations sociales, des modes de sociabilités, des interconnexions qui participent à l'ascension comme à la cohésion d'un groupe, d'une communauté ou d'une famille. Pour ce sujet, il s'agirait de comprendre si l'hégémonie économique de certains sucriers à la fin du XIX ${ }^{\mathrm{e}}$ siècle s'est établie par la mise en place d'un réseau social ponctuel et opportun?

\section{L'objet d'étude : famille ou communauté?}

La famille étudiée intègre à partir de la fin du XIX ${ }^{\mathrm{e}}$ siècle le groupe des « grands békés » : élite de la communauté du même nom, groupe social appartenant depuis son origine à la société martiniquaise, elle même hiérarchisée suivant deux critères essentiels : la couleur et le statut économique. L'étymologie du terme béké n'a jamais fait l'objet de recherches poussées, à tel point que l'imprécision demeure quant à la période de l'émergence de ce terme dans les anciennes colonies françaises. Les périodiques du début du $X X^{\mathrm{e}}$ siècle témoignent déjà de l'existence et de l'utilisation de ce terme.

En 1906, la presse se fait l'écho des débats portant sur la définition du terme. L'Opinion, organe de la démocratie martiniquaise, en donne la définition suivante :

«Le béké, il faut bien se le dire, le béké n'est pas toujours le blanc, c'est l'homme qui ayant la peau blanche a désir de voir ressusciter à son profit, les anciens privilèges dont bénéficiaient ici les patrons sous le régime monarchique ou sous le régime impérial. » ${ }^{3}$

On conçoit que ce terme renvoie pour beaucoup à une conception négative et péjorative de la place que le blanc créole tient dans la société coloniale. Ce terme correspondrait à la catégorie des blancs créoles qui formerait ce que Peter Hass désigne sous le terme de «communauté épistémique» et qui partagerait dans une combinaison unique et exceptionnelle des intérêts, des valeurs, un projet politique mais aussi des «croyances causales » («base consensuelle de connaissances techniques appliquée à l'interprétation

2. V. Gourdon, «Les témoins de mariage civil dans les villes européennes du XIX ${ }^{e}$ siècle : quel intérêt pour l'analyse des réseaux familiaux et sociaux?».

3. L'Opinion, organe de la démocratie martiniquaise, jeudi 21 juin 1906, n 1354 . 
commune d'un problème ») $)^{4}$. La cohésion du groupe implique l'existence de forces d'unifications plus importantes que celles de segmentation qui en dissipent souvent l'efficience.

Je ne reviendrai pas sur l'étude de la communauté qu'Édith Kovats Beaudoux a particulièrement bien définie dans son ensemble dans les années $1960^{5}$. Je tenterai ici de comprendre comment une famille parvient à devenir une entité autonome tout en faisant partie de l'ensemble. Le critère qui pose d'emblée question est celui de l'étonnante cohésion qui ressort des faits observés. Il est vrai que le groupe étudié est une famille ; elle bénéficie donc de la solidarité que Durkheim (dans De la division du travail social, 1893) qualifie de "solidarité mécanique », mais les choix qu'elle opère pour l'application de sa «solidarité organique $»^{6}$ la transforment en communauté. La préoccupation et l'objectif communs sont l'élévation socio-économique et la pérennisation du groupe familial, ce qui tranche nettement avec la pratique courante centrée sur la figure dominante.

\section{Le mariage, quel réseau familial ? Un réseau ouvert sur l'extérieur?}

L'étude de la généalogie de cette famille révèle une forte endogamie. Du XVII ${ }^{\mathrm{e}}$ siècle au milieu du $\mathrm{XX}^{\mathrm{e}}$ siècle, sur un ensemble de 63 mariages, 47 sont endogames (sept sont exogames: six avec des métropolitains, un avec un Guadeloupéen, et deux sont des mésalliances). Selon Leslie Page Moch, l'étude des témoins de mariages civils est « une des rares voies d'approche des réseaux sociaux concrets des individus au-delà des limites du ménage $»^{7}$. Les actes de mariage étudiés concernent une fratrie de six frères dont un se marie deux fois, l'échantillon de l'étude concerne donc sept mariages soit un nombre très restreint. Le regard critique de l'historien se doit de marquer un certain recul par rapport à cet effectif réduit, néanmoins, celui-ci concerne l'ensemble de la fratrie ; il donne donc une vision d'ensemble exhaustive de ses pratiques sociales, échelonnées sur presque deux décennies, entre 1871 et 1898 . Au sein de cette fratrie, la tendance générale est l'entre-soi familial.

V. Gourdon explique qu'il s'agit d'une caractéristique de la culture bourgeoise du XIX ${ }^{\mathrm{e}}$ siècle :

«Marquant l'unité et la continuité du groupe [...]. La ritualisation du mariage comme mise en scène de la famille est particulièrement poussée dans les codes de savoir-vivre qui décrivent sur un plan normatif les mœurs de la grande bourgeoisie à l'usage d'un public élargi à l'ensemble des classes moyennes : ne s'agit-il pas de célébrer, davantage que l'union de deux êtres, celle de deux lignées ? "

Au sein de la famille étudiée, le recours à des témoins extérieurs correspond à un quart seulement des effectifs. Dans la majorité des cas, il s'agit d'amis des époux. Ici encore, la pratique est commune à celle de la bourgeoisie occidentale qui sélectionne dans son réseau ceux « qui par leur situation sociale, ont acquis une certaine notoriété »".

4. P. M. Hasse, « Knowledge, Power and International Policy Coordination », p. 139.

5. É. Kovats Beaudoux, Les Blancs créoles de la Martinique, une minorité dominante.

6. «La solidarité organique existe grâce à des individus qui choisissent d'appartenir à un ou plusieurs groupes et à être en interaction avec d'autres. Les relations entre les individus et les groupes, chacun en retirant des avantages, est à la base de la solidarité organique. Celle-ci sera d'autant plus forte que les individus ou les groupes seront plus interdépendants les uns des autres » dans E. Kovats Beaudoux, Mariage et cohésion sociale chez les blancs créoles de la Martinique, p. 46.

7. L. Page Moch, « Networks among Bretons? The evidence for Paris, 1875-1925 », cité dans V. Gourdon, « Les témoins de mariage civil dans les villes européennes du XIX ${ }^{\mathrm{e}}$ siècle : quel intérêt pour l'analyse des réseaux familiaux et sociaux? », p. 62.

8. V. Gourdon, « Les témoins de mariage civil dans les villes européennes du XIX siècle », p. 75.

9. B. Gamba, "Histoire du mariage d'après les codes de savoir-vivre (XIXe-XXe siècles)", p. 109, cité dans

V. Gourdon, «Les témoins de mariage civil dans les villes européennes du XIX ${ }^{\mathrm{e}}$ siècle ». 
La moyenne d'âge des amis sélectionnés pour témoigner est élevée (50 ans), celle des témoins familiaux essentiellement des frères et des oncles germains est de 44 ans. On observe une différence notable entre les deux moyennes, différence qui ne suit pourtant pas la logique de la composition des deux catégories. Les témoins familiaux sont dans un tiers des cas les oncles des époux ce qui élève considérablement la moyenne d'âge. Les témoins extérieurs sont dans la très grande majorité des cas les amis des époux et devraient alors avoir un âge sensiblement égal aux époux, âgés d'en moyenne 33 ans pour les hommes, et de 21 ans pour les femmes. Un seul des témoins extérieurs n'est pas déclaré comme ami des époux, l'officier d'état-civil déclare qu'il a été « requis par les composantes ».

Il s'agit d'E. Bougenot, ingénieur métropolitain qui participera au développement de l'industrialisation sucrière à la Martinique. Ce témoin est cité en premier et constitue un hôte de marque en ce qu'il représente par sa position, la porte d'entrée du monde usinier. C'est à la fin des années 1860 que le père et patriarche de la fratrie en question, sucrier, comprend l'intérêt qu'il aurait à s'en rapprocher, compte tenu de l'étendue des compétences du brillant ingénieur. Il lui confie un de ses fils en 1868 aux fins de parfaire sa formation. Le virage vers l'industrialisation est amorcé par le biais de cette grande figure martiniquaise qui apparait deux fois en guise de témoins dans les sept mariages.

Ceci reproduit le schéma d'alliances stratégiques opéré un demi-siècle auparavant permettant le passage de la sphère caféière au monde sucrier. Mutation à laquelle tout caféier aspirait dans la colonie. Au fil des décennies, on constate une évolution du profil des témoins, ils appartiennent dans un premier temps presque exclusivement à la sphère des exploitants terriens. Les alliances évoluent ensuite vers le monde du négoce auquel il convient de s'associer, dans une colonie où les denrées se vendent par le biais de cette corporation. Ces évolutions procèdent de l'ascension sociale qui les sous-tend, fruit du travail et des choix judicieux qui l'ont conduit à sa valeur ajoutée. À la fin du XIX ${ }^{\mathrm{e}}$ siècle, le réseau s'élargit au monde industriel qui seul permet la pérennisation de l'économie sucrière.

\section{Une unité économique familiale forte, un réseau social horizontal}

Selon Édith Kovats, des tensions très réelles existent à tous les niveaux dans le groupe béké, notamment au moment de l'héritage. Elle explique qu' " il y a même des cas où ces tensions sont à la base d'une désagrégation au niveau familial $»^{10}$. Pour le cas étudié, la correspondance familiale, les comptes de tutelle et les successions révèlent une famille soudée ; ainsi les comptes du père sont ceux de ses enfants.

Depuis le début du XIX $X^{e}$ siècle jusqu'à la seconde moitié $d u X^{e}$ siècle, le patriarche familial tient le compte de toute la famille. En fait, l'affaire est familiale, toutes les habitations sucreries possédées par la famille sont communes et indivises. Il en va de même pour l'usine familiale qui exploite les cannes produites sur les propriétés des uns et des autres; les dividendes de cette dernière vont dans une caisse commune et sont ensuite répartis ${ }^{11}$. La famille est intimement liée, de sorte que chacun des membres contribue à la hauteur de ses capacités à la fortune et à la pérennisation de l'affaire familiale. Ainsi en 1883, l'oncle est en relation régulière (tous les quinze jours) avec son neveu localisé à Saint-Pierre, lequel est chargé de ses commissions. La correspondance fait mention de livraisons destinées à l'ensemble des habitations familiales. Chaque membre de la famille a sa fonction propre, sa spécialisation, et agit alors pour toute la famille. 
L'entre-soi est palpable, la famille se rejoint pour les congés (les hauteurs du MorneRouge ou du Diamant pour un changement d'air) ${ }^{12}$. Une ambition commune régit l'activité de l'ensemble masculin de la famille :

«Il y a là un devoir pour toi et pour moi, et ce serait être coupable vis-à-vis de Louise, tes enfants, et nos intérêts que de ne pas nous occuper affectueusement et journellement de $1^{\prime}$ habitation. Surtout pour la préparation des terres. $»^{13}$

L'étude de cette famille révèle un groupe uni et soudé dans l'affaire économique familiale. Son endogamie est le fruit de cette forte solidarité familiale comme de son fonctionnement quasi autarcique. Les jeunes s'intéressent de ce fait à leurs cousins et cousines, qu'ils rencontrent à l'occasion des réunions familiales régulières au cours du déjeuner dominical sur la propriété familiale. Ces unions qui participent, par l'absence de segmentations patrimoniales, à la pérennisation de l'outil de travail au sein de la famille, sont donc bien vues et encouragées. La famille ne se démarque pas en cela, du groupe social auquel elle appartient.

On voit apparaître dans cette analyse la place secondaire que tiennent les femmes au sein de cette famille. Au rythme de la correspondance, leur rôle apparaît comme en filigrane, certes un rôle de second plan dans ce système patriarcal, mais un rôle de soutien et de base avancée dans les stratégies de conquête familiale à travers le mariage. En effet, chose étonnante, alors que les femmes entretiennent habituellement une abondante correspondance, dans ce cas de figure la correspondance familiale est très peu témoin de courriers émanant de la plume de femmes. Ces dernières apparaissent alors de manière ponctuelle sous l'égide d'un mari ou d'un père. En 1888, les recommandations que donne un père à sa fille quelques jours après son mariage donne la ligne directrice de l'esprit familial :

«Tu venais de prendre la direction de ton ménage, chose qui t’avait été facile par la bonté de Gabriel pour toi. J'espère qu'avec la grâce de Dieu elle continuera. Gabriel en me quittant me l'a formellement promis et je compte sur cette promesse à toi ma fille à savoir attirer et conserver sa confiance en prenant part à tout ce qui peut l'intéresser et par ce fait t'intéresser aussi maintenant que ta vie est à deux, aussi intéressés l'un que l'autre à la réussite de vos petites affaires. ${ }^{14}$

Dans cette famille où l'industrie est la source de la réussite économique, les femmes tiennent un rôle de second plan et cela dès la fin du XVIII ${ }^{\mathrm{e}}$ siècle.

Ce constat est avéré par la répétition d'un même modèle à plusieurs années d'intervalle : le décès brutal d'un époux génère le veuvage précoce d'une jeune mère de plusieurs enfants, qui se retrouve à la tête d'un important patrimoine foncier. Tout naturellement, le frère le plus proche prend la direction des affaires économiques pérennisant ainsi la structure patriarcale de la famille. Les femmes sont donc écartées de la gestion par leur époux ou par leurs frères, néanmoins la teneur de la précédente lettre laisse envisager le degré d'instruction de ces femmes épouses qui indirectement tiennent une place d'écoute, de conseils et qui sont de la sorte averties des affaires économiques de la famille. On peut aisément comparer la situation et la place que tiennent les femmes de cette famille à celle qu'avait la mère de Pierre Dessalles. Ce dernier lui rendit compte quasi quotidiennement de la gestion de ses deux habitations, pendant dix ans à compter du départ en 1822 de celle-ci pour la métropole ${ }^{15}$. On est cependant très éloignés du rôle de choix que tenait la majorité des femmes blanches, ou libres de couleur, propriétaires d'exploitations caféières martiniquaises qui géraient et exploitaient seules leur habitation $^{16}$.

12. Fondation Clément, fonds Usine de Rivière-Salée, F006.01, lettre du 6 décembre 1879.

13. Fondation Clément, fonds Usine de Rivière-Salée, F006.01, lettre du 20 avril 1880.

14. Fondation Clément, F031/01/0014, correspondance Plissonneau 1888.

15. P. Dessalles, La vie d'un colon à la Martinique au XIX siècle. Correspondance 1808-1834, p. 55.

16. M. Hardy, Le monde du café à la Martinique du début du XVIII aux années 1860. 


\section{Liens horizontaux et verticaux, intérieurs et extérieurs à l'oligarchie}

En opposition avec l'analyse historiographique traditionnelle qui a tendu à faire de l'oligarchie un bloc de pouvoir séparé du reste de la population qu'elle domine, les études actuelles s'attachent à révéler la complexité des relations unissant différents groupes composant la société ${ }^{17}$. Dans cette mouvance, nous tenterons ici d'analyser les liaisons qui président entre la classe sucrière et l'élite de couleur (les deux reproduisant sensiblement les mêmes schémas internes) occupant la représentation politique de l'île à partir des années 1870, tout autant que celles qu'elle entretient avec les couches inférieures de la société gravitant autour d'elle. Quel parti prend ce groupe social dans le choix de ses relations, quels réseaux construit-il et dans quel but?

Édith Kovats, anthropologue de formation, explique que le groupe des blancs créoles doit faire face à des forces de dislocations, à des pressions externes. Il s'agit, selon elle :

«Des métropolitains qui essayent de planifier et diriger l'économie à travers leurs représentants politiques et économiques ensuite celles des éléments de couleur, que ce soit la classe ouvrière avec ses revendications, ou encore la bourgeoisie qui par sa concurrence menace les intérêts des békés. $»^{18}$

L'environnement immédiat des petits blancs des mornes correspond à une sphère de couleur et de " petits habitants ». Un rapport de l'audience de la cour d'assises du FortRoyal daté du 18 août 1841 donne un aperçu du quotidien au sein des campagnes martiniquaises, composées de petites habitations et des cases disséminées çà et là. Les relations inter-voisinages sont régulières, naturelles et se font, à en croire le rapport, sans discrimination de couleur. Dans les mornes de l'île, composés essentiellement de petites propriétés, la proximité de celles-ci favorise le brassage et les relations entre les différentes « races» évoluant au sein de ce territoire. Dans ce sens voici ce que dit le rapport d'audience :

«Il faut que nous vous engagions dans ce sentier, qui monte à toutes ces différentes cases d'habitation; que nous vous apprenions, la montre à la main, quelles courtes et rapides distances séparent toutes ces races voisines. ${ }^{19}$

Au sein des grandes plantations séparées souvent par plusieurs hectares de terre, le contact est plus réservé. L'habitation sucrerie forme un tout autosuffisant qui vit en autarcie. S'en suit la création de rapports de vassalité entre le patron et ses employés, comme il en était dans les provinces françaises où la dépendance sociale et économique est parfois extrême ${ }^{20}$. Des deux côtés, chacun travaille à l'instauration d'un équilibre. Les relations entretenues ne doivent pas perturber le rapport de soumission accepté des deux côtés à travers l'instauration d'un lien de clientèle. La générosité et la magnanimité servent alors la cause. Pour le patron, elles permettent de faire du bien et de satisfaire ceux qui contribuent à faire ce qu'il est. Pour les seconds, le patron se doit d'être généreux parce qu'il en a les moyens. L'examen de la correspondance donne la mesure de la normalité que constitue pour beaucoup une demande de prêt d'argent au patron, ou tout simplement, au notable que représente à cette époque l'usinier. Les emprunts sont courants; le patron est de la sorte un créancier. Dans les papiers de famille, les redevances de dettes sont pléthoriques, on y prête à tout va et à tout type de profil. À titre d'exemple, le 21 juin 1927, une employée fait appel à la magnanimité de son patron pour l'obtention d'un emprunt de 500 francs qui lui seront remboursés au moment de la récolte de ses cacaos. La dame en question vient de perdre son mari et parvient tout juste à subvenir aux premiers besoins de ses enfants, le prêt lui est accordé ${ }^{21}$.

17. C. Lemercier, « Analyse de réseaux et histoire ».

18. É. Kovats Beaudoux, Mariage et cohésion sociale chez les blancs créoles de la Martinique, p. 58.

19. Fondation Clément, F031.01.0001, extrait de plaidoirie à la cours d'assises de Fort-Royal le 18 août 1841.

20. «Par exemple des domestiques vis-à-vis de leur patron » dans V. Gourdon, "Les témoins de mariage civil dans les villes européennes du XIXe siècle », p. 78.

21. Fondation Clément, F031.01.105, demande d'emprunt datée du 21 juin 1927. 
Dans un cas bien précis, les nombreuses missives reçues en guise de félicitations pour la nomination à l'ordre de la Légion d'honneur de l'usinier va dans le sens de la reconnaissance qu'engagent les bonnes actions de ce dernier qui sait se faire aimer d'un grand nombre :

«Le tout-puissant connait aussi votre dévouement votre charité, et il prépare à ces mérites une belle récompense $»^{22}$

ou encore :

«Il se réjouit vivement de voir reconnaître par le gouvernement la bonté de votre cœur et votre action utile. $»^{23}$

Parallèlement un puissant réseau relationnel est tissé avec les sphères politiques martiniquaises en leur apportant un soutien à des moments clés de l'histoire électorale martiniquaise. À la suite de l'application du suffrage universel en 1870, l'élite de couleur passe à la tête de l'administration locale. La majorité des blancs créoles se détourne de la sphère politique pour se consacrer exclusivement aux activités économiques. Le représentant de la famille étudiée, qui appartient au groupe des usiniers, s'allie à l'Entente républicaine dont les intérêts semblent à première vue bien divergents. Cet organe politique correspond à une alliance des radicaux et des socialistes en la personne de Victor Sévère et Joseph Lagrosillière. On comprend qu'il s'agit là de pactes électoraux. Voici ce que Sévère aurait dit au cours d'une assemblée politique lors du choix des candidats des législatives de 1910 :

«Messieurs, [...] La politique de Lagrosillière est trop violente et son action contre l'usine sera trop dure. Ces messieurs vont prendre position contre nous et comme ils sont puissants, leur action pourrait vous faire bien du mal. Ils auront tout à perdre disent les uns, l'action directe disent les autres! $»^{24}$

On comprend le lien qui unit les deux hommes, V. Sévère cerne rapidement l'intérêt qu'il a à ne pas se mettre à dos le puissant lobby des usiniers. Cependant, ils finiront par avoir des relations qui dépassent $l^{\prime}$ « entente cordiale ». Voici comment V. Sévère commence une de ses lettres : « mon cher collègue et ami ${ }^{25}$.

De la même manière, notre représentant du groupe des usiniers est aussi très proche de Joseph Lagrosillière, référent des républicains socialistes martiniquais, qui lui demande le 15 janvier 1914 de bien vouloir faire partie du comité directeur de l'Entente républicaine ${ }^{26}$. Chacun cherche ses propres intérêts, toutes les alliances sont permises, les réseaux se tissent. On peut parler ici de ce que Michel Giraud désigne comme étant: "une adaptation dramatique généralisée » 27 des deux groupes (blanc et de couleur) et ce qu'Édith Kovats Beautoux désigne comme un groupe «à la fois isolé et fonctionnellement intégré » pour parler des blancs créoles $^{28}$. En Martinique, l'éloignement de la métropole favorise la mainmise des élites locales sur l'administration, tout comme en Chine où :

«Dans un contexte de flou juridique et normatif quasi-total, les réseaux de clientèles sont devenus un élément régulateur et parallèle essentiel, permettant de contourner le dispositif bureaucratique communiste et les dysfonctionnements de l'économie planifiée ${ }^{29}$

22. Fondation Clément, F031.03.0015, lettre de félicitation, le 25 janvier 1913.

23. Fondation Clément, F031.03.0015, lettre de félicitation, le 25 janvier 1913.

24. Fondation Clément, F031.03.0051, lettre du 30 mars 1910.

25. Fondation Clément, F031.03.0021, lettre du 6 février 1913.

26. Fondation Clément, F031.03.0021, lettre de Lagrosillière le 15 janvier 1914.

27. É. Kovats Beaudoux, Les Blancs créoles de la Martinique, une minorité dominante, préface.

28. Ibid., p. 8.

29. S. Balme, Entre soi. L'élite du pouvoir dans la Chine contemporaine, p. 7. 
Afin d'avoir carte blanche dans l'exercice du pouvoir il convient de s'allier le gouverneur, unique représentant de la métropole sur le territoire. «La fonctionnalité et la permanence de la relation ne dépendent pas systématiquement d'une allégeance forte des individus. Il s'agit de soutiens politiques utilitaristes qui n'intègrent pas seulement une dimension d'autorité ${ }^{30}$. On comprend que ces alliances aient été le fruit de stratégies bien plus que le résultat de convictions politiques communes et affichées. L'étude de cette famille sur cinq générations révèle que les alliances politiques s'opèrent à titre individuel au gré des besoins et des possibilités.

L'étude de cette famille n'offre certes qu'une illusion du fonctionnement de la société martiniquaise, mais elle permet d'approcher au plus près l'élite de la société martiniquaise permettant une analyse en amont de l'appréhension de l'unité actuelle de ce groupe. Cette étude révèle $\mathrm{qu}^{\prime}$ au $\mathrm{XIX}^{\mathrm{e}}$ et au début $\mathrm{du} \mathrm{XX}^{\mathrm{e}}$ siècle, l'ensemble de la famille est réquisitionnée à la cause commune, cause économique essentiellement.

\begin{abstract}
Résumé
L'historiographie a très peu porté sur la société martiniquaise et encore bien moins sur la population libre blanche formant l'élite de l'ancienne colonie. La recherche historique actuelle reste encore empreinte de non-dits sur cette classe «dominante ». Pourtant l'intérêt d'un tel sujet est indéniable dans l'appréhension des réseaux sociaux qui participent à l'identité du groupe social blanc et in fine de la société martiniquaise dans son ensemble. La toute récente thèse en histoire sociale sur le monde du café à la Martinique des XVIII ${ }^{\mathrm{e}}$ et XIX siècles a montré que l'univers blanc est parcellaire, la majorité de la population blanche appartient à un groupe social intermédiaire qui s'oppose dans ses pratiques et ses réseaux sociaux à l'élite sucrière blanche. L'abondante correspondance d'une famille martiniquaise confrontée aux archives notariales révèle les pratiques sociales et les stratégies matrimoniales d'une famille caféière dans ses débuts, sucrière ensuite, industrielle enfin.
\end{abstract}

\title{
Bibliographie
}

BALME Stéphanie, Entre soi. L'élite du pouvoir dans la Chine contemporaine., s.l., Librairie Arthème Fayard, 2004.

DeSSALLES Pierre, La vie d'un colon à la Martinique au XIX siècle. Correspondance 1808-1834, $2^{\mathrm{e}}$ éd., Courbevoir, Henri de Frémont, 1988.

GAMBA Béatrice, «Histoire du mariage d'après les codes de savoir-vivre (XIXXX $\mathrm{X}^{\mathrm{e}}$ siècles) », maîtrise d'histoire, 1998.

GOURDON Vincent, "Les témoins de mariage civil dans les villes européennes du XIX siècle : quel intérêt pour l'analyse des réseaux familiaux et sociaux ? ", Histoire, économie $\mathcal{E}$ société, $1^{\mathrm{er}}$ juin $2008,27^{\mathrm{e}}$ année, $\mathrm{n}^{\mathrm{o}} 2$, p. 61-87.

HARDY Marie, "Le monde du café à la Martinique du début du XVIII aux années 1860 », thèse de doctorat d'histoire, Université des Antilles et de la Guyane, Schoelcher, 2014.

HASSE Peter M., "Knowledge, Power and International Policy Coordination ", International Organisation, 1992, vol. 46, $\mathrm{n}^{\circ} 1$.

Kovats BEAUdOux Édith, Les Blancs créoles de la Martinique, une minorité dominante, s.l., L'Harmattan, 2002. 
Kovats BEAudoux Édith, «Mariage et cohésion sociale chez les blancs créoles de la Martinique », maîtrise en anthropologie, Université de Montréal, s.l., 1964, 107 p.

LEMERCIER Claire, "Analyse de réseaux et histoire», Revue d'histoire moderne et contemporaine, février 2005, $\mathrm{n}^{\circ}$ 52-2, p. 88-112.

PAge Moch Leslie, "Networks among Bretons ? The evidence for Paris, 1875-1925 », Continuity and Change, 2003, $\mathrm{n}^{\circ} 18$ (3), p. 421-455.

\section{Illustrations}

Figure 1 : Organisation sociétale post-esclavagiste (Sainton, 2009).

\section{Société esclavagiste}

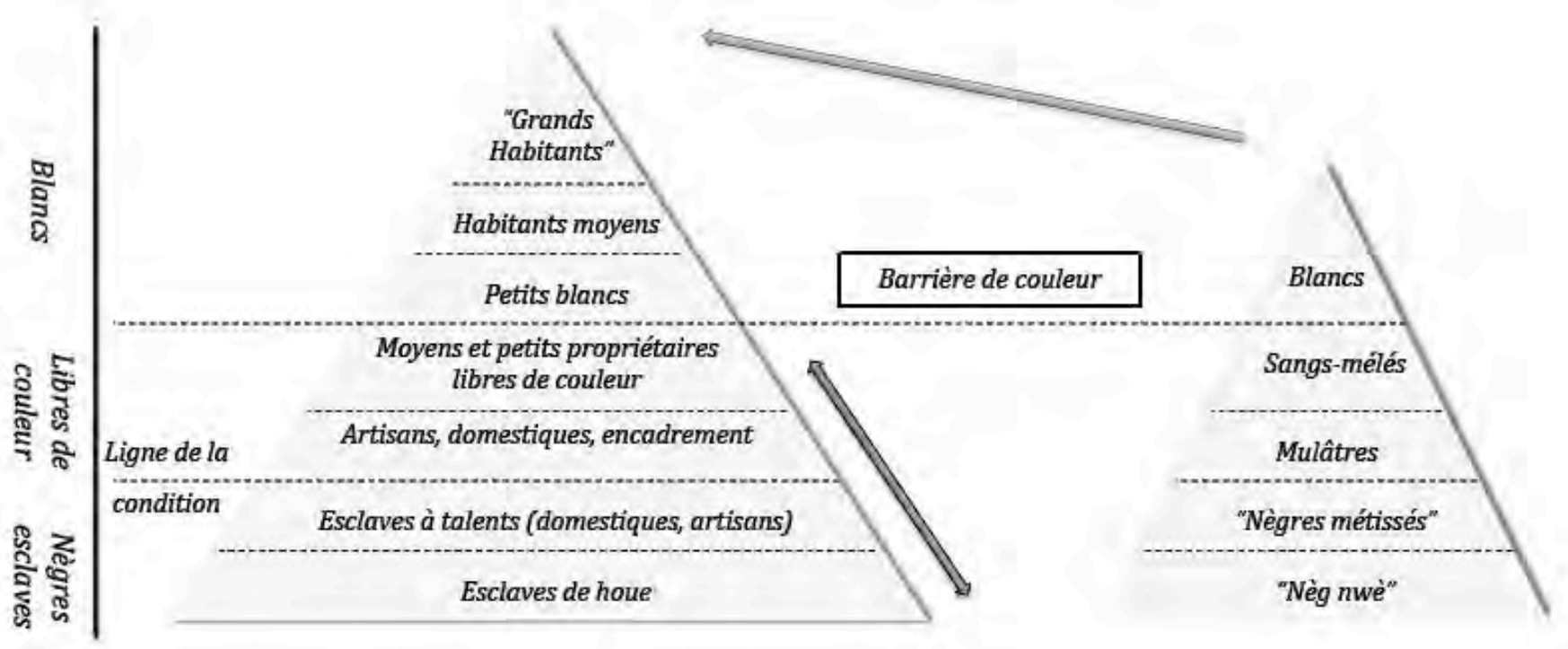


Figure 2 : Réseaux et société martiniquaise à la fin du XIX ${ }^{\mathrm{e}}$ siècle.

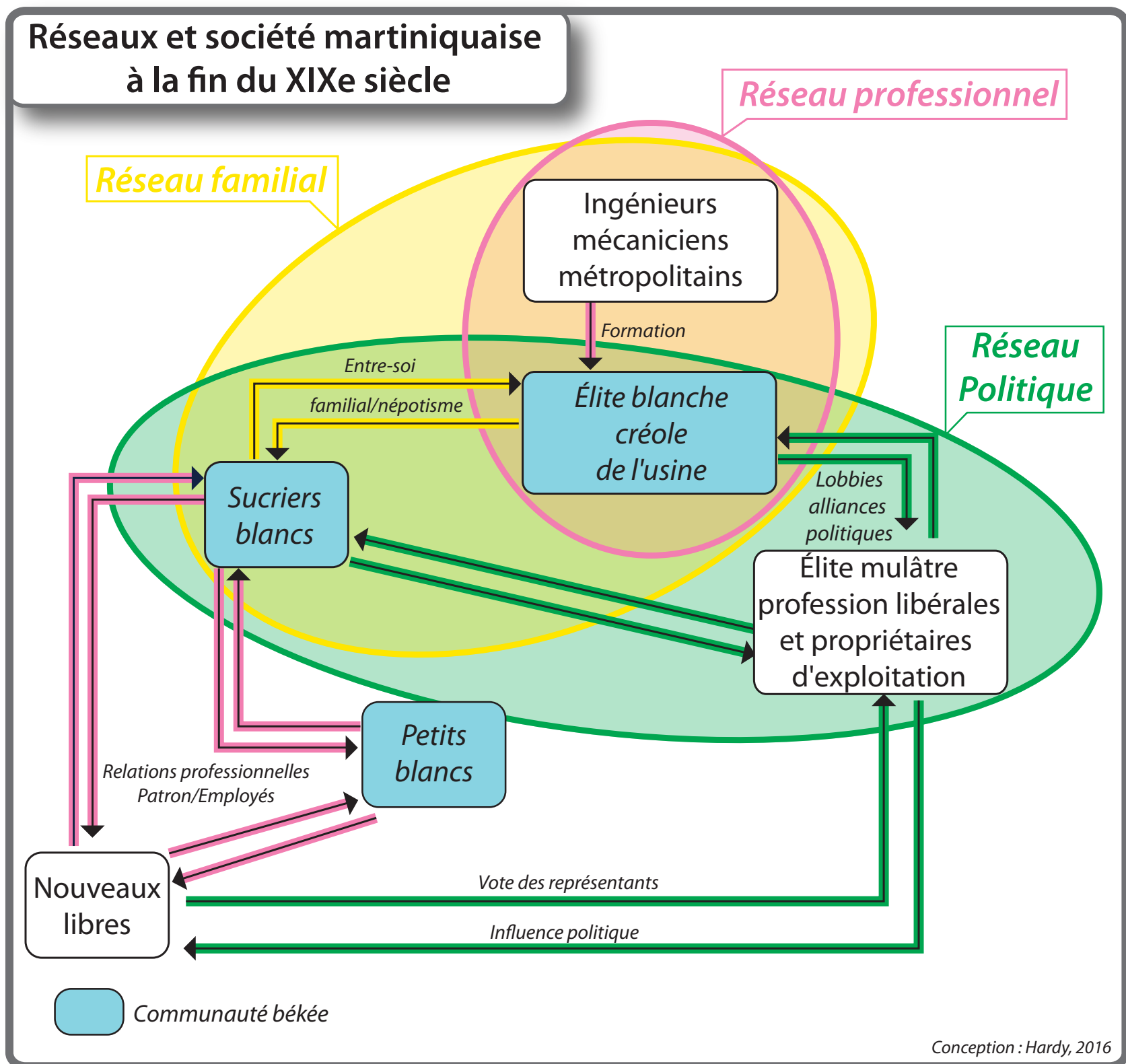



Les réseaux et le pouvoir 


\title{
L'impératrice byzantine au cour des réseaux aristocratiques L'exemple de Marie d'Alanie et d'Irène Doukaina-Comnène
}

\author{
Bénédicte BRUN \\ Doctorante, \\ Aix Marseille Université, CNRS, \\ LA3M UMR 7298 \\ Extrait de : Henri BRESC (dir.), Réseaux politiques et économiques, Paris, \\ Édition électronique du CTHS (Actes des congrès des sociétés historiques et scientifiques), 2016. \\ Cet article a été validé par le comité de lecture des Éditions du CTHS dans le cadre de la publication \\ des actes du $140^{\mathrm{e}}$ Congrès national des sociétés historiques et scientifiques tenu à Reims en 2015.
}

L'analyse de réseaux en histoire pose un problème de sources, qui présentent des lacunes sur la nature ou l'existence même de liens entre les individus. De plus, les noms propres des femmes y sont peu cités, puisque seule leur fonction de lien matrimonial importe, ce qui rend la tâche plus difficile encore. Reconstituer le réseau d'un individu demande au chercheur une lecture minutieuse et poussée. Nos principales sources ici sont Michel Psellos, Jean Skylitzès et Anne Comnène. Michel Psellos a été, en partie, témoin direct des évènements qu'il rapporte (des règnes de Michel V jusqu'à celui de Michel VII). Jean Skylitzès, qui écrit sous le règne $d^{\prime}$ Alexis $I^{\text {er }}(1081-1118)$, retrace l'histoire des dynasties amoriennes et macédoniennes jusqu'en 1057. Anne Comnène enfin, qui écrit sous le règne de son neveu Manuel I ${ }^{\text {er }}$ Comnène (1143-1180), est l'auteur de l'Alexiade, l'histoire du règne de son père, Alexis $\mathrm{I}^{\mathrm{er}}$ Comnène. Ces sources historiographiques, qui ont pour sujet le pouvoir impérial et la convoitise qu'il suscite, illustrent bien l'importance croissante des liens de parenté ainsi que le prestige de la bonne naissance (eugeneia) et du nom lignager. Comme le constate Angeliki Laiou ${ }^{1}$, Psellos ne fait que d'assez vagues allusions à la parenté, alors qu'Anne Comnène, qui écrit près d'un siècle plus tard, les décrit minutieusement, et pousse même ses recherches généalogiques sur quatre générations.

Dans la deuxième moitié du $\mathrm{XI}^{\mathrm{e}}$ siècle, les alliances par le mariage devinrent l'instrument de prédilection des familles de l'aristocratie byzantine pour constituer leurs réseaux. Deux critères principaux caractérisaient ces alliances : l'âge précoce des enfants que l'on unissait et l'endogamie.

Parallèlement à cette évolution, des normes avaient peu à peu été élaborées par l'Église et l'État afin d'encadrer la parenté et ses pratiques matrimoniales. Tout d'abord, le droit byzantin avait hérité du droit romain la notion de degré de parenté, ainsi que le comput centré sur Ego (c'est-à-dire la somme des degrés qui séparent les intéressés de leur ancêtre commun ou de l'individu dont le mariage a créé l'affinité) ${ }^{2}$. En 692 , le concile In Trullo interdisait définitivement le mariage entre cousins germains (exadelphoi) et codifiait les interdits pour affinité. En 726, la codification impériale de l'Éklogè étendait l'interdit d'alliance aux cousins issus de germains (disexadelphoi) et aux «frères spirituels » (par le

1. A. E. Laiou, Mariage, amour et parenté à Byzance, p. 47-48.

2. É. Patlagean, Un Moyen Âge grec, p. 88. 
baptême). En 997 enfin, le Tomos du patriarche Sisinnios interdisait les mariages au sixième degré d'affinité, faisant de l'argument de la confusion des noms de parenté un principe juridique ${ }^{3}$. Comme le fait remarquer Évelyne Patlagean ${ }^{4}$, ces empêchements poussèrent logiquement l'aristocratie byzantine à chercher plus loin ses alliances et à étendre un peu plus ses réseaux de parenté.

Enfin, effet inattendu de cette législation, l'aristocratie y trouva des prétextes de rupture d'alliances, essentiels à sa politique matrimoniale. Angeliki Laiou note que la plupart des procès intentés pour rompre un mariage ou des fiançailles au $\mathrm{XI}^{\mathrm{e}}$ siècle l'étaient par des aristocrates laïcs qui cherchaient à utiliser ces empêchements afin de rompre ou invalider une alliance qui ne leur était plus utile.

Le $\mathrm{XI}^{\mathrm{e}}$ siècle byzantin fut un siècle tourmenté qui vit d'abord la fin de la dynastie macédonienne en 1056, puis pas moins de cinq empereurs se succéder sur le trône jusqu'en 1078. Cette instabilité politique entraîna une lutte entre les familles de l'aristocratie, pour qui les alliances devenaient une condition nécessaire afin d'augmenter leur pouvoir social et politique et prétendre au trône. Durant cette période, nous constatons également une activité législative intense de la part de l'Église et de l'État concernant les normes et les empêchements de mariage. Si l'Église souhaitait exercer un contrôle moral, il est certain que l'État, en la personne de l'empereur surtout, souhaitait pouvoir contrôler au mieux les politiques matrimoniales de son aristocratie. Par exemple, É. Patlagean souligne la concordance de dates entre la menace à laquelle avait dû faire face Basile II (976-1025) contre l'alliance des Tzimiskès-Phocas-Sklèroi et Maléïnoi, et la promulgation du Tomos de Sisinnios qui s'intéressait de près aux alliances par affinité : l'empereur, ayant pu constater la grande portée politique de ces alliances, réagissait en conséquence 6 .

Les deux familles qui nous intéressent ici, les Doukai et les Comnènes, s'illustrèrent particulièrement dans leur habileté à mener des politiques matrimoniales efficaces et finalement parvenir à mettre sur le trône leur candidat Alexis Comnène en 1081. Cette réussite fut plus précisément l'œuvre de la mère d'Alexis, Anne Dalassènè, du césar Jean Doukas et de l'impératrice Marie d'Alanie.

Nous nous proposons, à travers les politiques matrimoniales menées par ces personnages, de dessiner les contours du rôle que pouvait jouer une aristocrate, plus précisément une impératrice, au sein de ces réseaux d'alliances. Plusieurs facteurs sont à prendre en compte : en premier lieu, l'enfantement : le taux de nuptialité représentait un atout majeur dans le jeu des alliances ${ }^{7}$. En second lieu, la légitimité dynastique apportée par l'impératrice. En troisième lieu, les origines familiales de l'impératrice : quel était en effet l'apport réel d'une impératrice d'origine étrangère dans le réseau qu'elle rejoignait? Le facteur personnel enfin : le fait d'appartenir à une famille, à un réseau, ne garantit pas que tous ses membres seront fidèles et solidaires les uns envers les autres, ou poursuivront les mêmes buts.

3. C. G. Pitsakis, «Législation et stratégies matrimoniales. Parenté et empêchements de mariage dans le droit byzantin », p. 683.

4. É. Patlagean, Un Moyen Âge grec, p. 93.

5. A. E. Laiou, Mariage, amour et parenté à Byzance., p. 30.

6. É. Patlagean, Un Moyen Âge grec, p. 124.

7. A. E. Laiou, Mariage, amour et parenté à Byzance, p. 28. 


\section{Des politiques matrimoniales actives : Marie d'Alanie et Anne Dalassènè}

Marie d d $^{\prime}$ lanie $^{8}$ était une princesse géorgienne. Lors de son arrivée à Constantinople à la fin des années 1060, pour épouser l'empereur Michel VII Doukas ${ }^{9}$ (1071-1078), elle ne représentait pas la première alliance entre les Bagratides et les empereurs de Constantinople.

Son père, Bagrat IV (1027-1072), avait lui-même passé trois ans comme otage à la cour de Basile $\mathrm{II}^{10}$, puis épousé une princesse byzantine, Hélène Argyropoulaina, la nièce de l'empereur Romain III Argyre (1028-1034). En secondes noces, il avait pris pour femme Boréna, sœur du chef de l'Ossétie (ou de l'Alanie ${ }^{11}$, dans le nord du Caucase) et mère de Marie.

J.-C. Cheynet met en avant le rôle de la lignée bagratide, qui renforça des liens déjà existants entre les Doukai, les Comnènes et les Cérulaires, ainsi que le rôle de la famille royale de Bulgarie au sein des parentés byzantines ${ }^{12}$. À la mort du souverain bulgare Jean Vladisthlav, Basile II avait pris sous sa protection sa veuve et ses enfants ${ }^{13}$ : ces derniers avaient été unis aux grandes familles de l'aristocratie d'Asie Mineure sous l'impulsion de l'empereur. Ainsi, Catherine de Bulgarie avait épousé Isaac Ir Comnène (1056-1059), sa nièce Romain IV Diogénès ${ }^{14}(1068-1071)$ et Marie de Bulgarie Andronic Doukas ${ }^{15}$.

Hormis ses dames de compagnie ${ }^{16}$, Marie d'Alanie était donc seule à la cour, sans réseau donné. La naissance d'un porphyrogénète en 1074, Constantin Doukas, conforta sa position d'impératrice. On constate également qu'elle apparait sur les monnaies émises par Michel VII, à l'instar de sa belle-mère l'impératrice Eudocie Makrembolitissa, considérée comme l'une des impératrices les plus puissantes du XI siècle. Lors du renversement de son époux par Nicéphore Botanéiatès (1078-1081), ce dernier choisit Marie comme nouvelle épouse, après avoir longuement hésité entre elle et Eudocie Makrembolitissa : c'est curieusement son apparent isolement et ses origines étrangères qui semblent avoir joué en sa faveur.

Le césar Jean Doukas, l'oncle de Michel VII, avait poussé Nicéphore à arrêter son choix sur Marie, arguant qu'il n'aurait ainsi pas de parents susceptibles de l'embarrasser ou de l'importuner $^{17}$. Ce mariage était en fait tout à fait illégal: Michel VII, contraint d'abdiquer, avait revêtu l'habit monastique. Marie n'était donc ni veuve, ni officiellement divorcée. Le premier prêtre sollicité par le césar pour célébrer cette union avait logiquement refusé. Quant à celui qui finit par accepter, il fut plus tard déposé, comme le prévoyait le Tomos de Sisinnios ${ }^{18}$.

En tant qu'impératrice, Marie avait mené une habile politique matrimoniale, plaçant ses proches dans des familles influentes à la cour :

8. Marie était son nom grec. Son vrai nom était Marthe.

9. Fils de Constantin X Doukas et d'Eudocie Makrembolitissa.

10. Jean Skylitzès, Empereurs de Constantinople, p. 305.

11. B. Martin-Hisard, «La vie de Georges l’Hagiorite », p. 19 : le royaume d'Alanie était un allié de longue date des Bagratides.

12. J.-Cl. Cheynet, Pouvoir et contestations à Byzance (963-1210), p. 279.

13. Jean Skylitzès, Empereurs de Constantinople, p. 299.

14. Ces deux mariages avaient été contractés avant qu'Isaac puis Romain accèdent à l'Empire.

15. Il s'agit des parents de la future impératrice Irène Doukaina.

16. B. Martin-Hisard, «La vie de Georges l'Hagiorite », p. 180 : Marie arriva à Constantinople avec des dames de compagnie, dont certaines lui étaient apparentées (notamment sa cousine germaine Irène, fille du prince d'Alanie).

17. Anne Comnène, Alexiade, III, 2, 3, p. 107.

18. É. Patlagean, Un Moyen Âge grec, p. 88. 
- sa cousine Irène, fille du roi d'Alanie, épousa Isaac Comnène, le frère d'Alexis, en $1071^{19}$.

- une cousine d'Irène épousa Théodore Gabras, alors duc de Trébizonde.

- une autre parente ${ }^{20}$ enfin épousa Constantin, le neveu du patriarche Michel Cérulaire ${ }^{21}$.

À travers ces quatre alliances, celle de Marie comprise, les Bagratides s'alliaient donc aux Doukai mais aussi à leurs alliés les Cérulaires ${ }^{22}$, opérant ainsi un renchaînement $\mathrm{d}^{\prime}$ alliance ${ }^{23}$. L'union avec les Comnènes, quant à elle, semblait préciser un rapprochement entre ces derniers et les Doukai.

Lorsque Marie comprit que Botanéiatès ne choisirait pas son fils Constantin Doukas pour lui succéder, elle renforça de manière significative son réseau en adoptant Alexis Comnène ${ }^{24}$.

Marie démontrait sa parfaite connaissance ou du moins sa bonne appréhension du fonctionnement de la parenté à Byzance : elle avait compris que l'adoption était le lien le plus fort qu'elle pouvait créer entre elle et Alexis à ce moment-là. Si le mariage d'Alexis avec Irène Doukaina unissait déjà les intérêts des deux familles, il ne liait pas directement Alexis et Marie. Elle établissait donc un canal de communication direct entre eux, faisant de lui le frère de son fils Constantin, soit un autre lien fort. Marie était donc bien consciente de la nécessité de renforcer son propre réseau, dit "égocentré ", parallèle à celui des Doukai : ses objectifs en effet différaient sensiblement de ceux du césar Jean, le chef de famille, qui était prêt à soutenir n'importe quelle action du moment qu'un Doukas (homme ou femme) montait sur le trône, tandis que Marie soutenait uniquement les ambitions impériales de son fils.

Cette adoption prenait place à un moment critique pour Marie et Alexis Comnène. La position de favori que ce dernier occupait alors à la cour suscitait la jalousie ${ }^{25}$. Le rituel ecclésial de l'adoption s'accompagnait d'un échange de cadeaux et/ou de faveurs: dans ce cas précis, Marie offrait à Alexis sa protection et son soutien contre ses ennemis à la cour et recevait en échange la reconnaissance de Constantin comme héritier du trône. Dans les faits, ce lien spirituel servait à faciliter les entrevues entre les conspirateurs : Anne Comnène établit clairement le lien entre le refus de Botanéiatès de faire de Constantin son héritier et la participation de Marie au complot des Comnènes ${ }^{26}$. Cette alliance se révéla profitable puisque c'est grâce à Marie que les frères Comnènes échappèrent au piège tendu par les hommes de l'empereur ${ }^{27}$.

Comme le souligne B. Hill ${ }^{28}$, Marie sut, face à une situation de crise, mettre en place un pouvoir alternatif à celui de son époux l'empereur ; cependant, à la différence de B. Hill, je relativiserais sa capacité à légitimer. Si Marie fournit en effet une légitimité dynastique à Nicéphore Botanéiatès, ce ne fut pas le cas pour Alexis. Ce dernier était déjà issu d'une famille qui avait occupé le trône, certes brièvement, et était, de plus, marié à une

19. Jean Skylitzès, Empereurs de Constantinople, p. 270 , note $\mathrm{n}^{\circ} 39$ et p.395, note $\mathrm{n}^{\circ} 4$ : les Comnènes étaient une famille originaire d'Asie Mineure. Le premier Comnène connu, Manuel Comnène-Erôtikos, s'était illustré comme stratège sous le règne de Basile II (976-1025); à sa mort, l'empereur avait pris en charge l'éducation de ses deux fils, Isaac, qu'il maria à Catherine de Bulgarie, et Jean, qui épousa Anne Dalassènè.

20. Paul Gautier, "La curieuse ascendance de Jean Tzetzès », p. 208 : il s'agit de l'arrière-grand-mère de Jean Tzetzès.

21. J.-Cl. Cheynet, Pouvoir et contestations à Byzance (963-1210), p. 314-315: Michel Cérulaire, patriarche de Constantinople et oncle de l'impératrice Eudocie Makrembolitissa; plutôt leader d'une faction politique qu'homme d'Eglise, il prit part de manière active à la vie politique et joua un rôle décisif dans l'accession au trône d'Isaac Ier Comnène.

22. N. Oikonomides, "Le serment de l'impératrice Eudocie : un épisode de l'histoire dynastique de Byzance », p. 119 : Constantin était le cousin d'Eudocie.

23. Mariage entre deux individus qui partagent en commun soit un consanguin éloigné, soit un allié.

24. Anne Comnène, Alexiade, II, 1, 5, p. 65.

25. Ibid., II, 1, 2-3, p.63-64.

26. Ibid., II, 2, 1, p. 66 .

27. Ibid., II, 4, 1-2, p. 71.

28. B. Hill, «Alexios I Komnenos and the Imperial Women », p. 38-39. 
Doukaina. Ainsi, lorsqu'il poussa Marie à l'adopter, Alexis répondait alors à un besoin pressant, celui d'une protection immédiate à la cour. De plus, l'adoption ouvrait des droits à la transmission du patrimoine : nous savons que Marie avait été richement dotée par Nicéphore Botanéiatès ${ }^{29}$. Le succès d'une révolte ne nécessitait-il pas, après tout, des richesses importantes, indispensables à la levée d'une armée ? Enfin, la dernière tentative de Botanéiatès pour conserver le pouvoir avait été de proposer d'adopter Alexis, afin de faire de lui son héritier ${ }^{30}$, démontrant ainsi que lui seul possédait la capacité de légitimer son successeur. Finalement, Marie ne put transmettre à elle seule la légitimité dynastique, ni à son fils Constantin, ni à son fils adoptif Alexis. Tous deux eurent besoin pour cela de l'appui du réseau Doukai.

La bonne compréhension du fonctionnement de la cour byzantine dont avait fait preuve Marie d'Alanie tout au long de sa carrière d'impératrice pourrait s'expliquer par le fait que sa grand-mère Marie et son père avaient tous deux passé beaucoup de temps à Constantinople. En 1031, la reine Marie (qui assurait alors la régence au nom de son fils Bagrat) et Romain III Argyre signèrent un traité de paix ; à cette occasion, Bagrat avait reçu la dignité de curopalate et épousé la nièce de l'empereur, Hélène ${ }^{31}$. Puis en 1048 environ, Bagrat et sa mère se rendirent à nouveau dans la capitale byzantine, cette fois pour demander à l'empereur Constantin IX Monomaque (1042-1055) de mettre un terme au conflit qui les opposait à Liparitès ${ }^{32}$. Alors que Bagrat était ensuite rentré en Géorgie, sa mère Marie était restée à Constantinople où elle avait revêtu l'habit monastique ${ }^{33}$. Entre 1052 et 1055 enfin, Bagrat avait séjourné de nouveau à la cour impériale ${ }^{34}$. Peu de temps après, l'impératrice Théodora avait réclamé la présence de Marie à la cour afin de l'adopter $^{35}$ : lorsque Marie s'était rendue à Constantinople en 1056, sa grand-mère Marie $s^{\prime} y$ trouvait déjà ${ }^{36}$. L'influence politique de la reine Marie ne devrait donc pas être négligée, que ce soit dans le choix de Marie comme fille adoptive de Théodora et peutêtre aussi dans celui de future impératrice ${ }^{37}$. La comparaison entre elle et Eudocie Makrembolitissa ou encore Anne Dalassènè semble ici justifiée.

Ces éléments nous permettent de déduire que Marie et sa famille connaissaient bien la capitale et le palais impérial, ce qui expliquerait également le choix de Marie comme fiancée de Michel VII : les impératrices étrangères étaient en effet rares à l'époque ; or, la menace grandissante des Turcs Seldjoukides avait rendu indispensable l'alliance avec les Bagratides, qui comptaient parmi leurs alliés les Alains ${ }^{38}$. Le réseau dont avait hérité

29. É. Malamut, Alexis $I^{e r}$ Comnène, p. 145 : Marie d'Alanie disposait de revenus économiques importants provenant de l'oikos des Manganes et du monastère de l'Hebdomon (soit des fondations fort riches).

30. Anne Comnène, Alexiade, II, 12, 2, p. 98-99.

31. B. Martin-Hisard, "La vie de Georges l'Hagiorite », p. 19 : le titre officiel de Bagrat IV était "roi des Apxazes et curopalate de tout l'Orient »; les Bagratides tenaient donc leur pouvoir de la reconnaissance de ce dernier par l'Empire Byzantin à travers ce titre de curopalate. Jean Skylitzès, Empereurs de Constantinople, p. 313 : le mariage eut lieu en 1032.

32. B. Martin-Hisard, «La vie de Georges l'Hagiorite», p. 23-24 : Bagrat venait certainement d'épouser Boréna ; cette visite inaugura un accroissement des échanges entre l'Empire et les Alains (c'est à la même époque également que l'empereur Monomaque prit pour maîtresse une Alaine de sang royal, soit une parente de Boréna).

33. Jean Skylitzès, Empereurs de Constantinople, p. 372 : probablement suite au viol dont elle fut victime par Liparitès.

34. B. Martin-Hisard, «La vie de Georges l'Hagiorite », p. 24 : un nouveau conflit avec Liparitès avait contraint Bagrat à demeurer à Constantinople, tandis que son adversaire exerçait effectivement le pouvoir au nom du fils de Bagrat, le futur Georges II.

35. L. Garland et St. Rapp, «Mary of Alania : Woman and Empress Between Two Worlds », p. 100 : les auteurs s'appuient sur une source géorgienne du $\mathrm{X}^{\mathrm{e}}$ siècle, La Vie de Georges l'Hagiorite.

36. Ibid., p. 100.

37. Ibid., p. 115-121 : les auteurs, d'après une source géorgienne, démontrent clairement que c'est déjà la reine Marie qui avait négocié le mariage de son fils Bagrat avec Hélène Argyropoulaina. Nous pouvons également soupçonner son influence dans l'adoption du prénom Marie par la jeune Marthe (Marie d'Alanie).

38. Ibid., p. 120 : le père de Bagrat, le roi Georges Ier, avait divorcé de la reine Marie pour épouser la fille du roi des Alains. Marie était revenue sur le devant de la scène politique lorsque le jeune Bagrat avait succédé à son père. 
Marie lui conférait donc une importance géopolitique, à laquelle venaient se cumuler les relations construites et entretenues par sa grand-mère puis par son père.

Marie ne fut pas la seule responsable du succès des Comnènes. L'impératrice avait, en la personne d'Anne Dalassènè ${ }^{39}$, leur mère, un allié de taille. Anne ne s'était, semble-t-il, jamais vraiment remise de ce que son époux Jean refusa de succéder à son frère Isaac $\mathrm{I}^{\text {er }}$ 40 $^{0}$. Ce dernier avait donc désigné Constantin Doukas pour lui succéder. Nous sommes en 1059: durant les vingt années suivantes, Anne travailla sans relâche à tisser un réseau liant sa famille aux plus puissantes familles de l'aristocratie byzantine.

Sous le règne de Constantin X Doukas (1059-1067), elle avait marié ses deux filles Marie et Eudocie : la première à Michel Tarônitès ${ }^{41}$, la deuxième à Nicéphore Mélissènos ${ }^{42}$. Puis, sous Romain IV Diogénès, sa fille Théodora avait épousé le fils de l'empereur, Constantin.

Le mariage de son fils Isaac avec la cousine de l'impératrice Marie en 1071, sous le règne de Michel VII, était certainement une belle réussite pour Anne Dalassènè qui avait été exilée avec sa famille suite à son implication dans un complot ${ }^{43}$; ce mariage marquait donc le retour en faveur des Comnènes à la cour. Puis, en 1078, Alexis épousait Irène Doukaina, la petite-cousine de Michel VII, peu de temps avant que ce dernier ne soit renversé par Nicéphore Botanéiatès. Sous le règne de ce dernier enfin, une des petitesfilles d'Anne épousait un parent de l'empereur. Peu à peu, les alliances conclues par Anne étaient de plus en plus prestigieuses. Elle réussit même «l'exploit remarquable » (pour reprendre l'expression de J.-C. Cheynet ${ }^{44}$ ), d'unir ses descendants aux trois familles qui avaient occupé le trône entre 1059 et 1081 : les Diogènai, les Doukai et les Botanéiatai. Elle est assurément le maître d'œuvre de la réussite des Comnènes.

\section{Un héritage précieux : Irène Doukaina}

Un réseau familial pouvait-il être considéré comme partie intégrante du patrimoine familial et donc s'hériter? Le cas d'Irène Doukaina peut nous aider à y répondre.

Michel Psellos fait remonter les origines de Constantin X Doukas et son frère Jean aux «... fameux Andronic et Constantin », au milieu du $x^{\mathrm{e}}$ siècle $^{45}$. Andronic Doukas, grand domestique des Scholes, s'était révolté en 904, sous le règne de Léon VI (886-912). Son fils Constantin l'avait imité en $913^{46}$. Il s'ensuivit une élimination si radicale de la famille Doukas qu'il est difficile de faire le lien entre les Doukai du $X^{e}$ siècle avec Constantin et Jean Doukas qui réapparaissent dans les sources un siècle plus tard, au moment de la

39. J.-Cl. Cheynet et J.-F. Vannier, Études prosopographiques, p. 76 : la famille des Dalassènoi compta tout au long du $\mathrm{XI}^{\mathrm{e}}$ siècle des militaires de haut rang dont le plus illustre, Constantin, faillit accéder à l'Empire par Zoé Porphyrogénète.

40. E. Malamut, Alexis I ${ }^{\text {er }}$ Comnène, p. 128.

41. Chr. Settipani, La continuité des élites à Byzance durant les siècles obscurs, p. 343 et 350 : les Tarônitai étaient une ancienne famille qui descendait des anciens princes du Tarôn, en Arménie ; grâce à cette alliance, la carrière de Michel fut fulgurante.

42. Ibid., p. 77 : les origines des Mélissènoi remontent au VIII siècle ; le premier membre connu de la famille était Michel, qui avait épousé sous le règne de Constantin V la sœur de l'impératrice; nous les retrouvons sur la scène politique tout au long des VIII ${ }^{e}$, IX $X^{e}$ et $X^{e}$ siècles avant une interruption de près d'un siècle, jusqu'à ce qu'ils réapparaissent lors de cette alliance avec les Comnènes.

43. En 1071, l'empereur Romain IV Diogénès avait été vaincu et fait prisonnier par les Turcs. Les Doukai, menés par le césar Jean, avaient saisi l'opportunité de recouvrer le pouvoir ; cependant, Romain IV, libéré, avait tenté un retour en force et, dans ce but, échangé des lettres non seulement avec son épouse l'impératrice Eudocie, mais également avec Anne Dalassènè avec qui, rappelons-le, il était lié. La découverte de cette correspondance avait condamné les deux femmes, ainsi que leurs enfants, à l'exil.

44. J.-Cl. Cheynet, Pouvoir et contestations à Byzance (963-1210), p. 277.

45. Michel Psellos, Chronographie ou Histoire d'un Siècle de Byzance, VII, 2, 6, p. 140.

46. Jean Skylitzès, Empereurs de Constantinople, p. 157-159 et p. 167-169 . 
conspiration contre Michel VI (1056) ${ }^{47}$. Cette révolte avait hissé sur le trône Isaac Comnène, bien que Constantin Doukas ait été un temps envisagé. Il accéda finalement à $l^{\prime}$ Empire trois ans plus tard, lorsqu'Isaac, malade, abdiqua en sa faveur ${ }^{48}$. Nous savons par Psellos et Skylitzès que la première épouse de Constantin Doukas était une Dalassènè $^{49}$. Lors de son avènement, il était déjà marié à Eudocie Makrembolitissa. Peu de temps avant de mourir, Constantin $X$ fit prêter serment à Eudocie de ne jamais se remarier et de gouverner aux côtés de son frère le césar Jean, sans introduire sa propre parenté $^{50}$. Ce serment avait pour but non dissimulé de protéger les intérêts de son fils et héritier, et plus largement ceux des Doukai, contre les ambitions d'autres familles, à commencer par celles des Makrembolitai ${ }^{51}$ et de leurs alliés les Cérulaires ${ }^{52}$.

Il serait intéressant de nous arrêter ici un instant sur les conséquences de la disparition d'un intermédiaire entre deux familles à travers deux exemples :

- le premier exemple est celui de la première épouse de Constantin Doukas, une Dalassènè, qui était morte prématurément. L'absence d'enfant impliquait qu'il n'y avait plus d'intermédiaire pour faire le lien entre les Dalassènoi et les Doukai. Nous pouvons donc en déduire que le candidat des Dalassènoi en 1056 était bel et bien Isaac Comnène et non Constantin Doukas.

- le deuxième exemple est celui d'Eudocie qui avait décidé de se remarier, malgré son serment, avec Romain Diogénès. De cette union étaient nés deux fils, qui représentaient pour les Doukai une menace certaine. De plus, nous savons par Psellos ${ }^{53}$ qu'Eudocie avait $^{\prime}$ soutenu le retour de Romain après sa défaite de 1071, s'opposant alors clairement à la politique de son propre fils Michel VII et du césar Jean qui avaient décidé d'affronter Romain ; ce dernier avait été finalement aveuglé (sur les ordres du césar certainement) et était mort des suites de ses blessures. Quant à Eudocie, devenue trop encombrante, elle avait été reléguée dans un monastère avec ses filles et les fils qu'elle avait eu de Romain ${ }^{54}$, Constantin, Léon et Nicéphore. Ici, la mort de Constantin X avait bel et bien affaibli, sinon brisé, les liens entre Eudocie et les Doukai, qui remplacèrent alors leur alliance avec les Makrembolitai et les Cérulaires par une alliance avec les Comnènes. Ainsi, dès le début de son règne personnel, Michel VII donna, comme nous l'avons vu, son accord pour le mariage de la cousine de son épouse Marie avec Isaac Comnène puis, pour celui de sa petite cousine Irène avec Alexis Comnène ${ }^{55}$.

L'idée de cette dernière alliance venait surtout du césar Jean Doukas dont l'avenir s'annonçait sombre : en effet, la santé de son fils Andronic (le père d'Irène) déclinait ; son neveu Michel VII avait fini par l'écarter de l'exercice du pouvoir ${ }^{56}$, neveu dont l'autorité s'affaiblissait. Quant aux Comnènes, Isaac et Alexis, ils étaient plus que jamais bien placés à la cour grâce à la politique matrimoniale menée avec une grande maîtrise par leur mère et chef de famille, Anne Dalassènè. Une alliance avec eux s'avérait donc

47. J.-Cl. Cheynet, Pouvoir et contestations à Byzance (963-1210), p. 339.

48. Michel Psellos, Chronographie ou Histoire d'un Siècle de Byzance, VII, 1, 33, p. 133-134.

49. Jean Skylitzès, Empereurs de Constantinople, p. 328. Michel Psellos, Chronographie ou Histoire d'un Siècle de Byzance, VII, 2, 6, p. 141.

50. Voir N. Oikonomides, «Le serment de l'impératrice Eudocie: un épisode de l'histoire dynastique de Byzance », p. 101-128.

51. J.-Cl. Cheynet, Pouvoir et contestations à Byzance (963-1210), p. 201, note 12 et p. 267 : les Makrembolitai faisaient partie des familles notables qui accaparèrent les fonctions civiles entre 1040 et 1100 ; ils appartenaient au clan constantinopolitain des Monomaques, Cérulaires et Doukai.

52. N. Oikonomides, "Le serment de l'impératrice Eudocie : un épisode de l'histoire dynastique de Byzance ", p. 119: Constantin $X$ se méfiait surtout des cousins d'Eudocie, Constantin et Nicéphore (les neveux du patriarche Michel Cérulaire).

53. Michel Psellos, Chronographie ou Histoire d'un Siècle de Byzance, Livre VII, III, 29, p. 165.

54. Anne Comnène, Alexiade, IV, 5, 3, p. 155 et X, 2, 2, p. 190 : Anne mentionne deux fils, Nicéphore et Léon, puis un troisième Constantin. En ce qui concerne l'imbroglio entre Léon et Constantin, voir Ibid., IV, 5 , note $n^{\circ} 1$, p. 155.

55. M. Angold, The Byzantine Empire, 1025-1204, p. 123 : l'auteur souligne dans ces mariages l'action décisive de l'eunuque Nicéphoritzès.

56. Ibid., p. 121 : évincé par l'eunuque Nicéphoritzès qu'il avait lui-même placé à la tête de l'administration, le césar s'était retiré dans ses propriétés à l'automne 1073. 
incontournable si le césar voulait maintenir sa famille au sommet de l'État. C'est ce même constat qui dut décider Anne Dalassènè à accepter cette union, si l'on tient compte de l'animosité qu'elle éprouvait à l'égard de cette famille qui lui avait volé le pouvoir en 1059. Toutefois, une fois l'alliance avec les Doukai conclue, Anne, fine tacticienne, ne négligea pas pour autant de s'allier à la nouvelle famille régnante, les Botanéiatai.

Le mariage $d$ 'Alexis avec Irène soudait donc les ambitions de ces deux familles qui travaillaient désormais à un seul et unique but, s'emparer à nouveau du trône.

Irène Doukaina héritait donc des ambitions de son grand-père, et de celles de toute une parenté, le réseau Doukai. Sa naissance mettait à sa disposition un éventail très large de contacts et donc d'alliés potentiels. Encore faudrait-il pouvoir mettre en exergue l'utilisation réelle qu'elle fit de ce réseau.

En 1078, Isaac et Alexis Comnène s'étaient mis au service du nouvel empereur Nicéphore III Botanéiatès. Ils bénéficiaient, grâce à la parenté d'Isaac avec Marie d'Alanie, d'un libre accès au gynécée où, durant trois ans, ils préparèrent consciencieusement leur révolte, sur les conseils avisés de leur mère. Ils passèrent à l'action dans la nuit du 14 février 1081 : avant de s'enfuir de la capitale, ils devaient rallier des généraux à leur cause. Bien qu'Alexis fût Domestique des Scholes, son frère Isaac, du fait de sa longue carrière militaire, demeurait plus populaire que lui auprès des armées. Isaac bénéficiait également de son statut d'aîné. Bien conscient de la position de favori de son frère, Alexis prit la précaution de faire avertir le césar de leur fuite : ce dernier, d'une rapidité de réaction et d'une efficacité redoutables, apporta alors non seulement des fonds monétaires indispensables à la levée de troupes mais aussi, appuyé par les frères d'Irène, il imposa Alexis à l'armée, après avoir mené une propagande auprès des militaires pour les décider à acclamer son candidat ${ }^{57}$. Le césar fut grandement aidé dans sa tâche par Georges Paléologue, l'époux d'Anne Doukaina (la sœur d'Irène) : convaincu par sa belle-mère, Marie de Bulgarie, de se rallier aux Comnènes ${ }^{58}$, son action fut décisive. À la tête de la flotte, il empêcha le rival et beau-frère d'Alexis, Mélissènos de pénétrer dans le port de Constantinople et prêter ainsi main-forte à l'empereur Botanéiatès ${ }^{59}$. Il veilla également, une fois la victoire acquise, à ce que la flotte acclamât Irène en même temps qu'elle acclamait Alexis, rappelant que c'était uniquement pour elle qu'il se battait ${ }^{60}$. Relevons ici que son propre père, Nicéphore Paléologue, était demeuré dans le camp opposé, celui de Botanéiatès $^{6}$. Nous en déduisons donc qu'il ne s'estimait pas tenu par la solidarité familiale que l'on pourrait supposer être inhérente à ce type de réseau. Irène pourrait ici être considérée comme l'intermédiaire entre Alexis et Georges puisqu'elle établit entre eux le lien de syngambroi (époux de deux sœurs), lien qui s'avéra déterminant dans l'engagement de Georges aux côtés d'Alexis.

Les Doukai avaient fait pencher la balance en faveur d'Alexis. Cependant, une fois qu'il eut pris possession du Grand Palais, il les installa dans un palais à part ${ }^{62}$ et se fit ensuite couronner seul par le patriarche Kosmas. Les Doukai durent attendre sept jours avant de voir Irène finalement couronnée. En effet, une atmosphère de flottement régnait sur le palais impérial à ce moment-là : Alexis était tiraillé entre l'attirance certaine qu'il éprouvait pour Marie et la nette conscience du soutien indispensable des Doukai. De l'aveu même de sa fille, Anne Comnène, son père refusait d'éloigner Marie, et les rumeurs les plus folles couraient à Constantinople, causant l'inquiétude de sa bellefamille ${ }^{63}$.

57. Anne Comnène, Alexiade, II, 7, 1-2, p. 84-85.

58. Ibid. II, 6, 1-2, p. 80.

59. Ibid., II, 11, 2-5, p. 95-97.

60. Ibid., III, 2, 1, p. 106.

61. Ibid., II, 6-7, p. 97-98.

62. Ibid., III, 1, 5, p. 105.

63. Ibid., III, 2, 7, p. 109. 
Là encore, la réaction énergique du césar s'avéra déterminante. Il fit à nouveau appel au patriarche Kosmas, qui lui était intimement lié64 ${ }^{6}$ : Anne Dalassènè tentait de pousser ce dernier à la démission afin de le remplacer par son propre candidat ${ }^{65}$. De son côté, le patriarche arguait qu'il ne quitterait pas son poste tant qu'il n'aurait pas couronné Irène de ses propres mains. Il obtint finalement gain de cause ${ }^{66}$. Anne demeurait donc hostile aux Doukai, estimant sans doute que leur soutien n'était plus nécessaire maintenant que son fils occupait le trône. Lorsqu'elle avait accepté le mariage d'Alexis avec Irène, elle était certainement loin de se douter que ce serait Alexis et non pas Isaac qui monterait sur le trône. Sans doute l'idée de devoir partager le pouvoir avec les Doukai lui était-elle insupportable.

Marie envisageait-elle de se marier une troisième fois? Marie et Alexis étaient de fait certainement amants (ils avaient le même âge, et les sources sont unanimes sur la beauté de Marie; Irène était à peine une adolescente et il semble que son mariage n'avait toujours pas été consommé). En tant que mère et fils spirituels, leur mariage serait tombé sous le coup de l'interdit ${ }^{67}, \mathrm{l}^{\prime}$ acte $\mathrm{d}^{\prime}$ adoption étant considéré comme une alliance et donc comparable à un mariage. Enfin, même si l'adoption n'avait pas eu lieu, le mariage d'Isaac Comnène avec la cousine de Marie rendait cette union impossible car, conformément au Tomos de Sisinnios, deux frères ne pouvaient épouser deux cousines germaines. Marie d'Alanie quitta finalement le Grand Palais, persuadée par le césar, en échange d'un sauf-conduit impérial qui reconnaissait Constantin comme co-empereur. La politique de Marie portait enfin ses fruits: elle n'était certes plus impératrice, mais désormais mère adoptive de l'empereur et mère biologique de l'héritier du trône, situation inédite dans l'histoire de Byzance.

Compte tenu des facteurs énoncés en introduction, nous constatons que c'est grâce au niveau de nuptialité élevé de sa famille qu'Anne Dalassènè était parvenue à tisser un réseau puissant : mère de huit enfants (5 fils et 3 filles), elle avait été à même de mettre en place un réseau étendu. Quant à Marie d'Alanie, elle avait eu la chance de disposer de jeunes parentes à marier.

C'est bien la maternité qui semble avoir dicté la politique matrimoniale de ces deux femmes: toutes deux n'hésitèrent pas à transgresser des interdits, participer à des complots, ou encore tenter d'annuler des alliances contractées précédemment, dans l'intérêt de leurs fils, Alexis et Constantin. Leurs stratégies respectives démontrent qu'elles avaient parfaitement intégré le fonctionnement de la parenté : si cela semble naturel dans le cas d'Anne Dalassènè, issue d'une des plus puissantes familles du XI ${ }^{\mathrm{ème}}$ siècle, cela est plus surprenant dans le cas de Marie qui, d'origine étrangère, réussit malgré cela à légitimer Nicéphore Botanéiatès.

Leur liberté d'action fut-elle rendue possible par un contexte politique tumultueux ? Sans doute puisque comme le constate B. Hill, une fois Alexis et sa dynastie installés sur le trône, nous constatons un effacement relatif des impératrices Comnènes dans les sources. Les femmes qui succédèrent à Marie d'Alanie et Irène Doukaina se consacrèrent en effet davantage au patronage littéraire et aux fondations monastiques, laissant la politique matrimoniale aux mains de leurs époux.

64. J.-Cl. Cheynet, Pouvoir et contestations à Byzance (963-1210), p. 314 : Kosmas était un client des Doukai. Anne Comnène, Alexiade, II, 12, 5, p. 100 : il était déjà intervenu une première fois à la demande du césar pour pousser Botanéiatès à abdiquer sans livrer bataille.

65. Ibid., III, 2, 7, p. 109 : le moine Eustratios, protégé d'Anne Dalassènè ; il aurait sûrement été plus enclin à dissoudre le mariage d'Alexis et d'Irène. 66. Ibid., III, 2, 7, p. 110.

Voir É. Malamut, Alexis I ${ }^{\text {er }}$ Comnène, p. 60 : 1'armée d'Alexis, lors de son entrée dans Constantinople, s'était livrée à un violent pillage au cours duquel les églises et les sanctuaires avaient été profanés; il est clair qu'Alexis et sa mère n'étaient pas en position de forcer le patriarche au départ.

67. É. Patlagean, "Christianisation et parenté rituelles: le domaine de Byzance », p. 626-627: l'adoption, devenue un rituel ecclésial, engendrait des empêchements de mariage. 
Le cas d'Irène Doukaina semble confirmer cette hypothèse : héritière d'un réseau qui l'avait hissée sur le trône à l'âge de quinze ans, une fois impératrice, elle ne semble pas avoir assumé de rôle dans les mariages de ses enfants ${ }^{68}$. Cependant, lorsqu'elle tenta à son tour de jouer un rôle politique, lors de la succession de son époux, elle se montra parfaitement imprévisible, prenant le parti de sa fille Anne et de son gendre Nicéphore Bryennios, contre son propre fils Jean, déjouant ainsi le comportement naturel que l'on pouvait attendre de la part d'une impératrice Comnène. En agissant de la sorte, Irène mettait en péril l'avenir de la dynastie. Devons-nous en déduire que malgré son mariage avec Alexis, Irène demeurait avant tout une Doukaina? En faveur éventuellement de cette hypothèse, l'examen de son sceau particulier, où elle avait fait graver le nom de Doukaina ${ }^{69}$.

\begin{abstract}
Résumé
Irène Doukaina est fiancée à Alexis Comnène avant qu'il ne devienne empereur de Constantinople. Cette alliance est celle de deux puissantes familles aristocratiques byzantines. Avant l'arrivée au pouvoir d'Alexis, le réseau «donné » d'Irène Doukaina va favoriser son ascension au trône en lui apportant l'appui indispensable du réseau Doukas. Une fois au pouvoir, Alexis hésite à épouser Irène : ne serait-il pas plus judicieux d'épouser l'impératrice en place Marie d'Alanie ? Là encore, le réseau d'Irène joue un rôle décisif en imposant son mariage et son couronnement en tant qu'Augusta. Comment les Doukai et les Comnènes utilisèrent-ils leurs réseaux pour se hisser jusqu'au trône? Comment Marie d'Alanie, d'origine étrangère et donc sans réseau " donné », tisse-t-elle son réseau acquis ? Une fois impératrice, comment Irène va-t-elle s'imposer définitivement au réseau Comnène et mettre un terme à leur rivalité avec les Doukai ? Nous nous proposons de suivre le cheminement de ces deux impératrices à travers les réseaux aristocratiques byzantins dont les alliances se font et se défont inlassablement. Nous analyserons également leur comportement et leur capacité de manœuvre au sein de ces réseaux.
\end{abstract}

\title{
Bibliographie
}

\section{Sources :}

Michel PSELlOS, Chronographie ou Histoire d'un Siècle de Byzance, trad.Émile Renauld, Paris, Les Belles Lettres, 2006.

Jean SKYLITZĖS, Empereurs de Constantinople, trad. Bernard Flusin, Paris, Lethielleux, 2003.

Anne COMNÈNE, Alexiade, trad. Bernard Leib, Paris, Les Belles Lettres, 1967.

68. B. Hill, «Alexios I Komnenos and the Imperial Women », p. 45-46.

69. J.-Cl. Cheynet, « Les sceaux des impératrices à Byzance». 


\section{Ouvrages secondaires :}

ANGOLD Michael, The Byzantine Empire, 1025-1204, Londres, Longman, 1984.

CHEYNET Jean-Claude, Pouvoir et Contestation à Byzance (963-1210), Paris, Publications de la Sorbonne, Centre de Recherches d'Histoire et de Civilisation Byzantines, 1996.

CHEYNET Jean-Claude et VANNIER Jean-François, Études prosopographiques, Paris, Éditions de la Sorbonne, 1986.

CHEYNET Jean-Claude, «Les sceaux des impératrices à Byzance », dans CONSTABLE Giles et ROUCHE Michel (éd.), Auctoritas, Mélanges offerts au professeur Olivier Guillot, Paris, PUPS, 2006, p. 397-408.

GARLAND Lynda et RAPP Stephen, «Mary of Alania : Women and Empress Between Two Worlds ", dans GARLAND Lynda (éd.), Byzantine Women, Varieties of experience (800-1200) (Centre for Hellenic Studies, King's College London, Publications 8), Aldeshot, Ashgate, 2006, p. 91-122.

GAUTIER Paul, «La curieuse ascendance de Jean Tzetzès », Revue des Études Byzantines, $\mathrm{n}^{\circ} 28,1970$, p. $207-220$.

HiLl Barbara, «Alexios I Komnenos and the Imperial Women » dans MulletT Margaret and SMYTHE Dion (éd.), Alexios I Komnenos, Belfast, Byzantine Texts, 1996, p. 37-54.

LAIOU Angeliki E., Mariage, amour et parenté à Byzance, Paris, De Boccard, 1992.

Malamut Élisabeth, Alexis I ${ }^{e r}$ Comnène, Paris, Ellipses, 2007.

MARTIN-HiSARD Bernadette, «La vie de Georges l'Hagiorite», Revue des Études Byzantines, $\mathrm{n}^{\circ}$ 64-65, 2006-2007, p. 5-204.

OIKONOMIDES Nicolas, "Le serment de l'impératrice Eudocie : un épisode de l'histoire dynastique de Byzance », Revue des Études Byzantines, n² 21, 1963, p. 101-128.

Patlagean Évelyne, Un Moyen Âge grec, Paris, Albin Michel, 2007.

PATLAGEAN Évelyne, "Christianisation et parenté rituelles : le domaine de Byzance », Annales. Économies, Sociétés, Civilisations, 33e année, n³ 3, 1978, p. 625-636.

PITSAKIS Constantin G., «Législation et stratégies matrimoniales. Parenté et empêchements de mariage dans le droit byzantin », L'Homme, n 154-155, avril-septembre 2000, p. 677-696.

SETtiPAni Christian, La Continuité des élites à Byzance durant les siècles obscurs, Paris, De Boccard, 2006. 


\section{Illustrations}

Figure 1 : Généalogie des Makrembolitai-Cérulaires.

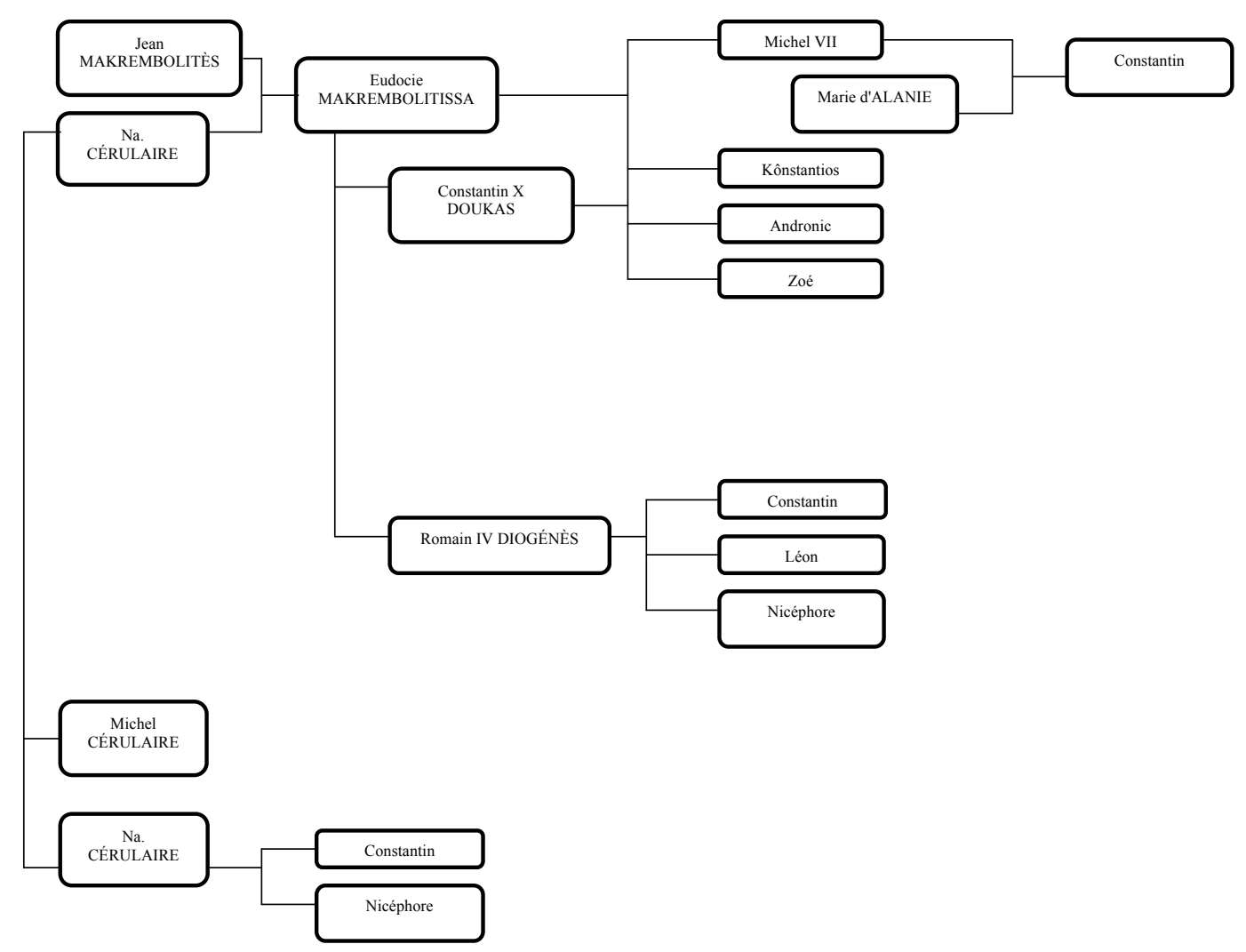


Figure 2 : Généalogie des Comnènes.

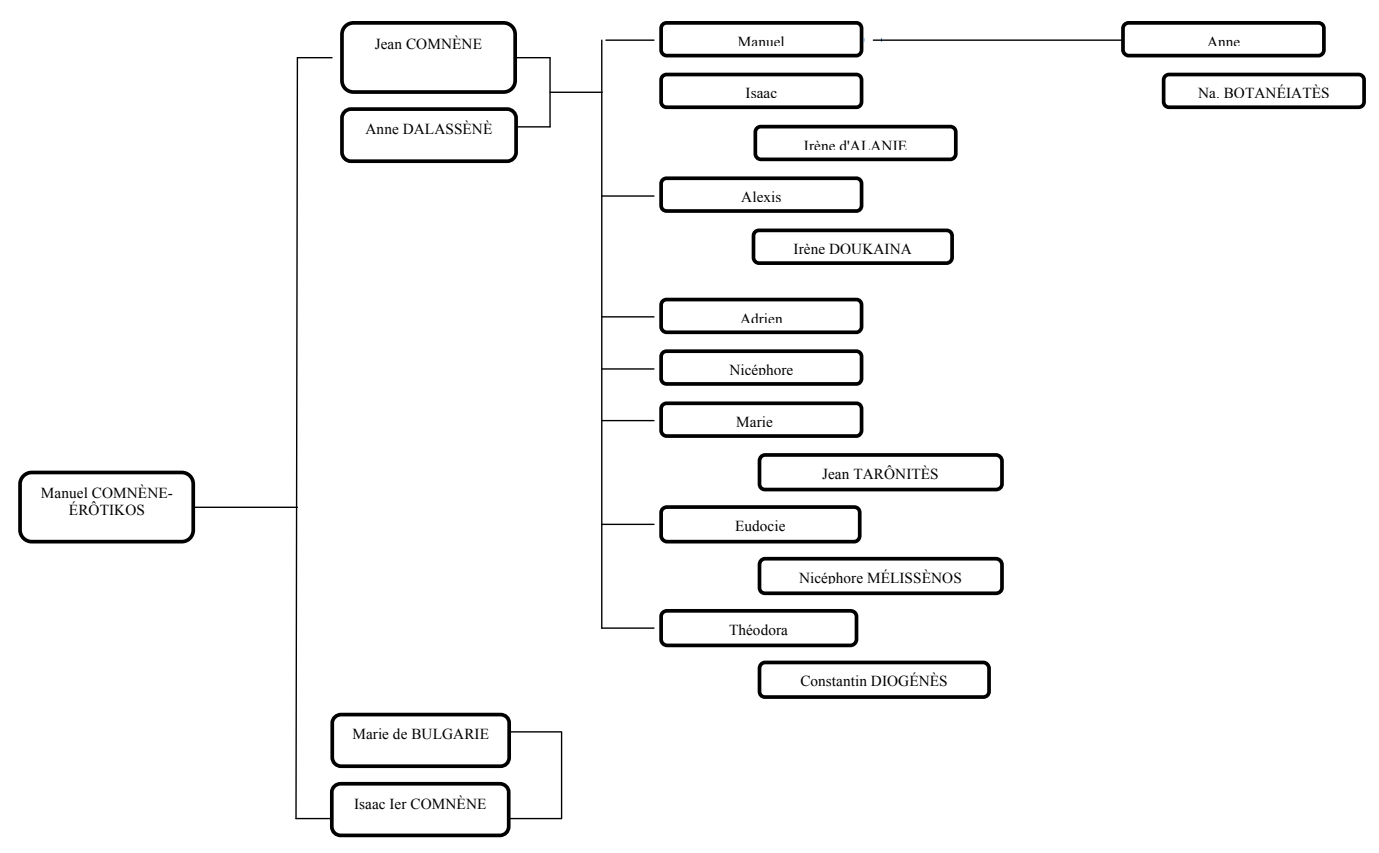

Figure 3 : Généalogie des Doukai.

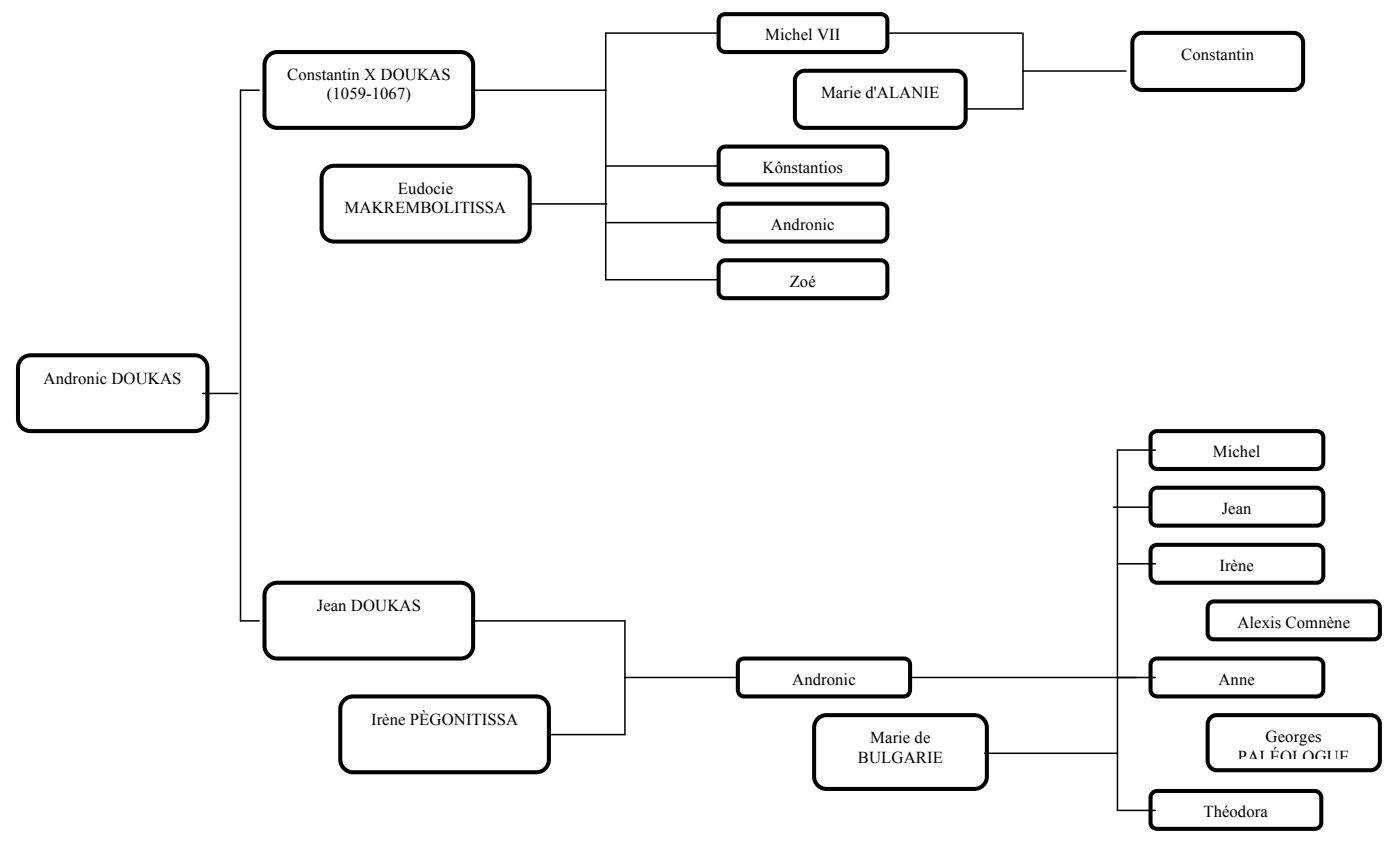




\title{
Côté ville et côté cour : concurrence ou complémentarité des réseaux en Italie centrale $X I V^{e}-X V^{e}$ siècles
}

\author{
Philippe JANSEN \\ Professeur histoire médiévale, \\ Université Côte d'Azur - CEPAM \\ Extrait de : Henri BRESC (dir.), Réseaux politiques et économiques, Paris, \\ Édition électronique du CTHS (Actes des congrès des sociétés historiques et scientifiques), 2016. \\ Cet article a été validé par le comité de lecture des Éditions du CTHS dans le cadre de la publication \\ des actes du $140^{\mathrm{e}}$ Congrès national des sociétés historiques et scientifiques tenu à Reims en 2015.
}

Les sources de l'histoire communale en Italie médiévale font un abondant usage du vocabulaire des réseaux politiques: pars, "factions », " sociétés », « adhérents », « fidèles », " rebelles ». La position sociale des citadins ne se définissait pas seulement par leur activité économique et leur richesse, plus ou moins formalisées au sein des Métiers, Arts ou Collèges. Elle était également définie par des liens transversaux fondés sur l'influence et la considération que justifiait le service de la chose publique. Ces liens s'exerçaient dans des cadres plus ou moins formels, depuis l'unité des familles aristocratiques jusqu'aux institutions complexes et réglementées des "sociétés de portes ", du popolo ou des partis, qui furent plus systématiquement identifiés à partir du $\mathrm{XIV}^{\mathrm{e}}$ siècle par les noms de «guelfes » ou de " gibelins " ${ }^{1}$. Surplombant et unifiant ces "réseaux » identifiés, les institutions de la commune étaient le lieu où se manifestaient publiquement les relations tissées entre citoyens. Le talent oratoire, le goût de gérer les affaires publiques se repéraient d'abord dans les prises de parole au sein des conseils communaux, puis s'exerçaient de manière plus concrète et manifeste dans les magistratures urbaines et les offices administratifs. Les actes produits par ces institutions, aussi bien que les chroniques, ont inspiré une historiographie abondante qui a parfois recherché dans l'expression des relations sociales et politiques du monde communal l'émergence de formes « modernes » des réseaux politiques ${ }^{2}$.

Parallèlement au monde de négociants, de chefs d'ateliers, de financiers et prêteurs, de notaires et de juristes, caractéristiques de la société citadine, les groupes aristocratiques urbains ont développé des liens fondés sur l'attrait social du prestige et du rang et sur la capacité de combattre, dans le cadre de la militia; l'influence acquise leur a permis de prendre le pouvoir au sein de certains régimes communaux qu'ils transformèrent en

1. Aux analyses, en partie dépassées, de Jacques Heers sur ce phénomène (J. Heers, Partis et vie politique dans l'Occident médiéval), on préférera plutôt à des études qui ont approfondi les modes de recrutement et le vocabulaire des factions en Italie, notamment les guelfes et les gibelins : S. Raveggi, M. Tarani, D. Medici et P. Parenti, Ghibellini, guelfi e popolo grasso. I detentori del potere politico a Firenze nella seconda metà del Dugento; R. M. Dessi, "I nomi dei Guelfi e dei Ghibellini da Carlo I d'Angiò a Petrarca », dans M. Gentile (ed.), Guelfi e ghibellini nell'Italia del Rinascimento, Roma, Viella, 2005, p. 3-78.

2. G. Salvemini, Magnati e popolani in Firenze dal 1280 al 1295, en 1899, fut l'un des premiers à faire de la «bourgeoisie marchande » un des facteurs de développement des institutions communales, face à l'aristocratie foncière. Un courant historiographique plus récent, illustré notamment par Emilio Cristiani, Nobiltà e popolo nel comune di Pisa (Naples, 1962), a mis en valeur au contraire la complexité des milieux dirigeants communaux, fondés sur des réseaux de clientèles de différentes origines. 
seigneuries personnelles ou familiales à partir de la seconde moitié $\mathrm{du} \mathrm{XII} \mathrm{XIècle}^{3}$, sans faire disparaître le cadre institutionnel préexistant.

Aux $X_{I V}{ }^{e}$ et $X V^{e}$ siècles, une nouvelle évolution socio-politique, qui retiendra ici notre attention, apparaît: quelques familles puissantes sont parvenues à édifier des principautés territoriales qui s'imposaient aux autonomies communales sans cependant les abolir. Machiavel, dans Le Prince qu'il dédie en 1515 au duc Laurent de Médicis, évoque ce phénomène des "principautés nouvelles» gouvernées par «ceux, qui de personnes privées, deviennent princes par la seule faveur de la fortune ${ }^{4}$ dont Francesco Sforza, duc de Milan en 1450, est donné en exemple. Même s'ils sont parfois issus des milieux urbains, ces nouveaux princes forgent leur puissance selon une logique différente ; ils ont cherché à constituer des liens de service et de fidélité autour de leur personne et de leur destinée individuelle, et non dans le cadre d'institutions collectives.

Les principes qui régissent l'activité des réseaux communaux d'une part, princiers de l'autre, paraissent contradictoires : les uns défendent en commun la capacité à édicter lois et statuts, les autres exercent une autorité par délégation individuelle et hiérarchique qui émane du prince. Mais l'opposition idéologique provient de textes qui exposent le point de vue des détenteurs du pouvoir plutôt que les intentions des membres des réseaux qui soutiennent leur cause. L'étude de la correspondance échangée entre seigneurs et autorités communales en Ombrie et dans les Marches, permet, pensons-nous, d'approcher l'idée que les membres de ces réseaux - et pas seulement leur chef - se faisaient de l'identité de leur forme d'association et des principes qui la fondaient.

\section{Participer à un réseau : un honneur, un service ou une faveur?}

Ces réseaux sont avant tout des réseaux politiques. Leurs principes organisateurs sont inspirés par les théories exprimées dès le XIII siècle par les grands juristes d'Italie, à partir des catégories aristotéliciennes de gouvernement ${ }^{5}$. Celles-ci mettaient en évidence l'antinomie du pouvoir d'un seul, qui pouvait tomber dans la tyrannie, et celui du groupe au service du bien commun. Les motifs de constitution et de fonctionnement des réseaux dans la ville ou la cour princière semblent ainsi s'exclure. Il nous faut dépasser ces principes et s'intéresser au vocabulaire des actes produits par les membres des réseaux eux-mêmes pour en préciser les logiques d'affirmation.

Participer à la gestion publique de la cité en siégeant dans les conseils communaux est un droit de citoyens, mais il ne suffit pas à constituer un réseau. Au sein des communes de modeste importance des Marches et de l'Ombrie (si l'on excepte Pérouse et Ancône), se détachent des «équipes» politiques qui contrôlent l'essentiel des décisions par leur participation régulière, récurrente et cumulée à plusieurs fonctions consultatives et exécutives. Ainsi, à Macerata entre 1380 et 1410, parmi la centaine de membres des conseils de la commune, on peut identifier environ trente citoyens omniprésents: ils monopolisent la parole et expriment les avis qui emporteront la majorité des votes au conseil ; ils exercent de nombreux mandats dans les offices de décision ${ }^{6}$. Tous les citoyens qui s'étaient associés pour prendre en ferme les recettes fiscales de la commune entre 1390 et 1404 avaient également acquis des compétences de gestionnaires au service de la commune: notaires et juristes de formation pour la plupart, ils ont presque tous été notaires du trésor de la commune ou du cadastre, puis camerlingues, et certains d'entre

3. J.-Cl. Maire Vigueur, Cavaliers et citoyens. Guerre, conflits et société dans l'Italie communale, XII'-XIII siècles, ouvrage essentiel pour comprendre le rôle de la noblesse dans les communes.

4. Machiavel, Le Prince, 1532, ch. 1; consulté sur wikisource dans la traduction française de 1825, le 21 avril 2015. 5. Voir en particulier Bartolo da Sassoferrato, De Regimine Civitatis, dans l'édition de Diego Quaglioni, Florence, 1983.

6. Ph. Jansen, Démographie et société dans les Marches à la fin du Moyen Âge : Macerata aux XIV et XV siècles, p. 510521. 
eux ont exercé plusieurs mandats de prieurs ${ }^{7}$. La présence des mêmes individus dans des fonctions publiques stratégiques révèle l'existence de relations inter-personnelles qui font réseau.

$\mathrm{D}^{\prime}$ autres réseaux institutionnels apparaissent également stratégiques : les rédacteurs et réformateurs des statuts, qui sont souvent d'anciens ou de futurs prieurs, les chanceliers et secrétaires qui archivent les délibérations; les suites des podestats, constituées autour de ces magistrats par des juristes compétents, et qui s'étoffent au fil des passages d'une ville à l'autre. L'expérience d'une administration extérieure à sa propre ville constitue une étape privilégiée dans leur carrière.

Dans leurs contrats d'association, les fermiers des finances n'évoquent jamais l'existence des liens personnels, ou des alliances familiales qui pouvaient exister entre eux, ni leur participation à des intérêts privés communs. Ils justifient au contraire les motifs de leur alliance en utilisant le vocabulaire politique que l'on retrouve dans les préambules des statuts communaux: maintenir la paix publique, la prospérité des habitants et la tranquillité de leur statut. Les réseaux politiques des communes justifient leurs existences par le souci d'en conserver le "bon état », c'est-à-dire de maintenir le bon ordre social. Leur identité spécifique ou partisane est niée, car elle serait contraire à l'idée de concorde qui doit unir les citoyens. Au nom de l'idéal politique affiché, les hommes des réseaux communaux mettent en avant des qualités distinctives de compétence et de probité. Les Riformanze des statuts de la commune de Macerata établies en 1398 énoncent les qualités morales et sociales requises pour accéder à certaines fonctions : les notaires qui doivent contrôler les élections aux autres offices communaux doivent être experti et pratici, tout comme les notaires de la suite du podestat et ceux du cadastre, simplement experti. Les greffiers pour le tribunal des appels doivent se montrer à la fois experti, fides et legales. Les syndics représentant la commune dans des négociations politiques sont recherchés parmi les prudentes cives et ceux qui doivent vérifier les comptes sont providi. Parmi les juristes de plus haut rang, le juge des appels doit être bonus et expertus judex; l'avocat de la commune est egregius et valens doctor seu jurisperitus ${ }^{8}$.

L'énoncé de ces qualités n'est pas une simple marque de prestige; il renvoie à des processus réels de formation des réseaux. Ceux-ci se constituent dès la jeunesse, par l'acquisition d'une formation intellectuelle commune, souvent partagée dans les mêmes lieux d'étude (il s'agit essentiellement des universités de Bologne et Padoue pour les régions prises en considération). La formation théorique et pratique, sanctionnée par un diplôme, et parfois par un examen organisé par la commune elle-même, est complétée par l'expérience acquise dans les offices et les bureaux publics. D'anciens condisciples d'études juridiques y rencontrent les financiers et marchands auxquels ils vont s'associer pour les fermes fiscales. Tous peuvent y faire la preuve de leur « expertise » qui est un autre critère essentiel; il se comprend de deux manières : c'est la manifestation d'une maîtrise théorique et pratique de la fonction (savoir tenir des comptes justes ou, pour les notaires, savoir utiliser les formulaires juridiques les plus appropriés à l'acte à rédiger) ; mais c'est aussi la reconnaissance officielle de cette capacité par une «expertise »: à Sassoferrato en 1457, l'examen communal permet de départager des notaires « experts » et «non experts». Un bon " réseau » au service de la commune peut, par ces procédures, être reconnu par l'opinion publique ${ }^{9}$. Les citoyens influents sont présentés dans les registres de délibérations comme des prudentes et des egregii cives; ils conjuguent la connaissance théorique et l'habileté négociatrice. Ceux qui ne possèdent pas ces qualités peuvent être suspectés de vouloir exercer le pouvoir par ambition personnelle ou partisane, et de subvertir ainsi la concorde sur laquelle repose le régime communal.

Les règles d'appartenance aux réseaux des cours princières relèvent d'autres choix, exprimés dans l'abondante correspondance des princes et par les ordonnances qu'ils

7. Idem, "L'investissement des institutions communales par les spécialistes des finances en Italie à la fin du Moyen Âge », p. 239-256.

8. Sur la mise en œuvre de ces critères, je renvoie à mon étude : Ph. Jansen, «Offices et service de la commune et du prince en Italie, XIII ${ }^{\mathrm{e}}-\mathrm{XV}^{\mathrm{e}}$ siècles », p. 120-121.

9. Ibid. Cf. Don U. Paoli, Statuto communale di Sassoferrato, 1993 ; 1. I, rubr.14, p. 40-42. 
adressent aux communes. Les princes insistent sur les qualités de comportement individuel et sur les liens d'affectivité. Ils revivifient le vocabulaire traditionnel des fidélités aristocratiques de type féodal. Ces «nouveaux seigneurs », qui descendaient parfois d'anciens notables urbains, n'ignoraient rien cependant des références politiques communales ; ils les utilisaient pour faire accepter les hommes qu'ils voulaient placer à la tête des administrations urbaines. Mais la compétence ne suffit pas : les princes exigent d'abord la garantie d'un comportement «fidèle», qui doit avoir pour préoccupation première d'agir pour défendre et accroître les biens de la famille princière. Lorsque Francesco Sforza, vicaire général du Pape dans les Marches, veut instituer en 1439 le milanais Pietro da Buzonigo chancelier de la commune de San Severino, il le décrit comme :

« Une personne intelligente, instruite et qui mérite tous les honneurs et offices, qui m'est un ami et serviteur très cher... et il nous est agréable que de tels hommes occupent les offices de nos terres. » ${ }^{10}$

L'année suivante, son frère Alessandro - son lieutenant dans les Marches - s'est emparé de la seigneurie de Pesaro; il nomme Tommaso Testagrossa collecteur des vivres pour l'armée auprès des communes et le présente comme nobili et circumspecto viro Thomassio Testagrossa dilecto familiari nostro ${ }^{11}$. Entrer dans le réseau au service du prince, quelle que soit l'origine sociale du bénéficiaire, c'est devenir membre de leur famille élective et non biologique. Francesco Sforza s'adressait aux prieurs communaux comme à des «Magnifiques hommes, frères très aimés ». Pier Paolo de Turris d'Ascoli, futur podestat de Macerata, est considéré comme "Noble homme, notre très cher ami » ${ }^{12}$. En 1451, un chevalier stipendié au service de Francesco Sforza se recommande, au moment de quitter son service, « à sa Seigneurie dont il sera toujours le serviteur et prie sa Seigneurie qu'elle veuille bien lui donner une bonne lettre de licenciement $»^{13}$.

Cette courte formule nous introduit au cœur du fonctionnement des réseaux princiers : l'affichage des liens d'affection met en œuvre un système de don et contre-don qui lie les membres du réseau tout en les maintenant dans une situation d'inégalité hiérarchique : à celui qui proteste de sa loyauté et de sa volonté de servir, le prince ne peut faire autrement que manifester son amitié par des faveurs; Francesco Sforza répond au chevalier :

«Il nous serait agréable de vous complaire et de faire pour vous une chose agréable, à cause de l'amour et de l'affection que nous vous portons pour vos vertus et parce que nous sommes tout à fait certains que vous nous avez toujours aimé de manière très singulière. ${ }^{14}$

Il autorise donc le chevalier à retourner dans le royaume de Naples. L'amitié et le service sont sources de récompense et d'honneur: la reconnaissance n'est pas recherchée dans l'opinion des pairs, essentielle dans les valeurs communales, mais dans le regard bienveillant du protecteur. La grâce dont le prince est pourvoyeur est également convoitée par d'autres puissants seigneurs, presque égaux par le rang, mais qui trouvent intérêt à se mettre à son service, pour conforter leurs alliances politiques: ainsi Sigismond Pandolfe Malatesta, nouvel allié de Sforza contre le comte d'Urbino, manifeste sa dévotion et sa fidélité au duc de Milan, pour obtenir de lui le titre de capitaine des

10. «persona intelligente, docta et che merita ogni honore, officio, et a mi è carissimo amico et servidore... et che ad noi è grato che simili homini stiano nelli officii delle terre nostre ", dans A. Gianandrea, Della signoria di Francesco Sforza nella Marca secondo le memorie e $i$ documenti dell'archivio settempedano, p. 39.

11. Lettre d'A. Sforza d'Adria, le 6 décembre 1440. Ed. G. Benaducci, Della signoria di Francesco Sforza nella Marca, e peculiarmente in Tolentino (dicembre 1433-agosto 1437), doc. L, p. 189.

12. Ibid., doc. XXII, p. XVII : « Magnifici tamquam fratres carissimi ».

13. Lettre du chevalier Giacomo Ferrario, 23 octobre 1451, cité par L. Rossi, « Nuove notizie su Federigo da Montefeltro, Sigismondo Malatesta e i Manfreedi d'Imola e di Faenza (1451)».

14. Ibid., réponse de F. Sforza le $1^{\text {er }}$ novembre 1451 : " haverimo caro de compiacervi e farve cosa grata per lo amore et affectione vi portiamo per le vertù vostre e perchè semo certissimi ne havate state sempre amato singulariter ». 
armées du duché, assorti d'un versement de 10000 ducats. Il l'en remercie en 1452 auprès du chevalier milanais Francesco da Cusano :

«Faites répondre à votre Hauteur en La remerciant du mieux qu'il sache et puisse pour l'amour que par continuelle expérience il voit que Votre Seigneurie lui porte, en disant qu'il est content et qu'il prendra les 10000 ducats... il ne doute pas que Votre Seigneurie n'agisse (en sa faveur) de bien en mieux, et surtout pour lui donner l'occasion de travailler pour elle et de faire l'expérience de l'amour, de la foi et de la dévotion qu'il Vous porte. ${ }^{15}$

La récompense doit prouver à tous le lien affectif qui cimente le réseau. Mais l'honneur donné au "serviteur » est aussi une délégation : le délégué qui par cet échange est entré dans la «famille» du prince doit être respecté comme sa propre représentation, quel que soit son rang, y compris par les représentants des communes. En 1434, Foschino degli Attendoli adresse à celles-ci son messager, le "noble homme» Venanzo di Carbone, citoyen de Macerata et impartit aux autorités de lui accorder « autant de confiance qu'à nous-même» et de «l'approvisionner en victuailles ${ }^{16}$. En 1442, Francesco Sforza ordonne aux autorités communales des Marches de recevoir les trois responsables du ravitaillement qu'il leur envoie par délégation et de « les recevoir, favoriser et leur obéir comme à nous-mêmes $»^{17}$.

Le vocabulaire des actes exprime bien deux conceptions antithétiques du réseau. "Côté ville», il se forme par la reconnaissance entre égaux de la connivence du savoir qui distingue les élites du commun et par la pratique d'actions communes, sources de confiances réciproques. "Côté cour", c'est un réseau d'amitié autour du puissant protecteur, une amitié qui doit veiller à toujours préserver et défendre l'intérêt de la tête du réseau, pourvoyeuse de faveur, voir de cadeaux, et de reconnaissance. L'image sobre du devoir d'un côté, le "goût d'être caressé " (selon l'expression de Francesco da Cusano ${ }^{18}$ ) de l'autre. En théorie, les membres de ces réseaux ne devraient pas se rencontrer et se mêler.

\section{Des concurrences atténuées par le relais des seigneuries urbaines}

Dans les faits, les conseillers des princes ne se recrutent pas uniquement parmi les nobles et les chevaliers de la terre, tandis que les communes n'excluent pas non plus les lignages aristocratiques de leurs réseaux politiques. Les réseaux princiers ne recrutent pas non plus, en règle générale, parmi les opposants au régime communal en place. Les princes ne cherchent pas en effet à renverser les régimes communaux, mais à obtenir au contraire leur ralliement et à s'en servir comme appuis auxiliaires : ce n'est donc pas leur intérêt que de paraître fomenter des réseaux factieux - sauf si le régime en place affiche une opposition frontale à leur égard.

15. Ibid., Lettre de Francesco Cusano du 3 avril 1452, qui rapporte à F. Sforza la teneur des propos de Sigismond Malatesta : " per sua parte respondesse alla V. Cel. ringraziando quella quanto el sa e po de l'amore che continuamente o per continue experienze el vede che la V. S. gli porta dicendi ch'el è contento tora e cossì accepta li diecimila ducati...se ne contentaria con dire ch'el non dubita che la V. S. ogni dì non gli faccia de bene in meglio et maxime avendo quella caxone de operarlo e fare experienza de l'amore, fede et devotione ch'el ve porta».

16. G. Benaducci, Della signoria di Francesco Sforza nella Marca..., op. cit., doc. VIII, p. 36 (29 mai 1434) : «...mittimus nobilem virum Carbonem Venantii de Macerata nuntium fidum, cui aliqua commissimus omnibus vobis explicanda et enarranda ex nostra parte. Placeat itaque tantam fidem impartiri tamquam nobis ipsis...Insuper praelibato Carbone de victu provideatis... ».

17. Ibid., doc.LXV, p. 204 (26 mai 1442) : " ...cum deputaverimus nobiles viros Ser Antonellus de Montemonaco, Cicchangeum de Montesancto et Gironimum de Montesancto, idcirco volumus et mandamus eis parere, favere et obedire tanquamm nobis et in nullo contrafacere... ».

18. Dans la lettre qui transmet les remerciements de Sigismond Malatesta (cf. note 15), Francesco da Cusano à propos d'un des familiers de Malatesta, Messer Accorso : «è omo che delecta d'essere accarezzato » 
Tandis que le popolo apparaît comme le creuset permettant l'interpénétration des deux types de réseaux dans les grandes communes d'Italie du nord ou de Toscane ${ }^{19}$, l'Ombrie et les Marches se distinguent par l'existence de seigneuries aristocratiques qui réussissent à faire perdurer leur pouvoir en s'appuyant sur les réseaux de pouvoir communal en place. Le phénomène n'est pas isolé. Les Varano, vieux lignage seigneurial de la vallée du Chienti, établissent la capitale de leurs États à Camerino dont ils exercent la podestatie à partir de 1259. Dès la fin du XIII ${ }^{\mathrm{e}}$ siècle, à Foligno, la famille des Trinci monopolise les principales magistratures de la commune. Des processus analogues s'observent avec les Chiavelli de Fabriano mais aussi avec les Smeducci de San Severino ou les Cima de Cingoli ${ }^{20}$.

Pour asseoir leur autorité au sein des sociétés communales, à la fin du XIII siècle ou au $\mathrm{XIV}^{\mathrm{e}}$ siècle, ces seigneuries locales n'ont pas cherché à encourager des ralliements personnels, fondés sur une quête de reconnaissances et de rétributions. Au contraire, elles justifient leur prise de contrôle des réseaux politiques traditionnels en utilisant la propagande communale fondée sur l'instruction et la compétence. Les statuts du Peuple de Foligno, rédigés en 1350, présentent les Trinci comme la seule famille capable de garantir l'unité civique, de dominer les réseaux de service pour éviter les factions :

«Nous pouvons dire, d'après des avis experts, que toute cette cité fut depuis des temps anciens gouvernée dans un état sain tranquille et prospère, et que sa puissance, ses honneurs et ses juridictions furent considérablement augmentés par des soins constants et des œuvres parfaites par Nallus, ancêtre de bonne mémoire des savants et magnifiques chevaliers messire Ugolino et messire Corrado, père et frère charnel de savant et magnifique chevalier messire Ugolino Novello... $»^{21}$

L'argumentation associe habilement la reconnaissance des vertus civiques qui identifiaient les réseaux communaux à la conception de la transmission dynastique de ces qualités : c'est une manière de convoquer la mémoire de plusieurs générations civiques pour défendre le réseau de pouvoir patiemment construit par une famille, en évitant la référence plus partisane à l'alliance guelfe, marque des Trinci.

À Camerino, la famille des Varano accepte la délégation de l'autorité podestariale sur la cité et son territoire des mains des plus hauts représentants communaux, les sept prieurs des Arts :

« D'après la forme des statuts et ordonnances de la commune de la cité de Camerino, les magnifiques et puissants seigneurs Messires Gentilpandolfo, Berardo, Piergentile et Giovanni, nés de magnifique et excellent seigneur Rodolfo fils de Messire Gentile de Varano, de célèbre et honorable mémoire, ont reçu attribution du pouvoir, de l'autorité et de la bayla sur le régime, la garde et le gouvernement de la dite cité de Camerino de son comté et de son district. ${ }^{22}$

La commune est l'unique source invoquée de légitimité. Mais la volonté de symbiose des Varano va plus loin. Les bribes de la documentation communale montrent que ces anciens seigneurs fonciers prennent à cœur leur rôle de "citoyens » et s'associent aux hommes des métiers pour tirer leur part de profits des secteurs productifs qui contribuent à l'essor de la cité. Les Varano sont ainsi devenus propriétaires d'ateliers de tissages et ont investi dans l'industrie papetière de Pioraco, qui concurrence celle de

19. Sur l'organisation interne du popolo, on renverra à l'article fondamental de P. Racine, «Le "popolo", groupe social ou groupe de pression? ", Nuova Rivista Storica, LXXIII, 1989, p. 133-150, et à E. Artifoni, " Una società di "popolo". Modelli istituzionali, parentele, aggregazioni socetarie e territoriali nel XIII secolo ".

20. Une étude comparative des ressorts et de la légitimité des seigneuries des Trinci à Foligno, da Varano à Camerino et Chiavelli à Fabriano a été proposée récemment par Fabrice Delzant dans une thèse encore inédite. Voir aussi, pour une perspective plus générale, Ph. Jansen, «Réseaux de clientèles et seigneurs dans les Marches, XIV ${ }^{\mathrm{e}}-\mathrm{XV}^{\mathrm{e}}$ siècles », p. 163-183.

21. F. Baldaccini et A. Messini, Statuta communis Fulginei, vol. II : Statutum populi Fulginei, rub. 188, p. 235-236.

22. ASPa, codice varanesco , fol. 350r, cité par J.-B. Delzant, « Magnificus dominus. Pouvoir, art et culture dans les seigneuries d'Italie centrale à la fin du Moyen Âge », p. 208. 
Fabriano $^{23}$. Princes et entrepreneurs, ils ne cherchent donc pas à susciter des réseaux fondés sur des valeurs opposées à celles de la cité.

La distinction entre les processus de constitution des réseaux politiques de la commune et ceux du seigneur local s'atténue, voire disparaît. Dans ce contexte, les réseaux d'administrateurs communaux peuvent accepter des missions que le seigneur leur confie pour réaliser des objectifs plus personnels, et en tirer des gratifications tout en continuant d'afficher les principes du bien public.

Ces lignages locaux ont assimilé leur propre puissance au rayonnement de la cité qu'ils gouvernent. Les réseaux formels constitués dans le cadre de la commune peuvent-ils également passer au service de puissants princes dont l'ambition est de bâtir un pouvoir régional et familial capable de dominer les juridictions communales, comme les Sforza (Francesco Sforza gouverne les Marches au nom de la papauté avec son frère Alessandro de 1433 à 1447), les Montefeltro ou leurs adversaires les Malatesta ${ }^{24}$ ?

\section{Les lieux et les temps du passage: les suites podestariales, les ambassades, les missions temporaires}

La correspondance échangée entre Francesco Sforza et les officiers qui le représentent dans les Marches après son départ pour hériter du duché de Milan au milieu du $\mathrm{XV}^{\mathrm{e}}$ siècle, publiée par L. Rossi, permet d'observer en action 75 individus en relation plus ou moins directe avec le duc de Milan, à titre de représentants, de messagers ou $\mathrm{d}^{\prime}$ interlocuteurs ${ }^{25}$.

Ce monde d'intervenants politiques à l'interface entre la famille du prince, côté cour, et les anciennes élites des communes, côté ville, est constitué en fait de deux groupes hiérarchisés que distinguent leurs fonctions et leurs logiques de réseaux.

Les hommes qui occupent les grands offices de la cour ducale de Milan, lorsqu'ils se rendent dans les Marches, ne se contentent pas d'exécuter des tâches administratives; ils sont de véritables ambassadeurs et informateurs politiques du prince: la richesse d'information de leurs lettres en témoigne. Les hommes des réseaux communaux des Marches ne figurent pas parmi les hommes de confiance et les conseillers du prince. Francesco Sforza ne les désigne jamais sous ce titre de "conseillers » qui peut-être leur accorderait trop d'influence, mais il les appelle ses « familiers ». Ce prédicat, on le sait, est une faveur, car il fait entrer son bénéficiaire dans le groupe des privilégiés admis dans l'intimité quotidienne du prince ; il implique toutes les références affectives sur lesquelles le prince entend fonder ses réseaux proches. Mais vers 1450, Sforza renouvelle le recrutement de ce réseau et écarte les conseillers qui l'avaient accompagné dans ses fonctions de vicaire temporel de la papauté dans les Marches ${ }^{26}$. Le réseau transformé des «familiers » exprime les ambitions du nouveau maître de Milan à l'échelle de l'Italie et conforte les alliances politiques en jeu. Il associe trois groupes distincts, qui se sont déjà organisés par l'affirmation de relations internes avant de répondre à l'appel du prince. Aux hommes qui se sont mis très tôt au service du condottiere Sforza lorsqu'il combattait en Italie du sud s'ajoutent des familles de la noblesse lombarde qui s'était élevée au

23. Depuis les milieu du $X V^{\mathrm{e}}$ siècle, les Varano ont acquis des droits dans l'activité des moulins à papier de Pioraco. A la fin du siècle, l'épouse de Giulio Cesare Varano investit mille florins dans la constitution d'une société de «l'art de la laine » avec d'autres marchands-artisans de Camerino ; un fils naturel de Giulio Cesare possédait un fondaco pour le commerce en ville. E. Di Stefano, Una città mercantile : Camerino nel tardo medioevo, p. 49-50 et 128 .

24. Pour le cadre d'ensemble des dominations politiques dans les Marches, nous renvoyons à Ph. Jansen, Démographie et société dans les Marches à la fin du Moyen Âge, p. 83-98.

25. L. Rossi, «Nuove notizie su Federigo da Montefeltro, Sigismondo Malatesta e i Manfredi d'Imola e di Faenza (1451) ». L'appendice documentaire comprend 112 documents édités.

26. Sur ces réseaux des Sforza pendant leur seigneurie dans les Marches, cf. Ph. Jansen, « Réseaux de clientèles et seigneurs dans les Marches, XIV e-XV siècles », p. 177-180. 
service des Visconti ; elles participent à la « dot d'influence » de la duchesse Bianca-Maria Visconti ${ }^{27}$ et leur engagement confirmé au service de la nouvelle dynastie en renforce la légitimité. Le troisième groupe comprend des représentants de grandes familles marchandes des villes alliées qui soutiennent la politique de Sforza, comme Florence. Un ancien sujet du royaume de Naples, comme le chancelier Cicco Simonetta, devenu son conseiller et propagandiste, côtoie ainsi un petit noble lombard comme Francesco da Cusano, envoyé en mission auprès de Sigismond Malatesta, ou le trésorier Boccacino degli Alamanni dont un parent, Andrea, fut deux fois prieur de Florence ${ }^{28}$. La recommandation du gouvernement de la cité alliée peut contribuer à étoffer le réseau, mais la diversité des milieux d'origine et des parcours fait du prince le principal fédérateur de ces hommes fortement imprégnés de culture humaniste.

Toutefois, le fait le plus nouveau est que plus de la moitié des intervenants dans ces relations entre Sforza, les Malatesta et le reste des Marches sont représentatifs des réseaux de pouvoir des communes des Marches. Ils sont connus par leurs lettres de mission ou comme signataires des actes qu'ils ont élaborés. Ils avaient donc accepté la reconnaissance du prince, et devenaient ses intermédiaires auprès des communes dont ils servaient les intérêts auparavant. Mais les citadins d'Ombrie et des Marches n'ont pas livré de ricordi détaillés à l'instar de leurs contemporains toscans. Le processus qui les conduit du service de la ville à celui de la cour, les motivations de ce passage restent difficiles à appréhender. Ils ne représentent pas toutes les catégories de citoyens, mais sont le plus souvent membres des familles les plus puissantes et reconnues des milieux dirigeants : ainsi, le traité conclu le 18 octobre 1434 entre la commune de Camerino et Francesco Sforza est signé par Arcangelo dei Chiavelli, descendant de la branche cadette des seigneurs de la ville voisine de Fabriano. Installé à Camerino, il s'est associé à une entreprise de fabrication du papier à Pioraco, encouragée par les ducs de Varano. Il est associé au représentant de Sforza, le chevalier siennois Franceso Salimbeni, docteur en lois, à Gasparro de Sassoferrato, notaire, qui sera chargé sept ans plus tard de récolter des vivres auprès de plusieurs communes, et à Matteo di Giacomo de Matheutiis, un des principaux marchands drapiers de Camerino; celui-ci est connu par ses relations d'affaires avec Marco Datini de Prato et il est cité parmi les principaux convives des fêtes du mariage conclu en 1451 entre le duc Giulio Cesare Varano et Giovanna Malatesta ${ }^{29}$. Le même Arcangelo Chiavelli négocie en 1439, au nom de la commune de Camerino, le troisième traité avec Francesco Sforza. Le document fut cette fois rédigé par le chancelier de Sforza, Cicco Simonetta et un notaire de la commune de Camerino, Giovanni di maestro Giacomo associé au médecin (et capitaine de cet art), maestro Giovanni di maestro Luca, syndic et orateur de la commune pendant la négociation, et au docteur en loi Messer Angelo Bonateta ${ }^{30}$.

Hommes de la cour et de la ville se retrouvent, dans ces négociations, unis par la culture des doctes, fondée sur le droit et la rhétorique, qu'ils ont pu partager et mettre en pratique dans le cadre des ambassades communales députées aux princes et dans les suites des podestats. Les citoyens appelés à diriger une commune extérieure (parfois dans une autre région : de nombreux marchésans ont ainsi administré la commune de Pérouse) étaient choisis parmi les familles nobles de leur cité ou les juristes. Ils réunissaient autour d'eux quelques concitoyens hommes de loi qui avaient toute leur confiance, mais

27. Le mariage entre Francesco Sforza et Bianca-Maria Visconti était prévu par le traité d'alliance conclu le 28 mars 1438 entre Philippe-Marie Visconti et Sforza. Retardé par les opérations militaires de Sforza dans les Marches, le mariage fut finalement célébré à Crémone le 26 octobre 1441. Bianca-Maria, fille unique, apporta à Sforza l'héritage du duché ; G. Benaducci, Della signoria di Francesco Sforza nella Marca, p. 114-119 et 194-195.

28. Cecco ou Cicco Simonetta était entré très jeune au service de Sforza, en 1421, en suivant son père intendant des domaines que le condottiere possédait en Calabre (de sa première femme Polisena Ruffo); il devint son conseiller et chancelier dans les Marches. A Milan, il devint chancelier du duc, et son principal conseiller. Cf. F. Catalana, Francesco Sforza, Milan, 1983. Francesco da Cusano, chevalier originaire de Lombardie, apparaît dans les années 1450 comme le représentant de Sforza auprès de Sigismond Malatesta, à la cour duquel il réside. Sur les Alamanni, voir Dizionario Bigrafico degli Italiani, t. I, p. 562-564.

29. Le traité est édité par B. Feliciangeli, «Delle relazioni di Francesco Sforza coi Camerti », p. 3-40. Sur Arcangelo dei Chiavelli et Giacomo des Mattheutiis, voir E. di Stefano, Camerino, città mercantile, p. 48-49. Pour F. Salimbeni, cf. Ph. Jansen, « Réseaux de clientèles et seigneurs dans les Marches », p. 178.

30. Texte du traité dans B. Feliciangeli, « Delle relazioni di Francesco Sforza coi Camerti », p. 456. 
étoffaient leur suite en y associant des personnes compétentes recrutées dans les communes où ils avaient exercé leurs charges. Plus que les ambassades communales, dont le recrutement était limité par l'obligation de représentativité locale, les suites des podestats ont associé presque systématiquement nobles et hommes de droits, et ont constitué des réseaux à assise régionale, plus à même de servir les ambitions princières ${ }^{31}$.

De l'exercice valorisant du pouvoir, ces hommes ont pu retirer la conviction d'une supériorité intellectuelle et pratique qui les rendaient dignes d'être les interlocuteurs des princes au nom des communes, ou de représenter le prince pour négocier avec les communes. Ils recevaient ces missions comme un honneur et l'occasion d'une double reconnaissance, assimilée à une noblesse de service. Pour tenir leur rang, les princes ne pouvaient confier leurs intérêts à des hommes de trop faible mérite : ils donnent presque systématiquement le qualificatif de « Noble homme » à ceux qu'ils envoient en leur nom solliciter les autorités urbaines. On observe donc une porosité évidente entre les réseaux communaux et les réseaux princiers; des citoyens bien instruits, mieux encore s'ils apparaissent bien nés, peuvent fréquenter les réseaux de cours; l'habitude de fréquenter les usages et les codes de vie aristocratique auprès des seigneurs locaux ont facilité le passage. Mais les dernières marches de l'ascension sont les plus difficiles à franchir : seul un petit nombre de ces citoyens, qui ont su sortir des réseaux de leur cité natale et ont réussi à se créer des contacts et des solidarités régionales, en particulier dans les fonctions de podestats, auront l'honneur d'être des familiers, admis à fréquenter en permanence la cour princière. Le passage de la ville à la cour, en définitive, ne bouleverse pas les structures des réseaux antérieurs ou leur logique de reconnaissance: elle atténue cependant les cadres formels et les garanties des institutions communales au profit du système de grâce et de disgrâce personnelle. En revanche, l'horizon d'action s'élargit: comme les princes, pour paraphraser Machiavel, les conseillers, d'hommes privés qu'ils étaient, deviennent membres de réseaux qui expriment la puissance publique et l'État.

\begin{abstract}
Résumé
Les régions d'Italie centrale ont connu au Moyen Âge une imbrication des régimes communaux et des seigneuries à caractère féodal ou urbain. Ces dernières ont évolué à la fin du Moyen Âge, en Italie du nord et du centre vers la constitution de principautés territoriales. La nature de ces pouvoirs semble antinomique: collective pour les premiers, personnelle et hiérarchique pour les seconds. L'abondance et la variété des sources produites par ces régimes permettent d'étudier comment s'affirmait la conscience d'appartenir à un réseau participant à ces pouvoirs, ainsi que les critères requis pour en faire partie. Aux principes de compétence et de pratique du pouvoir dans les communes s'oppose la logique d'amitié et de service autour du prince. Mais les deux logiques se confondent souvent, dans les Marches et en Ombrie, au sein des seigneuries urbaines qui $\mathrm{s}^{\prime}$ appuient sur les anciens réseaux communaux. La relation entre les deux types de réseaux, de ville et de cour, s'effectue, notamment sous les Sforza, par l'assimilation de certains réseaux de gouvernement urbain dans l'entourage du prince, par le relais des suites podestariales et des ambassades.
\end{abstract}

31. Sur les suites podestariales, voir Ph. Jansen, « Réseaux de clientèles et seigneurs dans les Marches », p. 170173. 


\section{Bibliographie}

ARTIFONI Enrico, « Una società di "popolo". Modelli istituzionali, parentele, aggregazioni socetarie e territoriali nel XIII secolo », Studi medievali, s. III, XXIV, 1983, p. 545-616.

BALDACCINI Francesco et Messini Andrea, Statuta communis Fulginei, vol. II : Statutum populi Fulginei, Pérouse (Fonti per la Storia dell'Umbria), 1969.

BenAducci Giovanni, Della signoria di Francesco Sforza nella Marca, e peculiarmente in Tolentino (dicembre 1433-agosto 1437), Tolentino, 1892.

Delzant Jean-Baptiste, «Magnificus dominus. Pouvoir, art et culture dans les seigneuries d'Italie centrale à la fin du Moyen Âge ", thèse de doctorat de l'Université Paris I Panthéon-Sorbonne, soutenue le 7 décembre 2013, 2 vol.

Dessi Rosa Maria, «I nomi dei Guelfi e dei Ghibellini da Carlo I d'Angiò a Petrarca », dans M. Gentile (éd.), Guelfi e ghibellini nell'Italia del Rinascimento, Roma, Viella, 2005, p. 378.

Di STEFANO Emmanuela, Una città mercantile : Camerino nel tardo medioevo, Camerino, 1998.

Feliciangeli Bernardo, «Delle relazioni di Francesco Sforza coi Camerti », Atti e Memorie della Deputazione di Storia Patria per le Marche, nouvelle série, t. V, 1908.

GIANANDREA Antonio, Della signoria di Francesco Sforza nella Marca secondo le memorie e $i$ documenti dell'archivio settempedano, Milan, 1885, réimpr. 1978.

JANSEN Philippe, «L'investissement des institutions communales par les spécialistes des finances en Italie à la fin du Moyen Âge », dans PONTET Josette (dir.) Des hommes et des pouvoirs dans la ville, XIV ${ }^{e}-X X^{e}$ siècle, Bordeaux, CESURB-Histoire, 1999, p. 239-256.

JANSEN Philippe, Démographie et société dans les Marches à la fin du Moyen Âge: Macerata aux $X I V^{e}$ et XV siècles, Rome, coll. de l'École Française de Rome, 2001.

JANSEN Philippe, "Offices et service de la commune et du prince en Italie, XIII$\mathrm{XV}^{\mathrm{e}}$ siècles ", dans CAROZZI Claude et TAVIANI-CAROZZI Huguette (dir.), Hiérarchies et services au Moyen Âge, Aix-en-Provence, Université de Provence, 2001, p. 105-140.

JANSEN Philippe, « Réseaux de clientèles et seigneurs dans les Marches, XIV -XV siècles », dans BARRAQUÉ Jean-Pierre et LAMAZOU-DuPlan Véronique (ed.), Minorités juives, pouvoirs, littérature politique en Péninsule ibérique, France et Italie au Moyen Âge, études offertes à Béatrice Leroy, Biarritz, éd. Atlantica, 2006, p. 163-183.

MAIRE Vigueur Jean-Claude, Cavaliers et citoyens. Guerre, conflits et société dans l'Italie communale, XII ${ }^{e}$-XIII ${ }^{e}$ siècles, Paris, 2003.

Raveggi S., Tarani M., Medici D. et Parenti Pietro, Ghibellini, guelfi e popolo grasso. I detentori del potere politico a Firenze nella seconda metà del Dugento, Florence, 1978.

ROSSI Luigi, "Nuove notizie su Federigo da Montefeltro, Sigismondo Malatesta e i Manfredi d'Imola e di Faenza (1451)», Atti e Memorie della società di Storia Patria per le Marche, nouv. serie, vol. III, fasc. IV, 1906 et vol. IV, fasc. III, 1907 ; rééd. Atti e Memorie, $1995, n^{\circ} 100$, p. 499-549. 


\section{Illustrations}

Carte des villes d'Ombrie et des Marches citées dans l'article.

Les noms soulignés indiquent des seigneuries urbaines.

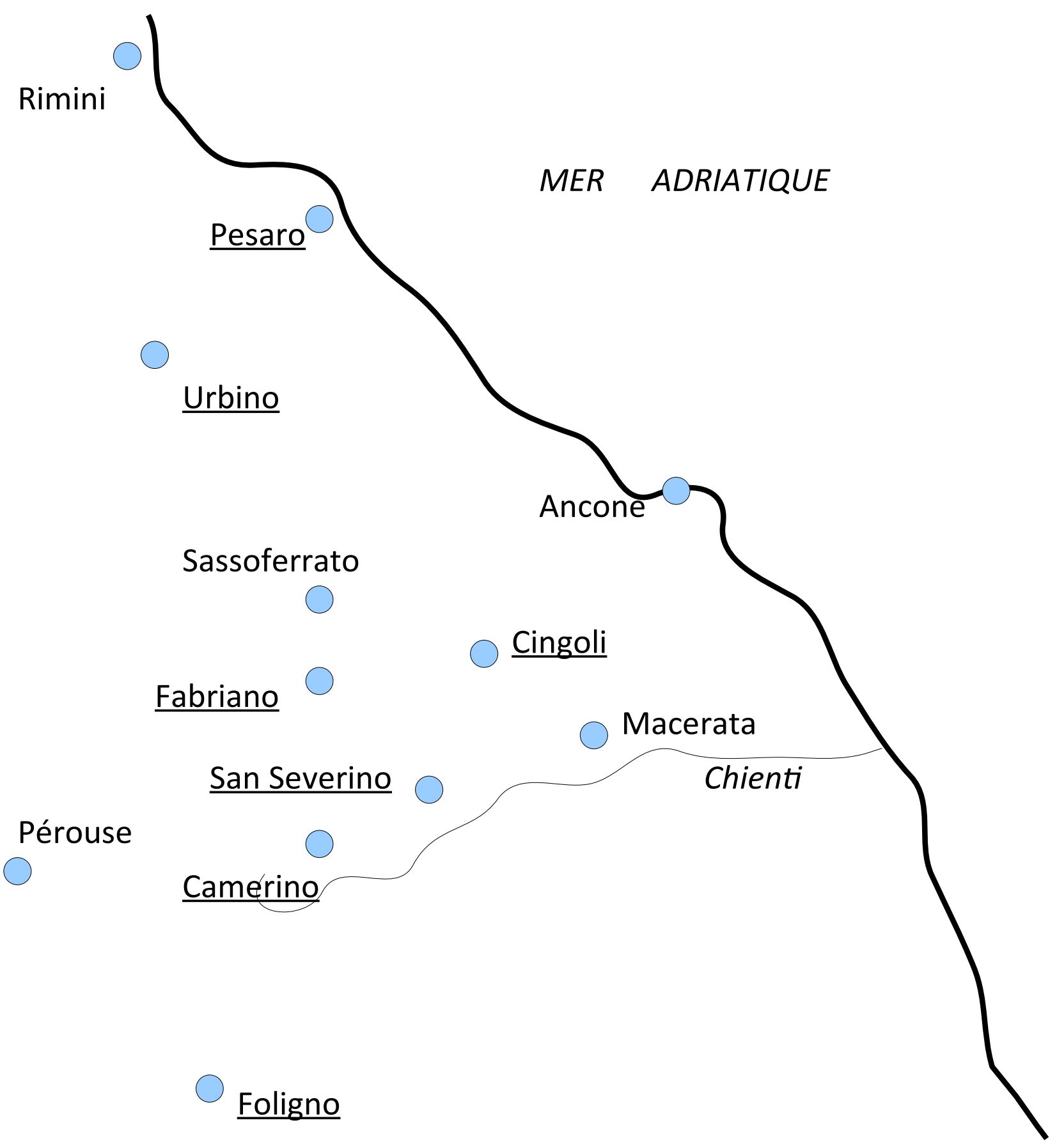

Ascoli Piceno 


\title{
Les échevins et prévôts des marchands dans le paysage institutionnel lyonnais (1680-1740)
}

\author{
Rosemonde LETRICOT \\ Doctorante en Histoire Moderne, \\ LARHRA (Laboratoire de recherches historiques Rhône-Alpes) \\ UMR5190 (Pôle Histoire Numérique), Université Jean Moulin Lyon 3 \\ Extrait de : Henri BRESC (dir.), Réseaux politiques et économiques, Paris, \\ Édition électronique du CTHS (Actes des congrès des sociétés historiques et scientifiques), 2016. \\ Cet article a été validé par le comité de lecture des Éditions du CTHS dans le cadre de la publication \\ des actes du $140^{\mathrm{e}}$ Congrès national des sociétés historiques et scientifiques tenu à Reims en 2015.
}

Sur les trente dernières années de sa vie, Léonard Michon (1675-1746), notable lyonnais, a entrepris la rédaction d'un « Journal de Lyon ou Mémoires historiques et politiques de ce qui s'est passé de plus remarquable dans la ville de Lyon et dans la province depuis le commencement du dix-huitième siècle jusqu'à présent », dont les sept volumes manuscrits sont aujourd'hui conservés aux musées Gadagne de Lyon ${ }^{1}$. Par la période couverte (de 1715 à 1744) et la richesse des descriptions, cet ouvrage exceptionnel livre de nombreux aspects de la vie politique, sociale, culturelle et religieuse de la ville. Si une faible part du récit relève d'évènements personnels de la vie de l'auteur, il n'est toutefois pas avare en commentaires et réflexions critiques sur certaines affaires publiques et davantage encore sur ses contemporains. En effet, au fil des pages, de nombreux portraits nous sont restitués sur de grands noms de la scène politique lyonnaise comme les Villeroy, les Perrichon, les Ravat, les Cholier, etc. Léonard Michon porte une attention particulière aux membres des principales institutions lyonnaises, notamment au moment de la nomination du corps consulaire.

Cet évènement qui rythme la vie municipale est décrit dans le Journal de Lyon aux alentours du 15 décembre de chaque année, date traditionnelle de renouvellement de la moitié du corps consulaire lyonnais. La composition du nouveau consulat y est dévoilée, de même que quelques repères biographiques sur ses nouveaux membres. Chaque nomination est l'occasion pour Léonard Michon de rappeler les relations dont chacun a pu bénéficier ainsi que les parcours individuels qui ont favorisé l'accession à cette place hautement convoitée par la bourgeoisie locale. Dans cet environnement mouvant, il est essentiel de savoir se positionner et d'user de l'appui de personnages éminents pour s'assurer l'anoblissement offert aux membres du consulat et à leur lignée.

À partir des observations issues des "Mémoires", complétées par des données prosopographiques relatives à l'histoire des institutions lyonnaises et des premiers résultats d'analyses quantitatives, il s'agira étudier le milieu consulaire en identifiant les attaches institutionnelles des échevins et des prévôts des marchands pour la période de 1680 à 1740. Quelle représentativité institutionnelle pouvons-nous distinguer au sein du consulat lyonnais? Voyons-nous des évolutions voire des orientations au cours du temps?

1. Musées Gadagne de Lyon, Inv. N 24811, « Journal de Lyon ou Mémoires historiques et politiques de ce qui s'est passé de plus remarquable dans la ville de Lyon et dans la province depuis le commencement du dixhuitième siècle jusqu'à présent ", 7 volumes. Voir la description faite dans l'ouvrage, M. A. Privat-Savigny (dir.), Lyon au XVIII ${ }^{e}$ : un siècle surprenant, Paris, Somogy édition d'art, catalogue d'exposition, Musées Gadagne, 2012 . 


\section{Les « Mémoires » de Léonard Michon : un objet d'histoire lyonnaise}

L'édition critique des « Mémoires » de Léonard Michon, en cours de composition², mettra à disposition une importante source de la vie politique lyonnaise. Léonard Michon voit le jour dans une famille aux origines marchandes, mais son père Annibal Michon intègre le consulat en exerçant la fonction de receveur des deniers communs de la ville de 1676 à 1680. Cet emploi nécessitait une assise forte dans le milieu marchand et financier pour se voir prêter l'argent dont le pouvoir consulaire avait besoin pour fonctionner ${ }^{3}$. Connecté aux familles Pupil et Ravat du côté de sa mère Bonne Bathéon, et aux Gaulthier et Colomby du côté de son père, Léonard Michon bénéficie d'un réseau familial étendu et très ancré dans le milieu institutionnel. C'est peut-être à partir de ses nombreux contacts familiaux qu'il tire les informations nécessaires à la rédaction de ses « Mémoires ».

Dans ce que nous pourrions considérer comme une préface à l'ouvrage, Léonard Michon expose les raisons qui l'ont poussé à cette entreprise d'envergure :

«J'ai dit, dans l'avertissement qui est à la tête de ce volume qui commence par les mémoires de M. Henri François Lambert d’Herbigny, intendant de la généralité de Lyon, que c'étaient ces mêmes mémoires qui m'avaient donné l'idée de faire un journal historique [...] et qui ferait une espèce de suite à ces premiers mémoires » $[\ldots]$

«Car, malgré les occupations indispensables attachées à l'état de chaque particulier, on sait, quand on veut, trouver du temps pour tout. l'application à l'histoire en est une des plus intéressantes et des plus propres à délasser l'esprit. »"

À plusieurs reprises, il insiste sur la portée historique de son projet, et ce n'est pas sans dimension symbolique que Léonard Michon place ses propres mémoires à la suite d'une copie de ceux de l'intendant d'Herbigny qui, pour le siècle précédent, avait rédigé un état des lieux de Lyon et du Lyonnais ${ }^{5}$. Toutefois, ces deux œuvres ne sont pas vraiment comparables dans la mesure où l'intendant d'Herbigny se devait de composer une synthèse administrative de la Généralité demandée à tous les intendants pour servir à l'instruction du Dauphin, alors que le Journal de Lyon reste un témoignage partial d'un homme qui prend tantôt le rôle d'observateur, tantôt celui d'acteur voire même de moralisateur sur les évènements qu'il décrit, avec l'idée de transmettre son expérience à ses descendants.

«J'ai eu en vue principalement l'instruction de ma famille et de mes enfants, entre les mains desquels j'espère que ces mémoires resteront. C'est pour cela que j y ai souvent mêlé des traits et des réflexions sur l'usage de la vie et sur le commerce du monde ; et que faisant voir le caractère des hommes, je me suis aussi développé moi-même pour me faire connaître à eux $[\ldots] »^{6}$

D'un point de vue thématique, nous pouvons distinguer trois grandes catégories $\mathrm{d}^{\prime}$ information. La première se rapporte à l'histoire des grandes familles lyonnaises par le biais des moments clés de la vie que sont les naissances, les unions et les décès. Il s'agit moins pour Léonard Michon de tenir un carnet mondain que de profiter de ces évènements pour se positionner au sein de son environnement social ${ }^{7}$. Aussi complète-t-il ses notes de nombreuses informations sur, par exemple, l'apport financier de chacun des époux, le montant des dots ou encore le partage des héritages l'amenant à décrire l'histoire de ces familles sur plusieurs générations. Nombreuses sont celles qui, comme la

2. L'édition critique des «Mémoires " de Léonard Michon est réalisée dans le cadre de ma thèse de doctorat sous la direction de Bernard Hours au sein de l'équipe du Pôle Histoire numérique du LARHRA. Une plateforme web sera dédiée à la mise en ligne du contenu et à la visualisation des données.

3. E. Vial, «Les receveurs ou trésoriers de la ville de Lyon », Revue d'histoire de Lyon, vol. VIII, (1909), p. 373-396.

4. Musées Gadagne de Lyon, Inv. N 24811, « Journal de Lyon... », volume 1, fol. 269.2.

5. J.-P. Gutton (dir.), L'Intendance de Lyonnais, Beaujolais, Forez en 1698 et en 1762 : édition critique du mémoire rédigé par Lambert d'Herbigny et des observations et compléments de La Michodière, Paris, CTHS, 1992.

6. Musées Gadagne de Lyon, Inv. N 24811, « Journal de Lyon... », volume 1, fol. 269.2v.

7. G. Cuer, "Léonard Michon, chroniqueur lyonnais du XVIII ${ }^{\mathrm{e}}$ siècle », dans Actes des journées d'études de l'Union des Sociétés historiques du Rhône, 1993, p.71-86. 
sienne, ont débuté dans le milieu du négoce avant de s'extraire de leur condition par l'achat d'un office ou par l'échevinage. Il est probable que ces références interviennent comme une légitimation de sa propre histoire familiale et de son statut.

La seconde catégorie rassemble les faits récurrents qui rythment la vie des Lyonnais: la vie religieuse faite de processions et de cérémonies; la vie publique ponctuée par les assemblées d'élus; la vie mondaine dont les bals, les jeux et les repas rassemblent la haute société lyonnaise. La part la plus importante des écrits concerne l'actualité et les intrigues de pouvoir que ce soit au sein d'un même corps institutionnel ou entre les différentes compagnies de la ville. Léonard Michon garde un œil constant sur les activités du consulat et sur la cour des monnaies qui sont à Lyon les deux compagnies complémentaires mais non moins concurrentes du bureau des Finances dont il fait partie. Enfin, il rend également compte de la manière dont les Lyonnais font face aux difficultés de leur temps. Commençant ses « Mémoires » l'année de la mort de Louis XIV en 1715, il est question de rareté des espèces et des denrées dans une France au bord de la faillite, du système de John Law, de la dévaluation de la monnaie ou encore de la résurgence de la peste à Marseille. Dans un registre plus joyeux, l'arrivée de personnages éminents ${ }^{8}$ ainsi que les mariages et les naissances princiers rassemblent la population lyonnaise autour de moments festifs.

\section{L'échevinat dans les textes et dans les faits}

Depuis l'obtention par les Lyonnais de la charte de franchise des mains de l'archevêque Pierre de Savoie en 1320, le consulat est l'un des principaux organes de la ville qui dirige l'action publique locale et gère les finances municipales". Sa composition a subi de nombreuses modifications au gré des amendements structuraux ou de la volonté royale. Elle passe de cinquante à douze consuls élus assistés de trois assemblées de notables et de maîtres des métiers au $\mathrm{XV}^{\mathrm{e}}$ siècle et au $\mathrm{XVI}^{\mathrm{e}}$ siècle, puis vingt-quatre et à nouveau douze conseillers pendant les troubles des guerres de religion à la suite desquelles Henri IV mettra la main sur le consulat de Lyon et en modifiera profondément l'organisation. En effet, l'édit de Chauny (décembre 1595) restreint le corps consulaire à quatre échevins dirigés par un prévôt des marchands. Ce dernier est mandaté pour deux ans reconductibles et est issu de la noblesse de naissance lyonnaise. Le groupe de quatre échevins, renouvelé pour moitié chaque année, est constitué de notables ayant résidé depuis au moins douze ans à Lyon. Depuis 1601, le prévôt des marchands est nommé directement par le roi via une lettre de cachet et les échevins sont élus, en théorie, par les terriers et maîtres des métiers de la ville. Toutefois, ces assemblées n'ont qu'une fonction symbolique car, depuis 1603, c'est le roi qui promeut les échevins à partir d'une liste que lui fournit le consulat. Il est d'usage de nommer un échevin du côté de Saint-Nizier, un du côté de Fourvière et d'avoir au moins un échevin gradué dans le groupe consulaire.

Comme le rappelait Georges $\mathrm{Cuer}^{10}$, la nomination à l'échevinage reste «l'aboutissement d'une véritable carrière des honneurs » qui permettait aux élus d'être anoblis au premier degré $^{11}$. Le parcours de Léonard Michon qui devient échevin en 1721, en est le parfait exemple. Reçu à l'âge de vingt-cinq ans, le 3 décembre 1700, à l'office d'avocat du roi au bureau des Finances de la Généralité de Lyon, il réalise l'une des plus longues carrières de la compagnie avec quarante-six années de service. Il complète son cursus honorum en devenant recteur de l'hôpital de la Charité en 1714 et 1715 . Son parcours lui ouvre

8. Notons par exemple, le passage à Lyon de deux ambassadeurs : Mehmet Riza Beg venant de Perse en 1715 et Mehmet Effendi, ambassadeur ottoman, en 1720.

9. P. Beghain, B. Benoit, G. Corneloup et B. Thévenon (coord.), Dictionnaire historique de Lyon, Lyon, S. Bachès, 2009. F. Bayard, Vivre à Lyon sous l'Ancien régime, Paris, Perrin, 1997. M. Garden, Lyon et les Lyonnais au XVIII siècle, Paris, Les Belles-Lettres, 1970, p. 501-506. G. Cuer, Lyon et le pouvoir central, Dissertation de 1'École nationale des Chartes, Paris, 1983.

10. G. Cuer, op. cit., p. 7.

11. F. Bluche, P. Durye, L'anoblissement par charge avant 1789, 2e éd., Paris, ICC, 2003. 
rapidement les portes du consulat. Vers la mi-décembre 1720, Léonard Michon reçoit sa lettre de nomination à l'échevinage signée de la main du Maréchal de Villeroy. S'il concède volontiers « qu'on ne donne point l'échevinage à gens qui ne le demandent point ou qui ne le font pas demander $»^{12}$, il paraît toutefois étonné d'une promotion si soudaine. Il est vrai qu'à 45 ans, Michon est un échevin relativement jeune si l'on considère l'âge moyen des membres du consulat pour cette période aux alentours de 53 ans $^{13}$. Par ailleurs, il semble que le bureau des finances $n^{\prime}$ ait pas investi massivement la fonction municipale. Déjà concernant la nomination de Philippe Bourlier quelques années auparavant, Léonard Michon notait que :

«La nomination de M. Bourlier a surpris beaucoup de gens. Non pas en ce qu'il est trésorier de France, et qu'il y avait plus de 90 ans qu'on n'avait vu des trésoriers de France échevins ; mais parce qu'on ne croyait pas qu'on choisit cette année-ci un officier du bureau des finances, mais bien seulement l'année prochaine. Car au reste quand on vit, l'année dernière, qu'un conseiller de la cour des monnaies avait accepté la place d'échevin, on ne douta plus que les trésoriers de France ne l'acceptassent aussi dans la suite. ${ }^{14}$

Il poursuit en expliquant que Philippe Bourlier avait tenté en vain d'obtenir la noblesse grâce à une dispense de degré de service délivrée par sa compagnie ${ }^{15}$. Malheureusement, en 1715 , le roi révoque la noblesse acquise par ce moyen ${ }^{16}$, obligeant Philippe Bourlier et tous ceux l'avaient obtenue de cette manière d'user de leurs relations pour être nommés au consulat. La famille de Neufville de Villeroy qui occupe à Lyon le gouvernement ainsi que l'archevêché ${ }^{17}$, reste l'intercesseur par excellence :

« [Philippe Bourlier] a, pour ce sujet, employé quelque ami secret auprès de M. le maréchal de Villeroy. Et on ne doute point que ce ne soient Mrs Anisson le père et M. d'Hauteroche, son fils conseiller au parlement, qui sont ses proches parents. ${ }^{18}$

De même, par sa proximité avec le gouverneur pour la gestion des affaires publiques, le prévôt des marchands peut s'avérer d'une aide précieuse dans cette course à l'échevinage. Pour sa propre nomination, Léonard Michon semble avoir fait appel à Pierre Cholier, prévôt des marchands de Lyon de 1716 à 1723, pour se faire connaître du Maréchal de Villeroy :

« Je fus le même jour sur le soir chez M. le prévôt des marchands pour le remercier, sachant bien qu'il avait eu bonne part à ma nomination par les témoignages avantageux qu'il avait rendus de moi au maréchal de Villeroy et en toutes sortes de rencontres. ${ }^{19}$

Ces exemples posent la question des origines de la nomination des échevins et des prévôts des marchands pour en comprendre les dynamiques sous-jacentes et les confronter à la vision que Léonard Michon porte sur la sphère politique lyonnaise.

\section{Quelques analyses quantitatives sur le milieu consulaire}

En prenant comme point de départ les informations données par Léonard Michon, nous

12. Musées Gadagne de Lyon, Inv. N 24811, « Journal de Lyon... », volume 2, fol. 22v.

13. E. Charavay, Les échevins et les prévôts des marchands lyonnais de la première moitié du XVIII siècle. Mémoire de maîtrise sous la direction de Bayard Françoise, Université Paris-Sorbonne, 1999.

14. Musées Gadagne de Lyon, Inv. N 24811, « Journal de Lyon... », volume 2, fol. 21v-22r.

15. Par l'édit de 1704, la compagnie acquit le privilège de donner une dispense de service à deux de ses officiers tous les cinq ans. Avec cette dispense, il était possible d'obtenir la noblesse sans l'obligation de servir vingt ans soi-même et son descendant.

16. K. Deharbe, Le bureau des finances de la généralité de Lyon XVI ${ }^{e}$ XVIII siècles, Aspects institutionnels et juridiques, XVI $I^{e}$ XVIII siècles, Paris, CHEFF, 2010, p. 105.

17. François de Neufville de Villeroy, maréchal de France, ami d'enfance de Louis XIV est gouverneur du Lyonnais depuis 1685. Son fils, François Paul de Neufville de Villeroy est nommé archevêque de Lyon en 1714.

18. Musées Gadagne de Lyon, Inv. N 24811, « Journal de Lyon... », volume 2, fol. 22r.

19. Ibid, fol. $80 \mathrm{v}$ 
nous sommes intéressés, dans un premier temps, à la composition du corps consulaire sur une période correspondant à la durée des "Mémoires » (de 1715 à 1744), avant d'étendre nos recherches plus en amont, à partir de 1680. Cela nous a permis d'intégrer la génération d'échevins et de prévôts des marchands antérieure à celle de Michon afin d'observer d'éventuelles évolutions entre la fin du XVII ${ }^{\mathrm{e}}$ siècle et le début du XVIII ${ }^{\mathrm{e}}$ siècle.

\section{Le cumul d'activités}

Nous nous sommes appuyés sur la liste des échevins et prévôts des marchands dressée par Claude Brossette en 1711 et complétée en $1726^{20}$. Nous avons collecté dans la base de données collaborative du LARHRA ${ }^{21}$ les informations relatives aux exercices de fonctions d'échevin et de prévôt des marchands entre 1680 et 1740 . Les dossiers rouges du fonds Frécon sur les familles consulaires lyonnaises ainsi que les informations tirées du Journal de Lyon ont également permis de compléter les données prosopographiques sur ces individus. Pour chacun d'entre eux, nous avons cherché à identifier les situations de cumul d'activité entre l'échevinage et une charge au sein d'une autre institution. Il s'agit de mettre à jour la diversité institutionnelle au sein du consulat et de vérifier notamment si, comme le dit Michon, le bureau des finances a été écarté des fonctions municipales.

Les informations de la base de données ont été extraites et traitées à l'aide du logiciel $\mathrm{R}^{22}$ et sont présentées ici sous la forme de réseaux de relations (Fig. 1 et Fig. 2) avec d'un côté des individus (cercles blancs) et de l'autre les compagnies de la ville (bureau des finances, cour des monnaies, sénéchaussée et présidial et consulat). Ce type de réseau est dit «biparti » dans la mesure où les sommets du graphe correspondent à deux types d'éléments différents ${ }^{23}$ : des individus et des acteurs collectifs. Chaque lien symbolise l'exercice d'une fonction au sein de l'institution à laquelle l'acteur est relié.

L'algorithme Fruchterman-Reingold, utilisé pour disposer automatiquement les nœuds dans l'espace, place les personnes cumulant deux fonctions institutionnelles entre les carrés de couleur représentant les institutions (en rouge le consulat, en bleu le bureau des finances, en vert la cour des monnaies et en gris la sénéchaussée et le siège présidial avant qu'ils ne soient fusionnés à la cour des monnaies en 1705). Nous dénombrons sur un total de 139 échevins et prévôts des marchands, 25 cumuls de charge. De manière générale, l'exercice du pouvoir municipal n'est pas incompatible avec la détention d'un office dans une autre institution puisqu'il y a constamment un voire deux officiers en double activité au sein du consulat. Du côté des institutions, l'initiative est même encouragée, comme le précise Léonard Michon pour sa compagnie :

«Il n'était plus le cas, dans notre compagnie, de faire les délicats sur le sujet de l'échevinage. Depuis quatre ou cinq ans, les difficultés sur cela s'aplanissaient de jour en jour et l'on ne doutait plus que les deux tiers des officiers qui n'ont pas acquis la noblesse de race ne souhaitassent très fort d'être nommés échevins pour l'acquérir [...] C'est pourquoi la compagnie, d'une commune voix, convint qu'il n'avait pas à hésiter pour accepter l'échevinage. ${ }^{24}$

En nous essayant à une représentation chronologique (Fig. 3) des mêmes données, nous avons produit un graphique comptabilisant le nombre de cumulant au sein du consulat et leur origine institutionnelle. Seules sont dénombrées les personnes en double activité,

20. C. Brossette, Histoire abrégée ou Eloge historique de la ville de Lion, Lyon, Girin, 1711. Du même auteur, Suite de l'Eloge historique de la ville de Lion, Lyon, Girin, 1726.

21. http://symogih.org. La base de données collaborative du LARHRA s'appuie sur la méthode SyMoGIH d'atomisation des données historiques. Cette méthode permet un travail cumulatif de collecte de données par les chercheurs du laboratoire quelle que soit la période ou la thématique de recherche. Sur la méthode SyMoGIH voir F. Beretta, P. Vernus, "Le projet SyMoGIH et la modélisation de l'information : une opération scientifique au service de l'histoire. ", Les Carnets du LARHRA, 2012, p. 81-107.

22. $\mathrm{R}$ est un logiciel de statistiques qui permet le traitement de masse d'informations. Il est de plus en plus utilisé en sciences humaines et sociales, notamment pour l'analyse de réseaux avec le package igraph qui est utilisé dans cette démonstration.

23. L. Beauguitte. L'analyse des graphes bipartis, 2013. bipartis, halshs-00794976v1

24. Musées Gadagne de Lyon, Inv. N 24811, « Journal de Lyon... », volume 2, fol. 22v. 
c'est pourquoi nous n'atteignons jamais le chiffre total de cinq membres consulaires.

Nous retrouvons une forte proportion de cumulant du côté de la sénéchaussée et de la cour des monnaies. Une lecture rapide du graphique laisserait penser que la sénéchaussée et le siège présidial de Lyon (représentés en orange) disparaissent du paysage politique local en 1704, alors qu'il s'agit en réalité de la date de création de la cour des monnaies de Lyon. En effet, pour ne pas déstabiliser la distribution des pouvoirs, cette dernière a été fusionnée à la sénéchaussée et siège présidial de la ville en 1705 à la demande du maréchal de Neufville de Villeroy, gouverneur du Lyonnais ${ }^{25}$. Il est intéressant de noter que le cumul de fonctions tend à se systématiser dans les premières décennies du XVIII siècle. Les longues prévôtés des marchands de Louis Ravat et de Pierre Cholier, qui eux-mêmes étaient conseillers à la cour des monnaies, ont contribué à faire augmenter ce chiffre. Nous remarquons l'absence de double appartenance institutionnelle pour les années 1704 à 1708 et 1730 à 1740.

Ces deux périodes se superposent aux prévôtés des marchands de Benoît Cachet de Montezan, conseiller au parlement des Dombes, et de Camille Perrichon, secrétaire perpétuel du consulat, qui respectivement dirigent l'hôtel de ville de 1704 à 1707 et de 1730 à 1739. La composition du consulat pour ces années est formée majoritairement d'échevins venant du monde marchand. Par ailleurs, ce graphe confirme la remarque de Léonard Michon, à savoir la faible participation du bureau des finances au pouvoir consulaire. Pour la fin du XVII siècle, seuls Louis Gayot et Laurent Pianello de la Valette, trésoriers de France, ont été nommés prévôts des marchands, respectivement pour les années 1681 à 1682 et 1687 à 1688 . Si pour la première moitié du XVIII siècle, les nominations semblent être davantage favorables à cette compagnie avec celles de Philippe Bourlier (1719-1720), Léonard Michon (1721-1722), Jacques Terrasse (1726-1727) et Mathieu Girard (1734-1735), elles restent encore marginales.

De nombreuses querelles ont opposé les institutions de la ville sur des sujets comme la préséance de leurs membres ou la concurrence des pouvoirs au gré des créations ou suppressions d'offices par le roi. La voirie et la vérification des comptes de la ville ont été une source de conflits récurrents entre le bureau des finances et le consulat. La suppression des dispenses de degré de service pourrait également expliquer le regain d'intérêt des membres du bureau des finances pour les charges municipales.

\section{L'influence sur les nominations}

Nous nous sommes également interrogés sur les relations qui peuvent influer sur la nomination au corps consulaire. Si la fonction de prévôt est complètement soumise à la volonté du roi, représenté localement par le Maréchal de Villeroy, celle d'échevin semble davantage liée à des dynamiques relationnelles. En relisant les "Mémoires » en détail, il est possible d'ajouter une dimension plus qualitative à nos précédents résultats.

À chaque mention de la nomination des nouveaux échevins par Léonard Michon, nous avons rassemblé sous de grandes catégories les raisons dominantes qui, selon lui, ont contribué à leur promotion. Le graphique qui en découle (Fig. 4) représente les échevins de 1715 à 1740 par des carrés en nuance de gris. Ils sont rassemblés, sur l'axe des ordonnées, selon l'origine dominante de la nomination, et en abscisse selon la date de leur échevinat. Par exemple, Jean-Baptiste Goiffon, échevin pour 1717 et 1718, relève de la catégorie "Villeroy», car ce fils de paysan, selon L. Michon, est devenu médecin particulier de Madame de Villeroy et de l'archevêque de Lyon, tous deux enfants du

25. L'édit d'avril 1705 prévoyait que les officiers de la sénéchaussée et du siège présidial soient intégrés à charge équivalente au sein de la cour des monnaies afin de ne pas créer de nouveaux offices qui, selon le Maréchal de Villeroy, auraient pu détourner les riches marchands de leur négoce et déstabiliser l'économie locale. G. Cuer, op. cit., p. 54 . 
Maréchal de Villeroy. Sa nomination à l'échevinat qui intervient quelques années seulement après la prise de fonction de l'archevêque en 1715, laisse entendre que celui-ci a œuvré en faveur de la nomination de son médecin. Nous remarquons également que l'influence de la famille de Villeroy est plus forte au moment où le Maréchal est exilé en ses terres de Neufville par le Régent en 1722. Son ingérence dans les affaires publiques se ressent alors très fortement au moment des nominations, mais il meurt en 1730, suivi une année plus tard par son fils, l'archevêque de Lyon.

De manière générale, le prévôt des marchands apparaît comme l'intermédiaire privilégié des échevins postulants. Sa mainmise sur les nominations s'intensifie des années 1730 à 1740 durant la longue prévôté de Camille Perrichon. En effet, à la mort du Maréchal de Villeroy, le duc de Villeroy souhaite garder le contrôle de Lyon en maintenant son homme de confiance à la tête du consulat. Il réussira à le faire pendant dix années durant lesquelles Camille Perrichon est seul maître à bord et verrouille totalement l'entrée au consulat. Non seulement il délaisse le milieu des officiers (ce que nous avions remarqué dans le graphique précédent), mais :

«Il inquiéta et tourmenta toutes les compagnies et presque toutes les communautés de la ville, soit pour les dégrader ou avilir, soit pour mettre entre elles la jalousie ou la division afin de les affaiblir. $»^{26}$

Cependant, il favorise son propre réseau relationnel, ce qui oblige la haute bourgeoisie lyonnaise à changer de stratégies et à recourir à de nouveaux intermédiaires. Sur le graphique, les carrés les plus sombres du graphique apparaissent effectivement au même moment et représentent le recours à de nouveaux intercesseurs que sont les personnes de la Cour et surtout l'intendant de Lyon, Pierre Poulletier. C'est le cas de Claude Gillet, subdélégué général de l'intendant, qui ne doit sa nomination qu'à la ténacité de Pierre Poulletier.

«Il y a même quelques années que l'intendant le demandait à M. Perrichon sans l'avoir pu obtenir quoique ce dernier le lui eut promis. M. Poulletier l'a pris à la fin sérieusement et M. Perrichon n'a pu s'en défendre. $»^{27}$

En présentant dans cet article quelques extraits du «Journal » de Léonard Michon, nous percevons toute la richesse de cette source encore inédite. Son auteur, témoin in situ des rouages du pouvoir, nous pousse à renouveler notre regard sur l'histoire des institutions lyonnaises et à procéder à de nouvelles analyses par l'utilisation des méthodes quantitatives et des bases de données. Le consulat de Lyon reste au centre des stratégies individuelles pour accéder à l'échevinat qui, au-delà de la dimension prestigieuse de la fonction, était l'un des chemins les plus courts pour atteindre la noblesse dite «de cloche ». Si l'exercice d'offices dans d'autres institutions de la ville permet d'étendre son réseau de connaissance et de marquer son statut social, l'appui de personnages puissants - qu'ils soient locaux comme le prévôt des marchands et l'intendant ou de la noblesse de sang comme les Villeroy - est recherché avant tout, mais prive le corps consulaire d'une relative indépendance politique. 


\begin{abstract}
Résumé
Cet article propose d'explorer une source de l'histoire lyonnaise aussi riche qu'étonnante : les « Mémoires » de Léonard Michon. Ce notable lyonnais, avocat du roi au Bureau des Finances et échevin de la ville, a composé, entre 1715 et 1744, sept volumes manuscrits sur la vie quotidienne de la haute société lyonnaise. Nous l'aborderons sous l'angle de l'histoire des institutions, en nous intéressant particulièrement au consulat de Lyon qui a rassemblé au cours du temps une population échevine aux origines variées. En croisant l'étude prosopographique de ses membres avec les informations relatives à la nomination des échevins tirées des « Mémoires », il s'agira d'apporter un nouvel éclairage sur la composition institutionnelle de ce corps et des moyens mis en œuvre par la haute bourgeoisie pour atteindre l'exercice du pouvoir municipal.
\end{abstract}

\title{
Bibliographie
}

BAYARD Françoise, Vivre à Lyon sous l'Ancien régime, Paris, Perrin, 1997.

BEAUGUITTE Laurent, L'analyse des graphes bipartis, $2013<$ halshs-00794976>

Beghain Patrice, BenOIT Bruno, CORneloup Gérard et ThévenON Bruno (coord.), Dictionnaire historique de Lyon, Lyon, S. Bachès, 2009.

BERETTA Francesco et VERNUS Pierre, «Le projet SyMoGIH et la modélisation de l'information: une opération scientifique au service de l'histoire », Les Carnets $d u$ LARHRA, 2012, p. 81-107.

BrossetTE Claude, Histoire abrégée ou Éloge historique de la ville de Lion, Lyon, Jean-Baptiste Girin éd., 1711.

BROSSETTE Claude, Suite de l'Eloge historique de la ville de Lion, Lyon, Jean-Baptiste Girin éd., 1726.

BLUCHE François, DuRYE Pierre, L'anoblissement par charge avant 1789, 2e éd., Paris, ICC, 2003.

CHARAVAY Éric, «Les échevins et les prévôts des marchands lyonnais de la première moitié du XVIII siècle ", Mémoire de maîtrise sous la direction de BAYARD Françoise, Université Paris-Sorbonne, 1999.

CUER Georges, "Lyon et le pouvoir central», Dissertation de l'École nationale des Chartes, Paris, 1983, 3 volumes.

CUER Georges, "Léonard Michon, chroniqueur lyonnais du XVIII siècle ", dans Actes des journées d'études de l'Union des Sociétés historiques du Rhône, 1993, p.71-86.

DEHARBE Karine, Le bureau des finances de la généralité de Lyon, XVI-XVIII ${ }^{\mathrm{e}}$ siècles, Aspects institutionnels et juridiques, Paris, Comité pour l'histoire économique et financière de la France, 2010.

GARDEN Maurice, Lyon et les Lyonnais au XVIII siècle, Paris, Les Belles Lettres, 1970.

GuTTON Jean-Pierre (dir.), L'Intendance de Lyonnais, Beaujolais, Forez en 1698 et en 1762 : édition critique du mémoire rédigé par Lambert d'Herbigny et des observations et compléments de La Michodière, Paris, CTHS, 1992.

PRIVAT-SAVIGNY Maria-Anne(dir.), Lyon au XVIII : un siècle surprenant, catalogue d'exposition, musée d'histoire de Lyon, 22 novembre 2012 - 5 mai 2013, Paris, Somogy, Musées Gadagne, 2012. 
VIAL Eugène, «Les receveurs ou trésoriers de la ville de Lyon », Revue d'histoire de Lyon, vol. VIII, (1909), p. 373-396.

\section{Illustrations}

Figure 1: Réseau des membres des quatre institutions lyonnaises: Consulat (rouge), Bureau des Finances (bleu), Sénéchaussée (gris), Cour des monnaies (vert).

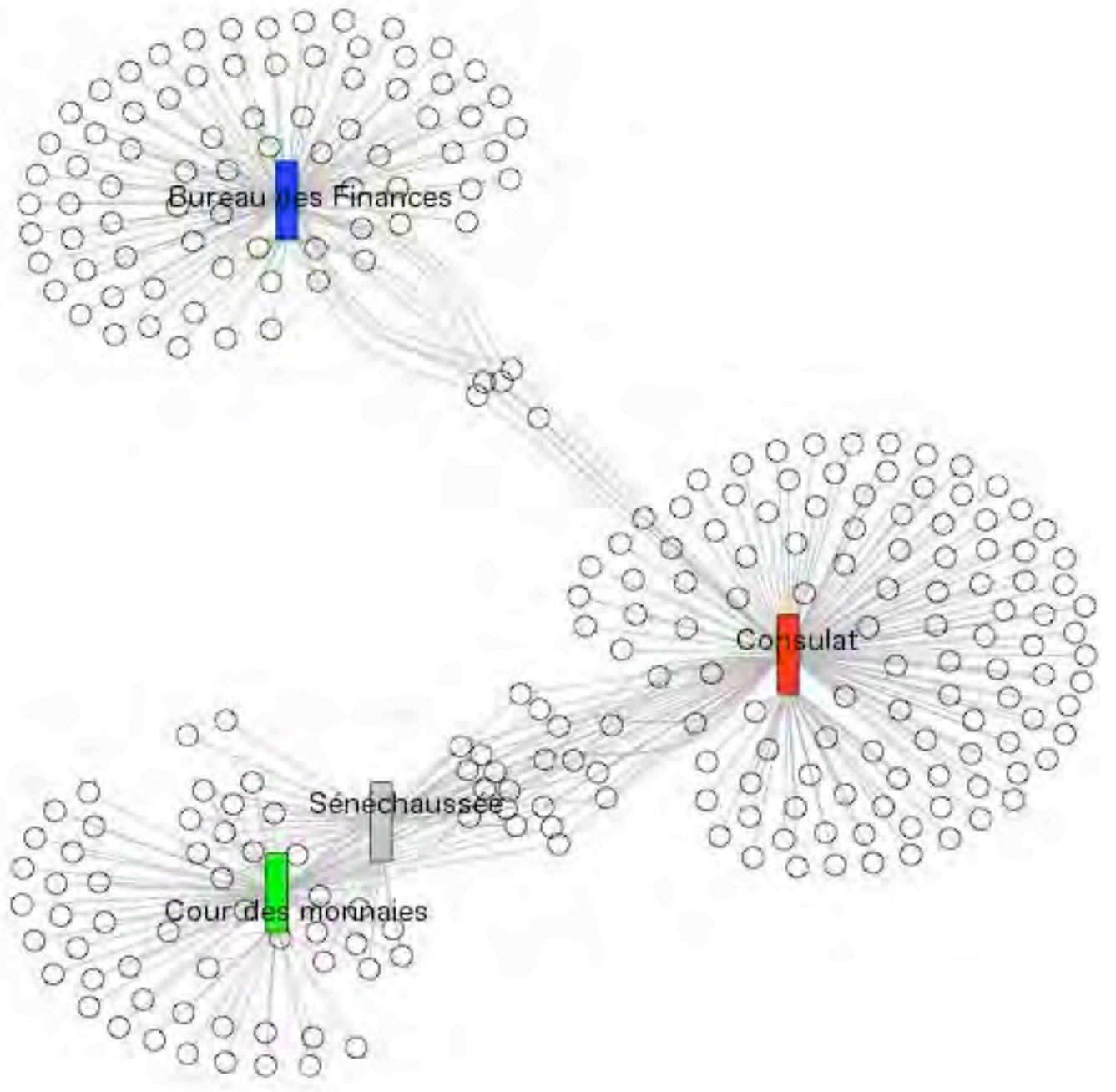


Figure 2 : Réseau simplifié des membres qui cumulent une activité institutionnelle.

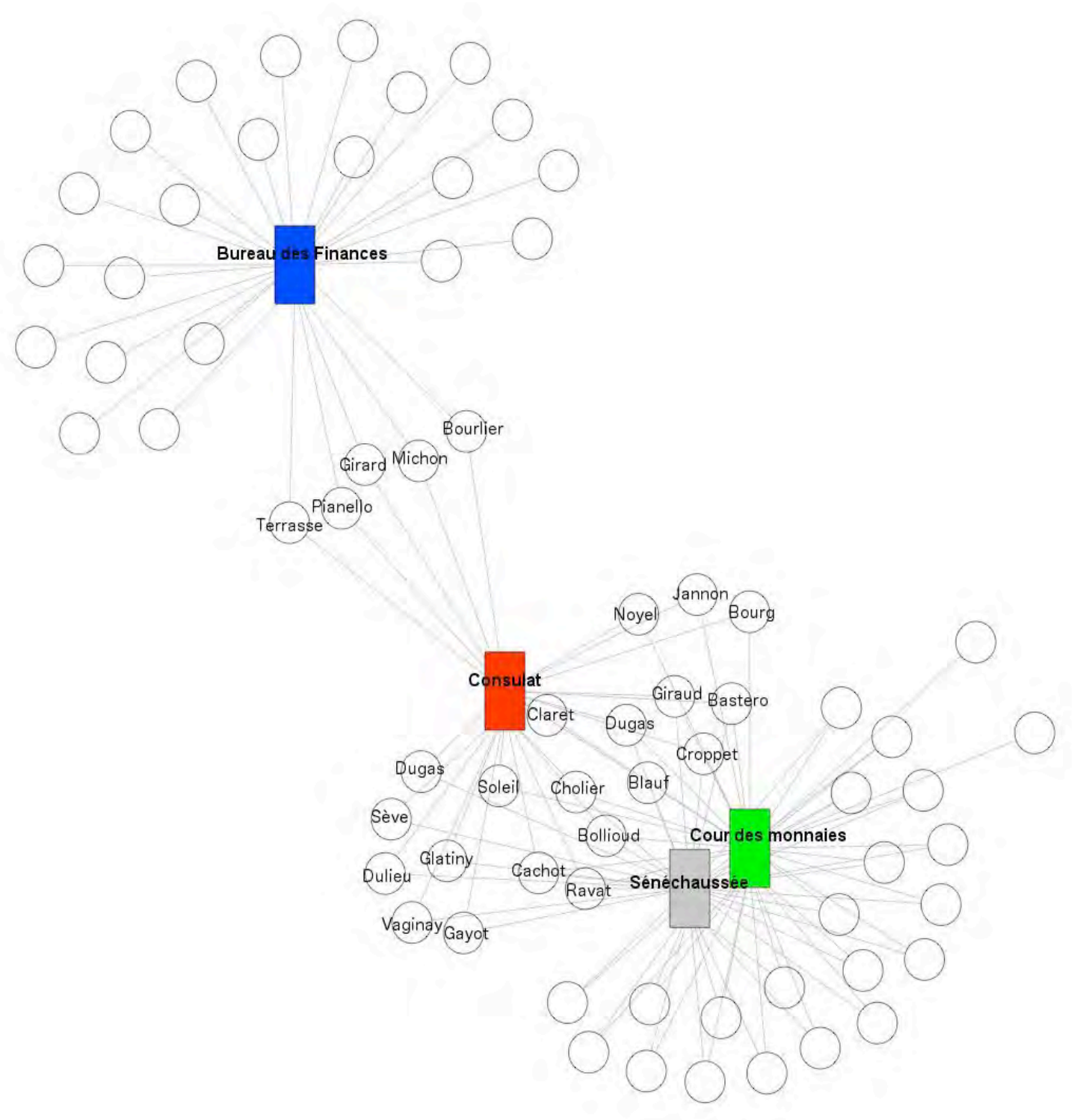


Figure 3: Catégorisation de l'influence sur les nominations des échevins selon les Mémoires de Léonard Michon.

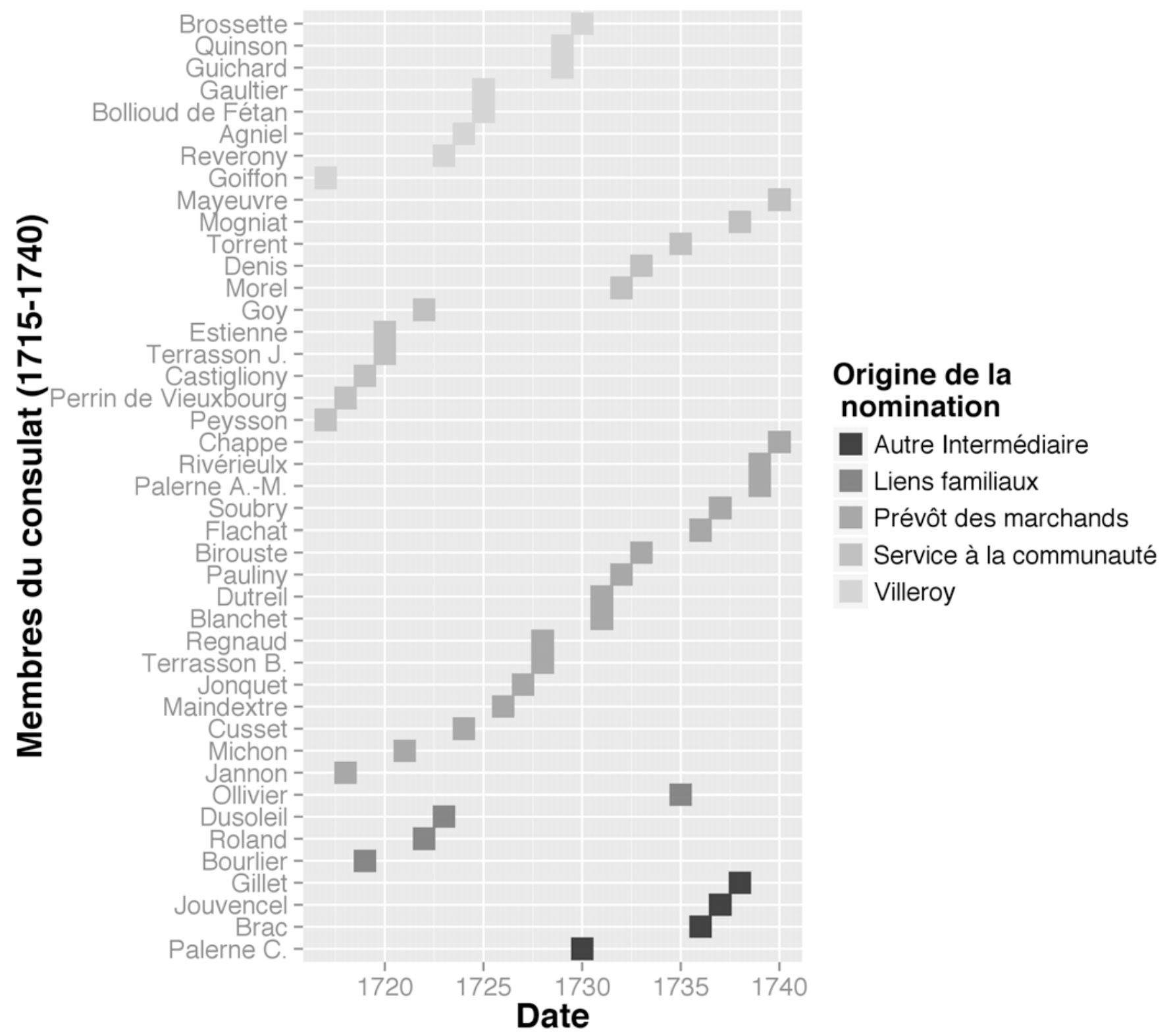


Graphique 1 : Nombre et origine institutionnelle des cumulants au sein du Consulat de Lyon pour la période 1680-1740.

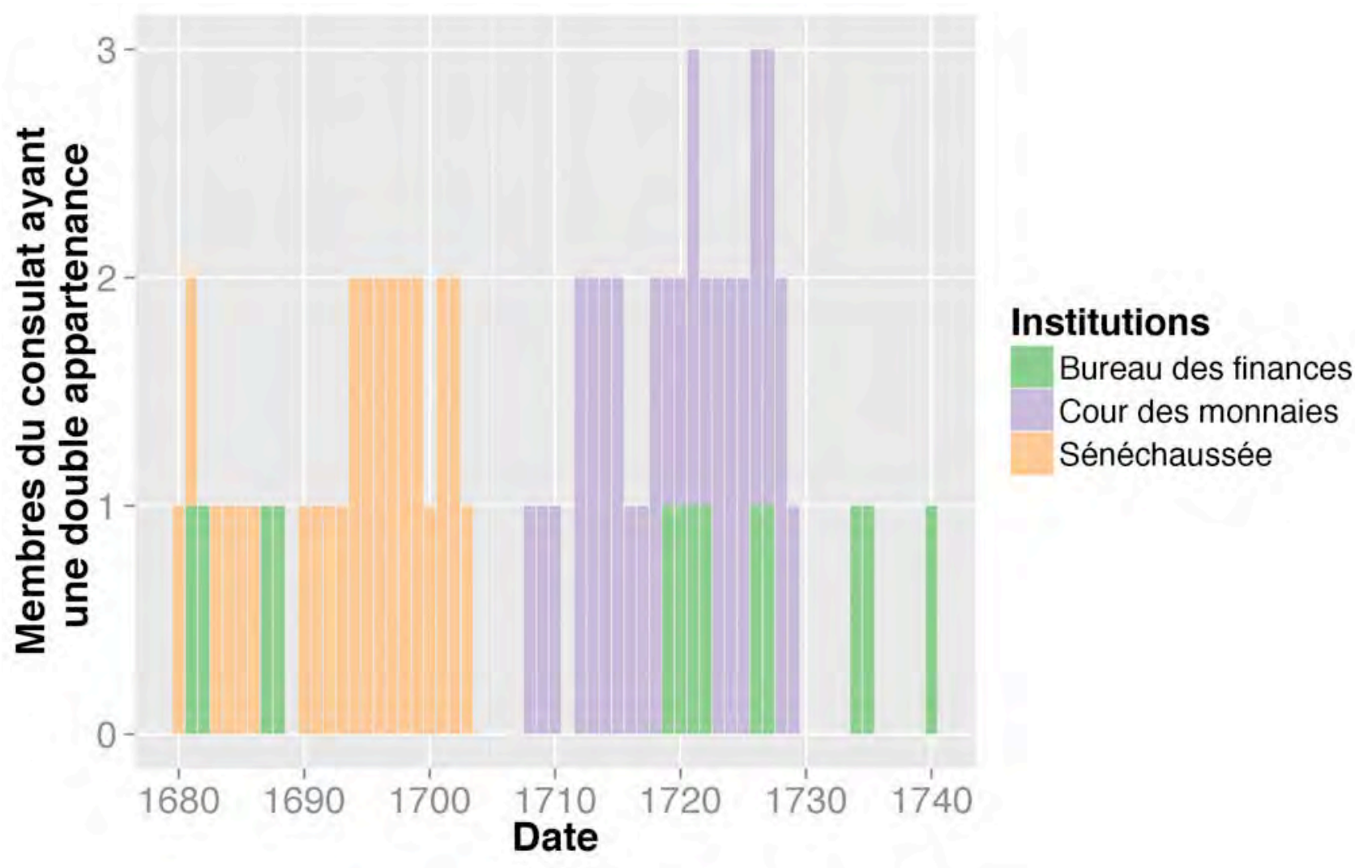




\title{
Réseaux et identité chez les Colombiens en France : un vécu transculturel
}

\author{
María Isabel QUINTANA MARÍN \\ Doctorante en Histoire de l'art, \\ Université Paris 1 Panthéon-Sorbonne \\ Mary Luz MARÍN POSADA \\ Doctorante en sociologie, chargée de cours, \\ Universidad de Antioquia, Medellín, COLOMBIE \\ Extrait de : Henri BRESC (dir.), Réseaux politiques et économiques, Paris, \\ Édition électronique du CTHS (Actes des congrès des sociétés historiques et scientifiques), 2016. \\ Cet article a été validé par le comité de lecture des Éditions du CTHS dans le cadre de la publication \\ des actes du $140^{\mathrm{e}}$ Congrès national des sociétés historiques et scientifiques tenu à Reims en 2015.
}

Selon les chiffres du Ministère des affaires étrangères de la Colombie, il y a actuellement 4,7 millions de Colombiens résidant à l'étranger, ce qui représente $10 \%$ de la population. Selon le gouvernement, la première cause d'émigration est la recherche d'emploi. La deuxième cause est le regroupement familial. La troisième cause serait la formation supérieure. Des Colombiens ont également quitté leur pays à cause des conflits internes. La migration peut donc avoir des raisons économiques, sociales, culturelles ou politiques.

Déterminer le nombre de migrants colombiens en France est difficile. Au début de l'année 2014, un peu plus de 14000 étaient inscrits au consulat de Colombie à Paris, selon les chiffres de l'ancien consul, Daniel García-Peña Jaramillo. Le nombre est sans doute beaucoup plus important si l'on tient compte des personnes qui n'ont pas de papiers et de celles non encore inscrites au consulat. La sociologue Anne Gincel parle de soixante mille, voire de soixante-dix mille personnes ${ }^{1}$.

Étant donné que le changement de contexte social produit des changements dans l'identité des individus, la question sur l'acquisition de sentiments d'appartenance collective chez les Colombiens résidant en France se pose. En premier lieu, cet article présente quelques stratégies destinées à préserver l'identité nationale des Colombiens qui se trouvent en France et leurs réponses à ces stratégies. Ensuite vient l'analyse de la manière dont un certain nombre de Colombiens pourrait développer d'autres appartenances à travers de réseaux sociaux. Il sera possible enfin de faire une synthèse sur le profil identitaire et le sentiment d'appartenance de cette population.

1. A. Gincel, « Santuario : un village colombien à Paris », [s.p.]. 


\section{Les Colombiens en France et leur identité nationale}

En France, les Colombiens ont des points de rencontre mettant en valeur leur culture. Quelques-uns existent grâce au programme Colombia Nos Une ${ }^{2}$, créé en 2003 et développé par un groupe interne du Ministère des affaires étrangères de la Colombie. L'objectif du programme est essentiellement d'établir des liens entre l'État et ses citoyens expatriés et entre les Colombiens qui se trouvent à l'étranger, afin de préserver l'identité nationale et de promouvoir le retour.

Colombia Nos Une est un programme global qui veut relier les Colombiens dans le monde. Pour ce faire, le réseau se tisse sur trois niveaux. Tout d'abord, il cherche à mettre en relation la communauté colombienne qui se trouve sur un même territoire ; puis, il veut rétablir et renforcer les liens entre la population migrante et le pays; enfin, il crée une connexion entre les Colombiens dispersés de par le monde grâce aux bulletins informatifs sur les activités consulaires dans les différents pays.

Un des axes de travail du programme se charge de promouvoir la communauté colombienne à l'étranger pour augmenter le capital social, aidant ainsi au progrès du pays et de la communauté. Les consulats sont chargés de mettre en place des stratégies, en promouvant, par exemple, des équipes de travail. C'est de cette manière que l'on peut rejoindre le réseau. Une des stratégies cible la communauté colombienne travaillant dans le domaine de l'art et de la culture. Étant donné le nombre non négligeable de jeunes artistes colombiens présents sur le territoire français, le consulat à Paris a ouvert un concours d'arts visuels. Selon l'ex-consul García-Peña Jaramillo, plus de 80 artistes se sont présentés aux concours en deux ans. Les dossiers permettent de découvrir que certains parmi eux, malgré l'éloignement, travaillent sur des sujets en rapport avec leur pays d'origine comme le paysage, la mémoire collective et la violence.

Des professionnels colombiens de l'art et de la culture ont rejoint le projet en tant que membres d'un comité de sélection et d'évaluation des travaux. Quelques-uns parmi eux ne se connaissaient pas avant d'entrer dans le réseau; il en va de même avec les artistes. Grâce à sa dimension participative, le projet a réussi à attirer des personnes qui se trouvaient pratiquement isolées de la communauté colombienne en France et de l'État. L'un des participants au programme déclare :

«J'ai toujours eu des liens avec la Colombie surtout pour des raisons affectives, car ma famille est là-bas. En revanche, avant d'entrer dans le réseau, le seul lien que j'entretenais avec l'État colombien était le vote. C'était la seule raison pour laquelle j'allais au consulat [...] Entrer dans le réseau est bénéfique ; ça aide à entretenir le sentiment d'appartenance nationale, et je découvre le grand potentiel des Colombiens en France. »

Au cours des dernières années, le consulat a fait des efforts pour promouvoir les arts et les lettres du pays. Il organise des entretiens avec des personnalités colombiennes célèbres sur le plan national ou international. Plusieurs écrivains ont présenté de nouveaux livres publiés en espagnol ou en français; il y a eu des concerts et des entretiens avec des artistes. Lors d'un entretien avec un peintre connu, l'assistance a eu l'occasion de discuter sur le problème du racisme en Colombie. Il faut dire que, malheureusement, les problèmes d'exclusion et d'inégalité sociale sont ancrés dans la société colombienne, et que les polarisations - entre les «bons » et les "mauvais », le «proche» et le «lointain » par exemple - créent des barrières qui empêchent que les individus se rapprochent les uns des autres.

L'objectif de ces événements consulaires est de tenir la communauté colombienne au courant des dernières nouvelles du pays. Ces événements sont ouverts aussi au public

2. En français : « La Colombie nous unit ». 
français et il est important de souligner que des invités français sont venus transmettre leurs connaissances sur la Colombie.

Le consulat réunit aussi la communauté colombienne à l'occasion de la fête de Noël. Les festivités de Noël en Colombie sont un ensemble de pratiques aussi bien religieuses que culturelles, héritage de la colonisation. Les Colombiens tiennent beaucoup à célébrer ces festivités. Par conséquent, le consulat compte sur une assistance nombreuse. D'autres points de rencontre sont mis en place par des associations.

Le consulat s'intéresse aussi aux associations et a mis à la disposition de la communauté un annuaire afin de stimuler la rencontre et la coopération. Parmi les associations, certaines s'efforcent de promouvoir la culture colombienne et participent à la réflexion sur le conflit interne que la Colombie subit depuis plus de cinquante ans. Plusieurs associations qui opèrent dans le domaine de l'humanitaire développent des projets au pays.

Un tournoi de football organisé par une association rassemble un grand nombre de personnes. Il faut souligner que le football est un élément important de cohésion chez les Colombiens et qu'il mobilise les foules. La communauté colombienne en France demeure passionnée et soutient un tournoi annuel au Parc de Vincennes à Paris. Des enfants et des adultes y participent. C'est l'occasion de déguster des plats traditionnels de la gastronomie colombienne.

Une autre association organise la fête nationale de la Colombie à Paris. Elle a lieu depuis 25 ans et attire un grand nombre de Colombiens. Elle dure toute une journée et permet d'apprécier les expressions de la culture colombienne comme la gastronomie, les danses, les costumes traditionnels et les rythmes régionaux.

Ces différentes activités, consulaires et associatives, sont la manifestation d'une identité nationale et l'expression du sentiment d'appartenance nationale de la communauté colombienne. Une partie de la communauté s'intéresse aux arts et aux lettres, et assiste aux entretiens programmés par le consulat. Elle veut rester au courant des nouvelles du pays sur le plan politique, social, économique et culturel, et profite des opportunités pour se réunir et discuter avec un vif intérêt sur des sujets comme le racisme et la paix en Colombie. C'est l'expression d'un sentiment d'appartenance. À travers le développement des projets associatifs consulaires, la communauté colombienne se sent soutenue et prise en compte par l'État colombien et en éprouve de la reconnaissance.

Les festivités organisées par les associations rassemblent un nombre considérable de Colombiens qui profitent pleinement de ces moments. Elles permettent de maintenir vivantes les traditions artistiques, religieuses, musicales et culinaires. La réceptivité et l'intérêt prouvent que, malgré les années passées en France, ces Colombiens n'oublient pas leurs racines et s'intéressent à entretenir les liens avec le pays.

\section{Le développement d'autres appartenances}

Néanmoins, certains centres d'intérêt de la communauté colombienne en France révèlent que celle-ci n'agit pas guidée exclusivement par son sentiment d'appartenance nationale. Tel est le cas des artistes, des professionnels de la culture et des associations. Les Colombiens impliqués dans le domaine des arts, par exemple, font preuve d'une expérience transculturelle. L'œuvre de quelques artistes révèle un intérêt pour la notion d'identité à des différents niveaux : familial, national et planétaire. À la question posée sur le rôle que joue leur identité colombienne dans leur processus créatif, les artistes ont répondu en soulignant le caractère évolutif de l'identité. Quelques-uns ont exprimé leur intérêt pour des sujets comme les influences culturelles et le dialogue avec «l'Autre », cet «Autre » impliqué dans la construction de leur identité et sans lequel ils ne seraient pas 
ce qu'ils sont maintenant. Cet «Autre » représente, affirment quelques-uns, la société française et les Latino-Américains. Certains artistes n'hésitent pas à se reconnaître au sein d'une grande communauté latino-américaine.

Les Colombiens intéressés par les arts et la culture extériorisent un désir de faire dialoguer leurs environnements: la Colombie avec le reste de l'Amérique latine; la Colombie et l'Europe ; l'Amérique latine et l'Europe. Une professionnelle colombienne affirme qu'elle a été attirée par la France à cause de sa richesse artistique. Elle s'est donnée comme objectif l'étude des rapports culturels entre l'Amérique latine et l'Europe, souhaitant développer un champ de vue élargi, cela en raison des racines qu'il faut chercher sur le Vieux Continent lors de l'étude de l'art latino-américain, ainsi que de tout ce que les pays de l'Amérique latine partagent du point de vue historique et artistique.

Cette partie de la communauté colombienne est dans une dynamique d'intégration dans la société française et s'intéresse à la pensée européenne. Les artistes développent d'autres filiations, impliqués à fond dans des projets en rapport avec leur environnement actuel. Certains d'entre eux font partie de collectifs d'artistes parmi lesquels il ne se trouve aucun autre Colombien, et cela non pas de manière préméditée, mais spontanée : «Les choses se sont présentées comme ça », raconte une artiste appartenant à l'un de ces groupes. D'autres, alors qu'ils travaillent sur la mémoire collective du peuple colombien, ont aussi des travaux sur la mémoire collective française et européenne, sur le souvenir et les traces laissées par les guerres mondiales, en admirant la manière dont la France et les pays européens respectent la Mémoire afin de ne pas reproduire les erreurs du passé.

Certains parcourent les côtes méditerranéennes qui relient trois continents en cherchant des sujets pour leur travail ; d'autres se sont impliqués dans des projets urbanistiques de la ville de Paris; quelques-uns sont dans l'éducation et d'autres dans le domaine de la recherche, prenant une part active dans le développement scientifique.

Au sujet de cette capacité à s'intégrer et d'accueillir la pensée d'autres cultures différentes à la nationale, Tzvetan Todorov rappelle une idée généralisée :

«De nombreuses personnes, en particulier des artistes et des intellectuels, font l'éloge de la pluralité des cultures, du mélange des voix, voire de la polyphonie démesurée, qui ne connaîtrait ni hiérarchie ni ordre ; elles se reconnaissent dans le cosmopolitisme, sinon dans le nomadisme généralisé, cadre approprié au sujet décentré que serait chacun de nous. »³

À ce sujet, il n'est pas rare, certes, de rencontrer des artistes colombiens qui ont séjourné dans d'autres pays avant d'arriver en France, ou qui pratiquent cette sorte de nomadisme culturel. Néanmoins, l'œuvre de certains d'entre eux montre que le sentiment d'appartenance nationale est encore présent, et qu'il ne s'agit pas de le remplacer par d'autres, malgré leur cosmopolitisme, mais de le faire dialoguer avec leurs nouvelles découvertes culturelles.

L'ouverture culturelle des Colombiens est visible aussi à travers le désir de fonder des associations sur le territoire français. Cela traduit une volonté de s'intégrer à la société française et de s'enraciner. Actuellement, il y a en France près de 80 associations d'initiative colombienne. Parmi elles, une cinquantaine est domiciliée en région parisienne. Des trente-sept associations de la région parisienne sur lesquelles il a été possible d'obtenir des informations, vingt et un, c'est-à-dire 56,7 \%, font, d'une manière ou d'une autre, un travail en rapport avec les manifestations culturelles.

Quatorze associations en rapport avec la culture - ce qui représente 66,6\% des associations avec ce profil-là -, promeuvent les expressions culturelles de divers pays. Six d'entre elles n'expriment pas un intérêt spécifique et sont ouvertes aux diverses manifestations culturelles et artistiques du monde entier; sept se focalisent sur l'Amérique latine; une association exprime un intérêt pour l'Amérique latine et pour certains pays européens de langue romane.

3. T. Todorov. L'homme dépaysé, p. 21. 
Il est donc possible d'affirmer que la partie de la communauté colombienne représentée par ces associations est motivée par un esprit d'échange international et de solidarité latino-américaine. "Nous, les Latinos, nous sommes comme des frères et sœurs, beaucoup de choses nous unissent», dit une femme colombienne qui vit en France depuis plus de trente ans en expliquant:

« C'est peut-être parce qu'au fond de tout, nous avons mené les mêmes luttes. Avoir quitté la Colombie m'a aidé à voir les choses que nous avons en commun avec les autres pays. J'ai une identité latino-américaine. »

Sept associations se consacrent à la culture colombienne et nourrissent de ce fait le sentiment d'appartenance nationale des Colombiens en France. Néanmoins, l'esprit d'échange y est aussi présent. Lors de la fête nationale de la Colombie, par exemple, il peut arriver que des groupes artistiques d'autres pays latino-américains soient invités, attirant ainsi une assistance qui n'est pas exclusivement colombienne.

D'autres associations travaillant dans d'autres domaines sont dans un esprit de collaboration internationale. Quelques-unes du domaine de l'humanitaire pensent à des projets à développer en Amérique latine et il arrive qu'elles travaillent en réseau avec des associations d'initiative française. Elles réfléchissent au problème de la violence afin de contribuer à la paix durable et mènent des missions concrètes pour la récupération de zones, l'éducation ou le logement. Quelques associations travaillent avec des organisations françaises au sujet de l'adoption. Entre 2004 et 2014, 2754 enfants colombiens ont été adoptés par des familles françaises, selon les chiffres de l'Agence française de l'adoption.

Il faut souligner que quelques associations travaillent à l'intégration des Colombiens qui viennent d'arriver en France, ce qui prouve que cette communauté n'a pas tendance à s'isoler, mais bien au contraire, à se trouver rapidement des repères sur le nouveau territoire.

En résumé, il est possible d'affirmer que les associations créées par des Colombiens mettent en évidence le développement d'appartenances autres que la nationale. Ainsi, parmi les 37 associations de la région parisienne, 24,3\% travaillent pour la culture et la communauté latino-américaine ; 8,1\% s'intéressent à l'Amérique latine ou aux pays de langue romane ; $16,2 \%$ ont une vision ouverte au monde entier. Ces chiffres représentent $48,6 \%$ des associations. Les autres $(51,4 \%)$ travaillent sur des projets en rapport avec la Colombie, tenant compte du fait que certaines d'entre elles ont des partenariats avec des associations françaises ou font des efforts pour l'intégration des Colombiens en France.

\section{La transculturation chez les Colombiens en France}

Les différents cas étudiés permettent de parler d'un processus de transculturation compris, dans les mots de Tzvetan Todorov, comme «l'acquisition d'un nouveau code sans que l'ancien soit perdu pour autant $»^{4}$. Chez ces immigrants qui s'installent en France se reproduit le vécu de Todorov en France :

"Je vis désormais dans un espace singulier, à la fois dehors et dedans : étranger "chez moi" (à Sofia), chez moi "à l'étranger" (à Paris). "

Au sujet de ce « biculturalisme », Todorov explique :

4. T. Todorov. L'homme dépaysé, p. 23.

5. T. Todorov. L'homme dépaysé, p. 23. 
«Je ne m'exagère pas l'originalité de cette expérience de biculturalisme. D'abord, je suis loin d'être le premier à l'éprouver; dans le champ de la culture et des arts, nombreux sont ceux qui ont été attirés par des métropoles comme Paris ou Londres, New York ou Toronto, et ce nombre ne fait que croître tous les jours. De plus, les identités culturelles ne sont pas seulement nationales, il en existe aussi d'autres liées aux groupes d'âge, de sexe, de profession, de milieu social; de nos jours, donc, tout un chacun a déjà vécu, même si c'est à des degrés inégaux, cette rencontre des cultures à l'intérieur de lui-même : nous sommes tous croisés. ${ }^{6}$

Le développement d'autres appartenances ne remplace pas pour autant le sentiment d'appartenance nationale. Cela est visible dans le travail des associations. Le ressenti d'une femme colombienne vis-à-vis des associations créées non seulement par des Colombiens, mais par d'autres latino-américains est que, malgré leur ouverture internationale, elles finissent toujours par "se pencher d'un côté», selon la nationalité des membres fondateurs. La correspondance de cette affirmation avec la réalité n'a pas été vérifiée, mais elle est fort probable. Dans cet ordre d'idées, Todorov explique :

«L'appartenance culturelle nationale est simplement la plus forte de toutes, parce qu'en elle se combinent les traces laissées - dans le corps et dans l'esprit - par la famille et la communauté, par la langue et la religion. $»^{7}$

Etre immigrant apporte une autre perspective du monde, explique une femme colombienne qui vit en France depuis quinze ans:

\begin{abstract}
«Quand on quitte pour la première fois son pays, on se rend compte que finalement le monde n'est pas si grand, et les frontières deviennent moins infranchissables. On apprend que tout au long de l'histoire, les pratiques culturelles, les religions, les langues ont circulé à travers le monde, et que certains aspects relient des pays apparemment différents. En termes de gastronomie par exemple, on voit que les Africains et les Colombiens ont des plats très similaires, ce qui met en évidence nos liens ancestraux avec l'Afrique. »
\end{abstract}

Vivre dans un pays étranger peut s'avérer positif pour apprendre à accepter et apprécier l'altérité, donnant en même temps plus d'objectivité quant aux codes du pays d'origine. Parmi les traits sociaux que quelques Colombiens admirent chez les Français, se trouve leur détermination à revendiquer leurs droits, à manifester contre ce qui provoque en eux de l'indignation, même s'ils ne sont pas toujours écoutés. Ils admirent aussi leur conscience historique et le respect de la mémoire collective. Du point de vue administratif, ils observent que les réglementations en France offrent plus de sécurité, $\mathrm{qu}^{\prime}$ il est possible de savoir avec plus d'assurance ce que l'on peut attendre de l'État et des individus.

La transculturation est réussie quand l'immigrant peut comprendre les codes des autochtones, ce qui peut prendre un certain temps. Une artiste explique que le plus difficile pour elle en France a été d'apprendre à communiquer avec les Français :

«Je parlais déjà le français, mais cela ne suffit pas de connaître une langue. Apprendre à communiquer, c'est aussi devenir sensible aux comportements que les gens d'un pays apprécient ou n'apprécient pas. Il faut adopter des codes. »

En termes de transculturation, la partie de la communauté colombienne observée montre une bonne capacité d'adaptation. Les artistes, les professionnels de la culture et les responsables d'associations peuvent de ce fait penser à la possibilité de s'installer en France. Une telle démarche semble être possible lorsque le choix d'un pays n'a pas été fait par contrainte. Dans ce cas-là, la France devient «le terrain fertile d'une expérience nouvelle». Todorov explique :

6. T. Todorov. L'homme dépaysé, p. 23.

7. T. Todorov. L'homme dépaysé, p. 23-24. 
«La coexistence de deux voix devient une menace, conduisant à la schizophrénie sociale, lorsque celles-ci sont en concurrence ; mais si elles forment une hiérarchie dont le principe a été librement choisi, on peut surmonter les angoisses du dédoublement et la coexistence devient le terrain fertile d'une expérience nouvelle. ${ }^{8}$

Sans ces «angoisses du dédoublement», la transculturation chez l'immigrant s'avère être une richesse.

L'observation de cette partie de la communauté colombienne résidant en France permet d'affirmer que, malgré les années passées loin du pays, les Colombiens n'oublient pas leurs racines, ce qui leur facilite la participation à des activités promouvant la préservation de l'identité nationale et la création de lien entre eux. Ils apprécient les initiatives du gouvernement dans ce sens-là, et ils sont prêts à prendre eux-mêmes des initiatives de promotion culturelle et de soutien à la communauté colombienne à travers des réseaux sociaux. Les Colombiens entretiennent des liens avec le pays pour des raisons affectives, économiques, politiques et culturelles.

Néanmoins, l'attachement au pays et le sentiment d'appartenance nationale ne les retiennent pas dans un nationalisme aliénant ou sectaire. En France, les Colombiens ont tendance à développer d'autres appartenances. De cette manière, ils font preuve non seulement de l'existence d'une identité nationale, mais aussi latino-américaine. De plus, les artistes et les associations montrent une volonté de vivre ensemble dans un dialogue avec la société française. L'échange avec la communauté de l'Amérique Latine et le contact avec la société française façonnent les identités individuelles et développent chez les migrants colombiens d'autres appartenances.

Au sujet du sentiment d'appartenance et de l'identité chez les Colombiens de France, il reste beaucoup à dire; $c^{\prime}$ est un champ encore très peu exploré et cet article ne se consacre qu'à une partie de la population. Une étude de grand intérêt serait celle de l'identité et des sentiments d'appartenance chez les Colombiens prisonniers en France, une partie de la population qui, étant donné les circonstances, reste marginalisée face aux initiatives de l'État colombien, aux initiatives communautaires et à la société française.

8. T. Todorov. L'homme dépaysé, p. 20. 


\begin{abstract}
Résumé
Selon les chiffres du ministère des affaires étrangères de la Colombie, 4,7 millions de Colombiens se trouvent à l'étranger. En France, plus ou moins quatorze mille sont enregistrés au consulat. Certaines études calculent un nombre de soixante mille, voire soixante-dix mille. Étant donné que ces chiffres sont considérables, et qu'il s'avère que le changement de contexte social se répercute sur l'identité des individus, cet article porte sur le développement d'appartenances collectives chez les Colombiens résidant en France. L'étude présente tout d'abord des stratégies menées par les ressortissants colombiens pour préserver l'identité nationale et la réponse de la communauté colombienne à ce sujet. Elle traite ensuite sur le rapport des Colombiens à d'autres communautés au cœur desquelles ils développent des appartenances. Enfin, vient une réflexion sur les appartenances multiples basée sur la notion de transculturation de Tzvetan Todorov.
\end{abstract}

\title{
Bibliographie
}

"Colombie », Agence française de l'adoption [En ligne], Paris : GIP AFA [Référence du 15 juin 2015], Accès internet :<URL : http://www.agence-adoption.fr/colombie/>.

Gincel Anne. "Santuario : un village colombien à Paris », Revue Hommes et migrations [En ligne], ${ }^{\circ}$ 1270, nov. - déc. 2007, [s.p.]. [Référence du 15 juin 2015]. Accès internet : <URL : http: / / www.hommes-et-migrations.fr/index.php? / numeros / migrations-latinoamericaines / 4920-santuario-un-village-colombien-a-paris $>$.

TODOROv Tzvetan, L'homme dépaysé, Paris, Éd. du Seuil, 1996. 
Du réseau au parti politique moderne et post-moderne 


\title{
Les " factieux de Lodève » : développement et déclin d'un réseau jacobin héraultais
}

\author{
Nathalie ALZAS \\ UMR TELEMME Aix \\ Extrait de : Henri BRESC (dir.), Réseaux politiques et économiques, Paris, \\ Édition électronique du CTHS (Actes des congrès des sociétés historiques et scientifiques), 2016. \\ Cet article a été validé par le comité de lecture des Éditions du CTHS dans le cadre de la publication \\ des actes du $140^{\circ}$ Congrès national des sociétés historiques et scientifiques tenu à Reims en 2015.
}

De nombreux travaux ont renouvelé l'étude du jacobinisme, de sa naissance, aux débuts de la Révolution, à son apogée en l'an II, jusqu'à ses mutations sous le Directoire. On sait, désormais, l'importance des néo-jacobins dans l'affirmation d'un mouvement démocratique en France. Le département de l'Hérault, par la richesse de ses archives, a fait l'objet de nombreuses recherches ${ }^{1}$, à partir de ses centres urbains, tel son chef-lieu, Montpellier, ou sa rivale Béziers. Mais des bourgades plus modestes, à l'image des communes du Bas-Languedoc étudiées par Georges Fournier ${ }^{2}$, révèlent, elles aussi, la vigueur des réseaux locaux. Plus au nord du département, le district de Lodève est un espace où un militantisme important se développe, y compris sous le Directoire, par un néo-jacobinisme vivace, ainsi à Gignac évoqué par Bernard Gainot ${ }^{3}$. Pour prolonger ces réflexions, cette étude se propose d'évoquer, à nouveau, ces réseaux républicains à partir de la ville de Lodève. Là, depuis 1789, des hommes d'influence se sont profondément investis dans la Révolution.

Lodève, aujourd'hui, semble à l'écart du dynamisme littoral héraultais et montpelliérain. Il en était tout autrement sous l'Ancien Régime. Son influence économique est alors forte, par ses manufactures de draps, fournisseurs privilégiés de l'armée royale, grâce à la protection d'un enfant du pays, le cardinal Fleury. Les fabricants et négociants lodévois sont liés à une finance languedocienne dynamique, ouverte sur l'espace national et les échanges internationaux. Certes, la crise de l'Ancien Régime finissant frappe durement l'activité drapière méridionale.

Dans ce contexte, la Révolution est bien accueillie à Lodève. L'équipement des gardes nationales, des bataillons de volontaires, puis l'entrée en guerre apportent une reprise inespérée. Les élites éclairées du Lodévois, essentiellement des manufacturiers, négociants, propriétaires fonciers, s'investissent dans les mutations politiques qui leur permettent de s'affirmer dans les administrations nées de la Révolution ${ }^{4}$. En 1790, le district de Lodève compte 9300 citoyens actifs environ, parmi lesquels émerge un vivier de militants révolutionnaires, auquel s'ajoutent, à partir des années 1792-1793, des sansculottes provenant de catégories sociales plus modestes. Une partie de ces citoyens forment les cadres de l'an II, dans les administrations de département, de district, la municipalité, le comité de surveillance. Compromis aux yeux des Thermidoriens, ils persistent dans leur engagement. Par voie de conséquence, la période thermidorienne et

1. J.-F. Dubost, «Le réseau des sociétés politiques dans le département de l'Hérault pendant la Révolution Française, 1789-1795 ».

2. G. Fournier, «Entre vallée de l'Hérault et vallée de la Garonne : les bastions fermement républicains sous le Directoire », dans Révolution et Contre-Révolution dans la France du Midi (1789-1799).

3. B. Gainot, 1789, un nouveau jacobinisme?

4. Pour alléger les notes, l'essentiel des informations sur l'administration du district de Lodève renverra à

N. Alzas, La liberté ou la mort. L'effort de guerre dans le département de l'Hérault pendant la Révolution. 
le Directoire sont un moment clef pour saisir la pérennité du militantisme parmi ceux que l'historiographie contemporaine évoque sous les termes de "fermes républicains", de «néo-jacobins", que leurs adversaires dénonçaient comme "factieux», "buveurs de sang » et qui, eux, s'appelaient tout simplement "patriotes». Le réseau républicain lodévois connut, en effet, deux temps majeurs de répression. Les principaux militants sont destitués et arrêtés en l'an III en tant que " terroristes ", puis à nouveau, inquiétés en thermidor an IV comme « robespierristes », adhérents à la « conspiration de Babeuf » 5 .

Sans surprise, le noyau dirigeant est composé de citoyens aisés, "gens à talents », comme on disait à l'époque, fortement insérés dans des réseaux familiaux, culturels et économiques au cœur de la cité lodévoise.

Ainsi, Bernard Barthélémy Luchaire, dénoncé en l'an IV en tant que «chef du parti terroriste ", correspond à ce profil de jacobin issu des élites éclairées de sa ville. Né en 1764, il s'inscrit dans la génération des 30-45 ans qui compose les principaux membres de la société politique et des administrations révolutionnaires. Il est le fils d'un négociant. Par sa mère, Luchaire est lié à des notabilités montpelliéraines, soulignant les relations étroites entre sa ville natale, manufacturière et le chef-lieu centre financier et culturel. Un de ses cousins est Auguste Broussonnet, professeur à la faculté de médecine, membre de l'Académie des Sciences. Les deux hommes partagent les mêmes curiosités intellectuelles. Bernard Barthélémy fait appel à l'éminent naturaliste pour expérimenter de nouvelles productions afin d'améliorer l'approvisionnement de ses concitoyens en l'an II, en implantant la culture de pommes de terre sur ses propriétés. Sa belle-famille le place encore davantage au cœur de sa cité. Luchaire, par son mariage en 1791, avec Justine Fabreguettes, s'allie à l'une des plus puissantes familles de fabricants de draps de la région. Son beau-père, Augustin Fabreguettes est, en effet, à la tête d'une manufacture qui emploie plusieurs centaines de personnes, dans ses ateliers de teinture, apprêts de la ville et par les activités de tissage dans les villages des alentours. Pendant de nombreuses années, les Fabreguettes "tiennent» ainsi Lodève. Augustin est sous-préfet de 1804 à 1813, poste où il a d'ailleurs succédé à son frère aîné ${ }^{6}$. D'ailleurs, on peut se demander dans quelle mesure l'arrestation de Luchaire, en l'an III, comme «terroriste », n'était pas motivée, pour certains de ses adversaires, par la volonté d'amoindrir la position de sa belle-famille. Il est également vrai que si Luchaire est défendu efficacement par Augustin Fabreguettes dans l'après-Thermidor, il a lui-même joué de toute son influence pour faire oublier l'engagement fédéraliste de celui-ci, en 1793. Ce réseau, puissant, s'appuie sur de nombreux hommes d'influence: Bernard Barthélèmy est également le beau-frère de Jacques Caylar, président du tribunal du district pendant toute une partie de la Révolution. Quant à sa propre fortune, elle est conséquente. Luchaire est propriétaire, depuis 1789, du domaine de Montplaisir, situé à cheval sur les communes d'Olmet et de Lodève ${ }^{7}$.

Sa position sociale est similaire à celle des autres chefs néo-jacobins du lieu. Jean Benoît cadet, présenté comme son alter ego dans les sources thermidoriennes, suit le même parcours. Les deux républicains ont été membres de la première municipalité révolutionnaire de Lodève, officiers de la Garde Nationale, membres de l'administration départementale, et du district. Abonné comme Luchaire au Tribun du Peuple de Babeuf ${ }^{8}$, Benoit cadet est l'un des plus riches contribuables de sa ville. Fabricant de draps, acheteur de biens nationaux, il s'est investi, lui aussi, dans la politique dès la préparation des États Généraux. Mais pour tous les principaux néo-jacobins du Lodévois, les fonctions d'administrateur au district jouent un rôle essentiel dans l'enracinement de leur engagement. En effet, de 1790 à l'an IV, une vingtaine d'hommes furent membres du district, les plus influents étant réélus ou reconduits dans leurs fonctions par les représentants du peuple à plusieurs reprises. Luchaire et Benoît cadet côtoient des

5. Archives départementales de l'Hérault, L701, Enquête faite par le commissaire nommé par le département de l'Hérault à la suite de dénonciations contre la municipalité (27 thermidor an IV-11 fructidor an IV).

6. H. Michel, G. Albert Roch, A. Cosson, Grands notables du Premier Empire, Gard Hérault Drôme.

7. H. Leroy-Beaulieu, «Les propriétaires de Montplaisir ou la rencontre de la technique de la politique et de l'économie ».

8. M.-A. Iafelice, « Le Babouvisme en province. Les abonnés méridionaux au Tribun du Peuple». 
hommes de loi, comme l'avocat Marquès lui aussi dénoncé en l'an IV comme «terroriste» ou bien encore le notaire Antoine Pons, figure majeure du néo-jacobinisme de Gignac. Ces hommes sont, pour la plupart, les plus imposés de leur commune, ce qui est logique : ils bénéficiaient de réseaux influents qui leur ont permis d'être les élus des administrations nouvelles, s'étant investis dès 1789 dans des actions collectives ${ }^{9}$. Quant aux plus jeunes, dénoncés parfois par des érudits du $\mathrm{XIX}^{\mathrm{e}}$ siècle comme des arrivistes parvenus au pouvoir grâce à la démagogie, ils se révèlent de fait issus des mêmes milieux. Ainsi, Henry Pradel, dit Regulus, membre du district de l'an II, décrit comme un extrémiste dangereux qui ne pourrait qu'être étranger à la région, est de fait le fils d'un négociant huppé, avec 600 livres de revenus fonciers. Presque tous ces administrateurs disposent de domestiques, (au moins une "fille de service » chez Luchaire et Benoît cadet), et emploient des ouvriers agricoles lors des gros travaux des champs. Les plus aisés, ont des "domestiques attachés à la terre » toute l'année. On est très loin de la légende noire thermidorienne qui faisait des hommes de l'an II des "gens sans aveu ", «illettrés », sans revenus fixes. Ces dénonciations sont de peu de poids devant les réalités sociologiques. Les néo-jacobins, à l'image de leurs adversaires thermidoriens, sont menés par une élite d'hommes de loi, manufacturiers, négociants, presque tous propriétaires fonciers conséquents. Il est difficile de démêler de véritables différences sociales entre les camps en présence. Certes, des personnages plus modestes sont également dénoncés comme "terroristes », essentiellement des commerçants et artisans lodévois, notamment des anciens membres du comité de surveillance et des militants actifs de la société populaire. Mais leur condition est loin de l'indigence et d'une quelconque marginalité sociale. Les néo-jacobins, pas plus qu'ailleurs, ne sont des aigris qui auraient trouvé dans la Révolution un exutoire ou une revanche sociale. C'est justement leur forte insertion dans la cité qui les a conduits à l'engagement politique.

En effet, les fonctions administratives ont joué un rôle majeur dans leur parcours. Les néo-jacobins ont occupé très tôt, dans la Révolution, des responsabilités qui les ont directement confrontés à des oppositions virulentes. Ils seraient ainsi devenus révolutionnaires comme les députés de l'Assemblée Nationale étudiés par Timoty Tacket $^{10}$. À Lodève, deux éléments majeurs ont pu intervenir dans la cristallisation des options politiques. D'une part, les soulèvements contre-révolutionnaires, réitérés, du sud du Massif Central (Ardèche, Lozère...) mirent sous pression des administrations lodévoises qui ne cessèrent d'être en alerte. La municipalité, le district, le comité de surveillance, multiplièrent les séances de crise afin de réagir à des mouvements qui prônaient le retour à l'Ancien Régime et la destruction des révolutionnaires. Souvent officiers de la Garde Nationale, les membres des administrations durent organiser une résistance armée aux initiatives royalistes. D'autre part, la guerre extérieure accentue l'engagement de notabilités traditionnellement liées aux fournitures militaires: la mobilisation patriotique est indissociable de l'activité de la ville drapière.

Certes, des profils apparemment atypiques existent parmi les néo-jacobins, mais ils révèlent d'autres caractéristiques du tissu économique et social de la région.

Mathieu Fulcrand Delpon est un des hommes de l'an II les plus dénoncés dans l'aprèsThermidor, par des adversaires qui lui reprochent son activisme, symbolisé par l'adoption du prénom de Marat. Il est issu d'une famille moins aisée que les autres figures de proue du mouvement néo-jacobin. Né en 1762, Marat Delpon quitte, vers 1780, le Lodévois pour s'installer à Saint-Domingue où il gère une entreprise de cabotage. Il semble avoir bénéficié d'un appui familial sur place, au moins de celui d'une tante. Son parcours l'insère dans l'ouverture du Languedoc sur l'outre-mer, des Amériques au Levant. Cependant, Marat Delpon se singularise ensuite. Il quitte, en 1792, SaintDomingue en proie à la guerre, et, rentre, via Marseille, à Lodève ${ }^{11}$. Là, il s'intègre à la société politique dont il devient l'un des militants les plus actifs. Ce comportement

9. Archives départementales de l'Hérault, L 4651 Répartition de la taxe de 1000000 livres sur les citoyens les plus aisés du district de Lodève, 10 juillet 1793.

10. T. Tackett, Par la volonté du peuple. Comment les députés de 1789 sont devenus révolutionnaires.

11. Archives départementales de l'Hérault, série L, Réfugiés des colonies, L 2916 et L 2926, états et pétitions des réfugiés pour obtenir des secours. 
l'oppose au positionnement d'autres "refugiés des isles» qui adoptent des opinions conservatrices, notamment à propos des questions coloniales. La société politique de Lodève est l'une des sociétés les plus puissantes de l'Hérault et l'une des plus précoces. Ses registres et sa correspondance rappellent que ces sociétés sont des organismes aux résonances complexes ${ }^{12}$. Il est bien sûr inutile de souligner l'importance de ce type de société dans la formation d'un militantisme révolutionnaire. Cependant, la lecture des registres de Lodève met en évidence le rôle des fabricants qui mêlent le patriotisme à une éthique et une philanthropie liées au rang social, aux nouveaux principes politiques ${ }^{13}$. Cette implication s'inscrit dans une continuité, on le sait. Les militants révolutionnaires (et souvent les contre-révolutionnaires) participèrent à d'autres lieux de sociabilité, sous l'Ancien Régime, tels les confréries de pénitents et la franc-maçonnerie. Il est d'ailleurs révélateur qu'un esclandre ait éclaté quelques années avant la Révolution, entre Benoît cadet, défendant sa confrérie de pénitents, et un concitoyen qui deviendra un de ses adversaires thermidoriens. Certes, on peut discerner, dans cet épisode, des luttes de clans au sein d'une même ville, mais également des conceptions opposées au niveau politique et social, avec un Benoît cadet soutenant des pratiques de sociabilité au nom d'un bien commun. Cette fidélité à une action collective se poursuit après Thermidor. Les néojacobins perpétuent des rencontres périodiques, après la fermeture du local de la société politique, désormais hors de Lodève, dans le domaine de Montplaisir de Bernard Barthélèmy Luchaire ${ }^{14}$. La préparation des élections ainsi que l'organisation de la Garde Nationale sont au centre de leurs préoccupations, accompagnés de la lecture de journaux et de brochures politiques. À Lodève comme ailleurs, deux cercles patriotes émergent. Un noyau dur de militants continue de se réunir fréquemment, conserve encore une partie du pouvoir local, et des sympathisants se mobilisent plus ponctuellement, en fonction de la conjoncture politique, lors d'élections.

Les réunions à Montplaisir font l'objet de dénonciations virulentes devant ces « conciliabules » jugés subversifs. Le refus d'une renaissance des sociétés populaires naît d'une impossibilité à concevoir un pluralisme politique, à un moment où le mouvement néo-jacobin tente de nouvelles voies démocratiques. La crainte d'un retour au pouvoir des hommes de l'an II explique l'arrestation et la perquisition du domicile de Luchaire en l'an III. Un juge de paix est mandaté pour chercher les documents compromettants, brochures politiques, correspondance, buste de Marat (dont un dénonciateur a attesté la présence). Cette sculpture affirmerait la filiation entre la ci-devant société politique et des réunions organisés à Montplaisir ${ }^{15}$. Il semble évident que Luchaire a conservé des symboles de l'ancienne société, et l'attachement à Marat en constituerait un élément significatif. Par sa culture, ses relations, l'ancien agent national du district est le centre de ralliement de ses amis politiques. Le domaine de Montplaisir accueillerait des personnalités du district et du département, afin de pérenniser un réseau jacobin capable de préparer et de gagner les élections. En effet, avec la disparition des sociétés populaires, la révocation de nombreux responsables, il faut éviter l'isolement de notabilités qui, seules dans leur bourgade, ne peuvent plus guère poursuivre une action politique efficace. Ainsi, l'ancien maire de Saint-Affrique, Bourguignon, le très engagé Escudier de Ceyras, et d'autres, issus de localités moins importantes, participeraient à une coordination d'ensemble impossible à leur seule échelle communale. Ce maillage jacobin serait consolidé par le séjour à Montplaisir de personnalités locales de plus grande envergure, notamment Franc Pavée. Cet ancien agent national du district de Montpellier est l'un des révolutionnaires les plus influents de l'Hérault en l'an $\mathrm{II}^{16}$. Par son passé

12. Vu la bibliographie immense sur ce thème, pour percevoir les chantiers en cours, nous renvoyons à l'atelier sur la Révolution du $140^{\mathrm{e}}$ Congrès National des Sociétés Historiques et Scientifiques (Reims, 2015), à paraitre. 13. Archives départementales de l'Hérault, L 8812-8813, registres de la société politique de Lodève (26 vendémiaire an II-21 ventôse an III).

14. Archives départementales de l'Hérault, L 4705 Lettre de l'agent national d'Olmet du 26 germinal an III à celui de Lodève sur la résidence de Luchaire. Archives départementales de l'Hérault, L701, Enquête faite par le commissaire nommé par le département de l'Hérault suite aux dénonciations contre la municipalité (27 thermidor an IV-11 fructidor an IV).

15. Archives départementales de l'Hérault, Q 756, Mise sous scellés et inventaire des papiers de Bernard Barthélémy Luchaire ( 9 et 19 prairial an III).

16. J. Sagnes, « Figures de révolutionnaires languedociens, nobles montagnards et prêtres éclairés ». 
(fonctions administratives et influence sur la puissante société populaire du chef-lieu), le ci-devant marquis de Villevielle reste une figure de ralliement majeure pour les jacobins lodèvois, afin qu'ils s'inscrivent dans un réseau plus vaste, national, pour continuer à exister politiquement. Des témoignages attestent de plusieurs séjours de Pavée chez Luchaire, et ce n'est pas, on s'en doute, pour y venir admirer les cultures de son hôte. Certes, les dénonciateurs de l'an IV rassemblent des rumeurs où s'expriment les haines et les ragots. Certaines informations restent invérifiables, tels des contacts supposés entre Luchaire et Cambon. En effet, la perquisition opérée à Montplaisir, en l'an III, est décevante pour $l^{\prime}$ historien ${ }^{17}$. Le juge de paix cherche, en vain, des éléments compromettants. Le buste de Marat est introuvable, la correspondance de Luchaire totalement absente. La famille du propriétaire - épouse, beau-père, beau-frère - assure, avec fermeté, sa défense et surveille avec attention la mise sous scellées, puis la fouille. Tout laisse penser qu'elle a fait disparaitre tout papier gênant. Aucune lettre n'est donc mentionnée et très peu d'ouvrages politiques. Seuls restent les nombreux travaux littéraires de Luchaire, dont on sait la passion pour les auteurs classiques, l'Antiquité et Rousseau, et dont la bibliothèque, à son apogée, comportait 4000 volumes.

Les documents datant de la Révolution sont finalement peu nombreux, limités à des pièces de théâtre, des brochures patriotes, pédagogiques ou techniques: catéchisme et alphabet républicain, manuel de fabrication de salpêtre. Les œuvres à succès du théâtre patriote suscitent l'intérêt de Luchaire, qui a conservé le célèbre Robert, chef des brigands, ainsi que ses suites. Cette présence atteste d'une diffusion d'une culture révolutionnaire commune parmi les administrateurs locaux ${ }^{18}$. Parmi les divers papiers recensés, une présence incite à la réflexion. L'ancien agent national du district de Lodève a mis de côté les appels nominaux concernant trois votes décisifs de la Convention : la condamnation de Louis XVI, la mise en accusation de Marat, et celle de Carrier. Ce type de document suscite généralement peu d'intérêt pour le chercheur tant il semble encombrer les dépôts d'archives. Mais sa conservation par Luchaire montre que ces appels nominaux pouvaient être utilisés par les camps en présence pour déterminer les positions politiques de chaque député, et savoir ainsi sur qui ils pouvaient compter. Ceci dit, mis à part un imprimé de Pavée et un écrit du conventionnel Noël Pointe, perdus dans le reste des papiers, aucun autre document ne laisse percevoir la poursuite des activités politiques de Luchaire après Thermidor. La cohésion de l'entourage montre son efficacité. En l'an IV, en face de leurs accusateurs, de nombreux témoins attestent du patriotisme et du souci de légalité d'une nébuleuse jacobine qui, avec Benoît cadet, contrôle encore la municipalité lodévoise. Quant aux réunions à Montplaisir, elles seraient simplement un moment récréatif où les principaux chefs politiques du lieu ne se rencontreraient que pour jouer aux boules...

La mobilisation électorale, les réunions pour préparer le renouvellement de la garde nationale sont niées, comme le port du bonnet rouge chez certains militants. Le républicanisme de ces néo-jacobins est donc difficile à appréhender, faute de sources. Mais des pratiques attestent d'une fidélité à une sociabilité et à des symboles dont $l^{\prime}$ héritage sera conséquent au $\mathrm{XIX}^{\mathrm{e}}$ siècle, ainsi la participation ponctuelle à des soupers, avec des toasts en l'honneur de la République et de personnalités. En 1795-1796, Robespierre, la constitution de 1793, seraient invoqués. Des toasts auraient été également prononcés en l'honneur de Babeuf et surtout de Drouet. L'hommage à ce dernier est intéressant, car l'homme de Varennes, beaucoup plus que le Tribun du Peuple, est une figure de ralliement pour ces républicains qui voient en lui l'incarnation de la Révolution et de la chute de la monarchie. Cette présence de Drouet, et d'autres révolutionnaires, dans la dite " conspiration de l'an IV » a sans doute suscité davantage l'intérêt des néojacobins lodévois que l'idéologie de Babeuf, plus éloignée de leurs pratiques politiques.

17. Archives départementales de l'Hérault, Q 756, Mise sous scellés et inventaire des papiers de Bernard Barthélémy Luchaire (9 et 19 prairial an III).

18. Ph. Bourdin, « Le brigand caché derrière les tréteaux de la Révolution. Traductions et trahisons d'auteurs ». 
Les néo-jacobins de Lodève se sont perçus comme les seuls républicains de leur cité, leurs adversaires étant confondus avec les royalistes. Suivant les aléas du Directoire, une partie de ces anciens dirigeants de l'an II continuent d'exercer des fonctions administratives et politiques au niveau local. Les choses sont plus difficiles pour les personnalités plus compromises ou plus isolées, tel Marat Delpon, redevenu Mathieu Fulcrand Delpon, artisan, chargé de famille, qui demande, vu ses difficultés pécuniaires, les secours dus aux « refugiés des isles ${ }^{19}$. Sous l'Empire, les néo-jacobins les plus en vue se retirent de la vie politique ou se montrent discrets. Luchaire se réfugie dans ses travaux littéraires, à Montplaisir, traduisant Virgile. Somme toute, les liens familiaux, culturels, politiques, ont permis de préserver la situation sociale de la plupart des néo-jacobins. La perte d'influence interviendrait sous la Restauration. Mais, en réalité, ce sont les dernières années de l'Empire qui atteignent ce réseau, bien plus que le retour de la monarchie. Les retards de paiement de l'État napoléonien plombent la manufacture lodévoise. La fin de la guerre sonne l'heure de la faillite pour de nombreuses maisons. Luchaire doit se séparer de Montplaisir. Lodève, centre d'un mouvement républicain, décline peu à peu, par l'effondrement de sa manufacture privée des commandes militaires. Cet effacement économique et politique laisse cependant un héritage républicain qui s'opposera, pendant tout le siècle, à un royalisme héraultais vigoureux: des descendants des néojacobins figurent, en effet, parmi les personnalités républicaines de l'Hérault du XIX ${ }^{\mathrm{e}}$ siècle.

\section{Résumé}

La complexité des réseaux politiques nés de la Révolution questionne les interactions entre héritages de l'ancien régime et innovations de la décennie 1789-1799. À Lodève, un réseau « jacobin » lie notabilités aisées, artisans modestes et notables villageois. Les clubs ont joué un rôle essentiel, mais aussi les administrations révolutionnaires, en l'an II, dans la consolidation de ce réseau, fragilisé ensuite par la répression du babouvisme. Malgré les aléas politiques du Directoire, puis de l'empire napoléonien, ces néo-jacobins laisseront un héritage politique conséquent pour les républicains du XIX ${ }^{\mathrm{e}}$ siècle. 


\section{Bibliographie}

Alzas Nathalie, La Liberté ou la mort. L'effort de guerre dans le département de l'Hérault pendant la Révolution. Aix, PUP, 2006.

BOURDIN Philippe, «Le brigand caché derrière les tréteaux de la Révolution. Traductions et trahisons d'auteurs ", Annales historiques de la Révolution française, $\mathrm{n}^{\circ} 364$, avril-juin 2011, p. 51-84.

Dubost Jean-François, «Le réseau des sociétés politiques dans le département de l'Hérault pendant la Révolution Française, 1789-1795 », Annales historiques de la Révolution française, $\mathrm{n}^{\circ} 278,1989$, p. 374-416.

FOURNIER Georges «Entre vallée de l'Hérault et vallée de la Garonne: les bastions fermement républicains sous le Directoire », Révolution et Contre-Révolution dans la France du Midi (1789-1799). Toulouse, PU du Mirail, 1991, p. 181-203.

GAINOT Bernard, 1789, un nouveau jacobinisme ? Paris, CTHS, 2001.

IAFELICE Michel-André, «Le Babouvisme en province. Les abonnés méridionaux au Tribun du Peuple », Cahiers d'histoire, n¹7, 1984, p. 94-114.

LeROY-BeAulieu Henry, «Les propriétaires de Montplaisir ou la rencontre de la technique de la politique et de l'économie », Bergasse Jean-Denis, (dir.) Hommage à Jacques Fabre de Morlhon. Mélanges historiques et généalogiques, Rouergue et Bas-Languedoc, Albi, osi, 1978 , p. $225-269$.

Michel Henri, Albert Roch Gérard, Cosson Armand, Grands notables du Premier Empire, Gard Hérault Drôme, Paris, CNRS, 1980.

SAGNES Jean, « Figures de révolutionnaires languedociens, nobles montagnards et prêtres éclairés ", La Révolution vécue par la province. Mentalités et expressions populaires en Occitanie, Actes du colloque de Puylaurens, CIDO, Béziers, 1990, p. 107-125.

TACKETT Timothy, Par la volonté du peuple. Comment les députés de 1789 sont devenus révolutionnaires. Paris, Albin Michel, 2007. 


\section{Illustrations}

Figure 1

\section{Bernard-Barthélemy Luchaire, jacobin lodévois et ses différents réseaux}

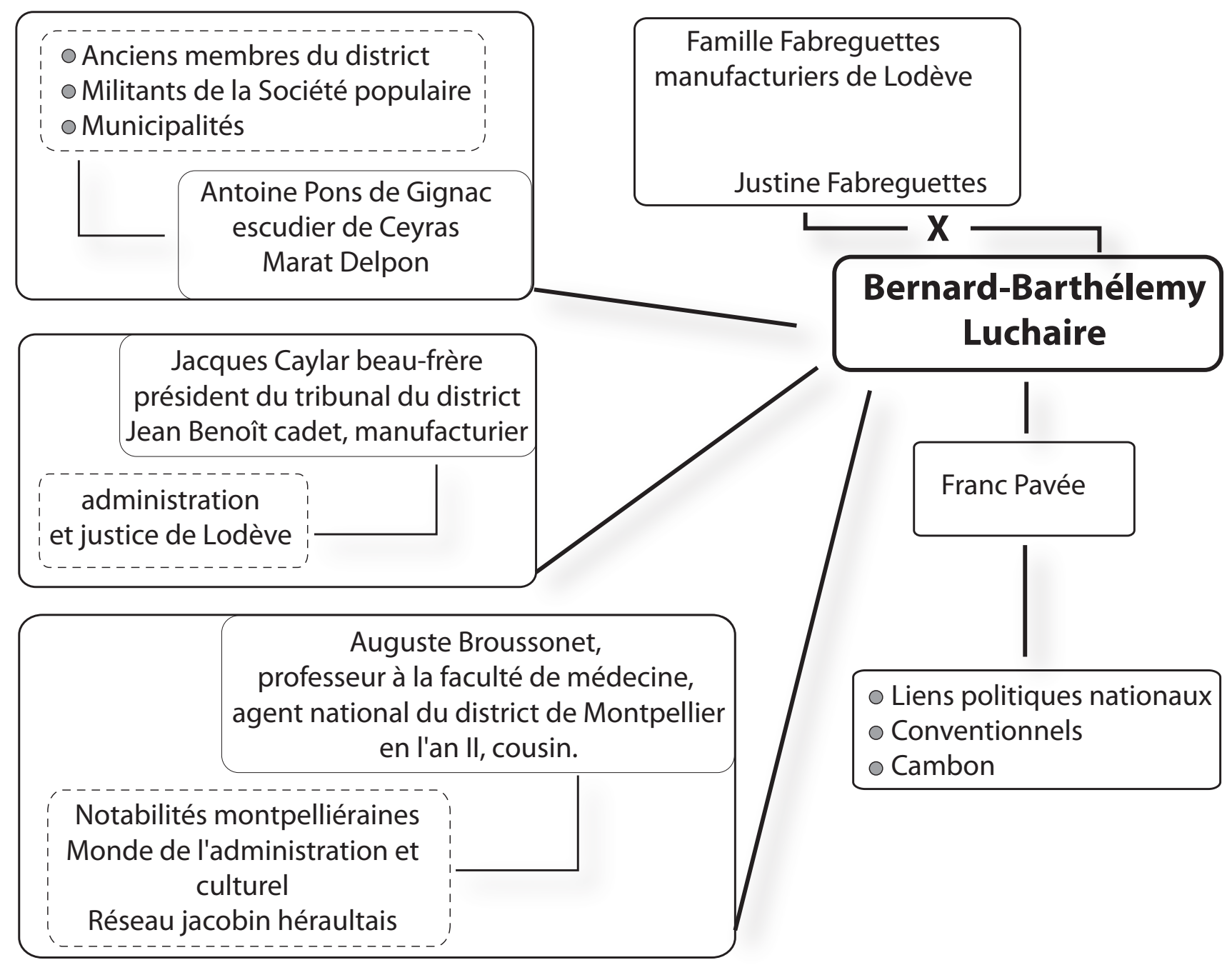




\title{
La Société des saisons : un réseau républicain sous la monarchie de Juillet
}

\author{
Jérôme LOUIS \\ Docteur en histoire, membre de l'Institut Napoléon \\ Extrait de : Henri BRESC (dir.), Réseaux politiques et économiques, Paris, \\ Édition électronique du CTHS (Actes des congrès des sociétés historiques et scientifiques), 2016. \\ Cet article a été validé par le comité de lecture des Éditions du CTHS dans le cadre de la publication \\ des actes du $140^{\circ}$ Congrès national des sociétés historiques et scientifiques tenu à Reims en 2015.
}

Des émeutes éclatent à Paris du 24 au 26 février 1834. Le gouvernement attribue ces mouvements aux partis d'opposition. Il les accuse de perpétuer l'agitation à Paris et des Canuts de Lyon, voire d'épauler le mouvement républicain des étrangers réfugiés en Suisse qui fomentent la révolution en Savoie et au Piémont ${ }^{1}$. Le 13 mars 1834, une loi interdit les associations de plus de 20 personnes. La Société des droits de l'homme et les républicains sont visés. Les débats attisent les peurs à l'égard des sociétés politiques de la Révolution. Ces « cavernes ténébreuses » attisant l'assassinat, la révolte, représentent des "souvenirs hideux» pour Lamartine, «odieux» pour Dumon, «terribles » pour Rémusat $^{2}$. En avril 1834, une insurrection fomentée par les sociétés secrètes éclate à Paris, Lyon et Saint-Étienne. Après le massacre de la rue Transnonain, la répression s'organise. L'attentat de Fieschi le 28 juillet 1835 pousse le gouvernement à faire voter «les lois infernales » qui limitent la liberté de la presse et facilitent la répression des délits politiques. Ce rétablissement de la censure ne respecte pas l'article 7 de la Charte. La loi du 10 avril 1834 aggrave les dispositions du code pénal. Désormais, les membres d'associations divisées en sections de moins de 20 personnes encourent de lourdes amendes et des peines de prison. La monarchie de Juillet subit les attaques répétées des républicains. Le 25 juin 1836, Alibaud tente d'assassiner le roi Louis-Philippe ${ }^{3}$, le 27 décembre Meunier qui a fait partie de la Société des familles tire sur la voiture du monarque, en 1837, Hubert prépare une nouvelle machine infernale. Le pouvoir décèle d'interminables complots.

\section{De la Société des droits de l'homme à la Société des saisons}

\section{La Société des familles et le complot des poudres}

La Société des droits de l'homme pilotait le mouvement anarchiste et républicain. Pépin, un des complices de Fieschi, avant de monter sur l'échafaud, signale au président de la Chambre des pairs l'existence d'une nouvelle société secrète. La Société des familles est fondée en juillet 1834. Les organisateurs de ce réseau sont Barbès et Blanqui, rejoints ensuite par l'étudiant en médecine Lamieussens et par Martin Bernard. Martin Bernard est sensible aux idées saint-simoniennes et à celles de Pierre Leroux. Ouvrier typographe, il participa à une grève des imprimeurs parisiens en 1833. En 1834, il publia un article dans la Revue républicaine intitulé :

1. La France parlementaire, (1834-1851), auvres oratoires et écrits politiques par Alphonse de Lamartine, Paris, tome I, 1864, Chambre des députés, séance du 13 mars 1834. Sur la loi contre les associations.

2. R. Huard, La naissance du parti politique en France, p. 77.

3. Dans la Revue Rétrospective de Taschereau, l'auteur affirme qu'on ignorait dans les sociétés secrètes le projet d'Alibaud. C'était une affaire isolée « car un assassinat ne peut être l'affaire d'un complot. " Revue Rétrospective, p. 4-5. 
«Sur les moyens de faire descendre la République dans l’atelier. »

La cérémonie d'initiation de Martin Bernard a lieu dans les catacombes de la rue Vaugirard $^{4}$ et son parrain est un ami de Fulgence Girard, Benjamin Vignerte. Il est 1'un des défenseurs des accusés d'avril 1835 et il prend rapidement part à la direction de la Société des familles comme le rappelle le préfet de police Gisquet ${ }^{5}$. Le 10 mars 1836, Barbès et Blanqui sont arrêtés par la police en train de charger des cartouches dans l'appartement qu'ils partagent, rue de l'Oursine, à Paris. On appréhende Beaufour et Robert, deux anciens saint-simoniens, ainsi que Robier, Canard et Daviat, étudiants en droit. Blanqui et Beaufour sont condamnés à deux ans de prison, deux ans de surveillance et 3000 francs d'amende. Lamieussens et Barbès le sont à un an de prison. Les autres écopent de sept à huit mois de prison. Martin Bernard est acquitté car il n’y a pas de preuves contre lui.

La Société des saisons est un réseau républicain clandestin actif sous la monarchie de Juillet qui poursuit l'action de la Société des familles. Martin Bernard, admirateur de Robespierre, joue un rôle primordial dans sa création, car Barbès et Blanqui sont emprisonnés. Dès le début de l'année 1837, il regroupe des membres de la Société des familles restés libres, d'autres rejoignent les Phalanges démocratiques dirigées par Mathieu d'Épinal, Pornin et Vilcocq. Le secret est érigé en principe absolu. Martin Bernard trouve le moyen de communiquer avec Blanqui «soit par lui-même, soit par des intermédiaires sûrs $»^{6}$. Le 8 mai 1837, une amnistie donne des troupes et des chefs à la nouvelle société secrète. La libération des comploteurs a été votée par la Chambre et promulguée par Louis-Philippe à l'occasion du mariage de son fils aîné le duc d'Orléans avec la princesse Hélène de Mecklembourg. Le jeune couple aux idées libérales a demandé cette faveur au roi. L'événement doit être un moment de réconciliation entre les Français. Blanqui et Barbès sont libérés. Blanqui reste sous résidence surveillée. Il s'installe à Gency près de Pontoise. Barbès a purgé sa peine à Carcassonne et il revient à Paris où il participe aux Saisons, ce qui lui vaut d'être arrêté, puis relâché à la suite d'un non-lieu. Il regagne sa propriété de Fourtou, dans le Midi.

\section{L'engagement solennel dans la Société des saisons}

Les nouveaux membres de la société secrète des Saisons sont accueillis lors d'une cérémonie initiatique. Le récipiendaire est reçu les yeux bandés. Comme dans les associations maçonniques, les hommes s'appellent frères. Le président demande au citoyen de se présenter, de donner son âge, sa profession, son lieu de naissance, sa domiciliation et ses moyens financiers. Le postulant doit avoir mûrement réfléchi. Le secret est exigé. Le président pose une série de questions au postulant qui doit prouver son attachement aux valeurs révolutionnaires. Ainsi, il faut répondre sur ce que l'on pense de la royauté et des rois :

«Qu'ils sont aussi dangereux pour le genre humain que le tigre pour les autres animaux. » ${ }^{7}$

Il convient d'affirmer que :

«L'aristocratie de naissance a été abolie en juillet 1830. Elle a été remplacée par l'aristocratie $\mathrm{d}^{\prime}$ argent, qui est aussi vorace que la précédente. ${ }^{8}$

Le but de l'association est de rétablir la république. Accepté, le sectionnaire prête serment :

4. C. Latta, Un Républicain méconnu, Martin Bernard: 1808-1883, p. 38.

5. H. Gisquet, Mémoires de M. Gisquet, ancien préfet de police, p. 34-35.

6. L. de la Hodde, Histoire des sociétés secrètes et du parti républicain de 1830 à 1848, p. 219.

7. Procès des accusés des 12 et 13 mai 1839, Paris, Pagnerre, 1839, p. 220.

8. Ibid. 
«Au nom de la République, je jure haine éternelle à tous les rois, à tous les aristocrates, à tous les oppresseurs de l'humanité. Je jure dévouement absolu au peuple, fraternité à tous les hommes, hors les aristocrates, je jure de punir les traîtres ; je promets de donner ma vie, de monter même sur l'échafaud, si ce sacrifice est nécessaire pour amener le règne de la souveraineté du peuple et de l'égalité. ${ }^{9}$

Le président lui met un poignard dans la main. L'engagement se poursuit :

«Que je sois puni de la mort des traîtres, que je sois percé de ce poignard si je viole ce serment. Je consens à être traité comme un traitre, si je révèle la moindre chose à quelque individu que ce soit, même à mon plus proche parent, s'il n'est point membre de l'association. $»^{10}$

Le récipiendaire reçoit un numéro d'inscription et doit se procurer armes et munitions. Chaque initié prend un nom de guerre ${ }^{11}$. Blanqui est le commandant en chef de l'armée républicaine. La plus petite subdivision de l'association forme une Semaine. Elle se compose de six hommes et d'un chef appelé Dimanche. Quatre Semaines réunies composent un Mois, 28 hommes sont placés sous la direction d'un responsable nommé Juillet. Trois Mois forment une Saison commandée par un supérieur appelé Printemps. Enfin, quatre Saisons deviennent une Année à la tête de laquelle se trouve un agent révolutionnaire. Un bataillon est fort de 336 hommes $^{12}$. Lucien de la Hodde, agent secret de la Préfecture de police, confie que «le système d'isolement pratiqué dans les Familles fut abandonné et fit place à des réunions indéterminées ${ }^{13}$. Ces rencontres ont lieu chez des mastroquets sous l'autorité d'un responsable qui vient donner ses instructions et délivrer un discours mobilisateur. La conspiration dans le peuple se plaît beaucoup le verre à la main ${ }^{14}$.

Outre les réunions régulières, une revue est organisée où l'agent révolutionnaire inspecte ses troupes. Pour l'occasion, on retient une grande voie jalonnée d'immeubles comme la rue Saint-Honoré ${ }^{15}$. Les hommes sont disséminés dans les rues latérales. Les chefs se tiennent au bord de la ligne principale et attendent. Dans chaque recoin, les chefs de la Société des saisons sont visités. Ils rendent compte des effectifs. Chaque membre se tient prêt pour le combat. Afin d'éviter les erreurs de la Société des familles, on prévoit de distribuer les munitions au dernier moment. Il ne faut pas éveiller les soupçons de la police ou être dénoncé ! Il est interdit de conserver toute trace écrite faisant référence à l'association.

\section{Les ramifications de la société secrète}

La Société des saisons se développe à Paris et en province. Les ouvriers ne rejoignent pas massivement ses rangs car ils ne sentent pas le besoin, «leur journée finie, de se livrer à des exercices politiques qui offraient des dangers clairs et des avantages fort obscurs ${ }^{16}$. Barbès l'implante à Carcassonne. Alberny est chargé de recruter dans cette ville. Après plusieurs mois de propagande, les Saisons recrutent à peine 500 personnes.

Barbès veut la grandeur de la France à l'extérieur. Il s'inquiète de voir grandir la puissance des Anglo-Saxons au détriment de la France, "la patrie du devoir, de l'égalité, de Jeanne d'Arc et du socialisme ${ }^{17}$. La Ligue des justes est une branche allemande du réseau. Ce groupe socialiste fondé en 1836 à Paris par des Allemands exilés, se fixe comme objectif de libérer les États allemands de l'oppression et de mettre un terme aux

9. Ibid., p. 221.

10. Ibid.

11. L'Ami de la religion, samedi 15 juin 1839 , p. 525 .

12. L. de la Hodde, Histoire des sociétés secrètes et du parti républicain de 1830 à 1848, p. 217.

13. Ibid.

14. Ibid.

15. La rue Saint-Honoré fut le théâtre des premiers combats des Trois Glorieuses.

16. L. de la Hodde, Histoire des sociétés secrètes et du parti républicain de 1830 à 1848, p. 220.

17. I. Tchernoff, Le Parti républicain sous la monarchie de Juillet, p. 363. 
divisions de l'humanité. Wilhelm Weitling, ouvrier tailleur suisse immigré en France depuis 1834, appartenant à la Ligue des bannis, est le principal théoricien de la Fédération des justes ou Bund des Gerechten. Ses principaux membres sont le cordonnier Heinrich Bauer, le typographe Karl Schapper, l'horloger Joseph Moll, le poète Germain Mœurer, le bottier Austen, le ferblantier Daniel Mayer.

Des proclamations sont imprimées. La première est intitulée $A u$ peuple. Elle est affichée sur les murs des quartiers de Paris en avril 1837. Elle a pour but d'inciter les ouvriers à se révolter. On y lit :

« N'avez-vous pas été trompés? Un autre Bourbon, entouré d'une poignée d'intrigants, ne vous a-t-il pas frustré de tous les avantages de votre victoire? Levez-vous, ouvriers, sortez de ce honteux et imprudent repos! Levez-vous pour briser le joug de la royauté et des Bourbons [...] pour émanciper le monde, pour le purger des crimes de la royauté, pour proclamer la république ! ${ }^{18}$

Des fabriques de cartouches sont établies rue Dauphine et rue Neuve-des-Bons-Enfants, ancien nom de la rue Radziwill. Le Moniteur républicain, qui compte huit numéros (novembre 1837-juillet 1838) ou l'Homme libre qui a quatre numéros (août-septembre 1838) relaient les idées de l'association. Le Moniteur républicain imprimé sur deux colonnes, est orné d'une vignette représentant la Liberté armée d'un fusil, assise sur des pavés et des barricades. On lit, à droite du fleuron : Unité, Égalité, Fraternité ; à gauche : Prudence, Courage, Persévérance ; au bas de la dernière ligne figurent : Imprimerie de la République. Le premier numéro publie la profession de foi :

«[...] Nous attaquerons le principe et la forme de gouvernement établi le 7 août 1830 par les 219 usurpateurs de la souveraineté nationale ; nous parlerons contre la royauté, contre le ridicule respect dû à la Charte et aux lois bâclées contre le peuple par MM. les ventrus tricolores $[\ldots] »^{19}$

On y enseigne que la République n'est pas un but, mais un moyen et qu'elle sera une réalité lorsque la terre appartiendra à tout le monde. Ces journaux sont jetés dans les boutiques, sous les portes, dans les allées des maisons et des exemplaires sont même envoyés par la poste. Des lettres sont envoyées un peu partout en France pour recruter des révolutionnaires. On les incite à venir dans la capitale pour s'enivrer « du parfum de la poudre à canon, de l'harmonie du boulet et de la conduite extra muros de la famille royale ${ }^{20}$. La réussite est garantie. "Nous sommes vingt-quatre millions de pauvres, écrit $l^{\prime}$ Homme libre dans son quatrième numéro, et nos ennemis sont en petit nombre ${ }^{21}$. Le 29 septembre 1838, Jean-Baptiste Guillemin, ouvrier typographe, est arrêté au moment où il travaille avec deux autres individus au tirage du quatrième numéro de l'Homme libre. Voyant l'officier de police, il se saisit d'un poignard qu'il porte à la ceinture de son pantalon. Il est traduit devant la cour d'assises de la Seine ${ }^{22}$.

Barbès est dans l'Aude pour la campagne électorale. Il souhaite retarder le moment d'agir. Duchâtel, le ministre de l'Intérieur, fait surveiller la Société des saisons et la Société des montagnards. Les Phalanges démocratiques et les Montagnards reprochent à la Société des saisons d'être passive. Cela la détermine à tenter l'insurrection du 12 mai $1839^{23}$. Roque, au 117 de la rue Montmartre, fond des balles et fabrique des cartouches. Les conjurés projettent de marcher sur les Tuileries et ne parlent que de République de 93 et de massacres. Le 23 avril 1839, la faction de Jean rejoint celle de Martin Bernard. Le 8 mai,

18. Rapport fait à la Cour les 11 et 12 juin 1839, par M. Mérilhou.

19. A. Zévaès, Une révolution manquée: l'insurrection du 12 mai 1839, p. 49.

20. L'Ami de la religion, samedi 15 juin 1839, évocation d'une lettre adressée à Marescal par Moulines le 4 avril 1839.

21. J. Jaurès, E. Fournière, Histoire socialiste, tome VIII, p. 344.

22. Archives nationales, BB21 442. Guillemin est condamné le 12 juin 1839 à cinq ans de prison pour délits politiques. Il est détenu au Mont-Saint-Michel à partir du 28 octobre 1839. Louis-Philippe lui accorde la grâce le 22 août 1841.

23. I. Tchernoff, Le Parti républicain sous la monarchie de Juillet, p. 375-376. 
Kenner, employé du National annonce qu'il a sondé les sous-officiers du $4^{\mathrm{e}}$ cuirassiers à Versailles et qu'ils pourraient se joindre au coup de force républicain. Des contacts sont établis avec des sous-officiers du $2^{\mathrm{e}}$ carabiniers $^{24}$.

Les chefs de la Société des saisons prévoient de prendre les armes le 5 mai 1839. Blanqui recule la date de huit jours. Il attend la relève de la garnison parisienne et mise sur l'inexpérience des soldats qui auraient des difficultés pour retrouver leur chemin dans le lacis des vieilles rues. Barbès est appelé par Blanqui à rejoindre Paris. Il tergiverse. Dans le second billet, Blanqui aurait écrit à Barbès que s'il ne revient pas, leurs amis diront qu'il est un lâche.

\section{L'insurrection des 12 et 13 mai 1839}

\section{Un rendez-vous manqué ?}

L'insurrection éclate le 12 mai 1839. Cette journée a été longuement méditée. Mille deux cents hommes ont été recrutés par la Société des saisons ${ }^{25}$. Le rassemblement est fixé à midi au coin de la rue Mandar et de la rue Montorgueil, rue Bourg-l'Abbé et rue Saint-Martin, en face du numéro 10. Ils sont seulement 300 à se présenter au rendez-vous. Ils sont censés s'être procuré un fusil chacun. Ils n'en ont pratiquement pas! Un va-et-vient a lieu entre les groupes. Les retardataires vont arriver. Vers 14 h 30, une vingtaine d'individus réunis au café Montmorency correspondent par les fenêtres du premier étage par signes avec d'autres qui se trouvent chez un marchand de vin. La Société des ouvriers chapeliers semble se joindre au mouvement.

Vers 15 heures, Martin Bernard, Ferrari, Labaume et d'autres sont aperçus en train de charrier une caisse en bois blanc. Ils la placent au milieu de la rue Bourg l'Abbé. Ils soulèvent le couvercle et distribuent entre 60 et 80 pistolets d'arçon. Au fond de la caisse se trouve un drapeau rouge dont un individu de 36 ans, forts favoris et collier brun, redingote vert-russe, casquette bleue, $\mathrm{s}^{\prime} \mathrm{empare}^{26}$. Blanqui installe un guidon rouge à son pistolet. Les chefs regroupent leurs hommes près de la boutique de l'armurier Lepage, à quelques centaines de mètres de leur dépôt de cartouches situé rue Quincampoix. Ils se dirigent vers le poste du Palais de justice dont ils s'emparent et tuent l'officier de service. Une proclamation est lue aux insurgés sur les marches de l'Hôtel de ville de Paris :

«Aux armes, citoyens!

L'heure fatale a sonné pour les oppresseurs. Le lâche tyran des Tuileries se rit de la faim qui déchire les entrailles du peuple; mais la mesure de ses crimes est comble. Ils vont enfin recevoir leur châtiment.

La France trahie, le sang de nos frères égorgés, crie vers vous, et demande vengeance; qu'elle soit terrible, car elle a trop tardé. Périsse enfin l'exploitation, et que l'égalité s'asseye triomphante sur les débris confondus de la royauté et de l'aristocratie.

Le gouvernement provisoire a choisi des chefs militaires pour diriger le combat; ces chefs sortent de vos rangs, suivez-les ! ils vous mènent à la victoire.

Sont nommés :

Auguste Blanqui, commandant en chef,

Barbès, Martin Bernard, Quignot, Meillard, Nétré, commandants des divisions de l'armée républicaine.

Peuple, lève-toi ! et tes ennemis disparaîtront comme la poussière devant l'ouragan.

24. Archives nationales, fond Duchâtel, 2AP/27/dossier 3. Renseignements confidentiels sur les menées des principaux membres de la Société des saisons et de celle des Montagnards, depuis le 1er avril jusqu'au jour de l'insurrection.

25. J. Jaurès, E. Fournière, Histoire socialiste, p. 343.

26. Archives nationales, fond Duchâtel, $2 \mathrm{AP} / 27 /$ dossier 3 . Renseignements confidentiels sur les menées des principaux membres de la Société des saisons et de celle des Montagnards, depuis le 1er avril jusqu'au jour de l'insurrection. 
Frappe, extermine sans pitié les vils satellites, complices volontaires de la tyrannie; mais tends la main à ces soldats sortis de ton sein, et qui ne tourneront point contre toi des armes parricides.

En avant! Vive la République!

Les membres du gouvernement provisoire. Barbès, Voyer d'Argenson, Auguste Blanqui, Lamennais, Martin Bernard, Dubosc, Laponneraye.

Paris, le 12 mai 1839. $»^{27}$

Cet appel a peu de succès. D'Argenson, vétéran républicain retiré de la vie politique, et l'abbé Lamennais ignorent cette décision de les appeler au gouvernement ${ }^{28}$. Laponneraye, fondateur du périodique L'Intelligence, et Dubosc sont en prison !

Quelques centaines de personnes se joignent aux émeutiers. Vers 17 h 15, une douzaine de conspirateurs arrivent rue Tiquetonne. Ils dépavent la voie et construisent des barricades. Pierre Lognon, marchand de vin au numéro 4, ferme sa boutique ${ }^{29}$. Les insurgés cassent un carreau et le marchand doit leur ouvrir sa porte. Ils veulent boire, ils fouillent la maison et ils s'emparent de son fusil de garde national. La troupe arrive et ils déguerpissent, après avoir échangé des coups de feu. Victor Hugo raconte ce qu'il voit des événements en sortant de son appartement. Il remarque, parmi les émeutiers, beaucoup d'enfants de 14-15 ans, qui ne savent pas charger leur fusil ou qui ne peuvent pas le porter. Il écrit dans Choses vues :

«Un de ceux qui ont tiré rue de Paradis est tombé sur son derrière après le coup. » ${ }^{30}$

Dans les Misérables, une anecdote est rapportée :

«Lors de l'insurrection du 12 mai 1839, rue Saint-Martin, un petit vieux homme infirme, traînant une charrette à bras surmontée d'un chiffon tricolore dans laquelle il y avait des carafes remplies d'un liquide quelconque, allait et venait de la barricade à la troupe et de la troupe à la barricade, offrant impartialement - des verres de coco - tantôt au gouvernement, tantôt à l'anarchie. ${ }^{31}$

Des magasins d'armes sont pillés. La Préfecture de police de Paris, le marché Saint-Jean et le poste de la place du Châtelet sont attaqués. Sur la barricade de la rue Saint-Denis, se trouvent Fombertaux, Vallière, Herbulet, le compositeur Guénot et un homme connu dans le quartier Beaubourg sous le nom de Chasseur d'Afrique. Des omnibus et des fiacres sont renversés. La police est repoussée. La troupe intervient. Ledoux, un garde national est tué. Un garde municipal est abattu rue Bourg l'Abbé. Le lieutenant-colonel Pellion, aide de camp du ministre de la Guerre est blessé à la place du Châtelet et transporté à l'hospice Saint-Louis. On lit dans le Charivari :

«À l'heure où nous écrivons, on avait déjà apporté à l'Hôtel-Dieu plus de vingt blessés, dont la moitié appartenait à l'armée. On remarquait parmi les autres des femmes et des vieillards. Plusieurs amputations ont été pratiquées, et malheureusement un grand nombre de ces blessés ont déjà succombé. $»^{32}$

Le maréchal Gérard prend le commandement de la garnison. La troupe intervient brutalement. Piéfort est atteint d'un coup de feu. Focillon et d'autres le transportent dans une maison de la rue de la Vieille Tannerie. Ces membres de la Société des saisons y sont arrêtés $^{33}$. Parmi les chefs de la révolte, Guignot et Meillard sont blessés. Barbès est touché par une balle au sommet du front, sur la barricade de la rue Greneta. On l'arrête les

27. Rapport Mérilhou cité par C. Latta, Un Républicain méconnu, Martin Bernard : 1808-1883, p. 56.

28. B. H. Moss, "Society of the Seasons", in E. L. Newman (ed.), Historical Dictionary of France from the 1815 Restoration to the Second Empire, p. 1007.

29. Cour des pairs. Attentat des 12 et 13 mai 1839, p. 23. Procès-verbal du commissaire de police Frédéric-André Petit.

30. V. Hugo, Choses vues 1830-1848, p. 140.

31. V. Hugo, Les Misérables, tome IV, p. 345.

32. Le Charivari du lundi 13 mai 1839.

33. Archives nationales, BB21 502. Parquet de la Cour Royale de Paris, 12 juin 1847. 
mains noires de poudre et la figure couverte de sang. Les insurgés ne parviennent ni à atteindre leurs objectifs, ni à déclencher une révolution. Alexandre Quarré, 23 ans, à la tête d'un mois avec le titre de Juillet, reconnaît avoir suivi passivement les rassemblements. Il a été inactif car son chef de saison est absent ${ }^{34}$. Le 13 mai, des agitateurs transportent un cadavre qu'ils veulent déposer dans la cour de l'École polytechnique. Le général Tholozé qui commande cette institution parvient à les repousser, non sans mal. Durant ces deux journées, on relève 77 tués et au moins 51 blessés du côté des insurgés, 28 morts et 62 blessés chez les militaires.

\section{Une bonne opération pour le gouvernement?}

Le président du Conseil Mathieu Molé a été battu aux élections. Les barricades n'ont pas tenu deux jours mais selon Jacques Bainville, l'agitation parlementaire a réveillé le parti de la Révolution. Jules Michelet évoque dans sa correspondance ces journées tragiques :

" Je suis heureux de voir que l'échauffourée de Paris n'ait pas eu son contrecoup à Lyon. Nous ne sommes pas quittes encore. Mais les associations qui ont pris ici un grand développement ne sont pas, je crois, très fortes hors de Paris. ${ }^{35}$

Bernard et Blanqui se soustraient aux forces de l'ordre, respectivement jusqu'aux 21 juin et 14 octobre. Les sections de la branche allemande sont entrainées dans la défaite. Karl Schapper et Heinrich Bauer sont pris ${ }^{36}$. Le gouvernement de Louis-Philippe les expulse, après une longue détention et ils s'exilent à Londres. Les Montagnards n'ont pas participé aux événements de 1839. Infiltrés par des policiers provocateurs, ils auraient abandonné puis poussé la Société des saisons à fomenter l'émeute pour permettre au gouvernement de se reconstituer, après l'interrègne ministériel issu des luttes de la coalition contre Molé, et de rallier la bourgeoisie autour de Louis-Philippe ${ }^{37}$.

La révolte a échoué mais la situation politique est renversée. Dès les premiers coups de fusil, Louis-Philippe a fait appeler le maréchal Soult et lui a dit :

«Maréchal, l'eau se trouble. Il faut pêcher des ministres. ${ }^{38}$

Un nouveau gouvernement est constitué sous la présidence de Soult, accouru l'un des premiers aux Tuileries pour témoigner son soutien au régime. Soult se frotte les mains et avec son accent méridional, il dit au roi :

«Cetté fois, sire, Jé crois qué nous férons notré coup ! ${ }^{39}$

Teste est nommé à la Justice, Schneider à la Guerre, Duperré à la Marine, Duchâtel à l'Intérieur, Cunin-Gridaine au Commerce, Dufaure aux Travaux publics, Villemain à l'Instruction publique et Passy aux Finances. Des secours sont accordés par le ministre de l'Intérieur à des victimes des événements des 12 et 13 mai 1839. La somme allouée va de 100 à 1000 francs. La femme d'un gardien de marché tué le 12 mai reçoit 200 francs. Muirson (fils), un Anglais blessé reçoit 300 francs $^{40}$.

\section{Les insurgés face à la Justice}

Des insurgés blessés sont soignés à l'Hôtel-Dieu. Un malheureux doit avoir la jambe amputée mais au moment où l'on s'apprête à l'opérer, un juge d'instruction assisté d'un greffier et d'un huissier déboule pour l'interroger. Le juge déclare :

34. Ibid., BB21 439. Rapport au Garde des Sceaux, 30 avril 1841.

35. J. Michelet, Correspondance générale, tome III, 54, à Quinet, 22 mai 1839.

36. K. Marx, « Révélations sur le procès des communistes de Cologne », L'Allemagne en 1848, p. 259.

37. É. Cabet, Le cataclysme social, cité par I. Tchernoff, Le Parti républicain sous la monarchie de Juillet, p. 376.

38. V. Hugo, Choses vues, p. 141.

39. Ibid., p. 141.

40. Archives nationales, fond Duchâtel, 2AP/27/dossier 3. 
«Cet homme est un insurgé ; il appartient à la justice. »

L'élève médecin rétorque que le malade a besoin de ménagements car la gangrène le dévore. Le juge insiste :

«Un petit interrogatoire ne lui ferait pas de mal. » ${ }^{41}$

L'élève s'oppose car la vie de son patient est en jeu. Le juge propose de mener les deux opérations en même temps :

«Ainsi, au lieu de lui couper la jambe, donnez-lui seulement... un clysobol. Je pourrai l'interroger par-devant pendant que vous lui administrerez la chose par-derrière. »

Le juge demande à être obéi et demande le nom du soignant qui lui assène s'appeler médecin. Un infirmier est interrogé et refuse de répondre. Il n'est pas un cafteur. Un agent de police depuis son lit dit le connaître, lorsqu'un élève qui le panse, lui applique un cataplasme sur la bouche. La force armée arrive et le juge la requiert. Un garde municipal, au bout de la salle, sur son "plumard", crie :

«Quel tapage, sacrédié ! Laissez-nous donc un peu la paix, mon juge! Le camarade insurgé et moi, nous nous racontons les détails de la chose et les actes de bravoure réciproques. Mais vous faites un sabbat qu'il n'y a pas moyen de s'entendre, quoi ! ${ }^{42}$

Le juge se retire. L'inhumanité de ses méthodes oblige les élèves médecins à rédiger une pétition adressée aux membres du conseil d'administration des hospices. L'élève conclut qu'il faudrait débaptiser l'Hôtel-Dieu et le nommer Hôtel-Diable en raison de l'inquisition du pouvoir policier et judiciaire.

Le procès, devant la Chambre des pairs, détermine les responsabilités. Emmanuel Arago et Dupont défendent Barbès et Martin Bernard. Plus de 750 dossiers d'inculpés aux procès se retrouvent devant la Cour des pairs. Du 14 mai au 30 juillet 1839, se tient un premier procès de 19 accusés. Un second procès de 34 autres accusés a lieu du 6 décembre 1839 au 4 février 1841. Dans son réquisitoire, Franck Carré insiste sur le meurtre du lieutenant Drouineau et Barbès est un assassin. Ce dernier rompt le silence et déclare au moment où l'interrogatoire du président le presse :

«Quand l'Indien est vaincu, quand le sort de la guerre l'a fait tomber au pouvoir de son ennemi, il ne songe point à se défendre, il n'a pas recours à de paroles vaines : il se résigne et donne sa tête à scalper. ${ }^{43}$

Pasquier observe que l'accusé a raison de se comparer à un sauvage. Barbès rétorque que le barbare est le scalpeur. "Je suis vaincu, tuez-moi », déclare-t-il ${ }^{44}$. Il attend son sort en prison. À la lecture de l'arrêt qui le frappe, il demande avec angoisse si Martin Bernard est condamné à mort. Il apprend avec joie que son ami a la vie sauve. Un bruit dans la prison lui fait croire que le moment est venu, il s'écrie :

«Saint-Just, Robespierre, Couthon, Babeuf, et vous aussi, mon père, ma mère, qui m'avez porté dans vos entrailles, priez pour moi, voici mon jour de gloire qui vient $! »^{45}$

Barbès et Blanqui sont condamnés à mort. La déportation attend Martin Bernard. La sœur de Barbès, Mme Carle, sollicite la clémence du monarque. Elle demande l'aide de Lamartine. L'intercession de Montalivet lui permet d'être reçue par Louis-Philippe qui lui dit que la décision ne dépend pas que de lui. Le Conseil des ministres souhaite laisser la justice suivre son cours. Des manifestations publiques réclament l'abolition de la peine de

41. Le Charivari du samedi 18 mai 1839.

42. Ibid.

43. Procès des accusés des 12 et 13 mai 1839 , p. 115.

44. P.-J. Proudhon, Les Confessions d'un révolutionnaire, p. 167.

45. J. Jaurès, E. Fournière, Histoire socialiste, p. 351-352. 
mort. Des lettres anonymes menacent la reine et ses enfants. Un Anglais qui a assisté au procès offre 100000 francs pour aider à l'évasion de Barbès ${ }^{46}$. Victor Hugo intervient auprès de Louis-Philippe. Son placet s'appuie sur la mort de la princesse Marie et sur la naissance du comte de Paris :

«Par votre ange envolé ainsi qu'une colombe! Par ce royal enfant, doux et frêle roseau! Grâce encore une fois! Grâce au nom de la tombe ! Grâce au nom du berceau ! " ${ }^{47}$

Le poème fait florès. Les peines sont commuées en déportations au Mont Saint-Michel.

\section{Le devenir de l'ancienne Société des saisons jusqu'en 1848}

\section{La Société des communistes et l'attentat de Darmès}

Depuis les journées des 12 et 13 mai 1839, les autorités redoutent des vengeances. En décembre, de nouvelles Saisons se forment avec Henri Dourille et Lucien de la Hodde. Ce dernier est un policier infiltré dans les rangs républicains. Lors de l'attentat de Darmès du 15 octobre 1840, les sociétés secrètes ressurgissent violemment. Elles changent de noms. À la Société des droits de l'homme a succédé la Société des saisons et à cette dernière celle des Communistes ${ }^{48}$. Les dénominations de Semaines, Mois, Printemps sont remplacées par les mots Métiers, Ateliers, Fabriques. Trois factions existent: les communistes, les réformistes les plus modérés et les égalitaires, les plus violents auxquels appartiennent Darmès et Quénisset ${ }^{49}$. Une autre société secrète se constitue autour de la rédaction de l'Humanitaire et un rapport parle des Bastilles, probablement une section de la Société des communistes. L'enquête met en cause le cocher Duclos qui est un membre influent des réseaux clandestins depuis $1832^{50}$. Il serait lié à Darmès. Après une perquisition, on retrouve chez Duclos, un papier où il est inscrit :

« Reçu du citoyen président 4 francs, 13 décembre 1832. Signé Delente. » ${ }^{51}$

L'examen découvre qu'il a été membre de la Société des droits de l'Homme. Fréquemment réprimandé par les agents de police pour mauvais stationnement de son cabriolet, il a développé une haine profonde à l'égard de l'autorité, déclarant:

«Quand donc, leur donnera-t-on des coups de fusil ? » ${ }^{52}$

Considère, garçon de caisse, aurait fourni la carabine à Darmès. Darmès est condamné à mort le 29 mai 1841 et exécuté deux jours plus tard. Le ministre de l'Intérieur écrit à son collègue de la Justice et lui fait part de ses inquiétudes, notamment sur la grâce accordée par le roi à Jules Longuet, condamné pour avoir participé aux journées des 12 et 13 mai 1839. L'économe de la Maison centrale de Doullens a écrit le 20 novembre 1839 :

«Longuet est fanatisé, il compte se venger aussitôt qu'il sera libre. On a fait une faute en commuant la peine de ce condamné. $»^{53}$

46. A. Zévaès, Une révolution manquée : l'insurrection du 12 mai 1839, p. 125.

47. V. Hugo, "Les rayons et les ombres, Troisième, Au roi Louis-Philippe après l'arrêt de mort prononcé le 12 juillet 1839 », CEuvres, p. 68.

48. L'ami de la religion et du roi : journal ecclésiastique, politique et littéraire, jeudi 13 mai 1841, p. 334

49. I. Tchernoff, Le Parti républicain sous la monarchie de Juillet, p. 377.

50. La Gazette des tribunaux des 24 et 25 mai 1841.

51. Ibid.

52. Ibid.

53. Archives nationales, BB21 439. Lettre du Ministère de l'Intérieur du 12 juin 1841. 


\section{Depuis la prison du Mont-Saint-Michel}

L'existence dans les cachots du Mont-Saint-Michel est horrible. Le prisonnier est privé de lumière et de soleil. Il est enfermé dans une chambre qui mesure $2 \mathrm{~m} 80$ de long sur $1 \mathrm{~m}$ 80 de large et qui est pourvue d'une meurtrière de $24 \mathrm{~cm}$ de large sur $66 \mathrm{~cm}$ de hauteur et garnie de barreaux à l'extérieur et à l'intérieur. L'air est putride et il se mêle aux exhalaisons méphitiques du baquet qui sert aux besoins et qui n'est vidé que toutes les 24 heures. Par leur inactivité, les détenus grossissent et leurs jambes s'affaiblissent pour finir par ne plus les soutenir. Le séjour dans les cellules du Mont-Saint-Michel engendre des œdèmes.

Les condamnés ont fini par mettre au point un projet d'évasion. Blanqui est le principal organisateur de l'évasion avec l'avocat Fulgence Girard qui, à l'extérieur, doit prendre en charge les évadés. Dans la nuit du 10 au 11 février 1842, vers trois heures du matin, Barbès, Blanqui, Martin Bernard, Huber, Constant et Alexandre Thomas tentent de s'évader. La corde est arrimée mais la tentative échoue car Barbès, descendu le premier, perd son appui, se met à tournoyer sur lui-même et tombe. L'alerte est aussitôt donnée par la sentinelle qui se trouve à proximité du point de chute de Barbès. À la fin de l'année 1843, il reste au Mont-Saint-Michel douze condamnés pour l'insurrection des 12 et 13 mai 1839. Ces derniers sont notés par le directeur. Martin Bernard :

«Réclame toujours, mais convenablement désormais, contre le système cellulaire auquel sont soumis les condamnés politiques. Partage son temps entre l'étude et le maintien chancelant de son influence sur les cinq ou six condamnés qui demeurent fidèles à Barbès. " ${ }^{54}$

Louis-Auguste Blanqui est :

«Toujours aussi insolent, aussi exigeant, aussi violent que par le passé. N'est sensible ni aux égards, ni aux faveurs qu'il sollicite. Recherche par tous les moyens la diffusion de ses plaintes au dehors et leur retentissement. Plusieurs lettres écrites par lui avec de l'encre sympathique ont été retenues et adressées au Ministre. $»^{55}$

En 1844, Blanqui est transféré à la prison-hôpital de Tours, en raison de son état de santé. Il y reste jusqu'en avril 1847. Libéré, il participe aux manifestations parisiennes de mars à mai pendant la révolution de 1848.

\section{Les règlements de compte en 1848}

Libéré de prison en 1848, Barbès forme le Club de la Révolution pour contrer la Centrale républicaine insurrectionnelle de Blanqui. Le 31 mars 1848, la rivalité entre Blanqui et Barbès éclate au grand jour avec la publication d'un document intitulé Revue Rétrospective (Archives secrètes du dernier gouvernement). Le papier a été rédigé par Jules Taschereau, ancien avocat devenu secrétaire général de la préfecture de la Seine sous la monarchie de Juillet, puis député à l'assemblée constituante. On y trouve une "déclaration faite par XXX devant le ministre de l'Intérieur » dans laquelle un dénonciateur donne à la police les noms des meneurs des sociétés secrètes complotant contre l'État en 1839. Eugène Fournière décrit les différences entre les deux personnages :

«Blanqui, froid, précis, méthodique, calculateur ; Barbès, emporté, capricieux, déréglé, tout de premier mouvement. Le premier établit une discipline et $\mathrm{s}^{\prime} \mathrm{y}$ soumet ; le second veut bien imposer la sienne, mais n'en accepte aucune de bon gré. $»^{56}$

54. A. Zévaès, Une révolution manquée : l'insurrection du 12 mai 1839, p. 192.

55. Ibid.

56. J. Jaurès, E. Fournière, Histoire socialiste, p. 344. 
Louis Blanc écrit à propos de Martin Bernard :

«Tête puissante, servie par un courage de soldat lacédémonien. ${ }^{57}$

Le mouchard qui a reçu Duchâtel, le ministre de la police, dans sa cellule ne peut être que Blanqui qui dément ces accusations, le 14 avril 1848, dans le tract Réponse du citoyen Auguste Blanqui. Le document Taschereau est utilisé par les adversaires de Blanqui et notamment par Barbès. La supposée trahison de Blanqui est discutée par les historiens. Le 15 mai 1848, des manifestants envahissent l'Assemblée constituante, où Barbès siège à l'extrême gauche comme député de l'Aude. Barbès tente de disperser la foule, mais il semble perdre la raison, croyant voir Blanqui. Il décide de prendre la tête du mouvement et le détourne vers l'hôtel de ville où il compte proclamer une république plus avancée. La garde nationale arrive et disperse les fauteurs de trouble. Jugé coupable d'avoir tenté de renverser le gouvernement et d'exciter à la guerre civile, Barbès est condamné à la déportation en avril 1849 par la Haute Cour de justice de Bourges.

La popularité d'un républicain se mesure à ses actions militantes. Ledru-Rollin est connu pour ses écrits contre l'état de siège en 1832, pour avoir condamné le massacre de la rue Transnonain. Il est avocat, mais dans ses Mémoires, Pierre Joigneaux explique :

«Or, à cette époque mouvementée et fiévreuse, nous nous attachions surtout aux personnalités militantes, chevronnées, aventureuses, promptes à la conspiration et aux coups de fusils. Ledru, qui n'avait pas reçu le baptême de la persécution, qui n'avait pas été de la Société des amis du peuple, ni de celle des Droits de l'homme, ni des Saisons, ni des Familles, manquait par conséquent de titres à la popularité. ${ }^{58}$

Le 19 janvier 1837 est déjouée la tentative d'attentat de Champion, un mécanicien qui a réalisé une machine infernale du type utilisée par celle de Fieschi. L'homme avoue avoir voulu tuer le roi, dit avoir agi seul et se pend dans sa cellule avec sa cravate. Blanqui, Barbès et Martin Bernard sont des babouvistes qui croient dans les insurrections populaires. La police semble avoir été prise de court par la Société des saisons le 12 mai 1839. Le Journal des Débats avoue : "Le complot avait été ourdi avec une discrétion qui avait mis en défaut la police du
royaume. ${ }^{59}$

Le Charivari en profite pour dénoncer des fonctionnaires payés à ne rien faire. On risque de «nous demander prochainement des millions pour payer l'infatigable vigilance des Argus borgnes de la rue de Jérusalem ${ }^{60}$.

Bernard H. Moss confirme que la Société des saisons a évité d'être infiltrée par la police qui avait une vague idée de son existence et surveillait la presse clandestine héritière des activités de la Société des droits de l'homme et de la Société des familles. La police aurait été soudainement illuminée car le Moniteur universel se hâte de proclamer que l'émeute de mai 1839 est l'œuvre du parti républicain. En 1848, un manifeste des sociétés secrètes est signé par des républicains de toutes tendances (Étienne Arago, Pierre Leroux, Albert et Marc Caussidière, Ferdinand Flocon et Louis-Joseph-Antoine Cahaigne). Il s'inspire de la déclaration des droits de 1793. Il rappelle le rôle des sociétés secrètes depuis 1815, celui de Jean-Baptiste Berton, Joseph-Augustin Caron, Jean-François Bories et d'autres sous la Restauration. Il proclame qu'après le règlement de la question politique depuis le 24 février 1848 et le triomphe de la République, il est maintenant urgent de résoudre la question sociale.

57. L. Blanc, Révolution française, histoire de dix ans, 1830-1840, tome V, p. 411.

58. P. Joigneaux, Souvenirs historiques, tome II, p. 6.

59. Journal politique et littéraire de Toulouse et de la Haute Garonne, jeudi 16 mai 1839.

60. Le Charivari du 14 mai 1839. 


\begin{abstract}
Résumé
La Société des saisons est un réseau républicain clandestin actif sous la monarchie de Juillet. Elle a été fondée en 1837 par Blanqui, Barbès et Bernard. Poursuivant l'action de la Société des familles, elle compte quelque 1500 partisans. La plus petite subdivision de l'association forme une Semaine. Elle se compose de six hommes et d'un chef appelé Dimanche. Quatre Semaines réunies composent un Mois, placé sous la direction d'un responsable nommé Juillet. Trois Mois forment une saison commandée par un supérieur appelé Printemps. Enfin, quatre Saisons deviennent une Année à la tête de laquelle se trouve un agent révolutionnaire. La Société organise une insurrection visant à renverser Louis-Philippe en 1839. Des magasins d'armes sont pillés. Les émeutiers attaquent le Palais de Justice et la Préfecture de police de Paris. L'affaire tourne mal. C'est l'échec. L'historien Georges Duveau a qualifié l'événement de farce tragique.
\end{abstract}

\title{
Bibliographie
}

AMINZADE Ronald, Ballots and barricades: class formation and republican politics in France, 1830-1871, Princeton university press, 1993.

BLANC Louis, Révolution française, histoire de dix ans, 1830-1840, Paris, Pagnerre, 1842-1844, 5 tomes.

Boudon Jacques-Olivier, Citoyenneté, République et Démocratie en France, 1789-1899, Paris, Armand Colin, 2014.

BordonOve Georges, Louis-Philippe : Roi des Français, Paris, Pygmalion, 2009.

CABET Étienne, Le cataclysme social ou conjurons la tempête, Paris, Au Bureau du Populaire, 1845.

Caucanas Sylvie, Cazals Rémy, Armand Barbès et les hommes de 1848, Actes du colloque tenus à Carcassonne les 6 et 7 novembre 1998, les Audois, 1999.

Flaubert Gustave, L'Éducation sentimentale, Paris, Michel Lévy, 1869.

GILMORE Jeanne, La République clandestine, 1818-1848, traduit de l'anglais par Jean-Baptiste DUROSELLE, Paris, Aubier, 1997.

GISQUET Henri, Mémoires de M. Gisquet, ancien préfet de police, écrits par lui-même, Bruxelles, Jamar, 1841, tome VI.

HARSIN Jill, Barricades: The War of the Streets in Revolutionary Paris 1830-1848, New York, Palgrave Macmillan, 2002.

HODDE Lucien de la, Histoire des sociétés secrètes et du parti républicain de 1830 à 1848, Paris, Julien Lanier, 1850.

HUARD Raymond, La naissance du parti politique en France, Paris, Sciences Po, 2013.

HUGO Victor, Choses vues 1830-1848, Paris, Gallimard, 1972.

Hugo Victor, Les Misérables, Paris, Didier Hallépée, 2012, tome IV.

Hugo Victor, CEuvres, Bruxelles, Meline, 1842, tome II.

JoIGNEAUX Pierre, Souvenirs historiques, Paris, Marpon et Flammarion, 1891, tome II. 
LATTA Claude, Un Républicain méconnu, Martin Bernard: 1808-1883, Saint-Étienne, Centre d'études foréziennes, 1978.

MARx Karl, L'Allemagne en 1848, traduction de Léon Rémy, Paris, Schleicher frères, 1901.

MERLE Roger, Armand Barbès : un révolutionnaire romantique, Toulouse, Privat, 1977.

MiCHeLET Jules, Correspondance générale, tome III, 1839-1842, Paris, H. Champion, 1995.

Moss Bernard H., "Society of the Seasons", in NEWMAN EDGAR Leon (ed.), Historical Dictionary of France from the 1815 Restoration to the Second Empire, Aldwych Press, Londres, 1987.

NORD Philip G., Le moment républicain: combats pour la démocratie dans la France du XIX $X^{e}$ siècle, traduit de l'anglais par Christophe JAQUET, Paris, Colin, 2013.

Proudhon Pierre-Joseph, Les Confessions d'un révolutionnaire, Paris, Garnier frères, 1851.

SINSOILLIEZ Robert, Prisonniers au Mont-Saint-Michel, Louviers, L'ancre de Marine, 2006.

TASCHEREAU Jules, Revue Rétrospective, Paris, Paulin, 1848.

TCHERNOFF Iouda, Le Parti Républicain sous la Monarchie de Juillet : formation et évolution de la doctrine républicaine, Paris, Pedone, 1901.

ZÉVAÈs Alexandre, Une révolution manquée : l'insurrection du 12 mai 1839, Éditions de La Nouvelle Revue critique, 1933. 


\section{Illustrations}

Figure 1 : «Décidément ! l'arbre est pourri, il n'y a pas une branche de bonne », déclarent deux bûcherons républicains et patriotes. La Caricature du 19 septembre 1833, $\mathrm{n}^{\circ} 150$, planche 313. (C) Domaine public

L'arbre en question est l'arbre généalogique des Bourbons. Une de ses branches, l'aînée, est déjà brisée et prête à se séparer du tronc. La branche qui subsiste, celle de LouisPhilippe et de ses enfants symbolisés par des poires, ne vaut guère mieux. Elle est grêle et peu solide sur sa base. L'un des bûcherons s'apprête à la couper.

\section{Sa Caricatuten (Joumel) it: iso}

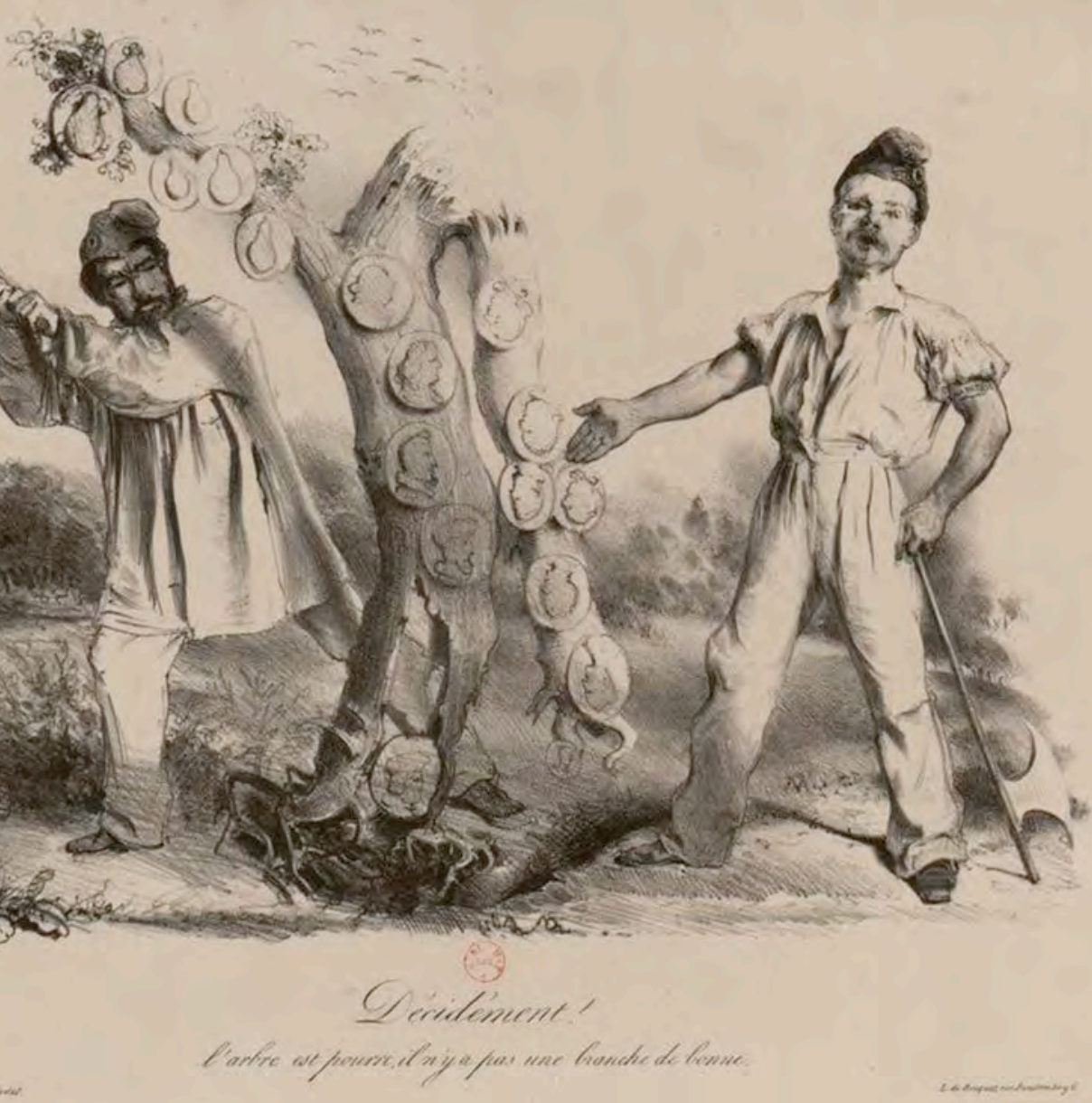


Figure 2 : Frontispice attribué à Joseph Bouchardy (1810-1870) des Rhapsodies de Pétrus Borel (1809-1859), Paris, Levavasseur, Palais Royal, 1832. (C) Domaine public

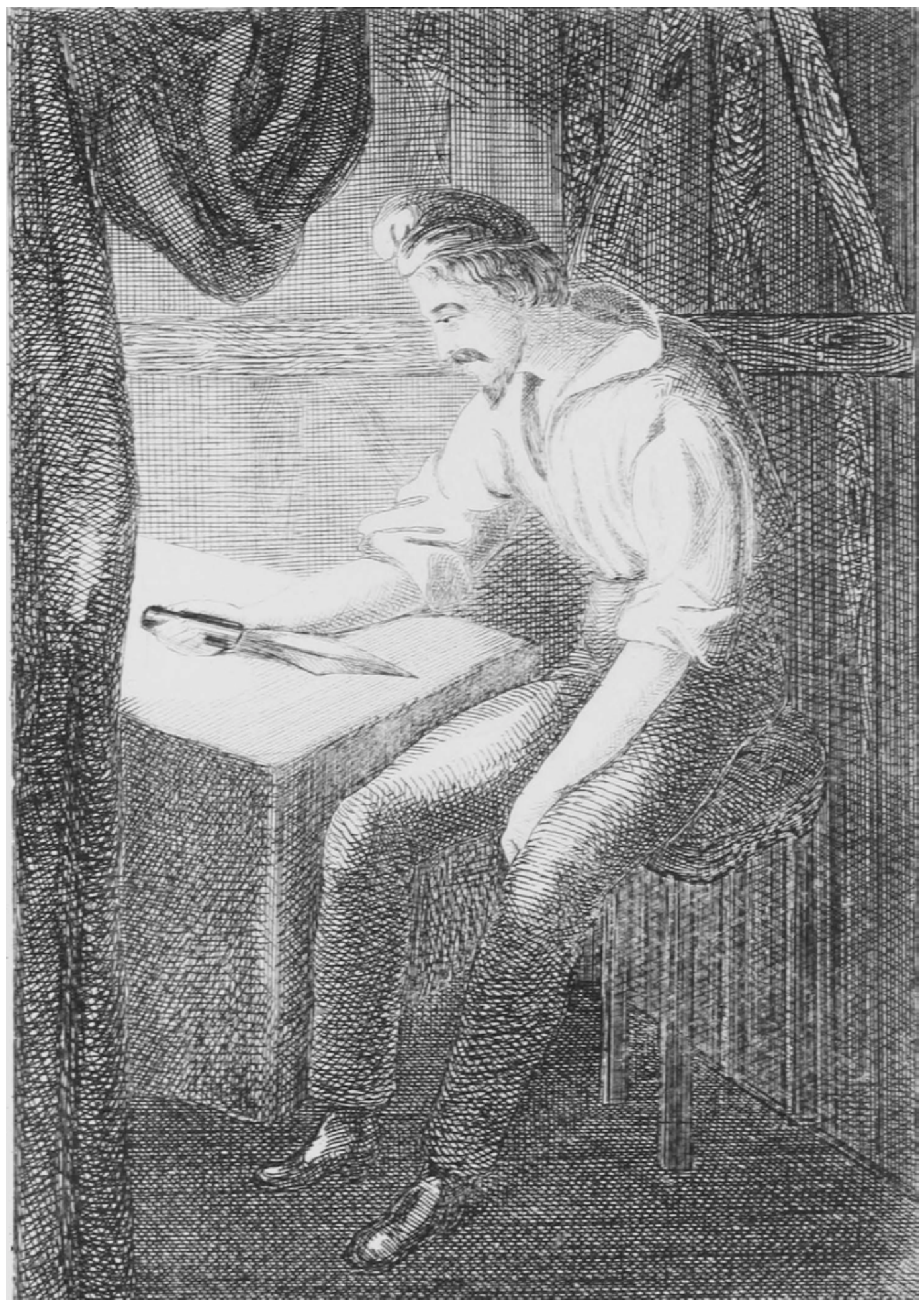




\title{
Un réseau politique de l'opposition libérale dans le département de la Meuse (1820-1830)
}

\author{
Jean-Paul STREIFF \\ Docteur en histoire moderne \\ et en histoire contemporaine \\ Société des Lettres, Sciences \\ et Arts de Bar-le-Duc \\ Extrait de : Henri BRESC (dir.), Réseaux politiques et économiques, Paris, \\ Édition électronique du CTHS (Actes des congrès des sociétés historiques et scientifiques), 2016. \\ Cet article a été validé par le comité de lecture des Éditions du CTHS dans le cadre de la publication \\ des actes du $140^{\mathrm{e}}$ Congrès national des sociétés historiques et scientifiques tenu à Reims en 2015.
}

L'abondance des documents, pour la période de la Restauration facilite l'étude de ce réseau de l'opposition libérale dans le département de la Meuse, entre 1820 et 1830. Les rapports de police, de gendarmerie, des préfets, les articles de presse, les biographies et les écrits les plus divers sont des sources précieuses pour retrouver les liens qui unissent des personnages. Il est utile également de connaître les protagonistes avant et après la période considérée. Leurs attitudes, leurs prises de position, leurs démarches au temps de la Révolution, puis sous la monarchie de Juillet et en 1848 éclairent aussi leurs relations, les liens qui les rapprochent et leurs choix politiques.

D'abord quels sont les personnages centraux ? Ceux qui constituent les pôles, les nœuds du réseau? Chacune de ces personnes ayant un rôle différent, quelles sont leurs relations? Qui rencontrent-elles? Qui les accompagne dans leurs démarches? Enfin comment opèrent-ils ? Par quels moyens ?

\section{Les personnages centraux}

Les députés libéraux constituent le noyau de l'organisation. Avec en premier lieu, PierreDieudonné-Louis Saulnier (Nancy, 1 janvier 1767-Paris, 23 février 1838).

\section{L'ancien préfet : Pierre-Dieudonné-Louis Saulnier ${ }^{1}$}

En 1798, il est commissaire du Directoire près l'Administration centrale du département de la Meurthe. C'est alors un républicain de gouvernement, sincèrement attaché aux conquêtes de la Révolution... Nommé préfet du département de la Meuse (2 mars 180019 avril 1804), il a la lourde charge de mettre en place les nouvelles administrations. Il reste en place jusqu'en 1804. Il est alors appelé au poste de secrétaire général du Grand juge, Claude-Ambroise Régnier (Blâmont, 5 novembre 1746-Patris, 25 juin 1814) qui dirige la justice et la police. Il reste en place sous Fouché et Savary jusqu'à sa révocation le 31 janvier 1815. Selon Louis Madelin, il aurait intrigué contre Fouché.

1. J.-P. Streiff, « Le premier préfet du département de la Meuse : Pierre-Dieudonné-Louis Saulnier ». 
Chevalier de l'Empire en 1808, membre de la Légion d'honneur, il est désigné par l'Empereur, en 1811, comme l'un des seize actionnaires du Journal de l'Empire confisqué à ses propriétaires. Rallié aux Bourbons sous la première Restauration, il est maintenu à son poste au ministère de la police générale par Louis XVIII. Mais, pendant les CentJours, rallié à Napoléon, il est destitué au retour du roi.

Les Meusiens ne l'ont pas oublié. En effet, dès 1815, il représente le département de la Meuse au corps législatif. En septembre 1816, la Chambre des députés est dissoute par l'Ordonnance du 5 septembre, mais il est réélu le 4 octobre 1816. Le même scénario se répète le 20 septembre 1817 et le 9 mai 1822. Il ne se représente pas en 1824 . Il siège sur les rangs de la « gauche libérale ». Il meurt à Paris le 23 février 1838.

\section{«La plume » de l'organisation : Charles-Guillaume Étienne ${ }^{2}$}

Le député Charles-Guillaume Étienne est la plume du réseau, personnalité marquante de la vie politique, journalistique, littéraire et théâtrale de l'Empire, de la Restauration et de la Monarchie de Juillet. Sept fois élu député de la Meuse, puis pair de France, il préside le Conseil général de la Meuse, après le maréchal Oudinot. À Paris, auteur de théâtre, académicien, directeur de journaux, deux fois président de la société des auteurs et compositeurs dramatiques, il participe entièrement à la vie littéraire et politique de la capitale. Meusien de Paris, il y défend les intérêts du département. Il est également en contact avec l'opposition parisienne.

« Napoléoniste» ou «buonapartiste», comme l'on disait alors, Étienne, de sa plume alerte et agressive, avec un ton très voltairien, combat la Restauration. Il est l'un des fondateurs du Nain jaune, de La Minerve et du Constitutionnel. Le Nain jaune, ou Journal des arts, des sciences et de la littérature est l'ancêtre du Canard Enchaîné. Il paraît du 15 décembre 1814 au 15 juillet 1815. Le journal attaque les partisans de l'Ancien Régime qualifiés de "Chevaliers de l'Éteignoir » et invente "l'ordre des Girouettes », après les Cent-Jours. En 1818, Étienne crée, avec quelques amis, La Minerve devenue La Minerve française $e^{3}$. Sous la direction de Benjamin Constant, il raille les ultras. Il fait le succès de la revue avec ses Lettres sur Paris. En 1819, il est rédacteur en chef et actionnaire du Constitutionnel, principal journal national d'opposition, et devient le dirigeant de l'opposition libérale dans le département de la Meuse. Il bataille sans cesse par la plume et la parole contre les Bourbons.

Dès 1813, Charles-Guillaume Étienne souhaite présider le collège d'arrondissement de Commercy "dans lequel sont situées ses propriétés. Ce n'est pas dans le but de se faire nommer candidat au corps législatif puisqu'il n'a que 36 ans $»^{4}$. Dès lors, CharlesGuillaume Étienne devient un rassembleur de terre. Il achète des propriétés à Sorcy ${ }^{5}$ et dans les villages voisins. Puis, à partir de 1814, il multiplie les achats fonciers et immobiliers afin d'atteindre une fortune suffisante pour être électeur, puis éligible ${ }^{6}$. Il achète en viager, en 1817, le petit château de Saint-Martin, écart de Sorcy ${ }^{7}$. Au décès, les biens accumulés à Sorcy et dans les villages voisins, terres, prés et bois, constituent un capital de $77252,40 \mathrm{~F}^{8}$.

2. J.-P. Streiff, « Un libéral meusien : Charles-Guillaume Étienne (1777-1845)».

3. Publié par les rédacteurs du Mercure de France qui vient d'être saisi, et dont le titre est repris en juillet 1819 par Mercure de France et chronique de Paris. Après mars 1820, Constant, Jouy et Aignan se replient sur La Renommée, Étienne, Jay, Dumoulin et Tissot rejoignent Le Constitutionnel et Lacretelle publie des brochures datées avril et mai 1820. La Minerve française est un hebdomadaire, annoncé à parution irrégulière pour contourner l'autorisation préalable.

4. Archives nationales, F/1c III/Meuse / 5 .

5. Sorcy, Meuse, arrondissement de Commercy, canton de Void.

6. Sous la Restauration, le cens électoral est de 300 F d'impôts et le cens d'éligibilité de $1000 \mathrm{~F}$.

7. Archives départementales de la Meuse, Comon notaire à Sorcy, acte du 26 mai 1817.

8. Archives départementales de la Meuse, 30 Q 125, Commercy, mutations par décès, nº 71, 5 septembre 1845. 
Dans la biographie qu'il a consacrée à Charles-Guillaume Étienne, Charles-Auguste Salmon ${ }^{9}$ décrit la résidence aménagée par l'écrivain et où il aime se reposer.

«Mais, si l'on voulait le bien connaître, il fallait le voir à la campagne, dans sa retraite chérie de Saint-Martin de Sorcy... Un parterre peuplé de fleurs plantées de ses mains; une pelouse, bornée par une rivière qui en dessinait les contours, charmaient l'œil des visiteurs, et les invitaient à se promener. ${ }^{10}$

Le 13 novembre 1820, à Bar-le-Duc, il est élu député, difficilement, avec 78 voix, au troisième tour de scrutin, battant le baron Charles-Adrien de Cholet ${ }^{11}$, représentant du pouvoir $^{12}$. Il est réélu député, le 16 mai 1822, à Verdun, avec 81 voix ${ }^{13}$.

Le préfet écrit à ce sujet :

«Le succès complet de l'opposition aux élections de 1820 et 1822, moins encore que les menées, les correspondances et la conduite d'un certain nombre d'ennemis de la légitimité à la tête desquels il faut citer M. Étienne ont fait naître dans le département de la Meuse ou du moins parmi une classe très nombreuse de ses habitants une sorte de haine et de défiance contre le gouvernement du Roi et des regrets de l'ancien ordre de choses qui se manifestent toutes les fois que l'activité des meneurs peut en indiquer une occasion. » ${ }^{14}$

Mais le 7 mars 1824, Étienne est « écrasé », avec seulement 19 voix, par Laurent Leclerc, élu avec 168 voix $^{15}$. À Verdun, le baron de Cholet, 97 voix, obtient sa revanche. CharlesGuillaume mène, dès lors, une bataille incessante contre le baron Romain ${ }^{16}$, préfet de la Meuse, qui a fraudé, rayant des libéraux des listes électorales et inscrivant des monarchistes à leur place.

\section{«L'épée » du mouvement : Jean-François Jacqueminot ${ }^{17}$}

L'épée de l'organisation est Jean-François Jacqueminot vicomte de Ham (Nancy, Meurthe-et-Moselle, 23 mai 1787-Meudon, Seine et Oise, 3 mars 1865), premier aide de camp du maréchal Oudinot, héros de la Bérézina et de la bataille des Quatre Bras, le colonel Jacqueminot, officier à la demi-solde, s'installe à Bar-le-Duc, auprès de sa famille. Jean-François Jacqueminot est le fils de Jean-Ignace-Jacques Jacqueminot comte de Ham ${ }^{18}$.

Le 5 mai 1822, le colonel s'associe avec ses parents pour fonder la société JacqueminotAubert et Compagnie. L'entreprise comprend la filature du coton, la fabrication de toiles de coton, unies et rayées et l'établissement d'un atelier de teinture. L'usine existait depuis

9. Charles-Auguste Salmon (Riche, Moselle, 8 ventôse An XIII/ 27 février 1805-Paris, 26 décembre 1892).

10. Les Affiches de la Meuse, 22 mars 1845.

11. Charles-Adrien baron de Cholet (Longeaux, Meuse, 12 juillet 1779-Mauvages, Meuse, 14 décembre 1868).

Conseiller général, député de la Meuse en 1824 et 1827, battu en 1830.

12. Archives départementales de la Meuse, 3 M 97, Élections 1816-1824.

13. Ibid.

14. Archives nationales, F/1c III/Meuse / 6. Rapport du préfet Romain du 19 août 1822.

15. Laurent Leclerc (Saint-Mihiel, Meuse, 2 juillet 1768-Saint-Mihiel, Meuse, 10 mai 1844). Receveur de l'enregistrement à Saint-Mihiel.

16. Archives nationales, F1bI/172/15.Charles-César Romain, baron, (Laon, paroisse Saint-Jean-au-Bourg, Aisne, 30 septembre 1788-Paris, 13 mars 1858). Sous-préfet d'Avallon 1813-1814, de Péronne 2-20 novembre 1814. Il rejoint Louis XVIII à Gand. Il reprend ses fonctions à Péronne, puis est nommé sous-préfet de Brest, du 9 au 24 janvier 1822, préfet de la Meuse, de juillet 1822 jusqu'au 3 mars 1828, préfet des Pyrénées-Orientales, de 1828 jusqu'en 1830.

17. Jean-François Jacqueminot (Nancy, Meurthe-et-Moselle, 23 mai 1787-Meudon, Seine-et-Oise), 3 mars 1865). E. Bourloton, G. Cougny, A. Robert, Dictionnaire des Parlementaires, tome III, p. 391, p. 811-812. Le 21 août 1828, il est élu député des Vosges. Il prend parti pour Louis-Philippe. Il est promu général de brigade et chef d'étatmajor de la garde nationale de Paris, lieutenant général en 1838 et commandant des gardes nationales de la Seine en 1842. Député de Paris et vice-président de la Chambre en 1837, il devient membre de la Chambre des pairs en 1846. Au moment de la révolution de 1848, son indécision lui vaut d'être remplacé par Bugeaud à la tête des gardes nationales et d'être mis à la retraite.

18. Jean-Ignace-Jacques Jacqueminot comte de Ham (Naives, Meuse, 14 janvier 1754-Paris, 13 juin 1813). Avocat à Nancy, il est député de la Meurthe au Conseil des Cinq-Cents, le 23 germinal an V (12 avril 1797). Rallié à Bonaparte, il entre au Sénat conservateur et est fait comte de Ham, par l'Empereur, le 26 avril 1808. Il participe à la rédaction du Code civil. Il est inhumé au Panthéon. 
un certain temps. La filature, très moderne, est entraînée par une machine à vapeur et les ateliers sont éclairés au gaz. Il possède des tissages à Obernai et à Châtenois dans le BasRhin. Il emploie essentiellement d'anciens soldats. Faut-il y voir un réseau de la Charbonnerie? Il rassemble des officiers à la demi-solde et, avec eux, parcourt le département pour diffuser les idées libérales.

\section{Rassembleurs d'opposants}

Saulnier, Étienne et Jacqueminot s'entourent des personnalités du département, militaires, maires et députés libéraux.

\section{Les députés libéraux}

L'étiquette libérale recouvre des idées politiques très différentes: bonapartistes, républicains, orléanistes se regroupent sous cette bannière de l'opposition aux Bourbons. Un autre préfet de la Meuse, nommé le 12 mars 1813, chambellan de Napoléon, LouisClair comte de Beaupoil de Saint-Aulaire ${ }^{19}$, est élu par les Meusiens. Noble d'Ancien Régime, Beaupoil de Saint-Aulaire est l'un des premiers élèves de l'École centrale des travaux publics (polytechnique). Il est confirmé préfet de la Meuse lors de la première Restauration, et nommé préfet de la Haute-Garonne le 13 octobre 1814. Il démissionne lors des Cent-Jours. Il reste cependant attaché au département, en étant élu député de la Meuse le 22 août 1815, puis de nouveau le 17 novembre $1827^{20}$. C'est un monarchiste modéré plutôt orléaniste.

Jean-Baptiste Raulin (Nantillois, Meuse, 27 janvier 1759-Montfaucon, Meuse, 14 décembre 1835) est un républicain affirmé. Il a participé à la prise de la Bastille. Avocat, juge de paix du canton de Montfaucon en 1816, il est destitué par la Restauration. Le grand collège de la Meuse, l'envoie à la Chambre, le 13 novembre 1820, par 80 voix (143 votants, 162 inscrits). Il est réélu, le 9 mai 1822, dans le $2^{\mathrm{e}}$ arrondissement électoral, à Verdun, par 160 voix (286 votants, 334 inscrits). Il siège à gauche. Sa famille confirme son ancrage républicain. Ainsi, Hector-Jacques Raulin, sous-préfet de Montmédy, en 1830, député en 1849, est incarcéré à Vincennes le 2 décembre 1851, lors du coup d'état de LouisNapoléon.

Joseph Vallée (Saint-Mihiel, Meuse, 18 décembre 1758-Paris, 3 octobre 1828), ancien avocat à Saint-Mihiel est député au Conseil des Cinq-Cents. Sous la Restauration, conseiller à la Cour de cassation, il est élu, le 20 septembre 1817, député du grand collège de la Meuse, par 161 voix (299 votants, 516 inscrits), et siège avec les libéraux.

Dominique-Christophe Bazoche (Saint-Mihiel, Meuse, 26 février 1757-Saint-Mihiel, Meuse, le 29 octobre 1817). Procureur général près la cour de justice criminelle de la Meuse, député (12 mai 1815), de la Chambre des Cent-Jours, le grand collège de la Meuse l'envoie à la Chambre, le 22 août 1815, avec 83 voix sur 263 inscrits. Libéral, il est réélu le 4 octobre 1816 (92 voix sur 154 votants et 254 inscrits).

Charles-Antoine Génin (Verdun, Meuse, 5 avril 1785-Wadelincourt, Ardennes, 27 janvier 1866), est élu député le 20 avril 1829, par les électeurs libéraux du 2e arrondissement de la Meuse (Verdun), avec 149 voix (246 votants et 284 inscrits), en remplacement de M. Beaupoil de Saint-Aulaire, nommé pair de France. Il siège au centre gauche et est un des 221.

19. Archives nationales, F1bI /173/1. Beaupoil de Saint Aulaire (Louis-Clair, comte de) (La Mancelière, BaguerPican, Ille-et-Vilaine, 9 avril 1778-Paris, 12 novembre 1854).

20. Pair de France en 1829, exclu en 1830. Il est ambassadeur de France, à Rome, en 1831, puis à Vienne, de 1833 à 1842 . 


\section{Les officiers à la demi-solde}

Le colonel Jacqueminot, libéral, fidèle à Napoléon, rassemble autour de lui les officiers à la demi-solde, les opposants au nouveau régime. Le colonel Amédée-Louis Despans de Cubières (Paris, 4 mars 1786-Paris, 6 août 1853), " ami intime du colonel Jacqueminot a beaucoup d'influence sur lui, partageant ses opinions politiques $»^{21}$. Il remplace le receveur général du département Alphonse Jean Buffault (1762-1844) dont il a épousé la nièce Marie-Aglaé Buffault.

Henry-Pierre Paillot, chef de bataillon, a des « opinions favorables à l'opposition, tête ardente et conduite légère, dévoué à Jacqueminot et de Cubières $»^{22}$. Frédéric Lanthonnet, chef d'escadron, est « dévoué aux colonels Jacqueminot et de Cubières dont il partage les opinions et les sentiments. Un caractère de bonhomie lui a concilié l'attachement d'un grand nombre d'habitants de la ville $»^{23}$. Pierre de Thionville, capitaine, «appartient à une bonne famille de Bar qui déplore la direction qu'il a prise, homme de mœurs légères et livré à la boisson ». Jean-Ogier Collas, sous-lieutenant, aux « opinions très mauvaises, homme grossier et méprisé par sa conduite privée mais recherché des libéraux à cause de ses sentiments politiques $»^{24}$. Narcisse Pérard, lieutenant, est un «très mauvais sujet, à la conduite méprisable, renvoyé de son corps pour cette raison, comme pour ses opinions exaltées $»^{25}$. Jean-Louis Thiry, sous-lieutenant, "son opinion est peu favorable au gouvernement voué aux officiers supérieurs les plus prononcés de cette opinion $»^{26}$. Le préfet, qui fait surveiller le groupe, écrit au directeur de la police, le 6 novembre 1823 :

«L'activité des correspondances, la fréquence et l'intimité des relations qui se sont établies depuis quinze jours entre les hommes de l'opposition comme d'après les efforts que font en ce moment plusieurs d'entre eux pour accroître et étendre leur influence dans ce département. Le colonel Jacqueminot qui paraît devoir diriger les manœuvres de l'opposition et devenir son principal agent dans la Meuse. Les ennemis du roi se groupent autour de lui. $»^{27}$

Dans un rapport du 4 décembre 1825, le préfet Romain note :

«Les mouvements de la Bourse et la mort du général Foy ont depuis quelques jours excité parmi les partisans de l'opposition dans ce département une activité de Rapports, une effervescence de discours qui me semblent devoir fixer l'attention de la haute Police... et spécialement sur le colonel Jacqueminot le plus ardent d'entre eux et leur chef $»^{28}$.

21. Fils du marquis, il naît le 4 mars 1786 . Soldat au $1^{\text {er }}$ régiment de cuirassiers, le 18 septembre 1802 , élève à l'École militaire, le 24 septembre 1803, sous-lieutenant le 23 octobre 1804 au 15e régiment d'infanterie de ligne. Lieutenant le 30 novembre 1806, aide de camp du général Morand le 12 janvier 1808, capitaine le 7 juin 1809 , chef de bataillon le 3 octobre 1813 et colonel du 18e régiment d'infanterie légère, le 19 novembre 1813 . Colonel "à la suite " au $1^{\text {er }}$ régiment d'infanterie légère, il est nommé colonel du régiment par Napoléon, le 21 mars 1815. Un état nominatif des officiers établi lors du licenciement de l'armée indique « de physique agréable, très instruit, excellent colonel, sert avec zèle et fermeté, conduite excellente ». Sa fortune est jugée confortable : « a de l'aisance ». Il est mis à la retraite. Il reprend du service en 1823. Lieutenant-général en 1825, pair de France, deux fois ministre de la guerre (du 31 mars au 12 mai 1839 et du 1er mars au 29 octobre 1840). Impliqué dans un scandale financier, l'affaire de corruption Teste, il est condamné à la dégradation civique en 1847, mais est réhabilité en 1852, d'après M. Prévost et J.-C. Roman d'Amat, Dictionnaire de biographie française, t. X, col. 15021505.

22. Archives nationales, F7 6741. Rapport du préfet au directeur de la police, du 6 novembre 1823. Surveillance du colonel Jacqueminot.

23. Ibid.

24. Ibid.

25. Ibid.

26. Ibid.

27. Ibid.

28. Ibid. 


\section{Les moyens d'action}

Pour les députés battus lors des élections de 1824, il s'agit de préparer la revanche, en contrant les méthodes du préfet. Les libéraux diffusent également leurs idées.

\section{Préparer les élections}

Le préfet a modifié les listes électorales en faveur des monarchistes, rayant des libéraux notoires pour des motifs plus discutables les uns que les autres. Enfin, un nombre important d'électeurs sans droits légaux ont été inscrits. Les libéraux diffusent un manuel électoral pour faciliter les démarches des électeurs et éviter les pièges tendus par l'administration.

Tout juste réélu, en 1828, Étienne attaque, à la Chambre, le préfet Romain :

«On a parlé de beaucoup de faits; on a dit qu'une association s'était formée pour les élections. Oui, Messieurs, mais c'est parce que, en 1824, le préfet s'était couvert de tous les méfaits. J'en citerai un qui m'est personnel. Le préfet tenait beaucoup à m'écarter de la liste des éligibles. Je possédais dans ce département une ferme depuis trois ans; le percepteur indiquait la quotité de mes contributions; il attestait que la mutation avait été déclarée, quoiqu'elle n'eût point encore eu lieu; le maire affirmait la date de ma possession. Cette ferme fut brûlée trois mois auparavant. Le préfet en reçut le rapport; malgré un fait si notoire, il exigea que je produisisse le contrat enregistré. Mais cela ne suffit pas; il ne restait plus que deux jours, et le préfet exigea de plus, la production des extraits de rôles, pièce par pièce. Il y en avait plus de cinq cents ; il aurait fallu dix jours pour les réunir ; heureusement le secrétaire de la mairie et plusieurs autres personnes passèrent la nuit pour les recueillir, et ce ne fut qu'au moment où la liste allait être fermée, que je pus faire la justification demandée.

Je vous le demande, Messieurs, n'êtes-vous pas indignés de cette partialité, de ces vexations? Je ne $\mathrm{m}^{\prime}$ en plaindrais pas, si elles n'atteignaient que moi, mais elles s'appliquent aussi aux habitants des campagnes, auxquels on fait perdre ainsi leurs journées, pour les dégoûter de l'exercice d'un droit qui leur devient si préjudiciable. C'est ainsi que, dans un département où la propriété est extrêmement morcelée, on renvoie les électeurs de percepteur en percepteur, de maire en maire, et qu'on les fatigue de marches onéreuses ; tandis que les favoris de l'administration sont inscrits sur les listes sans difficulté. Messieurs, ce n'est pas nous qui déconsidérons l'administration, quand nous rapportons de pareils faits ; c'est elle-même qui se déconsidère par ces odieuses menées.

Voix à gauche : Très bien, très bien. ${ }^{29}$

Le baron Romain est obligé de se défendre. Il envoie au ministre de l'Intérieur un épais dossier intitulé :

«Élections de 1827. Note du préfet de la Meuse sur les calomnies et les injures insérées contre les opérations électorales dans des Brochures anonymes ou des articles du Constitutionnel. Origines et causes des attaques de l'opposition contre le préfet de la Meuse ... ${ }^{30}$

Il réfute une à une chaque accusation. Toutefois, lors de la révision des listes électorales, le 22 janvier 1829, 45 électeurs ont été oubliés, 77 n'ont jamais atteint le cens électoral et sont supprimés, quatre n'ont jamais eu la capacité électorale ${ }^{31}$. La tricherie est évidente. Elle a permis l'élection du baron Philippe Desbassayns de Richemont, gendre du comte de Villèle, avec seulement quatre voix d'avance.

29. J. Mavidal, E. Laurent, Archives parlementaires, recueil complet des débats législatifs et politiques des Chambres françaises de 1800 à 1860, faisant suite à la réimpression de l'ancien "Moniteur » et comprenant un grand nombre de documents inédits, 2e série, 1800-1860, T. 52 (15 Mai 1827 au 7 Mars 1828), 19 février 1828, p. 701 et suivantes.

30. Archives nationales, F/1c III/ Meuse / 6.

31. Ibid. 
Les libéraux exultent lorsque le secrétaire particulier du préfet de la Meuse, Jean-Michel Bonnard $^{32}$ est condamné, le 19 avril 1828, par la cour d'assises de la Meuse, à huit années de bagne ${ }^{33}$. C'est lui qui, en 1824, a été chargé d'organiser les élections. En avril 1825, à seulement 23 ans, Bonnard est récompensé par le poste de percepteur, à Stainville ${ }^{34}$. Il détourne alors des sommes importantes. Quant au baron Romain, il est envoyé à Perpignan.

\section{Les brochures et les pamphlets}

Les libéraux diffusent des brochures qui précisent les droits des électeurs et propagent les idées libérales.

La société «Aide-toi, le Ciel t’aidera », fondée par François Guizot ${ }^{35}$, organise la riposte, en multipliant les opuscules, les réunions et en attaquant le préfet. Une brochure de propagande décrit le climat des élections législatives de 1824 :

«Séductions, menaces, fraudes, circulaires insultantes, glaive suspendu sur les têtes de tous les fonctionnaires publics devenus responsables du suffrage de leurs proches et même de leurs parents les plus éloignés..., secret du vote audacieusement foulé aux pieds, espions introduits dans le collège, enfin manœuvres honteuses, promesses illusoires, odieuses calomnies, rien ne fut épargné pour soumettre le vote d'un département qui avait gardé jusqu'alors, même sous les baïonnettes de l'étranger, cette virginité d'indépendance... Cette fois l'autorité a triomphé, mais sa victoire a été pour le département une défaite cruelle, dont le souvenir douloureux pèse sur tous les cœurs. $»^{36}$

Le 9 septembre 1827 le préfet rapporte :

«Monsieur Étienne pour rentrer à la chambre des députés, n'a épargné aucune course, aucune démarche pour accroître le nombre d'électeurs libéraux sur la première partie de la liste du jury et les maintenir ou les fortifier dans leur éloignement pour le gouvernement du roi. Jusqu'alors ses partisans ou les comités agissaient pour lui et étaient chargés de la distribution des brochures, mais il n'a voulu s'en rapporter qu'à lui-même du soin de faire lire un des écrits auxquels le parti paraît attacher le plus d'importance, la relation des funérailles de Monsieur Manuel etc., pendant un voyage qui vient de faire à Bar, il en a remis un exemplaire à chacun des électeurs qu'il visitait. » ${ }^{37}$

Des brochures sont publiées avec le patronage de la Société pour la liberté de la presse. Ce sont souvent des articles du Constitutionnel, imprimés probablement à la demande d'Étienne. Celui-ci les dédicace aux électeurs.

Le préfet, dans une lettre du 4 novembre 1827, écrit :

« Le colonel Jacqueminot depuis son retour à Bar, s'est mis, comme je le prévoyais, à la tête des agents de l'opposition qui préparent des élections contraires aux intérêts monarchiques. Il est dans ce département l'âme de ce parti et il le sert avec une ardeur, une activité, je dirais même un succès qui en font un des ennemis les plus dangereux du gouvernement et du roi. Dans ce moment il parcourt, ainsi que plusieurs autres agents de l'opposition, toutes les parties du département pour distribuer les pamphlets et avis qui arrivent chaque jour par les messageries de Paris. ${ }^{38}$

32. Jean-Michel Bonnard (Cartigny, Somme, 7 germinal an VI (26 mars 1798)-décès inconnu). Il épouse, à Marseille, le 22 février 1838, Thérèse-Magdelaine Gérin. Incarcéré au bagne de Toulon, libéré le 8 septembre 1834, il réside à Toulon jusqu'en février 1835, puis à Marseille. Le tribunal correctionnel de Marseille l'a condamné à un mois d'emprisonnement, pour complicité de délit d'usure.

33. Gazette des tribunaux, ${ }^{\circ} 859,8$ mai 1828 .

34. Stainville, Meuse, arrondissement de Bar-le-Duc, canton d'Ancerville.

35. François Guizot, (Nîmes, Gard, 4 octobre 1787-Saint-Ouen-le-Pin, Calvados, 12 septembre 1874), historien, académicien, plusieurs fois ministre sous la Monarchie de Juillet, président du Conseil en 1847.

36. Archives nationales, F/1c III/ Meuse / 6 .

37. Ibid.

38. Ibid. 
Le 7 novembre 1827, le baron Philippe Panon-Desbassayns de Richemont ${ }^{39}$ écrit à son beau-frère, le comte de Villèle :

«... nos enragés s'agitent dans tous les sens pour triompher à Verdun. Étienne y a passé huit jours. Le colonel Jacqueminot lui a succédé et d'autres émissaires sont en tournée dans les différents cantons... les royalistes ne marchent pas d'accord. Cette division enhardit nos adversaires. Dans cet état de choses, il serait indispensable de faire quelques efforts pour réunir les esprits. Un moyen qui réussit partout et plus particulièrement dans la Meuse serait de pouvoir donner à dîner aux électeurs. Personne n'en a les moyens à Verdun. Il serait cependant à désirer que l'évêque, le sous-préfet et le maire puissent recevoir les 300 membres du collège. Ne pourriez-vous pas leur faire accorder de 1000 à $1200 \mathrm{~F}$ à chacun pour les indemniser de leurs dépenses. Quant à moi, j'envoie mon cuisinier et mes gens à Verdun et mon intention est de recevoir le plus de monde possible... ${ }^{40}$

Les monarchistes ne font qu'imiter l'opposition qui organise banquet sur banquet.

\section{Les banquets}

Le pouvoir veille à encadrer toute activité suspecte par l'interdiction des associations et toute manifestation. Lorsque, dans sa dixième Lettre sur Paris, Charles-Guillaume Étienne relate le banquet de l'Arc-en-ciel organisé, à Paris, le mardi 5 mai 1818, pour honorer les députés libéraux, se doute-t-il que cette manifestation va se multiplier, jusqu'à la campagne des banquets de 1848 ? Cette réunion est un moyen d'échapper aux interdictions d'association et de manifestation. Voilà deux ans, écrit-il :

«À peine l'ami osait-il épancher son secret dans le sein de son ami; une réunion de trois personnes était un rassemblement, un tête-à-tête était suspect; aujourd'hui, quatre cents citoyens se convoquent et se parlent sans crainte, ils défient le soupçon qui les guette et la surveillance qui les écoute. $»^{41}$

Après la Terreur blanche, c'est la première fois que "plusieurs centaines de sympathisants de l'opposition libérale se trouvaient réunis en un lieu public $»^{42}$. L'habitué du "Déjeuner de la Fourchette» ne va pas cesser de banqueter. Le 25 novembre 1827, réélu député de la Meuse, il est honoré avec son collègue Saint-Aulaire :

«Le dimanche, une grande partie des citoyens de la ville [Bar-le-Duc] attendaient dans un silence profond, sur la place de la préfecture, le résultat du dépouillement du scrutin. Au moment où M. Étienne a obtenu la majorité, un électeur a lancé son chapeau ; c'était le signe du triomphe. À l'instant, les plus vives acclamations se sont fait entendre et se sont communiquées en moins de cinq minutes dans les quartiers les plus éloignés de la ville. Tous les électeurs et une multitude d'habitants sont venus féliciter le nouveau député, qui se trouvait chez le colonel Jacqueminot, son parent et ami... Aussitôt on décide qu'un banquet électoral sera offert aux deux nouveaux députés (M. De Saint-Aulaire était resté à Bar pour y exercer ses droits d'électeur). Les fanfares ont accompagné chacun des toasts qui ont été portés au milieu des plus vifs transports... M. le colonel Jacqueminot, M. Étienne et M. De Saint-Aulaire ont pris tour à tour la parole, et ont exprimé à l'assemblée avec une émotion profonde, tous les sentiments qui remplissaient leurs cœurs. ${ }^{43}$

Le préfet exprime son indignation au ministre de l'Intérieur, le 19 novembre 1827 :

«La ville de Bar a présenté après l'élection de $\mathrm{M}$. Étienne un spectacle vraiment affligeant parce que le peuple lui-même a pris part aux réjouissances des libéraux. Tout pourtant s'y

39. Philippe Panon-Desbassayns de Richemont (baron), (Saint-Denis-de-la-Réunion, Réunion, 3 février 1774Paris, 7 novembre 1840). Beau frère de Joseph, comte de Villèle (Toulouse, Haute-Garonne, 14 avril 1773Toulouse, Haute-Garonne, 13 mars 1854). Président du Conseil entre 1821 et 1828.

40. Archives nationales, F1c III/Meuse / 6 .

41. La Minerve française, II bis, mai 1818, p. 41-42. Lettre sur Paris $\mathrm{n}^{\circ} 10$.

42. V. Robert, Le temps des banquets. Politique et symbolique d'une génération (1818-1848), p. 35. Pierre-DieudonnéLouis Saulnier y participe.

43. Le Constitutionnel du 23 novembre 1827. 
est passé sans désordre, mais l'expression de la joie avait quelque chose de l'effervescence qui précède les mouvements populaires. Dieu préserve la France d'une Chambre où se trouveraient en majorité des députés comme ceux dont nous apprenons à chaque instant l'élection. »"

Le député participe, le 20 avril 1830, au banquet constitutionnel des Lorrains de Paris, et quelques jours plus tard, à Bar-le-Duc, une centaine de convives l'honorent pour sa participation à l'adresse des $221^{45}$.

\section{Un opposant très surveillé}

Étienne, principal dirigeant de l'opposition libérale, est surveillé par la police ${ }^{46}$. Ses déplacements sont autant espionnés que ceux de Benjamin Constant et du Marquis de Lafayette. En 1822, le préfet apprend que le député Manuel $^{47}$, « bête noire du pouvoir », est venu, en visite au petit château de Saint-Martin ${ }^{48}$. En août de la même année, Étienne est accueilli à Sorcy "par une sérénade qu'ont été lui donner la plupart des jeunes gens de Commercy sous la direction de Picquot fils auteur prétendu de la brochure intitulée : Encore un mot sur Napoléon ${ }^{49}$. Louis Picquot, né en 1804, n'a que 18 ans. En 1821, il a publié un opuscule de onze pages: Encore un mot sur Napoléon-le-Grand, précédé d'une adresse au Roi, dans lequel il réclame le rapatriement du corps de Bonaparte en France. Le lendemain, Étienne « assiste à un banquet en son honneur chez le sieur Picquot père » à Commercy.

Il se rend à Nancy, le 29 mai 1823. La gendarmerie de la Meurthe signale qu'Étienne a déjeuné chez le Sieur Turck-Bertier, « là il y a eu une réunion, plusieurs personnes y ont déjeuné ${ }^{50}$. Léopold-Louis Turck (1797-1887) est très lié à Philippe-Benjamin-Joseph Bûchez (1796-1865), un des fondateurs de la Charbonnerie en France, chargé d'organiser des ventes dans l'Est de la France. Bûchez est présent lors du déjeuner, d'où l'inquiétude des autorités.

En juillet 1823, Manuel accompagné de l'ancien maire de Rouen Charles-Louis ÉlieLefebvre, passe quelques jours à Sorcy avant de se rendre aux eaux de Plombières. Le réseau a des relations avec les libéraux des départements voisins la Meurthe et les Vosges.

\section{L'adhésion de la population}

Principal rédacteur de l'adresse des 221, Étienne se réjouit de la révolution de 1830. Récemment réélu député, son retour dans le département soulève l'enthousiasme de la population :

«Vers le milieu d'octobre 1830, il fit dans le département de la Meuse un voyage qui fut une sorte de course triomphale. Des communes entières, précédées de leurs maires, escortées des gardes nationales, lui servaient de cortège. C'étaient partout des cris, des transports, une joie qui tenait du délire... on applaudissait en lui les chambres, le gouvernement, le nouveau chef de l'État. M. Étienne ne pouvait s'y tromper. Ses réponses aux nombreux

44. Archives nationales, F/1c III/ Meuse / 6 .

45. Le Constitutionnel du 1er mai 1830. L'adresse au roi Charles X, signée par 221 députés, lui est adressée le 18 mars 1830. Elle exprime la défiance de la majorité libérale de la Chambre, à l'égard du ministère dirigé par le prince de Polignac. Le roi dissout la Chambre, le 16 mai. Mais les libéraux remportent les élections. C'est un des éléments déclencheurs de la révolution des Trois Glorieuses.

46. Archives nationales, F7 6718. Banquets, réceptions et voyages des députés. (1810-1830).

47. Jacques-Antoine Manuel (10 décembre 1775-20 août 1827), avocat, député libéral. Célèbre pour avoir été expulsé de la Chambre des députés, le 27 février 1823. De retour le lendemain, il prononce alors ces paroles : «M. le Président, j’ai annoncé hier que je ne céderais qu'à la violence, aujourd'hui je viens tenir ma parole ». Expulsé de force par des gendarmes, il est ovationné par la foule en sortant de la Chambre.

48. Archives nationales, F7 6719.

49. Louis Picquot est né en 1804, à Commercy.

50. Archives nationales, F7 6719. 
discours qui lui furent adressés exprimèrent constamment cette pensée, qui correspondait si bien au sentiment des populations. $»^{51}$

Une majorité de la population adhère au nouveau régime.

Le comte d'Arros, nouveau préfet du département ${ }^{52}$, dans une lettre du 16 décembre 1828 , confirme :

«... Le département de la Meuse est certainement l'un de ceux où les avantages de la révolution se sont le plus fait sentir et où le nombre de ceux qu'elle a élevés est le plus grand relativement au nombre de ceux dont elle a causé la ruine. On voit en effet d'un côté une population nombreuse enrichie par la suppression des charges féodales ou ecclésiastiques, par les ventes nationales, par les avantages communaux, par la cessation des entraves qui pesaient sur le commerce et sur l'industrie, par les emplois, les grades militaires dont il n'est presque pas une famille qui n'ait pris sa part ; et de l'autre une noblesse extrêmement peu nombreuse, les restes d'un clergé qui n'a jamais été riche, et les vieux titulaires de quelques offices supprimés... » ${ }^{53}$

D’autre part, il estime que 99 électeurs sur 120, dans le canton de Bar-le-Duc, ont des opinions de gauche et d'extrême gauche.

Ce réseau de résistance à la Restauration a d'abord des fins électorales et s'appuie sur les notables issus de la Révolution et de l'Empire. Affilié à l'association « Aide-toi, le ciel t'aidera », il trouve des relais parmi les électeurs et les opposants à la Monarchie. Distribuant des opuscules imprimés à Paris, se rassemblant lors de banquets, il diffuse ses idées parmi la population. Ainsi apparaît un mouvement politique, ancêtre des partis actuels. Les électeurs du département de la Meuse, très attachés aux conquêtes de la Révolution, n'adhèrent pas au système politique de la Restauration, mais approuveront la Monarchie de juillet 1830 .

\section{Résumé}

Sous la Restauration, aux marges de la légalité, l'opposition à la monarchie s'organise. Dans le département de la Meuse, ce réseau est ébauché par deux figures nationales: CharlesGuillaume Étienne (1778-1845) et Jean-François Jacqueminot (1787-1865). Charles-Guillaume Étienne, journaliste, académicien, député de la Meuse en 1820, dirige, à Paris, Le Constitutionnel, journal d'opposition au régime. Son relais dans la Meuse est le «colonel» Jean-François Jacqueminot, officier à la demi-solde devenu industriel à Bar-le-Duc et en Alsace. Étienne est réélu en 1822 mais battu en 1824. Lors de chaque élection, c'est une lutte réseau libéral contre réseau monarchiste qui s'engage avec l'aide d'une organisation semiclandestine, «Aide-toi, le ciel t'aidera ». Les moyens de propagande sont limités, réunions informelles, repas, banquets, opuscules, journaux, pour ces hommes surveillés par la police. Nous voyons ainsi apparaître un mouvement politique, ancêtre des partis actuels.

51. L. Thiessé, CEuvres de C.G. Étienne de l'Académie française avec des notices et des éclaircissements. Essai biographique et littéraire, tome V, p. CLXXVIII.

52. Archives nationales, F1bI / 155/8. Dossier du comte d'Arros.

53. Archives nationales, F7 6719. Lettre du préfet du 16 décembre 1828. 


\section{Bibliographie}

MAVIDAL Jérôme, LAURENT Émile, Archives parlementaires, recueil complet des débats législatifs et politiques des Chambres françaises de 1800 à 1860, faisant suite à la réimpression de l'ancien "Moniteur » et comprenant un grand nombre de documents inédits. $2^{\mathrm{e}}$ série, 1800-1860, Paris, 1862-1912.

PRÉVOST Marcel et ROMAN D’AmAT Jean-Charles, Dictionnaire de biographie française, Paris, Letouzey et Ané, 1932-2011, 21 vol.

ROBERT Adolphe, BOURLOTON Edgar et COUGNY Gaston, Dictionnaire des parlementaires français... depuis le $1^{\text {er }}$ mai 1789 jusqu'au $1^{\text {er }}$ mai 1889..., Paris, Bourloton, 1889-1891, 5 vol.

ROBERT Vincent, Le temps des banquets. Politique et symbolique d'une génération (1818-1848), Paris, Publications de la Sorbonne, 2010.

STREIFF Jean-Paul, « Le premier préfet du département de la Meuse : Pierre-DieudonnéLouis Saulnier ", Bulletin des Sociétés d'Histoire et d'Archéologie du département de la Meuse, $n^{\circ} 42-43,2010-2011$, p. 29-59.

STREIFF Jean-Paul, «Un libéral meusien: Charles-Guillaume Étienne (1777-1845)», Annales de l'Est, $\mathrm{n}^{\circ} 1-2013$, p. 213-231.

THIESSÉ Léon, CEuvres de C.G. Étienne de l'Académie française avec des notices et des éclaircissements. Essai biographique et littéraire, tome V, Paris, 1853. 


\section{Illustration}

Figure 1: représentation graphique du réseau de l'opposition libérale dans le département de la Meuse (1820-1830).

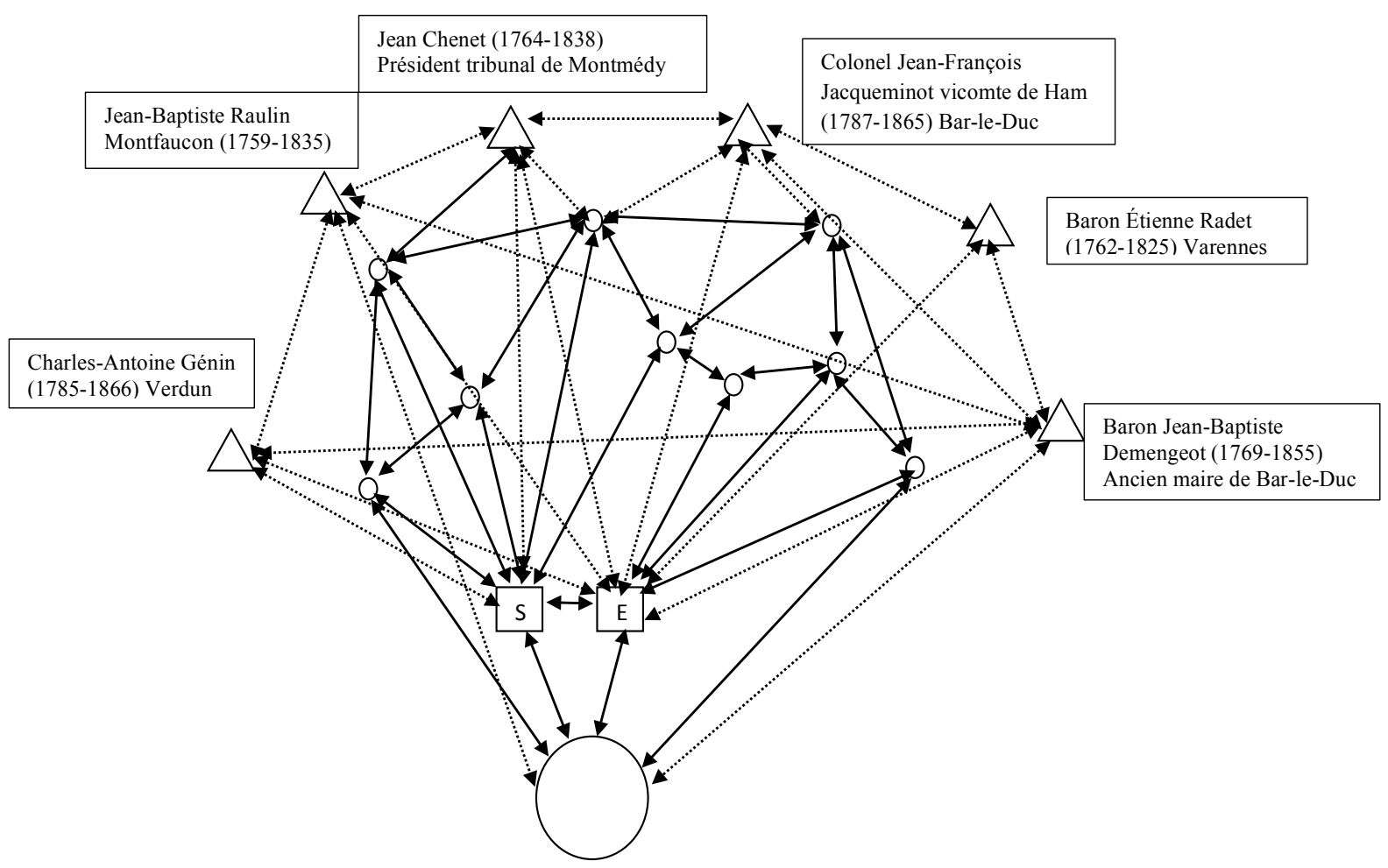

Représentation graphique du réseau de l'opposition libérale dans le département de la Meuse (1820-1830).

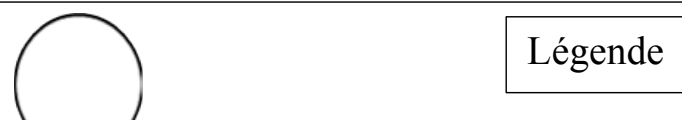

Aide-toi, le ciel t'aidera.

Députés S : Saulnier E : Étienne

$\bigcirc \quad$ Intermédiaires ( $₫$ des jeunes gens » selon la police)

$\triangle$ Quelques électeurs

$\stackrel{\leftrightarrow \cdots \cdots \cdots}{\longrightarrow}$ Relations 


\title{
Mettre à jour les réseaux politiques ou définir le populisme? L'attitude des médias face à la droite populiste allemande
}

\author{
Lionel PICARD \\ Professeur agrégé d'allemand, docteur en études germaniques \\ Univ. Bourgogne Franche-Comté, \\ Centre Interlangues Texte - Image - Langage (EA 4182)
}

Extrait de : Henri BRESC (dir.), Réseaux politiques et économiques, Paris, Édition électronique du CTHS (Actes des congrès des sociétés historiques et scientifiques), 2016.

Cet article a été validé par le comité de lecture des Éditions du CTHS dans le cadre de la publication des actes du $140^{\mathrm{e}}$ Congrès national des sociétés historiques et scientifiques tenu à Reims en 2015.

\begin{abstract}
Qu'est-ce que le populisme? La question a été maintes fois posée et n'en finit pas de mobiliser les chercheurs pour tenter de donner une définition d'un phénomène si protéiforme qu'il semble résister à l'épreuve. «L'élasticité de ce pseudo-concept ${ }^{1}{ }^{n}$ 'en finit pas d'étonner, de même que «sa résistance à la théorisation $»^{2}$. Expression du « dérèglement de la relation entre les électeurs et les élus, ou, pour utiliser une rhétorique populiste, entre le "peuple" et les "élites" »", le populisme politique, comme l'indique l'étymologie, prétend en appeler directement au peuple. Si le terme a connu un usage inflationniste au cours des dernières années, on ne peut que constater que cela n'a pas permis pour autant d'en définir davantage les contours.
\end{abstract}

Les médias sont chaque jour confrontés à cette difficulté puisque les mouvements, idées et porte-drapeaux du populisme politique se font entendre avec force et qu'il est courant de dénoncer avec vigueur la montée des populismes ${ }^{4}$. Les ténors de la droite populiste refusent d'être associés à cette famille politique et prétendent être simplement de droite, tout en rejetant avec véhémence les sympathies qu'on leur prête pour l'extrême droite. Les journaux consacrent parfois de longs articles au profil idéologique de mouvements ou de personnalités, mais cet exercice ne peut se répéter régulièrement. C'est pourquoi le recours au fonctionnement en réseau de la droite populiste peut être utile à la presse pour lui éviter de se livrer à un fastidieux travail explicatif. En associant les mouvements ou les personnes dont elle traite à d'autres groupes ou personnalités supposés connus du lecteur, les médias facilitent la compréhension sans passer par un pénible travail de définition.

Située entre le camp conservateur et l'extrême droite, la droite populiste allemande occupe un champ politique aux frontières mal délimitées et variables. Stephan Braun et Daniel Hörsch ${ }^{5}$ ont déjà montré le fonctionnement en réseau de la droite populiste. Ils expliquent ce phénomène avant tout par le fait qu'elle ne cherche pas vraiment à exercer le pouvoir et qu'elle s'attache surtout à diffuser ses idées dans l'opinion publique et les partis traditionnels. Ainsi, en mobilisant des personnalités qui servent de relais entre les partis de gouvernement et les franges extrémistes, la droite populiste fait en sorte d'influer sur l'évolution idéologique des grands partis.

1. J.-P. Rioux, « Le peuple à l'inconditionnel », p. 7.

2. J.-P. Rioux, « Le peuple à l'inconditionnel», p. 8

3. K. Priester, «Populismus als Protestbewegung », p. 20.

4. Le médiateur du Monde rend compte des réactions violentes et nombreuses auprès de la rédaction après la publication à la une du 8 février 2012 d'une manchette titrée " Mélenchon - Le Pen, le match des populismes » : P. Galinier, « Populisme, le mot qui fâche », www.lemonde.fr.

5. S. Braun et D. Hörsch (dir.), Rechte Netzwerke - eine Gefahr. 
Nous montrerons ici que le fonctionnement en réseau de la droite populiste est d'un grand secours pour les médias. On s'appuiera sur le site d'informations en ligne le plus consulté d'Allemagne ${ }^{6}$, SpiegelOnline, qui est la déclinaison électronique de l'hebdomadaire Der Spiegel. L'analyse portera sur trois moments de l'histoire récente de l'Allemagne où la droite populiste s'est fait entendre avec force dans la vie publique : la publication du livre de Thilo Sarrazin en 2010, la création du parti politique Alternative für Deutschland en 2013 et enfin l'émergence du mouvement de contestation Pegida en 2014.

\section{Thilo Sarrazin}

T. Sarrazin est un économiste, ancien cadre dirigeant de la Banque fédérale allemande. Membre du parti social-démocrate ${ }^{7}$ (SPD), il a siégé en tant que député chargé des Finances à la Diète régionale de Berlin de 2002 à 2009. Le 30 août 2010, il publie Deutschland schafft sich $a b^{8}$. Le succès est immédiat, les deux premières éditions (15000 puis 10000 exemplaires) s'écoulent en 2 jours. Les rééditions se succèdent à un rythme effréné et les ventes ne ralentissent pas. En quelques mois, le livre devient l'un des essais politiques les plus vendus d'Allemagne depuis 1945 (plus d'un million et demi d'exemplaires).

Dans son ouvrage, T. Sarrazin met en avant les problèmes auxquels l'Allemagne est confrontée selon lui et qui entraîneraient le pays vers un déclin inexorable. Il propose en outre toute une série de mesures qu'il faudrait prendre d'urgence afin d'enrayer ce déclin et de rétablir un ordre social et économique acceptable. La conjuration d'un déclin de sa propre culture associée avec des calculs démographiques et l'appel à une élite forte inscrit les visions apocalyptiques de T. Sarrazin dans une tradition politique de la droite allemande présente depuis la fin du XIX $\mathrm{X}^{\mathrm{e}}$ siècle ${ }^{9}$. T. Sarrazin s'en prend principalement aux immigrés qu'il accuse de mille maux. Qu'il s'agisse de la natalité jugée trop forte, de leur manque de qualification professionnelle (rapidement assimilée à une tare congénitale) ou de leur volonté ou capacité insuffisante à s'intégrer en Allemagne, les immigrés (musulmans en particulier) sont la cible principale des attaques de Sarrazin dans le chapitre intitulé «Immigration et intégration. Demander plus et offrir moins ${ }^{10}$. La politique sociale préconisée par Sarrazin n'épargne pas les plus modestes. Il n'hésite pas à stigmatiser les chômeurs qui s'accommoderaient d'indemnités considérables pour vivre aux crochets de la société, et plaide pour une remise à plat du système d'indemnisation-chômage afin de contraindre les demandeurs d'emploi à trouver un emploi ${ }^{11}$.

Les attaques contre les immigrés, les classes sociales les plus défavorisées et un système éducatif défaillant car trop peu élitiste rapprochent T. Sarrazin des mouvements de la droite populiste en Europe ${ }^{12}$. Pourtant, ce rapprochement surprend au premier abord puisque l'homme est membre de longue date du parti social-démocrate. La presse montre que le contenu du livre de Sarrazin et les thèses qu'il y développe n'ont que peu à voir avec le programme politique du SPD et que c'est plutôt du côté de la droite conservatrice, voire de l'extrême droite, que l'on trouvera les accointances les plus flagrantes.

En effet, le livre étant un énorme succès de librairie, il provoque un vif intérêt dans la société et les hommes politiques se doivent de prendre position pour ou contre

6. 108265799 consultations mensuelles du site effectuée depuis l'Allemagne en mai 2014 selon les chiffres donnés par l'Informationsgemeinschaft für Feststellung der Verbreitung von Werbeträgern e.V. Cf. http:/ / ausweisung.ivw-online.de/online/i.php?s=2\&a=152741 ; page consultée le 10 août 2015.

7. Sozialdemokratische Partei Deutschlands.

8. T. Sarrazin, Deutschland schafft sich $a b$ : Wie wir unser Land aufs Spiel setzen. La traduction française est publiée en 2013.

9. V. Weiß, Deutschlands Neue Rechte: Angriff der Eliten - Von Spengler bis Sarrazin, p. 13-14

10. T. Sarrazin, L'Allemagne disparaît, p. 263-345.

11. T. Sarrazin, L'Allemagne disparaît, p. 147-185.

12. O. Roy, «Carte blanche à l'identité », p. 96-97. 
T. Sarrazin. Le rejet est assez généralement partagé, mais il se trouve aussi des personnalités politiques éminentes pour défendre T. Sarrazin. Le parti d'extrême droite Parti national-démocrate $\mathrm{d}^{\prime}$ Allemagne ${ }^{13}$ (NPD) se réjouit du succès du livre, et n'hésite pas à reprendre à son compte les analyses et des déclarations de Sarrazin, profitant ainsi des polémiques et des débats suscités par le livre ${ }^{14}$. SpiegelOnline montre que les thèses développées par T. Sarrazin n'ont rien à voir avec le programme du NPD, mais le fait que l'extrême droite vienne faire la cour à l'essayiste à succès montre aussi dans quel environnement idéologique se situe T. Sarrazin.

La presse cite le nom de personnalités connues afin de montrer que les idées de T. Sarrazin sont proches de celles de la droite populiste bien que leur auteur en soit a priori bien éloigné. Erika Steinbach, une députée conservatrice en rupture avec son parti à la suite de ses prises de position trop radicales sur l'Histoire et les relations avec les voisins de l'Est européen, est associée au courant idéologique que T. Sarrazin semble pouvoir fédérer ${ }^{15}$.

Leader charismatique de la Fédération des expulsés allemands ${ }^{16}$ de l'après-guerre $(\mathrm{BdV})$, E. Steinbach est depuis longtemps une personnalité gênante au sein de son parti. Mais elle est la courroie de transmission indispensable entre le parti et une part conséquente de l'électorat traditionnel des conservateurs. S'adressant aux déçus du système politique, T. Sarrazin est susceptible de mobiliser autour de lui des personnalités venues d'horizons différents mais se retrouvant sur un terrain commun ${ }^{17}$. Se pose alors la question de savoir si c'est la droite conservatrice qui doit s'ouvrir aux tendances populistes qui se font entendre ou bien si les éléments les plus radicaux à l'intérieur du camp conservateur doivent quitter leur parti pour exprimer leurs idées polémiques publiquement et sans crainte de froisser le parti et ses dirigeants.

L'aile bavaroise du camp conservateur, l'Union des chrétiens-sociaux ${ }^{18}$ (CSU) se trouve alors au centre de toutes les attentions. Alliée à $1^{\prime}$ Union chrétienne-démocrate ${ }^{19}$ (CDU), elle complète le camp conservateur. Malgré leur alliance systématique au niveau fédéral, des différences notables existent entre les deux partis, la CSU étant nettement plus conservatrice que la CDU. Pierre Ayçoberry n'hésite pas à parler d'un «populisme permanent au gouvernement $»^{20}$ pour qualifier l'action de ce parti qui dirige la Bavière sans discontinuer depuis 1946.

Lorsqu'éclatent les polémiques liées à la publication du livre de T. Sarrazin, la CSU est opposée au cap politique suivi par A. Merkel (CDU). Les conservateurs sortent tout juste d'une coalition gouvernementale avec le parti social-démocrate et viennent de retrouver leur allié du Parti libéral-démocrate ${ }^{21}$ (FDP), et la CSU reproche à A. Merkel d'avoir laissé son parti dériver vers le centre depuis plusieurs années. De nombreux dirigeants de la CDU préconisent un retour aux valeurs traditionnelles du parti et présentent la CSU comme le modèle à suivre pour cette réorientation.

Cette situation n'est pas sans rappeler la fameuse déclaration de Franz Josef Strauß, le dirigeant historique de la CSU, qui aimait à dire qu' « à droite de la CSU, il ne peut y avoir de parti avec une légitimité démocratique $»^{22}$. Appliqué au cas de T. Sarrazin, cela signifie ni plus ni moins que les idées développées dans le best-seller ne peuvent rester longtemps ignorées, et que celles qui ne figurent pas déjà parmi les canons de la politique de la CSU doivent rapidement en trouver le chemin.

À l'inverse, Sarrazin sert à son tour de marqueur politique, et son nom est évoqué lorsqu'un article décrit les dérives populistes de la CSU dans les nouvelles règles qu'elle

13. Nationaldemokratische Partei Deutschlands.

14. B. Hans, « Polit-Propaganda : NPD wirbt in Berlin mit Sarrazin-Zitat », SpiegelOnline, 16 avril 2011.

15. R. Nelles, « Steinbach-Rückzug: Die Union wirft Ballast ab », SpiegelOnline, 9 septembre 2010.

16. Bund der Vertriebenen.

17. P. Wittrock et F. Gathmann, «Führungspersonal für Protestpartei. Provokateure, Frustrierte, Zauderer », SpiegelOnline, 14 septembre 2010.

18. Christlich-Soziale Union.

19. Christlich Demokratische Union Deutschlands.

20. P. Ayçoberry, «La version allemande », p. 188

21. Freie Demokratische Partei.

22. « (...) rechts von uns keine demokratisch legitimierte Partei geben darf ». F. J. Strauß, Erinnerungen, p. 530. 
prétend donner à la politique migratoire. Les orateurs qui se succèdent à la tribune d'un rassemblement politique annuel exigent que les immigrés aient plus de devoirs que de droits $^{23}$. La mention du nom de T. Sarrazin agit comme un signal à l'attention du lecteur pour lui indiquer que la CSU surfe ici sur la vague de son succès. Il s'agit ni plus ni moins d'un ajustement à l'air du temps marqué par le best-seller.

La diffusion de ses idées a atteint le cercle des partis établis. Sarrazin a joué le rôle de passeur entre des idées difficilement acceptables par les partis de gouvernement et la droite populiste. Pour les médias, la seule évocation du nom de T. Sarrazin permet de situer le cap politique de la CSU en matière de politique migratoire. Son livre a rencontré un tel succès que le nom de Sarrazin devient une référence quasi incontournable dans les articles traitant des sujets de prédilection de l'auteur. Les comparaisons européennes permettent de situer davantage T. Sarrazin sur ces questions: le refus du mariage homosexuel le rapproche de Béatrice Bourges du Printemps français ${ }^{24}$; SpiegelOnline l'associe pour son rejet de la monnaie unique à Marine Le Pen, Viktor Orban, Nigel Farage et Geert Wilders ${ }^{25}$.

Ce dernier est une figure d'autant plus marquante qu'il a réussi à contraindre les partis de gouvernement néerlandais à un accord avec son propre parti avant de former le gouvernement en 2010. SpiegelOnline se demande alors si T. Sarrazin peut créer un rassemblement à la droite de la droite sur des idées populistes ${ }^{26}$. En quelques mois seulement, le nom de T.Sarrazin est devenu un repère politique pour situer idéologiquement des idées ou des personnalités allemandes ou européennes.

L'Alternative pour l'Allemagne ${ }^{27}(\mathrm{AfD})$ est un parti politique apparu très récemment en Allemagne. Le congrès de fondation du parti s'est tenu le 14 avril 2013 à Berlin. Le rejet de la monnaie commune européenne et de la politique économique et monétaire de l'UE sont les deux principaux thèmes avec lesquels l'AfD s'est fait connaître ${ }^{28}$. Lors des différentes élections régionales, l'AfD a obtenu des scores significatifs pour un tout jeune parti ${ }^{29}$. C'est surtout le score obtenu lors des élections législatives de septembre 2013 qui a marqué les esprits car, avec 4,7\%, l'AfD échoue de peu à entrer au Bundestag, phénomène considéré comme quasi impossible pour un tout jeune parti ${ }^{30}$, susceptible de remettre en cause l'ordre établi des partis, d'autant que le parti libéral subit dans le même temps une défaite historique en obtenant un score similaire.

Les élections européennes de mai 2014 offrent au parti une tribune de choix pour exposer ses idées économiques et remettre en cause les différents plans de sauvetage de la Grèce. La chancelière A. Merkel et la Banque centrale européenne sont les principales cibles des attaques de l'AfD. Le parti obtient $7,1 \%$ des voix et 7 sièges de députés européens, victoire électorale paradoxale pour un parti qui rejette la classe politique $\mathrm{e}^{31}$. La création du parti est si récente que les chercheurs en sciences politiques ne s'accordent pas sur l'appartenance ou non de l'AfD à la droite populiste. La mise en cause de la monnaie commune ou de la politique de l'immigration ne suffit pas. De plus, le parti est soumis à

23. F. Gathmann et A. Reimann, « Populismus-Offensive: Union macht auf Sarrazin », SpiegelOnline, 10 mars 2011.

24. A. Langer, "Treffen von Rechtspopulisten. 'Ich habe selbst einige homosexuelle Freunde' », SpiegelOnline, 6 septembre 2013.

25. « Europäischer Rechtsruck. Auftritt der Anti-Euro-Krieger », SpiegelOnline, 18 avril 2011.

26. S. Weiland, " Pakt mit Wilders empört deutsche Politiker », SpiegelOnline, 30 septembre 2010.

27. Alternative für Deutschland.

28. Le rejet de l'euro et la critique de la construction européenne rappellent un autre parti populiste, le Bund Freier Bürger, dont le fondateur, Manfred Brunner, avait porté plainte contre le Traité de Maastricht. Cf. F. Hartleb, «Bund Freier Bürger - Offensive für Deutschland. Die Freiheitlichen (BFB - Die Offensive) », p. 200203.

29. En 2014, 12,2\% dans le Brandebourg, 9,7\% en Saxe et 10,6\% en Thuringe. En 2015, 6,1\% à Hambourg, dernier résultat connu au moment de la rédaction de cet article en août 2015.

30. C. Nestler et J. Rohgalf, « Eine deutsche Angst », p. 390.

31. Le paradoxe des «partis anti-partis » est une expression de la défiance envers la représentation politique, nouvelle forme du populisme en Europe. P. -A. Taguieff, Dictionnaire historique et critique du racisme, p. 1365. 
de fortes rivalités, tiraillé entre les aspirations parfois opposées de ses principaux dirigeants $^{32}$. Les querelles de personne et la mise en cause en interne de certains dirigeants empêchent le parti de présenter un programme aussi lisible que celui de partis plus établis. La question se pose de savoir si la création de ce parti répond au besoin de combler un vide dans l'espace entre partis conservateurs et extrême droite ${ }^{33}$. Le recours à des personnalités extérieures au parti permet aux médias de caractériser plus facilement un parti dont l'orientation politique manque de lisibilité. Le fonctionnement en réseau de la droite populiste permet de lever l'incertitude sur le positionnement idéologique de l'AfD.

Au début de son histoire, le parti est clairement identifié comme un parti anti-euro. Le rejet de la monnaie commune est à l'origine du mouvement, et c'est par ce biais que le parti se fait entendre dans les médias. D'autres thèmes se sont rapidement ajoutés, mais l'appellation « parti anti-euro » est pratique pour les médias, car elle permet d'insister sur le caractère contestataire du parti. La réussite aux élections européennes va permettre aux médias de mieux cerner l'identité politique du parti. Au lendemain des élections européennes, la direction du parti engage en effet des discussions afin de trouver un groupe parlementaire susceptible d'accueillir ses élus. Le parti est partagé entre d'une part la volonté de se joindre au groupe des "Conservateurs et réformistes européens » pour donner plus de crédibilité au mouvement et infléchir de l'intérieur la politique économique de l'UE et d'autre part une tendance à se rapprocher des eurodéputés les plus critiques du groupe «Europe de la liberté et de la démocratie directe ${ }^{34}$. Les négociations entre tous les partis européens donnent l'occasion de voir à travers les alliances possibles quel visage l'AfD souhaite présenter : le refus d'une alliance avec des députés d'extrême droite montre que l'AfD souhaite rester dans le champ démocratique. Le parti rejette la construction européenne dans ses formes actuelles, mais ne remet pas en cause le projet européen dans son ensemble. L'adhésion au groupe des conservateurs auquel appartiennent notamment les députés britanniques du parti de David Cameron est un échec pour la chancelière Merkel ${ }^{35}$, car l'AfD obtient des gages de respectabilité en se rapprochant des collaborateurs traditionnels des conservateurs allemands. Le parti s'éloigne ainsi du risque de marginalisation politique lié au rapprochement avec les eurosceptiques autour notamment du parti italien de Beppe Grillo (Mouvement 5 étoiles) ou du parti britannique UKIP (Parti pour l'indépendance du Royaume-Uni) dirigé par Nigel Farage.

SpiegelOnline suit attentivement les tractations au Parlement européen, car leur résultat est un signal fort de l'identité que revendique l'AfD, et les différentes prises de contacts et les alliances envisagées révèlent les proximités idéologiques avec des partis plus anciens. La victoire aux élections européennes ne laisse pas indifférents les contestataires parmi les conservateurs. Tandis que la direction du parti refuse tout rapprochement avec l'AfD, E. Steinbach entre autres plaide pour une collaboration et considère l'AfD «autant comme un adversaire que comme un partenaire potentiel $»^{36}$.

Si les querelles internes au parti entre l'aile nationale-conservatrice et l'aile libérale empêchent de cerner distinctement l'orientation idéologique du parti, les amitiés et les réseaux activés par les membres aident les utilisateurs de SpiegelOnline à comprendre où va le parti.

32. D. Bebnowski, Alternative für Deutschland. Aufstieg und gesellschaftliche Repräsentanz einer rechten populistischen Partei, p. 19-33.

33. A. Häusler et R. Roeser, «Die "Alternative für Deutschland" - eine Antwort auf die rechtspopulistische Lücke?», p. 101-129.

34. G. P. Schmitz, «In rechter Gesellschaft », SpiegelOnline, 6 juin 2014

35. G. P. Schmitz, C. Volkery et P. Wittrock, «AfD und Tories: Luckes Glück, Merkels Ärger », SpiegelOnline, 12 juin 2014.

36. M. Amann, «Interview mit Erika Steinbach. "Was ist aus meiner CDU geworden?" », SpiegelOnline, 1er juin 2014. 


\section{Pegida}

Le cas des Patriotes européens contre l'islamisation de l'Occident ${ }^{37}$ (Pegida) est beaucoup plus problématique que les deux précédents car radicalement novateur dans sa forme. Initié le 20 octobre 2014 à Dresde, le mouvement a rapidement pris de l'ampleur. Depuis cette date, une manifestation, que les organisateurs appellent «promenade vespérale ${ }^{38}$, a lieu presque chaque lundi dans la capitale de Saxe, rassemblant chaque fois plus de monde, jusqu'à un sommet à la mi-janvier 2015 avec 25000 participants. Depuis, la mobilisation rassemble de 2000 à 10000 personnes.

Ce mouvement prend pour cible une prétendue immigration incontrôlée qui mettrait en péril la culture occidentale, le pouvoir politique établi coupé du peuple et les médias à la solde de ce pouvoir. Il a pris une ampleur inattendue durant le mois de décembre 2014 au point de devenir le sujet politique principal et de contraindre A. Merkel, pourtant avare de prises de positions tranchées, à exprimer solennellement son rejet lors de son allocution du Nouvel an à la télévision ${ }^{39}$.

Tandis que l'AfD est un parti très structuré, malgré des faiblesses dues à sa création récente, Pegida n'est en rien comparable. En effet, le rassemblement est dirigé par une dizaine de personnes qui ne veulent pas que leur mouvement prenne une forme partisane $^{40}$. Ils se prétendent au-dessus de la logique des partis et refusent le dialogue avec les autres partis. L'AfD est toutefois une exception révélatrice, le vice-président de l'AfD Alexander Gauland considérant les organisateurs de Pegida comme des « alliés naturels ${ }^{41}$. Début janvier 2015, une «feuille de route » en 19 points est publiée sur internet. C'est l'un des rares documents qui permet de cerner les objectifs et les idées défendues par Pegida. On y retrouve les traits caractéristiques du populisme politique selon P.-A. Taguieff :

«La valorisation du peuple, opposé soit aux élites, soit aux étrangers, ou encore aux élites et aux étrangers. $\gg^{42}$

En effet, les dirigeants du mouvement comme la plupart des sympathisants, reprenant des termes hérités de l'idéologie national-socialiste, refusent de parler aux médias accusés de mentir et de trahir le peuple allemand. De plus, Pegida n'est présent sur internet que sur Facebook, il n'a pas de site propre. C'est sur ce compte que sont publiées les informations concernant l'organisation pratique des rendez-vous hebdomadaires à Dresde. Favorable à une démocratie directe, Pegida compte sur les rassemblements populaires de masse dans la rue, bien plus que sur la mobilisation en ligne.

Ici plus que jamais, les médias sont contraints d'observer les personnalités qui s'intéressent de près à Pegida pour brosser le portrait-robot des sympathisants. Or, il s'avère que les personnes qui se rendent à la manifestation du lundi ne sont pas que des anonymes désireux d'exprimer une crainte de l'avenir et un mécontentement face à la situation économique et sociale du pays. Les transfuges de l'AfD ne sont pas rares. Tatjana Festerling qui s'est présentée au nom de Pegida aux élections municipales à

37. Patriotische Europäer gegen die Islamisierung des Abendlandes.

38. Abendspaziergang.

39. "C'est pourquoi je dis à tous ceux qui se rendent à ces manifestations: ne suivez pas ceux qui vous appellent à le faire ! Car trop souvent, il y a des préjugés, il y a de la froideur, et même, il y a de la haine dans leurs cœurs! » Discours du Nouvel an de la chancelière Angela Merkel du 31 décembre 2014 diffusé à la radio et à la télévision: http://www.bundesregierung.de/Content/DE/Bulletin/2015/01/01-1-bk-neujahr.html ; page consultée le 12 août 2015.

40. L. Geiges, S. Margh et F. Walter, Pegida, p. 11-33.

41. S. Weiland, « Politiker-Streit über Dialog mit Pegida. Ja, nein, vielleicht », SpiegelOnline, 20 janvier 2015.

42. P.-A. Tagguieff, Dictionnaire historique et critique du racisme, p. 1363. 
Dresde au mois de juin ${ }^{43}$ est l'une des cofondatrices du parti anti-euro. Ces personnalités venues de l'AfD ou, à tout le moins, sympathisantes du parti, montrent la porosité entre les deux mouvements, signe que les thèmes de préoccupation communs (immigration, rejet de l'ordre établi, appel à plus de démocratie directe) permettent de brosser le portrait idéologique des mouvements. La distinction est d'autant plus facile à établir que T. Festerling a quitté l'AfD avant d'en être exclue officiellement pour ses déclarations suite à une manifestation de hooligans contre des salafistes à Cologne ${ }^{44}$. Elle est trop à droite pour l'AfD mais a le profil idéal d'une candidate pour Pegida. Lorsqu'au mois de février, le mouvement a semblé en perte de vitesse, au bord de la disparition, SpiegelOnline intitule un article "Pegida schafft sich $a b »{ }^{45}$ faisant clairement référence au livre de Sarrazin et aux mois durant lesquels le pays avait vécu au rythme des polémiques suscitées par ses thèses sur l'immigration ${ }^{46}$.

Mais les individus qui se distinguent le plus clairement dans la masse des participants aux rassemblements organisés par Pegida sont sans conteste les figures connues de l'extrême droite. Les journalistes ont prêté une grande attention à ces milliers de manifestants qui se sont rassemblés durant l'hiver 2014. Si la plupart d'entre eux ressemblaient à de parfaits citoyens lambda, la présence de hooligans et de néonazis à l'allure immédiatement reconnaissable a levé toute ambiguïté sur la proximité du mouvement avec l'extrême droite traditionnelle. Les dirigeants eux-mêmes ne sont pas exempts de toute collusion.

En février 2015, trois des principaux dirigeants ont quitté la direction collégiale en signe de protestation contre les dérapages trop fréquents en direction de l'extrême droite. La figure la plus connue du mouvement, Lutz Bachmann, a été contraint à se mettre provisoirement en retrait du mouvement après qu'une photo le représentant grimé en Hitler a été révélée sur internet. Après quelques semaines de silence, il est revenu sur le devant de la scène sans que les sympathisants du mouvement semblent lui en tenir rigueur.

Des membres du NPD sont également venus soutenir les manifestations de Pegida. Ils donnent aux médias l'occasion de situer ce mouvement qui se veut fédérateur, mais qui se caractérise avant tout par son rejet de certaines catégories de la population (immigrés, musulmans, journalistes, élites politiques). Lors d'une marche organisée à Munich sur le modèle de Pegida par son équivalent bavarois Bagida, les trains rameutant les néo-nazis de la région sont accueillis par André E., l'un des principaux mis en cause dans le procès du Mouvement clandestin national-socialiste ${ }^{47}$ (NSU) pour complicité de tentative de meurtre et soutien à une organisation terroriste ${ }^{48}$. Cette information donne à la presse l'occasion d'illustrer facilement la radicalité des manifestations dérivées de Pegida dans les autres villes d'Allemagne.

Partagée entre deux tendances, la direction du mouvement a éclaté au cœur de l'hiver. Le groupe réuni autour de Kathrin Oertel appartient à la branche la plus modérée. En témoignent les contacts noués avec l'AfD par l'entremise de sa représentante à Dresde, Frauke Petry (porte-parole du parti au niveau fédéral, et députée à la Diète régionale de Saxe depuis 2014). Les échanges entre les deux femmes ont été rendus publics au moment où L. Bachmann jetait le discrédit sur tout le mouvement. Ce rapprochement montre que Pegida rejette non pas l'ensemble des organisations politiques, mais plutôt les partis politiques établis. De son côté, L. Bachmann assume la radicalisation du mouvement que les médias mettent en évidence à l'occasion du rassemblement de salafistes à Wuppertal et de la contre-manifestation organisée par l'extrême droite. L. Bachmann monte à la tribune en compagnie de figures connues de l'extrême droite et se discrédite totalement

43. Elle a obtenu $9,6 \%$ des voix lors du premier tour.

44. C. Hebel, «Dresdner OB-Kandidatin Festerling. Zu rechts für die AfD - für Pegida gerade recht», SpiegelOnline, 14 avril 2015.

45. «Pegida disparaît».

46. F. Reinbold, «Zerwürfnis in Dresden. Pegida schafft sich ab », SpiegelOnline, 29 janvier 2015.

47. Nationalsozialistischer Untergrund.

48. F. Otto et F. Reinbold, " Anti-Islam-Bewegung Pegida. Irgendwann sind die Sohlen durch », SpiegelOnline, 13 janvier 2015. 
en lançant à la foule que les médias les traitent injustement d'extrémistes ${ }^{49}$. L. Bachmann utilise aussi l'AfD pour affirmer l'identité de Pegida: il rejette l'AfD qu'il juge trop intégrée au système politique en place $^{50}$.

En tant que parti contestataire, l'AfD est considérée par K. Oertel comme un partenaire acceptable. En quittant Pegida, elle semble disposée à créer un nouveau parti à droite de la CDU, manière de signifier qu'elle est plus proche des partis de gouvernement que des groupes radicaux ${ }^{51}$. De son côté, L. Bachmann, revenu à la tête de Pegida, a réussi à attirer de nouveau l'attention des médias en invitant G. Wilders, l'homme politique néerlandais connu pour sa critique radicale de l'islam, à la manifestation du 13 avril 2015. Les médias allemands voient dans cette invitation la confirmation que Pegida fait bien partie de la droite populiste et que le mouvement poursuit sa dérive vers l'extrême droite ${ }^{52}$. Les sympathisants continuent d'être appelés " citoyens en colère " ${ }^{53}$, mais on remarque que le cortège est de plus en plus fréquenté par des groupes organisés venus de loin, tandis que les citoyens venus spontanément ou par curiosité se font plus rares.

Considéré comme représentatif de la droite populiste, G. Wilders est aussi une personnalité politique connue au-delà des frontières néerlandaises et son aura rejaillit sur Pegida. On peut voir dans la présence de G. Wilders à Dresde la tentative d'établir des connexions internationales pour Pegida et de nouer des contacts avec d'autres partis idéologiquement proches. Comment montrer la dérive de Pegida vers l'extrême droite après les démissions en cascade à la tête du mouvement? Les slogans xénophobes, les provocations verbales lors des discours et les pancartes aux illustrations d'un goût douteux (A. Merkel grimée en Hitler) font partie du décorum habituel de Pegida. Une fois de plus, SpiegelOnline montre cette dérive droitière en évoquant les noms mais aussi les origines politiques des personnalités qui tiennent désormais les rênes du mouvement $^{54}$. G. Wilders pourrait ne pas être le dernier invité de dimension internationale: SpiegelOnline cite les noms de Marine Le Pen ou du dirigeant de l'extrême droite autrichienne Christian Strache comme orateurs potentiels ${ }^{55}$. Le réseau de la droite populiste s'étend à travers l'Europe entière et Pegida y est pleinement associé. Toutefois, en invitant G. Wilders, Pegida pourrait avoir franchi définitivement la zone de la droite populiste en direction de l'extrême droite. La présence de plus en plus massive de hooligans et de néo-nazis témoigne de ce changement ${ }^{56}$.

Les simples sympathisants de Pegida ne sortent pas indemnes des comptes rendus médiatiques. Ils ne sont pas toujours décrits comme de simples citoyens en colère, une tribune publiée sur SpiegelOnline ${ }^{57}$ les désigne comme des "suivistes ${ }^{58}$, mais le terme est aussi très connoté par le nazisme car il correspondait à la fin de la guerre à l'un des niveaux de classification de l'implication dans le nazisme lors des opérations de dénazification. Et cette tribune, publiée au lendemain de la commémoration de la libération du camp de Buchenwald, se termine par une mise en garde solennelle :

«Buchenwald et les autres camps ont été possibles seulement parce que trop de citoyens inquiets ont trouvé claires les paroles des populistes racistes, qu'ils les ont portés au pouvoir et les ont aidés à mettre en pratique leurs paroles. Non, à l'époque aussi, il n'y avait quasiment pas de nazis parmi eux, à ce que l'on dit. Rien que des suivistes. Ils sont toujours là. » ${ }^{59}$

49. J. Diehl, « Extremistentreff in Wuppertal. Spielplatz der Verirrten », SpiegelOnline, 14 mars 2015.

50. C. Hebel, « Tausende bei Demo in Dresden. Pegida-Organisator Bachmann keilt gegen AfD », SpiegelOnline, 17 mars 2015

51. F. Reinbold, «Ex-Pegida-Sprecherin. Oertel plant neue Bewegung 'rechts von der CDU' ", SpiegelOnline, 2 février 2015.

52. Syd, « Anti-Islam-Demo in Dresden. Geert Wilders kommt zu Pegida », SpiegelOnline, 20 mars 2015.

53. Wutbürger.

54. R. Nelles, «Wahl in Dresden. Pegida präsentiert Bürgermeister-Kandidatin », SpiegelOnline, 6 avril 2015.

55. S. Kuzmany, « Kommentar zu Pegida mit Wilders. Das große Comeback », SpiegelOnline, 13 avril 2015.

56. C. Hebel et B. Braden, « Rechtspopulist bei Pegida. Wilders biedert sich an », SpiegelOnline, 14 avril 2015.

57. S. Kuzmany, « Kommentar zu Pegida mit Wilders. Das große Comeback », SpiegelOnline, 13 avril 2015.

58. Mitläufer.

59. S. Kuzmany, « Kommentar zu Pegida mit Wilders. Das große Comeback », SpiegelOnline, 13 avril 2015. 
Inutile ici de recourir aux noms de personnalités pour établir des parallèles, la comparaison historique replace les méthodes populistes de Pegida dans un système de manipulation des masses bien connu.

Au cours des dernières années, l'Allemagne a été secouée par des démonstrations de force de la droite populiste. Qu'il s'agisse d'un intellectuel, d'un parti politique ou de manifestations populaires, les moyens d'expression sont certes différents, mais les idées restent les mêmes: rejet des élites, rejet de l'immigration, peur de voir disparaître l'identité nationale. La proximité entre les différentes manifestations de la droite populiste est rendue visible par les systèmes électroniques. Dans les publications en ligne utilisant les nuages de mots-clés (représentation visuelle des mots-clés), on s'aperçoit que l'AfD et Pegida sont systématiquement combinées et que le nom de Sarazin est également présent. Cela montre que les recherches sur internet associent ces éléments, et que les articles traitant de l'un des sujets en viennent inévitablement à aborder l'un des autres. Les liens hypertexte qui parsèment les articles en ligne du SpiegelOnline montrent que les articles sur Pegida sont souvent associés à ceux concernant l'AfD, et inversement. Dans cette mesure, il n'est guère surprenant que les personnalités évoquées soient rattachées aux deux mouvements, et que les passages de l'un à l'autre soient révélateurs également des échanges idéologiques.

Pour les médias, le recours au fonctionnement en réseau est donc pertinent car il permet de montrer les proximités des personnes et des idées, et en montrant comment les personnes se rencontrent et s'influencent, les médias révèlent la proximité des idées et la porosité entre des mouvements politiques. Le manque de temps et de personnel ne suffisent pas à expliquer ce phénomène. C'est aussi la conséquence de la difficulté pour les médias à dire simplement ce qu'est le populisme.

«Il faut en prendre son parti : la 'bonne définition' du populisme, réclamée par le public, est un leurre. (...) C'est faire le pari que populisme désigne un complexe d'idées, d'expériences et de pratiques qu'aucune typologie, si fouillée soit-elle, ne saurait épuiser. C'est reconnaître le populisme comme un objet versatile encore mal identifié et sur lequel il faut braquer plus $\mathrm{d}^{\prime}$ une lunette. ${ }^{60}$

\begin{abstract}
Résumé
En Allemagne, l'espace politique entre la droite parlementaire et l'extrême droite est peu structuré. Les limites entre chaque camp manquent de clarté et laissent la place au développement d'une zone intermédiaire où s'exprime un populisme rassemblant des personnalités venues de divers horizons (membres de partis politiques, d'associations, intellectuels). En effet, ces personnes font office de passeurs entre les deux pôles, et elles s'illustrent dans les médias en prenant position dans des débats politiques particuliers qu'elles animent par leur engagement volontiers polémique (souveraineté nationale, rejet de l'Europe, lutte contre l'immigration...).

Cet article analyse comment les médias utilisent le fonctionnement en réseau de la droite populiste pour surmonter les difficultés à définir les idées et les polémiques qui animent cet espace politique qui cherche à diffuser ses idées dans la société allemande et à les mettre à l'agenda politique des partis de gouvernement.
\end{abstract}




\section{Bibliographie}

AYÇOBERRY Pierre, «La version allemande », dans RIOUX Jean-Pierre (dir.), Les populismes, Paris, Perrin (tempus, 163), 2007, p. 179-195.

BEBNOWSKI David, Die Alternative für Deutschland. Aufstieg und gesellschaftliche Repräsentanz einer rechten populistischen Partei, Wiesbaden, Springer VS, 2015.

BRAUN Stephan et HÖRSCH Daniel (dir.), Rechte Netzwerke - eine Gefahr, Wiesbaden, VS Verlag, 2004.

GALINIER Pascal, «Populisme, le mot qui fâche», www.lemonde.fr, 17 février 2012, http:/ / www.lemonde.fr/idees/article/2012/02/17/ populisme-le-mot-quifache_1644984_3232.html

Geiges Lars, MARG Stine et WALter Franz, Pegida. Die schmutzige Seite der Zivilgesellschaft ?, Bonn, BPB (Schriftenreihe, 1595), 2015.

HARTLEB Florian, «Bund freier Bürger - Offensive für Deutschland. Die Freiheitlichen (BFB - Die Offensive)», dans DECKER Frank et NEU Viola (dir.), Handbuch der deutschen Parteien, 2. éd., Wiesbaden, Springer VS, 2013, p. 203.

HÄUSLER Alexander et ROESER Rainer, « Die 'Alternative für Deutschland' - eine Antwort auf die rechtspopulistische Lücke?», dans BRAUN Stephan, GEISLER Alexander et GERSTER Martin (dir.), Strategien der extremen Rechten. Hintergründe, Analysen, Antworten, Wiesbaden, Springer VS, 2015, p. 101-129.

Nestler Christine et RoHgalf Jan, "Eine deutsche Angst. Erfolgreiche Parteien rechts von der Union. Zur AfD und den gegenwärtigen Gelegenheitsstrukturen des Parteienwettbewerbs », Zeitschrift für Politik, vol. LI, n 4, 2014, p. 389-413.

PRIESTER Karin, «Populismus als Protestbewegung », dans HÄUSLER Alexander (dir.), Rechtspopulismus als 'Bürgerbewegung': Kampagnen gegen Islam und Moscheebau und kommunale Gegenstrategien, Wiesbaden, Verlag für Sozialwissenschaften, 2008, p. 19-37.

Rioux Jean-Pierre, "Le peuple à l'inconditionnel », dans Rioux Jean-Pierre (dir.), Les populismes, Paris, Perrin (Tempus, 163), 2007, p. 7-17.

ROGER Philippe, "Une notion floue et polysémique. Histoire d'un mot chargé d'idéologie », Le Monde, 10 février 2012, p. 20.

Roy Olivier, «Carte blanche à l'identité », Critique, tome LXVII, n 776-777, février 2012, p. 96-110.

SARRAZIN Thilo, Deutschland schafft sich ab: Wie wir unser Land aus Spiel setzen, Munich, Deutsche Verlags-Anstalt, 2010.

SARRAZIN Thilo, L'Allemagne disparaît : quand un pays se laisse mourir, Paris, Toucan, 2013.

STRAUß Franz Josef, Die Erinnerungen, Berlin, Siedler, 1989, p. 530.

TAGUIEFF Pierre-André, "Populisme(s) et national-populisme », dans TAGUIEFF PierreAndré (dir.), Dictionnaire historique et critique du racisme, Paris, Puf (Quadrige), 2013, p. 1359-1373.

WEIß Volker, Deutschlands Neue Rechte: Angriff der Eliten - Von Spengler bis Sarrazin, Paderborn, Schöningh, 2011. 